\title{
IINGUISTICS
}

\section{Theories of \\ Lexical Semantics}

Dirk Geeraerts

componential analysis

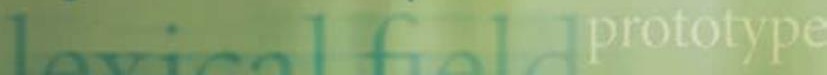

\section{cognitive moc}




\section{Theories of Lexical Semantics}


This page intentionally left blank 


\section{Theories of Lexical Semantics}

DIRK GEERAERTS 


\section{OXFORD \\ UNIVERSITY PRESS}

Great Clarendon Street, Oxford ox2 6DP

Oxford University Press is a department of the University of Oxford.

It furthers the University's objective of excellence in research, scholarship, and education by publishing worldwide in

Oxford New York

Auckland Cape Town Dar es Salaam Hong Kong Karachi

Kuala Lumpur Madrid Melbourne Mexico City Nairobi

New Delhi Shanghai Taipei Toronto

With offices in

Argentina Austria Brazil Chile Czech Republic France Greece

Guatemala Hungary Italy Japan Poland Portugal Singapore

South Korea Switzerland Thailand Turkey Ukraine Vietnam

Oxford is a registered trade mark of Oxford University Press

in the UK and in certain other countries

Published in the United States

by Oxford University Press Inc., New York

(C) Dirk Geeraerts 2010

The moral rights of the author have been asserted

Database right Oxford University Press (maker)

First published 2010

All rights reserved. No part of this publication may be reproduced, stored in a retrieval system, or transmitted, in any form or by any means, without the prior permission in writing of Oxford University Press, or as expressly permitted by law, or under terms agreed with the appropriate reprographics rights organization. Enquiries concerning reproduction outside the scope of the above should be sent to the Rights Department, Oxford University Press, at the address above

You must not circulate this book in any other binding or cover and you must impose the same condition on any acquirer

British Library Cataloguing in Publication Data

Data available

Library of Congress Cataloging-in-Publication Data

Geeraerts, Dirk, 1955-

Theories of lexical semantics / Dirk Geeraerts.

p. $\mathrm{cm}$.

Includes bibliographical references and index.

ISBN 978-0-19-870031-9 (pbk.) - ISBN 978-0-19-870030-2 (hbk.)

1. Semantics-Methodology. I. Title.

$\mathrm{P}_{325 . \mathrm{G} 42} 2009$

$401^{\prime} .43-\mathrm{dc} 22$

2009032334

Typeset by SPI Publisher Services, Pondicherry, India

Printed in Great Britain

on acid-free paper by

the MPG Books Group,

Bodmin and King's Lynn

ISBN 978-0-19-870030-2 (Hbk)

978-0-19-870031-9 (Pbk)

13579108642 
For my daughters 
This page intentionally left blank 


\section{Contents}

List of Figures

Preface

Introduction

1. Historical-philological Semantics

1.1. The birth of lexical semantics

1.1.1. Speculative etymology

1.1.2. The rhetorical tradition

1.1.3. Lexicography

1.2. The nature of meaning

1.2.1. Bréal on meaning and mind 10

1.2.2. Paul on context and usage 14

1.2.3. Variant voices 16

1.3. Classifications of semantic change 25

1.3.1. Main types of change $\quad 26$

1.3.2. Lower-level patterns 31

1.3.3. Classificatory complexities 35

1.4. Beyond historical-philological semantics 42

Further sources for Chapter 1

2. Structuralist Semantics 47

2.1. The structuralist conception of meaning 48

2.1.1. Arguing against historical-philological semantics 49

2.1.2. Types of structuralist semantics 52

2.2. Lexical field theory 53

2.2.1. Trier's concept of lexical fields 53

2.2.2. Lexical fields and syntagmatic relations 57

2.2.3. Lexical fields and formal relations 60

2.2.4. The discreteness of lexical fields 65

2.3. Componential analysis 70

2.3.1. Componential analysis in American ethnosemantics 71

2.3.2. Componential analysis in European structuralist semantics

$\begin{array}{lc}\text { 2.4. Relational semantics } & 80 \\ \text { 2.4.1. Major sense relations } & 82\end{array}$

$\begin{array}{ll}\text { 2.4.1. Theoretical issues } & 82 \\ \text { 2.4. The } & 88\end{array}$

2.5. Beyond structuralist semantics 91

Further sources for Chapter $2 \quad 98$ 
3. Generativist Semantics

101

3.1. Katzian semantics

102

3.1.1. Formal dictionary entries

102

3.1.2. The emulation of structuralist semantics 104

3.2. Tensions in generativist semantics

106

3.2.1. Minimal or maximal semantics?

106

3.2.2. Decompositional or axiomatic semantics? 113

3.3. Beyond generativist semantics

117

Further sources for Chapter 3

122

4. Neostructuralist Semantics

4.1. Elaborating the decompositional approach

126

4.1.1. Natural Semantic Metalanguage

4.1.2. Conceptual Semantics

4.1.3. Two-Level Semantics

4.1.4. Generative Lexicon

147

4.2. Elaborating the relational approach 156

$\begin{array}{lr}\text { 4.2.1. WordNet } & 158\end{array}$

$\begin{array}{ll}\text { 4.2.2. Lexical functions } & 161\end{array}$

4.2.3. Distributional corpus analysis $\quad 165$

$\begin{array}{ll}\text { Further sources for Chapter } 4 & 179\end{array}$

5. Cognitive Semantics 182

$\begin{array}{ll}\text { 5.1. Prototypicality and salience } & 183\end{array}$

$\begin{array}{lr}\text { 5.1.1. Prototypicality effects } & 184\end{array}$

5.1.2. Radial networks and polysemy 192

5.1.3. Basic levels and onomasiological salience 199

5.2. Conceptual metaphor and metonymy 203

5.2.1. Conceptual Metaphor Theory 204

5.2.2. Mental spaces and blending 210

5.2.3. Conceptual metonymy 213

5.3. Idealized Cognitive Models and frames 222

5.3.1. Idealized Cognitive Models 224

5.3.2. Frame semantics and FrameNet 225

5.4. Usage and change 229

5.4.1. Invited inference and pragmatics 230

5.4.2. Mechanisms and regularities 233

5.5. Cognitive semantics in context 239

5.5.1. Meaning in the mind 240

5.5.2. Meaning in culture and society 249

5.5.3. Meaning in text and discourse 258

$\begin{array}{ll}\text { Further sources for Chapter } 5 & 267\end{array}$ 
Conclusion

273

References

288

Author Index

328

Subject Index 


\section{List of Figures}

1.1. A comparison of Carnoy's and Stern's classification of semantic change $\quad 36$

2.1. Transitions in the German intellectual vocabulary according to Trier 55

2.2. The evolution of French maroufle according to Guiraud 61

2.3. Gilliéron's example of avoidance of homonymy 62

2.4. The classification of lexical changes according to Ullmann 64

2.5. The field of English cooking terms according to Lehrer 65

2.6. German Sessel and Stuhl according to Gipper 67

2.7. The field of 'beauty' in French according to Ducháček 69

2.8. The field of sitting furniture in French according to Pottier 76

3.1. English bachelor according to Katz and Fodor $\quad 102$

$\begin{array}{ll}\text { 3.2. English to kill according to McCawley } & 108\end{array}$

4.1. English run, put, and drink according to Jackendoff 139

4.2. English build according to Pustejovsky 149

4.3. Sample KWIC index 171

$\begin{array}{ll}\text { 5.1. Four types of prototypicality effects } & 189\end{array}$

5.2. Prototypicality effects in the category 'fruit' 191

5.3. Prototypicality effects in the extended category 'fruit' 194

5.4. Radial network analysis of 'fruit' 195

5.5. Taxonomical basic levels according to Berlin and Kay 200

5.6. The Grim Reaper according to Fauconnier and Turner 212

5.7. A prototype-based classification of metonymic patterns $\quad 218$

5.8. The COMMERCIAL TRANSACTION frame according to Fillmore and
Atkins

5.9. The diachronic onomasiology of 'match' according to Blank 238

C.1. Main lines in the theoretical history of lexical semantics 276

C.2. A semiotic triangle for lexical semantics $\quad 279$

C.3. Main lines in the descriptive history of lexical semantics 281

C.4. The parallelism between semasiology and onomasiology 284

C.5. Main lines in the methodological history of lexical semantics 286 


\section{Preface}

In spite of the growing importance of the lexicon in linguistic theory, no comprehensive overview of the major theoretical trends in lexical semantics is currently available. This book tries to fill that gap by presenting the major traditions of word meaning research in linguistics from a historical perspective, charting the evolution of the discipline from the mid nineteenth century to the present day. Its distant historical basis is a monograph written in Dutch that I published in 1986, and which contained a historical overview of lexical semantics in roughly the same way as the present one. Lexical semantics has boomed in the meantime, however, and both in structure and in detail the current text reflects the twenty years of lexical semantic research that separate it from the original publication.

Although my research efforts in the past quarter century-as a lexical semantician contributing to prototype theory and diachronic semantics, as a lexicologist studying lexical variation-have been situated specifically in the framework of cognitive semantics, this book is an outline of the major traditions, not an argument in favour of one or the other theory. But at the same time, as an overview it also presents a decidedly personal view of the discipline and its development. My theoretical preferences show up specifically in the perspective that determines the overall narrative. The relationship between meanings and concepts is one of the focal points of interest of cognitive semantics, and accordingly, how the various traditions deal with the challenges of this distinction will be a guiding theme throughout the text. More precisely, the historical lines that I will draw reveal that distinction as a dominant driving force behind the evolution of the field.

The final stage of writing the book was supported by a sabbatical leave from the University of Leuven and a grant from the FWO Research FoundationFlanders. Over the years, the list of people with whom I have been able to fruitfully discuss lexical matters has grown beyond a size fit for enumeration: I am grateful to all of them, for this book would have been so much poorer without their input. Special thanks go to Dirk Speelman, Kris Heylen and the other members of the Quantitative Lexicology and Variational Linguistics research team in Leuven, who held the fort during my leave; and to Fons Moerdijk and Gitte Kristiansen, whose critical support shored the inception 
and the completion of this manuscript like bookends. I hope that they will all be pleased with the final result, but I realize that the broad scope of the canvas to be covered implies that the strokes with which I have drawn my sketch may be too coarse for the connoisseurs. With the words of Diderot, I beg their indulgence: 'On doit exiger de moi que je cherche la vérité, mais non que je la trouve'. 


\section{Introduction}

The academic landscape of linguistics is a mountainous one. Broad vales where the main streams of research flow branch off into side valleys and even smaller dales where theories are refined and specific topics pursued. Working in their own dell of specialization, scholars will be well aware of their local disciplinary river system, but they may be less acquainted with research that lies beyond the mountain range of their own theoretical environment. They will be familiar with the highest peaks of alternative frameworks, but they may be less informed about the riches and challenges that may be found in their less visible regions. The present book, then, contributes to the cartography of linguistic lexical semantics. It will try to map out the landscape in such a way that researchers may easily acquaint themselves with the broader panorama, and may perhaps also more readily travel beyond their native territory.

But that's enough for introductory metaphor. In more concrete terms, what is the purpose of this book? This text is a synthetic attempt to present the major traditions of linguistic lexical semantic research in an accessible and insightful way. It takes a historical perspective, in the sense that the various traditions are introduced along a historical timeline starting in the middle of the nineteenth century. The presentation does not however take the form of a simple chronological enumeration of successive theories. Rather, the theoretical and methodological relationships among the approaches will be a major point of attention throughout the text. It will focus on the question how the various approaches are related to one another by links of affinity and elaboration, or rather, as the case may be, mutual opposition. A few specific questions may now be addressed to expand on this overall description.

\section{Scope}

In a nutshell, the theoretical frameworks that we will successively introduce are the following.

HISTORICAL-PHILOLOGICAL SEMANTICS-Historical-philological semantics is the diachronic approach to lexical semantics that dominated the discipline from 1850 to roughly 1930. Its basic interest lies in change of meaning; the practical results of this type of research chiefly take the form of classifications 
of mechanisms of semantic change, like metaphor, metonymy, generalization, specialization.

STRUCTURALIST SEMANTICS-Taking its inspiration from de Saussure, structuralist semantics (from 1930 onwards) rejects the atomistic approach of historical-philological semantics in favour of a systemic approach in which the mutual relations of meanings with regard to one another constitute the basis of the semantic analysis. Different approaches within structuralist semantics include lexical field theory, relational semantics, and componential analysis.

GENERATIVIST SEMANTICS-From 1960 onwards, aspects of structuralist semantics (componential analysis in particular) were incorporated into generative grammar. Within the history of lexical semantics, this period occupies a pivotal position. It introduces an attempt to formalize semantics as part of a formal grammar. At the same time, the mentalist orientation of generative grammar creates an interest in psychological adequacy. This double extension of componential analysis raises questions about formal and psychological adequacy that strongly influence the strands of research that emerged after the generativist period. Cognitive semantics focuses on the psychological side. It embodies a maximalist approach that intends to study linguistic meaning as part and parcel of cognition at large. By contrast, a number of other approaches stay closer to the structuralist inspiration, exploring forms of meaning description that are in various ways more restricted (and possibly more formalizable) than what is pursued in cognitive semantics.

NeOstruCturalist SEMANTiCs-Under this heading, we bring together the miscellaneous set of contemporary approaches that extrapolate the major types of structuralist semantics, but that do so in a post-generativist fashion. These theories build on structuralist ideas like decompositional or relational descriptions of semantic structure, but they do so with specific attention for the issues raised by generativist semantics, i.e. the possibility of formalization and the exact borderline between linguistic meaning and cognition at large.

COGNITIVE SEMANTICs-Cognitive semantics is the psychologically and cognitively oriented approach to semantics that developed from 1980 onwards. Innovations brought to the study of word meaning by cognitive semantics include prototype theory, conceptual metaphors, and frame semantics. Judged by the sheer amount of publications, this is probably the most productive framework in present-day lexical semantics. 


\section{Restrictions}

Given our initial characterization of the scope of this overview of lexical semantics, it may be useful to also mention some of the things that the book is not about.

In the first place, the focus on theoretical and descriptive linguistics means that a number of other branches of study that deal with word meaning are not directly taken into account. This is not an introduction to lexical semantics from, for instance, a philosophical, anthropological, or psychological point of view. Nor is it an introduction that focuses on lexical semantics in the context of applied linguistics-lexicography, computational linguistics, or language pedagogy. Including all these perspectives would have blown up the book beyond manageable proportions (and far beyond the expertise of the author). Also, an introduction to lexical semantics is not the same as an introduction to lexicology. The broader domain of lexicology would include topics like etymology, morphology, and social variation in the vocabulary, whereas lexical semantics concentrates strictly on meaning phenomena in the lexicon.

In the second place, this is a book about lexical semantics, not an introduction to the practice of lexical semantics. Learning how to actually conduct lexical semantics in any of the frameworks treated here would require a different type of text, focusing in particular on one of the individual approaches, or starting (as handbooks tend to do) from a set of lexical semantic phenomena, like synonymy, prototypicality or metaphor. It is not an introduction to the practice of lexical semantics, i.e. it is not a book on 'how to do lexical semantics'. It does not systematically guide the reader through a set of methods and techniques for doing actual research into word meaning, nor does it offer a wealth of study materials for the reader to practice his or her descriptive skills. Although such a book would probably be a helpful addition to the existing literature on lexical semantics, the present text has a theoretical rather than a practical orientation. It will try to show how people have actually been doing word meaning research in the last century and a half, what kind of questions they have asked and how they went about answering them. After reading the present text, readers should have become familiar with the main approaches that have dominated the history of lexical semantics-but the book does not claim that they will have acquired the skills to start doing actual research within the framework of one of those traditions themselves.

In the third place, neither is the book a full-fledged history of lexical semantics of the type that would primarily interest the historiographers of linguistics. The book does not intend to give a comprehensive picture of all 
the individual scholars who have contributed to the discipline, of the way in which their individual work evolved from one publication to another, or of the way in which they influenced one another; nor does it meticulously trace the intellectual history of such typically lexical semantic topics like synonymy or synecdoche. And from a bibliographical point of view, the book does not purport to give a state of the art report on the historiography of lexical semantics. Given its scope and its introductory purpose, the book necessarily presents no more than a selection of views, figures, and topics of research. It is a 'main lines' type of publication that should help newcomers in the field to get their theoretical orientations right, that is to say, it should help them to recognize specific studies as belonging to one or the other approach, and it should provide them with a background to compare various approaches amongst one another.

Finally, there are restrictions of a temporal and a linguistic nature. The book deals with lexical semantics in the context of modern linguistics, as an academic discipline that came into being in the course of the nineteenth century. The prehistory of lexical semantics, from Antiquity over the Middle Ages to the Age of Enlightenment, will only be touched upon briefly in the beginning of chapter 1 . Also, this is a book about the study of word meaning in the context of Western linguistics: other traditions will go unmentioned. Further, the book concentrates on research published in English, German, and French. With the possible exception of the productive Russian tradition of lexical research, it could certainly be demonstrated that these have in fact been the major publishing languages in the discipline, and at least in the earlier stages of its development, there seem to have been no major language barriers between these languages: on average, researchers from different countries seem to have been well aware of the studies being produced in other languages. In the later stages, of course, English became the medium par excellence for the transmission of ideas.

\section{Purpose and audience}

Against the background of these restrictions, what the present introduction would like to achieve can be formulated somewhat more precisely. Apart from an overview of the schools of thought and their relationships, an introduction of this type should include the main names, the main concepts, and the stock examples of lexical semantics. Even if one has become acquainted with the basic principles of the various schools of lexical semantics, one cannot claim to be well versed in lexical semantics if one is unfamiliar, say, with the name of Michel Bréal, or with the notion of conceptual metaphor, or with Katz 
and Fodor's analysis of the word bachelor. In this respect, an introduction of this kind will be successful if it can provide a number of specific types of information: it should introduce dominant ideas and frameworks; it should make the reader acquainted with the major figures in the development of the discipline; it should identify seminal publications and point to further reading.

However, the book tries to go beyond a mere description of the different approaches. It will try to provide a framework that makes sense of the succession of the different schools of thought. Lexical semantics is not a discipline in which one approach randomly follows the other. Rather, there is a certain logic behind the evolution. The book will try to reconstruct this logic — and the term reconstruct is used deliberately here: the underlying factors that will be focused on constitute a perspective, a framework that imposes a specific order on the historical materials, but that is not necessarily the only possible view of things. Two main lines of development, in fact, interconnect the theoretical approaches that will be presented in the separate chapters. On the one hand, the evolution of lexical semantics shows a great deal of progress, to the extent that the empirical domain of enquiry is systematically broadened in the process. On the other hand, the various theoretical approaches are at least partly in competition with one another, starting as they do from divergent basic assumptions. In giving an overview of these theoretical undercurrents, the Conclusion will stress that the development of lexical semantics is not just a succession of more or less unrelated approaches, but that there are both lines of contrast and similarity that link the theories to one another. The book, in other words, is concerned with the undercurrents of lexical semantics as well as with the currents, and the Conclusion explicitly tries to provide a synthetic view of the underlying factors.

The book primarily addresses all researchers in lexical semantics who are interested in the broader panorama and the historical evolution of their discipline. In a didactic context, the intended readership consists of intermediate level students of language and linguistics who have gone through an initial introduction to general linguistics and are ready to zoom in on the subdisciplines of linguistics. The intended audience is not restricted to linguists, though. The level of linguistic expertise required is minimal, so that the text might be suitable for any academic discipline in which a knowledge of this subfield of linguistics could be useful: anthropology, psychology, philosophy, literary studies, cognitive science. As mentioned above, the book does not as such offer an introduction to the study of word meaning as conducted within these neighbouring disciplines, but to the extent that they may profit from a 
closer acquaintance with linguistic lexical semantics, the book should be of some use.

\section{Organization and perspective}

The book has a chronological organization, in the sense that we will start with the oldest 'modern' form of lexical semantics, and trace the development up to the present day. Because different approaches currently co-exist, the structure cannot be purely chronological; the dominant contemporary approaches may be found both in chapter 4 and in chapter 5 . The main text of the chapters introduces the various approaches in a synthetic way, aiming for a concise presentation that is minimally cluttered by bibliographical references. The latter are to a large extent relegated to the suggestions for further reading that round off each chapter. These suggestions far from exhaust the field. Rather, they should be looked upon as mere starting-points for reading trajectories delving deeper than the schematic overview offered here. With regard to typographical conventions, italics will be used for sample words and sentences. Meanings and glosses are signalled by means of quotation marks, and small caps are used for conceptual patterns (a practice that is particularly relevant for cognitive semantics).

Taking into account that the book adopts a historical point of view, let us briefly consider the reasons for such a perspective: why pay attention to the history of the discipline at all? Wouldn't it be more appropriate to just give an introduction to the contemporary situation? There are two reasons why a historically organized introduction is useful.

First, restricting the exposé to the current situation might be acceptable if the development of the discipline is one of linear progression, in which what went before is hardly relevant for the contemporary concerns. But lexical semantics does not follow the pattern of evolution that we tend to associate with hard sciences like physics or biology. The succession of different theoretical perspectives in the study of word meaning does not in general imply that the older theory was simply refuted on empirical grounds and replaced by a better theory. Although there is, as we will try to show, a certain internal logic that connects the different stages in the development of the discipline, that logic does not imply that previous work became irrelevant as a result of subsequent steps. That too is something we will try to make clear: an awareness of older work may be fruitful for ongoing research.

Second, identifying the historical lines contributes to a better understanding of the present situation in lexical semantics. An understanding of the 
relationship between the currently fashionable theories may profit to no small extent, as the following chapters will demonstrate, from an analysis of their historical background. Precisely because they do not arise out of the blue but constitute the temporary endpoint of interconnected lines of development, it is instructive to try and describe the historical pattern behind the present-day scene. 
This page intentionally left blank 


\section{Historical-philological Semantics}

The first stage in the history of lexical semantics runs from roughly 1830 to 1930. Its dominant characteristic is the historical orientation of lexical semantic research; its main concern lies with changes of word meaningthe identification, classification, and explanation of semantic changes. Along these lines of research, a wealth of theoretical proposals and empirical descriptions was produced. Most of this has by now sunk into oblivion, however. In practical terms, the older monographs will be absent from all but the oldest and the largest academic libraries, and where they are available, there is likely to be a language barrier: most of the relevant works are written in German or French, languages that are not accessible to all. As a result, some of the topics that were investigated thoroughly in the older tradition are later being reinvented rather than rediscovered; we will see proof of this in later chapters.

An aspect of this lack of familiarity is also that the tradition is not known under a standard name. We could talk about 'traditional diachronic semantics', if we want to highlight the main thematic and methodological orientation, or about 'prestructuralist semantics' if we want to focus on its chronological position in the history of the discipline, but we will opt for 'historicalphilological semantics'. First, if we think of philology in terms of comparative philology - the study of the genetic relationships between languages and the reconstruction of protolanguages-we will see presently that traditional diachronic semantics originated in the margin of the investigation into the historical links between languages. Second, if we think of philology as the study of the cultural and historical background that is indispensable for an adequate understanding of the crucial texts, literary and others, of a certain era, we will see that traditional diachronic semantics is similarly characterized by an interpretative conception of meaning-a conception that is concerned with discovering the meanings inherent in older language materials. But these things will become clear in the course of the chapter. To begin with, we must have a look at what came before historical-philological semantics. 


\subsection{The birth of lexical semantics}

Lexical semantics as an academic discipline in its own right originated in the early nineteenth century, but that does not mean that matters of word meaning had not been discussed earlier. Three traditions are relevant: the tradition of speculative etymology, the teaching of rhetoric, and the compilation of dictionaries. Let us briefly see what each of the three traditions involves, and how they play a role in the birth of lexical semantics as an academic enterprise.

\subsubsection{Speculative etymology}

To understand the tradition of speculative etymology that reigned before the birth of comparative philology in the beginning of the nineteenth century, we have to go back to classical antiquity. In Plato's dialogue Cratylus (which may be regarded as the oldest surviving essay in the philosophy of language), Hermogenes argues with Socrates and Cratylus about the view that language is not conventional, but is rather subject to a criterion of appropriateness (Cratylus 383a, 383c-d, in the translation by Fowler 1963):

Cratylus, whom you see here, Socrates, says that everything has a right name of its own, which comes by nature, and that a name is not whatever people call a thing by agreement, just a piece of their own voice applied to the thing, but that there is a kind of inherent correctness in names, which is the same for all men, both Greeks and barbarians. [...] For my part, Socrates, I have often talked with Cratylus and many others, and cannot come to the conclusion that there is any correctness of names other than convention and agreement. For it seems to me that whatever name you give to a thing is its right name; and if you give up that name and change it for another, the later name is no less correct than the earlier.

According to the naturalist theory defended by Cratylus, the names of things should be 'right' in a very fundamental sense: they express the natural essence of the thing named. Why, for instance, is theous the name for 'god'? As one of many examples illustrating the non-conventional, non-arbitrary nature of words, Socrates explains (Cratylus 397d):

I think the earliest men in Greece believed only in those gods in whom many foreigners believe to day-sun, moon, earth, stars, and sky. They saw that all these were always moving in their courses and running, and so they called them gods (theous) from this running (thein) nature; then afterwards, when they gained knowledge of the other gods, they called them all by the same name.

Assuming that words are essentialist descriptions of the things they name, but at the same time taking for granted that the superficial form of the word as it has come down to us may hide its original constitution, etymological analysis takes the form of looking for the hidden original meaning of words. Although 
Plato's dialogue Cratylus is rather inconclusive with regard to the issues it raises, this type of speculative etymology was fully accepted up to the birth of comparative philology. An example from the Middle Ages may indicate the level of fancifulness reached.

The etymologies for Latin mors 'death' suggested in antiquity associate the word either with amarus 'bitter' or with Mars, the god of war 'who inflicts death'. Medieval authors by contrast drew the explanation of the word from the realm of Christian theology. The fifth century treatise Hypomnesticon is the first to link mors to morsus 'bite', an etymology that would be repeated by many authors: for the human race, death became a reality when the serpent in the Garden of Eden persuaded Adam and Eve to take a bite of the forbidden fruit, and God subsequently expelled them from the earthly paradise for having eaten from the Tree of the Knowledge of Good and Evil.

For our contemporary understanding, etymologies such as these are funny in a double sense: humorous and fantastic. But why exactly are they unscientific? What is it that distinguishes a speculative etymology from a scientific one? Typically, the speculative etymologies have two specific characteristics: they are based on a comparison of meanings, taking a lot of licence with the forms involved, and the entities they compare are words occurring within the same language. Without much restriction on the formal transformations that the words would have to undergo, they try to reduce a given name to other existing words. The criterion for success is whether the meaning of the reconstruction fits that of the target word, not whether the link is formally plausible.

The etymological approach that fits into the comparative philological model that developed in the nineteenth century has exactly the opposite features. First, it is primarily based on a comparison of forms rather than a comparison of meanings, and second, it focuses on the comparison of related forms in different languages. Thus, a systematic comparison of Greek theous with words like Avestan daêva 'demon', Latin deus 'god', Old Irish dia 'god', Old Norse tìvar 'gods', Old Prussian $\operatorname{deiw}(a)$ s 'god' suggests that these forms have a common Indo-European precursor. The origin of (for instance) the Greek word is not found in Greek itself, but in a protolanguage that can be reconstructed by comparing related forms. Moreover, such reconstructions are subject to formal restrictions: you can only align the Germanic form from Old Norse with the others if you can show that the word-initial $t$ in Germanic regularly corresponds with a $d$ in Latin, and similarly for the other languages. This is the notion of a sound law: the sound that we reconstruct as a $d$ in IndoEuropean, and which shows up as $d$ in Latin and other languages, surfaces on a regular basis as $t$ in the Germanic languages. Hence, Latin decem 'ten' corresponds with English ten, Dutch tien, Gothic taihun. 
So, the tradition of comparative philology with which scientific linguistics came into being in the late eighteenth and early nineteenth century straightforwardly rejected the type of thinking about word meaning that was part of the tradition of speculative etymology. But what then would be the place of diachronic lexical semantics in the new comparative paradigm? As an autonomous empirical discipline, linguistics comes into being as a form of historical research, and so, to begin with, the birth of historical linguistic semantics in the nineteenth century is merely one more aspect of the overall diachronic outlook of the first phase in the development of modern linguistics. However, the birth of semantics within that young linguistic science was not just a question of completeness, but also one of necessity. The study of meaning was not simply taken up out of a desire to study linguistic change in all of its aspects. Rather, a thorough knowledge of the mechanisms of semantic change appeared to be a prerequisite for adequate historical investigations into the formal aspects of languages-and, precisely, as a safeguard against curious and far-fetched etymologies of the kind we have been discussing. Let us have a look at an example to understand this argument better.

The methodology of comparative reconstruction requires that the word forms from different languages that are to be compared be semantically related. But such a relationship is not always obvious. For instance, throughout the older Germanic languages, there is a fairly systematic formal resemblance between words for the concept 'beech', and words for notions such as 'book' and 'letter'. Compare, for instance, Old High German buohha 'beech' and buoh 'book', or Old Saxon bôka 'beech' and bôk 'book, writing tablet'. Now, in order to justify a reconstruction of these forms as being related to the same Proto-Germanic root, their semantic relationship has to be clarified. In this particular case, an awareness of the frequently-occurring metonymical relationship between names for substances and the name of objects made of those substances (think of a glass, an iron, a cork, a paper) can be combined with archaeological evidence showing that wooden tablets were used for writing purposes. Considering a number of lexical forms as cognate requires that their semantic relationship can be plausibly established, and this in turn requires an overview of the regular mechanisms of semantic change (and of the historical context). As such, diachronic semantics was not merely taken up as an end in itself, but also as an auxiliary discipline for historical-linguistic reconstructions.

So, as a first factor in the birth of linguistic semantics, the age-old tradition of speculative etymologizing of word meanings was rejected in favour of an approach that would identify and classify regular mechanisms of semantic change: a good knowledge of such mechanisms would restrict fanciful seman- 
tic derivations of the traditional type. But where to start? If this was the initial programme for lexical semantics, where could it start looking for those mechanisms? This is where the rhetorical tradition comes in.

\subsubsection{The rhetorical tradition}

Rhetoric - the skill of using language to achieve a certain purpose, in particular, to persuade people-was a traditional part of the school curriculum from classical antiquity through the Middle Ages up to modern times. From a modern point of view, you could compare it to courses in essay writing and public speech (applied pragmatics, to put it more abstractly). Rhetoric was one of the seven subjects of the artes liberales, the liberal arts, which consisted of a set of three, the trivium, and a set of four, the quadrivium. The trivium linked up with what we would now call 'the arts', the quadrivium with the sciences. Subjects in the trivium were grammar, dialectics, and rhetoric; and subjects in the quadrivium were arithmetic, music, geometry, and astronomy. Rhetoric itself was traditionally divided into five parts: invention (the discovery of ideas for speaking or writing), arrangement (the organization of the text), style (the formulation of the ideas), memorization, and delivery. From the point of view of semantics, it is the stylistic component that is particularly important. The tradition of rhetoric (which in practice takes the form of a long series of treatises and textbooks) developed a large number of concepts to identify specific figures of speech, or 'rhetorical tropes': ways of formulation that would embellish a text or attract the attention of the audience. Some of these figures of speech are formal in nature, like alliteration, the repetition of the same sound in the beginning of several successive words: think of Caesar's veni, vidi, vici. Others involve syntactical patterns, like asyndeton, i.e. the absence of conjunctions between coordinate phrases, clauses, or words (here as well, veni, vidi, vici provides an illustration).

But a number of tropes refer to lexical and semantic phenomena, like euphemism, the substitution of an inoffensive or less offensive word for one that might be unpleasant. In Latin, the word penis originally meant 'tail', and the first meaning of vagina is 'sheath (of a sword)'; in both cases, a word with neutral associations is used for a taboo-laden concept. Metaphor and metonymy in particular are two fundamental semantic phenomena that will appear again and again in historical-philological semantics and that loomed large in the rhetorical tradition. Here is the way in which metaphor is introduced in Quintilian's Institutio Oratoria, a first-century textbook that deeply influenced the medieval and Renaissance schools of rhetoric (Quintilian VIII.6.4-9, as translated in Watson 1856): 
Metaphor is not only so natural to us, that the illiterate and others often use it unconsciously, but is so pleasing and ornamental, that, in any composition, however brilliant, it will always make itself apparent by its own lustre. If it be but rightly managed, it can never be either vulgar, mean, or disagreeable. It increases the copiousness of a language by allowing it to borrow what it does not naturally possess; and, what is its greatest achievement, it prevents an appellation from being wanting for anything whatever. [...] On the whole, the metaphor is a short comparison, differing from the comparison in this respect, that, in the one, an object is compared with the thing which we wish to illustrate. In the other, the object is put instead of the thing itself. It is a comparison, when I say that a man has done something like a lion; it is a metaphor, when I say of a man that he is a lion.

Metonymy is described as follows (Quintilian VIII.6.19-23):

Synecdoche is adapted to give variety to language by letting us understand the plural from the singular, the whole from a part, a genus from the species, something following from something preceding, and vice versa, but it is more freely allowed to poets than to orators. For prose, though it may admit mucro, 'a point' for a sword, and tectum, 'a roof' for a house, will not let us say puppis, 'a stern' for a ship, or quadrupes, 'a quadruped' for a horse. [...] From synecdoche, metonymy is not very different. It is the substitution of one word for another, and the Greek rhetoricians, as Cicero observes, call it 'hypallage'. It indicates an invention, by the inventor, or a thing possessed, by the possessor.

In view of the necessity to identify and classify regular patterns in the semantic behaviour of words, concepts such as these proved an excellent starting point for lexical semantics. At the same time, the quotations from Quintilian introduce a number of points that play a role in the development of lexical semantics. First, the demarcation between the various figures is not immediately obvious. Quintilian gives a definition of metaphor in terms of similarity, but synecdoche and metonymy are only defined by enumeration and example; also, the borderline between synecdoche and metonymy is explicitly recognized as being vague. The terminological differentiation between the mechanisms of semantic change will then obviously constitute a focus of attention for the historical-philological tradition.

Second, Quintilian's treatise is a textbook for (so to speak) professional writers and speakers, and accordingly discusses in which genres particular figures of speech may be appropriate. In contrast with the mainstream focus of the rhetorical tradition, however, historical-philological semantics looked at the rhetorical tropes not as decorative embellishments of stylistically refined texts, consciously applied by authors striving for a marked effect, but as wellentrenched features of the normal life of natural languages. Admittedly, a conception of the tropes as everyday phenomena could already be found in the 
older rhetorical treatises, as in the quotations from Quintilian. Here, to refer to another famous instance of the rhetorical tradition, is how César Chesneau Du Marsais begins his treatise Des tropes ou Des diferens sens dans lesquels on peut prendre un même mot dans une même langue of 1730 (in the original spelling):

On dit comunément que les figures sont des maniéres de parler éloignées de celles qui sont naturéles et ordinaires: que ce sont de certains tours et de certaines façons de s' exprimer, qui s'éloignent en quelque chose de la maniére comune et simple de parler [... bien loin que les figures soient des maniéres de parler éloignées de celles qui sont naturéles et ordinaires, il n'y a rien de si naturel, de si ordinaire, et de si comun que les figures dans le langage des homes. [... En éfet, je suis persuadé qu’il se fait plus de figures un jour de marché à la halle, qu'il ne s'en fait en plusieurs jours d' assemblées académiques.

(It is often said that the figures of speech are ways of speaking that are far removed from those that are natural and common; that they are formulations and ways of expression that in some respect move away from the regular and simple manner of speaking [...] But rather than being ways of speaking far removed from those that are natural and normal, there is nothing as ordinary, as usual, and as common as the figures of speech in the language of man [... In fact, I am convinced that more figures of speech are produced in one day at the market place, than in several days of an academic meeting.)

A treatise on 'the different meanings in which one may take one word in one language' (as it says in the title of Du Marsais's work) could just as well be called a treatise on semantics — but it is not until the nineteenth century that the perspective anticipated and announced by Du Marsais becomes dominant. When it does, what is the rhetorical terminology applied to?

\subsubsection{Lexicography}

Where does lexical semantics find its materials? The emerging discipline is faced with a task (to chart regular patterns of semantic behaviour) and comes equipped with an initial set of descriptive concepts (the rhetorical tropes), but what is its descriptive basis? Where do the examples come from? One source of examples is philological research into older texts, specifically, classical and biblical philology. Because the interpretation of the Greek, Latin, and Hebrew texts is often not immediately obvious, classical scholars naturally came across many intriguing instances of polysemy and semantic change. It is not a coincidence, from this perspective, that many of the earliest writers on semantic change were classical philologists. This holds for Karl Reisig, who may be credited with the oldest work in the historical-philological tradition (1839), but also for scholars like Haase, Heerdegen, Hey, and Hecht. When, in the course of the nineteenth century, interest in the older texts written in the 
modern languages increased, more such cases came to the fore in the context of medieval and Renaissance scholarship.

Another source of raw materials came from lexicography. While the earliest printed dictionaries were bilingual or multilingual dictionaries for translation, there gradually emerged an interest in dictionaries focusing on a single language. In 1612, the Accademia della Crusca in Florence published its Vocabolario degli Accademici della Crusca, a detailed monolingual dictionary of modern Italian, lavishly illustrated with quotations from literary authors. It would serve as an inspiration and a model for similar dictionaries of other European languages. The Académie française, for instance, started a dictionary project in 1635 and published a first complete version of the Dictionnaire de l'Académie française in 1694, and Samuel Johnson's Dictionary appeared in 1755. Such reference works would provide the lexical semantician of the nineteenth century with a wealth of examples of polysemous lexical itemsitems with numerous meanings whose internal relationship can be described in terms of metaphor, metonymy, and the like.

But the relationship between lexicography and lexical semantics would grow even stronger. Dictionaries such as the ones just mentioned, even though they contained actual usage data in the form of literary quotations, usually carried some degree of legislative, prescriptive intention: they were aimed at safeguarding the purity of the language, or at least describing normatively accepted usage. In the course of the nineteenth century, a new, more purely descriptive dictionary enters the scene: the historical dictionary that intended to chart the development of the language from the earliest origins to the present day. Major examples include the Deutsches Wörterbuch (started by Jakob and Wilhelm Grimm, 1854-1954), the Dictionnaire de la langue française (by Emile Littré 1877), the Oxford English Dictionary (founded by James Murray, 1884-1928), and-the largest dictionary in the world by any count-the Woordenboek der Nederlandsche Taal (started by Matthias de Vries in 1864, and completed in 1998). Here is how Murray (1884: vi) describes the purpose of the dictionary in the Preface to the first volume; it intends

(1) to show with regard to each individual word, when, how, in what shape, and with what significations it became English; what development of form and meaning it has since received; which of its uses have in the course of time become obsolete, and which still survive; what new uses have since risen, by what processes, and when: (2) to illustrate these facts by a series of quotations ranging from the first known occurrence of words to the latest, down to the present day; the word being thus made to exhibit its own history and meaning: and (3) to treat the etymology of each word strictly on the basis of historical fact, and in accordance with the methods and results of modern philological science. 
This statement brings together the lines we have indicated before: the interest in the semantic evolution of words, and the aspiration towards a scientific etymology. The grand historical dictionary projects that were started in the nineteenth century derive from the same concern as diachronic lexical semantics: a fascination with the correct description of the historical development of words and meanings. They testify that the nineteenth-century interest in the semantic histories of words led to a hitherto unsurpassed amount of descriptive work. As another indication of the intellectual link between theoretical semantics and lexicographical practice, we may note that two important theoreticians were at the same time the editors of a major dictionary: Paul compiled a Deutsches Wörterbuch (1897), and Darmesteter co-edited a Dictionnaire général de la langue française (Darmesteter and Hatzfeld 1890).

To summarize, when lexical semantics originates as a linguistic discipline, speculative etymology serves as a negative role model; lexicography and textual philology provide an empirical basis of descriptive lexicological data, and the tradition of rhetoric offers an initial set of terms and concepts for the classification of lexical semantic phenomena. But what exactly does the newborn discipline do with these starting points?

\subsection{The nature of meaning}

At the beginning of his Griechische Bedeutungslehre, Max Hecht sums up the disciplinary position of historical-philological semantics (1888: 5):

Insofern sie zugunsten der Lexikographie die Bedeutungen in zeitlicher Folge ordnet und im Interesse der Etymologie die Gesetze der Bedeutungsänderung aufstellt, hat sie sprachwissenschaftlichen Wert. Soweit sie aber diese Gesetze aus der Natur des Geistes herleitet und eine Geschichte der Vorstellungen gibt—Bedeutungen sind Vorstellungen—, fällt sie auf das Gebiet der empirischen Psychologie.

(Semantics is linguistically valuable to the extent that it chronologically classifies meanings in the interest of lexicography, and writes down the laws of semantic change in the interest of etymology. To the extent, however, that it derives these laws from the nature of the mind and that it writes a history of ideas - meanings are ideas-it falls within the realm of empirical psychology.)

This quotation (which will, incidentally, turn out to be quite important when we describe the transition from historical-philological to structuralist semantics) nicely ties in with the background sketched in the previous section: diachronic semantics is concerned with the classification of mechanisms of semantic change, an activity that links up with lexicography on the one hand and historical linguistics on the other. At the same time, Hecht's quotation introduces an additional aspect of historical-philological semantics: it is an 
approach that assumes a psychological conception of meaning, one in which the linguistic phenomena under study are seen as revealing characteristics of the human mind. These two perspectives in fact demarcate the domain of historical-philological semantics. On the one hand, it produces a wealth (not to say a plethora) of systems for the classification of semantic change. On the other, it engages in a thorough reflection on the nature of semantic facts.

In this section and the following one, we will take a closer look at both aspects of historical-philological semantics. In both cases, we will illustrate the historical-philological approach by looking more closely at the opinions of a few major figures representing the mainstream of this tradition. At the same time, we will briefly describe the differences of opinion and the diverging perspectives that inevitably exist within this extremely productive framework.

With regard to the psychological orientation of historical-philological semantics (which forms the focus of the present section), three steps need to be taken. First, we will introduce the overall characteristics of the approach on the basis of the work of the French linguist Michel Bréal. Next, we look at the very important addition to the psychological approach formulated by the German linguist Hermann Paul: he spells out the importance of context and usage for the explanation of semantic change. (It is no coincidence, by the way, that we focus on Bréal and Paul: France and Germany were the dominant countries in this period of the development of lexical semantics, and Bréal and Paul were leading figures within those national traditions.) And finally, we will add a number of nuances by looking at differences of opinion or perspective that exist within the psychological orientation of historical-philological semantics.

\subsubsection{Bréal on meaning and mind}

How then, to begin with, can we characterize the overall methodological and theoretical profile of a psychologically oriented historical-philological approach? There are three prominent features, which we will illustrate with quotations from Bréal (1897), not because Bréal is the first or the single most important exponent of historical semantics, but because his highly influential work clearly expresses the major methodological ideas. The three characteristics listed here need not be simultaneously present in all of the works belonging to the historical-philological era; they do, however, adequately characterize the basic methodological outlook that is shared by a majority of the semantic studies in this period. (But we will come back to the dissident voices in a moment.) 
First, it can hardly come as a surprise, after what we saw in the previous section, that semantics is defined as a historical discipline. Already on the first page of Bréal's Essai de sémantique, the diachronic orientation of semantics is indicated as an intuitively obvious matter of fact. Talking about linguistics, Bréal notes (1897: 1-3):

Si l'on se borne aux changements des voyelles et des consonnes, on réduit cette étude aux proportions d'une branche secondaire de l'acoustique et de la physiologie; si l'on se contente d'énumérer les pertes subies par le mécanisme grammatical, on donne l'illusion d'un édifice qui tombe en ruines; si l'on se retranche dans de vagues théories sur l'origine du langage, on ajoute, sans grand profit, un chapitre à l'histoire des systèmes. Il y a là, iI me semble, autre chose à faire [... ] La linguistique parle à l'homme de lui-même: elle lui montre comment il a construit, comment il a perfectionné, à travers des obstacles de toute nature et malgré d'inévitables lenteurs, malgré même des reculs momentanés, le plus nécessaire instrument de civilization.

(If one restricts oneself to the study of the changes of vowels and consonants, this discipline is reduced to a secondary branch of acoustics and physiology; if one merely enumerates the losses suffered by the grammatical mechanism, one creates the illusion of a building tumbling into ruins; if one hides behind vague theories about the origin of languages, one adds, without much profit, a chapter to the history of systems. There is, it seems to me, something else to be done [...] Linguistics talks to man about himself: it shows how he has constructed, how he has perfected, through difficulties of all sorts and in spite of an inevitable inertia, in spite even of temporary retreats, the most indispensable tool of civilization.)

It is even the case that an adequate understanding of words in their contemporary meaning requires a thorough knowledge of their semantic history: 'L'histoire peut seule nous donner aux mots le degré de précision dont nous avons besoin pour les bien comprendre' (Only history can give to the words the degree of precision that we require to understand them adequately) (1897: 124).

Second, Bréal highlights the psychological orientation of the study of meaning. There are actually two aspects to this: linguistic meaning in general is defined as a psychological phenomenon, and, more specifically, change of meaning is the result of psychological processes. With regard to the first feature, meanings are considered to be psychological entities, i.e. (kinds of) thoughts or ideas: '[Le langage] objective la pensée' (Language makes thought objective) (Bréal 1897: 273). The mental status of lexical meanings links up directly with the overall function of thinking, i.e. with the function of cognition as a reflection and reconstruction of experience. Language, one could say, has to do with categorization: it stores cognitive categories with which human beings make sense of the world: 'Le langage est une traduction de la réalité, une transposition où les objets figurent déjà généralisés et classifiés par 
le travail de la pensée' (Language is a translation of reality, a transposition in which particular objects only appear through the intermediary of the generalizing and classificatory efforts of thought) (1897: 275). Language, then, is not autonomous; it is linked with the total set of cognitive capacities that enable men to understand the world with ever more refined conceptual tools, and it is embedded in their experience of the world.

If meaning as such consists of cognitive categories-a psychological type of entity-then meaning changes must be the result of psychological processes. That is to say, the general mechanisms of semantic change that can be derived from the classificatory study of the history of words constitute patterns of thought of the human mind. Bréal calls these mechanisms 'les lois intellectuelles du langage' (the conceptual laws of language), but he hastens to add that 'law' means something different here than in the natural sciences: a law of semantic change is not a strict rule without exceptions, but it represents a tendency of the human cognitive apparatus to function in a particular way. In a passage that opposes restricting linguistics to the study of the formal aspects of language, he remarks (1897: 338-9):

Nous ne doutons pas que la linguistique, revenant de ses paradoxes et de ses partis pris, deviendra plus juste pour le premier moteur des langues, c'est-à-dire pour nousmêmes, pour l'intelligence humaine. Cette mystérieuse transformation qui fait sortir le français du latin, comme le persan du zend et l'anglais de l'anglo-saxon, et qui présente partout sur les faits essentiels un ensemble frappant de rencontres et d'identités, n'est pas le simple produit de la décadence des sons et de l'usure des flexions; sous ces phénomènes où tout nous parle de ruine, nous sentons l'action d'une pensée qui se dégage de la forme à laquelle elle est enchaînée, qui travaille à la modifier, et qui tire souvent avantage de ce qui semble d'abord perte et destruction. Mens agitat molem.

(We do not doubt that linguistics, giving up its paradoxical prejudices, will give a fairer treatment to the primary forces in languages, i.e. to ourselves and to human intelligence. The mysterious transformation that makes French grow out of Latin (just as Persian out of Zend, and English out of Anglo-Saxon), and that everywhere shows a remarkable set of similarities and parallelisms with regard to its essentials, is not simply the product of the decay of sounds and the wearing off of endings. Behind these phenomena in which everything seems to speak of decay, we feel the active efforts of human thought liberating itself from the form in which it is constrained, trying to modify it, and very often turning to its advantage what at first sight appears to be mere loss and destruction. Mind moves matter.)

The moving force of the human mind also shows up in the fact that the fundamental factor that brings the psychological mechanisms of semantic change into action consists of the communicative needs of the language user. Languages change because people try to express their thoughts as accurately and satisfactorily as possible (Bréal 1897: 8): 
Le but, en matière de langage, c'est d'être compris. L'enfant, pendant des mois, exerce sa langue à proférer des voyelles, à articuler des consonnes: combien d'avortements, avant de parvenir à prononcer clairement une syllabe! Les innovations grammaticales sont de la même sorte, avec cette différence que tout un peuple y collabore. Que de constructions maladroites, incorrectes, obscures, avant de trouver celle qui sera non pas l'expression adéquate (il n'en est point), mais du moins suffisante de la pensée.

(The goal, as far as language is concerned, is to be understood. During months, the child exercises his tongue to produce vowels, to articulate consonants: how many failures, before he can clearly pronounce a syllable! On the grammatical level, innovations are of the same sort, with this difference that an entire people is involved. How many clumsy, incorrect, obscure constructions, before the one is found that will be, not the perfect expression of thought (there is none), but at least a sufficient expression of it.)

The psychological orientation of semantics has methodological consequences (this is the third major feature of the historical-philological approach). In the following quotation, Bréal does not simply repeat the point that semantics is a historical science, but he also has something to say about the way in which that scientific project is put into practice (1897: 278):

Si l'on admet une différence entre les sciences historiques et les sciences naturelles, si l'on considère l'homme comme fournissant la matière d'un chapitre à part dans notre étude de l'univers, le langage, qui est l'oeuvre de l'homme, ne pourra pas rester sur l'autre bord, et la linguistique, par une conséquence nécessaire, fera partie des sciences historiques.

(If one admits that there is a distinction between the historical and the natural sciences, that is, if one considers man as being the subject matter of a separate chapter of our study of the universe, language (which is the product of man), cannot stay on the other side, and linguistics will inevitably be a branch of the historical sciences.)

Although Bréal does not mention the word as such, semantics as he describes it here is a hermeneutic discipline in the sense of the German philosopher Wilhelm Dilthey. Clearly, the natural sciences also study historical processes (as in geology or the study of biological evolution), and that is why the difference between the natural and the human sciences that is mentioned in the quotation has to be sought on the methodological level rather than on the level of the subject matter of both approaches. The distinction made by Bréal probably refers to the theories of Dilthey, whose views on the relationship between the natural and the human sciences (Naturwissenschaft versus Geisteswissenschaft) were widely popular near the end of the nineteenth century (see e.g. Dilthey 1910). The methodological independence of the human sciences with regard to the natural sciences resides in the fact that they try to understand, by means of an empathetic process of interpretation (Verstehen, understanding or comprehension), the cultural forms of expression in which men have, throughout history, laid down their experience of the world. 
The natural sciences, on the other hand, try to explain the characteristics of the material world by means of rigid laws. Next to having a historical and cultural orientation, the human sciences in the Diltheyan sense are hermeneutical par excellence: they try to reconstruct the original experience that lies at the basis of particular forms of human expression that have been transmitted from earlier times to the present day; they look for the expressive intention behind historical forms of expression.

The connection between the Diltheyan conception of the human sciences and the kind of linguistic semantics sketched above will be clear: through its historical approach, through its experiential orientation, and through the importance it attaches to the expressive intentions of language users as the source of linguistic change, historical-philological semantics fits nicely into the Diltheyan view of the human sciences. This is reflected on the methodological level. Because linguistic semantics is a historical discipline, its primary material consists of texts from dead languages or from previous stages in the development of a living language. Its basic methodological procedure is therefore the interpretation of those texts. Only afterwards can changes between periods (and the mechanisms guiding them) be recognized, classified, and explained. The primary methodological step of the historical semantician is that of the historical lexicographer and the philological scholar: to interpret historical texts against the background of their original context by trying to recover the original communicative intention of the author.

In sum, if we take Bréal as our starting point, historical-philological semantics is characterized by a focus on the dynamism of language, by a cognitive, psychological conception of meaning, and by an interpretative methodology. But how does a Bréal-like approach deal with the collective side of the language? This is where Hermann Paul's view of semantics provides an answer.

\subsubsection{Paul on context and usage}

If you focus on the individual creative acts that innovatively change the language, what exactly is the relationship with 'the language', given that language is indeed something more than a purely individual phenomenon? How does innovative individual behaviour relate to language as a shared institution? Hermann Paul's specification of a psychological conception of semantics, to which we now turn, provides an answer to precisely that problem. (His views are formulated in his influential introduction to historical linguistics, Prinzipien der Sprachgeschichte, first published in 1880 . The quotes below are from the 5th edition of 1920.)

The first pillar of Paul's approach involves the distinction between the 'usual' and the 'occasional' meaning of an expression. The usual meaning 
(usuelle Bedeutung) is the established meaning as shared by the members of a language community. The occasional meaning (okkasionelle Bedeutung) involves the modulations that the usual meaning can undergo in actual speech (1920: 75 ).

Wir verstehen also unter usueller Bedeutung den gesamten Vorstellungsinhalt, der sich für den Angehörigen einer Sprachgenossenschaft mit einem Worte verbindet, unter okkasioneller Bedeutung denjenigen Vorstellungsinhalt, welchen der Redende, indem er das Wort ausspricht, damit verbindet, und von welchem er erwartet, dass ihn auch der Hörende damit verbinde.

(By 'usual meaning', we understand the total representational content that is associated with a word for any member of a speech community. By 'occasional meaning', we understand the representational content that an interlocutor associates with a word when he uses it, and which he expects the hearer to associate with the word as well.)

If the usuelle Bedeutung is like the semantic description that would be recorded in a dictionary (fairly general, and in principle known to all the speakers of a language), then the okkasionelle Bedeutung is the concretization that such a general concept receives in the context of a specific utterance. The second pillar of Paul's conception of semantics is the insight that context is all-important to understand the shift from usual to occasional meaning. We can easily appreciate this point if we look at a number of different types of occasional meaning, and the way in which they derive from the usual meaning.

To begin with, let us note that there can be various usual meanings to a word: if a word is polysemous, the usual meaning involves a set of related meanings, a cluster of different well-established senses. The occasional meaning, on the other hand, is always a single reading. In many cases, then, realizing the occasional meaning amounts to selecting the appropriate reading from among the multiple established senses of a word. Paul highlights the importance of context in this process. German Blatt is likely to be interpreted differently in the context of a bookshop than when you are having a walk in the woods: 'sheet of paper' in the former case, 'leaf' in the latter.

In other cases, the contextualization of the usual meaning involves not a selection of one reading from among many existing ones, but the concrete specification of a more general sense. The word corn, for instance, used to be a cover term for all kinds of grain, but was differently specialized to 'wheat' in England, 'oats' in Scotland, and 'maize' in the United States, depending on the dominant variety of grain grown in each of these countries. Again, it is the context of use that triggers the specialized meaning.

Finally, there are instances in which the contextualized meaning does not contain all the features of the usual meaning. In a metaphoric expression like 
das Feuer der Leidenschaft 'the fire of passion', the combination of 'fire' with 'passion' signals that Feuer cannot be taken in its original reading.

So we see how the interplay of contextual triggers and usual meanings can give rise to occasional meanings. But what about the reverse process? How can occasional meanings give rise to usual meanings? The third pillar of Paul's views consists of a dialectic relationship between language structure and use: occasional meanings that are used very often may themselves become usual, i.e. they may acquire an independent status. So, on the one hand, usual meanings are the basis for deriving occasional ones, but on the other, the contextualized meanings may become conventional and decontextualized. The clearest criterion for a shift from the occasional to the usual level is the possibility of interpreting the new meaning independently. If corn evokes 'wheat' without specific clues in the linguistic or the extralinguistic environment, then we can be sure that the sense 'wheat' has become conventionalized.

In this way, Paul develops a pragmatic, usage-based theory of semantic change: the foundation of semantic change is the modulation of usual meanings into occasional meanings. And the mechanisms of semantic change that semanticians are so eager to classify are essentially the same mechanisms that allow speakers to modulate those usual meanings: in the corn and Feuer examples, we can see how specialization of meaning and metaphor (two types of semantic change that would traditionally be mentioned in classifications of semantic change) operate at the concrete utterance level.

\subsubsection{Variant voices}

The psychological conception of meaning so clearly expressed by Bréal and Paul is the mainstream view of historical-philological semantics: by and large, it is the view of writers like Wegener (1885), Hecht (1888), Hey (1892), Stöcklein (1898), Thomas $(1894,1896)$, Waag (1908), Erdmann (1910) in Germany, Paris (1887), Roudet (1921) and Esnault (1925) in France, Wellander (1917, 1921) in Sweden, Nyrop (1901-34, 1913) in Denmark, Van Helten (1912-13) in The Netherlands, Whitney (1875) and Oertel (1902) in the United States. But it is not the only view, and it did not gain prominence immediately. Moreover, the overall psychological orientation leaves room for a number of variants. Let us therefore try to summarize the main differences of opinion. We will have a look at four different lines of research: first, the 'logicalclassificatory' approaches that do not start from a psychological conception of meaning; second, alternative conceptions of the psychological aspects of meaning (which we introduced on the basis of Breal); third, extensions of the contextual view (which we introduced on the basis of Paul); and fourth, the introduction of onomasiological research. In chronological terms, the voices mentioned in this section come both from before and after the formulation 
of the standard view that we associate with Paul and Bréal. The differences of opinion and perspective discussed here far from exhaust the discussions that took place within the historical-philological tradition, but instead explore a number of major questions.

1 To begin with, the psychological orientation did not emerge immediately. In the first half of the nineteenth century, up to the 1860 , the focus lay on the mere identification of regular patterns of semantic development and the classification of those pathways of change, rather than on the cognitive background of such phenomena. This approach, which is often called 'logicalclassificatory' or 'logical-rhetorical' in contrast to 'psychological-explanatory', may be found in the work of Reisig (1839), Haase (1874-80), and Heerdegen (1875-81).

The essential distinction between the two approaches is the role of causality in semantics. One of the main reasons why scholars like Bréal and Paul opt for a psychological perspective is that it may provide an explanation for semantic change; as we saw in the quote from Bréal, words may change their meaning because language users are trying to express something new: individual speakers of the language change the language to adapt it to their needs. By contrast, the logical-classificatory approach either devotes less attention to explanatory questions, restricting its endeavours to the identification and classification of changes, or naively attributes the changes to 'the life of the language' rather than to the activity of the language user.

2 Expressions like 'the life of the language' would indeed seem to suggest that languages are entities in themselves, with an independent existence of their own. This is not an uncommon metaphor in nineteenth-century linguistics; a comparative philology that draws up 'family trees' describing how one 'mother language' may historically develop into several 'daughter languages' draws on the same image. In semantics, Arsène Darmesteter's La vie des mots (1887, first published in English 1886) is a prominent example of such an organicist metaphor. The book opens with the statement that 'les langues sont des organismes vivants dont la vie, pour être d'ordre purement intellectuel, n'en est pas moins réelle et peut se comparer à celle des organismes du règne végétal ou du règne animal' (Languages are living organisms the life of which, even though it is purely intellectual, is in no way less real, and may be compared to that of the organisms in the vegetable or animal kingdom) (1887:3). The organicist metaphor is then expanded throughout the book: there is a chapter on 'How words are born', one on 'How words live together', and a final one on 'How words die'.

Such an organicist metaphor obviously does not explain very much: as Bréal emphasized, you need a mind to get language moving. But whose mind? When 
we consider that question, we come across a difference of perspective within the group of psychologically inclined researchers. Bréal and Paul focus on the individual: you need the mind of the language user to get language moving. But Wilhelm Wundt's Völkerpsychologie (or 'peoples' psychology') (1900) takes a rather more collective approach: given that language is a collective entity rather than a purely individual one, the mind that is expressed in the language is primarily the mind of a people-a Volksgeist, in other words, the typical 'spirit of a nation or people' that defines their specific identity. The basics of the Völkerpsychologie were defined by Moritz Lazarus (1856-7) and Hermann Steinthal (1860), who co-founded the Zeitschrift für Völkerpsychologie und Sprachwissenschaft. They argued that individuals are heavily influenced in the way they think, feel, and act by the group to which they belong-and predominantly by the Volk, people or nation, of which they are a member. The specific 'soul' or 'spirit' of such a nation or people may be studied in the products in which it expresses itself, as in language.

This idea in itself had a considerable pedigree in German thinking: it had been typical of Romanticism, notably in the philosophy of Johann Gottfried von Herder, and it played a prominent role in the views of Wilhelm von Humboldt (1836). Von Humboldt, in fact, was important for the development of semantics because he introduced a conceptual distinction between an outer and an inner linguistic form (äussere Sprachform, innere Sprachform). The outer linguistic form is the material, phonetic side of language; the inner form is the specific semantic structure, lexical or grammatical, that lies behind the outer form and that differentiates one language from another. And it is precisely because languages carry with them different inner patterns of meaning that they can embody the specific view of a language community. Lazarus and Steinthal, then, built on Humboldt by taking his ideas to psychology, where they were further explored by Wundt.

Wundt (who is known as the father of experimental psychology, because he was the founder of the first psychology laboratory and exerted a major influence on the development of modern psychology) developed the Völkerpsychologie by focusing on three types of symbolic expression: language, myths, and customs. Not surprisingly, then, one of the ten volumes of his monumental Völkerpsychologie (1900) is devoted entirely to language and semantic change. However, except for some influence that he exerted on the classification of semantic changes, Wundt's Völkerpsychologie programme was not a big success in linguistics. In fact, the basic problem regarding the explanation of semantic change remained as unsolved as in an organicist conception of language. Postulating a collective mind does not explain how such a shared set of beliefs and values can emerge or change-unless you accept the unlikely assumption that it has an existence and a life of its own. 
(As we will see later, the impact of Humboldt does not stop with Wundt: a number of views in the structuralist era, like Weisgerber's, were influenced by Humboldt's idea of an 'inner form of language'.)

A rather different form of variation within the psychological approach involves the type of mental phenomena that lexical semantics focuses on. When one thinks of meaning as a mental, cognitive phenomenon, attention is automatically drawn towards descriptive concepts: the meaning of an expression like Christmas tree would be something like 'an evergreen tree (or an artificial imitation of it) that is put up in or near the house during the days surrounding Christmas and that is decorated with lights, baubles, festoons and the like'. However, the cognitive content of a word goes well beyond this immediate descriptive concept, and a number of researchers in the tradition of historical-philological semantics draw attention to the importance of such a wider notion of conceptual value. Karl Otto Erdmann (1910), in particular, introduces a set of terms that captures two important aspects of such a broader view of lexical meaning: Nebensinn and Gefühlswert. Nebensinn refers to the conceptual associations of an expression: what Christmas tree calls up mentally is not just the notion of a decorated tree, as defined above, but also the thought of a typical atmosphere, presents, family reunions, a special dinner, etc. All these associations belong to the knowledge we have of Christmas trees, and even if the features in question would not apply to all possible Christmas trees, they certainly relate to the typical Christmas tree, allowing for cultural differences. A psychologically oriented form of semantics necessarily has to include a description of this broader network of associations, if it is to do justice to the mental status of an expression like Christmas tree. Gefühlswert refers to the emotional value of words, in the sense in which words like boozed up, plastered, sodden have a more negative overtone than drunk - in the same way in which drunk itself is less neutral than inebriated or intoxicated.

In contemporary terminology, Nebensinn and Gefühlswert together could be referred to by the concept of 'connotation', i.e. the associated concepts, values, and feelings of a word, in contrast with 'denotation', as the primary referential meaning. Both notions are important for the further unfolding of our story. As far as the inclusion of Nebensinn in the scope of semantics is concerned, although it might seem pretty obvious when formulated in this way, it evokes one of the major tensions in the history of lexical semantics: how restrictive can or should a semantic description be? In particular, should it include the full range of cognitive associations of a word? This is a question we will have to come back to a number of times in the course of our story, and as we will see, it involves some of the basic underlying differences of opinion within lexical semantics. Gefühlswert, on the other hand, played a more direct 
role in the further development of historical-philological semantics. To begin with, as in Jaberg (1901, 1903, 1905), Schreuder (1929), Van Dongen (1933), the different ways in which the emotive value of a word may change need to be incorporated into a classification of semantic changes, and the specifics of the developments need to be described. The major types of emotive meaning change that are usually distinguished are pejorative change, i.e. a shift towards a (more) negative emotive meaning, and ameliorative change, i.e. shift towards a (more) positive emotive meaning. We will come back to this classificatory issue in section 1.3.1.

Going beyond such a classification of shifts of emotive meaning, scholars such as Sperber $(1914,1923)$ or Van Ginneken (1911-12, 1912-13) argue that emotive expressivity is a major cause of semantic change. A famous example is Sperber's analysis of metaphors used by frontline soldiers in World War I: a machine gun, for instance, was called machine à coudre (sewing machine) or moulin à café (coffee grinder). Sperber notes that the objective similarities which may explain the metaphoric image, like the sound that the machines make, explain only part of the metaphoric image. More important is the affective impact of the metaphor: the positive associations of the domestic objects that serve as a source for the metaphoric image remove some of the threat posed by the weapon that is the target of the image. The motivation for using the metaphor is not a conscious conceptual expressive need (talking about something that has no name yet), but instead a largely unconscious emotional need: the desire to neutralize the negative value of a lethal weapon by familiarizing it. Sperber's insistence on the role of such emotive factors in linguistic change aims to be a correction to Bréal's rather voluntaristic image of expressive needs: expressive needs do not only consist of the rational wish to communicate ideas, but can also be triggered by subconscious psychological stimuli.

3 Let us now turn to the third group of variant voices that we need to consider. In the previous group, we met with alternative conceptions of the psychological aspects of the standard model: a more collective interpretation, as in the Völkerpsychologie movement, or a more emotive interpretation, as in the work of Erdmann, Jaberg, or Sperber. In the present group of approaches, we accordingly look at alternative conceptions of the second pillar of the standard model, which we illustrated with the work of Paul. The dialectic relationship between language structure and use implies a contextualist view of meaning: meanings are modulated in the context of actual language use; that is how an okkasionelle Bedeutung comes into existence next to the usuelle Bedeutung. But the notion of context is obviously fairly broad: how exactly should it be filled in? There are two specific approaches that we will now 
focus on: a sociosemantic one, which gives a sociological interpretation of the contextualist aspects of historical-philological semantics, and a communicative one, which gives a pragmatic interpretation.

The sociosemantic approach originates in the work of Antoine Meillet (1906); it is further represented by Vendryès (1921) and to some extent by Nyrop (1913). The essential idea is that the social group in which a word is used may differentiate between polysemous readings of a word, or may lead to meaning change. Paul himself, as we saw, had already drawn attention to linguistic and extralinguistic context factors: the words with which a target word is combined (we used das Feuer der Leidenschaft as an example) or the situation in which it is used (which we illustrated with Blatt and its different readings). Meillet, then, adds social group as an important (to Meillet, perhaps all-important) context factor.

For one thing, social context differentiates between different senses. Referring to an example of Bréal's, Meillet notes that the polysemy of opération is resolved in different social contexts: for a mathematician it refers to calculations, for a doctor it refers to medical surgery, for a worker it invokes the functioning of a piece of machinery, and so on. Further, such contexts may not only disambiguate, they may also be the cause of semantic differentiation, when a new meaning arises within a specific social group. That is how Meillet explains the meaning 'to arrive' of French arriver, which etymologically means 'to reach the shore'. Arriver is derived from the reconstructed Latin form adripare, in which ripa is 'shore'. Within the social group of sailors, disembarking has the consequence of reaching one's destination, and when the word is taken over by the larger community of language users, only the latter reading is retained. Although the proponents of the sociosemantic approach may sometimes suggest the opposite, social factors such as these do not really compete with the traditional mechanisms of change (like metaphor and metonymy), but rather work together with them. In the example, the shift from 'to reach the shore' to 'to reach one's destination' is easily recognized as a metonymy, while at the same time the social background of the change is obvious.

For the pragmatic (rather than sociological) specification of the contextualist position, the essential idea is that context needs to be seen from a communicative point of view: meanings are dynamic not only as a function of the (situational or social) context, but also-and perhaps primarily-as a function of the communicative interaction between language users. This position is characterized in a nutshell by Wegener's statement 'dass die Worte zunächst nicht als Lautgefässe mit bestimmtem Inhalte erlernt werden, sondern als Mittel zu bestimmten Zwecken' ('that words are not primarily learnt as phonetic vessels with a clearly delineated content, but as instruments with a specific goal', 1885: 72). Words are tools for human interaction—for persuading, 
promising, pleasuring, passing on information-and their semantics has to be described accordingly. The consequences of this recognition are clearly articulated by Erdmann. He notices, to begin with, that not only polysemy but also vagueness is rampant in the lexicon. What for instance, is the meaning of der Deutsche, 'the German' (1910: 3)? When is someone a German? Various features may play a role: citizenship of the German Reich (remember that we are still before World War I), mother tongue, or descent. When the three features coincide, there is no problem, but when only one or two of the features can be applied, discussion may arise. The general model of word meaning that Erdmann derives from this recognition deserves a longer quotation, because it anticipates a number of developments further on in the history of lexical semantics (1910: 5).

Worte sind vielmehr im allgemeinen Zeichen für ziemlich unbestimmte Komplexe von Vorstellungen, die in mehr oder minder loser Weise zusammenhängen [...] Die Grenzen der Wortbedeutung sind verwaschen, verschwommen, zerfliessend. Treffender aber noch wird meines Erachtens der Sachverhalt gekennzeichnet, wenn man überhaupt nicht von Grenzlinien des Umfangs redet, sondern [...] von einem Grenzgebiet, das einen Kern einschliesst. [... ] Den Kern denken wir uns dann alle diejenigen Dinge oder anderen Vorstellungen enthaltend, denen unter allen Umständen die Benennung durch das fragliche Wort zukommt, während wir dem Grenzgebiet alle diejenigen Vorstellungen weisen, denen man die Benennung sowhol zu- wie absprechen kann.

(Words in general are rather signs for fairly unspecific complexes of mental representations that belong together more or less loosely [...] The boundaries of word meanings are vague, unclear, indeterminate. The situation is, I think, even more adequately described if one simply does not talk about the borderline of the range of a word, but [...] if one talks about a border area that includes a central one. [... In the central area we situate those things and other representations that would under all circumstances deserve to be named by the word in question, while in the border area we situate all those representations for which the name may or may not hold.)

Now, it would be easy to evaluate this vagueness as a defect of the language, as something that needs to be overcome; but if one takes a communicative perspective, it can be readily appreciated that the vagueness is often communicatively real. Take the German politician Bismarck's dictum Wir Deutsche fürchten Gott und sonst nichts in der Welt, 'we Germans fear God and nothing else in the world'. If we were to ask Bismarck, Erdmann argues (1910: 46), whether his statement also applies to the German-speaking Swiss or to speakers of Polish living within the boundaries of the German state, the answer would probably be that he simply did not have all those distinctions in mind, and that they are of no significance for his utterance. Communicatively 
speaking, in other words, the underspecified border area of the lexical concept is not disturbing.

4 The fourth line of research emphasizes the importance of an onomasiological perspective in lexicology. Although it has hardly found its way into the canonical English terminology of linguistics, the distinction between onomasiology and semasiology is a crucial one in the European tradition of lexicological research. Although it falls outside the period we are investigating in this chapter, the following quote from Kurt Baldinger illustrates the distinction quite nicely: 'Semasiology [...] considers the isolated word and the way its meanings are manifested, while onomasiology looks at the designations of a particular concept, that is, at a multiplicity of expressions which form a whole' (1980: 278). The distinction between semasiology and onomasiology, in other words, equals the distinction between meaning and naming: semasiology takes its starting point in the word as a form, and charts the meanings that the word can occur with; onomasiology takes its starting point in a concept, and investigates by which different expressions the concept can be designated, or named. Between the two, there is a difference of perspective: semasiology starts from the expression and looks at its meanings, onomasiology starts from the meaning and looks at the different expressions.

The term 'onomasiology' was introduced by Adolf Zauner (1903) in his study on body-part terms in the Romance languages, but that does not mean that onomasiological topics were absent from the earlier tradition. Let us first note that, from a diachronic perspective, one obvious way of filling in an onomasiological perspective would be an enquiry into lexicogenetic mechanisms. Lexicogenesis involves the mechanisms for introducing new pairs of word forms and word meanings-all the traditional mechanisms, in other words, like word formation, word creation (the creation of entirely new roots), borrowing, blending, truncation, ellipsis, or folk etymology, that introduce new items into the onomasiological inventory of a language. From this point of view, onomasiological change involves change in the lexicon at large, and not just changes of word meaning — but crucially, the semasiological extension of the range of meanings of an existing word is itself one of the major mechanisms of onomasiological change-one of the mechanisms, that is, through which a concept to be expressed gets linked to a lexical expression. In this sense, the study of onomasiological changes is more comprehensive than the study of semasiological changes, since it encompasses the latter (while the reverse is obviously not the case).

Now, although basically concerned with semasiological changes, the major semasiological treatises from Reisig (1839) to Stern (1931) do not restrict themselves to purely semasiological mechanisms like metaphor and metonymy, 
but also devote attention to mechanisms of onomasiological change like borrowing or folk etymology. In fact, we will suggest in section 1.3.3 that an insufficiently clear demarcation between onomasiological and semasiological mechanisms may well be a major point of criticism with regard to the type of semantic classification regularly produced in this period. At the same time, a specifically onomasiological tradition emerged in the margin of the overwhelmingly semasiological orientation of historical-philological semantics, viz. the Wörter und Sachen ('words and objects') movement inaugurated by Rudolf Meringer (1909) and Hugo Schuchardt (1912).

The principal idea is that the study of words, whether etymological, historical, or purely variational, needs to incorporate the study of the objects denoted by those words. As Meringer (1912) noted, in an article defining the scope and purpose of the journal Wörter und Sachen that he launched in 1909, 'Bedeutungswandel ist Sachwandel [...], und Sachwandel ist Kulturwandel' (Semantic change is object change [...], and object change is cultural change). The basic perspective is not so much 'What do words mean?' but 'How are things named and classified through language?' Although the study of abstract concepts is not excluded, the emphasis in the Wörter und Sachen approach tended to fall almost exclusively on concrete objects, either natural kinds like plants, animals, or body parts, or artefacts like tools and all other elements of the material culture of a given language community or a historical period. Inorder to study the language of an agricultural community, for instance, a good knowledge is required of its natural environment, farming techniques, customs, social organization, etc. The whole approach has in fact a strong cultural orientation, which is translated methodologically in interdisciplinary links with archaeological and historical research. The Wörter und Sachen movement, and the onomasiological perspective in general, also had an important influence on the development of dialect geography, and specifically on the dialect atlases that were produced, or at least started, in the first decades of the twentieth century. In the Atlas linguistique de la France by Jules Gilliéron (1902-20), the Sprach- und Sachatlas Italiens und der Südschweiz by Karl Jaberg and Jakob Jud (1928-40), and the Deutscher Sprachatlas by Ferdinand Wrede (1927-56), onomasiological maps show the words used for a given concept in the geographical areas covered by the map.

Although systematic onomasiological research occupies only a minor position in the context of historical-philological semantics at large, it is of particular importance for the further development of lexical semantics. As we will see in the next chapter, an onomasiological perspective dominated the second major stage in the history of the discipline-albeit in quite a different form than the Wörter und Sachen movement. 
To summarize the present section, we have introduced four groups of theoretical positions that deviate to some extent from (or at least add nuances to) the standpoint that we associated with the work of Bréal and Paul. A first group, which largely constitutes an older position than Bréal's and Paul's on the chronological line of development, is concerned with the logical-rhetorical classification of meaning changes without relating to psychology. A second group involves variations on the psychological position of Bréal and Paul. Here, we mentioned the Völkerpsychologie movement, and more importantly, those scholars that emphasized the role of non-conceptual, emotive forms of meaning in the development of vocabularies. A third group of voices comprises alternative ways of filling in the contextualist aspects of the standard position: either in a sociological vein, as in the French sociosemantic movement initiated by Meillet, or in a communicative, pragmatic vein. Finally, we pointed to the growing awareness of the distinction between a semasiological and an onomasiological perspective, as represented by the Wörter und Sachen movement.

The differences of opinion and focus covered by these various approaches far from exhaust the theoretical variation within the historical-philological tradition, but they do capture important tendencies that may help us to see some order in the abundance of historical-philological studies. More differences involve the classification of semantic changes, to which we now turn.

\subsection{Classifications of semantic change}

Classifications of semantic change are the main empirical output of historicalphilological semantics, and an in-depth study of the historical-philological era (which is not what we are aiming for here) would primarily take the form of a classification of such classifications. Rather than give intricate overviews of how many different classifications of semantic change the historicalphilological tradition produced and how they are related to one another, conceptually and genealogically, we will present the classificatory efforts in three steps, each time adding a level of complexity. In section 1.3.1, we present a panorama of some of the most common elements that may be found in such classifications: what are the phenomena that historical-philological semantics predominantly tends to examine? Section 1.3.2 adds one degree of nuance, demonstrating that historical-philological semantics does not stop at the level where we find phenomena like metaphor and metonymy, but also searches for lower-level patterns of semantic development. Section 1.3.3 focuses on the more elaborate schemas that appeared in the final stage of the development of historical-philological semantics. To get an idea of these culminating achievements, we will conclude the section with the classification suggested by Albert 
Carnoy (1927) and, contrasting with Carnoy's, the classification proposed by Gustaf Stern (1931). These sophisticated and detailed catalogues mark the end of a period, and they do so in a particularly symbolic way: Carnoy's $L a$ science $d u$ mot is exactly contemporaneous with Leo Weisgerber's vigorous attack on the tradition of historical semantics (Weisgerber 1927), an attack that marks the beginning of the structuralist era in lexical semantics. And the year of publication of Stern's Meaning and the Change of Meaning is the same year in which Jost Trier published his monograph Der deutsche Wortschatz im Sinnbezirk des Verstandes - the first major descriptive work in the new structuralist paradigm.

\subsubsection{Main types of change}

To get a good grip on the variety of phenomena that may appear in classifications of semantic change, we will distinguish between four groups of factors. The basic distinction is that between semasiological and onomasiological mechanisms. Semasiological mechanisms involve the creation of new readings within the range of application of an existing lexical item. Onomasiological (or 'lexicogenetic') mechanisms, conversely, involve changes through which a concept, regardless of whether or not it has previously been lexicalized, comes to be expressed by a new or alternative lexical item. Semasiological innovations provide existing words with new meanings. Onomasiological innovations couple concepts to words in a way that is not yet part of the lexical inventory of the language. Within the set of semasiological mechanisms, a further distinction involves that between changes of denotational, referential meaning and changes of connotational meaning (specifically, of emotive meaning or Gefühlswert). The changes of denotational meaning are divided into analogical changes and non-analogical changes, according to whether the new meaning does or does not copy the semantics of another, related expression. In this way, we can distinguish between four major groups.

1 The non-analogical changes of denotational meaning comprise the classical quartet of specialization, generalization, metonymy, and metaphor. We may call these 'classical' because they constitute the core of most classifications, and because they link up most closely with what may be found in the rhetorical tradition.

Semantic specialization and generalization are types of lexical-semantic change by means of which a lexical item develops a new meaning that stands in a relationship of, respectively, subordination or superordination to the older meaning. If the semantic range of application of an item is conceived of in set-theoretic terms, specialization implies that the range of application of the new meaning is a subset of the range of the old meaning. In the case of 
generalization, the new range includes the old one. Terminologically, 'restriction' and 'narrowing' of meaning equal 'specialization'; 'expansion', 'extension', 'schematization', and 'broadening' of meaning equal 'generalization'.

Examples of specialization are corn (as we saw earlier, originally a coverterm for all kinds of grain, now specialized to 'wheat' in England, to 'oats' in Scotland, and to 'maize' in the United States) and queen (originally 'wife, woman', now restricted to 'king's wife, or female sovereign'). Examples of generalization are moon (primarily the earth's satellite, but extended to any planet's satellite), and French arriver (which etymologically means 'to reach the river's shore, to come to the bank', but which now signifies 'to reach a destination' in general, as we have already noted). A comparison of the moon example and the corn example shows that the original meaning either may remain present or may disappear after the development of the new meaning.

Metonymy (including synecdoche-but see the remark at the beginning of section 1.3.2) is a semantic link between two readings of a lexical item that is based on a relationship of contiguity between the referents of the expression in each of those readings. When, for instance, one drinks a whole bottle, it is not the bottle but merely its contents that are consumed: bottle can be used to refer to a certain type of receptacle, and to the (spatially contiguous) contents of that receptacle. The concept of contiguity mentioned in the definition of metonymy should not be understood in a narrow sense as referring to spatial proximity only, but broadly as a general term for various associations in the spatial, temporal, or causal domain. Metaphor, on the other hand, is commonly analysed as being based on similarity rather than contiguity.

The definitional opposition between similarity and contiguity is not without problems: what exactly is meant by contiguity? We have already seen in our quotations from Quintilian that classical rhetoric seems to have had more difficulty in providing an analytical definition for metonymy/synecdoche than for metaphor, and the same holds true for the historical-philological tradition. In fact, the popularity of the cover term 'contiguity' is essentially due to the work of Ullmann $(1957,1962)$, which falls outside the historical-philological period. Much later in this book, we will look into the current debates about the distinction between the two mechanisms and their underlying basis: see section 5.2.3. In the meantime, we may accept the distinction between similaritybased and contiguity-based extensions of meaning as a first approximation. One additional remark should be made at this point, though.

The definitional problems, in fact, are not restricted to the concept of contiguity. Although this is not often discussed in the literature, note that the demarcation of metaphor in terms of similarity is deceptively simple. The difficulty becomes apparent when we consider the shift in meaning of, for instance, a word like Dutch blik, which initially names the material tin, 
and is then used to name cans for vegetables and the like. But cans can be called blik even if they are not made of tin or any other metal. These shifts can be easily explained in terms of similarity: using the old word blik 'a tin can' for the new object 'a can (in another material than tin)' is motivated by the fact that there is a functional similarity between both objects. But is this a metaphor? Assuming that there is a tendency to answer the question negatively, the definition of metaphor will have to be refined by stating, for instance, that metaphor involves figurative similarity. At the same time, the set of basic mechanisms will have to be expanded with the concept of changes based on literal similarity, to account for the shift in blik. This solution will, however, remain largely terminological as long as we do not have a theory of figurativeness - a theory, in other words, that allows us to determine when a particular word meaning is (possibly, to a certain degree) figurative or not.

2 Non-denotational meaning changes may involve any type of nonreferential meaning, but in actual practice, as we have already mentioned, the non-denotational semantic developments that have been discussed most extensively in the literature involve emotive meanings. The major types of emotive meaning change that are usually distinguished are pejorative change, i.e. a shift towards a (more) negative emotive meaning, and ameliorative change, i.e. a shift towards a (more) positive emotive meaning. An example of pejoration is silly, which formerly meant 'deserving sympathy, helpless or simple', but which has come to mean 'showing a lack of good judgement or common sense'. An example of amelioration is the history of the word knight, which originally meant 'boy, servant', and thus indicated a considerably more lowly social position than it does now.

Two further remarks need to be made. First, pejorative and ameliorative changes may or may not be accompanied by denotational changes. The shift that leads boor from 'peasant, farmer' to 'unmannered man' is simultaneously a shift of denotational and of emotional value. The transition seems impossible, however, without a primary shift that changes the emotive overtones of boor without changing the denotation. Rather in the way in which the negative expression whore contrasts with the neutral expression prostitute (while basically expressing the same denotational content), boor was a derogatory denomination for peasants before the negative part of its semantic value was detached and generalized into 'unmannered person'. Notice also, in this respect, that the pejorative or ameliorative change may or may not involve the retention of the original meaning. Boor has lost its original meaning, but its Dutch cognate boer has both the original reading 'farmer' and the pejorative reading 'unmannered person'. 
Second, we need to clarify the relationship between pejorative and ameliorative shifts on the one hand and euphemism and dysphemism on the other. Euphemism is the use of a positively (or less negatively) connoted word instead of a negatively connoted one with more or less the same denotational meaning. Thus, to pass away or to part with this life are euphemistic expressions for to die, just like public woman and prostitute for whore. Dysphemism is the use of a more negatively connoted, harsher, more offensive word, like calling a cemetery a boneyard. Now, note that euphemism presupposes a particular emotive value in the euphemistic expression, but does not as such change that value. Using prostitute as a euphemism for whore presupposes that the former word has fewer negative overtones than the latter, but it does not change those overtones: if it did, there would be no euphemistic effect. That is to say, whereas pejorative change is a diachronic semasiological process, devices such as euphemism and dysphemism primarily involve synchronic stylistic choices. However, the repeated use of a euphemism can be the cause of a semasiological change. The euphemistic effect may, in fact, wear off; the negative evaluation of the referent of the expression then gradually undermines the original euphemistic value of the expression. That is why some euphemisms are regularly replaced by others: cripple gave way to handicapped gave way to disabled gave way to physically challenged.

A similar pattern occurs with other stylistic devices. The two most commonly mentioned, apart from euphemism and dysphemism, are hyperbole and litotes. Hyperbole involves the exaggerated expression of a negative or positive appreciation of something, such as when someone is called an absolute genius when he has merely had a single bright idea, or when, conversely, someone's behaviour is called moronic when it is merely unwise or foolish. Litotes is the converse of hyperbole: expressing something in an attenuated way, like saying I wouldn't mind when you mean I'd very much like to. Now, whereas the use of hyperbole initially presupposes the stronger negative force of a word such as moronic as against unwise or foolish, the repeated use of the hyperbolic expression may erode its emotive force. Thus, dreadful in expressions like to be dreadfully sorry has gone through an ameliorative shift from 'to be dreaded' to the neutral meaning 'enormous', the link between both being the hyperbolic use of the original meaning.

3 The group of analogical changes involves those semantic shifts in which one word, so to speak, copies the polysemy of another word. If the two expressions belong to different languages, semantic borrowing obtains, that is, the process by means of which a word $\mathrm{x}$ in language $\mathrm{A}$ that translates the primary meaning of word $y$ in language $B$ copies a secondary meaning of $y$. (This process is also known as 'semantic calque'.) For instance, the Greek word angelos originally 
just meant 'messenger', but developed the meaning 'angel' by copying the polysemy of the Hebrew word $m l ' k$, which means 'human messenger, envoy' as well as 'heavenly messenger, angel'.

Within a single language, analogical changes on the basis of semantic associations can be observed when a semasiological extension in one element of a lexical field is imitated by other items in the same field. In contemporary Dutch, for instance, the use of zwart 'black' in expressions such as zwarte markt 'black market, illegitimate trade' and zwart geld 'black money, i.e. money earned on an illegitimate basis, specifically not having been reported to the tax service', seems to have paued the way for dralogous shifts in the meaning of other colour terms. Geld witwassen literally means 'to make money white by washing' but figuratively refers to the fiscal laundering of illegitimately earned money. Similarly, grijs 'grey' is used to characterize activities which, although not entirely illegal, evade existing rules and regulations: grijs rijden is not to pay full fare when using public transport, in contrast with zwart rijden, which implies not paying at all.

The analogical basis of a semantic change need not mean that the regular semasiological mechanisms do not apply. The development of $m l ' k$ from 'messenger' to 'heavenly messenger' in Hebrew is a specialization, but then so is the emergence of the secondary reading of angelos. The polysemy in Hebrew may have triggered the polysemy in Greek, but the relationship between the two meanings in Greek falls within the range of the core cases of semantic extension.

4 Although classifications of lexical-semantic changes are primarily concerned with semasiological phenomena, we will see in section 1.3.3 that they do not always succeed in clearly drawing the line with an onomasiological perspective. It should not be forgotten, in this respect, that the semasiological extension of the range of meanings of an existing word is itself one of the major mechanisms of onomasiological change-one of the mechanisms, that is, through which a concept to be expressed gets linked to a lexical expression. In this sense, the study of onomasiological changes is more comprehensive than the study of semasiological changes, since it encompasses the latter, while the reverse is obviously not the case. So let us have a very brief look at the most important lexicogenetic mechanisms. First, new words may be formed by word formation, that is, the regular application of morphological rules for derivation and composition. Second, new words may be formed by the transformation of the sound shape of existing words, for instance through clipping (pro from professional) or blending (brunch as the merger of breakfast and lunch). Third, new expressions may be borrowed from other languages. Fourth, new words may be created out of the blue, for instance on the basis 
of onomatopoeia, or in brand names like Kodak. And fifth, of course, new expressions may be semantic extensions of existing ones-but then we are back where we started.

\subsubsection{Lower-level patterns}

Now that we have an indication of the major elements that would go to make up classifications of semantic change, we may briefly have a look at the factors that lead to differences of classification. The major reason is that the various classifications pay a different amount of attention to the groups that we have distinguished. For instance, while the first group will be included in most classifications, the others may be represented only partially, or not at all.

A second reason for variation among the classifications resides in differences of opinion about the exact definition of specific elements. A word like synecdoche for instance, may receive different interpretations and may thus wind up in different places in the classificatory schemas. In the traditional rhetorical classification synecdoche refers to part-whole relations. It is then often seen as a specific type of metonymy; this is for instance the opinion of Dumarsais. So, one point of divergence between various classifications is whether or not they include cases of synecdoche under the umbrella of metonymy. But part-whole relations may be found in different places: when we fill up the car, the part-whole relation is a referential one; it exists between the elements in reality that a word refers to. But some authors, like Darmesteter, see part-whole relations on a metalinguistic level as well. It can then be said, for instance, that the two meanings of cat exhibit a partwhole relationship: the small, furry, domesticated Felis catus is part of the larger category Felis, which includes tigers, leopards, lions and others next to the domesticated cat (or conversely, we can say that the meaning 'Felis' is part of the meaning 'Felis catus'). If this extension of part-whole relations is accepted (which is far from obvious, actually), examples of specialization and generalization would have to be classified as cases of synecdoche-and this is, in fact, what Darmesteter does.

A third reason for variation involves the classificatory depth of the schemas. When it comes to listing subtypes of the main categories, some classifications restrict themselves to giving examples of the basic types only, whereas the more elaborate treatises present subclassifications - which may then vary from one another. As an example, we will now have a look at an inventory of metonymical patterns that are included in Paul (1920), Nyrop (1913), Waag (1908), and Esnault (1925). Let us first note that the subclassification of types of metonymy is most often based on an identification of the target and source concepts involved. Thus, the bottle example mentioned in section 1.3.1 exhibits the name of a receptacle (source) being used for its contents (target), a 
pattern that can be abbreviated as 'receptacle for contents'. Making use of this abbreviated notation, other common types of metonymy are the following: 'a spatial location for what is located there' (the whole theatre was in tears); 'a period of time for what happens in that period, for the people that live then, or for what it produces' (the nineteenth century was history-minded); 'a material for the product made from it' (cork); 'the origin for what originates from it' (astrakhan); 'an activity or event for its consequences' (when the blow you have received hurts, it is not the activity of your adversary that is painful, but the physical effects that it has on your body); 'an attribute for the entity that possesses the attribute' (majesty does not refer only to 'royal dignity or status', but also to the sovereign himself); 'part for whole' (hired hand). The relations can often work in the other direction as well. To fill up the car, for instance, illustrates a type 'whole for part'.

If we now turn to a comparison of the metonymies that we find in the work of Paul (1920), Nyrop (1913), Waag (1908), and Esnault (1925), we may identify the metonymical patterns by formulas of the type SPATIAL PART \& SPATIAL Whole. This indicates that the pattern generalizes over the two directions in which the metonymic association may work: part for whole, and whole for part. (The names given to the patterns do not necessarily correspond to the way in which they are identified by the original authors. The examples may be contemporary ones, or examples taken from older sources.)

SPATIAl PART \& SPATIAl Whole (Paul; Waag; Nyrop; Esnault)

Tony Blair was the Prime Minister of England (where England stands for the UK as a whole)

TEMPORAL PART \& TEMPORAL WHOLE (Waag)

German morgen 'morning' for 'tomorrow' (the morning is only a part of the day)

LOCATION \& LOCATED (Paul; Waag; Nyrop; Esnault)

the thunder woke up the whole house (i.e. the people in the house)

EFFECT \& CAUSE (Paul; Waag; Nyrop; Esnault)

Greek phobos 'flight' for 'fear'

SUBEVENT \& COMPLEX EVENT (Paul; Waag)

Mother is cooking potatoes (where cooking the potatoes stands for preparing an entire meal)

CHARACTERISTIC \& CHARACTERIZED ENTITY (Paul; Waag; Nyrop; Esnault) French une beauté 'a beauty' we need more brains (i.e. smart people) 
PRODUCER \& PRODUCT (Paul; Waag; Nyrop; Esnault)

I'm reading Shakespeare (his works)

CONTROLLER \& CONTROLLED (Waag; Nyrop)

Schwarzkopf defeated Iraq (i.e. the army that Schwarzkopf commanded)

CONTAINER \& CONTAINED (Waag) (Nyrop; Esnault)

French aimer la bouteille 'love the bottle, i.e. alcohol'

TEMPORAL CONTAINER \& CONTAINED (Esnault)

the nineteenth century was history-minded

MATERIAL \& OBJeCt (Nyrop; Esnault)

French carton 'cardboard' for 'cardboard box'

LOCATION \& PRODUCT (Nyrop; Esnault)

china (the country, the tableware originally produced there)

POSSESSOR \& POSSESSED (Esnault)

the long straw goes first for 'the person with the long straw'

ACTION \& PARTICIPANT (Paul; Waag; Nyrop)

to author a book

ACTION \& INSTRUMENT (Esnault)

the pen is mightier than the sword for 'writing is more powerful than fighting'

Piece Of Clothing \& PeRson (Paul; Waag; Nyrop; Esnault)

French une vieille perruque 'an old wig' for 'an old person'

MEMBER ENTITY \& COLLECTION (Waag)

Fritz 'a German, a German soldier' for 'the German army'

The list, to which we will return in section 5.2.3, shows that various authors identify different patterns of metonymy, and that some patterns (like SPATIAL PART \& SPATIAL WHOLE Or CAUSE \& EFFECT) are apparently more popular or salient than others. But the very fact that such configurations are listed is significant in itself. It shows that the historical-philological search for semantic regularity is not restricted to general mechanisms like metaphor and metonymy, but takes the form of a quest for the more specific moulds of polysemy. This holds not only for metonymy: in metaphor research we notice an interest in lower-level regularities, too. Without attempting a comparative analysis of the kind we illustrated for metonymy, let us have a look at some of the metaphoric patterns mentioned by Waag (1908). (All examples are German. They present a fraction only of the materials collected by Waag.) 


\section{METAPHORS BASED ON SIMILARITIES OF SHAPE AND APPEARANCE}

Concrete objects may be compared among one another, with the more common or more familiar object providing the source for naming the other. Body part terms, for instance, may be transferred to (parts of) plants, animals, artefacts, landscape features. Auge 'eye' provides a name for the round spots on the tail of peacocks and the wings of butterflies, for globules of fat floating on soup, and for the eyes of potatoes. Ohr 'ear' refers to the handle (the ear) of a cup. Zunge 'tongue' appears in Landzunge 'tongue, neck, finger of land; peninsula'. Nagel 'fingernail' is also the common name for the small metal spikes that we drive in with a hammer.

\section{METAPHORS BASED ON SIMILARITIES OF STRUCTURAL POSITION}

In a number of cases, it is not the shape of the object as such that is the basis for the metaphor, but the position of the object within the larger structure of which it is a part. Again restricting the examples to body parts, Kopf 'head' is used for the top of a mountain, even though the top does not have a round shape like heads do. In the same way, Fuss 'foot' is used as in foot of the mountain, merely because it is the nether part. Bauch 'belly' refers to the central part of a bottle, not just because it is the most rounded part, but also because it takes up the central position, below the Hals 'neck' (where we find the same combined motivation for the metaphor, which seems to invoke both the elongated shape and the upper position of the neck).

\section{METAPHORS BASED ON FUNCTIONAL SIMILARITIES}

The motivation for the metaphoric transfer need not involve concrete appearances but may be abstract, when the function of the source is compared to the function of the target. Thus, Haupt 'head' is used in a functional sense, to refer to the head of state, the head of the family, the master of a college etc. Similarly, die rechte Hand 'the right hand' is the main helper or instrument. Combined motivations of the type we saw before occur here too: the Fuss 'foot' of a table is functionally the area of support, but it is also the structurally lowest part, and the Flügel 'wing' of an airplane resembles a bird's both in function, position, and shape.

\section{METAPHORS RELATING SPACE AND TIME}

Polysemies between the spatial and the temporal domain abound: lange, kurze Zeit 'long, short time', Zeitpunkt 'point in time, exact moment', Zeitraum 'area in time, i.e. time period'. Temporal entities may be conceived as moving in time: die Zeit vergeht 'time passes', die Stunde kommt 'the hour comes, approaches', ein Witz folgte dem anderen 'one joke followed the other'. Spatial prepositions have temporal meanings: in dieser Woche 'in this week', zur Zeit 'at the time', über acht Tage 'over eight days, i.e. after eight days'.

\section{METAPHORS RELATING SPACE AND QUANTITY}

Words expressing spatial size and position are used to indicate abstract quantities and intensities: grosser Hitze 'big heat', hohe Alter 'high age', die Temperatur fällt 'the temperature drops', die Begeisterung steigt 'enthusiasm rises'. In quite a number of cases, the abstract quantity involves an evaluation; spatial size may express the degree 
to which something is positively or negatively appreciated, and spatial position may express an evaluative rank: sein Ansehen sinkt 'his prestige drops', ein grosser Charakter 'a great (grand, noble) character', von hoher Geburt 'of high birth', er stellt Ossian unter Homer 'he places Ossian below Homer'.

METAPHORS RELATING SENSORY DOMAINS

Synaesthetic metaphors connect one sensory domain to the other, as in knallrot 'loud, glaring red': the sound expressed by Knall 'bang, clap' is transferred to the visual domain. Conversely, ein schöner Ton 'a beautiful tone' contains a transfer from the visual to the auditory. Süsser Klang 'sweet sound' connects the gustatory and the auditory; scharfer Klang 'sharp sound' connects touch and hearing.

METAPHORS RELATING CORPOREAL AND COGNITIVE PHENOMENA

Bodily actions and experiences provide a basis for talking about psychological phenomena. Fassen 'to take hold of' also means 'to understand'; in the same way, begreifen 'to understand' is derived from greifen 'to grab'. Fühlen 'to feel' primarily refers to the sensory domain of touching, but is extended towards the emotions. Other sensory domains provide further examples, like the transfer from the visual to the cognitive domain in sehen 'to see' and hence 'to understand'; from the visual to the emotional in trübe 'turbid, cloudy' and hence 'sad'; from the gustatory to the emotional in ein bitteres, süsses Wort 'a bitter, sweet word'.

As in the case of the subtypes of metonymy, current research evidences a resurgence of the interest in metaphoric patterns such as these: see section 5.2.1. We will see there how such regularities are currently labelled on the basis of a general TARGET Is SOURCE pattern. For instance, some of the evaluative metaphors would be summarized as MORE IS UP, and some of the cognitive metaphors would fall under the label THINKING Is SEEING.

\subsubsection{Classificatory complexities}

Albert Carnoy's and Gustaf Stern's classification of semantic changes represent the final stage of the heyday of historical-philological semantics. In systems like Stern's and Carnoy's, the main types of semantic change that we distinguished in section 1.3.1 are maximally represented, and the classificatory depth is considerable: basic categories are divided into subclasses, which may then be divided into further subclasses, and so on, almost ad infinitum. One consequence of this is that works like Carnoy (1927) and Stern (1931), but also Nyrop (1913) or Waag (1908), remain copious treasures of examples for anyone interested in processes of semantic change: regardless of the classificatory framework they employ, the wealth of examples amassed in these works continues to amaze.

But typically also, these later classifications may include fundamental distinctions that are absent from the more straightforward ones like Paul's or 
Darmesteter's. In Carnoy's case, the main distinction in his classificatory schema, between métasémie évolutive and métasémie substitutive, derives from Wundt's distinction between 'regular' and 'singular' meaning changes. The former happen gradually and collectively, in the speech community as a whole. The latter take place individually and suddenly, as a consequence of a conscious effort of an individual language user. Carnoy talks about the intentional character of the second type, as opposed to the unintentional nature of the first type. This intentional, conscious act of the individual language user is an attempt to find a word that is more expressive, that better captures his ideas or feelings, than the ordinary word. It is precisely in this sense that the second type is referred to as 'substitutive' change. In Stern's case, the major addition involves a distinction between changes due to linguistic causes, and changes due to external causes. So what do these classifications look like when we consider them in more detail, and how similar are they?

In the following pages, we will summarily present the essentials of both Carnoy's and Stern's classification, focusing on the similarities. The correspondences between both classifications are summarized in Figure 1.1. It may be useful to use this figure as a background during the following exposé (which will take a highly condensed form). In the figure, the left-hand side presents

Carnoy

Stern

\begin{tabular}{|c|c|c|c|}
\hline $\begin{array}{r}\text { ecsémie, } \\
\text { prossémie, périsémie, } \\
\text { aposémie, amphisémie, } \\
\text { métendosémie }\end{array}$ & $\begin{array}{l}\text { métasémie } \\
\text { évolutive: } \\
\text { métasémie } \\
\text { simple }\end{array}$ & $\begin{array}{c}\text { unintentional } \\
\text { non-analogical } \\
\text { linguistic change }\end{array}$ & $\begin{array}{l}\text { Class V: Transfer } \\
\text { Class VI: Permutation } \\
\text { Class VII: Adequation }\end{array}$ \\
\hline $\begin{array}{r}\text { antisémie, } \\
\text { homosémie, } \\
\text { sysémie }\end{array}$ & $\begin{array}{l}\text { métasémie } \\
\text { évolutive: } \\
\text { métasémie } \\
\text { complexe }\end{array}$ & $\begin{array}{l}\text { unintentional } \\
\text { analogical } \\
\text { linguistic change }\end{array}$ & $\begin{array}{l}\text { Class II: Analogy } \\
\text { Class III: Shortening }\end{array}$ \\
\hline $\begin{array}{r}\text { diasémie évocative } \\
\text { (incl. métecsémie), } \\
\text { diasémie appréciative, } \\
\text { diasémie quantitative }\end{array}$ & $\begin{array}{l}\text { métasémie } \\
\text { substitutive: } \\
\text { diasémie }\end{array}$ & $\begin{array}{c}\text { intentional } \\
\text { linguistic change }\end{array}$ & Class IV: Nomination \\
\hline & & $\begin{array}{l}\text { change due } \\
\text { to external } \\
\text { causes }\end{array}$ & Class I: Substitution \\
\hline
\end{tabular}

FigURE 1.1. A comparison of Carnoy's and Stern's classification of semantic change 
the essentials of Carnoy's classification, while the right-hand side is devoted to Stern. The middle, darker-shaded columns identify the major categories of both classifications. They are situated side by side to bring out the correspondences; thus, métasémie simple on Carnoy's side matches unintentional, non-analogical linguistic change in Stern's schema. (In Stern's case, the overarching structure of major categories is reconstructed by bringing together the classificatory outlines on pages $166-9,175$, and 345 of his book.) The categories in the middle columns are expanded in the lighter-shaded areas to the left and right; thus, on the second row, métasémie complexe has antisémie, homosémie, sysémie as subdivisions, and on the third row, intentional linguistic change is specified as Class IV: Nomination. Now let us see what lies behind the categories.

1 The first subgroup within Carnoy's class of evolutionary changes, métasémie simple, corresponds with the first group of factors that we distinguished in 1.3.1, with two exceptions: the absence of metaphor (which is treated, under the label métecsémie, as a substitutive change), and the presence of métendosémie, which seems to be a new category. Ecsémie corresponds with meaning generalization, semantic specialization is called prossémie. Périsémie, aposémie, and amphisémie correspond with different types of metonymy. Amphisémie refers to metonymies that involve actions and qualities. Examples are French circulation (which indicates not only the act or process of circulating, but also the totality of people and vehicles participating in the traffic), and English authority (which is not just 'the quality of having expertise or power in a particular field', but also 'a person having that expertise or power'). Périsémie and aposémie both involve nominal concepts, like substances and entities. In cases of périsémie, the link between source and target is merely one of association (as when French bourse 'purse' is used for the money in it). In cases of aposémie, the link is one of dependence and origin, as in cause-effect or material-product metonymies.

Métendosémie, then, seems to fall outside the traditional classification. It comprises cases like French plume, which initially refers to a bird's feathers, but later on (like the English word pen, in fact) becomes the name for a particular type of writing instrument used for writing with ink. The difference with regular metonymies of the type discussed before seems to reside in the fact that the latter automatically involve a shift of reference, whereas the cases of métendosémie primarily exhibit a change of perspective, only later to be followed by a referential change. The feather used for writing can be thought of as a feather, and it can be thought of as a writing instrument, but the money in the purse can only be thought of as money, and not as a purse. It is not very clear, though, whether that is sufficient to distinguish this pattern from 
metonymy; after all, the conceptual link between the feather-as-object and the feather-as-instrument is a metonymic one.

Complex evolutionary change, métasémie complexe, involves the analogical changes that we mentioned as a third factor group in section 1.3.1. Three basic classes are distinguished, according to whether the influence is one of dissimilation, assimilation, or contagion. Semantic dissimilation, or antisémie, occurs when the meanings of words establish themselves in opposition to the meanings of other words. This happens, for instance, when synonyms are differentiated: the French words frêle and fragile both derive, through distinct historical routes, from Latin fragilis 'breakable', but this literal meaning is now only carried by fragile, while frêle has the derived meaning 'slender, of delicate build'. Semantic assimilation is captured by the term homosémie: words that are already partly similar come to resemble each other even more, as with interlinguistic calques (semantic loans). Semantic contagion or sysémie takes place along the syntagmatic axis: words that regularly occur in each other's vicinity influence each other's meaning. The English word premises, for instance, receives its meaning 'buildings and land on a particular site' through a reanalysis of the Latin expression praemissas mansiones 'the aforementioned constructions, the buildings in question' as used in official deeds of sale.

The distinction between the three kinds of substitutive changes, or diasémie, is based on the kind of effect that the substitution intends to obtain. While evocative substitutive changes tend to evoke a new and surprising view of things, appreciative substitutive changes are based on the favourable or unfavourable connotations attached to certain expressions, and quantitative substitutive changes tend to heighten or attenuate the intensity with which an idea is expressed. Diasémie quantitative, in fact, includes the traditional classes of hyperbole (hypersémie) and litotes (hyposémie). Diasémie appréciative comprises the traditional cases of euphemism and dysphemism, under the name of eusémie and dyssémie respectively.

Diasémie évocative is by far the largest class of substitutive changes. It includes three subclasses, of which métecsémie (or metaphor) is the most important one. In épisémie, the new expression is drawn from typical or salient characteristics of the concept to be named. When, for instance, le vert 'the green one' refers to the alcoholic drink absinthe, a picturesque (in Carnoy's words) feature of the designandum is chosen as the motif expressed in the name. In parasémie, the source domain is the same as the domain of the target concept: a concept of the same kind is substituted for the normal word. Thus, a humorous substitution of fabriquer 'manufacture' for faire 'to do, to make (in general)' involves related concepts. Not surprisingly, the mechanisms of the intentional, substitutive changes resemble those of the unintentional, 
evolutionary changes. An example like le vert, for instance, would probably be considered a case of metonymy from a more traditional point of view, while the fabriquer case would seem to be an example of generalization. If this is a general correspondence, then metaphor is the only traditional type of change restricted to substitutive changes: all metaphors, in other words, are supposed to be deliberately and consciously chosen expressions that are specifically lively and evocative.

2 In Stern's classification, to which we now turn, the distinction between change due to external causes and purely linguistic changes is based on the idea that in certain cases of meaning shift, the evolution is triggered by a change in the objects referred to. The English word artillery originally indicated weapons in general, and in particular arms for the throwing of missiles and projectiles, like bows, slings, and catapults. Because the arms used for warfare changed, the contemporary meaning is 'all the guns in an army'. A change in reality (the substitution of a certain object by another) leads to a change in the language. Similar are those cases in which our knowledge of the referents, or our attitude to them, changes. With the progress of science, for instance, the concept people associate with a word like electricity or atom changed.

Within the group of internal linguistic causes, Class II, 'Analogy', includes, among other things, the mutual semantic influence of formally related words. The English adjective fast, says Stern, has the almost contradictory meanings 'quick' on the one hand (a fast car) and 'fixed, immovable' on the other (when the colours of a shirt are not fast, you should be careful if you are going to wash it). If we focus on the adjective alone, it is difficult to explain the semantic shift, but the adverb fast does show a stepwise historical development from 'firmly' through 'vigorously, violently, eagerly' to 'swiftly'. As the semantic history of the adjective completely lacks the intermediate reading 'vigorous, violent, eager', we may conclude from the evidence that the meaning 'quick' of the adjective is modelled by analogy with the meaning 'in a quick way' of the adverb. The adjective, so to speak, borrows the meaning 'swift' from the cognate adverb. Class III, 'Shortening', involves cases of ellipsis, as in the shortening of narcissism to narcism, or that of private soldier (an ordinary soldier, originally in contrast with the aristocratic officers) to private 'common soldier'.

Under 'Nomination' and 'Transfer', Stern subsumes not only the classical mechanisms of meaning extension such as metaphor and metonymy, but also hyperbole and litotes, euphemism and dysphemism. Like Carnoy, Stern makes a distinction between intentional and unintentional changes. Class IV, 
'Nomination', refers to intentional processes, class V, 'Transfer', to the unintentional ones.

'Permutation' and 'adequation', finally, describe shifts in the way in which language users interpret the relation between linguistic expressions and their references. The English bead, which originally meant 'prayer', afterwards obtained the meaning 'pearl, little ball'. The ground for this transfer probably lies in the fact that at prayer a rosary was used, of which the little balls marked the counting of the prayers. In expressions like to count one's beads it might not have been clear to the language user whether bead referred to the prayer itself or to the balls in the rosary. 'Adequation' describes a similar shift in understanding a particular expression, but seems to be more concerned with secondary shifts, i.e. with shifts that follow a primary shift in meaning. Carnoy's illustration of métendosémie may serve as an example: once pen starts referring to metal writing instruments, the feather for writing will primarily be thought of as an instrument rather than a plume.

3 This survey does not do justice to all the details in either Carnoy's or Stern's classification. Both make further distinctions within each of the categories that they identify. What we have described here, however, is sufficient for a short discussion. The only major difference between the principles of Stern's classification and those of Carnoy's is the imposition of a distinction between changes due to linguistic causes and changes due to external causes. Apart from that, the similarities between the two schemas turn out to be greater than the disparities. Both authors present rich, richly-illustrated classifications that bring together elements from the main types of semantic change that we distinguished in 1.3.1: core mechanisms like metaphor and metonymy, changes of connotative meaning, and analogical changes. At the same time, in spite of the breadth and the depth of both works, they also seem to suffer from a similar problem, viz. the balance between a semasiological and an onomasiological perspective on lexical change. A first indication of the difficulty of keeping the two perspectives separated is the incorporation of elliptical changes, as in Stern's private soldier example. Is this best thought of as a change of meaning of an existing word, or should we rather say that a new word is introduced? As a noun, the word private did not exist before the shortening process, so we could just as well say that a new word is created. But then, why not also introduce other lexicogenetic mechanisms, of the type that we mentioned in 1.3.1? Further, it would seem that the two major innovations that we find in Carnoy's and Stern's classification (the distinction between intentional and unintentional changes, and the notion of externally caused changes) are also motivated by an implicit onomasiological way of thinking. 
First, take Stern's Class I. In what sense is an innovation in reality the cause of semantic mutations? From a semasiological point of view, the link between bows, slings, and catapults on the one hand and firearms on the other is simply one of functional similarity: no reason for positing a separate category. At the same time, the modification is never automatic: whether or not the old term artillery will be extended to the new firearms is not the result of the changes in the reality of warfare as such; it always depends on a decision of the language users to categorize the new things as similar to the old ones, instead of (for instance) just inventing a new term. That is where the onomasiological perspective comes in: the change in reality is important not because it automatically causes a semasiological change, but because it creates an onomasiological need, the need for either creating a new category or adapting an extant one.

Similarly, whether semantic shifts occur intentionally or non-intentionally (a distinction that is incorporated in both Carnoy's and Stern's systems) is basically an onomasiological process. If the intentional changes are those in which the language user deliberately achieves a special effect by the conscious substitution of one conspicuous or surprising or particularly expressive word for another, more common one, then intentionality primarily involves a process of onomasiological choice rather than a semasiological transformation. In addition, it may be briefly noted that there are independent reasons for being critical of the distinction between intentional and unintentional changes, in the sense that the distinction is an implicit dichotomization of what is essentially a cline. There is a continuum between the intentional and deliberate and the unintentional and spontaneous. But as the classification cannot capture the gradience, the historical linguist will encounter severe empirical difficulties determining not only at what point of the cline a particular change is to be situated, but also at what point the line between the two dichotomous classes would have to be drawn. To the extent that these difficulties may endanger the practical usefulness of the classification, the distinction between intentional and unintentional changes has to be treated with some reservation.

To conclude, if we see Stern and Carnoy as the culmination, or at least the endpoint, of the historical-philological tradition, we notice both strengths and weaknesses. A wealth of materials, both conceptually and descriptively, goes hand in hand with a tendency to over-classify, and an idiosyncratic (in Carnoy's case even arcane) terminology that seems deliberately to avoid the more established terms. At a fundamental level, there is a problem with the intrusion of an onomasiological perspective into a semasiological classification. 


\subsection{Beyond historical-philological semantics}

Even though most of the work in historical-philological semantics has become inaccessible to a contemporary international audience, the intrinsic value of this tradition can hardly be underestimated. The empirical scope of the framework is remarkable, even by present-day standards: a multitude of examples from a wide variety of languages serves to illustrate and define a broad variety of theoretical concepts. Later approaches in lexical semantics (specifically when they tend to discuss theoretical issues on the basis of a restricted set of data) often do not achieve the same descriptive breadth; and in this regard, it can only be regretted that so many interesting observations and fascinating phenomena from the realm of diachronic semantics remain largely unknown to present-day scholars. From a theoretical rather than a descriptive point of view, a similar reflection obtains. As we will see later, current developments in lexical semantics to a considerable extent constitute a return to the concerns of historical-philological semantics. Many of the older discussions on the subtleties of metaphor and metonymy or the psychological background of meaning in natural languages, then, could still be relevant for current discussions: we will return to the issue a number of times in the course of our text.

Next to the contribution of historical-philological semantics to the study of particular lexicological phenomena, the approach has a lasting theoretical importance because it draws attention to two concepts that will play a fundamental role in the assessment of any theory of lexical semantics. First, historical-philological semantics highlights the dynamic nature of meaning: meanings are not immutable, but change spontaneously and routinely as language is applied in new circumstances and contexts. As a consequence of the semantic changes it undergoes, a word acquires multiple meanings, and polysemy, as the situation resulting from such semantic shifts, is so to speak the natural condition of words. Theories of lexical semantics will therefore have to come to terms with polysemy, just as historical-philological semantics comes to terms with it by focusing on the diachronic mechanisms that lead from one meaning to the other.

Second, the historical-philological approach raises the question of how language relates to the life of the mind at large. Language definitely has a psychological side to it: we experience meanings as something 'in our head', in the same way in which other forms of knowledge are mental phenomena. But is it correct to do as historical-philological semantics does-to equate meanings with mental concepts in the broadest possible sense? Is it right to include all knowledge that can possibly be associated with a word into the meaning of that word, as when Erdmann incorporates the Nebensinn 
into word meaning? Or should lexical semantics be more parsimonious, and rule out ephemeral connotations and encyclopedic cognition from the very concept of lexical meaning? Again, this is a fundamental issue with which any theory of lexical semantics will have to come to terms, and which was put on the agenda by historical-philological semantics: how exactly is meaning a psychological phenomenon?

Now, if we move beyond the obvious merits of historical-philological semantics and adopt a more critical attitude, it is useful to distinguish between criticism that questions the fundamentals of the approach, and remarks that take the framework for granted but examine the way in which it lives up to its own programme. The former position leads to the next stage in the development of semantics: structuralist semantics rejects the diachronic focus of historical-philological semantics together with its psychological conception of meaning. We will see in the next chapter how exactly structuralist semantics motivates its dismissal of the fundamentals of historical-philological semantics. In the present section, however, we will consider to what extent historicalphilological semantics accomplishes its own objectives: given the lines it draws and the tasks it sets itself, where are the weak points? Two areas have to be mentioned: the methodology of semantic research and the classification of semantic changes.

With regard to the latter, we have seen that such classifications constitute the epitome of historical-philological semantics, but that does not mean that the actual proposals are beyond criticism. Specifically, the demarcation between semasiological and onomasiological perspectives is not a trivial matter, as we saw in our discussion of Carnoy and Stern.

From a methodological point of view, it is striking that the treatises produced in the framework of historical-philological semantics do not have systematic recourse to actual texts. There are notable exceptions, like the work of Haase (1874-80) or Nyrop (1913), who draw on actual textual material to illustrate their analyses, but very often, the examples of semantic change are presented and discussed in isolation, without textual context, and with an emphasis on shifts of conventional meaning, i.e. on semantic changes that have attained wide currency in the language in question. This relative neglect of actual texts is remarkable for an approach that emphasizes the pragmatic nature of semantic changes, as in the views of Paul that were sketched above. For an approach that pursues a usage-based conception of semantic change, one would expect more attention for concrete texts and textual dynamics of meaning. The empirical basis of historical-philological treatises, however broad it may be, seems to consist primarily of lexical uses as may be found in dictionaries: well-entrenched, easily recognizable semantic changes, rather than the more transient and particular changes that occur in individual texts. 
Methodologically speaking, it would seem that historical-philological semantics could profit from a bottom-up approach in which textual materials are used directly, much as a historical lexicographer would proceed. Indirectly, through their reliance on materials drawn from historical dictionaries, the diachronic semanticians do have a methodological basis in actual texts, but studying them directly is less frequent than one might expect.

Even more importantly, it is remarkable that an approach that focuses on the mechanisms of polysemy very much restricts its research to single instances of semantic change, in which one reading leads to the other. Focusing on such individual pairs of source meanings and derived readings obliterates the view on the overall structure of word meaning. How do these different derived senses belong together in the global semasiological structure of a word? Historical-philological semantics is concerned with the structure of polysemy, but what exactly does that structure look like, if you do not restrict the analysis to the separate steps that lead from one meaning to the other, but instead take into account the whole picture of all the shifts that occur within the semantic structure of a lexical item? Is that structure just the sum of the individual shifts, or are there any structural principles that hold together the meanings of a word over and above the individual binary links between existing and derived readings? Lexical studies concentrating on the full semantic range of a single word are rare in historical-philological semantics, however. In Chapter 5, we will learn how contemporary approaches to meaning change deal with this issue. But first, we have to pay attention to developments in lexical semantics for which diachronic semantics is much less central than it was for historical-philological semantics. 


\section{Further sources for Chapter 1}

We do not have at our disposal a general, encompassing study of the history of lexical semantics. Studies in the historiography of semantics mostly do not have the chronological and theoretical coverage of the present work; they tend to concentrate on individual authors, periods, or movements. The period treated in Gordon (1982) overlaps the most with the history treated here, but Gordon only studies a number of individual authors, up to the 1960s. A fragmentary coverage also characterizes Cruse (1986), which is still the only international textbook devoted specifically to lexical semantics, but which focuses nearly exclusively on the relational variety of structuralist semantics (as presented in section 2.4 of the present book). In general introductions to semantics or lexicology like Allan (2001), Löbner (2002), Lipka (2002), Cruse (2004), and Hurford, Heasley and Smith (2007), however, contemporary developments are making their appearance, specifically from the field of cognitive semantics. Saeed (2009) in particular devotes considerable attention to newer trends in word meaning research. The broadest coverage of lexical semantics is to be found in Blank (2001), a succinct but excellent introduction to lexical semantics, written in German, and in Cruse, Hundsnurscher, Job, and Lutzeier (2002), a voluminous reference work on all aspects of lexicology. General resources for the study of lexical semantics further include the bibliography of semantics compiled by Gordon $(1980,1987,1992)$ and the annotated bibliography of Gipper and Schwarz (1962-89). Specifically for the study of metaphor, we have a bibliography compiled by Van Noppen (1985) and Van Noppen and Hols (1990). In addition, there is a glossary of basic terms in semantics and pragmatics published by Cruse (2006), and a selection of 100 representative papers on lexicology edited by Hanks (2007), which also contains a number of less easily available publications.

The most accessible and comprehensive reference work about the period treated in the present chapter is Nerlich (1992). It individually discusses the various scholars of the historical-philological era, for Germany, France, and the Anglo-Saxon world, with a rich bibliography that points the way to many more primary and secondary publications than can be mentioned here. The older overviews of historical-philological semantics remain valuable sources, however. Kronasser (1952) and Quadri (1952) provide minute, thematically organized summaries of existing research in semasiology and onomasiology respectively, while Baldinger (1957) is a succinct outline of the tradition. In contrast with Kronasser and Quadri, Ullmann (1957) develops his own structuralist theory of semantic change, but his coverage of the older literature is excellent. More specialized historiographic work includes Knobloch (1988), Schmitter (1990), and Desmet (1996). 
More information about different classifications of semantic change may also be found in the literature just mentioned. Later studies in semantic change and introductions to diachronic semantics often also contain information about older approaches (and obviously, they also pay attention to semantic phenomena and mechanisms that go into such classifications). This holds in particular for Ullmann (1959, 1962), Dornseiff (1966), Waldron (1967), Sappan (1987), Warren (1992), Geeraerts (1997), Blank (1997), and Fritz (1998). While these works basically continue the traditional prevalence of the semasiological point of view, an onomasiological perspective is found in Grzega (2004) and in Tournier (1985), who offers an outstanding survey of lexicogenetic mechanisms. Grygiel and Kleparski (2007) present a comprehensive and instructive overview of the main trends in historical semantics from the nineteenth century up to the present day.

With regard to developments before the nineteenth century, a historical survey of etymological thinking in the past two centuries, in contrast with the practice of etymology in antiquity and the Middle Ages, is provided by Malkiel (1993). More specific information about the latter tradition is found in Klinck (1970), Herbermann (1981), and Del Bello (2007); the examples used in section 1.1 are taken from Klinck's study. As to the general history of rhetoric, Kennedy (1994) discusses the classical era and Fumaroli (1999) the period from the fifteenth to the twentieth centuries. More directly relevant for the study of figures of speech is Lausberg (1990), a monumental overview of the concepts of classical rhetoric.

On the history of lexicography, see MacArthur (1986). Lexicography, as a large-scale description of word meanings, is - at least in principle-a sister science of lexical semantics; in actual practice, the relationship is not always close. The corpus-based approaches to lexical description that will be discussed in Chapters 4 and 5 do bring the two disciplines closer together, though. General introductions to lexicography and overviews of theoretical lexicography (the science of dictionary-making) include Landau (1989), Svensén (1993), Hartmann (2001), Jackson (2002), Van Sterkenburg (2003), and Atkins and Rundell (2008), with Fontenelle (2008) as an accompanying reader. Atkins and Rundell in particular discuss the relevance and application of recent linguistic theories, such as prototype theory and frame semantics, and the importance of corpus-based analysis for dictionary-making. For an introduction to applied lexicology in the broader sense, including language teaching and stylistics next to lexicography, see Carter (1998). 


\section{Structuralist Semantics}

In section 1.2, we saw how Max Hecht appropriately summed up the position and the scope of historical-philological semantics: on the one hand, it yields classifications of semantic changes, on the other, it tries to explain those changes on a psychological basis. In 1927, the German linguist Leo Weisgerber used precisely that quote from Hecht as one of the starting points for his vigorously polemical article 'Die Bedeutungslehre: ein Irrweg der Sprachwissenschaft?' (Semantic theory: a wrong direction in linguistics?). Weisgerber leaves no doubt as to how the question should be answered: while he does make allowance for the practical value of the classificatory schemas that lexical semantics has so far come up with, the psychological conception of meaning is a major mistake, because it blocks an adequate view on language as a symbolic system. Weisgerber's article, which we will present in more detail in a moment, may properly be regarded as a first forceful theoretical proclamation of structuralist lexical semantics - the approach that would dominate the second stage in the history of lexical semantics. The first major descriptive achievement of structuralist semantics is Jost Trier's monograph of 1931 on the development of the German vocabulary in the Middle Ages. As we have already remarked, the two crucial publications marking the beginning of a new era coincide with the publication of two treatises (Carnoy's and Stern's) that constitute culminations of the previous period.

Taking its inspiration from the structuralist conception of language that is basically associated with the work of Ferdinand de Saussure, structuralist lexical semantics would be the main inspiration for innovation in word meaning research until well into the 1960s. And, as we will see in Chapter 4, the structuralist way of thinking continues to be an inspiration: a number of contemporary approaches may be seen as continuing lines first set out by one of the many forms of structuralist semantics. Precisely because there are many strands in structuralist semantics, we will first have to acquire a better idea of the principles of structuralism and how they could lead to new developments. This will be the topic of section 2.1. The following sections of the chapter will then separately take up the main forms of structuralist semantics. 


\subsection{The structuralist conception of meaning}

In order to fully appreciate the radical change that the structuralist approach brought about in the field of lexical semantics, a number of general characteristics of structuralism have to be understood first. The central idea is the notion that language has to be seen as a system, and not just as a loose bag of words. Natural languages are symbolic systems with properties and principles of their own, and it is precisely those properties and principles that determine the way in which the linguistic sign functions as a sign. To illustrate the idea and its consequences, let us have a look at the comparison between language and a chess game that de Saussure, the founding father of structuralism, described (1916: 125-7).

The value of each piece in a game of chess is entirely conventional. Which moves can be made with a pawn or a rook cannot be read off the pieces themselves, but is conventionally determined by the rules of the game. In the same way, it cannot in general be derived from the form of natural language words what each word stands for. Even though cases of onomatopoeia or compound words may be recognized as counterexamples, the form of lexical items is generally purely arbitrary, and it is this 'arbitrariness of the sign' that impels the linguist to describe language as a conventional system of rules. Languages are conventional in the same way that social practices like rules of courtesy are: they do not arise through explicit deliberations from individual to individual, nor are they the result of democratic decision-making; rather, they are handed down from generation to generation, modified if necessary as a response to changing circumstances.

Now, if it is part of the very essence of language to be a symbolic system with a conventional autonomy, then that is precisely the perspective that linguists should adopt. Describing the rules of the game is an adequate and sufficient way to describe chess; no factors that lie outside the system of rules itself (like the players' state of mind or the social status of chess in comparison with, say, draughts) need be invoked to explain how the game works. It is, of course, not impossible to study external factors such as the historical evolution of the form of the chess pieces, or the inventiveness with which individual players organize their play. None of these perspectives, however, touches the essence of the game, i.e. the set of rules. Similarly, linguistics should primarily describe natural language as a symbolic system in its own right. And because this description need not have recourse to factors that lie outside the symbolic system as such, linguistics itself may be considered an autonomous discipline: it does not borrow its methodology from other disciplines, but is a scientific discipline in its own right.

Further, the image of the chess game illustrates how language signs may be studied. The value of a separate piece in a chess game can only be defined 
with respect to the body of rules as a whole. The functional value of a pawn implicitly refers to the functional value of the other pieces: the fact that a pawn can normally only move one square on the chessboard at a time determines the significance of the pawn in comparison with the other pieces, which are permitted to move over longer stretches. However, the fact that the pawn can move diagonally across the board compensates for its restricted range, because a number of the other pieces are not allowed to move diagonally. It is only, in short, by comparing the possibilities of the various pieces that we can properly appreciate the value of the pawn. The same goes for the language system: the fact that we describe the linguistic sign as being part of such a system implies that we characterize the sign within the system, in its relations to other signs in the system.

But what are the consequences of taking such a view of language? The outcome can be described both negatively and positively. Negatively speaking, the new structuralist paradigm will reject some of the crucial tenets of historical-philological semantics: why exactly is it so different from what went before? From a more positive angle, it will introduce new ways of analysing the lexicon: how exactly can you describe the semantics of natural language as a structure?

\subsubsection{Arguing against historical-philological semantics}

Let us now look more closely into Weisgerber's criticism of historicalphilological semantics. Three critical points stand out: lexical semantics should reject a psychological conception of meaning, it should assume a synchronic outlook, and it should systematically adopt an onomasiological perspective.

First, from a structuralist point of view, the psychological conception of meaning that underlies the historical-philological research paradigm implies that the description of linguistic meaning starts off on an erroneous footing. It is indeed not language as a system, but the psychology of the language user that determines the perspective: historical-philological semantics overlooks the fact that meanings are an integral part of a system, and that it is only relative to that system, rather than to the psyche of the individual, that their value can be adequately determined. Or, as Weisgerber puts it (1927: 170):

Wort ist nicht Lautkomplex, dem ein bestimmter seelischer Inhalt oder Ausschnitt objektiver Wirklichkeit associativ zugeordnet wäre, sondern Wort ist untrennbare Verbindung eines lautlichen und eines inhaltlichen Teiles, aufgebaut auf der Funktion des Symbols. Bedeutung eines Wortes-ja das ist etwas was es nicht gibt, wenigstens nicht in den geläufigen Sinne. Bedeutung gibt es im Worte, und zwar als eine Funktion des lautlichen Teiles.

(A word is not a cluster of sounds with which one associates a specific psychological content or a chunk of objective reality, but a word is an unbreakable unity of a phonetic 
aspect and a conceptual aspect, construed in terms of the symbolic function. The meaning of a word-well, that is something that does not really exist, or at least not in the sense in which it is usually meant. The meaning inheres in the word, as a function of its phonetic part.)

If, as historical-philological semantics tends to say, the meaning of a word is a psychological concept or a mental representation, the suggestion seems to be that words are simply labels attached to pre-existing mental entities, like thoughts or concepts. The meaning of the word is then not a feature of the linguistic system, but something with a psychological reality of its own, something that exists independently of the language. From a structuralist perspective, that is a major misconception, because meaning will have to be defined as part of the language (the language as a system, to be precise) and not just as part of the mental life of the individual.

Second, it follows that the focus of the linguistic description will be synchronic rather than diachronic. A system of the type meant by structuralism is a synchronic phenomenon: it is a structure that functions in a certain period, and a change in the system (like a change in the rules of chess) would basically mark the transition of one period to the other. If the object of description is a system and not just an individual element, synchronic description logically precedes diachronic description.

Third, the emphasis shifts from the separate sign to the relations in the system as a whole. Considering a sign in its own right is awkward from a structuralist point of view: knowing what moves a pawn can make is not very revealing unless you can determine its value relative to the other pieces. More stringently: the value of any given item is determined by the oppositions it enters into with regard to other items; the semantic value of a word depends on the structure of the total field of related words.

The shift away from the individual sign entails a change from semasiology to onomasiology. If you focus the study of linguistic meaning on individual items, then you will automatically be interested in the different meanings items may have, and in the relations that exist among those meanings. But if you instead concentrate on the relationship between different items in the linguistic system, the centre of attention switches towards the way in which sets of words conceptually carve up the world in a certain way-from a semasiological interest in polysemy to an onomasiological interest in naming, in other words.

Weisgerber mentions German kinship names to illustrate the point. Words like Vater 'father', Mutter 'mother', Sohn 'son', and Tochter 'daughter' seem relatively straightforward, but even in this case, the linguistic division of reality is not a logical or a psychological necessity. Gender differences are 
reflected in the terminology, but in principle, a language could suffice with a neutral term like parent. With regard to a term like Enkel 'grandson' and Enkelin 'granddaughter', gender differences are to a certain extent disregarded: no distinction is made between the children of a son and the children of a daughter. In Onkel 'uncle' and Tante 'aunt', there is another distinction that is not reflected in the language: German does not make a distinction between maternal or paternal uncles and aunts. The way in which German classifies the world of kinship relations is not determined by reality as such, because it is easy to imagine alternative systems. Nor is it determined by the human psyche: otherwise, all languages and cultures would display the same system, and they definitely do not do so. In fact, if you look at older stages in the development of German, you may notice that the distinction between maternal and paternal lineage does play a role, as in the terms vetere 'father's brother, paternal uncle' and ôheim 'mother's brother, maternal uncle'.

Languages, then, constitute a conceptual layer between the mind and the world, and it is the architecture of that intermediate level that needs to be analysed in linguistic semantics. Weisgerber's conception of the internal semantic structure of natural languages is influenced not only by de Saussure but also by the philosophy of language of the German philosopher Wilhelm von Humboldt, mentioned in section 1.2.3. Von Humboldt argued that language should not be thought of as a stabilized product (an ergon, in the Greek terminology used by von Humboldt) but rather as a dynamic force (an energeia) with which people(s) shape their world. The innere Sprachform, the inner form of the language', reflects the specific way in which the speakers of a given language view the world. Weisgerber equates his structuralist view of linguistic meaning as 'carving up' the world with the Humboldtian innere Sprachform: the semantic system of a language (the way in which linguistic expressions delimit each other's domain) more or less imposes a conceptual structure on the world.

This Humboldtian interpretation of structuralist semantics is similar to what we saw earlier in connection with Wundt, Lazarus, and Steinthal, and it also bears a resemblance to the better-known linguistic relativity hypothesis that was formulated in the same period in the domain of anthropological linguistics by Edward Sapir (1929) and Benjamin L. Whorf (1956, originally 1939), and which is accordingly also known as the Sapir-Whorf hypothesis: does language indeed determine the way in which people see the world? We will have to come back to the epistemological consequences of this position (which is not necessarily shared by all structuralist semanticians), but at this point we first have to acquaint ourselves with the way in which the structuralist programme was realized. 


\subsubsection{Types of structuralist semantics}

In practice, what does it mean to have a structuralist semantics? Among the wide variety of theoretical positions and descriptive methods that emerged within the overall lines set out by a structuralist conception of meaning, three broad strands may be distinguished: lexical field theory, componential analysis, and relational semantics. The following sections of this chapter will treat these approaches in more detail, but let us now give a brief introduction.

Lexical field theory is the research programme that emanated most directly from a position taken by Weisgerber. The view that language constitutes an intermediate conceptual level between the mind and the world inspired the metaphoric notion of a lexical field: if you think of reality as a space of entities and events, language so to speak draws lines within that space, dividing up the field into conceptual plots. A lexical field, then, is a set of semantically related lexical items whose meanings are mutually interdependent and which together provide conceptual structure for a certain domain of reality.

Componential analysis, the second main methodology that we will distinguish within structuralist semantics, is a logical development from lexical field theory: once you have demarcated a lexical field, the internal relations within the field will have to be described in more detail. It is not sufficient to say that the items in the field are in mutual opposition-these oppositions will have to be identified and defined. Componential analysis is a method for describing such oppositions that takes its inspiration from structuralist phonology: just as phonemes are described structurally by their position on a set of contrastive dimensions (fricative or stop, voiced or voiceless, rounded or unrounded, etc.), words may be characterized on the basis of the dimensions that structure a lexical field. In Weisgerber's kinship example, such dimensions would for instance be gender, maternal or paternal lineage, and generation.

Relational semantics further develops the idea of describing the structural relations among related words, but restricts the theoretical vocabulary that may be used in such a description. In a componential analysis, descriptive features like gender and generation in a system of kinship vocabulary are realworld features; they describe the real-world characteristics of the referents of the described words. But structuralism is interested in the structure of the language rather than the structure of the world outside of language, and so it may want to use a different type of descriptive apparatus, one that is more purely linguistic. Relational semantics looks for such an apparatus in the form of lexical relations like synonymy (identity of meaning) and antonymy (oppositeness of meaning): the fact that aunt and uncle refer to the same genealogical generation is a fact about the world, but the fact that black and white are opposites is a fact about words and language. 
If we look at the history of lexical semantics from a sociological rather than a purely conceptual point of view, we may observe that the three traditions occupy different chronological and geographical positions. Lexical field theory is basically a continental European approach that emerged and blossomed from 1930 to 1960, predominantly in the work of German and French scholars. Componential analysis as represented in the work of Eugenio Coseriu, Bernard Pottier, and Algirdas Greimas developed in the 1960s from the European tradition of lexical field research, but seems to have materialized in parallel in the work of American anthropological linguists. As we shall see in the next chapter, it was incorporated into generative grammar in the 1960s, when generative grammar began to dominate the scene of theoretical linguistics, and from there exerted a crucial influence on the subsequent development of semantics. Relational semantics also came to the fore in the 196os, through the work of the British scholar John Lyons, and, like componential analysis, it was incorporated into mainstream theoretical linguistics via generative linguistics. In fact, the generativist description of lexical meaning that was developed by the American philosopher of language Jerrold J. Katz is probably the framework in which the underlying strands of structuralist semantics (the field and componential approach on the one hand, the relational approach on the other) are brought together most systematically. But we are already moving into a different phase then, so we have to leave that story for the next chapter.

\subsection{Lexical field theory}

Although the theoretical basis of the lexical field approach was established by Weisgerber, the single most influential study in the history of lexical field theory is Jost Trier's monograph Der Deutsche Wortschatz im Sinnbezirk des Verstandes: Die Geschichte eines sprachlichen Feldes of 1931. In this work, Trier gives a theoretical formulation of the field approach, and investigates how the terminology for mental properties evolves from Old High German up to the beginning of the thirteenth century. In Trier (1932) and (1934) an appendix was added which dealt with Middle High German, but the study which he originally anticipated, and which was intended to trace the lexical field in question up to contemporary German, was never completed. We will first have a closer look at Trier's work, and then explore the developments to which it gave rise.

\subsubsection{Trier's concept of lexical fields}

Theoretically, Trier starts from the fundamentally structuralist insight that only a mutual demarcation of the words under consideration can provide a decisive answer regarding their exact value. Words should not be considered in 
isolation, but in their relationship to semantically related words: demarcation is always a demarcation relative to other words; the notion 'demarcation' is vacuous to begin with unless at least one other entity is involved. Trier illustrates the idea with the image of a mosaic. The substance of human knowledge - the contents of cognition-is divided by language into a number of adjoining small areas, in the same way in which a mosaic divides twodimensional space by means of contiguous mosaic stones (1931: 3):

Das es [the word] im Gesamtfeld umgeben ist von bestimmt gelagerten Nachbarn, das gibt ihm die inhaltliche Bestimmtheit; denn diese Bestimmtheit entsteht durch Abgrenzung gegen Nachbarn. Die Stelle an der es, von ihnen umdrängt, in dem grossen Mosaik des Zeichenmantels als kleiner Stein sitzt, entscheidet über seinen Gehalt, sie weist ihm zu, was für einen Teil aus dem Gesamtblock der fraglichen Bewustseinsinhalte es herausschneidet und zeichenhaft darstelt.

(The fact that a word within a field is surrounded by neighbours with a specific position gives it its conceptual specificity; because this specificity derives from its demarcation with regard to its neighbours. The exact position in which it is placed as a small stone in the grand mosaic of signs decides on its value, it determines which part exactly from the global mass of the cognitive representation under consideration it carves out and represents symbolically.)

The image of the mosaic, as well as the term field to refer to a collection of sense-related words which delineate each other mutually, were borrowed by Trier from Ipsen (1924), a paper in which the field concept only plays a minor role. Apart from Ipsen, other precursors of the field idea may be found, even in the nineteenth century. Structuralist semantics may stress the importance of a systematic study of onomasiology, but an onomasiological point of view was not completely absent from historical-philological semantics, as we have seen. Analogical change, for instance, can hardly be conceived of without an onomasiological perspective.

To get an idea of how Trier brought the theoretical view into descriptive practice, we will focus on Trier (1934), in which a sub-area of the vocabulary concerning intellectual properties is dealt with, viz. the words denoting knowledge. At the beginning of the thirteenth century, courtly language possesses three core notions referring to types of knowledge: wisheit, kunst, and list. The distinction between the latter two reflects the architecture of the medieval class society. Kunst conveys the knowledge and skills of the courtly knight (viz. courtly love, the chivalric code of honour, and the liberal arts), whereas list is used to indicate the knowledge and the skills of those who do not belong to the nobility (such as the technical skills of the craftsmen). Wisheit is a general term which is used for the noblemen as well as for citizens; it is predominantly employed in a religious and ethical sense, similar to the Latin sapientia. One 
could say that wisheit refers to the general ability to occupy one's position in society (whatever that might be) with the appropriate knowledge and skills. The general term wisheit indicates that the distinct spheres of the noble kunst and the civil list are embedded in a common religious world order.

A century later, the division of the field had undergone considerable changes. List, which gradually acquires a derogative sense, somehow conveying 'artfulness, shrewdness', is replaced by wizzen, which does not however have exactly the same meaning as the earlier list. Kunst and wisheit as well have acquired a different scope. Wîsheit has ceased to be a general term. It conveys a specific type of knowledge: instead of the original reading, referring to the knowledge of one's own position in the predestined divine order and the skills which are required to occupy that position, wisheit now refers to religious knowledge in a maximally restricted sense, i.e. the knowledge of God. Kunst and wizzen indicate higher and lower forms of profane knowledge, without specific reference to social distinction. Wizzen gradually begins to refer to technical skills, like the skills of a craftsman, whereas kunst starts to denote pure forms of science and art. The example as a whole, summarized in Figure 2.1, demonstrates how lexical fields internally develop from one synchronic period into another: the way language carves up reality differs from period to period.

Should we be surprised by the fact that the first major achievement of the new approach to semantics belongs to the domain of diachronic linguistics? Was it not one of the tenets of structuralism that synchronic analysis should precede a diachronic analysis? But, in the first place, the advantages of the structuralist method over the historical-philological method are revealed most conspicuously when dealing with a topic that is congenial to the latter-with a diachronic study, in other words. In an enlightening retrospective article that he wrote more than 35 years after his seminal introduction of lexical fields, Trier (1968) emphasizes that the lexical field theory he developed emanated as much from the empirical difficulties encountered while doing historical meaning research as from his theoretical conviction, inspired by de Saussure and Weisgerber, that a different approach to semantics was necessary. While

1200

$\begin{array}{cc} & \text { wîsheit } \\ \text { kunst } & \text { list } \longrightarrow\end{array}$

1300

Wîsheit

kunst

wizzen

FIgURE 2.1. Transitions in the German intellectual vocabulary according to Trier 
diachronic semantics may be relatively uncomplicated when concrete objects such as 'hand' or 'arm' are involved, it becomes much more difficult to delineate meanings when abstract notions (such as intellectual skills) are at stake: in such a case, the contrastive method of the field approach may allow a better grip on the historical data.

In the second place, historical case studies are well suited to establish one of the quintessential principles of structuralist semantics, i.e. that vocabularies do not change purely through the semantic shift of individual words, but that they change as structures. Trier's study demonstrates precisely that, to be sure: by analysing the synchronic stages of the language separately, he is able to reveal that the vocabulary undergoes structural changes from one period to the other.

How did lexical field analysis evolve after Trier and Weisgerber? On the one hand, the structuralist foundations of the approach were enthusiastically and widely welcomed; on the other, critical comments were formulated which led to alternatives to Trier's specific realization of the lexical field approach. Two important points of criticism will be discussed in the following sections: the internal constitution of the lexical field, and the external boundaries of the field. These points do not cover the complete range of critical reactions with regard to Trier's views, but (together with the distinctiveness of items in the field, which will be the starting point for the next section) they are the ones that led most directly to changes and variants in the descriptive practice of the lexical field approach. More general points of criticism that may be levelled against the structuralist perspective as such will be presented in the final section of this chapter. It should be noted, in addition, that the descriptive, philological aspect of Trier's study also attracted criticism. Specifically, the texts on which his study is based cannot be considered representative for Old High German and Middle High German in general, as Trier restricted his study of the situation in 1300 to the texts of the mystic Eckehart. Because such factual considerations need not invalidate the essentials of the suggested method, we will restrict the discussion to the level of general methodological points.

As yet another point of criticism, we may note that the terminology of lexical field theory is relatively unstable. Mostly, lexical field, semantic field, and word field are treated as synonyms, but some authors have suggested distinct readings among these items. Thus, Lyons (1977: 253) distinguishes between a conceptual field as a structure of concepts on the semantic level, a structured conceptual area, and a lexical field as the set of lexical items that covers a specific conceptual field. So-called 'lexical gaps' occur when the coverage of the conceptual field by the lexical field is not complete: while horse is a cover term for stallion and mare, no similar term exists for bull and cow. Further, 
Lyons (1977: 268) makes a distinction between lexical field and semantic field according to whether the set of expressions that covers a conceptual field consists only of words, or also contains other units, such as idiomatic expressions. If the field of anger terms includes expressions like to boil over or to look daggers rather than just rage, fume, seethe, and the like, the field could be called semantic rather than lexical. Lipka (1990: 152) makes a similar distinction, but distinguishes terminologically between word field and lexical field, according to whether the set of lexemes contains only morphologically simple items or includes complex lexemes next to simple ones.

This terminological diversity is obviously not purely terminological: it involves substantial questions about what to incorporate in a lexical field. Do fields contain words only, and could these be words belonging to different word classes? And if you go beyond words, would you include inflected word forms next to multiword expressions? Questions such as these about the internal constitution of lexical fields are not restricted to the question of what type of elements go into the field: they specifically also involve the question of what relations to envisage. Two crucial points arise here: while the field conception introduced by Weisgerber and Trier takes into account semantic relations of similarity (the words in the field have similar meanings), should a field not also encompass formal relations, and should it not also consider co-occurrences between words? These are the two points that we will consider in the following two sections.

\subsubsection{Lexical fields and syntagmatic relations}

The question about co-occurrence relations relates to the Saussurean distinction between the paradigmatic and the syntagmatic axis of the language. The paradigmatic axis is concerned with associations of similarity: as far as its form is concerned, cat can be associated with mat or hat; with regard to its meaning, cat is associated with words like kitten or tomcat. The syntagmatic axis concerns the possibility for a lexical element to enter into larger wholes with other elements of the language: compounds and derivations in the morphological realm, and constituents and sentences in syntax. Paradigmatic relations constitute 'off-line' similarities, syntagmatic relations constitute 'online' co-occurrences.

Lexical fields as originally conceived are based on paradigmatic relations of similarity, but shouldn't syntagmatic relations be taken into account too? There are in fact two ways in which a syntagmatic analysis has been suggested to be relevant for structuralist semantics.

First, it gradually became clear that words may have specific combinatorial features which it would be natural to include in a field analysis. Traditionally, the possibilities for combining words with other words were looked at mainly 
from a purely syntactic point of view. The fact, for instance, that a word like take belongs to the syntactic category 'verb' implies that it can be combined with a noun as its subject. In 1934, however, the German linguist Walter Porzig pointed out that syntagmatic combinability has as much to do with aspects of meaning as with grammatical characteristics. If one asks someone: Gehen sie oder fahren sie nach Hause? 'Will you walk or drive home?', the choice that person is faced with is between going on foot and going by car, since these are designated by German gehen and fahren respectively. In other words, in the verb, information is enclosed about the instrument by means of which the designated activity is achieved. At the same time, a restriction is indicated on the combinability of the verb with adverbial modifiers which designate this instrument: given that reiten is the adequate expression for travelling on horseback, one can in einem Wagen fahren 'to drive a car', zu Fuss gehen 'to go on foot', and auf einem Pferde reiten 'to ride a horse', but one cannot in einem Wagen reiten 'to ride a car'. These restrictions on the expressions a lexical element can be combined with do not, to be sure, only occur between a verb and adverbial modifiers; one may for instance also encounter them between a verb and its object (to nod requires a head as its object), between a verb and its subject (to bark is only used for dogs, foxes, and squirrels), and between an adjective and the noun it is linked to (the adjective blond exclusively designates a hair colour). In general, the semantic affinity between co-occurring words can be described in terms of syntagmatic lexical relations, to be compared with paradigmatic lexical relations like similarity.

To identify these syntagmatic lexical relations, Porzig introduced the term wesenhafte Bedeutungsbeziehungen 'essential meaning relations'. This is the basis for defining a syntagmatic conception of the lexical field, as when he says that (1934: 78):

in einem wort ein anderes, das zu ihm in wesenhafter bedeutungsbeziehung steht, schon mitgesetzt is. Alle bedeutungen also, die in einem wort mitenthalten sind, auch wenn sie nicht ausgesprochen werden, gehören zu seinem bedeutungsfeld

(in one word another one, maintaining an essential semantic relationship with the first, may be implied. All concepts that are thus implied by a word, even when they are not explicitly expressed, therefore belong to the semantic field of that word).

For a considerable period in the development of structural linguistics, these syntagmatic affinities received less attention than the paradigmatic relations, but in the 1950 and 1960s, the concept surfaced under different names in structuralist and generativist semantics: Firth (1957a, 1957b) uses the term 'collocation', Katz and Fodor (1963) talk about 'selection restrictions', Weinreich (1966) mentions 'transfer features', and Coseriu (1967) discusses lexikalische Solidaritäten 'lexical solidarities'. 
The second way in which the syntagmatics of lexical items could play a role in lexical field analysis is more radical than the mere incorporation of lexical combinations into the notion of lexical field: if the environments in which a word occurs could be used to establish its meaning, structuralist semantics could receive a more objective methodological footing than it has in work like that of Trier and Weisgerber. The structuralist tenet that linguistic signs are a unity of form and meaning could be interpreted strictly as implying that no formal difference can exist without a meaning difference, and vice versa. From the syntagmatic perspective, this entails that any difference in meaning entails a difference in distribution, while all syntagmatic differences, conversely, are the expression of differences in meaning; any lexical meaning has its proper distribution, while significant distributional differences necessarily entail a difference of meaning. So, if we can objectively chart the distributional differences among lexical items, we can avoid the subjective, interpretive methodology of historical-philological semantics-and most lexical field theorists, in fact. Rather than rely on purely intuitive grounds to determine what meaning amounts to, distributionalists try to employ formal criteria to delimit meaning.

The general approach of a distributionalist method is summarized by John Rupert Firth's famous dictum: 'You shall know a word by the company it keeps' (1957b: 11). A similar assumption is expressed by the 'distributional hypothesis' as formulated by Harris (1954): words that occur in the same contexts tend to have similar meanings. We will return later, in section 4.2.3, to the way in which Firth's position inspired the development of corpus-linguistic studies of word meaning in British linguistics; but at this point, while we are still dealing with the earlier stages of structuralist semantics, we may turn to Apresjan (1966) for a concrete implementation of distributionalism; see also Dubois (1964). Let us have a look at one of Apresjan's examples.

Relying on lexicographic material and textual analysis, he concludes that the English verb to accede has three meanings. In the meaning 'to yield to, to agree with', as illustrated by he acceded to the request, the distributional pattern is $\mathrm{P}+$ accede + to $+\mathrm{C}$ '. In the meaning 'to enter', as illustrated by he acceded to the estate, the distributional pattern is $\mathrm{P}+$ accede + to $+\mathrm{C}$. And in the meaning 'to join', as illustrated by he acceded to the party, the distributional pattern is $\mathrm{P}+$ accede + to $+\mathrm{I}$ '. In the description of these patterns, $\mathrm{C}$ stands for nouns designating concrete things, and C' for nouns designating abstract things. I' is a subclass of $\mathrm{C}$, designating collective entities. $\mathrm{P}$ symbolizes a nominal constituent which designates a person. The distributional description, then, does not refer to purely syntactic categories like word classes, since the latter are themselves subdivided semantically. Given the objectivist goals of Apresjan's distributionalism, these semantic subclassifications would have to be based 
on non-interpretive criteria. Apresjan in fact uses a criterion of pronominal substitution: nouns of the A-class (animate) for instance can be substituted by he, she, or who, whereas constituents that refer to non-animate things (A') pattern with the pronouns it or what. The accede example does not suggest, by the way, that each meaning is associated with just one syntagmatic pattern. Rather, it is the set of possible patterns that differ from meaning to meaning. In the example, we have described only the distinctive patterns, not the patterns that are shared by all three meanings, like the elliptical pattern $\mathrm{P}+$ accede as in he acceded.

A distributional approach of this kind is obviously not without problems. For one thing, it is debatable to what extent the pronominal approach relies indirectly on intuitive interpretation: how do you know which pronoun to substitute, except on the basis of an initial interpretation? For another, there is the problem signalled by Lyons (1977: 612). Consider the milk has turned and the milk has gone sour. These sentences are semantically identical, apart from the fact that to turn and to go sour have a different distribution: to turn can be employed transitively or intransitively, whereas to go sour is only intransitive. This distributional difference would be misinterpreted if we cannot ascertain that to turn's intransitive reading is different from the transitive one. If we merely rely on formal distributional differences, to turn and to go sour as a whole are different semantically, since their distribution differs. But then we would fail to establish that in one of its syntagmatic possibilities, to turn is a synonym of to go sour. To determine the latter, word meanings have to be distinguished on independent grounds, i.e. we have to construct other than formal criteria of the type discussed here to see what a separate meaning amounts to.

At first sight, then, it would seem that the objectivist claims of distributionalism have to be treated with caution; the approach was never very prominent in the context of lexical field theory. However, we shall see in section 4.2.3 that contemporary developments in corpus-based lexical semantics are pursuing a promising line of research that gives a different and more sophisticated methodological twist to the distributionalist intuition.

\subsubsection{Lexical fields and formal relations}

A further question concerning the constitution of lexical fields is whether they should only be based on semantic relations, or whether formal association among items should also be included. The associative lexical networks mentioned by de Saussure contain both semantic and formal relations (1916: 174), whereas Trier's fields are based exclusively on semantic relations. In Guiraud (1956) we find a morphosemantic field conception more closely related to de Saussure, in which the field in which an item is situated contains 
formal as well as semantic associations. These formal associations in turn can be twofold: they may rest exclusively on similarities in the sound pattern of the words, as when chat 'cat' is linked to chas 'glue with a base of starch', or they may be due to formal and semantic relatedness at the same time; in the latter case, all the morphological derivations and compounds in which an item features are included in the field. Such a conception, in which the lexicon turns out to be a vast network of relations-semantic, formal, morphological, syntagmatic-did not gain wide currency within lexical field theory as it originally developed, but at the same time there was a general acceptance in structuralist linguistics that the structure of the lexicon included both formal and semantic relations. The fruitfulness of such a perspective would again appear from diachronic studies: some of the most relevant contributions made to historical semantics by structuralist semantics precisely involve looking at formal and semantic relations at the same time. A first example is given by Guiraud himself: maroufle can mean both '(big, fat) tomcat' and 'starch'. The latter sense may be based on the semantic association of maroufle with 'cat' and the formal association of chas with chat, as illustrated in Figure 2.2. (Note that the semantic change of maroufle may be analysed as an analogical change, in the sense introduced in section 1.3.1. Given its semantic similarity to chat, maroufle 'copies' the homonymy of chat/chas.) More elaborate examples of the fruitfulness of taking into account formal relations come from dialectology, and from the classification of semantic changes.

Guiraud's maroufle example shows that a structuralist conception of the lexicon may not only have a descriptive value for historical linguistics (which was Trier's point to begin with) but could also have an explanatory value: the architecture of the relations in the lexicon explains why certain changes (which at first sight might appear to be strange) can be explained. Structuralism in fact goes one step further in studying vocabulary change, when it sets

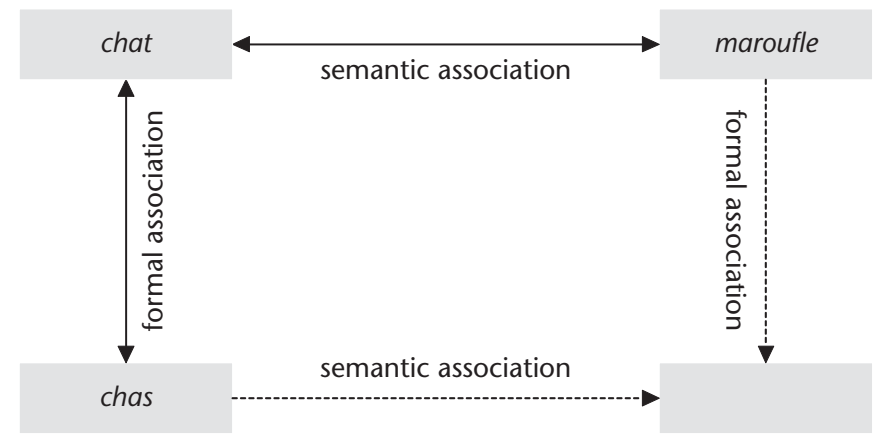

FIGURE 2.2. The evolution of French maroufle according to Guiraud 
out to look for the ultimate causes of meaning changes in the structure of a language: the value of a structuralist perspective can be supported even more strongly when it can be shown that certain structural configurations do not only allow for certain changes, but actually also trigger them. This would be the case when the original structural configurations are inconvenient for one or the other reason. The best-known illustration of such a process are the cases of 'avoidance of homonymy' which were brought to the attention of linguistics by the French dialectologist Jules Gilliéron (Gilliéron and Roques 1912). (Chronologically, this is a structuralist study avant la lettre, later invoked by structuralist semanticians as evidence for the usefulness of their approach.) The principle of avoidance of homonymy states that certain types of homonymy constitute an inconvenient 'pathological' situation that triggers a therapeutic reaction, resulting in the removal of the homonymy.

For instance, in the Gascon dialect area in the southwest of France, the regular operation of the dialect sound laws caused the Latin forms gallus 'rooster' and cattus 'cat' to merge into the form gat. Since this homonymy is likely to be inconvenient in an agricultural society, gat in the sense of 'rooster' is substituted by azan, the local variant of faisan 'pheasant', or by bigey, which is probably identical to vicaire 'curate' (see 2.5.1). The map in Figure 2.3 describes the dialect-geographical situation. Region I is the Basque area, and area II is the Catalonian area. The dotted line indicates the border between the northern area, where $l l$ and $t t$ do not merge, and the southern area, where they do. In that southern area, the original gallus forms appear to be replaced by forms that can be traced to faisan, to vicaire, or to poule (Latin pullus). The pullus forms extend beyond the border of the merger, though.

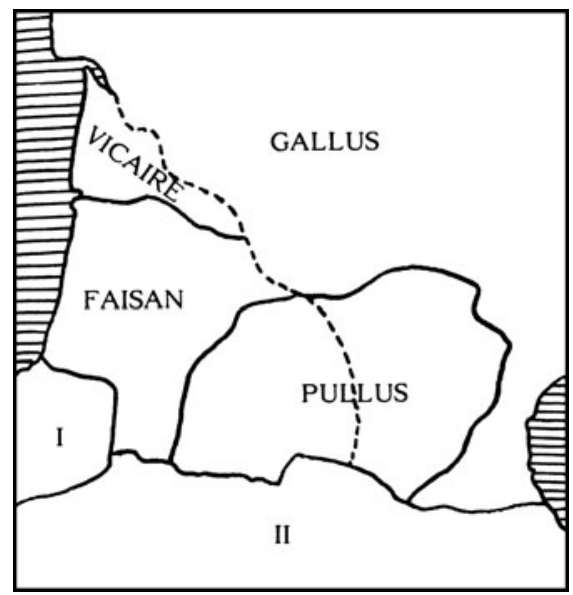

FIGURE 2.3. Gilliéron's example of avoidance of homonymy 
The map further shows how the northern boundary of the azan and bigey area coincides with the isogloss delineating the area in which Latin $l l$ appears as $t$. This coincidence is taken as evidence that the substitution of azan and bigey for gat 'rooster' is a therapeutic reaction against the homonymous configuration: the communicatively cumbersome homonymy of gat 'rooster' and gat 'cat' is discarded by introducing azan and bigey as onomasiological alternatives for gat 'rooster'. By analogy with Gilliéron's avoidance of homonymy, a principle of 'avoidance of polysemy' has been formulated (Goossens 1969). Both principles can be summarized under the general tendency 'one form, one meaning': any kind of ambiguity, whether homonymous or polysemous, is a potentially inconvenient configuration.

Yet another example of the productivity of envisaging formal relations together with semantic relations is the classification of semantic change. Stephen Ullmann $(1957,1962)$ developed a classification which is strongly reminiscent of traditional classifications popular in historical-philological semantics, to the extent that it incorporates a number of the mechanisms that we encountered in the previous chapter. However, he brings in specifically structuralist ideas by starting from the distinction between signifiant (the Saussurean term for the form of the word) and signifie (the content side of the word), and by linking the distinction between metaphor and metonymy to the Saussurean distinction between paradigmatic and syntagmatic relations. (A similar link is introduced in Jakobson 1971, originally 1956.) Such a conceptual link is possible because paradigmatic relations, as defined by de Saussure, are based on relationships of similarity, and syntagmatic relations are based on relationships of co-occurrence and association. As introduced by de Saussure, these relations apply primarily to the grammatical behaviour of words, but it is easy to see how they can be used in semantics. Metaphor has been defined in terms of conceptual similarity since classical antiquity, and metonymy basically involves the referential co-occurrence or association of source concepts and target concepts (summarized by Ullmann as 'contiguity'): the part exists together with the whole, the effect occurs in the vicinity of the cause, the characteristic feature is materially associated with the characterized entity, and so on. Cross-tabulation of the two distinctions-that between signifié and signifiant, and that between similarity and contiguity-yields the classification in Figure 2.4.

To illustrate: a metonymy like a glass (with a transfer of a certain material to the object which is composed of that material) implies that the signifiant, glass, is transferred from the signifie 'transparent solid material' to the signifié 'drinking vessel composed of that particular material'. This transfer is facilitated by the association of contiguity that exists between both signifiés. In metaphoric transfers, the source concept signifiant is transferred to the 


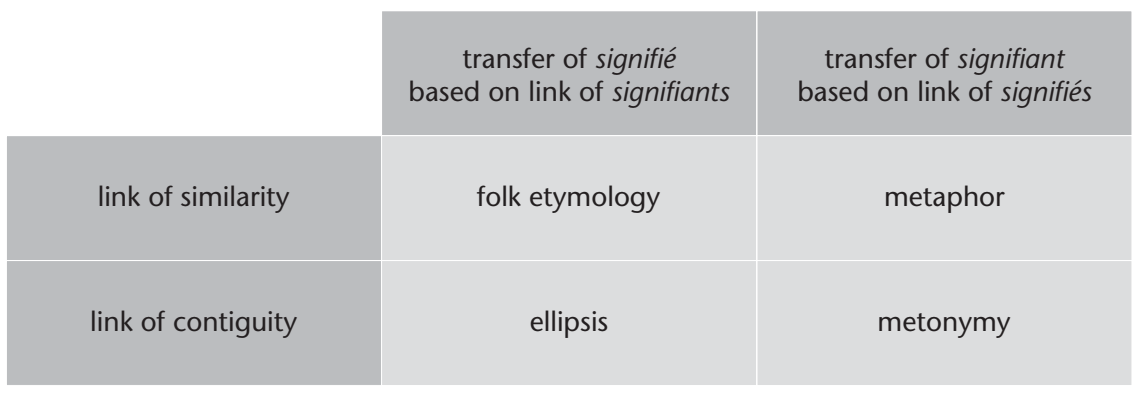

FIgURE 2.4. The classification of lexical changes according to Ullmann

target signifié given the association of similarity between the signifiés. The ingenious feature of Ullmann's classification is the way in which he extrapolates the distinction between contiguity and similarity to onomasiological changes. In ellipsis, for instance, there is a contiguity relationship between the expressions involved in the lexical change: one is part of the other. In cases of popular etymology, the signifiants exhibit a relationship of similarity. In historical linguistics, popular etymology (or 'folk etymology') refers to the process in which an etymologically obscure word is reinterpreted and transformed in such a way that its form becomes familiar and-ideally-its meaning becomes transparent. A fine example is the Dutch word hangmat 'hanging mat, hammock', which is an adaptation of the older form hamac, borrowed from Spanish hamaca, itself a loan from the Caribbean language of the Taíno. The unfamiliar hamac is replaced by a formally similar form that sounds familiar and that is semantically clearer and better motivated. In terms of the brief overview of onomasiological mechanisms that we presented in section 1.3.1, folk etymology is one way of transforming existing words.

In spite of its elegant systematicity, Ullmann's classification is not without problems. Structurally minded researchers may object that the classification is somehow half-hearted. Although it makes use of structuralist principles, it does not go beyond classifying the changes of individual words, i.e. it does not take the essential structuralist step of regarding diachronic semantics as a study of changes in the structure of the lexicon. From the perspective of historical-philological semantics, the classification is not particularly exhaustive: it contains only a small portion of the mechanisms we defined in the previous chapter, particularly the onomasiological mechanisms. Like Stern and Carnoy, Ullmann's classification combines onomasiological and semasiological perspectives, but does not take the logical step towards a fully onomasiological classification, in which the semasiological mechanisms receive a place as a subset of the global set of lexicogenetic processes. 


\subsubsection{The discreteness of lexical fields}

Trier's use of the mosaic image was not a happy one. To begin with, the image suggests that the mosaic covers the whole surface of the field, i.e. that there are no gaps in the lexical field, that no pieces are lacking in the mosaic. This Lückenlosigkeit (absence of hiatuses) is contradicted by the existence of lexical gaps, i.e. gaps in the lexical field that occur when a concept-that for reasons of systematicity seems to be a bona fide member of the conceptual field-is not lexicalized. By way of illustration, we may have a look at Figure 2.5, which analyses the field of the English terms for the notion 'cooking' - or at least, the most common terms. There are two analytic dimensions in the figure: the way in which the cooking heat is produced, and whether oil and/or water is used in the process. The figure is adapted from the work of Adrienne Lehrer, who contributed greatly to making lexical field analysis known to a wider audience of English-speaking linguists. Lehrer's analysis (1974: 100) reveals lexical gaps in the field: some of the systematically present conceptual possibilities are simply left unfilled-for instance, there is no word for the preparation of food in a pan without water and oil, nor for cooking with oil on a flame. Such examples are not difficult to replicate, and the conception of a closed system has been generally abandoned. Incidentally, we may note that Lehrer's use of labels to specify the content of the field constitutes an intermediate step towards the componential approaches that will be dealt with in the next section. As Lehrer remarks, it is but a small step from a representation like that in Figure 2.5 to a componential representation. A componential analysis

\begin{tabular}{|c|c|c|c|}
\hline & $\begin{array}{l}\text { conducted warmth } \\
\text { (oven) }\end{array}$ & $\begin{array}{l}\text { radiated warmth } \\
\text { (fire) }\end{array}$ & $\begin{array}{l}\text { hot surface } \\
\quad \text { (pan) }\end{array}$ \\
\hline $\begin{array}{c}\text { + water, -oil } \\
\text {-vapor }\end{array}$ & & boil & \\
\hline $\begin{array}{l}\text { + water, -oil } \\
\text { + vapor }\end{array}$ & & steam & \\
\hline + oil, -water & (oven-fry) & & fry \\
\hline - oil, -water & $\begin{array}{l}\text { bake } \\
\text { roast }\end{array}$ & $\begin{array}{l}\text { broil } \\
\text { roast }\end{array}$ & \\
\hline
\end{tabular}

FIgURE 2.5. The field of English cooking terms according to Lehrer 
presupposes a preliminary location of the examined words in a semantic field, after which the field is so to speak turned inside out: the labels which represent the dimensions of the field in the figure become components of the meaning of the separate words. But that will become clearer when we turn to componential analysis in section 2.3.

A further assumption that can be deduced from the image of the mosaic is that fields are, internally as well as externally, clearly delineated, i.e. that the words in a field, like mosaic pieces, are separated by means of sharp lines, and that different fields link up in the same clear-cut way. The whole lexicon would then be an enormous superfield falling apart in huge but clearly delineated sets, which in turn break up into smaller field structures, and so on until we reach the ultimate level of the mosaic stone, the word. This compartmentalization of the lexicon was criticized from different angles. In a study that anticipates types of research that would become characteristic for cognitive semantics, Helmut Gipper (1959) points out that the borderline between concepts tends to be diffuse. As a consequence, it is often difficult to indicate exactly where a field ends; discreteness will usually only be found in the core of a field, whereas there is a peripheral transition zone around the core where field membership is less clearly defined.

Gipper studies the meanings of the German words Stuhl 'chair' and Sessel 'comfortable chair'. Using visual representations of various kinds of chairs, he asked a few dozen informants to name the pictures that he presented to them. The results of the naming task revealed a major overlap between the range of Sessel and Stuhl; only in a limited number of cases was there complete agreement between the subjects in the task. At the same time, the structure of the field of Sessel and Stuhl is not completely arbitrary. The naming patterns are not random, but take a form that we may visualize as in Figure 2.6. The circle in the bottom part of the picture consists of the kinds of chairs that are exclusively, or nearly exclusively, called Sessel. Surrounding that inner circle is a cluster of items that are predominantly called Sessel, but may also be categorized as Stuhl. Analogously, the full circle in the upper part of the picture demarcates the items that are exclusively, or nearly exclusively called Stuhl. Surrounding that inner circle is a cluster of items that are predominantly called Stuhl, but may also be categorized as Sessel. The row of items in between the top and the bottom of the picture contains types of furniture whose denomination is indeterminate, i.e. for which neither Sessel nor Stuhl is dominant.

The configuration in this field, with clear central areas for the individual items surrounded by peripheral areas, is described in contemporary semantics as a prototypical organization: see section 5.1. The clear central cases of a 

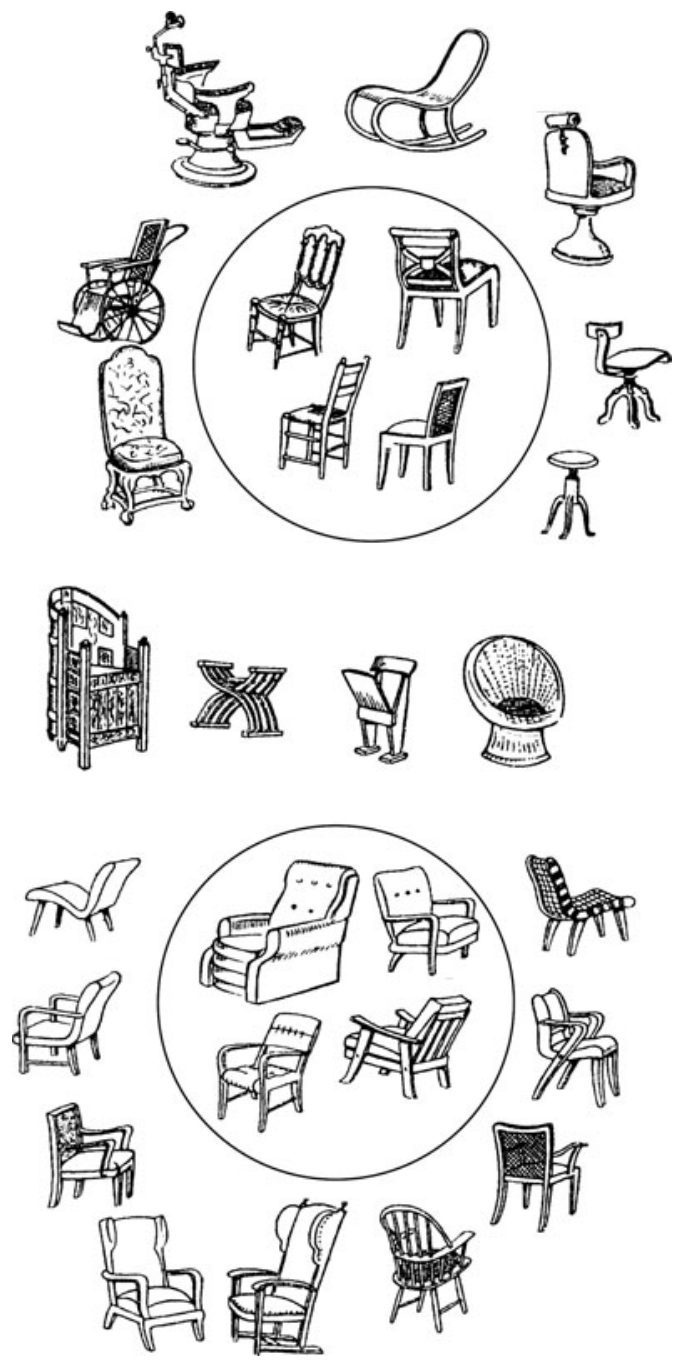

FIgURE 2.6. German Sessel and Stuhl according to Gipper

category constitute the prototype of that category, but the category as a whole need not be as clearly delineated as that centre. It will also be remembered that the configuration emerging in Figure 2.6 corresponds to a considerable extent with the image that Erdmann gave of categorical structure: see section 1.2.3. Gipper notices that the difference between the prototypes of Sessel and Stuhl is to some extent one of functional perspective: if the focus is on comfort, Sessel seems to be more appropriate (and this translates into the presence of features like armrests and upholstery); if the focus is on practical functionality, 
Stuhl is dominant. In more theoretical terms, he points out that Sessel and Stuhl support the structuralist idea that language to some extent imposes a structure on reality. The distinction between both categories is construed differently in English, in which armchair and easy chair seem to be subordinate to chair, rather than competing with it on the same level, as Sessel and Stuhl do. At the same time, the assumptions of lexical field theory are largely contradicted, at least if we assume a mosaic-like conception of lexical fields.

In this respect, it is worth mentioning that Trier (1968), looking back on the development of lexical field theory, regrets that he failed to correct Ipsen's mosaic image. This could have avoided, he admits, unnecessary confusion with regard to the character of lexical fields. The image of the closely fitting word and field boundaries, Trier suggests, should be replaced by a star-like conception of lexical fields in which the centre of the field sends out beams that are able to reach other cores with their extreme ends. Otto Ducháček (1959) proposes a graphical representation of a lexical field that nicely illustrates such a star-like conception. The conceptual field of beauty in modern French consists of a core with the word beau (and a number of morphologically related terms), surrounded by beams which reach out to adjoining fields from which the conceptual field of beauty has borrowed terms. The field is not a neatly circumscribed area, but instead consists of a semantic continuum from one core area to the other. Part of Ducháček's star-like analysis is represented in a simplified way in Figure 2.7. The figure shows, among others, that certain words which express the concept 'beauty', or some nuance of it, originate in the conceptual field of magic or love. The distance between the lexical items in the figure and the conceptual core of the field mirrors the central or peripheral status of the items: to the extent that words are located closer to the core concept, their meaning with respect to the notion 'beauty' is relatively more important than their original, etymological meaning which originates from the neighbouring fields. Sometimes, the link with the original field has disappeared completely. In charmant 'charming', the idea of 'spell, magic, magician's charm' has moved to the background in favour of the idea of elegance and attraction; by contrast, in the case of peripheral words like féerique 'fairytale-like' and ensorcelant 'bewitching', the notion of fairies and witches may still play a role.

But couldn't advocates of the 'clear demarcation' hypothesis argue that peripheral words simply belong to two fields at the same time? According to such a view, a word like merveilleux would have the literal meaning 'wonderful, miraculous, achieved by supernatural forces' in the field of magic, whereas in the field of beauty, it would mean 'extraordinary, and therefore worthy of admiration'. Both fields would then remain nicely separated: although there 


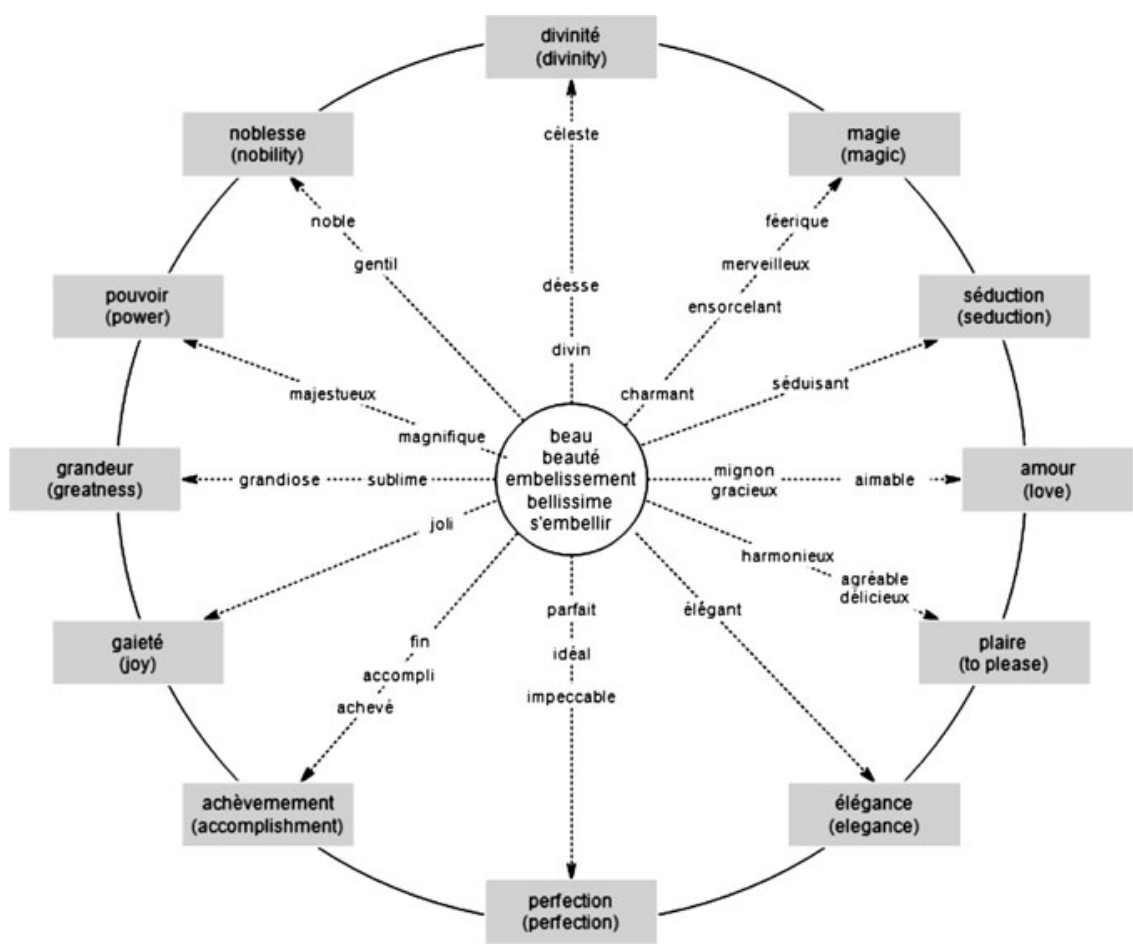

Figure 2.7. The field of 'beauty' in French according to Ducháček

is a word form that appears in both fields, each of the meanings belongs to one field only. Some meanings, however, do belong to two fields at the same time, or rather, fall between two fields. Noble, for instance, the term referring to an elevated, distinguished, and eminent type of beauty, is not only a subcategory of the latter, it is also one of the external manifestations which are connected to the concept of 'nobility'. Noble beauty is a kind of beauty that shows characteristics typical of the nobility (regardless of whether it is taken literally or figuratively); noblesse as an aesthetic feature belongs to the field of beauty as much as it constitutes a manifestation of a noble attitude. Achevé 'accomplished' likewise does not merely convey aesthetic perfection, but the kind of perfection that reveals an educated and well-trained artist or artisan. Since achevé in the aesthetic sense expresses both a specific kind of beauty and a specific kind of accomplishment, it is part of both fields at the same time: positing two different readings is not quite plausible in the case of achevé. In short, examples such as these suggest that the vagueness of boundaries is constituted by the linguistic facts themselves. This is an important insight, since 
problems of vagueness will play an important role in the later development of lexical semantics.

\subsection{Componential analysis}

If the semantic value of a word is determined by the mutual relationships between all the lexical items in a lexical field, how do we get started? If A determines B, and $\mathrm{B}$ at the same time determines A, how do we avoid circularity (Kandler 1959)? Distinctiveness as such, as an abstract principle, does not get us very far with the actual description of semantic values. Such a description requires an identification of the substance of the field: you cannot really describe the way in which language carves up the extralinguistic world unless you invoke some real conceptual content, like gender, lineage, and generation in the field of kinship terms, or social differences and types of skills in Trier's field of intellectual terms. But how then should that conceptual content be rendered?

Componential analysis provides a descriptive model for semantic content, based on the assumption that meanings can be described on the basis of a restricted set of conceptual building blocks-the semantic 'components' or 'features'. Componential analysis was developed in the second half of the 1950 and the beginning of the 1960 s by European as well as American linguists, largely independently of each other. Although both find a common inspiration in structural phonology, componential analysis in Europe grew out of lexical field theory, whereas in the United States it originated in the domain of anthropological linguistics, without any specific link to European field theory. The American branch emerged from linguistic anthropology, in studies like Kroeber (1952), Conklin (1955), Goodenough (1956), and Lounsbury (1956). In Europe, the first step in the direction of componential analysis can be found in the work of Louis Hjelmslev (1953), but the full development does not occur before the early 1960s, in the work of Bernard Pottier (1964, 1965), Eugenio Coseriu (1962, 1964, 1967), and Algirdas Greimas (1966).

In the context of a history of lexical semantics, componential analysis links up naturally with the semantic fields approach of the previous section. Its major impact, however, would not come from its European branch, but from its incorporation into generative grammar: the appearance of the famous article by Jerrold J. Katz and Jerry A. Fodor, 'The structure of a semantic theory' (1963), marked a theoretical migration of componential analysis from a structuralist to a generativist framework. As this transition lay at the basis of major new developments in lexical semantics, we shall devote a separate chapter to it. In the present section, we will look at the American 
branch of componential analysis, and then examine more closely the European approaches.

\subsubsection{Componential analysis in American ethnosemantics}

The fact that componential analysis emerged at all in the context of American mid twentieth century linguistics may seem somewhat surprising, if one takes into account that the structuralist climate in the United States was anything but favourable to semantic studies. This was mainly due to the fact that Leonard Bloomfield, the most influential figure of American structuralism, held the behaviourist view that the meaning of a linguistic form is something in extralinguistic reality - in particular, a psychological stimulus: 'By uttering a linguistic form, a speaker prompts his hearers to respond to a situation; this situation and the responses to it, are the linguistic meaning of the form' (1933: 158). If meaning is indeed equated with this type of non-linguistic reality, it should not be described by linguists: Bloomfield remarks that there is nothing in the form of the morphemes wolf, fox, and dog which tells us anything about the relations between their meanings, and that therefore the description of the latter is a problem for the zoologist rather than for the linguist (1933: 162). Under the influence of Bloomfield, American structuralism inclined towards a strongly formalist position that disfavoured the study of meaning as a branch of linguistics. Yet two factors would eventually lead to the emergence of a linguistic form of lexical semantics.

To begin with, Bloomfield did not ban semantic considerations altogether from linguistics: the fact that he included an extensive chapter on meaning change (with a traditional, historical-philological orientation) in his authoritative textbook Language (1933), plus his view that semantic considerations play a predominant part in the definition of morphemes, indicate sufficiently that he did not advocate a full elimination of semantic considerations from linguistics. At one point, he notes that a linguist, when he has been provided by experts with a definition of the meaning of male and female, can make use of these definitions to signal that this is also what underlies the difference between he and she, lion and lioness, gander and goose, and ram and ewe (1933: 146) - an observation that describes the principles of componential analysis in a nutshell. Extrapolating these aspects of Bloomfield's approach, Eugene Nida (1951) developed a structuralist terminology for meaning description. Even though Nida did not yet mention componential analysis (of which, however, he would later become one of the champions: see Nida 1975), his terminology reveals how semantic theory was developed following the model of structuralist phonology.

In phonology, differences in actually produced sounds (or phones) need not correspond to structurally relevant differences: one phoneme 
(a structurally relevant unit) may be realized as different allophones. In English, the phonemes / $/$ / and /d/ are structurally different because they distinguish among the members of a minimal pair like tip and dip, but the realization of $/ \mathrm{t} /$ in top and stop is not exactly the same: in many varieties of English, the pronunciation in top would be more aspirated than that in stop. These different phones (aspirated voiceless dental stop, non-aspirated voiceless dental stop) are allophones of the phoneme / $t /$. Now, given that Bloomfield had introduced the term sememe to refer to the meaning of a morpheme, the term seme could be used in parallel to phone: semes constitute the meaning of a morpheme in a particular context, and allosemes are semes in relationship to a specific sememe. This terminological parallelism with phonology (even though, as we will see, it could be construed in different ways) strategically legitimized semantic research: if the study of meaning could be built up along the same lines as phonology—the epitome of a structuralist approach to language - then surely it must be a bona fide subdiscipline of linguistics.

In Nida (1951) we also encounter the second factor that stimulated the birth of American structuralist semantics. The anthropological tradition in American linguistics had always had a strong interest in the relation between the investigated languages and the culture of the communities concerned: we mentioned earlier that the work of Sapir and Whorf raised the same Humboldtian issue of the relationship between language, thought, and culture that motivated Weisgerber. This interest obviously also has a purely practical nature: without knowledge of the underlying cultural background, it would be difficult to understand the native languages studied by the anthropologists. Nida (1945) provides a number of interesting illustrations of that fact, and in Nida (1951) he employs the cultural situatedness of language to argue for the inevitability of the development of a semantic theory. Terminologically, this is reflected in the distinction he makes between 'linguisemes' ( $a$ feature of meaning based on the linguistic context, like the word class of a lexical item) and an 'ethnoseme' (a feature of meaning based on the ethnological, cultural context - an encyclopedic feature, we might say).

As a consequence, it is not surprising that the method of componential analysis emerged from anthropological-linguistic studies. To illustrate, we will have a closer look at Goodenough's (1956) analysis of the kinship terms of the Micronesian language Truk. The first major step in the analysis consists of the identification of the semes: the referential denotata of the kinship expressions. Thus, semenapej refers to father, father's father, and mother's father-in an abbreviated notation $\mathrm{Fa}, \mathrm{FaFa}, \mathrm{MoFa}$. Without describing the entire field, other examples of kin term include jinenapej (Mo, FaMo, MoMo), feefinej (for male ego, where 'ego' is the reference person whose relations are being 
mapped: Si, FaBrDa, MoSiDa, FaMoBrDa, FaSiSoDa, but not WiBrWi; for female ego: no denotata), mwääni (for male ego: no denotata; for female ego: Br, MoSiSo, FaBrSo, FaMoBrSo, FaSiSoSo, but not $\mathrm{HuSiHu}$ ), pwiij (for male ego: Br, MoSiSo, FaBrSo, FaMoBrSo, FaSiSoSo, WiSiHu, etc.; for female ego: Si, MoSiDa, FaBrDa, FaMoBrDa, FaSiSoDa, HuBrWi, etc.), and jeesej (for male ego: $\mathrm{SiHu}$, WiBr, $\mathrm{FaBrDaHu}$, etc.; for female ego: BrWi, HuSi, $\mathrm{FaBr}-$ SoWi, etc.).

The second major step is again similar to what happens in structuralist phonology: different phonemes are distinguished on the basis of distinctive features, with each feature occupying a specific position on a contrastive dimension. The phonemes $/ \mathrm{t} /$ and $/ \mathrm{d} /$ share most of their distinctive features: /t/ is -syllabic, +consonantal, -sonorant, +anterior, +coronal, -voice, -continuant, - nasal, whereas /d/ is +consonantal, - sonorant, +anterior, +coronal, +voice, continuant, -nasal. If the same method is applied to the description of meaning, sememes can be grouped into complementary sets, just as phonemes can be classified into complementary sets of the type voiced/voiceless. The sememes of gander and goose, for instance, complement each other on the dimension of sex, and old and young are complementary on the dimension of age.

For the description of Truk kinship terms, Goodenough uses letters to identify nine relevant dimensions. A represents the general characteristic of being related to the reference person (ego). $B$ indicates generation, with the values $B_{1}$ for a senior generation, $B_{2}$ for the same generation, and $B_{3}$ for a junior generation. These generations have a culture-specific definition that differs from the usual genealogical one, but the specifics of that definition need not detain us here. $\mathrm{C}$ is the sex of the relative, with $\mathrm{C}_{1}$ for male and $\mathrm{C}_{2}$ for female. $\mathrm{D}$ involves symmetry of relationship to the connecting matrilineal group, with $\mathrm{D}_{1}$ for symmetrical and $\mathrm{D}_{2}$ for asymmetrical relationships. That is to say, the relationship is symmetrical if the named relative has the same tie to the connecting matrilineal group as ego; again, this is a specific feature that we need not explain in detail. E indicates sex relative to ego's sex, with $\mathrm{E}_{1}$ for same sex and $\mathrm{E}_{2}$ for opposite sex, and $\mathrm{F}$ indicates mode of relationship, with $F_{1}$ for consanguineal and $F_{2}$ for affine. $G$ refers to the age of the relative in comparison to ego's age, with $G_{1}$ for older and $G_{2}$ for younger. $H$ specifies matrilineal group membership relative to ego's, with $\mathrm{H}_{1}$ member of ego's group, $\mathrm{H}_{2}$ member of ego's father's group, and $\mathrm{H}_{\mathrm{I}}$ member of neither group. $\mathrm{J}$ specifies the nature of collateral removal, with $\mathrm{J}_{1}$ for lineal and $\mathrm{J}_{2}$ for not lineal.

Semenapej can now be componentially defined as $\mathrm{AB}_{1} \mathrm{C}_{1} \mathrm{~J}_{1}$ : it refers to all male members of an older generation than ego's of whom ego is a direct descendant (fathers and grandfathers). Similarly, jinenapej is $\mathrm{AB}_{1} \mathrm{C}_{2} \mathrm{~J}_{1}$, 
identifying the female ancestors of whom ego is a lineal descendant (mothers and grandmothers). Feefinej may be rendered as $\mathrm{AB}_{2} \mathrm{D}_{1} \mathrm{E}_{2} \mathrm{~F}_{1} \mathrm{C}_{2}$ : female blood relatives of the same generation of a male ego who have the same relationship to the matrilineal connecting group as ego (sisters, female cousins). The analysis draws the right boundaries for feefinej: feature $\mathrm{F}_{1}$ rules out $\mathrm{WiBrWi}$, who is not consanguineal, and feature $\mathrm{E}_{2}$ makes clear why the word is not used by women: women referring to their brothers or male cousins would use mwääni, defined as $A_{2} D_{1} E_{2} F_{1} C_{1}$. Feature $D$ turns out to be relevant when we ask how the speakers of Truk would name same sex relatives, like a man talking about his brothers or a woman talking about her sisters. This is where pwiij $\mathrm{AB}_{2} \mathrm{D}_{1} \mathrm{E}_{1}$ comes in: regardless of the sex of ego, it refers to same-sex relatives of the same generation as ego-except when a non-symmetrical relationship applies. In that case, jëesej, defined as $\mathrm{AB}_{2} \mathrm{D}_{2} \mathrm{E}_{1}$, is used.

Studies like Goodenough (1956) and the simultaneously published study by Lounsbury (1956) on Pawnee kinship terminology are to be considered milestones: for the first time in the history of lexical semantics a componential analysis of a lexical field on the basis of dimensional oppositions is presented. But as we noted, componential analysis developed more or less simultaneously as an offshoot of European field theory. Let us now turn to that part of the story.

\subsubsection{Componential analysis in European structuralist semantics}

How did componential analysis evolve from European word field theory? Trier's descriptive practice leaves something to be desired with respect to the precise relations between the words in a field. He restricts himself to informal descriptions and verbal definitions which are highly reminiscent of traditional philological semantics, and does not yet use clarificational graphical formats of the type illustrated by Figure 2.1 or 2.2. But even such graphical representations have a restricted value: from Figure 2.1 alone, it would be difficult to deduce what kunst and list convey exactly. As a consequence, lexical field theorists tried to find ways to characterize the words in a field more precisely in terms of their content. This process would result in the componential approach.

An initial step in the direction of componential analysis can be found in the work of Hjelmslev $(1953,1958)$. Developing de Saussure's notion of a language as a system of mutual relations, Hjelmslev formulated a rigorous theory of linguistics that focused on just the pure relations constituting linguistic structure; the substance behind those relations was not relevant from a linguistic point of view. In the field of semantics, he formulated the notion of 'content figurae', which we identify with distinctive features of the type we have just come across in the previous section. Practically speaking, however, Hjelmslev 
presents only a few simple examples of what the content figurae might imply, as when he analyses ram as 'he-sheep' and ewe as 'she-sheep', boy as 'he-child' and girl as 'she-child', stallion as 'he-horse' and mare as 'she-horse' (1953: 70)_ rather similar to the Bloomfield passage that we mentioned earlier. In spite of the scant illustrations, the fundamental idea is clear, however: meaning can be analysed in the form of distinctive oppositions.

The full development of this idea within European semantics does not emerge before the early 1960s, in the work of Pottier $(1964,1965)$, Coseriu (1962, 1964, 1967), and Greimas (1966). The fundamental notion in these studies is precisely the idea that lexical elements in a field are distinguished by functional oppositions. As Coseriu (1964: 157) concisely puts it: 'La théorie des champs conceptuels doit être combinée avec la doctrine fonctionelle des oppositions linguistiques' (Lexical field theory has to be supplemented with the functional doctrine of distinctive oppositions). In our treatment of Pottier, Greimas, and Coseriu, we will focus on the points in which these European forms of componential analysis differ from the ethnosemantic approaches discussed above: there are some differences of terminology, more attention is paid to the syntagmatic aspects of lexical structure, and the tendency to highlight the Saussurean legacy is stronger. We will focus on the work of Pottier and of Coseriu; while Greimas illustrates the same basic principles with regard to lexical analysis as Pottier and Coseriu, the focus in his 1966 monograph soon shifts towards the analysis of structural meaning patterns in texts, literary texts in particular. (Accordingly, the influence of Greimas on the development of literary theory is probably greater than his influence on linguistics.)

Pottier provides an example of structural semantic analysis in his description of a field consisting of the terms siège, pouf, tabouret, chaise, fauteuil, and canapé (a subfield of the field of furniture terms in French). The word which acts as a superordinate to the field under consideration is siège 'sitting equipment with legs'. The six words can be contrasted mutually as in Figure 2.8. (Note that the superordinate word siège is only characterized for the feature 'for sitting. The other features are necessary to distinguish the various kinds of siège 'seat' among one another.) The parallelism with Goodenough's method of description will be obvious: underlying dimensions structure the field, and the meaning of any single term in the field is established by the sum of the specific positions of the term on each of those dimensions.

The work of the structuralist semanticians of the European school tends to be rich in terminological distinctions, and Pottier's work is no exception. The values of the oppositional dimensions-the distinctive features of the type $+s 1,-s 2$ etc.- -are called sèmes, and the definition of a lexeme (lexical item) is a sémème. Sememes, then, are a collection of semes. It will be noted 


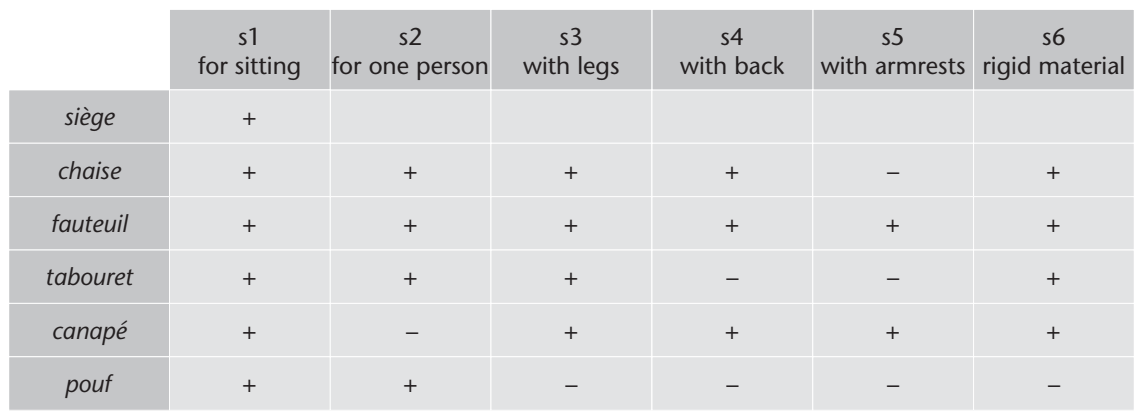

Figure 2.8. The field of sitting furniture in French according to Pottier

that this terminology-even though it originates as an extrapolation of the terminology of structuralist phonology just as much as the terminology of American ethnosemantics does-defines sème differently from what we saw earlier in connection with seme and alloseme: Pottier's sèmes are components of meaning, not types of denotata, as in Goodenough's paper. The superordinate status of siege, as the lexical item that demarcates the field, is expressed by the term archilexème, and the meaning of this archilexeme is the archisememe. The archisememe can be traced in the sememes of any of the separate lexemes in the field: the features that constitute the archisememe (in this case, s1 'for sitting') are not functional to differentiate pouf, tabouret, chaise, fauteuil, and canapé, but they do occur in the respective sememes, because pouf, tabouret, chaise, fauteuil, and canapé are all sièges 'seats'.

At this point, it becomes apparent that there is yet another background to be mentioned for componential analysis, next to the structuralist perspective which provides the inspiration for both American ethnosemantics and European structural semantics. Componential analysis, in fact, links up with the traditional lexicographical practice of defining words in an analytical way, by splitting them up into more basic concepts. Thus, a definition of ram as 'male sheep' uses the differentiating feature 'male' to distinguish the term ram from other items in the field of words referring to sheep. In the tradition of Aristotelian and Thomistic philosophy, this manner of defining is known as a definition 'per genus proximum et differentias specificas', i.e. (roughly) 'by stating the superordinate class to which something belongs, together with the specific characteristics that differentiate it from the other members of the class'. In Pottier's terminology, this translates as: 'by specifying the archilexeme together with the distinctive semes'.

This is not yet the whole story concerning Pottier's terminology, however, since he also adds a number of concepts relating to syntagmatic rather 
than paradigmatic associations in the lexicon. First, fonctèmes involve the description of grammatical meaning, such as word class. Second, classèmes involve syntagmatic semantic restrictions of the type that stipulates that a verb like eat requires an animate subject and an edible object (at least in its most common reading). Third, virtuèmes concern lexical associations of a probabilistic nature: a combination like voiture blanche 'white car' is more likely than a combination like voiture rayée de vermillon 'vermilionstriped car', even though there is no grammatical rule to bar combinations like the latter. Pottier's addition of various types of syntagmatic associations is an important step in comparison with the ethnosemantic approach, but as we will see in the next chapter, such syntagmatic relations also play an important part in the generative forms of componential analysis.

For a linguist with a Saussurean or Hjelmslevian mindset, Pottier's way of doing semantics may raise eyebrows. Are virtuèmes not a reflection of the experience language users have vis-à-vis the world rather than a reflection of the structure of language? Pottier explicitly defines virtuèmes in that way, when he states that they are 'affinités combinatoires, issues de l'expérience' (combinatorial associations, emerging from experience, 1964: 133). If voiture blanche is more likely than a combination like voiture rayée de vermillon, isn't that simply because we are more likely to come across white cars than run into vermilion-striped cars? Remember that structuralism had the intention of identifying the structure of the language, as different from our encyclopedic knowledge of the world - and our experience with types of cars belongs to our experience of the world rather than to our knowledge of the language. Come to think of it, isn't Pottier's analysis of the siège field basically a description of referents, of things in the world, rather than a description of semantic structures?

The specific formulation that Eugenio Coseriu gives of lexical field theory may be seen as a deliberate and methodical attempt to draw the consequences of a structuralist approach to meaning. As expounded in Coseriu (1966), there are two major elements in the theory: a systematic demarcation of the field of application of structural semantics, and a framework for the description of lexical items.

The demarcation of the proper object of investigation takes the form of seven successive distinctions, where with each successive step, one of the poles of the distinction is rejected as not relevant. First, Coseriu draws the distinction between extralinguistic reality and language, and obviously singles out language as the object of investigation. (This is less straightforward than it seems; we will return to this point in a moment.) Second, within the realm of 
language, the metalanguage (the language we use to talk about language) has to be excluded to the benefit of the primary object language. Third, within the primary object language, the study of synchronic structure takes precedence over the study of diachrony-as may be expected in a structuralist framework. Fourth, fixed expressions like sayings and proverbs have to be excluded from the analysis, since these may be considered 'repeated discourse', i.e. quotations, rather than productive language use. Fifth, although languages take the form of a 'diasystem' of geographical (diatopical), social (diastratal), and stylistic (diaphatic) language varieties, the structural analysis should concentrate on the 'functional language' that is homogeneous, i.e. free of differences in space, of differences in social layers, and of differences in stylistic level. Sixth, within that functional language, the object of investigation is the actual productive system of the language, and not the 'norm', the socially and traditionally fixed ways of speaking that are not necessarily functionally distinctive. Finally, the object of semantic analysis is the meaning or sense of a word (Bedeutung), and not its reference (Bezeichnung): the reference or denotatum of two expressions may be the same while their meaning may be different, as when Napoleon is referred to as 'the victor of Jena' and 'the defeated of Waterloo'

A number of Coseriu's distinctions are decidedly odd (if sayings and proverbs are 'repeated language', then why isn't normal lexical usage also a way of repeating what one has heard and learnt?) or unclear (what exactly is the 'norm' as opposed to the 'system'?). More importantly, Coseriu's stepwise delimitation of the object of investigation explicitly recognizes that the structural method of meaning cannot be applied to the entire lexicon. This does not follow just from the exclusion of 'repeated language', but also from the exclusion of terminologies, i.e. the specialized vocabularies of science and technology. According to Coseriu, these constitute mere 'nomenclatures', which directly name things in reality; as such, they do not exhibit the type of mutual distinctive oppositions that structural semantics is interested in. More generally, for large sections of the lexicon of a language, the only type of structure that can be discerned is enumeration, i.e. a type of structure that falls outside the structuralist perspective.

Going beyond the delimitation of the object of investigation, Coseriu's system for the description of structural relations largely resembles Pottier's. It includes both paradigmatic and syntagmatic associations. The paradigmatic structures divide into primary and secondary structures. The former divide further into lexical fields (the core of structuralist semantics) and lexical classes, which are comparable to Pottier's classèmes. The secondary structures relate to processes of word formation. 'Development', for instance, involves the relation between items like beau 'beautiful' and beauté 'beauty'. Syntagmatic 
structures (or lexikalische Solidaritäten) are subdivided differently than in Pottier's classification, but the details are not important here. More important is the recognition that in the central area of research, the lexical field, further methodological restrictions apply. To begin with, the definition of 'lexical field' is restrictive to the extent that associative fields are explicitly ruled out. Coseriu admits only fields that consist of lexical items that exhibit clear oppositions, like young and old, day and night, or tiède 'lukewarm', chaud 'warm', and brûlant 'hot', where the items (unidirectionally or bidirectionally) exclude each other. A field conception like the one illustrated by Ducháček's analysis of beauté in French is rejected as being purely associative, since there is no stringent opposition between the items in the field: things could easily be called both féerique and ensorcelant, for instance. Further, when it comes to the actual description of oppositional pairs like young and old, referential descriptions have to be avoided. The actual conditions, in terms of age for instance, for calling somebody or something young or old are deemed to belong to the description of the world, not to the description of the language.

This approach has consequences for diachronic semantics: meaning change is defined by Coseriu (1964) as a change in the system of oppositions that structure a lexical field. More precisely, he makes a distinction between nonfunctional lexical changes, which do not lead to a change in the field structure, and functional alterations that occur when the field's structure undergoes changes. An example of the first kind is the substitution of the Old French ive by Modern French jument 'mare', an onomasiological substitution which does not affect the organization of the field. A genuine structure change occurs with the Old French chef 'head', which becomes tête in Modern French, at least in the literal sense of 'head'. The Old French term, however, is retained in its metaphoric application, as when we talk about the 'head' or leader of a group of people. Looking at such reorganizations from a structural point of view, we may distinguish between the disappearance and the emergence of functional oppositions. The former is the case with Latin niger 'shining black' and ater 'dim black' which merge in French noir 'black': the functional distinction 'shining/non-shining' vanishes from the system, a process which is also noticeable in Latin albus 'dim white' and candidus 'shining white, snow white', both of which correspond to French blanc. Conversely, the evolution of Latin chef illustrates the addition of a structural opposition.

The stringent way in which Coseriu develops lexical field theory raises a fundamental issue to which we will have to return when we try to evaluate structural semantics. A strict implementation of the Saussurean view that languages have their own, non-encyclopedic conceptual structure seems to come at a price: that of a severe reduction of the descriptive scope of the 
theory. It is a consequence of the structuralist perspective that we should be able to make a principled distinction between world knowledge and linguistic conceptualization. But if we do so in the way suggested by Coseriu, what we are left with is the mere identification of oppositions in a restricted part of the lexicon. Could it be, then, that lexical semantics may have to choose between structuralist purity and descriptive relevance? Or could the descriptive scope of a structuralist approach be broadened by taking into account more relations rather than just oppositions? That, in fact, is the path followed by the approach to be presented in the following section.

As already stated, the European branch of componential analysis played a minor role in the further development of lexical semantics. This is predominantly because approaches like those of Pottier and Coseriu penetrated only with difficulty the international forum of linguistics of the latter part of the 2oth century, which had a decidedly Anglo-Saxon orientation. The American branch of componential analysis, by contrast, took advantage of its incorporation into transformationalist theories. Even so, the predominant impact of American componential analysis did not prevent the European tradition from being further developed. Important names within this tradition are Klaus Heger (1964), Horst Geckeler (1971a, 1971b), and Kurt Baldinger (1980). And as we already mentioned, European structuralist semantics had a definite impact outside linguistics through the work of Greimas, especially in literary studies.

\subsection{Relational semantics}

Although John Lyons does not refer to Coseriu, his conception of structuralist semantics (first presented in his book Structural Semantics of 1963) can be considered a systematic extension and improvement of Coseriu's suggestion of focusing semantics on the description of relations of opposition. What if the set of relevant semantic relations were defined more broadly, including synonymy? Such relations, linking one word to another on semantic grounds, are not unknown in traditional semantics. Dictionaries, for instance, have a long-standing tradition of describing words as being identical (synonymous) or opposite (antonymous) in meaning. The approach defined by Lyons, however, is theoretically articulated in a specifically structuralist fashion. Instead of deriving statements about the synonymy or antonymy of a word (and, in general, statements about the meaning relations it entertains) from a separate and independent description of the word's meaning, the meaning of the word could be defined as the total set of meaning relations in which it participates. A traditional (or perhaps naive) conception of synonymy would for instance describe the meaning of both quickly and speedily as in a fast way, not taking 
up much time', and then assert the synonymy of both terms on the basis of the identity in their content description. Lyons, by contrast, deliberately eschews such content descriptions, and equates the meaning of a word like quickly with the synonymy relation it has with speedily, plus any other relations of that kind (1963: 59):

It seems to me that many of the difficulties experienced by semanticists in the treatment of meaning-relations such as synonymy or antonymy are $[\ldots]$ being caused by their view of 'meaning' as prior to these relations. Such scholars as Trier and Weisgerber, it is true, have developed a theory of semantics which implies the priority of the meaning-relations, but $[\ldots]$ by framing their theory in terms of an a priori conceptual medium, they have considerably weakened the force of their arguments. I consider that the theory of meaning will be more solidly based if the meaning of a given linguistic unit is defined to be the set of (paradigmatic) relations that the unit in question contracts with other units of the language (in the context or in the contexts in which it occurs), without any attempt being made to set up 'contents' for these units.

In a later work he clarifies: 'The question 'What is the sense of $x$ ?' [...] is methodologically reducible to a set of questions, each of which is relational: Does sense-relation R hold between $x$ and y?' (1968: 444). To distinguish between the theoretically specific reading of 'meaning relation' that he introduces and the broader concept that he associates with Trier and Weisgerber, Lyons uses the term 'sense relations'. The 'meaning' captured by a broad, traditional form of content description is not something internal to the structure of the language (like the 'sense' that structuralist theory is interested in), but rather belongs to the level of reference-the encyclopedic level, we might say. In further work (1977, 1996), he links the distinction between sense in the theoretically specific reading and meaning to the distinction between semantics and pragmatics. The assumption is that semantics deals with the context-independent aspects of meaning as part of linguistic structure, whereas pragmatics deals with the context-dependent meaning that linguistic forms receive in contextually specific utterances (a distinction that is reminiscent of Paul's distinction between okkasionelle and usuelle Bedeutung, except that Paul did not imply that they belonged to different subdisciplines of linguistics).

In our treatment of relational semantics, first look at the major sense relations. We will then discuss a number of theoretical issues involved. It should be mentioned that the presentation in this section pays proportionately less attention to relational semantics than is customary in introductory linguistics. Linguistic textbooks of the past few decades have tended to present the study of word meaning predominantly in terms of sense relations, but 
because that is a serious underrepresentation both of what came before and of what came after the introduction of relational semantics, we try to offer a more balanced view.

\subsubsection{Major sense relations}

Let us first have a look at the sense relations that have been most extensively discussed: synonymy, hyponymy, antonymy, and meronymy. In this section, we briefly introduce the most common terminology associated with these concepts, together with subclassifications that have been proposed for the various relations. The main contribution to the study of sense relations after Lyons may be found in the work of Alan Cruse, whose 1986 book is the main background reference for the following pages. Murphy (2003) is a thoroughly documented critical overview of this research tradition and its current state.

1 The terms 'hyponymy' and 'hyperonymy' both refer to the relationship of semantic inclusion that holds between a more general term such as bird and a more specific one such as finch. Terminologically speaking, the more general term is the 'hyperonym' (sometimes 'hypernym') or superordinate term. The more specific term is the 'hyponym' or the subordinate term. In this respect, subordination or hyponymy could be thought of as the relationship of the hyponym with regard to the hyperonym, whereas superordination or hyperonymy would be the relationship of the hyperonym with regard to the hyponym. In practice, this shift of perspective is largely disregarded, and both terms are used interchangeably, with hyponymy-following the terminology introduced by Lyons (1963) - the more popular. Words that are hyponyms on the same level of the same hyperonym are 'co-hyponyms'. Thus, for instance, robin, swallow, and finch are co-hyponyms of bird. The reference to level in this definition of co-hyponymy is necessary because hyponymy is a transitive relationship: if tit is a hyponym of bird, and titmouse and titlark are hyponyms of tit, then titmouse and titlark are also hyponyms of bird, but clearly, titmouse and titlark could not be co-hyponyms of finch, which is situated on a different hierarchical level with regard to bird. It may also happen that the same term occurs on different levels of a taxonomy, such as when dog contrasts with cat on one level, but with bitch on a lower level of the taxonomy. Dog in the reading 'member of the species Canis familiaris' is then a hyperonym of $d o g$ in the reading 'male member of the species Canis familiaris'. Dog is, in other words, an 'auto-hyponymous' term. It will also be clear from this example that hyponymy, like synonymy and antonymy, is not strictly speaking a relationship between words, but between words in a particular reading. 
A hierarchical structure of hyponyms and hyperonyms is a 'taxonomy'. Distinguishing between an 'is a kind/type of' relation and a straightforward 'is a' relation, Cruse (1986) distinguishes taxonomies from non-taxonomical inclusion: whereas spaniel is a hyponym of dog, and kitten is a hyponym of cat, it is normal to say a spaniel is a kind of dog but awkward to say a kitten is a kind of cat. Cruse suggests using the term 'taxonomy' only for the first situation, which involves a hierarchical organization of kinds and species. This restricted use of 'taxonomy' is not the general practice, but the distinction pointed at by Cruse is relevant nevertheless.

Traditionally, hyperonyms play an important role in defining. As we mentioned a few pages earlier, in the scholastic conception of definition, an analytical definition (a definition that describes concepts in terms of characteristic or essential features, in contrast with a synonym definition) is supposed to consist of a genus proximum, i.e. the next higher superordinate term in a taxonomy, to which are added differentia specifica, i.e. the attributes that distinguish the concept to be defined from its co-hyponyms. And clearly, this model of definition also underlies the basic ideas of componential analysis. The definitional importance of hyponymy can be further specified by examining the notion of inclusion. The relationship of inclusion that lies at the basis of hyponymy may be viewed from an extensional point of view or from an intensional one, with what counts as the including term or the included one changing accordingly. Extensionally, the set of birds includes the set of finches; more generally, the referential range of the more general term includes that of the more specific one. Intensionally, the relation is reversed: the concept 'finch' includes the concept 'bird', in the sense that a finch is a bird; all the attributes that have to be used in defining birds will also have to be used in defining finches, and more particularly as that part of the concept 'finch' that specifies the birdiness of finches. More generally speaking, the definition of the more general term is included in the definition of the more specific one. We may note, though, that recent non-classical theories of categorization (to be treated in section 5.1) call this picture into question. If, along the lines set out by prototype theory, it is accepted that categories need not be definable by means of a necessary-and-sufficient set of attributes, the parallelism between the intensional and the extensional conception of hyponymy breaks down. For instance, penguin and swallow are both hyponyms of bird, but if it is accepted that there is no single, essentialist set of attributes defining the category 'bird', the kind of birdiness that is relevant for penguin is different from the one for swallow. Being able to fly, for instance, is not part of the birdiness of penguins. This is the problem of inheritance: hyponyms inherit all the attributes of their hyperonymical category if the latter is uniquely defined in the classical way, but 
what are the inherited attributes if the superordinate category cannot receive a traditional, essentialist definition?

2 'Synonymy' is a relationship of semantic identity, either between readings of a word or between words. The first perspective involves comparing words with their full range of applications, the second comparing words as they appear with a specific reading in a specific sentence. In both cases, the relationship may be complete or partial.

If synonymy is defined as a relationship between words in context, two items are synonymous if they may be substituted for each other in a given context, while retaining the semantic value of the expression as a whole. The substitution must work in both directions, to rule out hyponymous substitutions. In Kim was fined for speeding, a substitution by Kim was penalized for speeding is possible. Conversely, it is more difficult to go from Kim was penalized for speeding to Kim was fined for speeding, because the penalization may take other forms, like the withdrawal of Kim's driving licence. Partial synonymy between words in a context exists if substitutable items differ in some aspect of their meaning. This is particularly clear when non-denotational aspects of meaning, like emotive or stylistic shades of meaning, are at stake. Taking for granted that neither word exhibits differences of emotive or stylistic meaning, film and picture are completely synonymous in the reading 'cinematographic representation' with regard to a context like Did you see the latest_ with Kate Blanchett? Movie and picture, on the other hand, would be merely partially synonymous in the same context, given that the former word is more informal than the latter. Similarly, whore and prostitute may refer to the same person, but the former has a more negative charge. Such differences of stylistic or emotive meaning are often associated with specialized language: whereas gonorrhoea belongs to medical jargon, clap is the more popular (and more emotional) term. But language variation of this kind may also occur among words that are denotationally and connotationally identical in all other respects: underground and subway are only distinct to the extent that the former is typical for British English and the latter for American English.

If synonymy is defined as a relationship between words, total synonymy implies that the synonyms, first, have the same range of meanings and, second, are substitutable for each other in all relevant contexts without changing the meaning of the sentence as a whole. Words are partially synonymous if they are substitutable in one or more but not all of their readings, or if their readings are partially synonymous in the sense defined above. For instance, if picture and film share the reading 'cinematographic representation of a story' but not the reading 'painted or drawn portrait', this explains why film is substitutable 
for picture in the context Did you see the latest—with Kate Blanchett?, but not in the context This is the famous_—of Dr Gachet by Van Gogh. Partial synonymy defines sets of near-synonyms, like burial, deposition, entombment, exequies, funeral, inhumation, interment, last rites, obsequies, or aurora, break of day, crack of dawn, dawn, daybreak, daylight, first light, light, morn, morning, sunrise, sunup. There is a relation here with the notion of co-hyponyms. If, for instance, we are willing to accept funeral as a general term for the ritual act of disposing of a dead body, then the other terms are co-hyponyms.

Because the attribution of synonymy at the level of words clearly relies on a preliminary identification of synonymy at the level of senses, it is important to see that such a decision is not always obvious. In some cases, to begin with, the presence of identical readings does not seem to guarantee substitutability. This is often the case in idioms and collocations. For instance, dead has the reading 'completely' in expressions such as dead drunk and in dead silence, but although complete(ly) can replace dead in these expressions, the reverse is not the case in a context such as a-victory. In this case, the restriction seems to involve fine-grained semantic distinctions at the connotational level: drunk and silence share connotations of inactivity and stillness with death that victory does not. In other cases, the restrictions appear to be formal and idiosyncratic: you can kick the bucket, but you cannot kick the pail.

Further, how to describe the subtle nuances among near-synonyms is often unclear. What exactly is the relation between funeral and burial? From one point of view, burials are a kind of funeral, next to cremations. But burials also apply to animals, whereas we primarily think of human beings in the case of funerals. So perhaps burial is not after all a hyponym of funeral? Or should we say that burial has two readings, one associated with people and one associated with animals? But how should we decide? And how does burial differ from last rites? Is it only a difference of stylistic value, or could we say that last rites focuses more on the ritual behaviour that is part of the funeral, whereas burial highlights the act of laying the dead body in a grave or tomb? But if that is the case, would there not also be many contexts in which that distinction of focus is neutralized, roughly in the way in which Erdmann noticed how certain specifications of the concept 'German' may be contextually irrelevant (see section 1.2.3)? In short, the identification of synonymy rests on a prior analysis of the polysemy of lexical items, and there are various indications that establishing polysemy is a non-trivial matter: see section 5.1.2 for a further discussion.

3 'Antonymy', or oppositeness of meaning, is probably the most intensively researched of the sense relations, and various classifications and terminological proposals compete with one another. Our purpose here is not to 
compare these proposals, but only to introduce some frequently cited types of oppositeness of meaning. (The following classification is based on Lyons 1977 and Lehrer 2002.) A basic distinction opposes binary gradable, binary nongradable, and multiple antonyms. Within each of these classes, further types may be distinguished.

'Gradable antonyms' of the type tall/short consist of endpoints on a gradable scale; there are intermediate positions which may be lexicalized (like warm, tepid, cool on the scale defined by hot and cold), or which may be expressed by modifiers such as somewhat or very. Three subclasses of gradable antonyms may be distinguished. In the first place, 'polar antonyms' exhibit both symmetrical entailment and markedness. The symmetrical entailment means that the affirmation of one of the antonyms entails the negation of the other: tall implies not short, and short implies not tall. The markedness criterion means that one of the terms may be used as a neutral one which is not committed to one of the poles on the scale: the question How tall is $h e$ ? may receive the answer short. One of the terms in the antonymous pair is thus treated as co-hyponymous. In the second place, 'committed antonyms' are characterized by symmetrical entailment, but not by markedness: in the pair ferocious/meek, neither of the terms functions as a superordinate. In the third place, 'asymmetrical antonyms' like good/bad, clever/stupid, healthy/ill are ones in which there is an unmarked term, but which express an evaluative meaning that appears to restrict the symmetry. In polar antonymy, one can say both John is shorter than Mary, but both are tall, and John is taller than Mary, but both are short. In the case of asymmetrical antonyms, the first of these possibilities is blocked: ${ }^{\star}$ John is worse than Mary, but both are good versus John is better than Mary, but both are bad.

'Non-gradable antonyms' involve pairs like dead/alive, which do not define endpoints on a gradable scale. Again, we may mention three subclasses. In the first place, 'complementaries' consist of items that logically exclude each other without a third possibility or an intermediate position, like dead/alive. In the second place, 'perspectival opposition' or 'converseness' involves two terms that are positively related, in the sense that predication of one term entails that the other can be predicated too (and similarly for their negation); typically, however, predication of the opposite term involves a shift of perspective in the linguistic construal of an identical real-world situation or event. Thus, subject and prepositional object of be the husband of/be the wife of switch places: if $A$ is the husband of $B, B$ is the wife of $A$, and if $A$ is not the husband of $B, B$ is not the wife of $A$. In the same way, if A sells B to C, then C inevitably buys B from A. In the third place, 'directional opposition' involves various forms of spatial orientation relative to a point of reference, either in a static sense (as in the case of north/south or up/down) or in a dynamic sense (such as when a 
path is traversed in opposite directions, as in come/go). In the latter case, the term 'reversives' is sometimes used. The spatial orientation may be a literal one, as in come/go, but it may also be figurative, as in ask/answer, which may be conceptualized as one message moving from one person to another, and another message moving back, or in to be born/to die, where a metaphoric transition in and out of life is at stake.

The different types of 'multiple opposition' antonyms are subclassified according to the number of semantic dimensions involved. In the most common type, the 'scale', there is only one semantic dimension, such as temperature in the case of hot/warm/tepid/cool/cold. Clearly, this is the filled-out form of a binary gradable antonymy. Typically, the dimension of a scale is continuously gradable, and the terms in the scale indicate various degrees on the graded dimension. 'Ranks' are one-dimensional as well, but the relevant dimension is discontinuous and not gradable; an example is the set of items denoting military ranks (general/colonel/major/captain/lieutenant, etc.). In 'cycles' such as the days of the week or the months of the year, there is again only a single conceptual dimension (in this case, time), but the dimension does not have a polar structure (in the sense that there are two extremes like hot and cold). Finally, examples of 'multidimensional multiple opposition' can be directional, in which case various binary directional opposites are combined into a complex system of coordinates (north/south/east/west, or, taking the human body as a point of reference, left/right/in front/behind/up/down). More common, however, are examples of 'incompatibility', which is here used as a general term for the contrast between lexical items in a semantic field. As will be obvious from the examples of lexical fields that we discussed in sections 2.2 and 2.3, the words in a field are usually distinguished along various dimensions; for example, to distinguish ewe, ram, and lamb, at least the dimensions of age and sex are necessary. It should be noted that the strength of the semantic contrast has weakened considerably when this area of the classification is reached: the opposition between ram, ewe, and lamb is less specific than that between complementaries like odd and even.

In line with the basic assumptions of relational structuralist semantics, antonymous relations such as these are assumed to be stable, fixed configurations in the lexicon, as part of the structure of the language. But how sure is that? Based on actual textual evidence, Mettinger (1994) makes clear that there are many 'non-systematic' antonyms, which are not as entrenched in memory as the intuitively obvious examples that we have so far considered, but that are activated in a specific textual or situational context. Oral and rectal contrast in the context of methods for taking body temperature, but would they be recognized as binary opposites apart from that highly specific situation? Mettinger adduces examples of texts in which, among others, to live by one's wits 
contrasts with to live by one's looks, scholarship with domesticity, romance with real life, and listening with looking. In all of these cases, an understanding of the opposition relies on situated knowledge that is encyclopedic and textual rather than structural and purely linguistic. The contextuality of the oppositions is further supported by the observation that one lexical concept may enter into different relations of contrast depending on a particular construal in a given text. Thus, in Mettinger's examples, nature may contrast with art in one context, or with civilization in another. (Mettinger's method of looking at pairs of opposites as they occur in actual discourse is implemented on a larger scale by Jones 2002, who applies a corpus-based method to the identification of the textual functions of semantic opposition.)

4 A taxonomical, hyponymous relation is to be distinguished from a partwhole relation or 'meronymy'. Meronymy holds between pairs such as arm and elbow: arm is the holonym and elbow the meronym. Meronymy can be identified in terms of the predicates 'has' and 'is a part of' (an arm has an elbow, and an elbow is part of the arm), rather than in terms of the 'is a' relationship that obtains in the case of hyponymy (a finch is a bird). As analysed in Winston, Chaffin, and Herrmann (1987), the part-whole relation is not a unitary one, but comprises a number of subtypes, like the relation between component parts and the material entity to which they belong (keyboard/computer), the relation between a member and the collection to which it belongs (soldier/army), the relation between a material and the object of which it forms an ingredient or a constituent element (wood/door), or the relation between a component action and the overall activity of which it forms part (paying/shopping). (In section 5.2.3, this diversity of part-whole relations will be the basis for an analysis of the concept of metonymy.)

\subsubsection{Theoretical issues}

To what extent does the relational method live up to its explicit aim of providing a truly structuralist account of meaning? The question is theoretically important, because we have seen how the relational approach more or less represents the epitome of the structuralist case for an independent level of linguistic meaning. The lexical field approach, as the most immediate realization of the structuralist conception of meaning, needs to be supplemented with a substantive analysis of the conceptual relationship among the items in the field. Componential analysis is one way of achieving that, but in itself, a componential analysis does not necessarily distinguish between the description of encyclopedic relations and the description of linguistic (semantic) structure. Focusing on oppositional relations within a field, as Coseriu suggested, yields 
a more restricted descriptive scaffolding, but it is only the relational approach that completely develops the framework. So, what would be needed to say that the relational method is completely successful in realizing the structuralist intentions? Two points are crucial.

First, sense relations have to be methodologically independent of the broader type of content description that Lyons refers to. If sense relations really belong to the level of linguistic structure and the broader content description is situated on the encyclopedic or pragmatic level, then we should be able to establish sense relations without having recourse to that other level.

Second, sense relations should constitute a natural set that does not include any typically referential, encyclopedic relations. Note, for instance, that the verbs rise and raise exhibit a relationship that is known as a causative one: the action of raising is the cause of the rising, to raise is 'to make something rise'. Between composer and music, the same relationship of cause and effect (or at least causer and effect) would hold, as between cook and meal and numerous other lexical items. But such a causative relationship is not commonly recognized as a sense relation, because-one could say-it indicates a relationship between the referential entities involved rather than between the senses: the causative relationship exists between a person and a product, for instance, rather than between two words. By contrast, a hyponymous relationship is a genuine sense relation, because it can be defined in terms of inclusion between senses.

However, the distinction is far from being as obvious as a strict structuralist stance would require. For one thing, we have seen that meronymy is readily recognized as a sense relation: but part-whole relations like those between hand and finger are definitely of a referential and encyclopedic nature; they hold between things, not senses. Conversely, there would seem to be no principled objection against defining a sense relation (say, 'causonymy') that holds between a sense referring to a cause or causer and a sense referring to an effect, as a metalinguistic counterpart of the referential relationship that holds between the cause(r) and the effect. And frequency would not really help either: one might suggest that in order to file as a genuine sense relation, the semantic association has to be highly frequent-but 'causonymy' is probably no less frequent than meronymy. So what is there to stop us from adding ever more encyclopedic relations in disguise, thus undermining the structuralist starting point?

Furthermore, this discussion of the second requirement mentioned above makes it clear that there is a problem with the first requirement as well. Sense relations are supposed to be independent of a content description, but at the same time, identifying sense relations as a relationship between senses 
practically assumes a form of content description on the semantic level. As the discussion of synonymy made clear, distinguishing between different kinds of synonymy requires distinguishing between the various meanings of the words involved: questions about the polysemy of the words need to be answered before questions about synonymy can be settled. If the approach advocated by Lyons were feasible, it would be the other way round, and intuitions about synonymy relations should be able to decide on questions about polysemy. Our intuition about the synonymy between burial and last rites would be the methodological basis for determining whether burial is polysemous or not. But in practice, we do not seem to have very clear intuitions about that supposed synonymy, and questions about the semantic relationship between burial and last rites spontaneously shift towards a discussion of the meaning of those expressions on the level of the 'content description' that Lyons explicitly wants to avoid. Rather than being able to take our intuition of synonymy for granted, we start asking questions about descriptive features of a referential, encyclopedic kind, such as whether there is a focus on rituals in the one versus an emphasis on the act of burying in the other. If it is correct that our judgements of synonymy depend on such descriptive issues, the alleged methodological advantage of a relational approach evaporates. In a similar way, as Mettinger's examples of 'non-systematic' antonymy show, oppositeness of meaning, rather than being a stable structural characteristic of the mental lexicon, may be contextually induced against the background of encyclopedic and situational knowledge.

We may conclude, then, that the relational approach does not really succeed in establishing the structuralist ideal, for two reasons, corresponding to the two criteria mentioned above. In the first place, since sense relations hold not between full words but between words in a specific reading and a specific context, and since we seem to need other criteria than the sense relations themselves to establish what those readings are, it is difficult to maintain that a relational approach substitutes for a traditional semasiological 'content description'. It seems more appropriate to state that it depends on such an analysis. In Murphy (2003), a similar conclusion is argued in detail on the basis of a separate investigation of the various sense relations. Murphy makes a convincing case, backed up by ample references to the psycholinguistic literature on semantic relations, that sense relations are 'metalinguistic' in nature. Sense relations do not lie at the basis of our knowledge of the semantics of words, but our knowledge of the semantics of words lies at the basis of our ability to identify or attribute sense relations (on those special occasions in which, for instance, judgements about synonymy are required). In the second place, if relations like meronymy are accepted as bona fide sense relations (and they are accepted as such by leading scholars working within the sense relations 
model), it will be difficult to avoid other 'encyclopedic' relations from being considered, and the much-desired autonomy of semantic structure becomes unattainable.

More generally, the structuralist ideal of identifying a specifically linguistic level of semantic structure is not without problems: none of the structuralist frameworks that we have learnt about seems entirely immune to the objection that it does not systematically make a distinction between the linguistic level and the encyclopedic/pragmatic level. In contemporary lexical semantics, then, research into meaning relations does not particularly adhere to the structuralist creed.

\subsection{Beyond structuralist semantics}

Structuralist thinking had a major impact on lexical semantics: it shifted the attention from an almost exclusive focus on semantic change to the description of synchronic phenomena, and it provoked a change from semasiological to onomasiological studies, i.e. it pushed through the recognition that the vocabulary of the language is not just an unstructured bag of words, but a network of expressions that are mutually related by all kinds of semantic links. Admittedly, attention to onomasiological phenomena was not completely absent in historical-philological semantics: a phenomenon like analogical semantic change cannot be identified unless you take the vocabulary as a whole into account, and not just the individual word, and we noted that onomasiological, lexicogenetic mechanisms tended to creep into classifications of semantic change. But a systematic exploration of the different relations that tie lexical items together had to wait until the arrival of structuralist semantics. The invention of a terminology to describe onomasiological structures is a principal and lasting achievement of structuralist semantics. At the same time, however, our exploration of the different types of structuralist semantics has disclosed a number of problems that we may now spell out more systematically. Three points will be mentioned: the relevance of semasiology, the autonomy of structure, and the absence of a use-based onomasiology.

1 Structuralist theorizing underestimates the importance of the semasiological level. In an extreme formulation of the structuralist creed, semasiological analysis as such would be superfluous: if the meaning of a lexical item is exhausted by the onomasiological position or positions it occupies, why bother about a separate analysis of the internal structure of the word? If onomasiological structures are crucial for the establishment of meaning, then maybe the word should not even be considered a separate locus of semantic effects at all. 
It is easy to see, however, why such an extreme position cannot be maintained. In our discussion of the relational approach, we have already noted that establishing sense relations is methodologically dependent on a semasiological analysis: the view upheld by Lyons - that sense relations can be established regardless of a 'content description'-appeared difficult to maintain. Lexical field theory may inspire a similar conclusion. If semasiological polysemy is secondary with regard to onomasiological structure, polysemy could emerge from the fact that one word may belong to several fields, in several meanings. However, in connection with Ducháček's beauté field, we noted that some words seem to belong to different fields in just a single reading, like the words that belong both to the field of beauty and to that of magic. Obviously, if this is correct, belonging to multiple fields is not a criterion for polysemy, and the study of polysemy cannot simply be dissolved into the study of lexical fields and their overlap.

In the application of structural semantics to historical linguistics, a number of voices could be heard emphasizing the importance of a semasiological perspective next to an onomasiological one. As von Wartburg (1931) stressed, it should be explained not only why gat was replaced, but also why a term like bigey could serve as a surrogate. The fact that bigey is available as a substitute must be given a semasiological explanation in which the transfer from the original to the novel application is made acceptable. Von Wartburg, in fact, suggests that a humorous metaphor is involved : the curate (vicaire, bigey) plays the boss in a parish like the rooster plays the boss among his hens. An explicit demonstration of the integration of field analysis and a more traditional semasiological analysis is given by Baldinger (1964) in an extremely convincing way. On the basis of a field representation which is strongly reminiscent of Ducháček's, he shows how the word travail onomasiologically makes its way towards the core of the 'work' field, while at the same time the sense 'work' begins to occupy a more prominent position in the semasiological structure of the word, at the expense of the original meanings 'suffering, trouble, sorrow, poverty'. Baldinger concludes that diachronic semantics should neither be based exclusively on a semasiological, word-oriented method nor exclusively on an onomasiological, structure-oriented method.

But in spite of such voices, the interest of structuralist semantics for the problem of polysemy has been limited. As we saw when we talked about Nida and Lounsbury, a number of researchers (among them also Joos 1958 and Heger 1964) carried over the terminology of structuralist phonology to semantics, introducing the notion of 'alloseme' to make room for polysemous shades of meaning. But this interest in polysemy remained largely terminological: it was not accompanied by an investigation into the principles that govern semasiological polysemy, like the metonymical and metaphoric mechanisms 
that occupied such an important place in historical-philological semantics. Only in the work of more isolated representatives of structuralist thinking, like the Dutch linguist Anton Reichling (1935), do we find an attempt to analyse the mechanisms that underlie the internal coherence of polysemous words. If different lexical meanings are like allophones, it is indeed compulsory to pinpoint the way in which the different 'allosemes' belong together, and that is precisely what Reichling endeavours to do. Thinking in gestalt terms, he argues that the various readings of a polysemous word manifest an internal cohesion in such a way that they can be recognized as instantiations of one and the same semantic entity - the lexical meaning of the word. Reichling illustrates the idea with the meanings of the Dutch word spel 'game'. Although the readings of spel cannot be subsumed under a single definition that applies to all sorts of games, the readings in question show so many pairwise similarities that the entire set of readings may be perceived as a coherent, tightly knit whole. From a historical point of view, Reichling's analysis is interesting because it anticipates (like other work that we have come across) the prototype-theoretical semasiology that will be discussed in section 5.1. One of the pillars of prototype semantics is precisely the idea that lexical items can be semantically coherent even though they cannot be captured in a single definition. However, since Reichling's work remained untranslated, his views did not have a major impact on the main currents of structuralism.

Overall, the structuralist focus on onomasiology has tended to throw the semasiological baby out with the historical-philological bathwater. It will come as no surprise, then, that we will be able to see later that the poststructuralist developments in lexical semantics are characterized by a renewed interest in the problem of polysemy.

2 The structuralist tenet that it is possible to identify an entirely languageinternal level of semantic structure may be difficult to maintain. The crucial problem is one of demarcation: if there is an essential distinction between linguistic semantic knowledge as part of the language, and conceptual knowledge in general, as part of our knowledge of the world, where exactly do we find the boundary? How easy would it actually be to draw a neat boundary around the structures that constitute semantic knowledge according to the structuralist point of view? Our overview of the different types of structuralism makes clear that the answer is not obvious.

Within a lexical fields approach, for instance, fields appear to be fuzzy, not just with regard to each other (as in Ducháček's field analysis) but also internally, if we consider the example provided by Gipper of the mutual delimitation of Sessel and Stuhl. Now think of the effect that Gipper's findings would have on a componential analysis of the Pottier-type: what Pottier has 
to offer seems to apply to the clear centres of categories like Sessel or Stuhl, but if the more peripheral instances are included, the componential analysis would become much more intricate-and it would certainly be considered an 'encyclopedic' analysis, involving all possible kinds of referential and functional features. According to Pottier's analysis, a chair is a seat for one with legs and a back and without armrest in a hard material; the distinctive semantic structure that Pottier's componential analysis is able to identify for chaise is based on these features. But it is not so difficult to see that there might be things that we call chaise that do not conform to the set of features named by Pottier, and that is also, of course, what Gipper's analysis of the variability of actual examples of chairs would suggest. A seat for one with a solid block as lower part rather than legs would probably still be considered a chair, and chairs with armrests are definitely not a pure fantasy. A dilemma then arises. On the one hand, as a proponent of structuralism, you might be inclined to think that the fact that chairs sometimes have armrests, or sometimes have a solid base rather than legs, is merely an encyclopedic piece of knowledge that need not be included in the analysis of linguistic meaning. On the other hand, if you assume that a description of linguistic meaning should fit all the cases that occur as examples of a word, then such 'encyclopedic' features could not be excluded from the analysis, and the analysis as a whole would become less neat and orderly than the notion of 'structure' seems to imply.

In addition, note that the contrast between two elements in a lexical field may be paraphrased in different ways. When the referents of the terms concerned have features in common, it becomes difficult to select a feature from this collection that can with certainty be labelled 'semantic'. For example: in the classical Aristotelian definition of the human being as a creature which is endowed with reason ('animal rationale'), one could substitute the distinctive feature 'rational' with a number of characteristics which in themselves are coextensive with the distinctive feature 'rational', but which must nevertheless be taken to be encyclopedic when the paraphrase 'creature endowed with reason' is considered to be a genuinely semantic definition. Features like 'being able to smile' or 'being an erect biped', 'possessing the most complex brain structure' are all unique for the human species, and as such sufficiently delineate the species from others: so why would 'endowed with reason' be semantic and 'being an erect biped' be encyclopedic, rather than the other way round?

Faced with this inevitable drift towards an encyclopedic description in which the idea of a strictly delineated and well-defined structure needs to be abandoned, structuralist semantics may take different paths. First, linking up with the position defended by Lyons, it could be argued that a full content 
description is not necessary: there does exist a language-internal structure, but it does not cover the full spectrum of meaning description. The referential aspects of the use of words (such as the fact that chairs may or may not have armrests) may be left aside, to the benefit of the relational aspects of meaning, which constitute the only truly linguistic type of meaning. However, even in this case, demarcational problems were seen to arise, as with the inclusion of meronymy: how to stop their inclusion except by arbitrary decree-but if you cannot stop their inclusion, how to avoid an encyclopedic type of description? Conversely, assuming that the reductionist programme can be realized, how relevant would the results be? Having only structural relations and oppositions, without any 'encyclopedic' content analysis, boils down to knowing that certain words differ in meaning, but not (exactly) how they differ.

Second, the neatness of a well-ordered, well-delineated description might be salvaged by arguing that, roughly speaking, the mind is neat but the world is fuzzy. Our concept of chaise, Sessel, Stuhl or whatever is well defined and clearly delineated, but its application to the world may be muddled-because the world itself is more varied than our concepts allow. This is a position that is most forcefully advocated by Anna Wierzbicka and her Natural Semantic Metalanguage approach, which will be presented in section 4.1.1.

And third, structuralist semantics might simply surrender, and describe structures in the lexicon without claiming to unearth a specifically linguistic, non-encyclopedic level of structure. An outspoken example is the work of Georges Matoré (1953), who describes lexical fields from a historical, sociological point of view-or perhaps the other way round, who describes the mentality in various periods of social history through an analysis of the vocabulary of those periods. Within the vocabulary of given historical era, some words have a special significance. On the one hand, these would be words like ésotérique, which is introduced in the French vocabulary round 1755, and which marks the beginning of the romanticist reaction against rationalism, or magasin, which makes its entrance between 1820 and 1825 and which signals the birth of a new system of commerce and distribution. Words like these are mot-témoins, words that witness a particularly significant change in social history. On the other hand, there are mot-clés, keywords that are central to the beliefs and norms of a given period. During the post-Napoleonic restoration period in France, for instance, bourgeois would be such a keyword, indicating the central sociological importance of conservative middle-class values after a period of revolutionary zeal and imperialist ambition. But whatever the details, the recognition of mot-clés and mot-témoins does not aim at detecting a linguistic structure; it envisages a historical and sociological (and hence, undoubtedly encyclopedic) reality. 
In short, we may conclude that the basic tenet of structuralism is not without problems: the distinction between a semantic and an encyclopedic level of semantic description is not as stable as the structuralist position assumes. Does that also mean that there is no language-specific structure? Thinking back to Weisgerber's seminal paper, we recall that it was precisely the interest in language-specific meanings that motivated the development of structural semantics. So, should the problems with the distinction between semantic and encyclopedic descriptions be taken to mean that there are no language-specific semantic phenomena? Not necessarily. Languages may still have their own structuring of encyclopedic knowledge: encyclopedic knowledge need not be universal. At the same time, the extent to which language-specific patterns of encyclopedic knowledge influence cognition cannot simply be established by looking at language alone.

3 A final point that we need to mention concerns the very concept of onomasiology that structuralist semantics focuses on. In the structuralist conception of onomasiology, onomasiological research is all about structures in the vocabulary: transcending the semasiological confines of earlier historicalphilological semantics takes the form of looking at ensembles of lexical units, rather than just individual items. But is that all there is to onomasiology? Let us have another look at the quotation from Baldinger that we introduced in section 1.2.3: 'Semasiology [...] considers the isolated word and the way its meanings are manifested, while onomasiology looks at the designations of a particular concept, that is, at a multiplicity of expressions which form a whole' (1980: 278). The two descriptions of onomasiology that Baldinger mentions are not exactly equivalent. On the one hand, studying 'a multiplicity of expressions which form a whole' leads to the structuralist conception of onomasiology with which we have become acquainted in this chapter, i.e. to the study of semantically related expressions-as in lexical field theory, or the study of the lexicon as a relational network of words interconnected by links of a hyponymous, antonymous, synonymous nature, etc. On the other hand, studying 'the designations of a particular concept' opens the way for a contextualized, pragmatic conception of onomasiology, involving the actual choices made for a particular name as a designation of a particular concept or a particular referent. This distinction can be further equated with the distinction between an investigation of structure and an investigation of use, or between an investigation of langue and an investigation of parole. The structural conception deals with sets of related expressions, and asks the question: what are the relations among the alternative expressions? The pragmatic conception deals with the actual choices made from among a set of related expressions, and asks the question: what factors determine the choice for one 
or the other alternative? Gipper's study may again serve as an example: given the variability in the use of Sessel and Stuhl, and given the marked overlap between the two terms (often, the same terms apply to the same objects, and it is even the case that the same speakers apply both terms to the same objects), the question is not so much: 'What is the semantic dividing line between Sessel and Stuhl?' but rather: 'What are the factors that determine whether one term rather than the other is chosen for naming a given entity?'

But while this constitutes an extremely relevant perspective, structuralist semantics does not pay systematic attention to the question-which is understandable, given the principled preference it has for an investigation of structure rather than use. If we now take an anticipatory look at the further development of lexical semantics, we may note that the absence of a pragmatic, usage-based onomasiology is the most resilient of the three critical points mentioned here. The inevitability of a semasiological analysis, and the difficulty of separating encyclopedic knowledge and strictly semantic knowledge, will be addressed directly by later approaches, specifically the ones mentioned in Chapters 4 and 5. But a pragmatic onomasiology is still largely waiting for more systematic attention. 


\section{Further sources for Chapter 2}

A general introduction to the different types of structuralist thinking in linguistics, not specifically geared towards semantics or lexicology, may be found in Lepschy (1970). Apart from the references in the general works that we mentioned in the previous chapter, broad overviews of (different kinds of) structuralist semantics-often as chapters in a work of broader scope-are provided by Lehrer (1974), Coseriu and Geckeler (1981), Kastovsky (1982), Lipka (2002), Kühlwein (2002), and Murphy (2003). A useful collection of reprinted papers from the German tradition is Schmidt (1973). To get an idea of the position of structural semantics in the context of the evolution of lexical semantics, it is also instructive to consult a number of volumes that contain papers from older and younger traditions alike. In volumes like Hüllen and Schulze (1988), Lehrer and Kittay (1992), and Lutzeier (1993) one may find representatives of lexical field research and componential analysis together with work coming from (or looking in the direction of) cognitive semantics.

Introductions to and overviews of lexical field theory are provided by Öhmann (1951a, 1951b), Quadri (1952), Spence (1961), Hoberg (1970), and Geckeler (1971a, 1971b). Studies that are sometimes named as forerunners of lexical field research include Meyer (1910), which focuses on ordered sets of words like military ranks, and Voigt (1874), which shows how an initial semantic change in one of the elements of a Latin set of legal terms systematically influenced the other items in the field.

Beside the studies mentioned in section 2.2.1, other work broadly situated along the Trier-Weisgerber line includes Ipsen (1932), Jolles (1934), Bechtoldt (1935), and Weisgerber (1962a, 1962b). The philological and historical accuracy of Trier's work is critically discussed in Rothwell (1962), and specifically in Scheidweiler (1941a, 1941b, 1942); see further Dornseiff (1944).

The less stringent, somewhat vaguer field notion that we associated with Ducháček and Matoré is further illustrated by Ducháček $(1960,1961,1968)$ and Matoré $(1951,1985,1988)$. The loosest conception of semantic fields is probably that of Bally (1940), whose champ associatif is indeed no more than the set of expressions that are mentally associated, by denotational or connotational semantic links, with the source word.

In his major work, Porzig (1950) identifies his own wesenhafte Bedeutungsbeziehungen as syntaktische Felder in contrast with the parataktische Felder of Trier and Weisgerber; but the approach is not worked out with much descriptive breadth. The distributional approach suggested by Dubois is further illustrated in the volumes of his 1965-9 grammar. The most extensive and systematic illustration of a distributional method (apart from the tradition of corpus linguistics inspired by Firth; see section 4.2.3), however, is to be found 
in the work of Apresjan: see the German translation of his book on structuralist method (1971) and the English translation of a collection of articles in Apresjan (2000). For more work from the Russian tradition of lexicology, see the translations in Wolski (1982). Work by Firth is collected in Firth (1957a) and Palmer (1968).

Regarding the influence of field theories and structural thinking on diachronic semantics, more examples of homonymic clashes are mentioned in Dauzat (1922). The notion received a fair amount of attention, but in general it is treated with considerable caution, because too many homonymic pairs continue to exist in a language for the principle to have much explanatory value (see e.g. de la Cruz Cabanillas 1999). A more convincing approach to proving the fruitfulness of the field approach for diachronic studies is that taken by Lehrer $(1978,1985)$. She investigates whether there is any regularity in the semantic extension of lexical fields, and concludes that the field relationship of lexical items creates a potential for semantic changes: if a subset of items in a given field undergoes an extension towards another field, the rest of the items in the first field also become available for extension to the second field. Semantic relationships in the fields remain the same: synonyms remain synonyms, antonyms remain antonyms, and so on. With section 1.3.1 in mind, we can reformulate this as follows: the grouping of words in lexical fields defines pathways of analogical change.

At this point, we should also mention the impact of field-oriented thinking in two disciplines bordering on theoretical linguistics. First, structuralist ideas led to a renewed attention in lexicography for onomasiological dictionaries, i.e. reference works that organize vocabularies not on an alphabetical basis, but on the basis of the semantic association between words, like thesauri and synonym dictionaries. Such onomasiological dictionaries have a long pedigree in practical lexicography (see e.g. Hüllen 1999), but in the structuralist era they received specific attention in theoretical lexicography, and new thematically organized dictionaries were developed. A selection of the relevant literature includes Dornseiff (1959) as an example of an actual dictionary project, and Hallig and von Wartburg (1952), Glinz (1954), von Wartburg (1957), and Baldinger (1960) as examples of the theoretical reflection triggered by structuralist semantics.

Second, a method for structuring sets of words in terms of their emotive meaning rather than their referential meaning was developed in a psycholinguistic context, in the form of Osgood's semantic differential technique (Osgood, Suci, and Tannenbaum 1957, Snider and Osgood 1969). In a semantic differential, subjects rate a word (or a thing, or a person) with regard to a set of bipolar adjectives, like warm/cold, beautiful/ugly, good/evil. The position on these rating scales gives an idea of the affective value of the word. By analysing 
the effect of different kinds of adjectival pairs, Osgood, May, and Miron (1975) concluded that three basic attitudinal patterns shape people's reactions: evaluation (good/bad), potency (strong/weak), and activity (active/passive).

An advanced introduction to componential analysis is Leech (1974), which includes references to the incorporation of componential analysis in formal grammar that we will discuss in the next chapter. For an introduction from a more descriptive point of view, see Nida (1975).

Beyond the works already mentioned, componential analysis of the ethnosemantic type is further illustrated and/or discussed in Wallace and Atkins (1960), Frake (1962), Burling (1964), Conklin (1962, 1964), Lounsbury (1964), and Romney and D'Andrade (1964). Two books that look back on the history of cognitive anthropology and the role of componential analysis are D'Andrade (1995) and Kronenfeld (1996). Interestingly, both books link up with post-structuralist lines of research that play a crucial role in cognitive semantics, as we will see in Chapter 5: Kronenfeld discusses prototype semantics (see section 5.1), and D'Andrade emphasizes the role of models (see section 5.2). For the latter, see also Palmer (1996).

In linguistics, informal analyses of lexical fields and lexical relations that follow the direction of componential analysis may be found in Leisi (1975, originally 1952) and Oksaar (1958). More formalized approaches appear, among others, in Ebeling (1960), Lamb (1964), Bendix (1966), Lipka (1972), Wotjak (1977), and the studies that will be presented in Chapter 3. In the French tradition, the componential method described by Pottier did not gain prominence. Pottier's own later work is grammatically oriented rather than lexically; see Pottier (1992). (An overview of the evolution of semantics-not specifically lexical semantics-in French linguistics is presented in Larrivée 2008.) For the application of the Greimasian framework to literary studies, see Greimas $(1970,1983)$ and Culler (1975) for the overall development of a structuralist literary theory.

For the Coseriu school, we may mention, beyond the references given above, Coseriu $(1975,1980)$ and Geckeler $(1973,1988)$. For an overview of other work in this tradition, see Geckeler (1993). For the relational approach, apart from the works by Lyons, Cruse, and Murphy mentioned in the main text, see the overview of lexical relations in Evens, Litowitz, Markowitz, Smith, and Werner (1980). Lutzeier (1981) investigates the relations between lexical field theory and relational semantics. 


\section{Generativist Semantics}

In section 2.3, we saw how a componential analysis of meaning emerged in the context of a structuralist conception of semantics. The major breakthrough of componential analysis occurred outside the structuralist framework, however, when Jerrold J. Katz and Jerry A. Fodor introduced componential analysis into generative grammar. Their paper 'The structure of a semantic theory' of 1963 is a landmark in the history of lexical semantics, not because it presented a model of description that is currently still widely used (it has in fact been entirely superseded by other approaches) but because the discussions it engendered from its first formulation in the early 1960 s up to the mid1970 occupy a pivotal role in the development of lexical semantics. Before dealing with any details, let us identify the essence of the developments. Characterized in a nutshell, the Katzian model (Katz rather than Fodor became the main spokesman of the approach) is a combination of a structuralist method of analysis, a formalist system of description, and a mentalist conception of meaning. The first feature-Katzian semantics as the culmination of structuralist semantics-evidently refers to the preceding history of lexical semantics. The other two characteristics are singular additions of the Katzian approach: explicit attention for the description of meaning in the context of a formal grammar, and a renewed interest in the psychological reality of meaning. Both features play an important role in the further development of semantics-not just lexical semantics, but linguistic semantics in the broader sense. They raise new questions, and they suggest new adequacy criteria for the description of meaning. To what extent should it be a formal description, and if it is to be formalized, in what way? And should it take into account psychological criteria, and if so, how can it adequately do so? It is exactly because of these additional features of generativist semantics, and the role they would play in later developments, that we devote a separate chapter (if only a brief one) to the generativist framework. At first sight, the model put forward by Katz and Fodor is merely a passing variant of componential analysis, and that is how it is treated in many overviews of semantics. But if we take into account the questions it raised about formal methods and the cognitive reality of semantic descriptions, it needs to be presented in more detail. 


\subsection{Katzian semantics}

'The structure of a semantic theory' was a seminal paper, functioning as a catalyst in the development of lexical semantics. But, as it often happens, the 1963 views did not survive the far-reaching evolution that they contributed to. In what follows, we start with a brief account of the approach of Katz and Fodor, and then sketch how it gave rise to further developments.

\subsubsection{Formal dictionary entries}

Katz and Fodor's componential analysis does not take its starting point in a contrastive analysis of a set of words belonging to the same lexical field, as was the case for Pottier's analysis of seating terms or in the ethnosemantic analysis of kinship terms. Rather, they give an example of the way in which the different meanings of one single word, when analysed componentially, can be represented in a formalized dictionary as part of a formal grammar (like the generative grammars that were rapidly becoming fashionable when Katz and Fodor presented their model). What the dictionary entry for the English word bachelor would look like is demonstrated in Figure 3.1. Next to word form and word class, two types of semantic components can be found in the diagram: markers and distinguishers (indicated with round and square brackets respectively). The first constitute what is called the 'systematic' part of the meaning of an item, i.e. those aspects in terms of which selection restric-

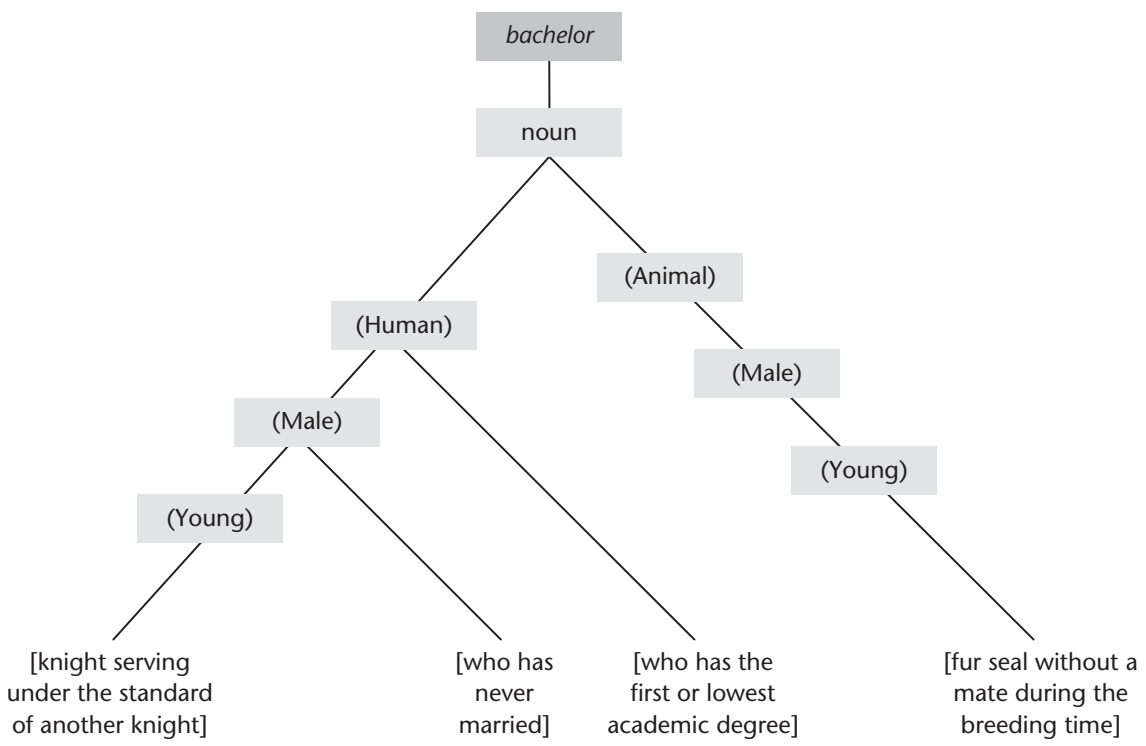

FIGURE 3.1. English bachelor according to Katz and Fodor 
tions (syntagmatic relations of the kind that we introduced in section 2.2.2) are formulated. A verb like speak, for instance, requires a human subject, and so (Human) features as a marker. Distinguishers, on the other hand, represent what is idiosyncratic about the meaning of an item. Next to criteria of systematicity and economy, the decision to consider a descriptive feature a marker or a distinguisher is determined by the question whether that feature is needed for the disambiguation of sentences. For instance, in order to explain why language users do not interpret the sentence the old bachelor finally died as being ambiguous between a 'shield-bearer, armiger' reading and an 'unmarried' reading of bachelor, a distinguisher like [young knight serving under the standard of another knight] would be split up into the marker (Young) and the distinguisher [knight serving under the standard of another knight]. In other words, the absence of ambiguity can be accounted for by supposing that the semantic component 'young' is a marker. An anomaly would in fact arise within the noun phrase the old bachelor if the marker (Young) of the noun combines with the marker (Old) that is activated by the adjective. The unequivocal interpretation of the old bachelor finally died indicates that this anomalous interpretation is indeed ruled out.

But how can the rejection of such an anomaly be accounted for on formal grounds? We can understand that language users reject the contradictory reading of the noun phrase, but how does a formal grammar avoid the anomalous interpretation? Since a formal grammar of the generative type purports to characterize the well-formed sentences of a language, and only those, how does it exclude anomalous interpretations? The introduction of this question in the realm of lexical semantics is a crucial development, because it links up the study of word meaning with the syntactic description of the language, and so promotes semantics to a fully-fledged component of a formal grammarwhich it had not been in the early stages of generative grammar. This incorporation of semantics in the grammar would have far-reaching consequences for generative grammar-consequences that we will return to in section 3.2.

In Katz and Fodor's model, the formal mechanism behind the exclusion of semantic anomalies consists of so-called projection rules. Projection rules are responsible for the combination of the lexical meanings of individual words in a sentence into constituent meanings, and the combination of the latter into a representation of the sentential meaning. In a constituent like the old bachelor, the individual semantic representations of the, old, and bachelor are amalgamated into a meaning representation of the noun phrase the old bachelor. If bachelor is interpreted in the 'shield-bearer, armiger'-sense, the meaning representation of the old bachelor features the simultaneous occurrence of (Old) and (Young), and this has to be rejected as anomalous. If bachelor, on the other hand, is given the 'unmarried' reading or the 'holder of a certain 
academic degree' reading, no anomaly emerges. Of course, this only works if the formal grammar 'knows' that (Old) and (Young) are mutually exclusive, but here another aspect of lexical semantics plays a role: 'old' and 'young' form an antonymous pair (an 'antonymous n-tuple' in the terminology of Katzian semantics), and this antonymous relationship accounts for the noncombinability. Note further that projection rules underlie the operation of selection restrictions: when amalgamating subject and verb, the grammar checks whether the overall meaning interpretation, resulting from the projection rules, conforms to the constraints imposed by the selection restrictions.

\subsubsection{The emulation of structuralist semantics}

The Katz and Fodor approach to semantic description received its most elaborate statement in Katz (1972). If we try to place the framework in the context of the history of lexical semantics, we need to see how it brings together the major concerns of structuralist semantics, but at the same time goes beyond structuralism as we introduced it in the previous chapter.

The structuralist character of the Katzian approach does not just reside in the use of a componential method of description, but links up more essentially with Katz's methodological perspective. Katz (1972) draws a methodological comparison between the semantics of natural language and physics. Just as the latter postulates abstract entities which are not directly perceptible (like gravity or molecular structures) to explain observable characteristics of and relations between things (the falling of an apple, certain chemical reactions), linguistics too can postulate underlying structures, like formal dictionary entries and projection rules, to account for observable linguistic characteristics and relations. Those observable characteristics take the form of judgements that language users can pronounce with regard to the semantic properties of sentences. Given their ability to interpret utterances, language users would know, for instance, whether or not a certain interpretation is an anomaly. From this methodological perspective, the empirical basis of semantics is a collection of judgements with regard to semantic properties and relations (Katz 1972: 4):

We shall attempt to answer the question 'What is meaning?' by constructing a theory that explicates the concept of meaning within the framework of a full systematization of the empirical facts about semantic structure in natural language. [...] Here, our pretheoretical intuitions about meaning can guide us. Clearly, an answer to the question 'What is meaning?' presupposes answers to such questions as 'What is sameness of meaning?' 'What are similarity and difference of meaning?' 'What are meaningfulness and meaninglessness?' 'What is multiplicity or ambiguity of meaning?' 'What is truth by virtue of meaning?' 
Crucially, then, the actual phenomena Katz wants to see accounted for are mainly the lexical properties and relations that came to the fore in structuralist semantics, i.e. the semantic identity of words (synonymy), oppositeness of meaning (antonymy), taxonomical organization, and the semantic relations between the terms in a lexical field. In particular, the incorporation of lexical semantics into a formal grammar adds syntagmatic relations to the set of phenomena to be considered. We can appreciate, then, that the different types of structural phenomena that we encountered in the previous chapter come together as parts of the observational basis of Katzian semantics: both paradigmatic and syntagmatic structural meaning relations are among the phenomena that a formal grammar has to account for. At the same time, we can recognize the two essential ways in which the Katzian approach moves beyond its structuralist basis.

In the first place, formalization plays an essential role in the Katzian model. The type of structuralist semantics that we learnt about in the previous chapter is to a large degree a classificatory enterprise, to the extent that paradigmatic and syntagmatic semantic relations and properties are identified and categorized. Katz, however, does not merely want to determine those relations and properties, but takes them as the input for a further step, i.e. to show how they follow automatically from the underlying featural representations of meaning and the working of the projection rules. We have already indicated how the recognition of a semantic anomaly might work, so let us have a brief look at hyponymy as a further example. The grammar should be able to decide automatically whether or not two words are hyponymous (whether the one is a superordinate with respect to the other), and for this purpose it will have to contain a formal definition of the concept 'hyponymy'. That definition might stipulate that an item $C_{i}$ is hyponymous with regard to an item $C_{j}$ belonging to the same word class, if one of $\mathrm{C}_{j}$ 's meanings (formally represented as a configuration of features) is part of one of the meanings of $\mathrm{C}_{\mathrm{i}}$ - or rather, formally speaking, of the corresponding feature definition. For instance, if one of the meanings of bachelor is represented by (Human)(Male)[Who has never married], and if one of the readings of man is represented by (Human)(Male), then we can easily decide that bachelor is a hyponym of man: the componential definition of bachelor includes the componential definition of man, and that inclusion constitutes the formal definition of hyponymy. In this sense, the componential representation of meaning becomes a formal basis, not just for describing the meaning of words, but for a strict definition of semantic phenomena like anomaly and hyponymy.

In the second place, Katz and Fodor introduce a psychological element into natural language semantics. The object of investigation is not primarily identified as 'the structure of the language', but as an ability of the language 
user: the explicit aim of linguistic semantics is to describe the ability of the language user to interpret sentences (1963: 176). This obviously ties in with the Chomskyan introduction of the linguistic competence of the language user as the proper object of linguistics. Rather than thinking about language as something that exists as such, as a system that can be studied in its own right and apart from the people who use it, language receives a mentalist interpretation. As we have seen, the practical realization of this mentalist turn is the identification of user judgements as the observational basis of semantics.

In short, Katzian semantics epitomizes structuralist semantics by maximally taking into account the various structuralist phenomena, but at the same time goes well beyond the approaches mentioned in the previous chapter, by introducing a highly formalized description, and by giving lexical semantics a mentalist twist. Further developments in lexical semantics may now be linked to these two added features. For each of them, questions arise with regard to the adequacy of the Katzian proposals. As we will see presently, these questions lead to forms of description that differ considerably from the original Katz and Fodor model.

\subsection{Tensions in generativist semantics}

Many suggestions were made to improve the formal apparatus introduced by Katz and Fodor. In this section, we discuss two important and interrelated developments: the gradual introduction of representational formats inspired by symbolic logic, and the contrast between a decompositional and an axiomatic semantic representation. In each case, the discussion of the formal, representational matters will be a basis on which to raise underlying questions about the role and scope of the semantic component of a grammar.

\subsubsection{Minimal or maximal semantics?}

Several suggestions were made to improve the type of componential description that was introduced by Katz and Fodor (1963). The distinction between markers and distinguishers, for instance, was fairly quickly abandoned, for reasons that we will come back to later. Also, alternatives were formulated for the way in which individual semantic features were represented. In this respect, let us note that the components which appear in the work of Katz and Fodor do not show the plus/minus notation that is used by Pottier: features like (Old) and (Young) co-occur, but from their formal representation it does not emerge that they are the poles of a functional opposition, as would be the case if they were rendered as +OLD versus - OLD. In subsequent work, Katz (partially) switched to a notational system based on a plus/minus notation, and many authors have varied upon this basic pattern of representation. For 
instance, for describing multiple oppositions ('antonymous n-tuples' in Katz's terminology), we may follow the notation suggested by Leech (1974):

1 PENETRABLE: solid

2 PENETRABLE: liquid

3 PENETRABLE: gas

Leech (1974) contains more proposals for the refinement of feature representations, proposals which can also be frequently encountered in the work of other authors. Such adaptations of the feature notation are less important, however, than the changes that followed from the gradual rapprochement between linguistic semantics and logical semantics.

The initial impetus came from the recognition that the amalgamation process carried out by the projection rules garbled the syntactic structures of the sentences involved. As Weinreich (1966) remarked, the projection rules blur the distinction between cats chase mice and mice chase cats: the result of the amalgamating process is an unstructured set of features, and this set is identical for both sentences, since they are composed of the same lexical items. Katz $(1966,1967)$ then introduced 'complex markers' of the following type (the item to be described is chase):

((Activity of X) (Nature: Physical)) ((Motion)(Rate :(Fast))(Character :

(Following Y) $)))$, (Intention of X : (Trying to catch $((\mathrm{Y})($ Motion $))))$.

Complex markers of this type were meant to ensure that amalgamated semantic representations would still have structure: in cats chase mice, $\mathrm{X}$ would be substituted by the representation of cats, and Y by the representation of mice, and in mice chase cats, the opposite would be the case. It was, however, pointed out, among others by Bierwisch (1969), that the formal apparatus of symbolic logic would yield a far more economical solution to the descriptive problem. By using the symbolism of predicate logic, the difference between cats chase mice and mice chase cats could be reduced to different ways of filling in the arguments of the two-place predicate $\operatorname{CHASE}(\mathrm{x}, \mathrm{y})$.

The idea of merging the apparatus of formal logic into natural language semantics was enthusiastically adopted by the Generative Semantics movement, the branch of generative grammar that endeavoured to put semantics, instead of syntax, first in the architecture of a formal grammar. But the Generative Semantics way of using logic was very creative (or idiosyncratic, perhaps). For one thing, predicate logic would not normally include a componential breakdown of the predicates. The English verb chase would be simply represented by $\operatorname{CHASE}(\mathrm{x}, \mathrm{y})$ - or another symbol, for that matter. Generative Semantics, by contrast, adopted the decompositional format of 
Katzian semantics and structuralist componential analysis. Semantic features would now be interpreted as predicates in the sense of predicate logic, and the meaning of a componentially analysed lexical item would be represented as a complex proposition.

Further, in its attempt to design a semantically based syntax, Generative Semantics equated the standard categories of predicate logic with specific word classes traditionally known from natural language syntax. Propositions would be equated with sentences (S), predicates, quantifiers and operators with verbs $(\mathrm{V})$, and arguments with nouns $(\mathrm{N})$. In addition, the familiar tree structures of generative syntax, instead of the linear representations of standard logic, would be used to represent semantic structure. A much-discussed example of the descriptive practice of Generative Semantics (as widely discussed, in fact, as Katz and Fodor's bachelor) is McCawley's (1968) analysis of the verb to kill: see Figure 3.2.

But the Generative Semantics version of incorporating logical symbolism was not quite satisfactory either. Logicians would object to the conflation of predicates, quantifiers, and operators, because these play a quite distinct role in the system of logic. More fundamentally, they objected to the fact that linguistic decompositional semantics has no theory of truth, i.e. a theory of how language connects to the world. (This is a point that we will return to in section 3.3.) On the linguistic side, the 'semantics first' attitude of Generative Semantics met with serious opposition, in the sense that a dominant tendency within the generative grammar movement insisted on restricting rather than enhancing the role of meaning in the grammar. The schism between the proponents of an autonomous syntax with minimal semantics and the defenders of a maximally semantic approach was intense, and influenced the history of

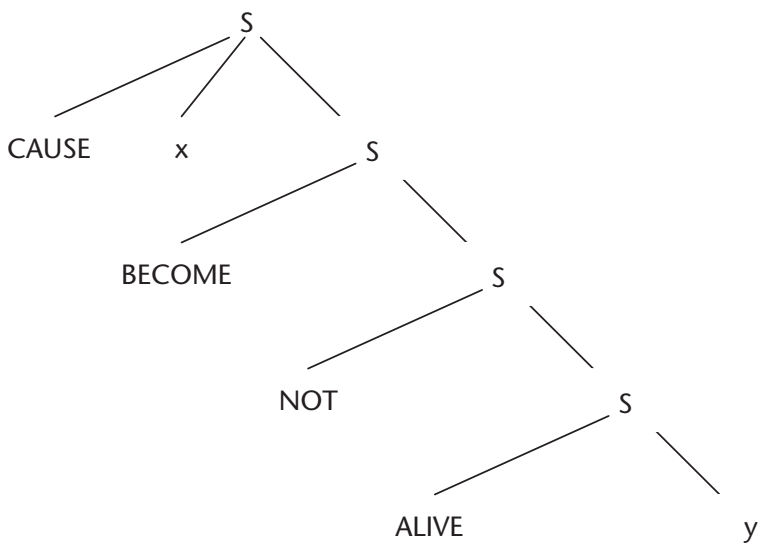

Figure 3.2. English to kill according to McCawley 
modern linguistics to a considerable extent. Although the chasm belongs to the story of theoretical linguistics at large rather than to the story of lexical semantics, it is useful to say something more about it, because it does have an influence on the development of lexical semantics.

On the one hand, Katz and Fodor's incorporation of semantics into the formal theory of grammar constituted a major shift of perspective for generative linguistics. In the initial phase of its development, in Chomsky's Syntactic Structures (1957), no place was reserved for semantics: a grammar describes the formal (phonologic and syntactic) features of a language, but an additional semantic representation is passed over. Katz and Fodor, then, demonstrated that a formalized semantic description could be incorporated into the generative framework. They were successful to the extent that, next to the traditional syntactic and phonologic component, Chomsky explicitly incorporated a semantic component in his Aspects of the Theory of Syntax (1965), the so-called Standard Theory of generative grammar.

On the other hand, the incorporation of meaning carried a danger with it for the essentials of the generative programme. If the main aim of linguistics is to identify the genetic basis of the language capacity of the human species, then meaning is not the most obvious place to start. The meanings expressed in a language are typically historically and culturally diverse, and the vocabulary of a language is probably that part of the language that is most subject to change. Putting meaning in primary position in the architecture of a grammar is therefore somewhat counterintuitive from the point of view of the Chomskyan research programme. There is a firm conviction in Chomskyan linguistics that the genetic essence of natural language is syntactic, i.e. that what makes language uniquely human is its syntactic complexity and creativity, not its symbolic quality as such. It is no surprise, then, that the 'semantics first' position of Generative Semantics was rejected by its theoretical counterpart, Interpretive Semantics. While Generative Semantics proposed that the underlying representation of a sentence would be a semantic one (or at least, a hybrid semantico-syntactic one of the type we see in Figure 3.2), Interpretive Semantics took the position that the basic structure of a sentence is a syntactic one, and that semantics only comes in as an interpretation of those syntactic structures. (Technically speaking, there is more involved in the opposition between both approaches, notably in terms of the meaning-preserving or meaning-changing role of transformations. That part of the history need not be pursued here, however.)

The bitter debate between Generative and Interpretive Semantics was largely settled in favour of the latter: mainstream generative grammar adopted a much more restrictive attitude with regard to the incorporation of semantics in the grammar than was the tendency in Generative Semantics. In 
the subsequent stages of the development of generative grammar, semantics would typically involve topics like the argument structure of the sentence, the interpretation of quantifiers, and the coreference relations of anaphors and pronouns. Lexical semantics became a minor topic within formal grammar. The fact that the broad semantic interest of Generative Semantics was ousted from generative grammar does not imply, however, that it disappeared completely. In a sense, the questions that motivated Generative Semantics reappeared in the approaches that we will present in Chapter 5 , and that take a broad and non-restrictive view of meaning. The link is to some extent personal: linguists like George Lakoff, Charles Fillmore, and Ron Langacker, who were situated on the Generative Semantics rather than the Interpretive Semantics side, became crucial sources of inspiration for cognitive semantics.

One specific instance of the restrictive stance of generativist semantics concerns the relationship between semantic and encyclopedic knowledge, or more broadly, between linguistic meaning and cognition at large-a relationship that we have encountered a number of times already in our history of lexical semantics. As we saw earlier, Katz and Fodor endeavour to describe 'the ability to interpret sentences' of the language user. They recognize, however, that this is an aim that might be too broadly defined: the act of interpretation involves the full extent of the language user's knowledge, including his knowledge of the world rather than just his knowledge of the language. At the same time, the focus of linguistics should be on knowledge of the language, not knowledge of the world: an upper limit to the scope of a semantic theory is therefore necessary. Katz and Fodor try to define that limit in the following way: 'Grammars seek to describe the structure of a sentence in isolation from its possible settings in linguistic discourse (written or verbal), or in nonlinguistic contexts (social or physical)' (1963: 173).

To illustrate the point, they observe that sentences may be disambiguated on several grounds. A sentence like the shooting of the hunters was terrible, Katz and Fodor argue, is not ambiguous when it is uttered as an answer to the question how good was the shooting of the hunters?, but it is ambiguous when uttered in isolation, when it is not obvious whether the hunters do the shooting or whether they are being shot. Next to disambiguating linguistic contexts (like questions), the 'socio-physical setting' is a potentially disambiguating factor: this is the happiest night of my life is anomalous when expressed at noon. Finally, there is the language user's knowledge of the world. This type of knowledge allows the language user to recognize that take back can be employed differently in the sentences should we take the bus back to the zoo? and should we take the lion back to the zoo? Katz and Fodor argue that 'to account for the way in which settings determine how an utterance is understood' is too far-fetched an aim for semantics. For two reasons, such an approach 
is impossible: first, one would no longer be able to discriminate between linguistic knowledge and world knowledge, and second, the researcher would need a full account of all world knowledge, plus a method for formalizing it: 'For practically any item of information about the world, the reader will find it a relatively easy matter to construct an ambiguous sentence whose resolution in context requires the representation of that item' (1963: 179). In other words, we notice that Katz and Fodor, following the basic tendency of structuralism, explicitly try to distinguish between semantic and encyclopedic knowledge.

But do they succeed in doing so in a principled way? We may illustrate the difficulties that they encounter in two ways, by looking at the distinction first between analyticity and syntheticity and then between markers and distinguishers. As we have seen, the properties that Katz tries to account for on the basis of a componential definition of lexical meaning do not only include lexical relations like synonymy and hyponymy, but also include sentential properties. Anomalies like red is green, for instance, are properties of sentences, not of lexical items. One of the important sentential properties is that of analyticity versus syntheticity. A sentence like uncles are males is an analytic truth, i.e. a truth that holds on semantic grounds, in contrast to uncles are generous, of which the truth or falsity must be determined case by case on factual grounds. With regard to the formal description of analyticity, a sentence is analytical if the meaning of its predicate is a component of the meaning of the noun. The conceptual pair synthetic/analytic links up with logical semantics, where the pair of concepts was borrowed by Carnap from Kant. Carnap states: 'The truth of some statements is logical, necessary, based upon meaning, while that of other statements is empirical, contingent, based upon facts of the world.' (1956: 222). The first class of truths are called analytic, whereas the second is called synthetic. Analytical truths are logical truths like a sentence is true or it is false (there is no third possibility), but also sentences like if John is a bachelor, then he is not married: such a sentence is necessarily true on the basis of the meaning of bachelor and married (being a bachelor inevitably implies being unmarried).

The distinction between analyticity and syntheticity is related to the distinction between semantic and encyclopedic data, because analyticity is based on the meaning, and the meaning alone, of the terms involved. Conversely, the truth of synthetic statements is said to depend on facts in the world. So, if we intend to use the notion of analyticity to separate semantic from encyclopedic knowledge, all the features that enter into the definition of an item should have the same status as not married in the definition of bachelor: all the features should be inextricably and necessarily implied by the item. But if we think of the vagueness in the demarcation of word meaning that was signalled by Erdmann (see 1.2.3, and compare 5.1), it seems likely that the semantic features 
that may be invoked to define a lexical item do not always have this analytic status. If this is indeed the case, the distinction between analyticity and syntheticity is probably not a successful method for distinguishing between a semantic and an encyclopedic level of description.

Other problems surface when we consider the distinction between markers and distinguishers. This is probably the aspect of the original Katz and Fodor theory which was criticized most sharply, and Katz manifested considerable flexibility in the reinterpretation of his original views. As we mentioned, distinguishers were originally characterized by the fact that they represent the idiosyncratic meaning aspects of a word, whereas markers are supposed to account for the systematic relations between the lexical items of a language. On the basis of this distinction, Bolinger (1965) suggested regarding distinguishers as the representation of the encyclopedic information associated with a word. However, given this interpretation, the difficulty of distinguishing between markers and distinguishers would also be an indication of the difficulty of maintaining a strict distinction between semantic knowledge and encyclopedic knowledge. Bolinger cites two phenomena that point in the direction of such a difficulty.

To begin with, he argues that the distinction between semantic and encyclopedic knowledge as applied by Katz and Fodor rests on arbitrary grounds. Bolinger's argument relies on the role that markers and distinguishers play in selection restrictions (which, as will be remembered, take care of syntagmatic semantic restrictions). If a feature contributes to the disambiguation of a sentence (out of context), then it is a marker, and that disambiguation process often involves selection restrictions: certain interpretations of a word can be excluded when they are at odds with the selection restrictions of the relevant words in the sentence. If ball in the bachelor hit the colourful ball is interpreted in the sense of 'dancing party', it violates the selection restrictions of hit, which stipulate that it cannot have abstracta as its object. Thus, restrictions enable us to disambiguate ball. But Katz and Fodor admit that encyclopedic knowledge could have similar effects. They cite the sentences our store sells alligator shoes and our store sells horse shoes, arguing that the interpretation of those sentences is based on world knowledge, viz. the fact that alligators are not normally shod like horses, whereas on the other hand some shoes for people are made of crocodile leather. Shoe, then, has two meanings: on the one hand 'protective covering of the human foot' and on the other 'metal band applied to the bottom of an animal's hoof'. The anomaly of combining the second reading of shoe with the specifying noun alligator could be expressed by attributing the following selection restrictions. The first meaning has the selection restriction: <specifying noun: (Material normally employed for the sheathing of the human foot) $>$ whereas the second meaning is accompanied 
by the specification: <specifying noun: (Shoe-wearing animal) $>$. Katz and Fodor note that the relevant features here are definitely encyclopedic in nature.

That recognition is obviously not without problems, for how should this encyclopedic character be established without arbitrariness? Bolinger questions why (Young), as in the definition of bachelor, is a semantic feature, whereas (Shoe-wearing) is not. After all, the fact that shield-bearers are young knights is as encyclopedic a fact as the observation that alligators are not normally shod the way horses are. One cannot arbitrarily distinguish between both facts by simply postulating that the latter is a state of affairs in the world, whereas the former belongs to linguistic structure.

Further, Bolinger demonstrates that the distinguishers that are included in the Katz and Fodor definition of bachelor can be systematically eliminated in favour of strings of markers. Remember that Katz and Fodor use the ambiguity of sentences to decide whether a feature is a marker or not. From the observation that the old bachelor finally died is not ambiguous, they conclude that the distinguisher [young knight serving under the standard of another knight] has to be separated into the marker (Young) and the distinguisher [knight serving under the standard of another knight]. Bolinger shows by analogy that the univocality of a number of carefully selected examples leads to the conclusion that all distinguishers identified by Katz and Fodor should be promoted to the status of markers.

In a similar vein, Weinreich (1966) observed that contradictions can be found in the definition of markers and distinguishers: if systematic semantic relations must be accounted for exclusively in terms of markers, and the difference between colours happens to be a difference between distinguishers (as is stated by Katz and Fodor), then the anomaly red is green cannot be explained in the system of Katz and Fodor-and explaining anomalies is, of course, one of the criteria for the success of their theory. Anomalies like red is green again suggest that the features that Katz and Fodor included as distinguishers need to be recognized as markers. But at the same time, since so many of these distinguishers smack of world knowledge, the strict distinction between world knowledge and encyclopedic knowledge is called into question.

\subsubsection{Decompositional or axiomatic semantics?}

The merger between componential analysis and formal logic that was attempted by the Generative Semantics movement was not unproblematic, as we have already hinted. In section 3.3, we will see that the logicians objected to the purely 'translational' nature of componential descriptions as customary in linguistics, and accordingly took into their own hands the development of a logic-based linguistic description. Tensions between the logical tradition 
and linguistics showed up in yet another way, in the debate surrounding the incorporation of meaning postulates into formal descriptions of meaning. Meaning postulates were introduced by Carnap (1956) to describe analytic truths. If bachelors are necessarily unmarried, a logical truth holds stating that:

$$
\forall \mathrm{X}: \operatorname{BACHELOR}(\mathrm{x}) \rightarrow \sim \operatorname{MARRIED}(\mathrm{x})
$$

- that is to say, 'for all $\mathrm{x}$, it holds that if $\mathrm{x}$ is a bachelor, $\mathrm{x}$ is not married'. These meaning postulates or 'semantic axioms' seemed to cause a problem for componential analysis, because they suggested a method of having a formal description of meaning that was not decompositional. Let us first note that meaning postulates can capture all the information that would go into componential definitions of a Katzian kind, as was demonstrated particularly in the work of Dowty (1979). A Generative Semantics-like analysis could be rendered as follows (with much simplification-Dowty uses the advanced formalism of intensional logic rather than first order predicate logic):

$$
\begin{gathered}
\forall \mathrm{x} \forall \mathrm{y}: \operatorname{seEK}(\mathrm{x}, \mathrm{y}) \leftrightarrow \operatorname{Try}(\mathrm{x}, \operatorname{find}(\mathrm{x}, \mathrm{y})) \\
\forall \mathrm{x} \forall \mathrm{y}: \operatorname{Kill}(\mathrm{x}, \mathrm{y}) \leftrightarrow \operatorname{CaUse}(\mathrm{x}, \operatorname{Become}(\mathrm{y}, \sim \operatorname{ALive}(\mathrm{y})))
\end{gathered}
$$

More simple componential definitions have an equivalent in:

$$
\forall \mathrm{X}: \operatorname{MAN}(\mathrm{x}) \leftrightarrow \operatorname{HUMAN}(\mathrm{x}) \& \operatorname{MALE}(\mathrm{x})
$$

Superficially speaking, there would not appear to be much representational difference between a componential and an axiomatic representation. However, while it is possible to represent all linguistic componential definitions in an axiomatic format, the reverse is not the case: there are relevant types of semantic information that cannot be expressed componentially but that are easy to render by means of postulates. A clear example is the transitivity and symmetry of predicates. If Heleen is Ineke's sister, then Ineke is Heleen's sister: sister is a symmetrical predicate. If Pablo is taller than Line and Line is taller than Celeste, then Pablo is taller than Celeste: we say that taller than is a transitive predicate. Katz struggled hard to account for these characteristics of predicates on a purely componential basis, but eventually admitted (1977a) that postulates had to be added to the componential repertoire. The logical axioms would be as follows:

$$
\begin{gathered}
\forall \mathrm{x} \forall \mathrm{y}: \operatorname{sister}(\mathrm{x}, \mathrm{y}) \leftrightarrow \operatorname{sister}(\mathrm{y}, \mathrm{x}) \\
\forall \mathrm{x} \forall \mathrm{y} \forall \mathrm{z}: \operatorname{TALLER}-\mathrm{THAN}(\mathrm{x}, \mathrm{y}) \& \operatorname{TALlER}-\mathrm{Than}(\mathrm{y}, \mathrm{z}) \rightarrow \operatorname{TALLER}-\mathrm{THAN}(\mathrm{x}, \mathrm{z})
\end{gathered}
$$

There is, in other words, no complete equivalence between a decompositional and an axiomatic approach: in some form, axioms would seem to be necessary 
in any case. In a componential system, axioms are also used as an economical device. If an animal is a dog, it can bark; but does that mean that spaniel, poodle, and basset each receive the feature CAN BARK in their componential definition next to the feature DOG? It is more economical to include an axiom to the effect that the feature DOG implies the feature CAN BARK. Axioms of this kind are known as 'redundancy rules'.

But the difference between a decompositional representation as customary in linguistics and the postulate-based format of logic involved yet another, more crucial feature. Semantic decomposition in linguistics is reductionist, in the sense that the vocabulary of natural languages is translated into a formal language that is more limited in size. If, in a differential analysis of the relations in a lexical field, the distinctive oppositions are as numerous as the items to be described, nothing much is gained: we want the explanatory concepts to be more basic and more limited in number than the vocabulary to be explained. As in common dictionaries, componential definitions describe more complex concepts in terms of more primitive ones. The features used in the componential analysis are therefore sometimes called 'semantic primitives'. In a logical format such a reductive tendency is not implied: every item of the natural language vocabulary may receive its own translation into a logical predicate, and the number of formal predicates need not be smaller than the size of the original vocabulary. To illustrate the difference, take our earlier definition of one of the readings of man as Human Male. In a reductive framework the question arises whether Male rather than Female is the semantic primitive: is male equivalent to +MALE or to - FEMALE? The question is evidently triggered by the reductionist format: if one assumes that there has to be a more primitive concept, it is an open question whether that should be MALE or FEMALE. But in an axiomatic non-reductionist framework, a decision need not be made. The word female may be mapped onto the formal predicate FEMALE and male onto the formal predicate MALE, and their relationship may be expressed by the following meaning postulate:

$$
\forall \mathrm{X}: \operatorname{MALE}(\mathrm{x}) \leftrightarrow \sim \operatorname{FEMALE}(\mathrm{x})
$$

From this point of view, the distinction between an axiomatic and a decompositional analysis is not one that involves the representational power of the two formats, but it is an empirical one that involves questions of cognitive adequacy: to what extent is our mental lexicon actually decompositional?

One way of tackling that question is to check the equivalence of the decompositional definition with the meaning of the item to be defined. Thus, Fodor (1970) pointed out that kill and cause to die are not entirely equivalent. If I accidentally drop a banana skin in the staircase of the faculty building, and the dean slips on it in a lethal fall, I have caused the dean to die, but I did not 
kill him in the usual sense of killing. More important from the perspective of the development of lexical semantics is the introduction of experimental data into the debate. If the difference between an axiomatic and a decompositional meaning representation involves matters of cognitive reality, psycholinguistic methods may be introduced into the discussion. In Fodor, Fodor, and Garrett (1975), sentences with implicit negations are compared with similar sentences that make the negation explicit. If bachelor is 'unmarried man', then there is a hidden negation in the sentence If practically all the men in the room are bachelors, then few men in the room have wives. By contrast, If practically all the men in the room are not married, then few men in the room have wives makes the negation explicit. The experiments reported on in Fodor et al. (1975) show that the reaction time needed for a correct evaluation of the validity of the argument was considerably lower in the bachelor-type sentence. Such sentences are not only significantly easier than sentences with explicit negatives like not married, but also than sentences with morphological negatives like unmarried. Such differences should not exist if the mental representation of bachelor is 'unmarried man': the negation would then be immediately present in all sentence types under consideration. Fodor et al. (1975) conclude that there is no evidence for the psychological reality of a decompositional kind of definition. (For Fodor, this was obviously a break with the position taken by Katz and Fodor 1963.)

Katz's reaction to these and similar results was symptomatic for a choice that the generativist approach to semantics had to face. In his 1981 book, Katz argues that psychological experiments like those of Fodor et al. are not directly relevant to his conception of semantics. His intention is to develop a theory of semantic competence-the ability to interpret sentences in abstractowhereas experiments like Fodor et al.s deal with the actual process of mental processing, and therefore belong to the study of performance rather than competence. Katz claims to be interested in what it means to understand the sentence, not in how the understanding is achieved. The psychological processes and mental operations involved are the legitimate subject matter of psycholinguistics, and hence involve psycholinguistic methods, but linguistics proper is interested in something else: in competence. The distinction between competence and performance that Katz tries to play out here may be seen as yet another instance of the tension between a minimalist and a maximalist attitude towards semantics. In the previous section, the distinction between semantic and encyclopedic knowledge came to the fore as one instantiation of that tension. In the present section, we see another example, in the distinction between an 'off-line' interpretation of mentalism versus an 'on-line' interpretation, i.e. one that would take into account all that is known about the actual psychological processing of meaning. 
In the larger scheme of things, this is an important observation. It shows that the mentalist stance of Katz and Fodor opened the way towards a radically maximalist conception of lexical semantics that would try to achieve cognitive adequacy in the fullest sense, by starting from what was known in cognitive psychology about conceptual organization and categorization. In Chapter 5, we will see how cognitive semantics emerges from such a starting point.

\subsection{Beyond generativist semantics}

Generativist semantics combined basic descriptive principles of structuralist descent with two novel (or at least relatively novel) features: a renewed interest in the mental reality of those descriptions, and the incorporation of the description of word meaning into a formal grammar. Both features engendered debate. In the first place, if you try to see linguistic meaning in the context of human cognition, how restrictive should your linguistic analysis be? Would you still believe in the structuralist assumption of a strictly and particularly 'linguistic' type of meaning, distinct from world knowledge, or would you opt for a rich meaning description in which the borderline between both types of meaning would be blurred, if not abolished altogether? In the second place, if you are interested in formalization, what would your formalization look like and how will you judge its adequacy? We can get a fairly good grip on the developments in linguistic semantics after the generativist period if we see them as specific answers to these questions. This is not to say that the later developments always start out from a direct discussion of the generativist framework, but it should certainly be recognized that a double inspiration emerged from the incorporation of semantics into generative grammar: to deal with issues of cognitive adequacy, and to deal with issues of formal adequacy.

With regard to each of these issues, two broad developments may be distinguished. Concerning the first issue (which is the one that we will focus on in the following chapters), a maximalist approach to semantic description abandons the ideal of achieving some form of autonomous semantics, and aims for a type of meaning description that radically embraces the idea that there are close and inseparable ties between 'word knowledge' and 'world knowledge'. This trend is most clearly embodied by the cognitive semantics movement that forms the subject matter of Chapter 5. More restrictive approaches, conversely, do try to create a space for encyclopedic knowledge and cognition at large in their overall model, but at the same time maintain the idea of a specifically linguistic, semantic level of representation. The most important of these restrictive models are introduced 
in Chapter 4. With regard to the second issue, the interest in formalization contributed to the emergence of two ways of formalizing the semantics of natural language that lie outside the focus of our overview: computational semantics and formal semantics. Neither is exclusively or even specifically geared towards lexical semantics, and in addition, computational semantics has an applied orientation. (The two are not strictly separated, by the way: a considerable portion of computational approaches is based on logical formalisms.)

'Computational semantics' as used here is the description of meaning in natural language in the context of computational linguistics. It is the attempt to simulate language-related knowledge and reasoning on a computer: how is meaning most adequately represented in a digital environment, and how can that formal representation be used in automated inferencing processes? As an attempt to digitally represent and process natural language, it belongs together with Artificial intelligence and cognitive science. Computational linguistics in the sense of natural language processing has an applied orientation, either serving as a tool for descriptive and theoretical linguistics, as in computeraided corpus linguistics, or aiming at practical applications in language technology, such as machine translation.

'Formal semantics' is the application of logical forms of description to natural language semantics. It emerged when the gradually growing interest in formal logic displayed by the generativist linguists did not go unnoticed by the logicians themselves. The way in which the linguists applied the logical formalism, as we have seen, did not comply with the requirements of rigour customary in logical semantics, and step by step, logicians like Donald Davidson (1967) and Richard Montague (see Thomason 1974b) took up the challenge and developed their own systems for the logical description of natural language. The central objection of formal semantics against linguistic decompositional semantics is that the latter has no theory of truth, i.e. a theory of how language connects to the world. The main argument is voiced by David Lewis: the componential approach is no more than a translation of one language (natural language) into another (the formalism of Katzian semantics, ironically termed 'Markerese' by Lewis 1972: 169):

Semantic interpretation by means of them [markers] amounts merely to a translation algorithm from the object language to the auxiliary language Markerese. But we can know the Markerese translation of an English sentence without knowing the first thing about the meaning of that sentence: namely the conditions under which it would be true.

In order to arrive at a better understanding of what formal semantics means by a connection between language and the world, let us briefly explain the 
essentials of logical truth theories. In the truth-theoretical approach to meaning, truth is seen, quite intuitively, as the correspondence between language and the world. But as the world cannot be entered directly into the description, a model of the world needs to be introduced. Such a model consists primarily of an ontology: a specification of the types of entities that may be stipulated in the world. In a simple, so-called extensional version of predicate logic (we will not go into the more complex systems or the alternative ontologies), the world consists primarily of individuals and truth values. Linguistic expressions of different kinds have different extensions or 'denotata': things in the world corresponding to the expressions. An expression like Aristotle, naming a unique individual, has that individual as its extension, but a predicate like philosopher has a set of individuals as its denotatum. Informally speaking, we can think of the extension of philosopher as the set of all philosophers. Propositions like Aristotle is a philosopher have a truth value (either o or 1, for falsehood or correctness) as their extension. Describing truth values in a straightforward set-theoretical model like this then takes the form of saying that Aristotle is a philosopher is true (has truth value 1) if the extension of Aristotle is a member of the set that is the extension of philosopher. A major part of the logical semantician's work consists of stipulating how the interpretation of a complex expression, like the proposition Aristotle is a philosopher, can be compositionally built up from the interpretation of its primary building blocks, like Aristotle or philosopher.

This sketch may also make clear how the idea of explaining the relation between language and the world is in a sense shared but differently interpreted in formal semantics and cognitive semantics. In a cognitively oriented theory, the link with the world would be ensured by the association between linguistic expressions and other forms of knowledge, like perceptual knowledge. Language breaks through its own boundaries through the fact that linguistic expressions link up with world knowledge, like knowledge that allows us to make contact with the world through the senses. Such an approach does not yield a truth theory as formal semantics does, but it does provide an alternative answer (at least in principle) to the question of how to link language to the world. These are two fundamentally different perspectives, then: a psychological one that sees the link between language and the world in terms of human experience and mental activities, and an epistemological one that reasons in terms of truth and truth conditions.

In what follows, we will not attempt to give a full overview of either formal or computational semantics: both are currently highly productive frameworks for the description of natural language, but both have a scope that extends far beyond the lexicon. Even with regard to the treatment of word meaning in both approaches, however, the presentation will be restricted. With regard to 
lexical semantics within formal semantics, we need to recognize first that the full description of word meaning is not a major point of interest within this theoretical framework. As Thomason (1974a: 48-9) remarked in his introduction to Montague's selected papers:

The problems of semantic theory should be distinguished from those of lexicography. It is the business of semantics to account for meanings. A central goal of this account is to explain how different kinds of meanings attach to different syntactic categories; another is to explain how the meanings of phrases depend on those of their components [...] But we should not expect a semantic theory to furnish an account of how any two expressions belonging to the same syntactic category differ in meaning. Walk and run for instance, and unicorn and zebra, certainly do differ in meaning, and we require a dictionary of English to tell us how. But the making of the dictionary demands considerable knowledge of the world. The task of explaining the particular meanings of various basic expressions will obviously presuppose, if not factual information, at least a minutely detailed terminology for classifying things of all kinds.

On the other hand, studies like Dowty's showed how the formal apparatus for going beyond such a minimalist stance is indeed available to formal semantics. In actual practice, logical approaches to natural language, to the extent that they are interested in lexical matters at all, often focus on lexical classes with properties that are specifically interesting from a logical point of view, like indexicals, connectives, temporal expressions, or negative polarity items. In what follows, we will not try to present a summary of these thematic fields of enquiry, but will instead concentrate on the Generative Lexicon framework initiated by James Pustejovsky. This is in fact the major approach linking up with the tradition of formal semantics that attempts to articulate an encompassing model for the description of word meaning; it will be discussed in detail in section 4.1.4.

With regard to lexical semantics within computational linguistics, we will be likewise restrictive, in the same way in which we have been restrictive towards other forms of lexical research with an applied orientation, like lexicography. Rather than try to give an exhaustive coverage of the different kinds of lexical representation proposed in Artificial Intelligence and computational lexicography as disciplines in their own right, we will point out where specific projects and frameworks in theoretical linguistics made relevant contributions to computational lexical semantics, be it descriptive formalisms, machine-readable dictionaries, or lexical databases. This will be specifically the case in section 4.2, where we will describe how various strands of neostructuralist semantics link up with computational lexical semantics. 
So let us summarize. Leaving apart the emergence of formal semantics and computational semantics as disciplines in their own right, what particular effect did the issues of formal and psychological adequacy, as raised by generativist semantics, have on the development of linguistic lexical semantics? On one side, in the cognitive semantics approach, there materialized a type of meaning description that paid less attention to formalization, but that explicitly opted for a maximalist, encyclopedic, psychologically realist form of semantics, and that thus broke radically with the legacy of structuralism. On the other side, we find theories that continue the lines set out by structuralism, but that do so with specific attention for the concerns issuing from generativist semantics: the demarcation of linguistic knowledge with regard to cognition in the broader sense, and the possibility of formalizing linguistic meaning. The more far-reaching, cognitive semantics option will be the subject matter of Chapter 5. The lines of research that transform the structuralist inspiration are presented in Chapter 4. 


\section{Further sources for Chapter 3}

The history of the schism between Generative Semantics and Interpretive Semantics is told in Newmeyer (1980) and Harris (1993); the latter pays ample attention to the personal background of the conflicts. Fodor (1977) describes the theoretical and descriptive issues involved. After the introduction of semantics in generative grammar in Katz and Fodor (1963), Katz and Postal (1964) postulated that the transformations that linked surface structure and deep structure in the then current model of transformational grammar would be meaning-preserving. This paved the way to identifying deep structure (and ultimately, the grammatical description as a whole) with semantic structure. This Generative Semantics position is found, among others, in Lakoff (1971a, 1971b, 1972) and McCawley (1971). The alternative Interpretive Semantics position is defended in Jackendoff (1972).

The Generative Semantics approach did not have an impact on diachronic semantics (although see Fritz 1974 for a notable exception). 'Standard' componential analysis in the study of meaning change is illustrated by the work of Voyles (1973), Werth (1974), and Kleparski (1990).

Influential early voices arguing for an adoption of logical formalisms are Weinreich (1963) and Bierwisch (1969, 1970, 1971). In the transition from the use of formal logic in Generativist Semantics to formal semantics as we now know it, a decisive factor was Richard Montague's application of intensional logic to natural language (Thomason 1974b). Montague's approach was introduced to linguists by Partee (1975, 1976), Dowty, Wall, and Peters (1981), and others. Recent introductions to formal semantics in its current state include Chierchia and McConnell-Ginet (2000), Kearns (2000), and Portner (2005). Portner and Partee (2002) is a reader that includes essential papers; von Stechow and Wunderlich (1991) and Lappin (1996) are reference works covering various aspects of formal semantics.

Within the history of logic, the purely descriptive use of logic was somewhat of an innovation, because logical formalization had often been seen, specifically in the first half of the twentieth century, as a way of improving natural language - notably, as a way of avoiding the lack of clarity in natural language by adopting the rigour of a logical formalism and a logical argumentation. For an introduction to the philosophical issues involved, see Haack (1978: 86-134). An illuminating overview of the historical links between logic and linguistics may be found in Seuren (1998).

Classical philosophical discussions of the difficulties surrounding the distinction between analytic and synthetic statements are White (1952) and Quine (1953). In the discussion between an axiomatic and a decompositional approach, further contributions include Bar Hillel (1967) and Staal (1967) 
in favour of postulates, versus Katz and Nagel (1974) and Katz (1977b). In Fodor (1975), Fodor, Garrett, Walker, and Parkes (1980), and Fodor and Lepore (1992), the criticism against a decompositional approach is radicalized into a rejection of definitions per se, i.e. a denunciation of the idea that the meanings of a linguistic expression have internal structure. This 'holist' position arises from a combination of two arguments: if you believe that it is necessary to have some sort of primitive concepts that link directly to the world, and if you are at the same time convinced that there is no compelling reason to think of those primitive concepts in a decompositional way, as being smaller than words, then each word is its own primitive concept. Fodor gives a nativist interpretation to this view: all atomic concepts are innate. Not surprisingly, this is a controversial position: how innate would the concepts chiaroscuro or cicisbeo be? Critical views with regard to the holist position are voiced, among others, in Laurence and Margolis (1999) and Wilks (2001); see also the discussion of semantic primitives in section 4.1.1. (The emphasis on innate ideas in the holist position has a certain Platonic ring to it. This is explicitly the case in Katz's later work, beginning with Katz (1981), which has no direct impact on lexical semantics, but which we mention for the sake of completeness. Katz argues that linguistic objects, like Platonic ideas, are abstract notions that exist independently of us and that we learn about through pure intuition.)

Boden (2006) is a historical overview of cognitive science. Leading textbooks for the fields of artificial intelligence and natural language processing are, respectively, Russell and Norvig (2003) and Jurafsky and Martin (2008). While the methods for the representation of meaning have changed considerably in the course of time (see the next chapter for more specific references about recent developments), we may observe at this point that the early representational formats made use of the same basic formats that we have encountered in linguistic semantics. Wilks (1972) and Winograd (1972), for instance, use a representational system based on primitive concepts, similar to what we find in decompositional semantics in linguistics, while Quillian (1968) and Lindsay and Norman (1972) develop a relational network representation. 


\section{Neostructuralist Semantics}

In the context of contemporary linguistics, the relational approach is probably the most widespread type of 'classical' structuralist semantics. At the same time, there currently exist a number of frameworks for doing lexical semantics that may be linked to the different forms of structuralist semantics that we have so far encountered, but that build on this structuralist background in original ways. In the present chapter, we will learn about a number of frameworks that constitute alternatives for the classical, and to some extent better known, types of structuralist semantics. In the previous chapter we saw how the incorporation of componential analysis in generative grammar stimulated the interest in two aspects of lexical semantics that were relatively unimportant for the original structuralist approaches: on the one hand, the psychological reality of semantic analyses, and on the other, the adequacy of formal representations of word meaning. The first of these new points of interest contributed to the emergence of a theoretical framework that departs from the structuralist principles in major respects. This is the cognitive semantics movement that will be presented in the next chapter. The subject matter of the present chapter, with some nuances, consists of those approaches that do not take such a radical step, but that directly or indirectly continue ideas set out by structuralism against the background of the concerns issuing from generativist semantics: the demarcation of linguistic knowledge with regard to cognition in the broader sense, and the possibility of formalizing linguistic meaning.

The theories brought together here may in fact be grouped in several ways. In the first place, we may have a look at the different structuralist phenomena that they focus on. (This is also the way in the chapter will be divided into sections.) A first group of approaches has a componential orientation. Wierzbicka's Natural Semantic Metalanguage paradigm is an alternative for the classical componential approach: it abandons the idea that meaning components derive from distinctive oppositions within a lexical field, but rather assumes that there exists a universal set of semantic primitives that may be discovered by defining words through a process of reductive paraphrase. A decompositional approach to meaning also lies at the basis of Jackendoff's 
Conceptual Semantics, Bierwisch's Two-Level Semantics, and Pustejovsky's Generative Lexicon. In contrast with Wierzbicka's Natural Semantic Metalanguage, these three models are interested in a formal representation of word meaning, but like Wierzbicka, they open up the decompositional analysis of meaning towards a broader cognitive context, focusing on contextual mechanisms of meaning determination and modulation. In the second group, both the WordNet project and Mel'čuk's lexical functions paradigm are developments of relational semantics. WordNet is a large-scale documentation of lexical relations, and Mel'čuk makes use of a much broader set of lexical relations than the typical collection that we explored earlier. The distributional corpus analysis paradigm also focuses on lexical relations, but on syntagmatic ones rather than the more usual paradigmatic ones. In that sense, it is an alternative implementation of the distributionalist perspective: rather than using relatively simple syntactic patterns to chart the distribution of a word, it employs advanced quantitative techniques to get a grip on the way words pattern in large corpora.

In the second place, these approaches deal differently with the legacy of generativist semantics, if we see that legacy in terms of the focal points mentioned above: the psychological reality of semantic analyses, and the adequacy of formal representations of word meaning. By and large, the decompositional approaches (Wierzbicka, Jackendoff, Bierwisch, Pustejovsky) are interested in the interaction between the lexicon and cognition in the broader sense, either by looking for the cognitive foundations of componential descriptions of meaning, or by looking at the interface phenomena between linguistic semantics and contextual or non-linguistic information. In the relational approaches (WordNet, Mel'čuk, distributional corpus analysis), on the other hand, this theoretical focus is less prominent (even though WordNet originates from psycholinguistics rather than linguistics pure and simple). Conversely, the approaches in this group link up to a greater or lesser extent with computational lexical semantics. They either provide lexical resources for computational lexical semantics, like the electronic dictionaries produced in the context of the WordNet project or Mel'cuk's Meaning-Text Theory, or they develop computational methods for extracting semantic information from large corpora, as in the distributional corpus analysis paradigm. An interest in formalization is not absent in the first group, however: Bierwisch, Jackendoff, and Pustejovsky all develop formal representational formats, and in particular, Pustejovsky's Generative Lexicon, which is couched in the apparatus of formal semantics, has explicit computational ambitions.

In the third place, we could make a distinction according to the direct link of the frameworks with generativist semantics: which are the ones that grew more or less directly out of the tradition of generative grammar, in contrast 
with approaches that have their roots more directly in the structuralist tradition(s)? From this perspective, the Jackendoff, Bierwisch, and Pustejovsky theories might appropriately be called types of 'neogenerativist' semantics, whereas the others are instead 'neostructuralist' ones in a more restricted sense. (This is the approach followed in Geeraerts 2006b: 398-415.)

Three more introductory remarks are needed. First, the frameworks presented in the following pages enjoy different degrees of popularity. In the first group, Wierzbicka's and Pustejovsky's model are productive approaches with an appeal that reaches well beyond the immediate circle of their initiators. Bierwisch's and Jackendoff's, on the other hand, remain more isolated. Within the second group, WordNet is a widely used resource, while Mel'cuk's model is somewhat less known. The most dynamically developing approach within this group, however, is probably the corpus-based distributional method. Second, we need to keep in mind that most of the theories treated in this chapter exist parallel to the cognitive semantics movement that is the subject matter of Chapter 5 (and at least in one case, the Natural Semantic Metalanguage approach, it is sometimes ranged with cognitive semantics: see Geeraerts 2006b: 398-415). The narrative here stops being chronological, and at a number of points, we will have to anticipate topics that will be treated more extensively in the next chapter. And third, despite the title of the chapter, none of the theories brought together in this chapter would be likely to present themselves under the heading 'neostructuralist': in line with the historical perspective of our overview, that label emphasizes a particular aspect of the historical lineage of the theories, but it is not one the theories themselves have adopted.

\subsection{Elaborating the decompositional approach}

It is instructive to think of the models in this section as different ways of coming to terms with the dilemma of a cognitive twist in lexical semantics. On the one hand, a decompositional method has a reductionist tendency: it reduces the semantic description to a set of primitive meaning components, and looks for a truly linguistic level of description, contrasting with an encyclopedic level. On the other hand, a theory that aims at psychological adequacy will inevitably have to face the fuzziness and flexibility of language use. If, for instance, you include the referential level in the investigation-in the way Gipper did with his analysis of Sessel and Stuhl - the semantic picture becomes more complicated than if you just stick to an a priori contrastive analysis of the type that Pottier applied to his set of furniture terms. The decompositional models in this section basically represent three strategies of reconciling the reductionist tendency of componential analysis with the 
expansionist tendency of a perspective that takes cognition seriously. (Needless to say, a more radical approach, as illustrated by cognitive semantics, does not try to achieve a reconciliation, but wholeheartedly embraces a maximalist view.)

Aphoristically, the three positions are as follows: 'the mind is neat but the world is fuzzy', 'conceptual knowledge is parsimonious, but perceptual knowledge is abundant', and 'semantics is stable but pragmatics is flexible'. The first position is taken in Wierzbicka's Natural Semantic Metalanguage approach. It implies that the concepts we have in our head are clearly delineated, in spite of the fact that we have to apply them to a world that is essentially blurry. If we can just tap into the clarity that is in our own head, the unclarities of the world need not bother us. The second position is illustrated by Jackendoff's Conceptual Semantics. It implies that a sparse conceptual representation at the linguistic level can be combined with a rich and flexible representation at the perceptual level (or, rather, at the level of various non-conceptual modes of knowledge). The decompositional description of meaning at the linguistic level can be kept tidy and well-delineated if we accept a close link between the conceptual level and vision, motor schemas, and other non-conceptual cognitive modes. The third position is typical of the Two-Level Semantics of Bierwisch, and to some extent of Pustejovsky's Generative Lexicon. It implies that well-defined semantic descriptions may be modulated or refined at the pragmatic level, under the influence of situational or contextual factors. If we can describe the mechanisms that engender such pragmatic specifications of meaning, we can safeguard the neatness of the semantic description. In the following pages, we will present these positions in more detail, and indicate the difficulties that they have to take into account.

\subsubsection{Natural Semantic Metalanguage}

Componential definitions of meaning often come with the assumption that definitions are couched in a vocabulary of primitive concepts, i.e. concepts that are not themselves defined. The motivation for such an assumption is an epistemological one: if all the words in a language are defined by other words, we stay within the language and there is no relationship between language and world. The advantage of having definitional elements that themselves remain undefined resides in the possibility of avoiding circularity: if the definitional language and the defined language are identical, words would ultimately be defined in terms of themselves - in which case the explanatory value of definitions would seem to disappear as a whole. This motivation for having undefined primitive elements imposes an important restriction on the set of primitive features. In fact, if achieving non-circularity is the point, the set of primitives should be smaller than the set of words to be defined: there is no 
reductive or explanatory value in a set of undefined defining elements that is as large as the set of concepts to be defined.

But what would those primitive concepts be? The Natural Semantic Metalanguage approach originated by Anna Wierzbicka (1972) and developed in numerous books (among them Wierzbicka 1985, 1992, 1996, 1997, 1999, 2003; Goddard and Wierzbicka 1994, 2002) is the most advanced attempt in contemporary semantics to establish an inventory of universal primitive concepts. Wierzbicka's model of semantic description rests on two pillars, in fact: the vocabulary of universal, primitive concepts, and a definitional practice characterized as 'reductive paraphrase'. In the pages to follow, we will have a closer look at each of these points, and then specify a number of problems faced by Natural Semantic Metalanguage.

1 With regard to the first pillar, Wierzbicka insists on the requirement that definitions be written in natural, non-technical language, and not in some formalized representational language. Semantic primitives, then, to the extent that they are indeed universal, should be lexicalized in all languages of the world. Cliff Goddard, who is the main representative of the Natural Semantic Metalanguage framework next to Wierzbicka (Goddard 2006b, 2008), defines this requirement as the Strong Lexicalization Hypothesis: primitive concepts are universally lexicalized (Goddard 1994: 13). The concepts that are universal (in contrast with culturally specific ones) are expressed in all languages, by a specific word or at least a specific expression.

The current set of semantic primitives identified as part of the Natural Semantic Metalanguage runs to 60. The catalogue included in Goddard (2006a: 4) consists of the following classes and items:

substantives: I, YOU, SOMEONE/PERSON, SOMETHING, THING, PEOPLE, BODY relational substantives: KIND, PART

determiners: THIS, THE SAME, OTHER/ELSE

quantifiers: ONE, TWO, MUCH/MANY, SOME, ALL

evaluators: GOOD, BAD

descriptors: BIG, SMALL

mental/experiential predicates: THINK, KNOW, WANT, FEEL, SEE, HEAR speech: SAY, WORDS, TRUE

actions, events, movement, contact: DO, HAPPEN, MOVE, TOUCH

location, existence, possession, specification: BE (SOMEWHERE), THERE

IS/EXIST, HAVE, BE (SOMEONE/SOMETHING)

life and death: LIVE, DIE

time: WHEN/TIME, NOW, BEFORE, AFTER, A LONG TIME, A SHORT TIME, 
Space: WHERE/PLACE, HERE, ABOVE, BELOW, FAR, NEAR, SIDE, INSIDE logical concepts: NOT, MAYBE, CAN, BECAUSE, IF augmentor, intensifier: VERY, MORE similarity: LIKE

Of course, the English words in this list are not the universal concepts themselves: they are merely the language-specific expression of the concepts. Equivalent expressions for the first three classes in French and Spanish, for instance, would be as follows:

French:

substantives: je, tu, quelqu'un (personne), gens, quelque chose, corps

determiners: ce, même, autre

quantifiers: un, deux, quelques (certains), tout, beaucoup

Spanish:

substantives: yo, tú, alguien (persona), gente, algo (cosa), cuerpo

determiners: este, mismo, otro

quantifiers: uno, dos, algunos, todo, mucho

The set of primitives has grown considerably over the years: in her first major publication, Wierzbicka (1972) identified no more than fourteen primitives, ten of which survive in the present inventory. Some of the concepts in the inventory appear in more than one form in a given language, like much and many in the English list, to be compared with French beaucoup or Spanish mucho. This is called 'allolexy': formal restrictions in a given language may require different forms for the same underlying concept, such as when $I$ appears as $m e$ in object function.

2 The second pillar of the Natural Semantic Metalanguage is known as 'reductive paraphrase'-basically, writing definitions couched in the vocabulary of universal primitive concepts. Here, for instance, is Wierzbicka's definition of English sad (1996: 180):

$\mathrm{X}$ is sad $=$

$\mathrm{X}$ feels something

sometimes a person thinks something like this:

something bad happened

if I didn't know that it happened,

I would say: I don't want it to happen

I don't say this now

because I know: I can't do anything

because of this, this person feels something bad

$\mathrm{X}$ feels something like this 
In actual practice, though, the definitions often make use of non-primitive elements (which may then supposedly be analysed in a succession of further steps until the level of primitives is reached). As an example, we may consider Wierzbicka's definition of English green in contrast to Welsh gwyrrd. The two expressions are near-synonymous, but gwyrrd seems to be restricted to relatively livelier, brighter, fresher greens. Wierzbicka (1996: 306-7) tries to capture the difference by including a reference to wetness after rain in the definition of the Welsh word:

$\mathrm{X}$ is green $=$

in some places many things grow out of the ground

when one sees things like $\mathrm{X}$ one can think of this

$\mathrm{X}$ is gwyrrd $=$

in some places many things grow out of the ground

at some times there is water in these places (after rain)

when one sees things like $\mathrm{X}$ one can think of this

These examples illustrate a further important feature of Wierzbicka's approach. The information included in the definition does not primarily involve the objective features of the referents of the expressions, but rather what people think about those referents. A description like the one Pottier gave of furniture items is typically a referential one: you describe the characteristics of the entities that fall within the range of the category chaise, canapé, and so forth. Applying such an approach to colour terms would mean identifying the colour frequencies of the entities that can be called green in English or gwyrrd in Welsh. But Wierzbicka objects to such a procedure because it does not sufficiently capture the cognitive content of the concept; it does not point to what people think when they say something is green.

The difference in approach may be further illustrated if we consider what Wierzbicka has to say about Labov's study on cups and mugs. Using an experimental method, Labov $(1973,1978)$ studied the variable denotation of cups and cup-like containers-the fact, that is, that words like cup, mug, bowl, or glass may refer to objects that do not have a uniform appearance. Cups may differ in size, in the ratio of width to depth, in the presence or absence of a stem or a handle, in the material used. All these variable features (and more) imply that a word like cup is referentially vague: the exact boundary of the denotational range of the word is not immediately given, and the experiments set up by Labov precisely try to get a better grip on the denotational boundaries of words like сир and the internal structure of their denotation. Needless to say, the methodological design and the theoretical impact of the research question are highly reminiscent of Gipper's study on Sessel/Stuhl, except that Labov's study is carried out with more technical refinement than Gipper's. 
Practically speaking, Labov presented his subjects with a set of pictures of cup-like and mug-like objects. These stimuli differed systematically across a number of dimensions. One set of stimuli increased the width of the cups while keeping the height constant with regard to the first item in the array, whereas another set increased the height while keeping the width constant. Further variations departed from the canonical concave shape by introducing cylindrical, conical, and angular shapes, by adding a stem, by leaving out the regular handle, or conversely, by adding a second handle. In other sets of experimental stimuli, the material of the cups was specified as china, glass, paper, and metal. Additional subtlety was introduced by specifying a context of use for the objects. In the basic experiment, subjects were simply asked to name the objects initially without being given a specific context, and then while being asked to imagine that someone was drinking coffee from the vessels. In a third series, they were asked to imagine that the objects were placed on a dinner table, filled with mashed potatoes. And in a final series, the objects were supposed to be standing on a shelf, filled with flowers.

The experimental data show that a discrete and conjunctive model of definitions (as would be associated with a componential approach to the lexicon) does not work. Following a componential model, a definition would basically take the form of a conjunction of features: something is called a cup if it has characteristics $\mathrm{A}, \mathrm{B}$, and $\mathrm{C}$, where $\mathrm{A}, \mathrm{B}$, and $\mathrm{C}$ are each discrete (the feature, or a specific value of the features, is either present or not). According to such a model, the boundary between the things that are cups and the things that are not cups would be sharp; only the objects that have the features A and $\mathrm{B}$ and $\mathrm{C}$ together pass the test for inclusion in the referential range of the item.

Within his own work, dominated as it is by sociolinguistic studies, Labov's lexical study of cups and mugs represents only a sideline. In a lexicological context, however, it is one of the first recent voices to question a discrete model of categorization and definition-the kind of question that would be crucial to the birth of cognitive semantics as discussed in Chapter 5. Wierzbicka, however, explicitly defends the discreteness of semantics. In a discussion of Labov's study, she notes that to state the meaning of a word, it is not sufficient to study its applicability to a collection of objects or to describe the visual image of those objects. Rather, one must study the structure of the concept which underlies and explains that applicability. In the case of words describing natural kinds or human artefacts, to understand the structure of the concept means to discover and describe fully and accurately the internal logic of the concept, through methodical introspection and thinking, rather than through experimentation or empirical observation of the range of application of the item (Wierzbicka 1985: 19). The actual definitions of cup and mug that 
Wierzbicka comes up with take two pages each (1985:33-6), which is too long to be repeated here. The gist of the approach may, however, be illustrated by the following quotation (1985: 59):

A Chinese cup, small, thin, dainty, handleless and saucerless can still be recognized as a cup —as long as it is clearly adequate for drinking hot tea from, in a formal setting (at a table), being able to raise it to the mouth with one hand. This means that while a saucer and a handle are definitely included in the prototype of a cup (an 'ideal' cup must have a handle, and a saucer), they are not included in what might be called the essential part of the concept. On the other hand, the components 'needed to drink hot liquids from' and 'small enough for people to be able to raise them easily to the mouth with one hand' have to be included in it.

The crucial feature here is Wierzbicka's belief that, in spite of the apparent variability in the use and shape of cups and mugs, there is an essential core in the definition of cup and mug, which is present every time the categories are used. Variability and referential indeterminacy in the use of lexical items is real, but the concept that is realized in those variable uses is nevertheless invariant. The referential usage of a word may be flexible, heterogeneous, and not clearly delineated, but the concept that is realized in all of those instances of use is precise, discrete, and uniform. In the larger context of lexical semantics, this is an entirely different way of dealing with the variability in the use of a word compared to what a maximalist form of semantics would do. In a maximalist approach, the semanticians would try to determine what the structure of the variability looks like-that is to say, under which conditions which variant is produced. Wierzbicka by contrast acknowledges the variability only as the basis for a reductive strategy. It is not the variation that needs to be described, but the semantic invariant that is allegedly present in all instances of variation. It is in this sense that we could say earlier that, according to the Natural Semantic Metalanguage, discreteness is in the head and fuzziness is in the world: language users apply clear-cut and well-defined concepts to name and describe a world that is much more indefinite and much less well-behaved.

3 But how easy it is to maintain such a position? In a critical appraisal of Natural Semantic Metalanguage, we need to have a separate look at each of the two pillars of the theory. With regard to the primitive building blocks of the reductive paraphrases, let us first observe that there is no well-defined method for assessing the universality of concepts. Wierzbicka and Goddard emphasize that the identification of primitives follows from the definitional practice in a Natural Semantic Metalanguage context: it is by actually writing definitions in a Natural Semantic Metalanguage framework that the relevance of postulating 
one set of primitives rather than another becomes clear. That is also why the set of primitives changes over time: it is not settled in an a priori way, but emerges by trial and error. However, this is a very schematic description of the method that does not really indicate what exactly 'error' would mean. The definitional practice of the Natural Semantic Metalanguage framework leaves room for many different basic vocabularies, so how would one decide between alternative options? The theory does not specify a systematic procedure for this, and if one looks more closely at the various criteria that may be derived from the theoretical statements, problems are apparent.

One might think, for instance, that a definition making use of true primitives is more intelligible than any other (because the primitive concepts are so accessible to all), but the proponents of Natural Semantic Metalanguage do not systematically test their definitions in this way, by subjecting them to the judgement of a panel of users. If one takes some of the existing definitions at face value, there are reasons for doubt. If we didn't know that the definition of gwyrrd is roughly like that of green, would we understand it at all? And would we grasp it more readily than a definition such as may be found in a traditional dictionary? As Riemer (2006) remarks in his critical scrutiny of the foundations of the Wierzbickian approach, the intelligibility of a definition probably depends less on whether the component elements are conceptually primitive than on the question whether they are previously known and sufficiently familiar to the reader.

Further, Goddard's Strong Lexicalization Hypothesis might provide a practical method for establishing primitives, but only if it takes the form of a systematic comparison of a large-in principle exhaustive-set of languages. However, even within the current set of 60-odd primitives, there are doubts about their universal lexicalization. Bohnemeyer (2003) argues convincingly that BEFORE and AFTER do not have lexical counterparts in Yukatek Maya. More importantly from a methodological point of view, such a comparison of languages requires that the concepts to be compared are uniform across the different languages. There should be no subtle interlinguistic differences in the meaning of the words that express the primitives, and that meaning should be unitary and self-evident. Obviously, this could not be achieved by starting from a definition of the primitive concepts: the primes are indefinable by definition. Goddard (2002) suggests a solution to this problem by working with 'canonical contexts', i.e. sets of sentences or sentence fragments that illustrate the relevant grammatical contexts for each putative prime. The difference between This person cannot move and Her words move me, for instance, would allow the researchers to maintain a distinction between the literal (probably primitive) and the derived, figurative reading of move. But, as Riemer (2006) points out, this only works if the canonical contexts themselves are sufficiently 
univocal to ensure the identification of the intended meaning. Even in a simple case like This person cannot move, that is not evident. It could mean that someone is unable to change the position of his body, but also that he could not change the position of the movable parts of his body, while his overall position remains stationary. Which is meant? And further, the sentence could mean that the person cannot change the place where he is staying, or that he is unwilling to change his ideas on a certain issue: even in an apparently simple case, the canonical contexts method is vulnerable for polysemy and semantic nuances.

Clearly, then, the methodological basis for identifying semantic primitives is not yet as firm as the Natural Semantic Metalanguage approach would have it. But couldn't the proponents reply that a set of primitive concepts is epistemologically necessary in any case, and that they are at least close to defining such a set-even if they have not yet reached a final conclusion? The appeal of non-circular definitions seems to be that they might explain how the gap between linguistic meaning and extralinguistic reality is bridged: if determining whether a concept $A$ applies to thing $B$ entails checking whether the features that make up the definition of A apply to B as an extralinguistic entity, words are related to the world through the intermediary of primitive features. But obviously, this does not explain how the basic features themselves bridge the gap: the 'referential connection' problem for words remains unsolved as long as it is not solved for the primitives. And we do want to solve it, because we do not want to claim that language exists in an idealistic mental realm of its own, isolated from the sensory world. So, if we think about how primitive concepts might link to the extralinguistic world, we would probably think about a direct or indirect connection between those concepts and sensorimotor experiences. For a primitive like touch, this would be fairly straightforward, but the others too could not just remain concepts: they would have to be defined as sensorimotor experiences, lest we accept an idealistically isolated realm of language, cut off from the extralinguistic world.

But if the 'referential connection' problem could be solved for primitive features, the same solution might very well be applicable to words as a whole. If we postulate a mechanism for associating conceptual primitives with nonconceptual data, then the same mechanism could also be applied to other concepts. So, if non-circularity does not as such solve the referential problem, decomposition is not a priori to be preferred over non-decompositional approaches - or, at least, postulating a universal vocabulary of primitive concepts is not an epistemological necessity. In other words, if we can follow this argument, not only is defining a set of primitive concepts difficult, it may not even be necessary. 
The situation is not much more convincing with regard to the second pillar of the Natural Semantic Metalanguage approach. If the definitions are supposed to be generally applicable to all instances in which a word is used, it should be checked rigorously, on the basis of a broad sample of actual language use, whether the features that are mentioned as being universal within a concept indeed apply to all the relevant cases; if they do not, it should be checked whether the remaining features are sufficient to distinguish the concept from others. Such an empirical test is illustrated in Geeraerts (1993) and Geeraerts, Grondelaers, and Bakema (1994). If, for instance, one takes Wierzbicka's definition of fruit (1985: 299-300), then a first step consists of filtering that definition for features that are not generally applicable to fruit (like having a skin that is harder than the parts, an attribute that does not hold for strawberries). After the elimination of the characteristics that are not general, the remaining set of attributes appears to be insufficient to exclude nuts, herbs, and large collections of vegetables from the category 'fruit'. Let us spell out the argument in detail. (We will come back to the example in 5.1.1.)

The following characteristics mentioned by Wierzbicka are not generalthat is, they are not shared by all examples of fruit. (Wierzbicka's formulations are repeated here, though not in the order in which she presents them.)

(a) They have a skin harder than the parts inside.

(b) They have some small parts inside, separate from the other parts, not good to eat. These parts put into the ground could grow into new things of the same kind growing out of the ground.

(c) They are good to eat without being cooked, without having anything done to them, without any other things, and people can eat them for pleasure.

(d) Eating them uncooked makes one feel good.

(e) Before they are good to eat they can be sour.

(f) They have a lot of juice.

(g) Their juice is good to drink.

(h) They are also good to eat dried.

Characteristic (a) is contradicted by the strawberry, which has no skin worthy of that name. Strawberries likewise do not have the seeds mentioned in (b); bananas are another case in point. Attributes (c) and (d) indicate that fruit can be eaten (with pleasant results) without further preparation, but this does not seem to hold for the lemon, whose sour taste generally requires sugaring. Even if this counterexample were not accepted, adding (c) and (d) to the list of attributes that are general for fruit would not solve the problem that that list does not suffice to distinguish fruits from some vegetables and nuts. Attributes (e) and (f) are not valid for the banana: first, an unripe banana is bitter rather 
than sour, and second, there is no juice in a banana. Because the generality of (g) depends on the generality of (f), it may likewise be discarded. Finally, as far as (h) is concerned, it is difficult to imagine a dried lemon as being good to eat.

Next, there is a set of characteristics whose non-generality seems to be accepted (or at least, implied) by Wierzbicka herself.

(i) Wanting to imagine such things, people would imagine them as growing on trees.

(j) They can be small enough for a person to be able to put easily more than one thing of this kind into the mouth and eat them all at the same time, or too big for a person to be expected to eat a whole one, bit by bit, at one time, but wanting to imagine such things, people would imagine them as too big for a person to put a whole one easily into the mouth and eat it, and not too big for a person to be expected to eat a whole one, bit by bit, at one time, holding it in one hand.

(k) After they have become good to eat they are sweet, or slightly sweet, or sour but good to eat with something sweet.

(l) Wanting to imagine such things after they have become good to eat, people would imagine things which are slightly sweet.

(m) Things on which such things can grow can also grow in some places where people don't cause them to grow, but wanting to imagine such things, people would imagine them as growing on things growing out of the ground in places where people cause them to grow.

While $(\mathrm{k})$ is a disjunctively defined attribute (i.e. a superficial combination of two characteristics neither of which is general when taken separately), the other features are introduced by the formula 'wanting to imagine such things, people would imagine them as'; this would seem to indicate that the attribute is merely typically associated with the concept, rather than being general. For instance, the sweetness mentioned in (1) does not hold for lemons, and berries do not grow on trees, in contradistinction with the feature involved in (i).

The set of general characteristics that is left over after the elimination of the previous sets contains the following features.

(n) They grow as parts of certain things growing out of the ground.

(o) They don't grow in the ground.

(p) They become good to eat after they have grown long enough on the things growing out of the ground.

(q) Before they are good to eat they are green or greenish outside. 
(r) People cause things of this kind to grow in many places because they want to have those things for people to eat.

(s) They are good to eat cooked with sugar, or cooked as part of some things which have sugar in them.

Is this set minimally specific? Up to characteristic ( $r$ ), the set applies not only to fruit, but also to nuts, herbs, and large collections of vegetables (though not to the ones that grow in the ground, like carrots), so that the crucially distinctive attribute would be (s). However, if one takes into consideration the use of almonds and other nuts in certain types of pastry, the use of herbs (such as tansy) in pancakes, and the habit of cooking rhubarb with sugar, it soon becomes clear that there are counterexamples with regard to (s) in each of the three categories (nuts, herbs, and vegetables). All in all, most of the attributes mentioned by Wierzbicka are not general, whereas those that are, taken together, apparently do not suffice to exclude non-fruits.

Of course, the Natural Semantic Metalanguage approach tends to make itself immune to such empirical tests by proclaiming that only an introspective method is adequate to identify the concept that we associate with a word, and that is allegedly active in the language user's mind any time a word is uttered. Even from a strictly introspective point of view, however, the latter assumption is doubtful. It seems to imply that the actual context of use would not be able to override the 'essential' features residing in the concept. So, even if the word cup is applied to an extremely peripheral instance of the category (say, a plastic cup in your desk drawer filled with paperclips and pencils), you would still think of that cup as a drinking vessel, and if fruit is used to talk about strawberries, you would still think of it as having a skin that is harder than the parts, or as growing on trees. Would you? As Kay (2003) remarks in his discussion of Wierzbicka's analysis of colour words, that mechanism is introspectively not very likely: if you see a green traffic light, do you think of things growing out of the ground?

\subsubsection{Conceptual Semantics}

The Natural Semantic Metalanguage approach to lexical analysis smacks of idealism. Meanings are purely linguistic, and they are, as such, entirely conceptual: there is no explicitly described or acknowledged link between meaning and extralinguistic knowledge. An entirely different approach to safeguarding a specifically linguistic level of semantic description, different from world knowledge in the larger sense, would be to consider linguistic meaning in combination with (rather than in opposition to) extralinguistic knowledge, and to define a plausible division of labour between the two. In such a modular approach, linguistic meaning is still different from other forms of knowledge, 
like visual memory and perceptual knowledge in general, but at the same time, it would not need to carry the total burden of representing our knowledge of how to use words: part of that task could be delegated to other modules of cognition.

This is indeed the approach developed by Ray Jackendoff in his model of Conceptual Semantics: the formal semantic representation does not contain all the information that is relevant to explain the language user's conceptual competence. Rather, that information is to be situated on the level of 'conceptual structure'; within such conceptual structures, other modes of cognition, like perceptual knowledge and motor schemas, may play their role together with linguistic knowledge. As Jackendoff (1996: 104) explains, 'There is no privileged level of "linguistic semantics" at which specifically linguistic effects of meaning can be separated out from more general cognitive effects such as categorization and interpretation of deixis.' Conceptual structure, in other words, acts as an interface between the formal structures of language and other, non-linguistic modes of knowledge. With regard to phonology and syntax, Jackendoff adheres to the generativist, Chomskyan idea of an autonomous syntax, but at the same time, in an un-Chomskyan way, the autonomy of syntax does not mean than language can be studied autonomously: research into linguistic meaning implies doing cognitive psychology. Accordingly, Jackendoff consistently tries to confront his work on linguistic structure with psychological findings. The description of spatial language, for instance, is situated against the background of psychological theories of spatial language and visual cognition.

This interface function is reflected in the form that lexical entries take in Jackendoff's model. Figure 4.1 gives a few examples of such entries, each of them defining a verb. Below the specification of the item, we find an indication of the word class, followed by the subcategorization frame of the word. This subcategorization frame specifies the syntactic environment in which a word appears. Put, for instance, is used in a context like put the lid on the box: a noun phrase functions as direct object, in combination with a prepositional phrase indicating the direction of the act of putting. Run occurs with an optional prepositional phrase: you can run, or run to the door. Drink is a straightforward transitive verb. The remaining part of the entries describes the meaning of the verbs, but in such a way that the link to the syntactic information is transparent. This is achieved by means of the indices on the constituents. The meaning description of put is, informally, paraphrased as an event in which one thing (the subject of the verb, which is always indexed as ' $i$ ') causes an event in which another thing (labelled ' $j$ ' and corresponding to the direct object in the subcategorization frame) moves along a spatial path. 


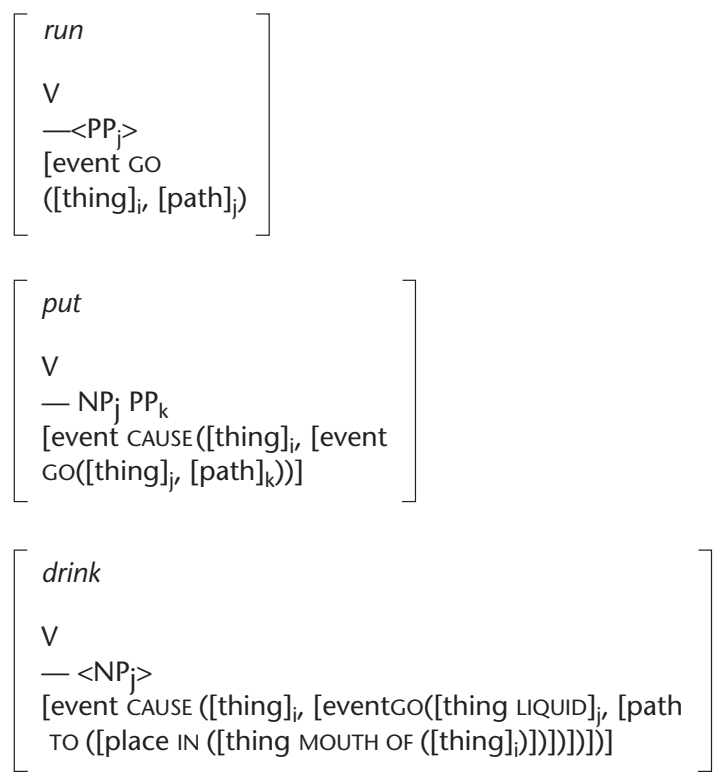

FIGURE 4.1. English run, put, and drink according to Jackendoff

Run expresses an event in which a thing (the subject) moves along the path optionally expressed by the prepositional phrase, and drink is an event in which the subject causes the movement of a liquid something into its own mouth.

The explicit link between the syntactic and the semantic parts of the entries reveals the influence of the debates surrounding Katzian semantics: formal decompositional descriptions in the post-generativist era take good care to indicate the internal structure of semantic descriptions, and the way in which the semantic information is connected to the syntactic environment in which the words appear. The semantic description itself, on the other hand, crucially hinges on a restricted set of conceptual primitives of the type eVEnt, STATE, THing, PATH, PLACE, PROPERTY, AMOUnt. These constitute an ontology, in the sense that they are assumed to be innate and universal categories of human cognition. They are cross-modal, in the sense of being associated with other modes of knowledge. The categories THING and GO, for instance, are said to correspond with certain patterns of perceptual and motor information respectively. In this respect, lexical entries of the type illustrated above do indeed function as interfaces, pointing in two directions: on the one hand, they have a link with the autonomous syntactic module; 
on the other, they look toward non-linguistic modes of information and knowledge.

The basic ontological categories may be expanded into more specific patterns by rules of the following kind:

$$
\begin{aligned}
& {[\text { event }] \rightarrow[\text { event Go }([\text { thing }],[\text { path }])]} \\
& {[\text { event }] \rightarrow[\text { event staY }([\text { thing }],[\text { place }])]} \\
& {[\text { event }] \rightarrow[\text { event CAUSE }([\text { thing }],[\text { event }])]}
\end{aligned}
$$

These rules work recursively. In the entry for drink, the drinking event is specified as a causative one, and the caused event is further detailed as a change of place. The [path] component is filled in according to one of the patterns for [path], which we are not listing here. In representations like the ones given above, GO, CAUSE, and similar components are functions taking arguments. When the arguments are linked to specified syntactic constituents, as in an actual sentence, the arguments may be completed with the corresponding constituents. Thus, a sentence like John runs from the park to the library may be rendered as:

[event Go ([thing John], [path From [place park] тo [place library]]).

But clearly, a definition of run with a formula like this one does not provide a lot of semantic detail. The description in fact is hardly a definition: typical definitional information about matters like relative speed or manner of motion are not incorporated into the formula. The underspecified nature of the formula also appears from the fact that run, jog, trot, or walk will have the same representation. How can the additional information be accounted for and how can the verbs be distinguished? Here, the cross-modal link with non-conceptual kinds of cognition turns out to be crucial. Differences between running and jogging may be stored in the visual information that may be associated with the verbs. Referring to Marr's 3-D model of perceptual representation, Jackendoff suggests that the lexical entry for words such as run and jog should include a 3-D representation in addition to the phonological, syntactic, and conceptual structures (1990: 34):

How is one to distinguish, say, running and jogging from loping, or throwing from tossing from lobbing? If the lexical entries for these verbs contain a 3-D model representation of the action in question, no distinction at all needs to be made in conceptual structure. The first set of verbs will all simply be treated in conceptual structure as verbs of locomotion, the second set as verbs of propulsion. Thus again we are relieved of the need for otiose analyses of such fine-grained distinctions. 
In addition, the extralinguistic factors associated with the conceptual structures are not rigid; they do not function as a set of necessary and sufficient conditions, but rather have the status of default options, of preferred interpretations that may be subject to contextual modification. In this way, Jackendoff tries to give a place to the indeterminacies and fuzzy boundaries of word meanings that we have come across a number of times already, from Erdmann through Gipper to Labov, and that will play a central role in the development of cognitive semantics. Jackendoff (1983) introduces the term 'preference rules' to specify the status he attributes to his descriptions of word meaning: to cope with exceptions and with graded judgements about membership in a category (about whether something is a cup, for instance), the features in the semantic descriptions have to be seen as typicality conditions rather than as necessary characteristics.

In actual practice, Jackendoff has devoted more attention to the interface between syntax and semantics than to the flexible use of words or to the detailed description of the interplay between conceptual structure and extralinguistic knowledge. The latter part of the model is not elaborated with the same formal rigour as the more grammar-oriented sections. As was the case with Wierzbicka's Natural Semantic Metalanguage, the principled acceptance of flexibility and fuzziness in the use of words does not lead to an active, maximalist investigation of that variability and the way in which it might affect the semantic definitions. And with regard to the method for establishing the universality of the conceptual primes, Conceptual Semantics is even more underspecified than Wierzbicka's Natural Semantic Metalanguage. But even though the link with extralinguistic cognition is more a stipulated principle than a fully spelled out descriptive framework, the proposal to account for the fuzziness and flexibility of language through its link with other modes of cognition invites a number of remarks.

First, Jackendoff does not specify the criteria for distinguishing conceptual features from information stored in non-conceptual modes of representation. Talking about the difference between duck and goose, he mentions (1990: 33) that it would be 'patently ridiculous' to suggest a feature like [ \pm LONG NECK] as a conceptual primitive, with possibly universal status. But then, would features like MOUTH OF, ROOM, TRAIN, COMPOSE, which appear in some of Jackendoff s (1996) examples, be primitive? And how could one make the difference? Componential definitions need not be exhaustive according to Jackendoff's framework, but one would still need criteria to determine what enters into a conceptual description and what can be relegated to the nonconceptual cognitive modules. 
Second, if we decide to separate conceptual knowledge and other modes of cognition, it is an open question whether all the information we need to describe the fine-grained semantics of words is always perceptual, or at least non-conceptual. This is a line of criticism pursued by Taylor (1996): if we have a closer look at the differences between run and jog, is it always the case that the differences reside in perceptual data? While run is basically a form of locomotion that is faster than walking and that involves specific bodily movements, jogging is a way of running ('leisurely running', perhaps) that evokes the conventional background of a certain lifestyle. Stereotypically, jogging is what middle-class people in affluent societies do as part of their leisure time, with the explicit purpose of contributing to their health and physical wellbeing. It involves a particular outfit: you may have to run even on occasions when you are wearing a business suit, but if you are going to jog, you will put on sports clothes; performing the movements of jogging in a business suit might not be recognized as jogging. Also, it implies a specific trajectory: you can run from any A to B, but if you jog, you typically follow a circular trajectory that brings you back to your starting point. All of these features distinguishing running from jogging are perceptual in a weak sense only; primarily, they rely on conceptual knowledge about social groups and individual purposes. If we assume that all of this low-level information needs to be incorporated into the contrastive definition of run and jog, then perceptual information alone will not suffice.

Third, Jackendoff's argumentation rests on the assumption that there is no overlap between conceptual and perceptual information. But how plausible is that? We may have a picture in our head of an attribute like [ \pm LONG NECK], but that does not rule out the existence of a concept 'long neck'. In fact, the very fact that we can easily introduce the notion 'long neck' in our present discussion, seems to indicate that we can easily activate a conceptual and not just a perceptual representation of the feature in question. But if the relevant bits of information, like [ \pm LONG NECK], can have both a perceptual and conceptual representation, why favour the perceptual mode? Conversely, accommodating the relevant information in the conceptual mode would inevitably introduce some of the fuzziness that Jackendoff tries to transfer to the perceptual mode.

\subsubsection{Two-Level Semantics}

Jackendoff's Conceptual Semantics introduces a division of labour between linguistic knowledge and world knowledge, but the division is a static one. It is so to speak a division in long-term memory that does not have a lot to say about how the two types of knowledge interact dynamically in a specific context. The two-level model as initiated by Manfred Bierwisch (1983a, 
1983b, 1987, 1988), and further developed by Ewald Lang (Bierwisch and Lang (1989; Lang 1991, 1993, 1994) does precisely that. It provides a model for the interaction of word knowledge and world knowledge in actual contexts of use. The two-level approach (or Zwei-Ebenen-Semantik), like Conceptual Semantics, takes a modular view of cognition. Cognitive behaviour is determined by the interaction of systems and subsystems that operate as largely autonomous modules of the mind. In particular, polysemy in natural language may be adequately described by distinguishing between two levels of knowledge representation: semantic form and conceptual structure.

'Semantic form' is a linguistic entity. It is the language-specific description of a lexical item as part of a formalized lexicon of the language. In a decompositional way, it specifies the conditions for associating that item with entities on the level of conceptual structure. Crucially, it contains variables and parameters that may be set through the interaction with conceptual structure. At the same time, semantic form contains grammatical information that specifies how a given item can contribute to the formation of more complex syntactic structures.

'Conceptual structure', on the second level, consists of languageindependent elements and systems of conceptual information. Concepts corresponding to concrete objects for instance, would be represented by object schemata that specify the defining properties of the class of spatial objects, and that may help to fill in variables and parameters in the definition of lexical items at the level of semantic form. We thus get a division of labour between semantic form and conceptual structure. Each word will have a single unitary meaning at the level of semantic form, but through the interaction with contextually specific conceptual factors, the item receives a range of contextual interpretations. It will be clear now in what way Bierwisch goes beyond an approach like Jackendoff's. Bierwisch tries to specify how the interaction of context and meaning works in a contextually dynamic way. More explicitly than Jackendoff, the two-level approach deals with meaning variation, and as we will see, accounting for polysemy and semantic flexibility is a major focus in contemporary lexical semantics. Let us now have a brief look at some examples illustrating the two-level approach.

The first example concerns words like university or school, which refer to an institution (the university offers scholarships for foreign students), but which may also refer to the buildings housing that institution (the university lies to the north of the historical centre). A general semantic entry of the logical format 
may, for the specific entry of university, be filled out as

$$
\lambda \mathrm{x} \text { [purpose }[\mathrm{x} \mathrm{w}] \& \text { advanced study and teaching }[\mathrm{w}]]
$$

In a semantic entry like this, $\mathrm{x}$ is a variable whose value is set at the second level of analysis. The two interpretations of university that we just illustrated correspond to two ways of specifying $\mathrm{x}$ :

$$
\begin{aligned}
& \lambda \mathrm{x} \text { [institution [x] \& purpose [x w] } \\
& \lambda \mathrm{x} \text { [Building }[\mathrm{x}] \text { \& purpose }[\mathrm{x} \mathrm{w}]]
\end{aligned}
$$

A second example is taken from Lang (1993). He notes that German breit 'wide' may receive a lexical entry of the following form:

$$
\lambda \mathrm{c} \lambda \mathrm{x}[\text { [QUANT ACROSS } \mathrm{d} \mathrm{x}] \geq[\mathrm{v}+\mathrm{c}]]
$$

The ACross component of the definition refers to the horizontal dimension of spatial configurations, and QUANT ACROss is a quantity on that dimension, measured against the norm $\mathrm{v}$. Things that are breit exceed that norm by at least the quantity c. Essential to the two-level model, the value $\mathrm{v}$ is determined contextually. Take a case like Brett 'board'. If you think of a board in horizontal position, like a tabletop, one of the things that could be said is Das Brett is breit und lang genug aber zu dunn 'the board is wide enough and long enough, but too thin'. Assuming that the board has a rectangular shape, there is a shorter side $a$ and a longer side $b$. In the sentence just mentioned, the norm $\mathrm{v}$ would be contextually set by $a$, given the contrast between breit and lang. But consider the same board hanging against the wall with $a$ in vertical position and $b$ in horizontal position. The same sentence Das Brett is breit und hoch genug aber zu dünn 'the board is wide enough and high enough, but too thin' would then induce an interpretation of $\mathrm{v}$ according to the dimension $b$ rather than $a$, as $a$ would be associated with hoch 'high, tall'.

Without going into further technical details, we can appreciate that the twolevel approach, like Wierzbicka's and Jackendoff's, belongs to a broader class of parsimonious models of lexical semantics: models that explicitly take into account the contextual flexibility of meaning, but that try to keep the actual definitional description within bounds, by relegating most of the flexibility to another level of description. Thus, Bierwisch distinguishes a linguistic level with a unique and unitary semantic definition from a contextual level where context factors may produce modulations and elaborations of that unitary meaning. Rather than discussing the particulars of the two-level approach, let us consider the general merits of such a 'pragmatization' strategy, i.e. the strategy of keeping the semantics clean and sober by deferring semantic flexibility 
to the pragmatic level of contextualized usage. Up to a point, a model taking into account pragmatic flexibility is simply inevitable: if creativity in language is real, then we simply cannot have all the relevant meanings stored in our mental lexicon. If using vocabulary in a specific setting would just amount to choosing from a set of polysemous readings stored in our mental lexicon, then surely language change and linguistic creativity would be ruled out. So we do indeed need to describe the mechanisms of contextual creativity. But does that inevitably lead to a parsimonious description of a Bierwisch kind? What are the difficulties that a parsimonious pragmatization strategy has to deal with?

A first general difficulty is the problem of definitional adequacy that we already raised in relation to Natural Semantic Metalanguage. If you believe in unitary meanings, you should not just postulate them, but you should prove their appropriateness. Now, from a descriptive perspective, a unitary meaning is one that covers all the instances of use of an item, and that does so in a distinctive way, i.e. in a way that adequately distinguishes the item from alternatives. In the case of Bierwisch, a description like $\lambda \mathrm{x}$ [PURPOSE $[\mathrm{x} \mathrm{w}] \&$ ADVANCED STUDY AND TEACHING [w] ] for university does not seem to conform to that requirement. On the one hand, it is highly questionable whether the so-called McDonald's University, where employees are trained, is correctly described by the tag 'advanced'. That need not be detrimental to Bierwisch's definition if we consider this usage to illustrate a different meaning - but then we will need good operational criteria for distinguishing between polysemy and vagueness, which is not a clear matter (as we will see in some detail in 5.1.2). On the other hand, if we retain the tag 'advanced', the definition is not unique for university, because there are other words in the lexical field of institutions for higher education that would also fall in the same category: academy, college, school (in one of its readings). To describe the difficulty in general terms: a parsimonious approach to lexical semantics is likely to suggest fairly abstract and schematic definitions, but the more abstract and schematic a definition, the more likely it is to be over-general and insufficiently distinctive.

A second, related question is to what extent processes of contextualization can be adequately understood without reference to a wider context of encyclopedic knowledge (which would automatically make the semantic description less spartan). Taylor (1994; see also 1995) makes a convincing case that the possibility of activating either the 'institution' or the 'building' reading of the German words Parlament 'parliament' and Regierung 'government', which feature among Bierwisch's examples, depends on encyclopedic knowledge. A parliament is primarily an institution, housed in a 
specially dedicated building, while a government does not characteristically occupy a specific site (though individual ministries might). Not surprisingly, a topological reading of Regierung is questionable, as the examples show:

\section{Das Parlament liegt am Stadtrand}

The Parliament is situated on the outskirts of the city

? Die Regierung liegt am Stadtrand

? The government is situated on the outskirts of the city

? Der Palast hat die Frage bereits entschieden

The Palace has already come to a decision on the issue

In the same vein, the different behaviour of Palast and palace in German and English, which is duly noted by Bierwisch, would seem to follow from the fact that speakers of (British) English are familiar with the Palace as the official site of an extant monarchy, whereas for speakers of German, the institutional reading is virtually non-existent.

A third difficulty involves language change. A parsimonious approach makes a distinction between semantic information that is stored in the (mental) lexicon and readings that are derived pragmatically, in context. It would seem that imposing such a distinction saves the stored lexicon (which is also the one that linguists tend to focus on) from becoming cluttered and fuzzy: what can be derived need not be listed, and the stored meanings themselves can be kept simple. But if we take into account language change, such a strict distinction between what is stored and what is derived cannot be maintained. Pragmatic, context-dependent meanings have to be able to permeate to the level of semantics. In a historical perspective, the distinction between a semantic and a pragmatic level in the description of lexical meaning echoes Paul's distinction between aktuelle and usuelle Bedeutung (see 1.2.2), but of course, Paul was well aware that actual meanings may be promoted to usual ones. Such a process requires that a reading that is at one point pragmatically derived leaves a trace in the mental lexicon of the language user: language users remember hearing/reading or saying/writing it, and the more they use it, the more entrenched and conventional it becomes. Language change, in other words, blurs the distinction between the two levels. The recognition that a certain interpretation can be reached contextually does not exclude that it will also have to leave a trace, however weak, in the stored inventory of items; if not, the inventory would never change. In that sense, the pragmatization of polysemy does not really keep the semantics restricted and tidy.

In contemporary diachronic semantics, the bridging function of pragmatic interpretations is well known. We will return more extensively to current 
developments in diachronic semantics in section 5.4, but it seems appropriate to consider a standard example of the interface between semantics and pragmatics, derived from König and Traugott (1988), in the present context. Utterances expressing a temporal succession of events or situations may, by pragmatic inference, be understood as expressing causality rather than just temporal sequence. This shift from a temporal to a causative reading of the connectives is mediated by instances of use in which both cooccur. In the following series of examples, (b) is a bridging context between (a) and (c):

(a) temporal: I have done quite a bit of writing since we last met

(b) temporal and causal: Since you lost your favourite fountain pen, you seem to have been suffering from writer's block

(c) causal: Since he didn't want me to sign with a pencil, he lent me his pen

In a two-level framework, since in (b) would be a contextual reading of the temporal reading as illustrated by (a). Because the causal reading is pragmatically derived in the context of use, it need not be stored in the semantic inventory. Reading (c), on the other hand, should be included in the semantics, as a polysemous sense of since. But to promote the causal reading to conventional status, the mental lexicon will have to keep track of cases like (b): the more bridging contexts occur, the more likely it is that the causal reading will be detached from the temporal one. As such, being derived pragmatically as a conversational implicature does not contrast with being stored, contrary to what a parsimonious separation of semantics and pragmatics implies.

\subsubsection{Generative Lexicon}

The most elaborate formalized componential model in contemporary semantics is the Generative Lexicon defined by Pustejovsky (1995a). Because the Generative Lexicon framework attracts considerable attention, we will take a closer at look at it than we took at the Conceptual Semantics and Twolevel Semantics models. Four points will be discussed: the general features of the model; the representational format used in the Generative Lexicon; the various ways in which the model is being further developed; and some points of criticism.

1 The overall position of the model in the context of lexical semantics is characterized by two features. First, more so than any of the approaches mentioned in the previous chapter and the previous sections, Pustejovsky is interested in the description of regular polysemy. Regular polysemy, as defined 
by Apresjan (1973), refers to the existence of polysemous patterns in the lexicon:

Polysemy of the word A with the meanings $a_{i}$ and $a_{j}$ is called regular if, in a given language, there exists at least one other word $B$ with the meanings $b_{i}$ and $b_{j}$, which are semantically distinguished from each other in the same way as $a_{i}$ and $a_{j}$ and if $a_{i}$ and $b_{i}, a_{j}$ and $b_{j}$ are non synonymous.

(Apresjan 1973: 16)

Examples of regular polysemy (which is also called 'logical polysemy' by Pustejovsky) include cases like the university example that we came across in the work of Bierwisch, but also other metonymies, like the alternation between a countable object reading and an uncountable mass reading in I put a glass on the table versus the present is made of glass. The creative possibilities of this object/mass alternation may be recognized from examples like after the unhappy encounter, the floor was littered with Ming vase. The pattern may occur in the other direction too, when nouns that usually appear with an uncountable reading are used not as mass nouns but as object nouns: he ordered two coffees.

Further examples of regular polysemy include the relationship between product and producer (the journal lies on the tablelthe journal was taken over by Rupert Murdoch), between process and result (my purchases took me just under an hour/the purchases are still in the trunk of the car), or between contents and container (the whole lecture hall laughed/the lecture hall is at the end of the corridor). More patterns of regular/logical polysemy for which Pustejovsky intends to account involve adjectives like fast in a fast car (moving at a high speed) versus a fast track (enabling a high speed), or sad in I feel sad (in a sorrowful emotional state) versus a sad film (expressing or causing a sorrowful emotional state). Verbs too exhibit regular polysemy: witness the telic reading of follow in please follow me to the exit versus the atelic reading of the same item in the red car followed me for a few minutes but then turned in the direction of Brussels. For anyone acquainted with the tradition of lexical semantics, and specifically with the traditional focus of diachronic semantics on mechanisms and patterns of semantic change, polysemous patterns like these will be familiar: see section 1.3.2. In the context of formal grammar, however, they introduced a new element in semantic theory formation.

A second general characteristic of the Generative Lexicon, next to its intention to account for regular polysemy and creative language use, is its position within the discipline. To begin with, it grows out of generativist semantics, and not just because it offers a decompositional model of the lexicon in the context of a formal grammar: it explicitly tries to emulate Katzian semantics by going beyond what Pustejovsky calls a Sense Enumeration Lexicon, i.e. a formal lexicon that merely lists word senses and does not account for the 


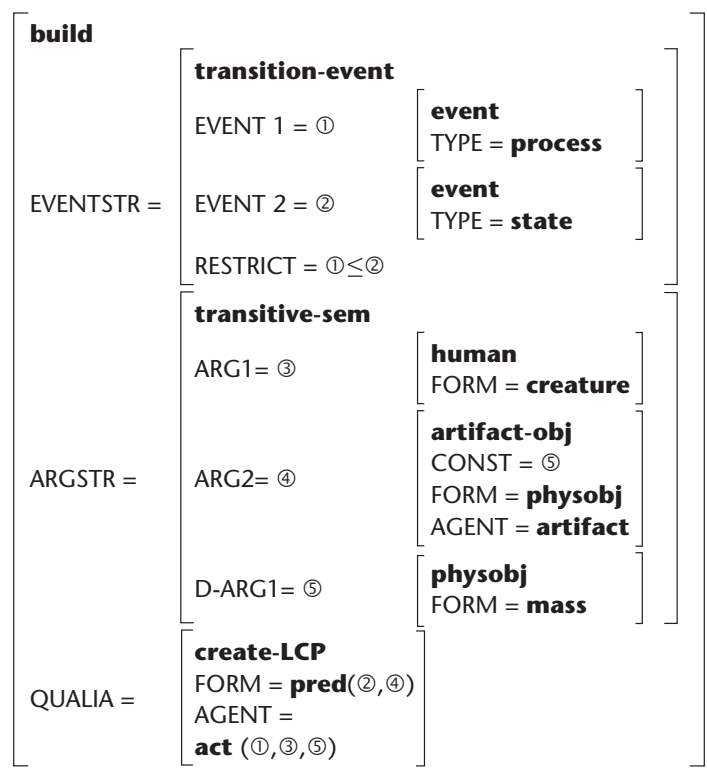

FIgUre 4.2. English build according to Pustejovsky

dynamics of language. In its concern to explain the creative use of language, it focuses on the lexicon as a key element underlying this phenomenon, and thus opposes static views of the lexicon. But the Generative Lexicon goes beyond a Katz-type lexical semantics in yet other ways: it explicitly links up with logical representations of meaning, and it tries to provide a representational format that may be used in computational linguistics.

2 But what does the format actually look like? Without being too technical, let us have a look at the essentials. Essentially, the Generative Lexicon posits a number of procedures for generating semantic interpretations for words in particular contexts. These procedures do not produce readings out of the blue; they take into account the knowledge that is encoded in the system for each lexical item. This encoded knowledge conforms to a general pattern with different types of information structure, the most important of which are the following: the 'argument structure' specifies the number and nature of the arguments to a predicate; the 'event structure' defines the event type of the expression, and possibly also the internal event structure; and the 'qualia structure' is a structured set of descriptive characteristics that corresponds most closely to the more traditional kinds of componential definition of meaning. To illustrate, let us have a look at a simplified description of the verb build as rendered in Pustejovsky (1995b) (Figure 4.2). 
The event structure specifies that build refers to an event with two subevents, $e_{1}$ and $e_{2}$, the first of which is a process and the second of which is the state that results from the process of building. The relationship between the two subevents is expressed by the RESTRICT part, which specifies that the two subevents are successively ordered parts of the overall event (the process of building precedes the resultative state). Also, the first subevent is the most important one, i.e. the HEAD in the event structure.

The argument structure specifies three arguments for build. The first two, corresponding to syntactic subject and object, are necessarily expressed. The description states that the first argument needs to be an animate individual; the qualia structure of the constituent filling the first argument position needs to have the feature 'creature' as a formal quale. (More about qualia structures follows shortly.) The second argument is an artefact. The third argument in the example is a so-called 'default' one, i.e. it is presupposed in the semantics, but is not necessarily expressed; in this case, it refers to the material with which something is built.

The qualia structure (which indirectly derives from Aristotle) involves four broad categories of characteristics. Formal qualia indicate, briefly, what something is, distinguishing it in the larger domain to which it belongs. Constitutive qualia involve the constituent parts of something; they answer the question what something is made of. Telic qualia indicate the purpose of the thing (if there is one). And agentive qualia answer the question how something came into being. The kind of qualia that play a role in the description of a lexeme broadly characterize its overall semantic type. In natural types, for instance, only formal and constitutive qualia play a role, whereas artefactual types would be concepts making reference to telic or agentive qualia. In the build example, the qualia structure takes the form of an LCP or Lexical Conceptual Paradigm, indicating the various roles that an item can perform, i.e. referring to an act of building or referring to the resultative. The process subevent of building is an agentive event that involves the syntactic subject ARG1 and the default argument D-ARG1. This process gives rise to the state subevent, i.e. the existence of the ARG2 argument.

A fourth type of information structure, not present in the example given above, is the lexical inheritance structure, which basically expresses taxonomic relations between lexical items, in the sense in which $S U V$ is a hyponym of car and in which car is itself a hyponym of vehicle.

The really generative part of the system resides in the ways in which a predicate can combine with its argument. Following Pustejovsky (2006), there are three ways in which such a combination can take place. In the case of Type Matching, the process of selection proceeds in a straightforward way: the type that is required by the function corresponding to a predicate is satisfied by the 
encoded form of the argument. If the verb flow requires that its first argument is a liquid, and if beer is characterized as a liquid, then the beer flows is an unproblematic construction. In the case of what Pustejovsky calls Accommodation, the type that is required by the function is inherited by the argument through the lexical inheritance structure. If the verb drive requires that its direct object is a car, then no linguist drives a $S U V$ is recognized as acceptable because $S U V$ inherits the car characterization through the lexical inheritance structure. In the case of Type Coercion, the type a function requires is not met with by the argument, neither directly (as in the case of Type Matching) or indirectly (as in the case of Accommodation), but it is imposed on the argument. Type Coercion, in other words, is 'a semantic operation that converts an argument to the type which is expected by a function, where it would otherwise result in a type error' (Pustejovsky 1995a: 59). Type Coercion comes in two flavours: Exploitation and Introduction.

With Exploitation, Type Coercion takes part of the type encoded with the argument to conform to the requirements associated with the function expressed by the predicate. This applies specifically to so-called complex types, in which the semantic description combines two distinct and possibly even incompatible interpretations. A noun like breakfast is characterized both as event and as food, and book has both the type 'physical object' and the type 'information'. Technically, complex types of this kind are rendered as so-called 'dotted types': physobj •info. Exploitation then ensures that only that part of the dotted type is selected that corresponds to the requirements imposed by the predicate. For example, given that the verb buy selects for a physical object as its second argument, the sentence Julia bought a book is interpreted in a physical sense, without reference to the information-carrying nature of books.

Introduction, finally, is the converse of Exploitation: instead of neutralizing part of a dotted type, it expands an encoded type to conform to the complex type required by the predicate. Thus, given that read requires a direct object with the dotted type physobj -info, like book, the initial 'info' type of the noun rumour will be expanded to physobj -info in the context of a sentence like we all read the rumour about the cook and the headmaster.

3 Against the background of the reductive approaches that we discussed in the previous sections, the Generative Lexicon is the most productive and sophisticated type of post-generativist formal decompositional semantics: whereas the two-level approach and even Jackendoff's Conceptual Semantics remain relatively restricted, the perspective developed by Pustejovsky is being developed in different directions. Three lines of development may be mentioned. 
In the first place, the success of Pustejovsky's intention to contribute to computational linguistics is visible, among other things, in the strong presence of the Generative Lexicon in Saint-Dizier and Viegas (1995), a collected volume which is devoted specifically to computational lexical semantics (but which does, it should be added, underrepresent the statistical tendencies in computational lexicology; see section 4.2.3 below). Currently, attempts are being made to strengthen the empirical basis of the approach by incorporating findings from large-scale corpus analyses (see Hanks and Pustejovsky 2005, Hanks 2006, Pustejovsky and Rumshisky 2008, Rumshisky 2008, Pustejovsky and Jezek 2008). Like all the formal componential approaches discussed in this section, the Generative Lexicon is very much a top-down theory, one in which the formal and theoretical framework is formulated on the basis of a relatively small (in some cases very small) number of examples. The necessity of confronting such an approach with actual data appears from a study carried out by Kilgarriff (2001). He noted that the Generative Lexicon was barely able to account for the neologisms that could be found in corpus data: the vast majority of the novel uses identified by Kilgarriff did not fit into the Generative Lexicon patterns. Findings such as these indicate that the Generative Lexicon may profit from a broader empirical basis.

In the second place, the formal apparatus of the Generative Lexicon is being further refined. An important addition is Copestake and Briscoe's suggestion for the introduction of lexical rules into the format of the Generative Lexicon. Copestake and Briscoe (1996) observe that the regular polysemy that is of central concern to Pustejovsky may be represented more economically than in Pustejovsky's original suggestions. As we mentioned, there is a systematic relation between countable and uncountable readings of words like fish: you can catch a fish, but you can also eat fish. In the formulation of the Generative Lexicon, this could be accounted for by adding a dotted type physobj - mass to the description of fish and similar words. Copestake and Briscoe (1996) suggest capturing the generalization by means of a lexical rule, which will formulate the regularity as a possible transformation on the semantic representation of lexical items. Without going into the technical format, such a rule might say that an item with the feature 'lex-count noun' may be changed to one with the feature 'lex-uncount noun'. Lexical rules are a powerful mechanism: instead of stipulating the polysemy in an individual lexical entry, it takes the form of a general rule.

In Asher and Lascarides (2001), lexical rules of this kind are used to suggest a solution for another potential problem with Pustejovsky's approach. The Generative Lexicon stresses what would traditionally be considered metonymic shifts of meaning, whereas metaphor is hardly mentioned. Asher and Lascarides, then, show how lexical rules may help to formulate 
metaphoric transfers. Focusing on verbs of movement (or 'change of location'), Asher and Lascarides note that the metaphoric uses of verbs of movement preserve the essential structure of the path involved in the change of state referred to by the verb. Taking the French verb entrer 'to enter' as an example, they point out that it requires the interior of a physical location as an argument, expressing the movement from a position close to that location to the inside of it. Metaphorically, the argument need not be a physical entity, but it must have an extension so that a figurative 'inside' may be envisaged. Feelings, and psychological states in general, fit that pattern, because states extend in time, and thus have an extension. A sentence like Jean est entré en crise 'John entered a crisis' is perfectly acceptable then, while John entered the line of permissible behaviour is not, because the line does not have an interior, not even in a metaphoric reading. Asher and Lascarides then introduce a Metaphor Lexical Rule to account for the structure-preserving nature of figurative language. The rule expresses that the orthography, the syntax, and the descriptive features (qualia) of the conventional senses of words are preserved in their metaphoric usage. The semantic type of the metaphoric sense, however, can be anything, regardless of the original type. So if the conventional entry of entrer mentions that it is a change of location event, this semantic type may be overruled by the Metaphor Lexical Rule. But the restrictions on the use of entrer (like the fact that it needs an argument with an extension) are preserved.

In the third place, Asher, Lascarides, and Copestake have emphasized that the contextual disambiguation of lexical items does not just depend on the words that the item co-occurs with, i.e. on the type of mechanism that Pustejovsky focuses on. The general strategy of the Generative Lexicon is to have an underspecified lexical representation, which is then contextually interpreted on the basis of the sentential context: see the mechanisms of Accommodation and Type Coercion. But such a contextual interpretation, as argued by Asher and Alex Lascarides (1996) and Lascarides and Copestake (1998), is not restricted to the domain of the sentence. It may also invoke general principles of pragmatics and discourse organization. From a theoretical point of view, the importance of such an additional layer of analysis can hardly be underestimated. Like all the approaches in this section, the Generative Lexicon makes a distinction between the linguistic core of lexical semantic description and another, extralinguistic level. We have seen in the previous sections that making such a distinction requires either a principled criterion for demarcating the two or an attempt at describing the non-central component, so that at least the combined effect of both layers might become explicit. To put it more simply, if you make a principled distinction between semantics and pragmatics, the pragmatics should not be swept under the rug. The additions suggested 
by Asher, Lascarides, and Copestake are an important step towards such an encompassing model. (At the same time, if one compares the 'Metaphor in discourse' article by Asher and Lascarides 2001 with Semino's book of the same title of 2008, which is situated in the paradigm of cognitive semantics, the descriptive scope of the former turns out to be extremely limited.)

To see how it works, we may again take Asher and Lascarides 2001) as our starting point. They note that there is a specific type of metaphor, which may then be described by a specific Lexical Metaphor Rule, in which concepts referring to physical objects are applied to humans. The adjectives that apply to the physical object are then also metaphorically valid for the human target of the metaphor. Thus, John is a rock may be interpreted as 'John is solid, heavy, hard to move', as the case may be. But the lexical rule as such does not give many clues as to the actual interpretation: whether it is the solid reliability of John that is focused on, or rather his stubborn unwillingness to change position, is a pragmatic inference that invokes general background knowledge on behalf of the language user. Because pebble does not carry the same associations as rock, the sentence Sam is a pebble does not trigger similar metaphoric readings. In a contrastive discourse context, however, a metaphoric reading for Sam is a pebble is more likely: John is a rock, but Sam is a pebble. Here, the contrast relation (cued by the conjunction but) provides the necessary trigger to produce a metaphoric reading for pebble: the contrast relation asks for a maximal coherence between the conjoined sentences, but at the same time demands a contrasting theme between them. The correspondence is achieved by ensuring a metaphoric interpretation, not just for rock (which gets its metaphoric reading regardless of the conjunction), but also for pebble. The contrasting theme is found by comparing the qualia of rock and pebble: the relative sizes of rocks and pebbles as included in the qualia structure of the items lead to an interpretation of pebble as 'less reliable', or, maximizing the contrast, as 'unreliable'.

4 Even though we did not focus on the technicalities of the model, it will be clear by now that the Generative Lexicon is the most advanced approach among the formal componential theories that we have brought together here in section 4.1. Like Conceptual Semantics and like the two-level model (but unlike Natural Semantic Metalanguage), it tries to account for the contextual flexibility of meaning, and it does so in a technically more elaborate way than the other two models, all the more so if we further take into account the attempts by Asher and Lascarides to specify pragmatic, discourse-oriented principles of interpretation that are complementary to the semantic, sentenceoriented principles highlighted by Pustejovsky himself. At the same time, the type of problems that we identified with regard to the other models remain 
relevant for the Generative Lexicon: how easy is it to draw a principled distinction between semantic information and pragmatic or extralinguistic factors, and how does one identify the elementary building blocks of the componential analyses of meaning?

With regard to the first problem, let us note that the objections formulated by Taylor with regard to the two-level approach could also apply to the Generative Lexicon. The Generative Lexicon specifies the mechanisms that allow for the use of university as either a building or an institution, but the mechanism as such would also allow for sentences like Der Palast hat die Frage bereits entschieden, in which the 'institution' reading is not appropriate. If the approach aims at explaining these restrictions on regular polysemy, the encyclopedic factors pointed to by Taylor would need to be incorporated in the theory. There are other respects, too, in which the framework seems to be overgenerating. By Type Coercion, Sidney began a novel is interpreted as 'Sidney began reading a novel', because begin requires an argument of the event type, and because novel —even though its formal type is that of a physical object-has a telic quale of the event type:

$$
\left[\begin{array}{l}
\operatorname{novel}(x) \\
\operatorname{CONST}=\operatorname{pages}(z) \\
\text { FORM }=\operatorname{physobj}(x) \\
\text { TELIC }=\operatorname{read}(P, y, x)
\end{array}\right]
$$

But now take a noun like sweater. In the telic role, we expect the concept 'to wear' just as we find 'to read' for novel. Still, coercing the reading 'Sidney began to wear a sweater' for Sidney began a sweater is much more difficult.

The qualia structure may not only overgenerate, it may also, as demonstrated by Jayez (2001), undergenerate. Bouillon and Busa (2001) argue that vehicle terms contain a telic role that specifies their primary goal as instruments for transport. In the Generative Lexicon framework, assuming that the French verb attendre 'to wait' requires an argument referring to an event, the sentence J'attends le bus receives a plausible interpretation as 'I wait to board the bus so that I can be transported to some other location'. But as Jayez points out, there could be many reasons for waiting for the bus. You may have the intention of taking a picture of it, of saying hello to the driver, of checking if it runs on time, of welcoming a visiting friend, and so on. In cases such as these, the flexibility of interpretation induced by the real-world context of use appears to be much bigger than the Generative Lexicon can handle. Similarly, the pragmatic principles adduced by Asher and Lascarides, like the principle of contrast, do not exhaust the relevant factors, as they specify themselves: the exact interpretation of metaphoric values for rock and pebble depends on 
the general background knowledge of the language users. But if this information is relevant, how should it be formally incorporated-or if it should not, how do we distinguish between what is background knowledge and what is not?

With regard to the status of the features in Pustejovskyan definitions, is a feature like 'physical object' a primitive concept in the way Wierzbicka intends the term? Is the concept of physical objects clear and constant, or does it itself stand for a complex and contextually flexible category, a category that involves a richer type of semantics than the formalism suggests? What exactly are physical objects? There is no problem with clear cases like tables and chairs-material, movable, with indubitable borderlines-but to what extent are clouds or a fire physical objects? Is an internet connection (with some tangible parts and some immaterial ones) a material object? The suggestion that the formal simplicity of the qualia hides a flexibility of the same character as the overall semantic flexibility that it is supposed to explain, is further strengthened when we have a look at the metaphoric lexical rule proposed by Asher and Lascarides. Here, too, there seems to be a hidden polysemy or vagueness: are the qualia in the derived reading not themselves metaphoric? Is the extension of a psychological state the same as that of the location? If we say that a psychological state (of the kind that we can enter into) has an extension, are we not using the term 'extension' itself in a metaphoric sense? Formalization is supposed to achieve greater precision in the description, but how precise are the elementary building blocks of the formalized componential readings?

\subsection{Elaborating the relational approach}

The frameworks introduced in the previous section were all extensions of a componential method for the description of lexical meaning: either through new formats of formalization, or through a systematic search for primitive elements, they develop the idea of a decompositional form of description that emerged in the context of structuralist semantics and that was introduced into formal grammar by Katz and Fodor. In the present section, we focus on approaches that develop other aspects of the structuralist paradigm, specifically, various types of lexical relations. A second common feature of the approaches in this section is that they all have a link with computational semantics. The link is different for the first two approaches as compared to the third, however. The first two, the WordNet project and Mel'čuk's Meaning-Text Theory, provide data or descriptive formats that contribute to the construction of formalized lexicons. Because a lot of the relevant information about a language can be linked to the vocabulary of the 
language, language technology and linguistic engineering require machinereadable dictionaries (or 'lexicons') that may be included in computational applications. Like the Generative Lexicon, WordNet and the Meaning-Text Theory directly or indirectly open up perspectives for the production of such lexicons.

The third approach that will be discussed in the present section takes quite another angle towards computational linguistics. To see the difference, we need to add a few words about the history of computational linguisticsmore specifically, about a major paradigm shift that has been taking place since the 1990s. Charting the domain of computational lexical semantics as such is beyond the scope of this book: we are interested in lexical semantics within theoretical and descriptive linguistics, and computational linguisticsthe field of research that deals with the computational processing of natural language-is primarily an applied discipline (even though the relationship between computational and theoretical linguistics is not quite that simple). But in order to understand how there are two radically different ways in which linguistic lexical semantics may link up with computational lexical semantics, we need to know just a little more about the internal development of computational linguistics.

If we abstract away from the experiments in machine translation that constituted the start of computational linguistics in the 1950 s and the early 1960s, computational linguistics went through two main stages, one running from the 1960 s to the 1980 s, and one that emerged in the 1990s. In the first phase of the development, the dominant methodological paradigm is sometimes referred to as Symbolic Natural Language Processing, while the 1990s witnessed the rise of Statistical Natural Language Processing.

In Symbolic Natural Language Processing, linguistic knowledge is encoded in a formal language, for instance the type logic of Pustejovsky's Generative Lexicon. Computation then takes the form of symbol manipulation: the encoded information is transformed according to specific rules. Again, coercion in the Generative Lexicon is a case in point: the coercion mechanism produces a contextually appropriate reading. The link between Symbolic Natural Language Processing and linguistics is fairly close: very often, the representational format used in computational linguistics derives from formal grammars like Lexical Functional Grammar or Head-Driven Phrase Structure Grammar.

In Statistical Natural Language Processing, by contrast, linguistic knowledge primarily takes the form of patterns that may be extracted by statistical analysis from large corpora. How a language behaves is attested in corpora with actual language data, and so, if we can identify the patterns of behaviour by examining the corpora, we tap into a huge reservoir of linguistic knowledge. 
When in the 1990s more and more digitized text corpora became available, like the British National Corpus in 1994, computational linguistics witnessed an explosion of corpus-based machine learning research. Using statistical learning algorithms, these programmes retrieve linguistic information from corpora without having recourse to a 'translation' into a formal language of representation.

The relations between the approaches presented in this section and Natural Language Processing have to be defined against the background of these two movements in Natural Language Processing. The distributional corpus analysis that forms the subject matter of the third part of this section links up with the statistical paradigm in computational linguistics, while the production of machine-readable dictionaries rather links up with the symbolic paradigm.

\subsubsection{WordNet}

WordNet is a practical application of the concept of sense relations: it provides a lexical database for English and a growing number of other languages organized according to sense relations. WordNet was developed by the American psycholinguists George Miller (who initiated the project) and Christiane Fellbaum. (A brief overview of the history of the project is given in Miller and Fellbaum 2007. The major publication discussing the project is Fellbaum 1998.) WordNet was initially compiled for English, but similar databases have been built or are being built for numerous other languages. EuroWordNet, for instance, is a multilingual database for Dutch, Italian, Spanish, German, French, Czech, and Estonian, with wordnets structured in the same way as the American WordNet for English. The development of international wordnets is coordinated by the Global WordNet Organization. So how exactly does it connect to relational semantics?

In the WordNet database, nouns, verbs, adjectives, and adverbs are grouped into sets of synonyms; these synonym sets (commonly known as synsets) and the lexical items they contain are mutually linked by means of sense relations. For the noun chair, for instance, WordNet provides the following set of readings.

1. chair —a seat for one person, with a support for the back: he put his coat over the back of the chair and sat down

2. professorship, chair-the position of professor: he was awarded an endowed chair in economics

3. president, chairman, chairwoman, chair, chairperson-the officer who presides at the meetings of an organization: address your remarks to the chairperson 
4. electric chair, chair, death chair, hot seat - an instrument of execution by electrocution; resembles an ordinary seat for one person: the murderer was sentenced to die in the chair

It will be noted that each of the readings is represented by a synset, a definition, and an example. At the same time, it will be clear that the elements in the synsets may be near-synonyms rather than strict synonyms: chairwoman and chairman could be considered hyponyms of chair rather than synonyms. For each of the readings, sets of hyponyms and hyperonyms are listed. Below are the hyperonyms of the second reading and the hyponyms of the first reading (the indents in the first set signal a shift to the next higher level in the hierarchical organization):

professorship, chair

$=>$ position, post, berth, office, spot, billet, place, situation

$=>$ occupation, business, job, line of work, line

$=>$ activity

$=>$ act, human action, human activity

$=>$ event

$=>$ psychological feature

$=>$ abstraction

$=>$ abstract entity

$=>$ entity

chair

$=>$ armchair

$=>$ barber chair

$=>$ chaise longue, chaise, daybed

$=>$ Eames chair

$=>$ fighting chair

$=>$ folding chair

$=>$ highchair, feeding chair

$=>$ ladder-back, ladder-back chair

$=>$ lawn chair, garden chair

$=>$ rocking chair, rocker

$=>$ straight chair, side chair

$=>$ swivel chair

$=>$ tablet-armed chair

$=>$ throne

$=>$ wheelchair

The sense relations further involve holonyms and meronyms (like back and leg for the first reading of chair), and antonyms. The set of sense relations for 
verbs is different from that for nouns. Next to antonyms and hyperonyms, hyponymy-like relations take the form of different types of entailment. The fact that something is a throne entails that it is a chair, but in the case of verbs, the entailments may be further subdivided. Next to strict entailments (if you snore, it means you sleep), troponyms involve specific ways of doing an action: to sleepwalk, stride, shuffle, stroll, slouch, etc. are particular ways of walking. In these two cases, the basic action and the entailment occur at the same time: the entailment is temporal. Two other types of entailment (presupposition and causation) lack such a temporal entailment: to succeed presupposes to try, but the attempt comes before the success; similarly, showing something is a cause of seeing. For adjectives and adverbs, the relevant sense relations are mostly antonyms.

The WordNet database does not just contain single lexical items; it also includes multiword expressions (like kick the bucket in the synset of die). Function words are not included, however; it only describes nouns, verbs, adjectives, and adverbs. In addition to the sense relations, WordNet provides information about derivationally related words, about the sentence frames in which verbs appear, and about the relative frequency of the words.

As WordNet provides a freely accessible, large-scale database for English and other languages, it is widely used in computational linguistics as a resource for lexical information. At the same time, it is subject to a number of restrictions (which the developers are ready to acknowledge): the subtler distinctions among the elements of a synset are beyond the scope of the description, syntagmatic relations are not envisaged, and (at least in some cases) the set of sense relations could be refined (specifically, there is no differentiation between different types of antonyms).

From a theoretical point of view, it is important to note that WordNet does not claim that the relational structure exhausts the semantic description of the words, as would be the case in a strictly structuralist interpretation of lexical relations. The very fact that classical dictionary-like definitions are added to the relational information is a sufficient indication of the fact that the network information does not completely replace such definitional information. Further, it needs to be remarked that WordNet originally aimed at psychological adequacy, i.e. it intended specifically to include relational information that could be certified on the basis of psycholinguistic experimental evidence like speech errors, aphasia studies, and word association experiments (see Beckwith, Fellbaum, Gross, and Miller 1991). During the actual compilation of the WordNet database, that goal was abandoned: the amount of available psycholinguistic data is not sufficient to cover a lexicon of the size treated in WordNet. WordNet is a machine-readable dictionary in the field of computational lexicology, not a model of the mental lexicon belonging to the field of psycholinguistics. 


\subsubsection{Lexical functions}

The semantic relations used in the relational type of semantics introduced by Lyons are purely paradigmatic, and they consist of a relatively restricted set of metalinguistic (or at least, allegedly metalinguistic) associations. But paradigmatic semantic relations might be taken much more broadly. The observation that the person in charge of a faculty is called a dean would not normally lead to postulating a lexical relation 'head of' between faculty and dean. However, the same relation exists between board and chairman, ship and captain, airplane and captain, school and headmaster or director, army and general, company and CEO, tribe and chief, and a number of other lexical sets. In Igor Mel'čuk's Meaning-Text Theory (Mel'čuk 1988b,1989, 1995, 1996, 1998; Mel'čuk 1995), frequently occurring relations of this type are identified as 'lexical functions'.

Once this enlargement of semantic relations to lexical functions has been effected, other possibilities open up. Between the noun city and the adjective urban, or countryside and rural, the relationship is both semantic ('pertaining to, relating to') and grammatical ('adjective corresponding to the noun'). On top of that, the same relation also touches upon the morphology of the language in the case of education and educational, face and facial, function and functional. Further, lexical functions may relate lexical items to phrases and not just to other lexical items: the same function that links joy to joyfully also yields with joy. And lexical functions play a role in the description of lexical-syntactic patterns. Given a noun denoting an action, for instance, we may define a lexical function that yields a verb which takes the agent of the action as its grammatical subject, and the keyword noun as its direct object: this function associates the English noun question with the verb ask. If the lexical functions are indeed as frequent as they are supposed to be, we should be able to apply them cross-linguistically. Thus, we can take the translations of question to see how ask a question translates into various languages: the same function that connects question to ask joins Dutch vraag to stellen, French question to poser, German Frage to stellen, and Spanish pregunta to hacer. Lexical functions, then, do not only specify paradigmatic semantic relations between lexemes: they also describe the syntagmatic co-occurrence restrictions between words. In the example, literally translating the pattern of one language to the other reveals the restrictions. Literally translating from Dutch, French, or German to English might suggest that place a question is the correct English equivalent, which obviously it is not.

So far, the Meaning-Text Theory has been applied primarily to Russian and French. It distinguishes more than 6o lexical functions. These lexical functions occupy a central position in the Explanatory Combinatorial Dictionary (Mel'čuk, Clas, and Arbatchewsky-Jumarie 1984-99) that is the main 
practical achievement of Meaning-Text Theory. To get a better idea of the scope and content of Explanatory Combinatorial Dictionaries, we can have a look at the dictionary entry for revulsion (see Mel'cuk 1996). Leaving aside the illustrative quotations, the entry consists of three parts: an analytical definition in propositional form, a 'government pattern' that specifies the syntactic environments in which the item can occur, and the list of lexical functions in which it participates. The entry (with some simplifications) then takes the following form.

\section{Revulsion}

\section{DEFINITION}

$X$ 's revulsion for $Y=X$ 's (strong) negative emotion about $X$ similar to what people normally experience when they are in contact with something that makes them sick and such that it causes that $\mathrm{X}$ wants to avoid any contact with Y

GOVERNMENT PATTERN

$\mathrm{X}$ 1. N's 2. $\mathrm{A}_{\text {poss }}$

$\mathrm{Y}$ 1. against $\mathrm{N}$ 2. at $\mathrm{N}$ 3. for $\mathrm{N}$ 4. toward $\mathrm{N}$

John's (his) revulsion against racism (against greed/the dismal results of his endeavour); John's (his) revulsion at such behaviour (at the sight of sea food); John's (his) revulsion for work (for all those killings); John's (his) revulsion for (toward) these scoundrels/toward the government; John's (his) revulsion ${ }^{*}$ at these shouts [correct: ... for these shouts]

\section{LEXICAL FUNCTIONS}

Syn $\subset$

Syn $\cap$

Antin

Conv $_{21}$ Antiก

$\mathrm{A}_{1}$

$\mathrm{Able}_{2}$

Magn

AntiMagn

$\operatorname{Adv}_{1}$

Propt

Oper $_{1}$

Magn + Oper 1

Magn + Labor $_{21}$

$\mathrm{Conv}_{12} \mathrm{Caus}_{2} \mathrm{Oper}_{1}$

$\operatorname{Adv}_{1}$ Manif distaste

repugnance; repulsion; disgust; loathing attraction

appeal

revulsed

revulsive

deep $<$ extreme $<<$ utmost

slight

in $[\sim]$

from $[\sim]$

experience, feel $[\sim]$

be filled [with $\sim$ ]

fill [ $\mathrm{N}$ with $\sim$ ]

be driven [to $\sim$ ]

with $[\sim]$ 
The $\mathrm{X}$ line in the 'government pattern' specifies the constructions in which the $\mathrm{N}$ is the agent or subject of the revulsion. The $\mathrm{Y}$ line lists the patterns specifying the object of the revulsion. It may be noted that the examples of the government patterns indicate restrictions on the combinatorial possibilities that are not covered by the lexical functions.

The lexical functions fall into different groups. A first set corresponds with relations that we have become acquainted with in the previous section. Syn identifies synonyms, or rather, words that can be substituted for the keyword. The subscripted index specifies whether the substitutive term is broader $(\supset)$, narrower $(\subset)$, or intersecting $(\cap)$ with regard to the keyword. In the terminology of relational semantics, this means that distaste is listed as a subordinate concept with regard to revulsion, whereas repugnance, repulsion, disgust, loathing are synonyms or near-synonyms. Anti identifies antonyms, and Conv refers to converses, i.e. words that denote a relation that is the converse of the relation expressed by the keyword. Such converses involve a switch among the participant roles: if receive is the converse of give, the subject of give surfaces as the object of receive, and vice versa. These participant roles (called 'actants' by Mel'čuk) are indicated by the numeric subscripts: ${ }_{1}$ is the agent or subject of the action expressed by the keyword ${ }_{2}$ its object. In the converse, the order of ${ }_{1}$ and ${ }_{2}$ is obviously reversed. The revulsion entry does not contain a straightforward example of a converse, but appeal illustrates another feature of lexical functions: they can be construed compositionally, in the sense that appeal is the converse of attraction, i.e. it is the converse of the antonym of the keyword. (The starting point is the situation in which $\mathrm{X}$ feels revulsion for $\mathrm{Y}$. The antonymous situation is one in which $\mathrm{X}$ feels attraction for $\mathrm{Y}$. The converse situation is $\mathrm{Y}$ appealing to $\mathrm{X}$.)

The next function, A, identifies a morphological derivation: the synonymous adjective corresponding to the noun revulsion is revulsed. A derivation from the noun to an adverbial expression is identified by Adv; the example shows that in this case, the result is indeed an adverbial phrase, in revulsion, and not a single adverb. In the list, Adv also occurs in the composite function $\operatorname{Adv}_{1}$ Manif. While Manif gives a verb expressing the action through which the keyword manifests itself, $\operatorname{Adv}_{1}$ Manif specifies a corresponding adverbial. Propt is somewhat similar to $\mathrm{Adv}$, to the extent that it identifies the preposition that can be used to build an adverbial phrase expressing the concept 'because of, as a result of the keyword'.

Able is one of a set of functions qualifying the actants; it indicates the capability of the first, second, etc. actant to perform the action inherent in the keyword. Thus, if $\mathrm{Able}_{2}$ yields revulsive, then that is the word to name the things that cause revulsion. Magn is one of a set of functions qualifying the keyword. Magn indicates the standard intensifier for the keyword, with 
possible further gradations, as in the example. According to the principle of composite functions, AntiMagn names the antonym of the intensifying expression.

The lexical functions in the previous group are all paradigmatic ones. The remaining ones are syntagmatic functions. Oper associates the keyword with the verb that has the first, second, etc. actant of the keyword as its grammatical subject and the keyword as its direct object. Magn+Oper then points to the intensified version of that verb. Labor produces a verb that has the actants of the keyword as subject and direct object, and the keyword itself as a third constituent. For revulsion, Magn + Labor $_{21}$ is such a verb or verbal expression that has the second actant of revulsion (the entity that causes the revulsion) as subject and the first actant (the entity feeling the revulsion) as direct object and that expresses intensity: fill $N$ with revulsion. The final function in the list, $\mathrm{Conv}_{12} \mathrm{Caus}_{2} \mathrm{Oper}_{1}$ contains the causative function Caus: $\mathrm{Caus}_{2} \mathrm{Oper}_{1}$ is the action or event that causes the first actant to experience revulsion; $\mathrm{Conv}_{12} \mathrm{Caus}_{2} \mathrm{Oper}_{1}$ then is the same action or event, with the original first actant as subject.

It will be clear from this sample entry that the lexical functions approach constitutes a fertile and versatile framework for the semantic description of the lexicon. From a practical point of view, the Explanatory Combinatorial Dictionary, based on the concept of lexical functions, constitutes a much richer source of information than WordNet, based on the more traditional concept of sense relations. As shown by the first group of functions that we distinguished in the example, the relations that are distinguished by traditional, Lyons-type relational semantics are included in the set of lexical functions. But at the same time, the set of lexical functions is much broader than that. It contains a whole series of paradigmatic relations that are absent from the usual set of semantic relations, and it adds a whole array of syntagmatic relations. Not surprisingly, the concept of an Explanatory Combinatorial Dictionary receives considerable attention from lexicographers and computational linguists and lexicographers: see Fontenelle $(1997,1998)$, Palmer and Polguère (1995), Ramos, Tutin, and Lapalme, (1995) for examples. At the same time, compiling an Explanatory Combinatorial Dictionary according to the principles of the Meaning-Text Theory is a labour-intensive enterprise: the fact that WordNet is used more in computational circles than Mel'cuk-type dictionaries is due to the simple fact that WordNet covers larger vocabularies and many more languages than the Explanatory Combinatorial Dictionary project can offer.

But what about the theoretical position of Mel'cuk's use of lexical functions? If we assume that the lexical functions approach is a structuralist approach, there would be two questions to ask: does the set of lexical functions associated 
with a particular keyword suffice for the semantic description of that keyword, and does the approach succeed in keeping the semantic level and the encyclopedic level separate (i.e. does it succeed in describing a purely linguistic structure of conceptualization)? The first question, however, does not seem to be quite appropriate. The very fact that the entries in an Explanatory Combinatorial Dictionary contain an analytical definition next to a relational description by means of lexical functions indicates that the latter is not meant as a substitute for a more traditional form of semantic description.

The second question is more pertinent, because the distinction between a linguistic and an encyclopedic level of conceptual analysis does play a role in the Meaning-Text Theory. For instance, Mel'čuk (1996: 99) does not include part-whole relations into the set of lexical functions, because they are considered to belong to the encyclopedic description of the lexeme. Other scholars working within the lexical functions paradigm, however, have argued on predominantly practical grounds for the inclusion of meronymic relations as a Part function linking finger to hand, room to house, page to book, and so on: see Fontenelle (1997). Surely, if Cap is included as the 'head of' relationship that exists between faculty and dean and the other examples we mentioned earlier, then a 'part of' relationship is no less a valid lexical function. There are still other lexical functions, in fact, that are similar to part-whole relations. For instance, Mult links the keyword to a group to which it belongs, like bee to swarm, and Centr singles out the middle of a spatio-temporal entity, like core with regard to apple. But if, on the basis of existing functions like Cap, Mult, and Centr, meronymy is accepted as a lexical function, then all of the lexical functions like 'head of' and 'part of' will have to be recognized as typically encyclopedic rather than linguistic. In short, the demarcational problems that we have already encountered a number of times are as real for Meaning-Text Theory as for the other frameworks (like Wierzbicka's or Pustejovsky's) that try to couch semantic description in a restricted, reductive metalanguage.

\subsubsection{Distributional corpus analysis}

The relational approaches in the previous two sections were based on paradigmatic relations. But as we saw in section 2.2.2, structuralist semantics distinguishes a paradigmatic and a syntagmatic perspective, and the latter lies at the basis of a distributionalist method for lexical semantics: examine the syntagmatic environments in which a word occurs, and you will know more about the kind of word you are dealing with. In this section, we will have a look at the various forms taken by distributional analysis in the post-generativist era. In particular, we will show how a distributional way of thinking led to a most innovative and dynamic methodology, based on the statistical analysis of lexical phenomena in large text corpora. 
Not all current forms of distributionalism are corpus-based, however. Linking the semantics of words to their syntactic behaviour has a particular appeal for formal theories of grammar, for which the syntactic analysis of the language is a central goal. Note for instance that Jackendoff's rewriting of ontological categories like EVENT into specific patterns like [event GO ([thing], [path])] is also a way of identifying the syntactic environments in which predicates expressing events may occur: each of the constituents in the expanded formula gets a specific syntactic expression in the kind of formalized lemma that is used in the Conceptual Semantics framework. Given this natural affinity between syntactic theory and a syntagmatic, distributionalist lexicology, it is not surprising to find distributional approaches that are inspired by generative grammar and related theories. An influential example is Levin's classification of English verbs (1993). From the point of view of lexical semantics, we can see Levin's approach as an attempt to define lexical fields on the basis of the syntagmatic properties of the verbs. Instead of grouping the items on the basis of their referential, denotational properties - as Pottier did with the chairs or as the American anthropologists did with the kinship termsLevin distinguishes between subsets in the vocabulary of English verbs on the basis of their syntactic behaviour. More specifically, she takes into account patterns of alternations of the kind that were studied as 'transformations' in generative grammar.

To illustrate the methodology, let us look at one particular class identified by Levin, the 'verbs of social interaction' (Levin 1993: 200-202). Simplifying, three alternations are relevant for the description of these verbs. The Simple Reciprocal Alternation (Intransitive) links the patterns 'NP1 V [pP P NP2]' and '[NP NP1 and NP2] V'. The Understood Reciprocal Object Alternation links '[NP NP1 and $\mathrm{NP}_{2}$ ] V' and 'NP1 V NP2'. The With Preposition Drop Alternation links 'NP1 V [PP with $\mathrm{NP}_{2}$ ]' and 'NP1 V NP2'. If we then have a look at three specific verbs of social interaction, mingle, marry, and meet, we notice that they behave differently with regard to the three alternations.

Simple Reciprocal Alternation:

Brenda mingled with Molly/Brenda and Molly mingled

*Bill married with Kathy/Bill and Kathy married

Ellen met with Helen/Ellen and Helen met

Understood Reciprocal Object Alternation:

*Brenda mingled Molly/Brenda and Molly mingled

Bill married Kathy/Bill and Mary married

Ellen met Helen/Ellen and Helen met 
With Preposition Drop Alternation:

Brenda mingled with Molly $/{ }^{\star}$ Brenda mingled Molly

*Bill married with Kathy/Bill married Kathy

Ellen met with Helen/Ellen met Helen

If we translate this into a componential analysis, with the alternations as the distribution-based descriptive features, we get the following three classes:

mingle verbs:

+ Simple Reciprocal Alternation

- Understood Reciprocal Object Alternation

- With Preposition Drop Alternation

marry verbs:

- Simple Reciprocal Alternation

+ Understood Reciprocal Object Alternation

- With Preposition Drop Alternation

meet verbs:

+ Simple Reciprocal Alternation

+ Understood Reciprocal Object Alternation

+ With Preposition Drop Alternation

Levin shows that these patterns indeed apply to entire sets of verbs, and not just to the three examples. Among many others, agree, correspond, differ, quarrel, struggle behave like mingle. Date, divorce, embrace, kiss, pet behave like marry, and battle, consult, debate, fight, visit behave like meet.

Levin's work proved seminal for the study of the interface between syntax and lexicon, but the major advances in the distributional approach to lexical semantics per se did not come from syntax-oriented projects like Levin's, but rather from the application of a distributional way of thinking to large text corpora. In the words of John Sinclair, who is one the pioneers of the approach, a corpus is 'a collection of naturally occurring language text, chosen to characterise a state or variety of a language' (1991: 171). Three major features characterize this tradition of research: its usage-based corpus methodology, the central role of the notion of collocation, and the technological background of the approach.

1 The distributional patterns identified and classified by Levin are situated on the level of 'the' language, that is to say, they assume that language is primarily a linguistic structure that exists independently of a how the language is actually used. That is a dichotomous assumption that has an almost foundational value in modern linguistics: de Saussure distinguished between langue and parole 
(language structure and language use), and Chomsky formulated a related distinction between competence and performance. In the mainstream line of development of twentieth-century linguistics, those distinctions are often interpreted in such a way that langue competence constitutes the proper object of enquiry of linguistics, whereas parole performance is of minor importance. Needless to say, this attitude has an affinity with the reductive views of lexical semantics that we have run into earlier in this book: a strict separation between langue and parole in the field of grammatical theory resembles the strict separation of semantics and pragmatics in the field of lexical description.

By contrast, distributional corpus analysis takes a radical usage-based rather than system-based approach: it considers the analysis of actual linguistic behaviour to be the ultimate methodological foundation of linguistics. In the linguistic climate of the 1970s, when the scene of grammatical theory was dominated by the introspective methodology of Chomskyan linguistics, such a usage-based approach went against the grain of the prevalent opinions; but if we think about it in more historical depth, we can appreciate that it did not emerge out of the blue. This holds for the development of corpus linguistics as a whole, but we will concentrate here on corpus-based lexicology (which in fact constitutes only a small part of corpus linguistics in the broad sense; see Halliday, Teubert, Yallop, and Čermáková 2004: 107-17 for a brief history of corpus linguistics in general).

One obvious source of distributional corpus-based lexicology is the structuralist interest in syntagmatic relations and, more particularly, the Firthian aphorism that we quoted earlier: 'You shall know a word by the company it keeps'. What better way can we have to know which company a word keeps than to look at what language users actually do with their vocabulary?

A second source, of a more philosophical kind, consists of those pragmatist theories in the philosophy of language that emphasized that language was a form of action. An early voice (and an influence on Firth) was that of the anthropologist Bronislaw Malinowski. He argued not only that language had to be investigated in a contextualized way (for which he introduced the notion 'context of situation'), but also that language is best seen as a mode of action: 'The main function of language is not to express thought, not to duplicate mental processes, but rather to play an active pragmatic part in human behaviour' (Malinowski 1935: 7). A related opinion is Wittgenstein's view that meaning is use (1953). These viewpoints had a considerable influence on the development of philosophical and linguistic pragmatics, most directly through John Austin's lectures of 1955, later published as the well-known How to do Things with Words (1962). Through the lineage of Firth, however, the pragmatic conception of language also stimulated the development of a usagebased methodology for linguistic research. 
A final and principal source is the tradition of lexicography. Sinclair applied and developed his ideas through his work on the Collins Cobuild English Language Dictionary (Sinclair and Hanks 1987), for which a 20 million-word corpus of contemporary English was compiled. This makes the Cobuild dictionary the first contemporary dictionary of English to be based on a dedicated corpus-but that does not mean that working with text corpora was a novelty for dictionary makers. The great historical dictionary projects that we mentioned in section 1.1.3 were, in their own painstakingly manual way, corpus-based-a dictionary like the Oxford English Dictionary (Murray 1884) rests on a huge collection of quotations extracted from historical texts-and the method used by the historical lexicographers for analysing and classifying those quotations was surely also based on the principle of interpretation in context, i.e. on the examination of the elements co-occurring with the target word. The systematicity with which the data are collected and scrutinized may have improved, but the idea itself of using a large repository of real language data as the empirical basis for semantic descriptions is a continuation of the finest traditions of philological and lexicographical work rather than a radical break with the past.

2 The distributional analysis in the corpus-based approach is not restricted to constituents and syntactic classes, as in Levin's example, but it takes into account the actual words in the context of which the target word appears. Firth (1957b) remarked that part of the 'meaning' of cows can be indicated by such collocations as They are milking the cows, Cows give milk. This observation is taken as a methodological starting point: the words co-occurring with another one help to identify the properties of the word under scrutiny. An example (taken from Stubbs 2002: 15) may illustrate the basic idea. A classical example of homonymy in English is the item bank, which is either a financial institution or an area of sloping ground, specifically the raised ground on the side of the river or underneath a shallow layer of water. The sets of words that these two exemplars of bank normally occur with hardly overlap at all. Looking at compounds on the one hand, and on the other at co-occurring items within a few words to the left or right of bank, Stubbs comes up with the following lists:

bank account, bank balance, bank robbery, piggybank cashier, deposit, financial, money, overdraft, pay, steal sand bank, canal bank, river bank, the South Bank, the Left Bank, Dogger bank, Rockall Bank, Icelandic Banks cave, cod, fish, float, headland, sailing, sea, water 
The entities in the environment of the two homonyms appear to differentiate efficiently and effectively between the two meanings, and in that sense, a systematic analysis of the co-occurring items would appear to be an excellent methodological ground for lexical-semantic analysis.

In theoretical terms, the essential concept here is that of collocation, defined as 'a lexical relation between two or more words which have a tendency to co-occur within a few words of each other in running text' (Stubbs 2002: 24). Collocations in this broad sense may take different shapes, though. To get an idea of the various levels at which the co-occurrence of words (and sets of words) may be defined, we may look at the four types distinguished by Sinclair (1991, 1996): collocation, colligation, semantic preference, and semantic prosody.

'Collocation' in the most immediate sense is the co-occurrence of words or word forms in a line of text. Terminologically, the target word is often called the 'node', and the co-occurring word the 'collocate'. A common way of examining collocations is to produce a concordance of a text or a set of texts, i.e. an alphabetical list of the words in those texts, presented in their immediate context. The usual way of representing a concordance is the Key Word in Context index (or KWIC-index). By way of illustration, Figure 4.3 presents part of a KWIC-index on the Introduction of this book. Of the 52 hits for the item semantics in the text of the Introduction, 31 occur in the combination lexical semantics. The other top collocates are cognitive (6 times), structuralist (5), is (5, to the right of semantics: semantics is), and historical-philological (3). None of this is surprising, but that is exactly why we can appreciate that a distributional investigation throws a revealing light on the way in which words are used in a given source.

The node of a collocation analysis may be a word form or a word, if lemmatization can be applied, i.e. if all the inflectional forms of a word are treated as instances of a single lexical unit. Also, nodes may themselves be complex expressions or phrases. The semantics example suggests that cognitive semantics may be treated as a unit in its own right in the text under consideration, so we may then feed cognitive semantics into a collocational analysis. A further refinement involves the treatment of function words like $a$, the, is, are, by, from. The co-occurrence pattern semantics is probably does not tell us a lot about the meaning of semantics. Such less illuminating words are called stop words, and stop lists may be used as filters to fine-tune the result of a collocational analysis.

Following Firth, Sinclair defines 'colligation' as 'the co-occurrence of grammatical choices' (1996: 85), i.e. the syntactic pattern with which a word appears. Co-occurrences, in other words, are now defined between the node and a syntactic class. In our semantics example, the dominant pattern is one in 
enerativist period. Cognitive semantics focuses on the psychological what is pursued in cognitive semantics. neostructuralist semantics cognition at large. cognitive semantics - Cognitive semantics is the gnitive semantics - Cognitive semantics is the psychologically and co of word meaning by cognitive semantics include prototype theory, con ularly relevant for cognitive semantics). Taking into account that th duces an attempt to formalize semantics as part of a formal grammar. nceptual metaphors, and frame semantics. Judged by the sheer amount 0 ential analysis. generativist semantics - From 1960 onwards, aspects issues raised by generativist semantics, i.e. the possibility of form ography of linguistic lexical semantics. It will try to map out the 1 iachronic approach to lexical semantics that dominated the discipline Within the history of lexical semantics, this period occupies a pivot mework in present-day lexical semantics. Restrictions Given our init e of this overview of lexical semantics, it may be useful to also men ot an introduction to lexical semantics from, for instance, a philoso ction that focuses on lexical semantics in the context of applied lin o, an introduction to lexical semantics is not the same as an introdu d morphology, whereas lexical semantics concentrates strictly on mean this is a book about lexical semantics, not an introduction to the $p$ on to the practice of lexical semantics. Learning how to actually con w to actually conduct lexical semantics in any of the frameworks trea into the practice of lexical semantics, i.e. it is not a book on 'ho a book on 'how to do lexical semantics'. It does not systematically xisting literature on lexical semantics, the present text has a theor inated the history of lexical semantics - but the book does not claim ll-fledged history of lexical semantics of the type that would primar the historiography of lexical semantics. Given its scope and its intr - The book deals with lexical semantics in the context of modern ling ry. The prehistory of lexical semantics, from Antiquity over the Midd the stock examples of lexical semantics. Even if one has become acqua he various schools of lexical semantics, one cannot claim to be well to be well versed in lexical semantics if one is unfamiliar, say, wi $t$ schools of thought. Lexical semantics is not a discipline in which and, the evolution of lexical semantics shows a great deal of progres at the development of lexical semantics is not just a succession of $\mathrm{m}$ the undercurrents of lexical semantics as well as with the currents, tance with linguistic lexical semantics, the book should be of some u dest 'modern' form of lexical semantics, and trace the development up mporary concerns. But lexical semantics does not follow the pattern 0 present situation in lexical semantics. An understanding of the rela semantics. neostructuralist semantics - Under this heading, we brin ing. historical-philological semantics - Historical-philological sem ics - Historica-philological semantics is the diachronic approach to ch of historical-philological semantics in favour of a systemic appro ical field theory, relational semantics, and componential analysis. $g$ specialization. structuralist semantics - Taking its inspiration from om De Saussure, structuralist semantics (from 1930 onwards) rejects t proaches within structuralist semantics include lexical field theory, rds, aspects of structuralist semantics (componential analysis in par major types of structuralist semantics, but that do so in a post-gen nitively oriented approach to semantics that developed from 1980 onwa

FIgURE 4.3. Sample KWIC index 
which semantics occurs with an adjective to its left; only in a few cases do we find other configurations, as in formalize semantics or frame semantics.

'Semantic preference' is situated at an intermediate level of abstraction, in between syntactic colligation and lexical collocation. Similar to what we encountered as selection restrictions in Katzian semantics, it involves the relation between the node and a set of semantically related words. In the example, the majority of the top collocates of semantics (cognitive, structuralist, historical-philological) have a meaningful feature in common; they invoke what we might call 'linguistic methodologies'. The topmost collocate, lexical, falls outside this semantic class, however; it belongs rather to a set of words referring to 'linguistic fields of description' (although the other adjectives that would go into that class, like morphological or discursive, apparently do not play a role in the text of the Introduction). In Sinclair (1996) the phrase naked eye appears to co-occur, in the third position preceding the node, with expressions that come predominantly from two classes: the top collocates in that position are see/seen and visible/invisible, but more verbs include detect, spot, appear, perceive, view, recognize, read, study, judge, tell, and more adjectives include apparent, evident, obvious, undetectable. Combining the level of colligation and that of semantic preference, we may then say that the third position to the left of naked eye is dominantly filled by a verb or adjective referring to (in)visibility.

'Semantic prosody' (sometimes also called 'discourse prosody') looks at cooccurrences not from a purely lexical perspective (as in collocation), nor from a syntactic perspective (as in the case of colligation, looking at grammatical categories), nor from a semantic perspective (as in semantic preference, looking at semantically defined lexical sets), but from a connotational perspective, i.e. from the point of view of the emotive or evaluative attitude expressed by the surrounding words. It refers to the fact that words may have a tendency to line up with either positively or negatively evaluated words. For an illustration, we turn to Stubbs 2002: 105-8). Stubbs uses a particular format to represent what he calls the 'lexical profile' of a word or expression: the top collocates of that word, together with frequency information that helps to interpret the findings. The figure following the node specifies the absolute number of hits for the item in the investigated corpus, while the percentages accompanying the collocates say something about the relative weight of those collocates (either individually or collectively) within the set of hits. Let us look at a few examples:

derive $767<$ benefit(s), pleasure, satisfaction, comfort $>20 \%$ discoveries $1,009<$ new $8 \%$, important $4 \%$, great $3 \%$, exciting $2 \%>$ easing $1,607<$ tension(s) $9 \%$, sanctions $5 \%$, pressure $2 \%>$ 
excessive $3,406<$ force $10 \%$, anxiety $2 \%$, violence $1 \%$, loss $1 \%$,

bleeding $1 \%>$

expression $6,628<$ freedom $5 \%$, artistic, creative $>7 \%$

load $4,140<$ rubbish $5 \%$, old $2 \%$, crap $1 \%>$

These figures reveal that derive, discoveries, and expression have positive semantic prosody, i.e. are associated with pleasant things, while easing, excessive, and load have negative semantic prosody.

3 Distributional corpus analysis relies on information technology. In the most trivial sense, the corpora are digital ones, and retrieving information from the collections of texts requires software, like concordancing programmes. But the link with information technology goes much further than that, and actually creates a strong association between distributional corpus analysis and statistical computational linguistics, going well beyond the corpus-based lexicography that got the whole thing started. To understand the emergence of this link, we first have to understand the necessity of statistical analysis for a distributional approach.

Why do we consider certain co-occurring items to be 'top collocates'? A naive answer might be to point to their frequency in the list of collocates, but then is would be a top collocate in our semantics example; it has the same frequency as structuralist. We are not likely to include is, because we assume that there is nothing special about the frequency of the copula: it would probably rank high in the list of collocates of any noun. In the case of is, we may solve the problem by including it in the list of stop words, but that doesn't solve the difficulty on a more general level: how do we know that a high frequency of co-occurrence is not just due to chance? That is where the statistics comes in.

In Church and Hanks (1990), a Pointwise Mutual Information index is defined in terms of the probability of occurrence of the combination $x, y$ compared to the probabilities of $\mathrm{x}$ and $\mathrm{y}$ separately. The probability $\mathrm{P}(\mathrm{x})$ of $\mathrm{x}$ and $\mathrm{P}(\mathrm{y})$ of $\mathrm{y}$ in a corpus is given by their relative frequency in the corpus. Given these probabilities, the theoretical probability of $\mathrm{x}$ and $\mathrm{y}$ occurring together is, by a general law of probability theory, the product of $\mathrm{P}(\mathrm{x})$ and $\mathrm{P}(\mathrm{y})$. But we can also measure the actual probability of $\mathrm{x}, \mathrm{y}$, by determining its relative frequency in the corpus. Then, we compare $\mathrm{P}(\mathrm{x}, \mathrm{y})$ with $\mathrm{P}(\mathrm{x}) * \mathrm{P}(\mathrm{y})$ : if the probability $\mathrm{P}(\mathrm{x}, \mathrm{y})$ of the combination is bigger than what we might expect on the basis of the probabilities $\mathrm{P}(\mathrm{x})$ and $\mathrm{P}(\mathrm{y})$ of the constituent parts, then we have an indication that the observed collocation is not just due to chance. So, Pointwise Mutual Information compares the probability of observing $\mathrm{x}$ and $\mathrm{y}$ together (the joint probability) with the probabilities of 
observing $\mathrm{x}$ and $\mathrm{y}$ independently (chance). If there is an actual collocational association between $\mathrm{x}$ and $\mathrm{y}$, then the joint probability $\mathrm{P}(\mathrm{x}, \mathrm{y})$ will be much larger than chance $\mathrm{P}(\mathrm{x})^{*} \mathrm{P}(\mathrm{y})$. (We pass over a number of technical refinements here: the calculation of $\mathrm{P}(\mathrm{x}, \mathrm{y})$ takes into account the span within which collocates are sought to the left and the right of the node, and the Pointwise Mutual Information score $(\mathrm{x}, \mathrm{y}) / \mathrm{P}(\mathrm{x})^{*} \mathrm{P}(\mathrm{y})$ is transformed on a logarithmic scale.) In short, a statistical analysis of co-occurrences can help researchers to avoid an impressionistic identification of collocations on the basis of corpus data.

Once we have a statistical measure of association like the Pointwise Mutual Information index, possibilities open up that would be difficult to follow through without quantification. For instance, a whole variety of association measures has been suggested and researched, among which Dunning's loglikelihood ratio (1993) is one of the more popular. Or consider the concept of 'keyword'. When you do a statistical analysis on the combination of two words $\mathrm{x}$ and $\mathrm{y}$, you check whether that combination is surprising. But suppose that $y$ is not a word but a text; you can then check whether the co-occurrence of $\mathrm{x}$ and $\mathrm{y}$-i.e. the occurrence of $\mathrm{x}$ in $\mathrm{y}$-is unexpected, and if it is, you may conclude that $\mathrm{x}$ is in some way typical or characteristic for text $\mathrm{y}$. That is the basic idea behind the concept of 'keyword' as introduced by Mike Scott (1997). Keywords are useful, among other things, for determining the topic of a text.

The statistical turn in thinking about contextual distributions allowed for a rapprochement with another class of quantitative distributional models, which originated in the field of information retrieval and Natural Language Processing rather than corpus-based lexicology. These are the so-called 'word space models'. This name refers to all approaches to lexical semantics that model the meaning of a word in terms of the contexts in which it is used, and in which a target word is analysed in terms of a context vector. Such a vector contains the target's values for a multitude of contextual features, and the nature of these contextual features allows us to distinguish between three major types of word space models.

First, word-based models simply look at the words that appear in the context of the target, without considering the syntactic relations between them. This is the approach that corresponds most directly with the collocational approach that we have so far dealt with: context is defined as the set of $n$ words around the target, and targets will be similar if they often occur with the same words in their neighbourhood.

Second, syntax-based models focus on the syntactic relationships in which a target word takes part. Here two words will be similar when they often appear in the same syntactic roles, like being the subject of the verb fly or being the prepositional object of the preposition $b y$. Up to a point, this is a 
refinement and specification of the word-based models: instead of a word as such, the relevant context feature is a word in a certain syntactic relation to the target.

Third, document-based models use some sort of textual entity as features. Their context vectors note what documents, sections, articles, sentences, or similar stretches of text a target word appears in. Roughly speaking, we can think of this as a reversal of the keywords approach: instead of looking for words that are characteristic of a given text, the model treats the texts in which a word appears as characteristic features of that item. Two words will thus be distributionally similar if they often occur together in the same section, for instance.

Despite these differences in the choice of context features, document-based, word-based and syntax-based models share a large part of their architectures. Their search for semantically related words proceeds as follows. First, the model builds a context vector for each word under investigation: for each target word, it is recorded if and how many times it co-occurs with any context feature-be it a word, a word in a syntactic function, or a text. All these context vectors together form the so-called 'word-by-feature matrix'. The values in this matrix, which are originally the simple co-occurrence frequencies of the target and its features, are then weighted. This is done for the same reason that a collocational approach introduced stop lists and statistical measures of association: the raw frequencies in themselves are not very informative about the meaning of a target. In a word-based model, for instance, frequent contextual features like be or man will automatically have much higher cooccurrence frequencies than relatively infrequent contextual features, like leaf or branch, while the latter may contain much more useful information about the meaning of a word. Therefore, the mere frequencies of co-occurrence are generally replaced by a value that is more informative about the statistical relationship between a word and its features, like point-wise mutual information. After this weighting phase, sometimes the dimensionality of the word-byfeature matrix is reduced with mathematical techniques like Singular Value Decomposition or Non-Negative Matrix Factorization. Apart from reducing the time that is needed to calculate the distributional similarity between two words, these techniques are also often claimed to uncover dimensions that contain more semantic information than the original contextual features. Finally, the distributional similarity between two target words is calculated as the similarity between their context vectors, on the basis of a mathematical function like the cosine.

The actual appeal of distributional models of lexical semantics is apparent from the large variety of tasks to which they are applied, both in computational linguistics and in cognitive science. In computational linguistics, these 
approaches are used for tasks in the framework of automatic thesaurus extraction, automated essay evaluation, and question answering, to name just a few examples. In cognitive science, distributional approaches have proved successful in topics as diverse as the modelling of language acquisition, priming effects, semantic dyslexia, and sentence and discourse comprehension. Specific applications in the domain of lexical studies include word sense discrimination and word sense disambiguation (Agirre and Edmonds 2006), metaphor processing (Kintsch 2008), and the automatic discovery of synonyms.

A closer look at the latter task may help us to evaluate the state of affairs in this branch of study: the research community is a dynamic and productive one, but the applied context in which the research takes place seems to imply that theoretical concerns are not dominant. In practice, relatively little is as yet known about the precise semantic effect of the various distributional models. In the case at hand, almost all distributional models have been applied to both the modelling of synonyms and that of associations. Synonymy has been modelled with document-based (Landauer and Dumais 2007), syntax-based (Padó and Lapata 2007), and word-based (Van der Plas 2008) approaches as well as with collocation measures (Terra and Clarke 2003). So is there no method that would be particularly suited for one or the other task? Given the variety of methods, the research community is starting to appreciate the need for a detailed investigation of the relationship between distributional similarity and semantic relatedness. The first studies already reveal some converging trends (see Van der Plas 2008, Heylen, Peirsman, Geeraerts, and Speelman 2008 for more detailed treatments). For the modelling of synonymy, it is claimed that syntax-based word space models outperform all other approaches. Similarly, word-based models have been shown to perform better than document-based approaches. But such findings only mark the beginning of the theoretical screening of statistical corpus methods. Overall, the interaction between theoretical lexical semantics (of the kind presented in this book) and statistical lexical semantics is still rather restricted. Theoretically thoroughgoing reflections on the foundations of computational approaches to lexical semantics (like Kilgarriff 1997, who exposed the uncritical reliance in much work in computational lexicography on a naive view of word senses) remain relatively rare among the work produced in this domain.

To round off, how can we evaluate distributional corpus analysis and statistical semantics as a new approach in word meaning research? In the first place, because of its radical usage-based nature, this is by far the least structuralist of the 'neostructuralist' approaches. In most of the frameworks brought together in the present chapter, we noticed traces of the reductionist and exclusionary tendencies of older forms of structuralism: the tendencies, in other words, 
to strictly separate semantics from pragmatics (and if possible to exclude the pragmatics), and to describe meaning in a reduced vocabulary of primitive concepts or metalinguistic relations. With regard to all of these approaches, we have had to point to demarcational problems: restricting semantics in these ways is not as easy as one might wish. Distributional corpus analysis, by contrast, takes one part of the heritage of structuralism - the idea of working with the syntagmatic relations between words-and develops it in a non-reductionist, usage-oriented way. Extrapolating a structuralist notion in a decidedly non-structuralist way might seem paradoxical, but it is less so if one takes into account the notion of context. The reductionist aspects of structuralism are a form of decontextualization: taking meaning away from the actual context of use to the realm of linguistic structure. But syntagmatic relations are by definition contextual; once you start focusing on them (which older structuralism did not do systematically), they act like a contextualist Trojan horse (so to speak) in the decontextualizing structuralist framework.

In the second place, through its statistical elaboration, distributional corpus analysis links up with the statistical trends in Natural Language Processing that gained prominence in the 1990s. Other attempts at formalizing semantics, and specifically all kinds of formal componential analysis, relate to the 'symbolic' type of computational linguistics and Natural Language Processing. Given the problems of demarcation and selection of primitives that such symbolic approaches in lexical semantics are faced with, distributional corpus analysis has the clear advantage of making contact with the probabilistic paradigm in computational linguistics.

In the third place, distributional corpus analysis has the additional advantage of resting on a broad empirical basis of huge quantities of corpus material. We may remember that lexical semantic studies in the older historical-philological paradigm tended to be rich in examples and illustrations. Later theories, in particular those in the generativist tradition, sometimes based their discussions on a very limited set of case studies-just think of the role the bachelor and kill examples played in the development of generativist semantics. While this restricted empirical scope is certainly not a general characteristic of the neostructuralist approaches, the corpus approach is definitely the best-documented one.

Counterbalancing these positive points, two critical remarks need to be formulated. First, there is the unclarity that we discussed in the previous pages: distributional corpus analysis is primarily a method, not a model. It opens up an impressive amount of empirical data, but how exactly those data may be interpreted is not always given by the technique itself. The question is a general one, in fact: when we place lexical semantics on a broad empirical basis, what kind of information can we retrieve from what kind of method, 
and conversely, what technique, or variant of a technique, is most appropriate for studying which semantic phenomenon? Distributional corpus analysis has not yet reached the stage where it can present a stable set of methodological procedures coupled to specific descriptive questions. We may use sociolinguistics as a point of comparison. If you study language attitudes, you know that there is a specific set of experimental techniques, like matched guise and mixed guise investigations, that is particularly suited to the purpose. And if you do elicitation research, you know that it is important to avoid the 'observer's paradox'. But it is too early for statistical, corpus-based semantics to present a similar inventory of topics-cum-techniques. The observation that distributional corpus analysis has not reached that stage yet is certainly not a reason to the abandon the approach; rather, it defines a promising and exciting research programme.

Second, related to the first point, there is a question about the possible limits of a distributional analysis. Could the semantic information included in the distributional corpus behaviour of words exhaust the semantic information at the disposal of language users? To situate the question, let us consider the following quote from Sinclair (2004: 29):

Tending towards open choice is what we can dub the terminological tendency, which is the tendency for a word to have a fixed meaning in reference to the world [...] Tending towards idiomaticity is the phraseological tendency, where words tend to go together and make meanings by their combinations. Here is collocation, and other features of idiomaticity.

Sinclair distinguishes between the possibility of words combining freely ('open choice') and the combinatorial restrictions that come with collocational behaviour. These two formal patterns of behaviour are correlated with two types of meaning: meaning as reference to the world, and meaning arising from contextual combinations. Distributional corpus analysis provides sophisticated ways of studying the latter on an unprecedented scale-but would that take away the necessity of studying the former separately, with different kinds of methods? The issue is an open one, but it hinges on the methodological question whether all the relevant information that language users have about the reference of words, may be retrieved from a corpus. Think, for instance, of the kind of visual and functional information that goes into Gipper's and Pottier's analysis of furniture terms: could we get the same insights into the structure of the field if we only considered textual data? Or would it still be necessary to combine corpus methods with methods exploring other modes of cognition, like referential description or maybe even psychological experimentation? To repeat, the question is an open one, but it needs to be asked in the context of a contextualizing approach to the lexicon: is the corpus sufficient as a context? 


\section{Further sources for Chapter 4}

The best place to get started on the abundant literature in the Natural Semantic Metalanguage framework is Goddard's highly readable introduction (1998). Goddard (2006b) and Peeters (2006) are recent collections testifying to the liveliness of the approach. The remarks by Bohnemeyer and Kay mentioned in connection with Natural Semantic Metalanguage come from a special issue of the journal Theoretical Linguistics devoted to the Wierzbickian framework. Next to a position paper by Durst (2003), it contains critical reflections by, among others, Koptjevskaja-Tamm and Ahlgren (2003) and Matthewson (2003). The idealist methodology of the framework is criticized in Geeraerts (1999). Further criticism relates to the reductive attitude of Wierzbicka with regard to intralinguistic variation; see Kristiansen and Geeraerts (2007).

Next to Jackendoff's books mentioned in the main text $(1983,1990)$, Jackendoff $(2002,2007 \mathrm{~b})$ describes the broader context of his work. Particularly interesting are publications that contain a comparison between Jackendoff's views and other theories covered in our overview. Wierzbicka (2007) and Jackendoff (2007a) discuss the relationship between their respective approaches. Jackendoff (1996) and Taylor (1996), as cited earlier, come from a thematic issue of the journal Cognitive Linguistics devoted to a confrontation between Jackendoff's cognitive approach and cognitive semantics. In that issue, Deane (1996) offers a systematic summary and criticism of Jackendoff's approach that may well serve as a first introduction. In addition, see Jackendoff and Aaron (1991) for a discussion of Lakoff's Conceptual Metaphor Theory (see section 5.2.1).

The two-level approach has been applied specifically to spatial expressions, like prepositions, dimensional adjectives, verbs of movement; see Habel (1989), Maienborn (1991), Herweg (1991), Kaufmann (1993), and Wunderlich 1991, 1993) for more examples. Beside the work of Taylor cited in the text, see Meyer (1994) for a critical evaluation of the approach. The nonexclusive nature of contextually deriving the meaning of a word and storing it in the lexicon is similar to what is known in Cognitive Linguistics as the rule/list fallacy (Langacker 1991). The pragmatic approach to language change is further discussed in section 5.4.1.

Important collections including work in the Generative Lexicon line are Pustejovsky and Boguraev (1996) and Bouillon and Busa (2001). A further indication (see Ruimy, Gola, and Monachini 2001) of the Generative Lexicon's appeal in computational linguistics is the SIMPLE lexicon (Semantic Information for Multifunctional Plurilingual Lexica). The project, funded by the European Union, took place around the turn of the millennium and aimed at building semantic lexica for the twelve languages that had earlier been 
included in the European PAROLE project. For a central subset of the PAROLE lexica, the goal of SIMPLE was to provide semantic codings according to the theoretical framework of the Generative Lexicon. The project was discontinued, though. In the main text of the chapter, reference was made to the current attempts to apply distributional corpus techniques to the Generative Lexicon framework. A similar type of bridging research is the work of Buitelaar (1998), who combines WordNet and the Generative Lexicon framework.

The tendency to make a distinction between a parsimonious semantics (characterized by minimal polysemy and maximal definitional discreteness) and a rich, flexible pragmatics is not restricted to the theories mentioned in section 4.1. It may also be found in publications not situated in any particular theoretical framework, such as Ruhl (1989).

Early descriptions of WordNet may be found in Miller and Fellbaum (1991), and in a thematic issue of the International Journal of Lexicography, edited by Miller in 1990. For EuroWordNet, see Vossen $(2004,1998)$. Current developments in the Global WordNet project concern the construction of a Global Grid, meant as a set of concepts encoded as Wordnet synsets in as many languages as possible and mapped to definitions in the so-called Suggested Upper Merged Ontology (Niles and Pease 2003, Fellbaum and Vossen 2007).

The basics of the Meaning-Text Theory were developed in the 1960s in the context of the Moscow School of Semantics, which also includes Apresjan, and whose basic ideas about the role and status of a descriptive metalanguage in semantics are similar to those of Wierzbicka; compare Apresjan, Mel'čuk, and Zholkovsky (1969) for an early formulation of the approach, and see Apresjan (2000: 215-30) for a comparison between the 'Russian' school and Wierzbicka's 'Polish' school. For collective volumes devoted to the MeaningText Theory, see Steele (1990) and Wanner (1996, 2007). The Meaning-Text Theory makes use of a dependency syntax: see Mel'čuk (1988a). An application to language teaching is given in Mel'čuk (2007).

The evolution of neo-Firthian research is sketched in Stubbs (1993). Partington (1998) is an entry-level introduction to collocational corpus analysis, while Stubbs (2002) offers a more detailed view. Further examples include Moon (1998) on idioms, Louw (1993) on semantic prosody, and Hoey (1991, 2005) on 'lexical priming'. (Priming as meant by Hoey involves a theory of lexical acquisition: as a word is learnt through multiple encounters with it in speech and writing, it is invested with the cumulative effects of those encounters, so that it is part of our knowledge of the word that it co-occurs with other words.) The members of the original Cobuild team continued the lexicographical lines set out by Sinclair in other dictionary projects; compare Atkins and Rundell (2008) and Hanks (2008). (The latter paper is part of 
a thematic issue of the International Journal of Lexicography devoted to the legacy of John Sinclair.)

An important practical result of the collocational, corpus-based approach to lexical description is the development of easy-to-use corpus tools allowing for statistical collocational analysis, like Mike Scott's WordSmith Tools (Scott 1999) and Adam Kilgarriff's Sketch Engine (Kilgarriff, Rychlý, Smrž, and Tugwell 2004).

Important collections in the field of computational lexical semantics and computational lexicography are Atkins and Zampolli (1994), Saint-Dizier and Viegas (1995), Wilks, Slator and Guthrie, (1996), and Viegas (1999), plus the various proceedings volumes of the CompLex conferences, like Kiefer, Kiss, and Pajzs (2005). For the statistical trend in Natural Language Processing in the broadest sense, see standard textbooks on Natural Language Processing like Jurafsky and Martin (2008) or, more specifically, Charniak (1996) and Manning and Schütze (1999). For current developments, see the state-of-theart overview of word sense disambiguation in Agirre and Edmonds (2006), and specific chapters in Kytö and Lüdeling (2008). 


\section{5}

\section{Cognitive Semantics}

The tension between a maximalist and a minimalist understanding of lexical semantics, which we formulated in the context of generativist semantics, takes many forms. It may relate to the old question of the borderline between word knowledge and world knowledge. It may involve the dividing line between semantics and pragmatics. It may surface as a methodological choice between a structure-oriented or a usage-oriented mode of investigation. Or it may turn on the degree of cognitive realism that a theory of word meaning should try to achieve. In the previous chapter, specifically in the first section, we came across a number of theories that tried in various ways to maintain the distinction, but that met with demarcational difficulties: the restrictive and reductive attitude implicit in the various shapes of a minimalist stance is not so easy to achieve. In the present chapter, we focus on an approach that explicitly embraces a maximalist position: one in which the distinction between semantics and pragmatics is irrelevant, in which language is seen in the context of cognition at large, in which language use is the methodological basis of linguisticsat least in principle. Cognitive semantics emerged in the 1980 os as part of Cognitive Linguistics, a loosely structured theoretical movement that opposed the autonomy of grammar and the secondary position of semantics in the generativist theory of language.

In the following sections, four specific contributions of cognitive semantics to the study of word meaning will be presented: the prototype model of category structure, the conceptual theory of metaphor and metonymy, Idealized Cognitive Models and frame theory, and the contributions of cognitive semantics to the study of meaning change. These four topics illustrate three leading ideas of a cognitive linguistic conception of language: a belief in the contextual, pragmatic flexibility of meaning, the conviction that meaning is a cognitive phenomenon that exceeds the boundaries of the word, and the principle that meaning involves perspectivization. The first idea inspires an investigation of how language use leads to change (section 5.4), and how the dynamism of meaning manifests itself in the structure of categories (5.1). The second idea points to a description of meaning structures (5.3) and semantic mechanisms (5.2) that go beyond the lexical level. The third idea 
motivates an exploration of the way in which word meaning involves seeing one thing in terms of another: new concepts are related to existing ones, through metaphor and metonymy (5.2), or through the extension of a prototype (5.1).

Section 5.5 rounds off the chapter with a critical view: does cognitive semantics live up to its ambition of providing a maximalist, maximally contextualized description of meaning? It will be shown that this is not yet entirely the case, and that there is still some extra ground to conquer for the cognitive enterprise. The chapter is longer than the previous ones. This reflects the fact that in sheer numbers of people involved and publications produced, cognitive semantics is arguably the most popular framework for the study of lexical meaning in contemporary linguistics. (As elsewhere in the book, it should be kept in mind that we focus on theoretical and descriptive linguistics. The statement does not apply to applied linguistics.)

\subsection{Prototypicality and salience}

The prototype-based conception of categorization originated in the mid-1970s with Eleanor Rosch's psycholinguistic research into the internal structure of categories. (Overviews may be found in Rosch 1978, 1988, and Mervis and Rosch 1981; the basic research is reported on mainly in Rosch 1973a, 1973b, 1975a, 1975b, 1977, Rosch and Mervis 1975, and Rosch, Mervis, Gray, Johnson, and Boyes-Braem 1976.) From its psycholinguistic origins, prototype theory moved in two directions. On the one hand, Rosch's findings and proposals were taken up by formal psycholexicology (and, more generally, informationprocessing psychology), which tries to devise formal models for human conceptual memory and its operation: see section 5.5.1 for the current state of the field. On the other hand, prototype theory has had a steadily growing success in linguistics since the mid-1980s. It is the latter development that we shall be concerned with here.

In the light of our historical overview, the prototype-based approach to semantic structure focuses on the kind of phenomena that were noticed by scholars like Erdmann (see 1.2.3) or Gipper (see 2.2.4) but that had hardly received systematic theoretical attention: linguistic categories may be fuzzy at the edges but clear in the centre. What does this imply for the way we think about category structure? Section 5.1.1 presents Rosch's seminal research. It also describes how the model was taken up in linguistics, and specifically, how various types of prototype effects were identified. Section 5.1.2 discusses the extension of the model to polysemous expressions. Section 5.1.3 describes the basic-level hypothesis, which is related to prototypicality: while 
the prototype model introduces the concept of salience in semasiological analyses, the basic-level model introduces it in the taxonomies.

\subsubsection{Prototypicality effects}

We will first present the original experimental results of Rosch and her colleagues, and then consider the general model of prototypicality effects that was developed in linguistic lexical semantics on the basis of the results obtained by Rosch.

1 Rosch's results initially relate to perceptual categories. Brent Berlin and Paul Kay's anthropological study of colour terms (1969) suggested that there were certain universal principles at work in this field. Berlin and Kay studied the primary colour terms in a wide variety of languages, primary terms being selected on the basis of the fact that they consisted of only one morpheme, that they were generally known by the speakers of the language, that they did not belong to the referential domain of another colour term, and that they were not confined to a particular kind of object (such as blonde, which is only used of hair and beer). Berlin and Kay reached the following conclusions. First, all languages select their primary colour terms from a set of eleven: black, white, red, yellow, green, blue, brown, purple, pink, orange, and grey. Second, there is a hierarchy among these terms, with five levels, as follows:

$$
\begin{aligned}
& \text { black } \\
& \text { white }>\text { red }>\begin{array}{l}
\text { yellow } \\
\text { green } \\
\text { blue }
\end{array}>\text { brown }>\begin{array}{l}
\text { purple } \\
\text { pink } \\
\text { orange } \\
\text { grey }
\end{array}
\end{aligned}
$$

The hierarchy implies that in a language with two colour terms (the minimum, obviously), these terms will be black and white. A language with three terms invariably has red as the additional one. The fourth, fifth, and sixth terms are chosen from among the colours on the third level, and so on. Third, an experiment with colour chips showed that the hues indicated by the informants as the best exemplars of a particular colour were almost the same for all informants, independent of their language (with the exception of white, which could have its focus in white, red, or yellow, and black, which could have it in black or brown). But while the identification of the focal colours was almost unanimous, the borderlines of the colours were specified with much less consistency. Berlin and Kay concluded that colour terms, which had traditionally been considered rather arbitrary, exhibited a marked crosslinguistic systematicity.

Rosch (who published under the name Heider before 1973) inferred from these results that particular areas of the colour spectrum are more salient 
than others, and conjectured that these focal colours would be more easily encoded linguistically and more easily remembered than less salient colours. The first part of the hypothesis was tested (Heider 1972) by presenting to a number of test subjects a set of chips with focal as well as non-focal colours, and by asking them what they would call those particular colours in their language. Focal colours appeared to receive shorter names and to be named faster than the colours from the intermediate areas. The second part of the hypothesis was confirmed as well (Heider 1972, Heider and Olivier 1972). Two groups of informants, one American, the other one Dani (a primitive tribe in New Guinea with a two-term colour vocabulary), were shown cards with different focal as well as non-focal colours, each for five seconds. After 30 seconds, they were asked to indicate the colours they had been shown in a set of samples. Both groups appeared to recognize focal colours faster than other colours. Americans appeared to be more accurate on average than the Dani, a finding that Rosch connected with the existence of a larger set of colour terms in English. This experimental corroboration of the psychological salience of focal colours received further support from an experiment in which colour terms were taught to the Dani; this appeared to be easier for focal terms. The psychological salience of particular perceptual features can be extended to other domains (see Rosch 1977: 15-18). Psychological research reveals, for instance, that facial expressions are interpreted against the background of six primary emotions that function as salient reference points: happiness, sadness, fear, disgust, surprise, anger. And, as was already maintained by the gestalt psychologists, some geometrical forms are more salient as well-a hypothesis that Rosch also confirmed with an experiment with the Dani.

Rosch concluded that the tendency to define categories in a rigid way clashes with the actual psychological situation. Perceptually based categories do not have sharply delimited borders. Instead of clear demarcations between equally important conceptual areas, one finds marginal areas between categories that are only unambiguously defined in their focal points. Rosch developed this observation into a more general prototypical view of natural language categories-more particularly, categories naming natural objects. The theory implies that the range of application of such categories is concentrated round focal points represented by prototypical members of the category. The attributes of these focal members are structurally the most salient properties of the concept in question, and conversely, a particular member of the category occupies a focal position because it exhibits the most salient features.

The experimental evidence for this prototypical model is best illustrated by tests in which informants were asked to classify a set of objects that were 
all contained in the same superordinate category, according to the extent to which they considered these objects to be good examples of the category (Rosch 1975b). The various test subjects showed a considerable similarity in the order of their classifications. The most typical instance of the category 'bird', for instance, was considered to be the robin. Next came, in that order, the sparrow, the bluejay, the bluebird, the canary, the blackbird, and the dove. At the lower end of the prototypicality scale, chickens, turkeys, ostriches, penguins, and peacocks are to be found. Intermediate are ravens, goldfinches, pheasants, and crows. For the category 'furniture', chairs rated high, drawers intermediate, and telephones low. Other categories investigated were the following (for each we give an example of a typical member, one with intermediate ranking, and one rating low): toys (doll, puzzle, bow and arrow), sports (football, skating, checkers), clothing (pants, shoes, bracelet), vegetables (carrot, potato, rice), fruit (apple, watermelon, coconut), carpenter's tools (hammer, awl, axe), vehicles (automobile, tractor, elevator), weapons (gun, bow, rope).

Further evidence for degrees of category membership was obtained from experiments showing that the prototypical organization of knowledge influences on-line processing. For instance, when subjects are asked to evaluate the truth of a sentence of the type 'A (member of a category) is a (name of the category)'-like a robin is a bird-then it takes more time for nonprototypical members to be recognized than typical ones. When informants are asked to enumerate the members of a category, typical members are more often named than marginal ones. Also, substituting a member of the category for the name of that category in a sentence yields more acceptable sentences if the member is typical. In a sentence that expresses a typical feature of birds ( $a$ bird can fly), it will be easier to replace bird by robin or eagle than by less typical instances of the category. Finally, in the course of language acquisition, typical instances of a category are learnt earlier than non-typical cases.

All these indications for gradedness in the semantics of natural language categories led to the formulation of a general view of categorial structure, summarized as follows:

when describing categories analytically, most traditions of thought have treated category membership as a digital, all-or-none phenomenon. That is, much work in philosophy, psychology, linguistics, and anthropology assumes that categories are logical bounded entities, membership in which is defined by an item's possession of a simple set of criterial features, in which all instances possessing the criterial attributes have a full and equal degree of membership. In contrast, it has recently been argued [...] that some natural categories are analog and must be represented logically in a manner which reflects their analog structure.

(Rosch and Mervis 1975: 573-4) 
2 Rosch's prototype results were introduced in linguistics in the early 1980 . In the course of the linguistic elaboration of the model, it became clear that it was important to clearly distinguish between the various phenomena that may be associated with prototypicality. An analysis of the relationship between these features reveals that prototypicality is itself, in the words of Posner (1986), a prototypical concept. As a first step, we shall have a look at four characteristics that are frequently mentioned as typical of prototypicality. First, prototypical categories exhibit degrees of typicality: not every member is equally representative for a category. Second, prototypical categories exhibit a family resemblance structure, or more generally, their semantic structure takes the form of a radial set of clustered and overlapping readings. Third, prototypical categories are blurred at the edges. Fourth, prototypical categories cannot be defined by means of a single set of criterial (necessary and sufficient) attributes. For each of these features, let us add a quotation from early prototype studies to illustrate the point.

By prototypes of categories we have generally meant the clearest cases of category membership defined operationally by people's judgments of goodness of membership in the category $[\ldots]$ we can judge how clear a case something is and deal with categories on the basis of clear cases in the total absence of information about boundaries.

(Rosch 1978: 36)

The purpose of the present research was to explore one of the major structural principles which, we believe, may govern the formation of the prototype structure of semantic categories. This principle was first suggested in philosophy; Wittgenstein (1953) argued that the referents of a word need not have common elements to be understood and used in the normal functioning of language. He suggested that, rather, a family resemblance might be what linked the various referents of a word. A family resemblance relationship takes the form $\mathrm{AB}, \mathrm{BC}, \mathrm{CD}, \mathrm{DE}$. That is, each item has at least one, and probably several, elements in common with one or more items, but no, or few, elements are common to all items.

(Rosch and Mervis 1975: 574-5)

New trends in categorization research have brought into investigation and debate some of the major issues in conception and learning whose solution had been unquestioned in earlier approaches. Empirical findings have established that $[\ldots]$ category boundaries are not necessarily definite.

(Mervis and Rosch 1981: 109)

We have argued that many words $[\ldots]$ have as their meanings not a list of necessary and sufficient conditions that a thing or event must satisfy to count as a member of the category denoted by the word, but rather a psychological object or process which we have called a prototype.

(Coleman and Kay 1981: 43)

The four features are not necessarily co-extensive; they do not always co-occur. There is now a consensus in the linguistic literature on prototypicality that the characteristics enumerated above are prototypicality effects that 
may be exhibited in various combinations by individual lexical items, and may have very different sources. Also, the four features are systematically related along two dimensions. On the one hand, the first and the third characteristics take into account the referential, extensional structure of a category. In particular, they look at the members of a category; they observe, respectively, that not all members of a category are equal in representativeness for that category, and that the referential boundaries of a category are not always determinate. On the other hand, these two aspects (non-equality and non-discreteness) recur on the intensional level, where the definitional rather than the referential structure of a category is envisaged. For one thing, non-discreteness shows up in the fact that there is no single definition in terms of necessary and sufficient attributes for a prototypical concept. For another, the clustering of meanings that is typical of family resemblances and radial sets implies that not every reading is structurally equally important (and a similar observation can be made with regard to the components into which those meanings may be analysed). If, for instance, one has a family resemblance relationship of the form $\mathrm{AB}, \mathrm{BC}, \mathrm{CD}, \mathrm{DE}$, then the cases $\mathrm{BC}$ and $\mathrm{CD}$ have greater structural weight than $\mathrm{AB}$ and $\mathrm{DE}$.

The concept of prototypicality, in short, is itself a prototypically clustered one in which the concepts of non-discreteness and non-equality (either on the intensional or on the extensional level) play a major distinctive role. Nondiscreteness involves the existence of demarcation problems and the flexible applicability of categories. Non-equality involves the fact that categories have internal structure: not all members or readings that fall within the boundaries of the category need have equal status, but some may be more central than others; categories often consist of a dominant core area surrounded by a less salient periphery.

The distinction between non-discreteness (the existence of demarcation problems) and non-equality (the existence of an internal structure involving a categorial core versus a periphery) cross-classifies with the distinction between an intensional perspective (which looks at the senses of a lexical item and their definition), and an extensional perspective (which looks at the referential range of application of a lexical item, or that of an individual sense of that item). The cross-classification between both relevant distinctions (the distinction between non-discreteness and non-equality, and the distinction between an intensional and an extensional perspective) yields a two-dimensional conceptual map of prototypicality effects, in which the four characteristics mentioned before are charted in their mutual relationships. Figure 5.1 schematically represents these relationships.

Characteristic (a) illustrates the extensional non-equality of semantic structures: some members of a category are more typical or more salient 
extensional characterization

(on the level of exemplars)

(a) differences of typicality and membership salience

(c) fuzziness at the edges, membership uncertainty intensional characterization (on the level of definition)

(b) clustering into family resemblances

(d) absence of necessaryand-sufficient definitions

FIGURE 5.1. Four types of prototypicality effects

representatives of the category than others. Characteristic (b) instantiates intensional non-equality: the readings of a lexical item may form a set with one or more core cases surrounded by peripheral readings emanating from the central, most salient readings. Characteristic (c) manifests the notion of extensional non-discreteness: there may be fluctuations at the boundary of a category. And characteristic (d) represents intensional non-discreteness: the definitional demarcation of lexical categories may be problematic, measured against the background of the classical requirement that definitions take the form of a set of necessary attributes that are jointly sufficient to delimit the category in contrast with others.

To illustrate the characteristics, let us look at the category 'fruit', which we have already come across in section 4.1.1. We saw there that at least one of the four prototypicality effects applies to 'fruit': it is not obvious to find a classical definition, in terms of general and distinctive features, for the category. But what about the other features of prototypicality? The category 'fruit' is among the categories originally studied by Rosch. The experimental results exemplify the third characteristic mentioned above: for American subjects, oranges, apples, and bananas are the most typical fruits, while pineapples, watermelons, and pomegranates receive low typicality ratings. But now consider coconuts and olives. Is a coconut or an olive a fruit? Notice, first, that we are not concerned with the technical, biological reading of fruit, but with folk models of fruit as a certain category of edible things. Technically, any seed-containing part of a plant is the fruit of that plant; as such, nuts in general are fruit. In ordinary language, on the other hand, nuts and fruit are basically distinct categories (regardless of the possible boundary status of the coconut): nuts are dry and hard, while fruits are soft, sweet, and juicy; also, the situations in which nuts and fruits are eaten are typically different. Second, category membership is not the same thing as typicality: a penguin 
is undoubtedly an uncharacteristic kind of bird, but it is a bird nonetheless; as to the olive, the question is not just whether it is a typical fruit, but rather whether it is a fruit at all.

This indeterminacy about membership establishes the fourth characteristic, but it also has an immediate bearing on the attempt to define fruit in intensional terms. In fact, a definitional analysis is initially hampered by the uncertainty surrounding the boundaries of the category. If there is a consensus that olives are not fruit, we should not include the olive in an analysis of fruit. Conversely, if an olive is considered to be a fruit (however peripheral and uncharacteristic), it will have to be included. To circumvent the problem with olives and their likes, we may restrict the definitional analysis to clear cases of fruit, that is, cases for which doubts about membership do not play a role. Even for these clear cases, it can be shown that classical definability does not apply, as we suggested in section 4.2.1.

Assuming, then, that we cannot define the uncontroversial core members of fruit in a classical, necessary-and-sufficient fashion, we can also appreciate the importance of characteristic (b). If fruit receives a classical definition in terms of necessary and sufficient attributes, all the definitional attributes have the same range of application (viz. the category fruit as a whole). However, because such a classical definition cannot be given, the attributes that enter into the semantic description of fruit demarcate various subsets from within the entire range of application of fruit. As a whole, the description of fruit then takes the form of a cluster of partially (but multiply) overlapping sets. For a restricted number of examples of fruit, the definitional situation is illustrated in Figure 5.2. The starting point is the suggestion that fruit refers to the sweet and juicy edible seed-bearing part of a wood-plant (in contrast with a herbaceous plant), and is commonly used as a dessert rather than a main dish. The top part of the figure gives a componential analysis which shows that the common features are not sufficiently distinctive: the only common feature is 'edible seed-bearing part of a plant', but that feature alone includes vegetables like pea-pods. The bottom part shows how such a situation corresponds with a cluster of overlapping sets.

3 In the fruit example, all the relevant features of prototypicality are present, but that is definitely not the case for all categories. Take bird. It is one of the natural kind terms for which Rosch originally established typicality effects (robins are more typical birds than ostriches), and if you try to do a definitional analysis, you get the same pattern as with fruit: the features that remain after you remove those that are not shared by all birds, are not sufficient to distinguish birds from other species. But at the same time, the boundaries of bird are clear-cut. At least with regard to our own, real world, the denotation 


\begin{tabular}{|c|c|c|c|c|c|}
\hline & $\begin{array}{c}\text { edible seed- } \\
\text { bearing part }\end{array}$ & $\begin{array}{c}\text { of wood- } \\
\text { plant }\end{array}$ & juicy & sweet & $\begin{array}{c}\text { used as } \\
\text { dessert }\end{array}$ \\
\hline apple & + & + & + & + & + \\
\hline strawberry & + & - & + & + & + \\
\hline banana & + & + & - & + & + \\
\hline lemon & + & + & + & - & - \\
\hline
\end{tabular}

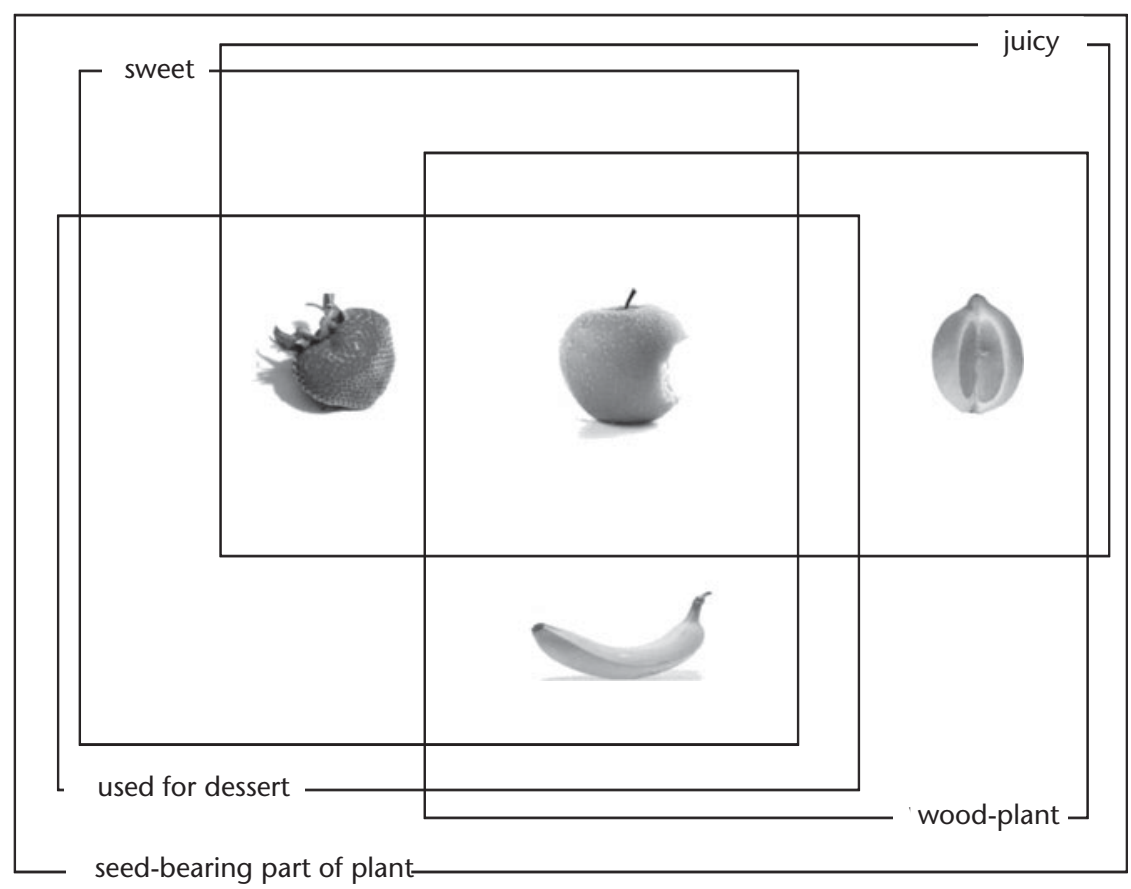

Figure 5.2. Prototypicality effects in the category 'fruit'

of bird is determinate; educated speakers of English know very well where birds end and non-birds begin. They know, for instance, that a bat is not a bird but that a penguin is. The existence of prototypicality effects in clearly bounded concepts such as bird implies that a strict distinction has to be made between degree of membership and degree of representativity. Membership in the category bird is discrete; something is or is not a bird. But some birds may be birdier than others: the swallow remains a more typical bird than the ostrich. 
In addition, take the category odd number. Armstrong, Gleitman, and Gleitman (1983) showed experimentally that even a mathematical concept such as odd number exhibits psychological representativity effects. This might seem remarkable, since odd number is a classical concept in all other respects: it receives a clear definition, does not exhibit a family resemblance structure or a radial set of clustered meanings, does not have blurred edges. However, degrees of representativity among odd numbers are not surprising if the experiential nature of concepts is taken into account. For instance, because the even or uneven character of a large number can be determined easily by looking at the final digit, it is no wonder that uneven numbers below 10 carry more psychological weight: they are procedurally of primary importance.

On the basis of these examples, it is now easy to see to what extent 'prototypicality' is itself a prototypical notion. If the four features mentioned in Figure 5.2 are typical of prototypicality, then fruit, with four features, is a more typical case of prototypicality than bird, which has only three; and odd number could be considered a borderline case.

\subsubsection{Radial networks and polysemy}

The importance of family resemblance structures-the second characteristic mentioned above-may be illustrated in yet another way, by looking at clusters of different senses rather than the structure of a single meaning. In this section, we first present the extension of prototype theory to the description of polysemy. This leads to a discussion of the criteria that may be used to distinguish polysemy from vagueness.

1 So far, we have been concerned only with the most common, everyday meaning of fruit (roughly, 'soft and sweet edible part of a tree or a bush'). There are other meanings of fruit, however. (The following discussion follows the main lines of the description in the New Shorter Oxford English Dictionary.) In its technical sense ('the seed-bearing part of a plant or tree'), the word also refers to things that lie outside the range of application of the basic reading, such as acorns and pea pods. In an expression like the fruits of nature, fruits of the ground, the meaning is even more general, as the word refers to everything that grows and that can be eaten by people, including for instance grains and vegetables. Further, there is a range of figurative readings, including the abstract sense 'the result or outcome of an action' (as in the fruits of his labour or his work bore fruit), or the somewhat archaic reading 'offspring, progeny' (as in the biblical expressions the fruit of the womb, the fruit of his loins). Moreover, the 'result or outcome' sense often appears in a specialized form, as 'gain or profit'. These meanings do not exist in isolation, but they are related in various ways to the central sense and to one another. The technical reading 
('seed-containing part') and the sense illustrated by the fruits of nature are both related to the central meaning by a process of generalization. The technical reading generalizes over the biological function of the things covered by the central meaning, whereas the meaning 'everything that grows and that can be eaten by people' focuses on the function that those things have for human beings. The figurative uses, on the other hand, are linked to the other meanings by a metaphoric link, but notice also that the meaning 'offspring' is still closer to the central sense, because it remains within the biological domain. The overall picture, in short, is similar to that found within the single sense 'soft and sweet edible part of a tree or a bush': we find a cluster of mutually interrelated readings, concentrating round a core reading (the basic sense that we analysed in the previous section). Family resemblance effects, then, do not only apply within a single sense of a word like fruit, but also characterize the relationship among the various senses of a word.

In Figure 5.3, the relevant relations are charted on the same model as Figure 5.2. The different senses are indicated with glosses only, not by means of fully-fledged dictionary definitions. The analytic groups are as follows:

a. being sweet, juicy, commonly used as dessert

b. being the seed-bearing part of a plant

c. being the edible result of a vegetable process

d. being the natural result of an organic process

e. being the positive outcome of a process or activity

f. being the outcome of a process or activity

As in Figure 5.2, we note that there is no single feature or set of features which is general for all the cases mentioned and which is at the same time distinctive. (The feature 'product, outcome of a process' does not sufficiently distinguish fruit from other categories. It equates fruit with result, but it is not difficult to find instances of use of result where fruit is not substitutable.) At the same time, we find evidence for core readings and structurally salient features, with the core reading combining a maximum of salient features. In linguistic lexical semantics, this structural similarity between the semantic architecture of single senses and that of polysemous words led to an extrapolation of the prototype model to the study of polysemy. This shift, which is general in cognitive semantics, invites two further comments.

First, a popular representational format for such prototype-based polysemous structure is the radial network model, first introduced by Claudia Brugman (1988, originally 1981) in her analysis of the English preposition over, and popularized through George Lakoff's influential Women, Fire, and Dangerous Things (1987). In a radial network, the senses are related to the prototype and to one another by means of individual links, which may then be labelled with 


\begin{tabular}{|r|c|c|c|c|c|c|}
\hline & a & b & c & d & e & f \\
\hline apple, oranges etc. & + & + & + & + & + & + \\
\hline 'fruits of the earth' & - & - & + & + & + & + \\
\hline seed-bearing part & - & + & + & + & - & + \\
\hline 'fruit of the womb' & - & - & - & + & + & + \\
\hline advantage, profit & - & - & - & - & + & + \\
\hline product, outcome & - & - & - & - & - & + \\
\hline
\end{tabular}

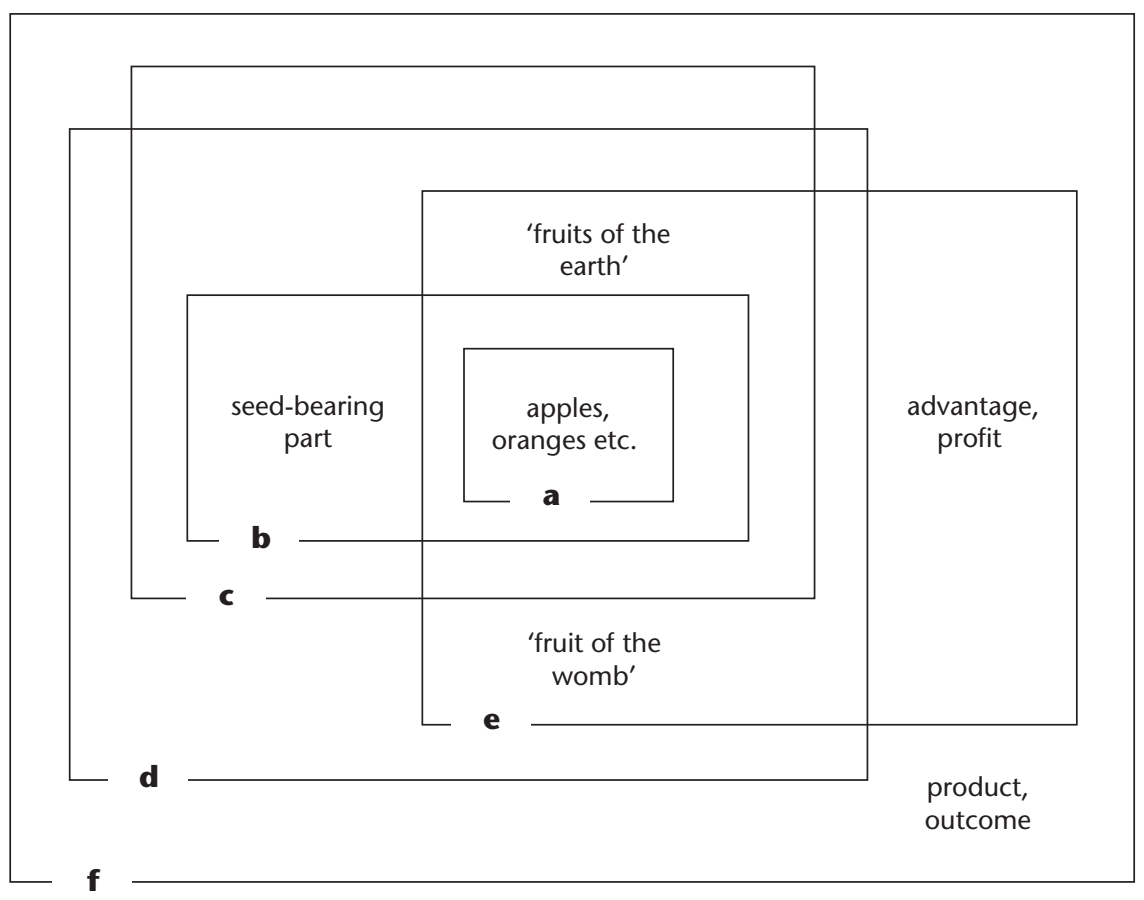

Figure 5.3. Prototypicality effects in the extended category 'fruit'

the kind of semantic relation that underlies them. The process is illustrated in Figure 5.4. One advantage of this kind of representation is the possibility of including metonymic links. All the examples of prototype-based categorial structure that we have seen so far involve relations of similarity-literal or figurative similarity-between the readings involved. If you stay within a single meaning, metonymies will not occur: all the instances of use will be related by some form of similarity, which can be expressed by shared features. But if you 


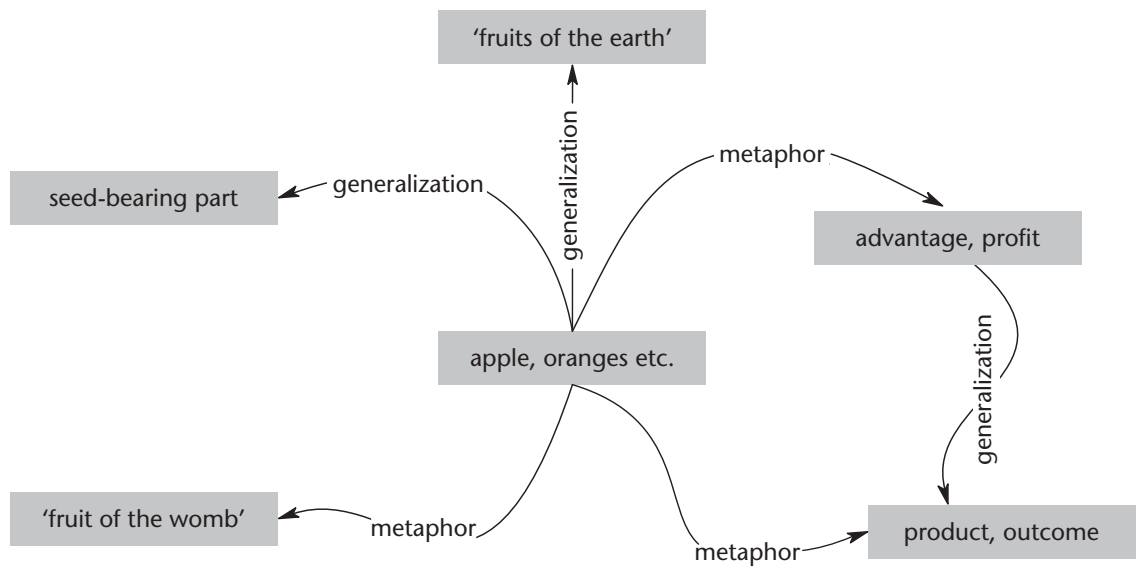

FIgURE 5.4. Radial network analysis of 'fruit'

shift to polysemous items, metonymies will enter the picture, and in order to represent their relation to the rest of the category, drawing a metonymic link in a radial set representation is an obvious and easy solution.

At the same time, radial network representations of the kind illustrated in Figure 5.4 have the disadvantage of representing the meanings as relatively isolated entities. The complex and subtle interrelations that are revealed when we look at the features involved are not made explicit, and the whole radial network picture evokes a rather atomistic view of the meanings in a polysemous cluster. The radial network representation suggests that the dynamism of a polysemous category primarily takes the form of individual extensions from one sense to another. This may hide from our view the possibility that the dimensions that shape the polysemous cluster may connect different senses at the same time. As this is made clearer by a representation like that in Figure 5.3, it is always advisable to combine both types of analysis. In the practice of representation, it is for instance possible to project the lower part of Figure 5.3 onto Figure 5.4.

The second point to be discussed is more theoretical and far-reaching. Is it acceptable to situate prototypicality both among senses and within senses? The question is forcefully asked by Georges Kleiber $(1988,1990)$ : are not the kind of phenomena studied at the level of different senses so theoretically different from the phenomena studied at the level of a single sense that it might be better to keep them apart? One answer to this question could be purely practical. Even if it is not prudent, in a theoretical sense, to equate the within-sense and the among-sense levels, the 'prototype-based' phenomena that we discover on the level of polysemous clusters are worthy of description, and if a prototype model (even if it is a debatable extension of the original one) 
helps to describe them, so much the better. But a more principled answer is necessary too. It touches upon the possibility of systematically distinguishing between the within-sense and the among-sense levels: how stable is the distinction between the semantic level (that of senses) and the referential level (that of category members)?

2 Research in cognitive semantics suggests that the borderline between both levels is not stable. The synchronic instability of the borderline between the level of senses and the level of referents is discussed in Taylor (1992), Geeraerts (1993), and Tuggy (1993). The common strategy of these articles is to show that different polysemy criteria (i.e. criteria that may be invoked to establish that a particular interpretation of a lexical item constitutes a separate sense rather than just being a case of vagueness or generality) may be mutually contradictory, or may each yield different results in different contexts. The importance that prototype theory attaches to the structural similarities between the referential and the semantic levels, then, contrasts with Kleiber's view (1990) that the extrapolation of prototype-theoretical studies from the referential to the semantic level somehow weakens the theory. By contrast, the impossibility of maintaining the distinction between both levels in a stable way makes the extrapolation more plausible. Because the concept is such a central one in lexical semantics, let us have a closer look at this line of argumentation: what are the criteria for distinguishing polysemy from underspecification, and how effective are they?

The distinction between polysemy and vagueness involves the question whether a particular semantic specification is part of the stable semantic structure of the item, or is the result of a transient contextual specification. For instance, neighbour is not polysemous between the readings 'male dweller next door' and 'female dweller next door', in the sense that the utterance my neighbour is a civil servant will not be recognized as requiring disambiguation in the way that she is a plain girl ('ugly' or 'unsophisticated'?) does. The semantic information that is associated with the item neighbour in the lexicon does not, in other words, contain a specification regarding sex; neighbour is vague (or general, or unspecified) as to the dimension of sex. This notion of 'conceptual underspecification' has to be kept distinct from three other forms of semantic indeterminacy. First, the semantic lack of specification illustrated above differs from the 'referential indeterminacy' that may characterize the individual members of a category, as illustrated by knee: it is impossible to indicate precisely where the knee ends and the rest of the leg begins. Second, referential indeterminacy may involve 'fuzzy boundaries' of conceptual categories, as illustrated by any colour term: it is impossible to draw a line within the spectrum between those hues that are a member of the category red 
and those that are not. Third, the semantic underspecification of individual meanings differs from the 'interpretative indeterminacy' that occurs when a given utterance cannot be contextually disambiguated. For instance, when the polysemy underlying she is a plain girl ('simple' or 'ugly') cannot be resolved on the basis of the available information, the interpretation is indeterminate, and the utterance is said to exhibit ambiguity.

Since at least some of these alternative forms of indeterminacy may themselves be referred to as 'vagueness', the discussion of vagueness (as contrasting with polysemy) is beset by terminological pitfalls. The difficulties created by the terminological overlap are enhanced by the existence of various kinds of tests for distinguishing between vagueness and polysemy. Without discussing all the specific tests that have been suggested, three types of criterion can be distinguished.

First, from the truth-theoretical point of view taken by Quine (1960: 129), a lexical item is polysemous if it can simultaneously be clearly true and clearly false of the same referent. Considering the readings 'harbour' and 'fortified sweet wine from Portugal' of port, the polysemy of that item is established by sentences such as Sandeman is a port (in a bottle), but not a port (with ships).

Second, linguistic tests involve acceptability judgements about sentences that contain two related occurrences of the item under consideration (one of which may be implicit); if the grammatical relationship between both occurrences requires their semantic identity, the resulting sentence may be an indication for the polysemy of the item. For instance, the identity test described by Zwicky and Sadock (1975) involves 'identity-of-sense anaphora'. Thus, at midnight the ship passed the port, and so did the bartender is awkward if the two lexical meanings of port are at stake; disregarding puns, it can only mean that the ship and the bartender alike passed the harbour, or conversely that both moved a particular kind of wine from one place to another. A 'crossed' reading, in which the first occurrence of port refers to the harbour and the second to wine, is normally excluded. By contrast, the fact that the notions 'vintage sweet wine from Portugal' and 'blended sweet wine from Portugal' can be crossed in Vintage Noval is a port, and so is blended Sandeman indicates that port is vague rather than polysemous with regard to the distinction between blended and vintage wines.

Third, the definitional criterion (as informally stated by Aristotle in the Posterior Analytics II.xiii) specifies that an item has more than one lexical meaning if there is no minimally specific definition covering the extension of the item as a whole, and that it has no more lexical meanings than there are maximally general definitions necessary to describe its extension. Definitions of lexical items should be maximally general in the sense that they should 
cover as large a subset of the extension of an item as possible. Thus, separate definitions for 'blended sweet fortified wine from Portugal' and 'vintage sweet fortified wine from Portugal' could not be considered definitions of lexical meanings, because they can be brought together under the definition 'sweet fortified wine from Portugal'. On the other hand, definitions should be minimally specific in the sense that they should be sufficient to distinguish the item from other non-synonymous items. A maximally general definition covering both port 'harbour' and port 'kind of wine' under the definition 'thing, entity' is excluded because it does not capture the specificity of port as distinct from other words.

The existence of various polysemy tests is non-trivial for two fundamental, interlocking reasons. An examination of the type conducted by Geeraerts (1993) reveals, first, that the three types of criteria may be in mutual conflict, in the sense that they need not lead to the same conclusion in the same circumstances. In the case of autohyponymous words, for instance, the definitional approach does not reveal an ambiguity, whereas the Quinean criterion does. Dog is autohyponymous between the readings 'Canis familiaris', contrasting with cat or wolf, and 'male Canis familiaris', contrasting with bitch. A definition of $d o g$ as 'male Canis familiaris', however, does not conform to the definitional criterion of maximal coverage, because it defines a proper subset of the 'Canis familiaris' reading. On the other hand, the sentence Lady is a dog, but not a dog, which exemplifies the logical criterion, cannot be ruled out as ungrammatical.

Second, each of the criteria taken separately need not lead to a stable distinction between polysemy and vagueness, in the sense that what is a distinct meaning according to one of the tests in one context may be reduced to a case of vagueness according to the same test in another context. Without trying to be exhaustive, let us cite a few examples involving the linguistic criterion. Contextual influences on the linguistic test have been (implicitly or explicitly) noted by several authors. In fact, the recognition occurs relatively early in the literature on the subject. When Lakoff (1970) introduced the and so construction as a criterion for polysemy, he argued that hit is ambiguous between an intentional and an unintentional reading, because John hit the wall and so did Fred would constitute an anomalous utterance in situations in which John hit the wall intentionally but Fred only did so by accident, or the other way round. Catlin and Catlin (1972), however, noted that the sentence could easily be uttered in a context involving imitation. A situation in which John hits his head against the wall after stumbling over his vacuum cleaner, and is then comically imitated by Fred, might very well be described by the sentence in question. Nunberg (1979) further drew the attention to sentences such as The newspaper has decided to change its size, which features intuitively 
distinct senses of newspaper ('management, board of directors' and 'material publication').

Similar cases can be found involving coordination rather than anaphora. For instance, Norrick (1981: 115) contrasted the decidedly odd sentence Judy's dissertation is thought provoking and yellowed with age with the perfectly natural construction Judy's dissertation is still thought provoking though yellowed with age. If the coordination generally requires that dissertation be used in the same sense with regard to both elements of the coordinated predicate, the sentences show that the distinction between the dissertation as a material product and its contents may or may not play a role. Cruse (1982) noted that none of the following series of sentences containing coordination produces feelings of oddity: John likes blondes and racehorses, John likes racehorses and fast cars, John likes cars and elegant clothes, John likes elegant clothes and expensive aftershave, John likes expensive aftershave and vintage port, John likes vintage port and marshmallows. Coordinating the first item in the series with the last, however, does produce an awkward sentence. So, while the awkwardness of John likes blondes and marshmallows would normally be taken as evidence for the polysemy of like, the pairings mentioned above suggest that there is a continuum of meaning rather than a dichotomy. Cruse concludes that readings which are close together can be co-ordinated without oddity, but if they are sufficiently far apart, they are incompatible. If this picture is correct, it does not make sense to ask how many senses of like there are: 'There is just a seamless fabric of meaning-potential' (1982: 79).

It now appears that the contextual flexibility of meaning, which is a natural component of a cognitive semantic conception of lexical semantics, may take radical forms: it does not just involve a context-driven choice between existing meanings, or the on-the-spot creation of new ones, but it blurs and dynamizes the very distinction between polysemy and vagueness. Once again, we may refer to Erdmann: his discussion of the Bismarck quote (see 1.2.3) shows precisely how semantic distinctions that are relevant and distinctive in one context may be neutralized or ignored in another.

\subsubsection{Basic levels and onomasiological salience}

Possibly the major innovation of the prototype model of categorization is to give salience a place in the description of semasiological structure: next to the qualitative relations among the elements in a semasiological structure (like metaphor and metonymy), a quantifiable centre-periphery relationship is introduced as part of the architecture. We have seen how that idea was first introduced for the description of monosemous categories, and was then extrapolated to polysemous lexical items. But there is another extension to 


\begin{tabular}{|c|c|c|c|}
\hline & \multicolumn{2}{|c|}{ ethnobiological examples } & clothing terms \\
\hline kingdom & plant & animal & garment \\
\hline life form & tree & fish & outer garment \\
\hline intermediate & evergreen & freshwater fish & - \\
\hline generic & pine & bass & trousers \\
\hline specific & whitepine & black bass & ski pants \\
\hline varietal & western whitepine & large-mouthed bass & stretch ski pants \\
\hline
\end{tabular}

Figure 5.5. Taxonomical basic levels according to Berlin and Kay

consider: can the concept of salience be transferred from the semasiological to the onomasiological domain?

Differences of onomasiological salience have so far been described primarily in terms of the 'basic-level hypothesis'. The hypothesis is based on the ethnolinguistic observation that folk classifications of biological domains usually conform to a general organizational principle, in the sense that they consist of five or six taxonomical levels (Berlin, Breedlove, and Raven 1973, 1974, Berlin 1976, 1978). Figure 5.5 illustrates the idea with two sets of examples. The highest rank in the taxonomy is that of the 'unique beginner', which names a major domain like plant and animal. The domain of the unique beginner is subdivided by just a few general 'life forms', which are in turn specified by 'folk genera' like pine, oak, beech, ash, elm, chestnut. (The 'intermediate' level is an optional one.) A folk genus may be further specified by 'folk specifics' and 'varietal taxa'. To the extent that the generic level is the core of any folk biological category, it is the basic level: 'Generic taxa are highly salient and are the first terms encountered in ethnobiological enquiry, presumably because they refer to the most commonly used, everyday categories of folk biological knowledge' (Berlin 1978: 17). The generic level, in other words, is onomasiologically salient: within the lexical field defined by the taxonomy, the generic level specifies a set of salient items. In this sense, the basic level embodies a set of naming preferences: given a particular referent, the most likely name for that referent from among the alternatives provided by the taxonomy will be the name situated at the basic level.

Apart from embodying a concept of onomasiological salience, basic-level categories are claimed to exhibit a number of other characteristics. From a psychological point of view, they are conceptualized as perceptual and functional gestalts. From a developmental point of view, they are early in acquisition, i.e. 
they are the first terms of the taxonomy learnt by the child. From a linguistic point of view, they are named by short, morphologically simple items. And from a conceptual point of view, Rosch et al. (1976) claim that the basic level constitutes the level where prototype effects are most outspoken, in the sense that they maximize the number of attributes shared by members of the category, and minimize the number of attributes shared with members of other categories.

The basic-level model was developed for the description of the folk classification of natural kinds. It is an open question to what extent it may be generalized to all kinds of taxonomies, like the taxonomical classification of artefacts. If we apply the basic-level model to the lexical field of clothing terminology, items like trousers, skirt, sweater, dress are to be considered basic level categories: their overall frequency in actual language use is high, they are learnt early in acquisition, and they typically have the monomorphemic form of basic level categories. A further extrapolation yields the right-hand side of Figure 5.5, in which garment is considered a unique beginner in contrast with, say, utensil or toy.

Note, however, that differences of onomasiological preference also occur among categories on the same level in a taxonomical hierarchy. The basic-level model contains a hypothesis about alternative categorizations of referents: if a particular referent (a particular piece of clothing) can be alternatively categorized as a garment, a skirt, or a wraparound skirt, the choice will be preferentially made for the basic-level category 'skirt'. But analogously, if a particular referent can be alternatively categorized as a wraparound skirt or a miniskirt, there could just as well be a preferential choice: when you encounter something that is both a wraparound skirt and a miniskirt, what is the most natural way of naming that referent? If, then, we have to reckon with intra-level differences of salience next to inter-level differences, the concept of onomasiological salience has to be generalized in such a way that it relates to individual categories at any level of the hierarchy (or what is left of it when all forms of hierarchical fuzziness are taken into account). Terminologically, this concept of 'generalized onomasiological salience' can be equated with the notion of 'entrenchment'. Ronald Langacker (1987: 59-60) introduces the concept in connection with the process of unit formation: a particular linguistic construct (such as a new compound, or the use of a word in a new reading) may gradually transcend its initial incidental status by being used more often, until it is so firmly entrenched in the grammar or the lexicon that it has become a regular, well-established unit of the linguistic system. Metaphorically speaking, entrenchment is a form of conceptual 'wiring in': a well-entrenched concept is more firmly anchored in the language user's knowledge of the language. 
The generalized concept of entrenchment, defined as onomasiological salience, may be operationally defined as the ratio between (a) the frequency with which the members of a lexical category are named with an item that is a unique name for that category, (b) and the total frequency with which the category occurs in a corpus. For instance, the lexical category 'apple' will be highly entrenched if, of a total of 100 references to apples, 60 per cent or so occur with the name apple rather than with hyperonyms like fruit or hyponyms like Granny Smith or Cox's Orange Pippin. Generalized onomasiological entrenchment is studied in Geeraerts, Grondelaers, and Bakema (1994).

But if it is useful to introduce the notion of salience into the study of taxonomies, shouldn't the extrapolation of the prototype model to taxonomies be completed by checking for fuzziness (that other pillar of prototypicality)? The basic-level model would seem to presuppose the existence of a clear taxonomical organization, but there are at least two reasons for questioning the neatness of the division into levels that is presupposed by the basic-level model.

For one thing, uncertainties about inclusion relations undermine the stability of the taxonomical hierarchy. If it is indeterminate whether culottes 'divided skirt, garment for women that hangs like a skirt but has separate legs, as in trousers' is a hyponym of trousers or skirt, it is also unclear whether culottes is to be situated one level below these terms, or on the same level. Such indeterminacies follow from the existence of semasiological salience effects: if it is unclear whether culottes is a member of the category 'trousers', the structure of the taxonomy likewise becomes diffuse.

For another, the lexicon is not a single taxonomical tree with ever more detailed branchings of nodes, but is characterized by multiple overlapping hierarchies. Consider, for instance, how a Dutch item like dameskledingstuk 'woman's garment, item of clothing typically or exclusively worn by women' would have to be included in a taxonomical model of the lexicon. If we start from the distinction between skirts and trousers, then wikkelrok 'wraparound skirt' and plooirok 'pleated skirt' belong to one category, and jeans and legging to the other. But if we start from the distinction between dameskledingstuk 'woman's garment' and herenkledingstuk 'man's garment', then wikkelrok, plooirok, and legging belong together. In this case, a classification on the basis of gender-specificity cross-classifies with a classification based on functional gestalts like broek and rok. So can we say that dameskledingstuk belongs to the same level as broek 'pair of trousers' and rok? Whereas the latter items would probably be basic-level terms, this could hardly be the case for dameskledingstuk. But how can the level of dameskledingstuk be determined at all, if it does not fit into the same taxonomical hierarchy as broek and rok? In a basic-level model of onomasiological salience, the lower degree of salience 
of dameskledingstuk would have to result from its taxonomical position with regard to the level where broek and rok are situated; but this taxonomical position is unclear because dameskledingstuk cross-classifies with the broek/rokclassification. In the anthropological literature on taxonomies, this point has been discussed in detail by Atran (1990). He argues that the basic-level model does not apply to artefacts, because artefacts, in contrast with natural kinds, can be linked to various superordinate categories.

In the same way in which we encountered a structural homology between the referential level and the sense level when we considered the semasiological structuring of words, we have now come across a similar homology between characteristics of semasiological and onomasiological structures of a taxonomical kind. Taxonomies no less than semasiological structures are potentially characterized by fuzziness and differences of structural weight. This homology should not really surprise us: why should semantic categories have different characteristics when they are found within the structure of a single word, or when they are found across different words, within the vocabulary as a whole? The patterns of thought at work in both cases remain the same, and semantic categories remain semantic categories, whether they have an infralexical or a supralexical status.

\subsection{Conceptual metaphor and metonymy}

The interest in the internal structure of lexical items, as illustrated and embodied by the research covered in the previous section, automatically entails an interest in the semantic relations that interconnect the various readings of an item. Within a radial set for instance, the elements are connected not only through the fact that a less prototypical sense derives from a more central one, but also through a specific mechanism of semantic extension: similarity, or metaphor, or metonymy-basically, any of the mechanisms of meaning change that constituted the focus of historical-philological semantics. That is, overall, a major resemblance between cognitive semantics and historical philological semantics: both embrace a psychological, encyclopedic conception of linguistic meaning, and both have a primary interest in the flexible dynamism of meaning. At the same time, the diachronic perspective is not as dominant in cognitive semantics as it is in historical-philological semantics: the cognitive mechanisms of meaning extension, like metaphor and metonymy, are now primarily analysed as synchronic phenomena.

Metaphor, in particular, constitutes a major area of investigation for cognitive semantics. After all, metaphor is the mechanism par excellence for 'seeing one thing in terms of another. There seemed to be a general rise in the interest for metaphor and figurative language round 1980 (witness the collections of 
papers published by Ortony 1979 and Honeck and Hoffman 1980), but the major impetus came from George Lakoff and Mark Johnson's Metaphors We Live By (1980), a book that was an eye-opener for a new generation of linguists. In the linguistic climate of the 1970s, dominated by the formal framework of generative grammar, semantics seemed a peripheral issue, specifically after the demise of Generative Semantics. But Metaphors We Live By, more perhaps than the other foundational publications in cognitive semantics, was instrumental in putting semantics back on the research agenda. We start, in 5.2.1, with an introduction to Lakoff's Conceptual Metaphor Theory, the 'standard' view of metaphor in cognitive semantics. Section 5.2.2 is devoted to the conceptual integration framework, which offers an extension of Conceptual Metaphor Theory. Section 5.2.3 discusses the contribution of cognitive semantics to the study of metonymy.

\subsubsection{Conceptual Metaphor Theory}

Conceptual Metaphor Theory rests on three essential propositions: first, the view that metaphor is a cognitive phenomenon, rather than a purely lexical one; second, the view that metaphor should be analysed as a mapping between two domains; and three, the notion that linguistic semantics is experientially grounded. In this section, we will first have a closer look at each of these three pillars of Conceptual Metaphor Theory. A final point in the section is devoted to the main methodological criticism that is often levelled against the approach. The following section (5.2.2) will be devoted to a theoretical framework that is related to Conceptual Metaphor Theory, viz. the mental spaces approach. The standard formulation of the theory is Lakoff and Johnson (1980). Further central works are Lakoff (1987), and Lakoff and Johnson (1999), with Kövecses (2002) as a comprehensive and easily accessible introduction.

1 The cognitive nature of metaphor involves the fact that it is not a purely lexical phenomenon, situated superficially at the level of the language, but is instead a deep-seated conceptual phenomenon that shapes the way we think (and not just the way we speak). Proponents of Conceptual Metaphor Theory have sometimes tended to overemphasize the novelty of this view. If we think back on what we learnt about historical-philological semantics, it should be clear that in the tradition of linguistic semantics, metaphor was not just seen as a rhetorical embellishment, as the enthusiasts of Conceptual Metaphor Theory tend to claim: already in the historical-philological tradition, metaphor was recognized as a cognitive rather than a stylistic mechanism. Further precursors from the history of linguistics and philosophy are mentioned in Jäkel $(1997,1999)$ and Nerlich and Clarke (2007). But even if the cognitive 
conception is not as revolutionary as suggested, Conceptual Metaphor Theory systematically adduces various kinds of evidence for the conceptual rather than just lexical nature of metaphors.

First, metaphor comes in patterns that transcend the individual lexical item. Three typical examples are the following. (Not all the examples given by Lakoff and Johnson are reproduced. Note that it is customary for Conceptual Metaphor Theory to indicate metaphoric patterns by small capitals.)

\section{THEORIES AND ARGUMENTS ARE BUILDINGS}

Is that the foundation for your theory? The theory needs more support. The argument is shaky. We need some more facts or the argument will fall apart. We need to construct a strong argument for that. We need to buttress the theory with solid arguments. The argument collapsed. The theory will stand or fall on the strength of that argument.

LOVE IS A JOURNEY

Look how far we've come. We are at a crossroads. We'll just have to go our separate ways. We cannot turn back now. We are stuck. This relationship is a dead-end street. I don't think this relationship is going anywhere. It's been a long, bumpy road. We have gotten off the track.

MORE IS UP, LESS IS DOWN

The number of books printed each year keeps going up. My income rose last year. The number of errors he made is incredibly low. His income fell last year. He is under age. If you are too hot, turn the heat down.

Second, metaphoric images may be used creatively. The sets of expressions that illustrate metaphoric patterns are open-ended; they do not only comprise conventionalized expressions, but may also attract new ones. If theories are buildings, you could say things like Complex theories usually have problems with the plumbing: the metaphoric image is a live one that may be exploited for construing new expressions. An expression like to walk on cloud nine 'to be very happy' may be expanded in non-conventional ways: You may be walking on cloud nine now, but don't forget there's a world with other people underneath. Such extensions show that the image contained in to walk on cloud nine is a live one. The creative use of metaphors also shows up in the entailments that metaphoric patterns allow. If arguments are journeys (This observation points the way to an elegant solution, we will proceed in a step-by-step fashion, etc.), we can combine that knowledge with information that journeys are defined by paths. Then, it follows that arguments are defined by a path: Do you follow my argument? Now we've gone off in the wrong direction again. He strayed from the line of argument. I'm lost. 
Third, metaphoric patterns occur outside language. A simple case is a 'thumbs up' gesture: if good is up and bad is down (Things are looking up. We hit a peak last year, but it's been downhill ever since. Things are at an all-time low), then a 'thumbs up' gesture is straightforwardly motivated by the metaphoric pattern. Pointing upward is a sign of positive affect, just as the expression up is correlated with the positive end of an evaluative scale. Non-linguistic metaphors have been identified in many areas, including advertising (Forceville 1996, Ungerer 2000), gesture (McNeill 1995, Cienki and Müller 2008), sign language (Wilcox 2001), and mathematics (Lakoff and Núñez 2000).

2 The second pillar of Conceptual Metaphor Theory is the analysis of the mappings inherent in metaphoric patterns. Metaphors conceptualize a target domain in terms of the source domain, and such a mapping takes the form of an alignment between aspects of the source and target. In the terminology introduced into literary studies by Richards (1936), the source domain corresponds to the 'vehicle' of the metaphor, the target domain corresponds to the 'tenor', and mapping corresponds to the 'ground'. For LOVE IS A JOURNEY, for instance, the following correspondences (adapted from Kövecses 2002: 7) hold:

SOURCE

the travellers

the means of transport

the journey

the obstacles encountered

decisions about which way to go

the destination of the journey

\section{TARGET}

the lovers

the relationship itself

the evolution of the relationship

the difficulties experienced

choices about what to do

the goals of the relationship

Mappings such as these are not exhaustive, in the sense that there may be features of the source that would not normally be mapped onto the target. A journey, for instance, may imply making reservations and bookings, but that is not immediately applicable to the target domain 'love'.

The mapping relation between source and target may be used to distinguish between different types of metaphor. For one thing, Conceptual Metaphor Theory distinguishes between simple and complex metaphors. Take Reddy's CONDUIT METAPHOR of communicative behaviour, illustrated by examples like the following (Reddy 1979):

It is hard to get that idea across to him. I gave you that idea. It is difficult to put my ideas into words. Try to pack more thought into a fewer words. The meaning is right there in the words. Your words carry little meaning. Your words seem hollow. The sentence is without meaning. 
This metaphor appears to combine three more basic ones: ideas are objects, expressions are containers, and communication is sending (of ideas/objects in expressions/containers). Another classification introduced by Lakoff and Johnson distinguishes between structural metaphors, ontological metaphors, and orientational metaphors. Structural metaphors are based on mappings to provide a rich structure of correspondences between the domains. LOVE Is A JOURNEY is an example: see the structure of correspondences given above. Ontological metaphors assign broad categories, with a less clearly marked internal structure. Personifications, for instance, conceptualize a wide variety of non-human entities in terms of human characteristics; Lakoff and Johnson (1980: 33) cite examples like the following:

Inflation is eating up our profits. His religion tells him that he cannot drink fine French wines. This fact argues against the standard theories. Our biggest enemy right now is inflation. Cancer finally caught up with him.

Orientational metaphors are of the MORE IS UP type: they apply a spatial or sensorimotor image schema (like vertical orientation) to an abstract domain. The notion of image schema is a key illustration of the third essential feature of Conceptual Metaphor Theory, viz. its experientialist nature.

3 The third pillar of Conceptual Metaphor Theory is the idea that metaphors are grounded in experience: language is shaped by human experience. An important line of research associated with Conceptual Metaphor Theory focuses on the corporeal nature of this experiential grounding-the notion of embodiment. Although the concept of embodiment is a multifaceted one (see Rohrer 2006 for a brief history of embodiment in Cognitive Linguistics), the basic inspiration derives from Lakoff and Johnson's observation that there is directionality in metaphor. Not only do we understand one concept in terms of another, but we commonly also structure less concrete and vaguer concepts in terms of more concrete and more sharply delineated ones (1980: 112). The body, then, is a source domain par excellence for such experientially grounded metaphoric mappings. Johnson (1987) specified this notion of embodiment by identifying so-called 'image schemas', as embodied experiential gestalts: 'An image schema is a recurring dynamic pattern of our perceptual interactions and motor programmes that gives coherence and structure to our experience' (1987: xiv). Containment, for instance, is an image schema related to our frequent experience of inserting objects into and removing them from bounded areas. Metaphoric uses of the containment image schema occur when someone enters into a depression, to take an example: the abstract emotional condition is seen as a container restricting the person's behaviour. (The importance of such functional aspects of spatial configurations, over and above the purely 
topological aspects, was first noted by Vandeloise 1986 and Herskovits 1986.) Image schemas in this sense are pre-conceptual in that they are assumed to develop before conceptual thinking.

Staying close to the initial formulation, a core list of image schemas, taken from Johnson 1987 and Lakoff 1987) includes the following: CONTAINMENT, SOURCE PATH GOAL, LINK, PART WHOLE, CENTRE-PERIPHERY, BALANCE, UPDOWN, FRONT-BACK, plus a number of schemas involving aspects of 'force dynamics': ENABLEMENT, BLOCKAGE, COUNTERFORCE, ATTRACTION, COMPULSION, RESTRAINT, REMOVAL, DIVERSION. But the set of image schemas was not meant by Lakoff and Johnson to be closed, and many other candidates were suggested. Johnson (1987) added the following: CONTACT, SCALE, NEAR FAR, SURFACE, FULL EMPTY, PROCESS, CYCLE, ITERATION, MERGING, MATCHING, Splitting, овject, collection. Some of the examples in this list are less clearly perceptually basic than the original notion of image schema suggests. A cycle, for instance, probably has less experiential immediacy than the notion of part-whole or containment. Johnson introduces the cycle image schema as 'a temporal circle', which already points to a complex rather than conceptually simple notion. Similar questions may be asked with regard to image schema candidates like CEASING TO EXIST, introduced by Turner (1991: 174), or CAUSED мотіоN, introduced by Mandler (1992): how experientially basic are these?

Reacting against the danger of an all too vague and wide conception of image schemas, Grady (1997, 1999, Grady, Taub, and Morgan 1996) argues for a distinction between sensory and non-sensory schemas, with image schemas restricted to fundamental units of sensory perception. Grady makes a distinction between three degrees of abstractness in the analysis of schemas: concrete sensory schemas such as height, non-sensory response schemas such as quantity, and superschemas such as scalarity. Linked to this typology of schemas, he further distinguishes a class of primary metaphors that essentially map basic sensory schemas onto non-sensory ones, as in MORE IS UP, where height functions as a source domain for quantity. Superschemas express the shared properties between the sensory and the non-sensory schemas: 'more' can be seen as 'up' because in both cases, gradedness plays a crucial role. Primary (or 'correlational') metaphors are not based on resemblances that can be mapped out as structural similarities, as we illustrated with LOVE Is A JOURNEY, but on correlations experienced in childhood: the child building a tower with blocks learns by experience that more blocks build a higher tower.

4 Conceptual Metaphor Theory attracts a tremendous amount of research, but at the same time, critical voices may be heard, specifically of a methodological kind. In its standard form, in fact, Conceptual Metaphor Theory has a methodological facility that many find disconcerting. It seems sufficient to 
posit a metaphoric pattern of the type LOVE IS WAR and then to find as many expressions as possible that fit the pattern. But what if the initial pattern was attributed incorrectly? Repeating the mistake with successive expressions will not remedy the initial inaccuracy. Rather, for each individual expression that is allocated to a certain metaphoric pattern, it would have to be established that that pattern is indeed the correct one. The problem of finding the right metaphoric pattern may be specified in two different ways.

First, each metaphoric pattern will have to be compared to competing patterns. Following the example presented in Haser (2005), we may have a closer look at the metaphoric pattern ARGUMENT Is WAR. Quite a number of the expressions that are mentioned in defence of this metaphor may be attributed to alternatives which, each in their turn, have a corroborating set of expressions associated with them. The expressions that Lakoff and Johnson cite as cases of ARGUMENT IS WAR include win, defend, and on target. But the latter expression could also be seen as illustrating ARGUMENT IS (IM)PROPER PLACEMENT/POSITIONING, as in to the point, beside the mark, hit the pin/nail on the head, well-placed, wide of the mark. Defend could be ranged with ARGUMENT IS PRESERVATION FROM INJURY OR DESTRUCTION, as in vindicate, save, rescue, uphold, fortify. And win could go with ARGUMENT Is GAME-PLAYING, as in lay one's cards on the table, trump card, gambit, play down, to make a game of. In all of these cases, it would have to be established that it is more appropriate to attribute an expression to ARGUMENT IS WAR than to any of the alternative conceptual metaphors.

Second, following remarks that were voiced early on in the critical reception of Lakoff and Johnson (see Geeraerts 1981, Traugott 1985a), let us note that alleged metaphors need to be carefully placed within the full polysemous structure of the expressions involved. Conceptual Metaphor Theory tends to discern metaphors by comparing figurative readings with the basic meaning of a word, but if we take into account the radial network structure of linguistic concepts, any existing reading in the network could be the starting point for a new metaphor. In its simplest form, this observation implies that Conceptual Metaphor Theory should take into account the existence of dead metaphors, i.e. expressions that may be metaphoric from a diachronic point of view, but that have lost their metaphoric motivation for the average contemporary language user. For instance, strike is said to be used metaphorically in I was struck by his sincerity, illustrating the metaphor EMOTIONAL EFFECT IS PHYSICAL CONTACT (Lakoff and Johnson 1980: 50). But it would be at least as reasonable to hold that strike has developed the literal meaning 'to surprise, to affect suddenly', which is so common and conventional that it no longer evokes any metaphoric mapping. Similarly, to give birth to in the theory of relativity gave birth to an enormous number of ideas in physics is interpreted metaphorically 
in terms of the metaphor IDEAS ARE PEOPLE (Lakoff and Johnson 1980: 47). But one could claim that the expression has at least two literal meanings: the prototypical 'to bring into the world a child' and the peripheral 'to bring forth in general, to cause to come into existence.' Consider the sentence Will the Web 2.0 give birth to new journalism? Should we posit a metaphor TECHNOLOGIES ARE PEOPLE, or would it not be easier to assume that give birth has developed a general reading that may be used indiscriminately to ideas and technologies? Similarly, an expression such as we are stuck is explained in terms of LOVE Is A JOURNey. However, the same expression can be used in other circumstances, for instance, when finding no solution to a problem. Conceptual Metaphor Theory would have to invoke a metaphor FINDING solutions is A JOURNEY to make the example fit the framework. If, on the other hand, the general meaning 'to be unable to do anything further because of difficulties' is posited as part of the semasiological network of to be stuck, a much simpler solution arises: there would be no need for two independent metaphoric structures.

Taking into account the semasiological structure of expressions in this way would have an additional advantage. The interpretation of an expression such as the foot of the mountain need not have a recourse to a general metaphor $\mathrm{A}$ MOUNTAIN IS A PERSON, which explains no other metaphoric expressions (as Lakoff and Johnson admit): there would just be an extension of the semasiological structure of foot, whereas the meaning of mountain could be left for what it is. In particular, it need not be personalized.

Two things follow from these critical observations: from a diachronic perspective, establishing the source of a metaphor requires meticulous historical research, and from a synchronic perspective, it needs to be established whether an alleged metaphoric mapping is indeed a live one. In section 5.5, we will review a number of attempts to deal with these questions.

\subsubsection{Mental spaces and blending}

Conceptual Metaphor Theory has been expanded descriptively in numerous directions: see the 'Further sources' section at the end of the chapter. In this section, we pay attention to what is probably the biggest theoretical extension of Conceptual Metaphor Theory-the introduction of the apparatus of blending theory. This analytic framework was introduced by Gilles Fauconnier and Mark Turner $(1994,1995,1998)$, as a development of earlier work by Fauconnier (1985). Further references to central works of blending theory include Fauconnier (1997), Coulson (2001), and Fauconnier and Turner (2002).

The descriptive model of conceptual integration (or blending, as it is commonly known) involves four spaces, instead of the two conceptual domains of standard Conceptual Metaphor Theory. Two of the four spaces, the input 
spaces, correspond to the source and target domain of Conceptual Metaphor Theory. The crucial addition of blending theory is the blend space, which represents the interaction of the input spaces: in the blended space, knowledge of source and target inputs combines into a coherent information structure that is temporarily activated in the mind of the language user. The fourth space in Fauconnier and Turner's analytic schema is the generic space, which contains schematic material shared by the two input spaces. To see how it works, we may have a look at one of the standard examples of a blend, viz. the Grim Reaper, the traditional representation of death as a cloaked skeleton with a scythe. The image has death as a target domain, but there appear to be two source domains involved: that of the reaper and that of a killer. Death is personified as a reaper, but the reaper has lost his usual positive connotation. Reapers harvest food, which is a positively evaluated action, whereas the Reaper in the image turns out to be a killer with negative intentions.

Schematically, the Grim Reaper blend may be represented as in Figure 5.6. The features in square brackets are the ones that are not retained in the final blended image. While the table in the upper part presents an analytic schema, the canonical representation in the blending theory formalism takes the form represented in the lower part of the figure; the bottom circle is the blended space. To complete the regular type of representation according to the blending model, the elements of the input spaces would have to be connected individually, where appropriate, with the elements of the blended space. In Figure 5.6, this is omitted so as not to clutter the representation. Further, the generic space is not drawn in the example. In this case, it would include the generic elements 'agent', 'action' and so on.

Given the example, we may now specify the advantages of the blending model over a standard Conceptual Metaphor Theory representation. First, the blending approach highlights the interaction of source and target domains, clarifying that blended spaces contain features that belong to neither of the input domains. The Grim Reaper does not as such belong to the target domain of death, but neither does he reside in the input space of farming and harvesting, because his grim features do not fit there. This emphasizes the constructive nature of metaphors: they do not just exploit perceived similarities, but build meaningful structures. Second, the blending apparatus provides an insightful tool for analysing more complex metaphors, ones that involve various input domains, like the Grim Reaper example. Third, blending theorists tend to pay more attention to the way in which metaphoric structures are created ad hoc in discourse, where standard Conceptual Metaphor Theory tends to focus on more conventional language, fixed expressions, idioms, and proverbs. This is not immediately obvious from the Grim Reaper example, 


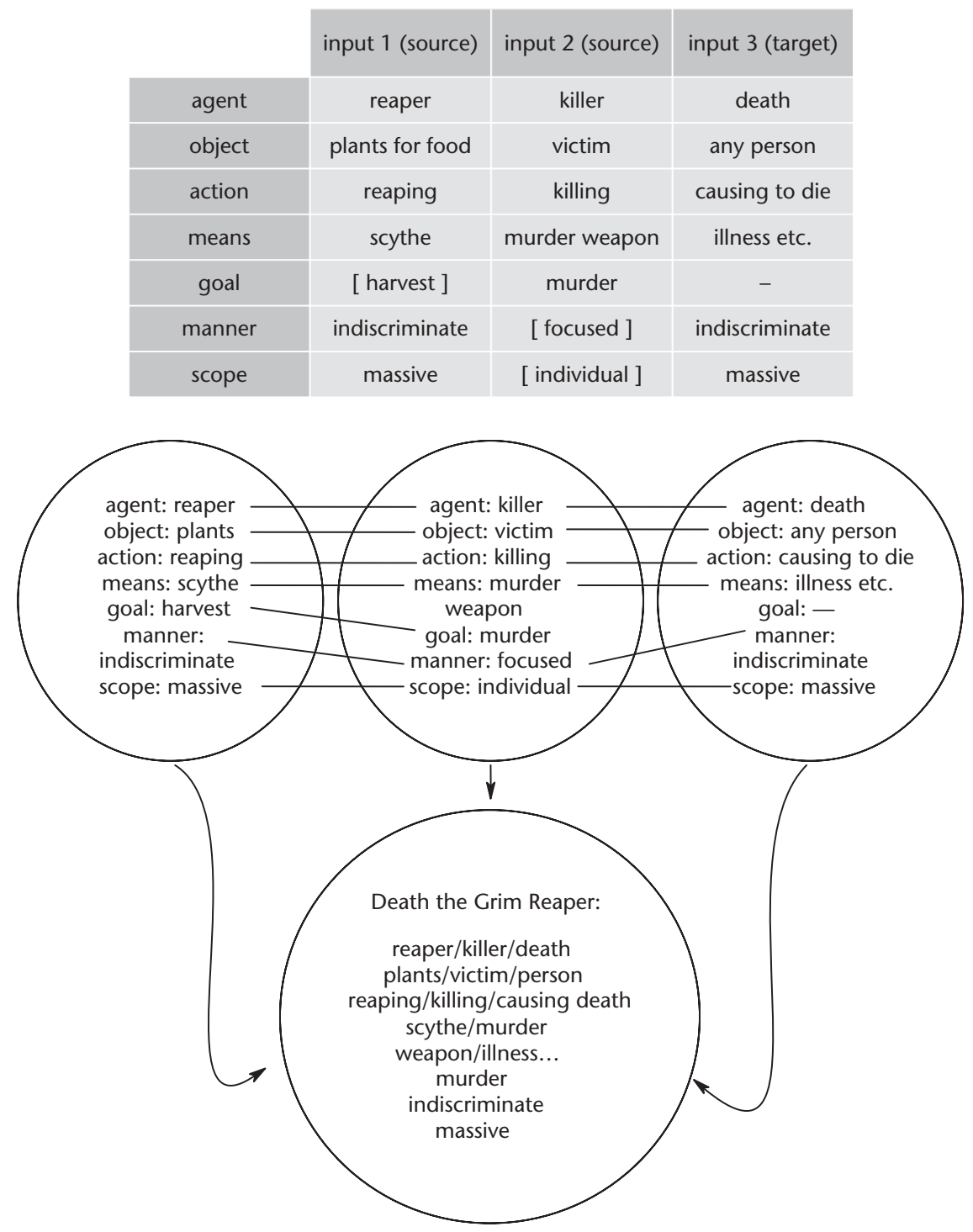

FIgURE 5.6. The Grim Reaper according to Fauconnier and Turner

but note that the conceptual integration framework is frequently used in the field of literary studies and humour research. Fourth, the conceptual integration mechanism is not restricted to the analysis of metaphor. It is a general procedure in human cognition, consisting of the innovative combination of conceptual materials from the distinct sources. Blending, for instance, proves very well suited to describing the semantics of counterfactual statements like 
In France, Watergate would not have hurt Nixon (Fauconnier and Turner 2002: 225-6). Because this exceeds the lexical boundaries of the present study, we will not provide an example of the analysis of counterfactuals. Note, however, that if blending theory covers a wider range of cognitive phenomena than just metaphor and figurative language, the question arises in what way metaphor is specific as a type of conceptual integration. An answer is suggested by Grady, Oakley and Coulson (1999), who argue that in metaphoric blends, the fusion of elements from the input spaces is subject to specific restrictions that would not apply in the case of counterfactuals or other types of conceptual integration.

Given these differences with the standard Conceptual Metaphor Theory, should we say that the conceptual integration framework constitutes a break with what went before, or is it rather a continuation? Enthusiasts of the blending approach sometimes argue that there is an essential difference between, on the one hand, understanding A through B and, on the other, taking elements from $\mathrm{A}$ and $\mathrm{B}$ in order to combine them in $\mathrm{C}$, as something completely new. But this way of putting the matter downplays the fact that $\mathrm{C}$, the blended space, is still about understanding A through B. There is in fact an asymmetry in the way the input spaces contribute to the blend. Inferences in the blended space $\mathrm{C}$ that go against the common understanding of A are blocked: the Grim Reaper does not wait for his victims to have reached a mature age, while the harvester definitely needs to wait until the grain is ripe if the harvest is to be as positive as intended. By contrast, inferences in $C$ that go against the common understanding of B are not blocked: that is why Grim Reapers are grim, violent, harmful, destructive, while normal reapers are not. From this perspective, it seems more appropriate to think of blending as a refinement and an expansion of Conceptual Metaphor Theory-admittedly, one with more expressive and analytic power than the original.

\subsubsection{Conceptual metonymy}

In Lakoff and Johnson (1980), metonymy already figured next to metaphor as one of the conceptual mechanisms behind the semantic structure of language. That clearly should not come as a surprise: an approach that is interested in the semantic mechanisms behind language use and linguistic structures is likely to rediscover the traditional mechanisms of semantic extension. Lakoff and Johnson (1980: 38-9) list a number of metonymic patterns that might have been taken straightforwardly from a historical-philological treatise on semantic change, like the ones we discussed in section 1.3.2. (although, as in the case of metaphor research, this historical lineage is all but ignored by Lakoff and Johnson): 
THE PART FOR THE WHOLE

We don't hire longhairs. Get your butt over here. The Giants need a stronger arm in right field.

PRODUCER FOR PRODUCT

He's got a Picasso in his den. I hate to read Heidegger. He bought a Ford.

OBJECT USED FOR USER

The sax has the flu today. The buses are on strike. The gun he hired wanted 50 grand.

\section{CONTROLLER FOR CONTROLLED}

Nixon bombed Hanoi. Napoleon lost at Waterloo. The Mercedes rear-ended me.

THE PLACE FOR THE INSTITUTION

Washington is insensitive to the needs of the people. Paris is introducing longer skirts this season. Wall Street is in a panic.

\section{THE PLACE FOR THE EVENT}

Pearl Harbour still has an effect on our foreign policy. Watergate changed our politics. Let's not let Thailand become another Vietnam.

Lakoff and Johnson emphasize the fact that metonymic concepts like these are conceptual and not purely linguistic, in much the same way that metaphoric concepts are. In the first place, metonymic concepts allow us to think of one thing in terms of its relation to something else. In that sense, we can distinguish a source and target in the description of metonymy just as we can for metaphors. In the second place, metonymies are systematic in the sense that they form patterns that apply to more than just an individual lexical item. In third place, metonymic concepts structure not just the language, but also the language users' thoughts, attitudes, and actions. Saying that Nixon bombed Hanoi is not just a way of referring to the air force by means of its chief commander, but it is also a way to think of Nixon as ordering the bombing and of holding him responsible for it, even though he may not have dropped the bombs himself. In the fourth place, metonymic concepts are grounded in experience. If you have no idea of the historical events that happened at Pearl Harbor and the effect they had on the involvement of the United States in World War II, the sentence Pearl Harbor still has an effect on our foreign policy will not make a lot of sense to you.

From the late 1990s on (somewhat later than the rise in popularity of metaphor studies), the renewed interest in metonymy led to an upsurge of publications, which may to a large extent be found in a number of collective volumes: Panther and Radden (1999), Barcelona (2000), Dirven and 
Pörings (2002), and Panther and Thornburg (2003). In this section, we will focus on what has been one of the main topics in that wave of studiesthe demarcation of metonymy with regard to metaphor. In addition, we will briefly introduce the concept of 'metaphtonymy'.

1 With regard to the demarcation of metonymy, we need to distinguish between, roughly, a domain-based and a prototype-based view. Both approaches are characteristically cognitive semantic: the domain-based approach to the extent that it defines metaphor and metonymy in terms of larger knowledge structures, and the prototype-based approach to the extent that it applies the principles of categorization that were discussed in section 5.1 to the category 'metonymy' as such.

The standard view of metonymy in cognitive semantics, initiated by Lakoff and Johnson (1980: 36) and Lakoff and Turner (1989: 103), is to define metonymy in contrast to metaphor by invoking the number of conceptual domains involved in the conceptualization process: metaphors involve two conceptual domains, metonymies only one. If you call an aggressive opponent a crocodile, you metaphorically map the animal domain onto the human domain. Conversely, if you have a crocodile handbag, you stay within the animal domain but metonymically focus on the leather produced from the animal skin rather than on the animal as a whole. The appeal of this approach for cognitive semantics will be obvious: it is a simple definition that makes a straightforward distinction between two basic mechanisms of conceptualization, it is an innovation with regard to the older definitions that invoked similarity versus contiguity as the basis of metaphor and metonymy, and it rests on an idea that is essential to cognitive semantics, i.e. that knowledge is structured in larger entities (in this case, domains).

In spite of its popularity (see e.g. Barcelona 2002, Kövecses, 2002, Kövecses and Radden 1998), however, the domain approach has also been the object of much criticism (see e.g. Feyaerts 1999, Riemer 2001, Taylor 2002, Panther 2006, Panther and Thornburg 2007). First, the notion of domain is not well defined, neither theoretically nor methodologically: there is no stable and well-established heuristic in cognitive semantics to distinguish one domain from the other or to determine a generally acceptable ontology of domains. Second, counterexamples to the domain hypothesis are not difficult to find. The counterexamples work in two directions.

On the one hand, we find semantic extensions that cross domains but are not metaphoric. As noted by Croft (1993), in Proust is tough to read, the source belongs to the domain of human beings, but the target to that of creative activity. The distinction between concreteness and abstractness (in the example, the distinction between the human person versus the intellectual product of 
his creative activity) is often used as an indication of metaphoricity. If someone is drowning in work, we recognize the metaphor because the drowning is abstract rather than concrete. But if we accept the concrete/abstract distinction as indicating cross-domain mappings in such an example, we are forced to accept that Proust is tough to read is a cross-domain metonymy.

On the other hand, we also find intra-domain mappings that are not metonymical: in Maggie Thatcher is the Ronald Reagan of the UK (John Barnden, p.c.), we come across a similarity-based conceptualization that definitely stays within the same domain. A similar example is there are dirty fingers on the window, referring to a trace left on the window pane. This phrase can be explained metaphorically, if the crucial relationship is the similarity between the fingers and their prints on the window, as well as metonymically, if the fingers are seen as the cause of the visual image. So either we have a visual similarity or a cause/effect metonymy (or both), but in both cases, the entities and domains involved remain the same: how could a difference in the relevant domains explain the difference between metaphor and metonymy, if the entities and the domains are exactly the same in both perspectives?

Difficulties such as these led Croft (1993) to suggest a revision of the domain hypothesis. Croft proposes to replace 'domain' by 'domain matrix'. He argues that a concept is profiled against a possibly complex domain structure or matrix. That is to say, a concept like Proust is characterized both in the concrete domain of human beings and in the abstract domain of artistic products, and possibly in a number of additional domains. Metonymy is then said to involve domain highlighting (compare Cruse 1986: 53), in the sense that the metonymy makes primary a domain that is secondary in the literal meaning: Proust's primary domain is that of a human being, but the secondary domain of artistic production is promoted by the metonymy. Hence, the definition of metonymy may be rephrased as a mapping that occurs within a single domain matrix, not across domains or domain matrices. Ruiz de Mendoza Ibáñez (2000, Ruiz de Mendoza Ibáñez and Otal Campo 2002) follows up on this refinement of the domain hypothesis by making a terminological distinction between domains and subdomains: what Croft would call 'domains within a domain matrix' are subdomains within a domain for Ruiz de Mendoza Ibáñez, and domain highlighting is the contextual promotion of a subdomain. Crucially, Ruiz de Mendoza Ibáñez takes into account not just the domain matrix of the metonymic source but also that of the metonymic target. This allows him to make a distinction between source-in-target and target-insource metonymies. The distinction may be illustrated with the sentences The red shirts won the match and This book is utterly boring. In the shirt example, the source is a subdomain of the target: the gaudily coloured shirts are a distinctive characteristic in the field of football players. With the book example, by 
contrast, the target is a subdomain of the source: content is a salient property in the domain of books. This distinction between target-in-source and sourcein-target phenomena links up with the reversibility of metonymical patterns that has been a well-known fact since the earliest works on the topic: there are part-whole metonymies, like we need a few extra hands to do the job, and there are whole-part metonymies, like I need to fill up the car.

These refinements of the domain hypothesis do not, however, solve the problem regarding the demarcation of metaphor and metonymy. They do efficiently address the cross-domain shift in Proust is easy to read, which is reconceptualized as a mapping within a domain matrix or one between a domain and a subdomain, but they do not succeed in avoiding the difficulties raised by an example like Maggie Thatcher is the Ronald Reagan of the UK. Considerations such as these led a number of researchers to adhere to the more traditional distinction between metaphor and metonymy in terms of similarity and contiguity. In Dirven (1993, revised version 2002), for instance, this is done through the intermediary of Jakobson's reformulation of the distinction in terms of paradigmatic and syntagmatic relations (Jakobson 1971). In the work of Panther and Thornburg (2007, Panther 2006), the chosen background is a Peircean semiotics, with metonymy as an indexically rather than an iconically motivated sign. In both these cases, the underlying dimensions are essentially the same as in the similarity/contiguity distinction: on the one hand, an association defined by analogy and resemblance, on the other, one defined by co-occurrence and adjacency.

But contiguity is probably as vague a notion as 'domain'; after all, the proponents of a domain-based approach often mention the unclarity of contiguity as one the main reasons for looking for another criterion. So how do those who doubt the domain hypothesis deal with the difficulty of clearly delineating the concept of contiguity? The solution may lie in a prototypebased analysis of contiguity, as presented in Peirsman and Geeraerts (2006). The basic strategy is a familiar one for cognitive semantics: concepts that may be difficult to define usually have a clear core; an analysis of the concept as a whole then takes the form of analysing the extensions that start out from that prototypical core area. In a prototypical analysis of conceptual contiguity, it seems intuitively straightforward to postulate spatial or material contiguity as the prototypical core. More specifically, with spatial part-whole relations as their point of departure, Peirsman and Geeraerts show how a large sample of traditionally recognized metonymic patterns (which they collected mostly from the historical-philological literature on semantic change) can be plausibly connected to that categorial centre by means of three interacting dimensions. That is to say, examples of metonymy which do not immediately look like cases of contiguity find a natural place when one takes into 


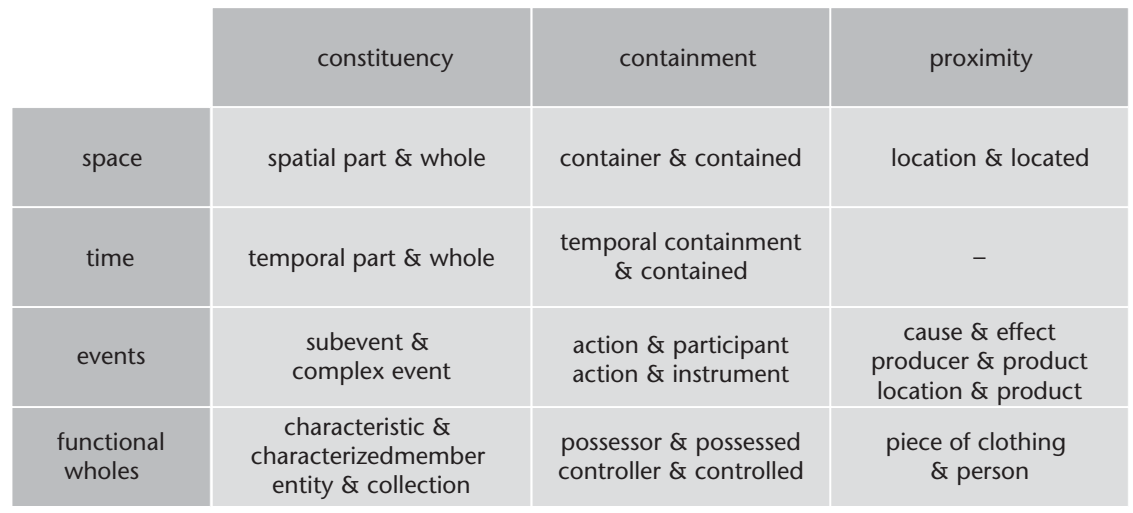

FIgURE 5.7. A prototype-based classification of metonymic patterns

account the prototype-based architecture of the category. (The following discussion is considerably simplified in comparison with Peirsman and Geeraerts 2006.)

The first of the three dimensions, 'strength of contact', extends the prototypical core in the direction of containment and proximity, i.e. if a partwhole relation (constituency) is considered the strongest and clearest form of contiguity, then we may identify containment and proximity as weaker or looser forms. In the case of containment, the relationship between source and target is not as strong as in the case of constituency, but the source does exert a restrictive force on the target. In the case of proximity, the spatial cooccurrence of source and target is even more coincidental or non-restrictive. Metonymic patterns which illustrate the three cases were mentioned in section 1.3.2: SPATIAL PART \& SPATIAL WHOLE, CONTAINER \& CONTAINED, LOCATION \& LOCATED. In each of these examples there is a spatial relatedness, but the closeness and the strength of the relation diminishes from one thing being an integral part of another to an accidental spatial proximity.

The second classificatory dimension is probably the most important one, as it involves a shift from the spatial and the material domain to more abstract ones, like time and events. The contiguity relationships that exist prototypically in material, spatial assemblies are then applied metaphorically in non-spatial domains. In Figure 5.7, the patterns introduced in section 1.3.2 are situated against a cross-classification of the two dimensions (strength of contact and domain) that we have so far identified. A few remarks may clarify the figure. While the extension of space to time is straightforward, note that actions, events, and processes may also be seen as consisting of parts, with the participating entities included in the containing event. In 
ACTION/EVENT/PROCESS \& PARTICIPANT, for instance, the container is not a spatial or purely temporal entity, but an action, event, or process, with the participants as its contents. (This is a productive type, with many subtypes, which we will not list here.) A loosening of the strength of contact between the source and the target takes us further from containment to proximity relations between or within two actions, events or processes. This relationship lies at the basis of the salient CAUSE \& EFFECT pattern, and also motivates patterns that link participants which are joined in an action, event, process, like producer \& PRoduct or OBJeCt \& USER. Finally, the basic metonymic patterns may be extended to assemblies and collections, i.e. to entities that are functional wholes rather than spatial, temporal, action-related wholes. This involves cases in which a characteristic part of a functional aggregate-an organization, organism, ensemble-provides the names for the totality. (In some cases, the borderline with the original spatial domain may be fuzzy; brains define someone functionally as a smart person, but they are also a material part of the body.)

The third dimension involves the 'boundedness' of one or two of the contiguous entities; it helps to see how bounded objects can be contextualized as a part of an unbounded one, or the other way round. In the MATERIAL \& овјест pattern (illustrated earlier (1.3.2) by French carton 'cardboard' for 'cardboard box'), for instance, substances are conceived of as parts which constitute or make up things, or conversely, things are conceived as bounded entities 'carved out' from unbound masses. As a further indication of the cross-classification that exists between the three dimensions, note that the introduction of unboundedness is not restricted to a material, spatial pattern like material \& овJест. Interestingly, in the domain of events, actions, and processes, the unbounded part-whole relationship also exists between actions and states. In sentences such as Mary speaks Spanish, John smokes, or Harry drinks, the activities of speaking, smoking, and drinking metonymically stand for the states of which they are a part. Speaking, for instance, is only one sub-activity of the general knowledge of a language. Similarly, the references to the actions of smoking and drinking actually mean that John is a smoker and Harry an alcoholic. Since actions, events, and processes are temporally bounded, while states are unbounded, these examples instantiate the same structural type as MATERial \& OBJeCt. (On this ACTUAL \& potential pattern, see Panther and Thornburg 1999.) And in the domain of functional assemblies, the CHARACTERISTIC \& CHARACTERIZED ENTITY pattern is not only illustrated by examples referring to material characteristics of the brains type, but also by a case like (a) youth or (a) beauty, in which an immaterial, unbound feature provides the name for someone having that characteristic. 
So, if we start out from spatial, material constituency (part-whole relations) as the core of the concept, contiguity can be analysed as a prototypically organized category, in which three interacting dimensions (strength of contact, domain of application, and boundedness) define the extensions from the prototypical centre. Within the context of cognitive semantics, such a prototype-based definition of metonymy as resting on contiguity provides a valid alternative for the domain-based definition.

2 In addition to the demarcation of metonymy, considerable attention was directed to the interaction between metaphor and metonymy. Goossens (1990) gives a name to the phenomenon, 'metaphtonymy', and recognizes two subtypes: metaphor from metonymy, and metaphor within metonymy/metonymy within metaphor. 'Metaphor from metonymy' refers to a sequential operation of the two mechanisms, and 'metonymy within metaphor/metaphor within metonymy' involves a simultaneous, parallel type of interaction. The first type is illustrated by the verb giggle. The verb initially means 'to laugh in a nervous way', but this meaning can be used metonymically in a context like 'Oh dear', she giggled, 'I'd quite forgotten', in which giggle comes to mean 'say while giggling'. A further extension towards 'to say as if giggling' then constitutes the 'metaphor from metonymy' reading. Metonymy within metaphor involves cases like catch someone's ear 'ensure someone's attention'. Such examples (which invariably seem to involve idiomatic expressions rather than single lexemes) are metaphoric in the sense that the hunting scene evoked by catch $x$ is interpreted figuratively. But within that metaphor, the constituent ear gets a metonymic interpretation, as it stands for the person's listening attention. Let us now have a closer look at each of the two cases.

The type of metaphtonymy in which metaphor and metonymy occur simultaneously rather than consecutively links up with an example like dirty fingers on the window, in which the derived reading may be motivated simultaneously as a metonymy based on a causal relation, and as metaphor based on similarity. Going beyond such simple cases, the examples discussed by Goossens can best be described by systematically charting the semantic processes that occur both in the constituent parts of a compound expression, and in the expression as a whole: see Geeraerts (2002) for a theoretical analysis and Deignan (2005a) for a corpus analysis.

While the simultaneous type of metaphtonymy primarily raises descriptive questions, the successive type leads to an interesting theoretical point. Successive applications of metaphor and metonymy are quite common if we think of the semasiological evolution of lexical items. Take a word like glass. One semantic line of development, which can be traced by means of the 
definitions in the New Shorter Oxford English Dictionary, consist of the following steps:

A substance, usu. transparent, lustrous, hard, and brittle, made by fusing soda or potash or both with other ingredients.

A glass vessel or receptacle.

A double-chambered glass receptacle containing sand etc. for the measurement of a specified unit of time.

An allotted period of existence.

In terms of semantic extensions, the successive steps here involve a metonymy followed by a specialization followed by a metaphor. (The final reading, which is now archaic, is illustrated in the dictionary with the quotation The glass of this worthless dynasty is run out.) Such successive steps may of course also be of the same kind, like the 'serial metonymy' discussed in Nerlich and Clarke (2001).

The sequences of metaphor and metonymy that most caught the attention of cognitive semantics are of a slightly different kind. They do not concern examples in which the output of one mechanism is the input for another one, but rather cases in which a reading that is initially metonymically motivated is reinterpreted as a metaphor. To beat one's breast is an example: when the religious ritual disappears, the metonymic motivation is lost and the expression may be reinterpreted. In the simplest case, only the derived reading is retained: from 'to express guilt by beating one's breast', the language moves to 'express guilt' as such. But the meaning that was originally motivated metonymically may also give way to a metaphoric reinterpretation. If soldiers fall in a battle, the initial image is metonymical, but if that motivation wanes, falling and dying may be seen as figuratively related. The violent termination of human life is compared to a falling object: like an object dropping down, the change of state is sudden and unintentional, and the orientational metaphor UP Is GOOD, DOWN Is BAD adequately captures the affective impact of the event.

Recognition of this kind of process implies that a number of alleged metaphors may in fact have a metonymic origin, with the metaphor as a reinterpretation of the initial metonymy. The ANGER IS HEAT metaphor for instance, which looms large in the Conceptual Metaphor Theory literature, is said to originate in the physical sensation of a rising body temperature (Kövecses 1986). Obviously, this ties in neatly with the embodiment thesis (but see section 5.5.2 for a more nuanced view). In a similar vein, it has been observed by Radden (2002) that primary metaphors as identified by Grady reflect metonymical experiences: the correlations that Grady mentions to explain the metaphors exist between experiences that are metonymically related to the source and target concepts. Thus, for instance, if we have a 
metaphoric pattern HAPPY IS BRIGHT, that could be because a light and sunny day may cause a feeling of wellbeing that is similar to feelings induced by a state of happiness.

\subsection{Idealized Cognitive Models and frames}

Cognitive semantics, as we have already noted, takes a maximalist perspective on meaning, one in which differences between semantic and encyclopedic knowledge, or more generally, between semantics and pragmatics, are not taken as a point of departure. Giving up the distinction is relevant for the description of separate lexical items: it implies that it is no longer necessary to draw the borderline between strictly definitional and merely descriptive features. But taking an encyclopedic perspective has a further consequence: encyclopedic information does not usually take the form of single concepts, of the type that correspond to a single lexical item. Rather, our knowledge of the world is organized in broader categories, 'larger chunks of knowledge': we know how to bake pancakes, what it implies to go to the library to consult a book, what the administrative organization of our country looks like, when World War I started and when it ended-and all of these forms of knowledge far transcend the boundaries of a single lexical item. An encyclopedic conception of linguistic meaning, then, requires a way of representing those larger chunks of knowledge, together with a means of linking all the relevant lexical items to that broader conceptual structure.

The latter point implies that cognitive semantics is also to a large extent an onomasiological approach, in the sense that it looks at sets of lexical items at the same time, rather than just considering separate elements. Conceptual Metaphor Theory, of course, illustrates this supra-lexical tendency very well. These 'onomasiological' leanings of cognitive semantics mean that it is to some extent comparable to lexical field approaches and to structuralist approaches in general. At the same time, there are fundamental differences. The difference between a cognitive semantic approach and a more classical lexical field approach is described by Fillmore and Atkins (1992: 76-7):

A major activity for lexical semanticists influenced by the field notion is that of cataloguing the kind of inter-item relations that can be defined for the elements of the lexicon, and characterising the kinds of lexical sets that are structured in terms of such relationships. Semantic theories founded on the notion of cognitive frames or knowledge schemata, by contrast, approach the description of lexical meaning in a quite different way. In such theories, the word's meaning can be understood only with reference to a structured background of experience, beliefs, or practices, constituting a kind of conceptual prerequisite for understanding the meaning. Speakers can be said to know the meaning of the word only by first understanding the background frames 
that motivated the concept that the word encodes. Within such an approach, words and word senses are not related to each other directly, word to word, but only by way of the links to common background frames and indications of the manner in which their meanings highlight particular elements of such frames.

Such a conception of meaning is, needless to say, explicitly encyclopedic in nature. Throughout our discussion of structuralist semantics and its aftermath, we have already come across various reasons for doubting whether a strict distinction between semantic and encyclopedic knowledge can be maintained. At this point, we may add the simple but compelling argument presented by Lehrer (1992). (It will be recalled that Lehrer played an important role in bringing lexical field theory to the attention of an English-speaking audience.) In a discussion of naming practices, looking at pet names, automobile names, street names, university buildings, and the like, she notes that these often come from preferential semantic fields, like animal names for cars (Jaguar, Mustang, Cougar...). However, lexical fields alone cannot explain why particular names are successful ones. Over the Edge is an appropriate name for a racehorse, but as Lehrer (1992: 137) remarks, no standard semantic field approach can deal with that phenomenon: a broader and more encyclopedic view of semantic organization is needed to explain the fact.

Now, if we look at the concepts that cognitive semantics uses to describe these larger structures of knowledge, two notions stand out: that of Idealized Cognitive Model and that of 'frame'. The first is primarily connected with the name of George Lakoff (1987), and the second with that of Charles Fillmore $(1975,1977 \mathrm{~b}, 1985,1987)$. Describing the differences between these two notions is somewhat hampered by terminological confusion. On the one hand, Fillmore uses the notion of 'frame' both in a broad sense and in a more restricted sense. In the broadest sense, illustrated by the Fillmore and Atkins quotation above, the notion of 'frame' is largely synonymous with that of Idealized Cognitive Model, referring in general to the knowledge structures that embody our thinking about the world. In the more restricted sense, it refers to a specific type of knowledge organization in the lexicon. On the other hand, Lakoff's terminology is not entirely stable either. In his work focusing on political debate in the US (Lakoff 1996, 2004), he uses the word 'framing' to refer to the way in which Idealized Cognitive Models (and specifically, metaphoric models) can be used to redirect public debate about social and political issues. In this context, it should also be mentioned that using the notion of 'frame' to refer to the coherent sets of beliefs and expectations that shape our way of thinking and talking about specific domains of the world is not restricted to cognitive semantics: it is well known from the sociological 
work of Goffman (1974) on symbolic interaction, and from Minsky's proposals for the representation of knowledge in artificial intelligence (1974). Furthermore, the idea that human cognition takes the form of structures of knowledge stored in long-term memory has a strong interdisciplinary presence under other names than that of 'frame': in psychology, it may be traced to Bartlett's notion of schema (1932) and to gestalt psychology, and in artificial intelligence, it is present not only in the form of Minsky's frames but also, for instance, in the 'scripts' of Schank and Abelson (1977).

In this section, we will briefly introduce the broader concept of frame under the heading of Idealized Cognitive Model, and then describe in more detail Fillmore's restricted notion of frame, together with its computational extension in the FrameNet project.

\subsubsection{Idealized Cognitive Models}

Elaborating the ideas that he first presented under the name of 'linguistic gestalts' (1977), Lakoff (1987) introduced the concept of Idealized Cognitive Model (or ICM) as a way of capturing the idea-fundamental to cognitive semantics - that our knowledge of language is intimately related to our knowledge of the world, and that such knowledge of the world takes the form of cognitive models: structured sets of beliefs and expectations that direct cognitive processing, including the use of language. The models are called 'idealized' because they are abstractions from the actual world: they do not capture all the complexity of reality, but provide a conceptual mould for flexibly dealing with that complexity. In that sense, they may typically lie at the basis of prototype effects (or conversely, we might say that the central, prototypical cases of individual lexical categories tend to function as cognitive models).

A case in point is Lakoff's discussion of bachelor (an iconic item in lexical semantics, as we have seen). Fillmore (1982: 34) made the observation that for a bachelor to be defined as an unmarried adult male, certain expectations about marriage and marriageable age have to obtain. Men participating in long-term unmarried couplings would not ordinarily be described as bachelors (or singles, to use the more contemporary term); nor would the pope, or a boy abandoned in the jungle and grown to maturity away from contact with human society. Lakoff (1987) elaborates on Fillmore's observation, and emphasizes the fact that the set of expectations that sanctions the featural definition of bachelor as an unmarried adult male is indeed an idealization, to the extent that it abstracts away from certain aspects of reality, like the existence of religious institutions that require a vow of chastity, or same-sex partnerships. 
Lakoff (1987) refines his introduction of Idealized Cognitive Models by providing a classification of different types of ICMs, according to the basic type of semantics embodied in the models. Next to the more usual propositional models (of the bachelor type, for instance), all the kinds of semantic phenomena that we discussed earlier may lie at the heart of an Idealized Cognitive Model. A metaphoric pattern of the type Love Is WAR, for instance, may be classified as a metaphoric Idealized Cognitive Model. Similarly, there are image-schematic models, and metonymic models. This subclassification of ICMs reveals that the notion of Idealized Cognitive Model is a fairly unrestrained one, which hardly imposes any constraints on semantic descriptions. In this sense, the notion of ICM is best seen as a cover-term for the various models of (encyclopedic) knowledge that cognitive semantics pays attention to, but not as a specific descriptive model.

\subsubsection{Frame semantics and FrameNet}

When 'frame' is not just used as a broad synonym of Idealized Cognitive Model, Fillmore's more technical usage of the term refers to a specific way of analysing the semantics of natural language, which grew out of his work on case grammar (1977a). As typical features of this type of analysis we should mention the following: frame theory is specifically interested in the way in which language may be used to perspectivize an underlying conceptualization of the world-it is not just that we see the world in terms of conceptual models, but those models may be verbalized in different ways. Each different way of bringing a conceptual model to expression, so to speak, adds another layer of meaning: the models themselves are meaningful ways of thinking about the world, but the way we express the models while talking adds perspective. In the context of Cognitive Linguistics in the larger sense, perspectivization is seen as a crucial aspect of meaning construal: see Verhagen (2007) for an overview.

This overall starting point of Fillmorean frame theory leads to a description on two levels. On the one hand, a description of the referential situation or event consists of an identification of the relevant elements and entities and the conceptual role they play in the situation or event. On the other hand, the more purely linguistic part of the analysis indicates how certain expressions and grammatical patterns highlight aspects of that situation or event. In an early stage of frame theory, the two levels of description were terminologically conveniently distinguished by the terms 'scene' and 'frame' respectively. The scene was the underlying conceptual structure, whereas the notion of frame referred to the grammatical patterns highlighting parts of the scene. In later developments of the theory however, the terminological distinction was abandoned, and only the term 'frame' remained in use. 


\begin{tabular}{|c|c|c|c|c|}
\hline & buyer & seller & goods & money \\
\hline buy & subject & (to) & direct object & (for) \\
\hline sell & (to) & subject & direct object & (for) \\
\hline charge & (indirect object) & subject & (for) & direct object \\
\hline spend & subject & - & for/on & direct object \\
\hline pay & subject & (indirect object) & (for) & direct object \\
\hline pay & subject & (to) & for & direct object \\
\hline cost & (indirect object) & - & subject & direct object \\
\hline
\end{tabular}

Figure 5.8. The COMmercial transaction frame according to Fillmore and Atkins

To illustrate, we will present two examples of frame analysis, the RISK frame and the COMMERCIAL TRANSACTION frame. The commercial transaction frame involves words like buy and sell. The commercial transaction frame can be characterized informally by a scenario in which one person gets control or possession of something from a second person, as a result of a mutual agreement through which the first person gives the second person a sum of money. Background knowledge involved in this scenario includes an understanding of ownership relations, a money economy, and commercial contracts. The basic categories needed for describing the lexical meanings of the verbs linked to the commercial transaction scene include Buyer, Seller, Goods, and Money. Verbs like buy and sell then each encode a certain perspective on the commercial transaction scene by highlighting specific elements of the scene. In the case of buy, for instance, the buyer appears as the subject of the sentence and the goods as the direct object; the seller and the money appear in prepositional phrases: Paloma bought a book from Teresa for $€_{30}$. In the case of sell, on the other hand, it is the seller that appears as a subject: Teresa sold a book to Paloma for $€_{30}$. A more extended set of verbs is charted in Figure 5.8. The cells indicate in what syntactic form the elements of the frame appear in the syntagmatic pattern of the verbs. (Elements between brackets are optional. Empty cells indicate that the element is not relevant for the verb in question. The table is slightly simplified in comparison with Fillmore and Atkins 1992.)

The RISK frame contains the following set of elements (Fillmore and Atkins 1994: 367-8): 
Protagonist the central person in the frame

Bad the possible bad outcome or harm

Decision the decision that could trigger this

Goal the desired outcome

Setting the situation within which the risk exists

Possession something or someone valued by the protagonist and endangered in the situation

Source something or someone which could cause the harm

In Fillmore and Atkins $(1992,1994)$, this set of frame elements is the starting point for an analysis of sample sentences taken from a corpus of American English (see also Fillmore 1992, Fillmore and Atkins 2000). The analysis proceeds in the same way as we saw in the case of the commercial transaction scene: semantic roles in the frame are linked to grammatical forms of expression. Thus, a sentence like Why should he risk his life to try to save Brooks? could be analysed and tagged as Why should $\{\text { he }\}_{\text {Protagonist }}$ risk $\{\text { his life }\}_{\text {Possession }}$ $\{\text { to try to save Brooks }\}_{\text {Goal }}$ ? As before, one particular element of the frame may be expressed by different grammatical forms. For instance, the possible Bad outcome may be expressed by a gerund, as in we risked being killed, but also by a nominal phrase, as in we risked death to help you. In the same way, the Decision is expressed by a gerund in he risked swimming in the river, and by a nominal phrase in he risked a swim (or metonymically, he risked the river). A difference with the example of a commercial transaction scene is that the RISK frame allows us to see how elements from different word classes can be related to the same background: the RISK frame describes the behaviour of both the verb to risk and the noun risk. For instance, a combination of the Protagonist and the Possession can be expressed by the sentence he risked his life, but also by he put his life at risk. A combination of the Protagonist and a Bad outcome is present in both he risked falling down and he ran the risk of falling down.

The collaboration between Fillmore and Atkins from which we quoted earlier set off two extensions of frame semantics: first, the systematic use of corpus materials as the main source of empirical evidence for the frametheoretical analyses, and second, the development of an electronic dictionary with frame-theoretical descriptions. In a nutshell, these two developments go together in the Berkeley FrameNet project, which attempts to do for frame semantics what WordNet did for structuralist lexical relations (Johnson, Fillmore, Wood, Ruppenhofer, Urban, Petruck, and Baker 2002; Ruppenhofer, Ellsworth, Petruck, Johnson, and Scheffczyk 2006). The on-line FrameNet lexical database currently consists of more than 10,00o lexical units (that is, words or expressions paired to meanings), associated with roughly 900 
hierarchically ordered frames, and illustrated by more than 135,000 annotated sentences taken from corpora.

The information may be accessed by starting from the frames, or by starting from the lexical units. As an example, let us consider the frame Revenge. Simplifying, the description of the frame consists of a definition, a list of the frame elements, and an enumeration of the lexical units associated with the frame. (Non-core frame elements are not included in the example below.)

\section{Definition}

This frame concerns the infliction of punishment in return for a wrong suffered. An Avenger performs a Punishment on a Offender as a consequence of an earlier action by the Offender, the Injury. The Avenger inflicting the Punishment need not be the same as the Injured_Party who suffered the Injury, but the Avenger does have to share the judgment that the Offender's action was wrong. The judgment that the Offender had inflicted an Injury is made without regard to the law.

\section{Frame Elements}

Avenger: The Avenger exacts revenge from the Offender for the Injury.

Injured_Party: This frame element identifies the constituent that encodes who or what suffered the Injury at the hands of the Offender. Sometimes, an abstract concept such as a person's honour or their blood is presented as the element that has suffered the Injury. These also constitute instances of Injured_Party.

Injury: The Injury is the injurious action committed by the Offender against the Injured_Party. This Frame Element need not always be realized, although it is conceptually necessary.

Offender: The Offender has committed the earlier Injury for which the Avenger seeks revenge.

Punishment: The Avenger carries out a Punishment in order to exact revenge on the Offender.

\section{Lexical Units}

avenge.v, avenger.n, get_back_((at)).v, get_even.v, payback.n, retaliate.v, retaliation.n, retribution.n, retributive.a, retributory.a, revenge.n, revenge.v, revengeful.a, revenger.n, sanction.n, vengeance.n, vengeful.a, vindictive.a

If we then turn to one of the lexical units, like vengeance, we again get a definition ('punishment inflicted in retaliation for an injury or offence'), together with a detailed description of the relevant grammatical patterns. These are, not surprisingly, characterized both in terms of the configurations 
of frame elements that they exhibit and in terms of the syntactic valence patterns that instantiate those configurations. Annotated sentences from the corpora exemplifying the valence patterns may be retrieved separately. The sentences below illustrate some of the possibilities for vengeance as attested in the corpus.

My God, $\{\text { she }\}_{\text {Avenger }}$ would have vengeance $\{\text { for this }\}_{\text {Injury }}$ !

After all, $\{\mathrm{I}\}_{\text {Avenger }}$ had taken vengeance $\{$ on her behalf as well as mine $\}_{\text {Injured_Party. }}$.

Some made hazardous, roundabout trips to join the Pretender via the Orkney Islands and Norway, but $\{\text { the government's }\}_{\text {Avenger }}$ vengeance $\{$ on those who could not get away $\}_{\text {Offender }}$ was relatively restrained.

$\{\mathrm{He}\}_{\text {Avenger }}$ had meted out vengeance $\{\text { to his chief enemy, Grant }\}_{\text {Offender, }}$, so any further attack upon mere pawns would be unnecessary.

There are many who believe $\{\text { this disease }\}_{\text {Punishment }}$ is $\left\{\right.$ God's $_{\text {Avenger }}$ vengeance.

The example may also make clear in what way the FrameNet lexical database differs from Mel'čuk's Explanatory Combinatorial Dictionary, with which there might seem to be a superficial resemblance. First, while the Explanatory Combinatorial Dictionary-and WordNet, for that matterrelate words among one another, the FrameNet lexical database relates words to frames. The relations between the words derive indirectly from this direct link to the frame. Second, the semantic functions in the FrameNet lexicon are defined relative to a frame too, in contrast with the lexical functions in the Explanatory Combinatorial Dictionary, which are general ones, holding for the lexicon as a whole.

The elaboration of a lexical database like FrameNet is an important development in the context of cognitive semantics, because it constitutes a link with computational lexical semantics. In general, the cognitive semantics movement is not as interested in an attempt to formalize semantic descriptions as are many of the neostructuralist models. Against the background of the questions that were activated by generativist semantics-the question of formalization and the question of cognitive adequacy-cognitive semantics clearly gives precedence to the latter. The FrameNet lexical database, however, is a major exception to this tendency.

\subsection{Usage and change}

Cognitive semantics has a natural affinity with historical-philological semantics: its emphasis on the flexibility of meaning, its broadly encyclopedic conception of meaning, and its cognitive orientation as such constitute an implicit 
return to the interests of prestructuralist types of semantics. Not surprisingly, cognitive semantics has shown a specific interest in diachronic semantics. In this section, we briefly survey the relevant work, from two different perspectives: the overall usage-based model of change and the descriptive contributions of cognitive semantics.

\subsubsection{Invited inference and pragmatics}

As a usage-based approach to meaning in general, cognitive semantics obviously takes a usage-based approach to meaning change in particular: new word senses emerge in the context of actual language use. Conceptually, this implies a distinction between decontextualized, coded meanings (stored in the language user's semantic memory) and contextualized readings that are realized in a specific discourse context. We have already discussed aspects of such a model in Chapter 4, and we are aware that from a historical point of view, this is not a novel idea: it is easily recognized as essentially the same model that lies behind Paul's distinction between an usuelle Bedeutung and an okkasionelle Bedeutung (see 1.2.2). That historical precedent is not often recognized by contemporary theorists, an example of the phenomenon we announced in the introduction to Chapter 1: the scholarship that emerged in the historical-philological era is not well known. The overall model comes in a number of terminological and theoretical guises, but the most articulate formulation is without doubt the Invited Inferencing Theory of Semantic Change initiated by Elizabeth Traugott $(1982,1985 \mathrm{~b}, 1988,1989)$ and described in great detail by Traugott and Dasher (2005). A crucial advance in comparison to earlier or more simple formulations of a usage-based model of change is the explicit reference to pragmatics in the Invited Inferencing Theory of Semantic Change. In fact, if new meanings arise at the level of discourse, the apparatus of linguistic pragmatics should be applicable to the relevant processes. Simplifying, this link with pragmatics takes two forms.

First, the contextualization of coded meanings takes shape through 'invited inferences', interpretations that are not expressed explicitly but are nevertheless intended or at least allowed by the speaker/writer. In a standard case of metonymy like Don't forget to fill up the car, the conclusion that it is not the entire car that needs to be filled with fuel is not an accident; it is intended by the speaker/writer. To explain how and when such inferences come about, Traugott and Dasher refer to the neo-Gricean pragmatic principles formulated by Horn (1984). These principles distinguish between a Q-heuristic (like the first Gricean maxim of Quantity: 'make your contribution sufficiently informative, and mean no more than that'), an R-heuristic (invoking the second Gricean maxim of Quantity, and the maxim of Relevance: 'say or write no more than you must, and mean more thereby'), and an M-heuristic 
(specifying Manner: 'marked expressions signal a marked meaning'). It is the application of the R-heuristic that can result in semantic change of the invited inference kind: the speaker/writer uses an expression that is less explicit than it might be, but the full interpretation can be safely retrieved by the hearer/reader.

Second, drawing on a distinction introduced by Levinson (1995), Traugott and Dasher suggest the following path for the process by means of which such invited inferences become conventionalized. As a first step, following the mechanism that we just described, a conventional coded meaning gives rise to an utterance-token meaning, in a particular context. As a second step, the utterance-token meaning may crystallize into an utterance-type meaning, i.e. a generalized invited inference that is the default interpretation of an expression but that may still be cancelled. For instance, after in After the trip to Minnesota she felt very tired would normally be interpreted as implying a causal link, but that inference may be blocked in a sentence like After the trip to Minnesota she felt very tired. It turned out that she had been sick for quite some time. In the latter sentence, it is no longer implied that she felt tired because of the trip. Finally, the utterance-type meaning may further stabilize into a new coded meaning, existing alongside the original one and sometimes replacing it. Note that the situation in which the inferences are activated together with the original meaning function as a bridging context between the new and the old meaning. An example of the process of conventionalization of implicature was presented earlier: see the reference to König and Traugott (1988) in section 4.1.3. Here, it may be useful to briefly discuss a few theoretical points raised by the Invited Inferencing Theory of Semantic Change.

In the first place, although the examples given so far only involve metonymies, the model is a general one. Novel metaphors too, for instance, may be seen as emerging in the form of invited inferences: a lover who addresses his beloved as squirrel triggers the implication that he sees her as lively and dynamic. Nevertheless, in the actual applications of the Invited Inferencing Theory of Semantic Change, the emphasis is on metonymic relations, and there may be a tendency to see invited inferences as a particular type of metonymy only. To avoid terminological confusion, it may be useful to distinguish between two levels that play a role here. On the level of speech acts, an inference is by definition metonymic: the utterance Squirrel, I love you triggers the thought 'He cannot mean that I am a rodent, so he must mean that I am agile, industrious, and inquisitive'. That is a process that is easily recognized as an example of a cause/effect metonymy. On the level of the propositional meaning of the predicates, however, the relation between the 'rodent' reading and the figurative reading cannot be classified as metonymic.

In the second place, let us repeat a point made earlier: making room for the contextual determination of meaning does not automatically imply 
that the stored meanings are monosemous or highly schematic. Sometimes, prototype-theoretical models of the type introduced in section 5.1 are reproached for being hyper-polysemous; it is unintuitive, so the argument goes, to include so many different readings in the mental representation of a word's meaning. But if the more specific readings are contextually derived specifications, it would seem that they need not be included in the structural depiction, and a far more parsimonious type of semantic description can be achieved. However, as we have discussed in section 4.1.3, it is an illusion to think that this approach does away with the necessity for a fine-grained account of the possibilities of use of a word. A psychologically realistic description of semantic change requires that contextualized readings leave traces: the traces are needed to ensure that, as a result of the growing entrenchment of peripheral readings, the internal structure of a category may change. That is also why there is a natural affinity between the usage-based model of semantic change and the prototype-based model of synchronic semasiological structure. The central senses that we find within prototypically organized categories are likely to be more conventional, while (traces of) less conventionalized readings would wind up in the less frequent periphery.

In the third place, we need to be aware that the mechanism of contextual specification does not entirely explain the process of conventionalization. If new meanings arise through the conventionalization of implicatures, then the recognition of the implicature by the hearer/speaker is only a first step: numerous language users have to do the same for the new reading to become conventional. Rudi Keller (1994) has introduced a revealing terminology to describe this kind of phenomenon. Borrowing a term from economic theory, he suggests that linguistic change may be described as an 'invisible hand' process. As applied to economic theory, the invisible hand metaphor involves two levels of analysis. On the micro-level, the economic life of a community consists of countless individual actions and transactions. Macro-economically, however, these individual actions result in global phenomena, such as inflation or an economic boom. Crucially, the individuals who engage in the basic transactions do not have the conscious private intention of, for instance, changing the rate of inflation. Nor do they act in accordance with a collective decision. Rather, phenomena like inflation are a cumulative consequence on the macro-level of a myriad of individual acts on the micro-level. Similarly, changes spread through a linguistic community as if guided by an invisible force, whereas the actual process involves a multitude of communicative acts.

The invisible hand metaphor, however, stops short of indicating precisely how the transition from the individual level to the global level occurs. What exactly are the mechanisms that enable the cumulative effects? Logically speaking, two situations may occur: either the changes work in parallel, or they take 
place serially. The first situation occurs when members of a speech community are confronted with the same communicative, expressive problem, and independently choose the same solution. The spread of a word like computer over many languages may (at least to some extent) have proceeded in this way. More or less simultaneously, a number of people face the problem of giving a name to the new thing in their native language; independently of one another, they then adopt the original name that comes with the newly introduced object. The second type occurs when the members of a speech community imitate each other. For instance, when one person introduces a loan word, a few others may imitate the initiator, and they in turn may be imitated by others, and so on. In the same way, the overall picture of a traffic jam is one in which a great number of cars appear to be halted by an invisible hand, while what actually happens is a cumulative process of individual actions: when the first car brakes to avoid a dog running across the road, the car behind him has to slow down to avoid an accident, and so on. But while these models of parallel and serial development are entirely plausible, our actual knowledge of the forces that determine how specific concepts evolve, is still relatively poor: the social nature of semantic conventionalization and lexical change is generally acknowledged, but seldom studied systematically.

\subsubsection{Mechanisms and regularities}

The descriptive contributions of cognitive semantics to diachronic semantics that we will focus on here lie in three fields: the diachronic application of prototype theory as a model of semasiological change, the search for regularities in semasiological changes, and the study of salience effects in diachronic onomasiology. In section 5.5.2, we will in addition have things to say about diachronic metaphor studies.

1 The relevance of prototype theory for the description and explanation of semasiological changes is analysed at length by Geeraerts (1997). Each of the prototypicality effects discerned in section 5.1.1 is shown to have specific consequences for diachronic semantics. Without going into too much detail, let us consider two examples, corresponding to features (a) and (c) of Figure 5.1.

By emphasizing the extensional non-equality of lexical-semantic structure, prototype theory highlights the fact that changes in the referential range of one specific word meaning may take the form of modulations on the core cases within that referential range. Changes in the extension of a single sense of a lexical item are likely to take the form of an expansion of the prototypical centre of that extension. If the referents that may be found in the range of application of a particular lexical meaning do not have equal status, the more salient members will probably be more stable (diachronically speaking) than 
the less salient ones. Changes will then take the form of modulations on the central cases: if a particular meaning starts off as a name for referents exhibiting the features $\mathrm{ABCDE}$, the subsequent expansion of the category will consist of variations on that type of referent. The further the expansion extends, the less features the peripheral cases will have in common with the prototypical centre. A first layer of extensions, for instance, might consist of referents exhibiting features $A B C D, B C D E$, or ACDE. A further growth of the peripheral area could then involve feature sets $A B C, B C D, C D E$, or $A C D$, to name just a few. In Geeraerts (1997), this hypothesis is supported by a case study involving a close inspection of the development of the clothing term legging in Dutch over the years 1988 to 1991 . The term was introduced as a neologism in 1988, as a name for close-fitting, long, elastic women's trousers. Over the five years studied, when the term was getting more and more popular, this initial type remains the core of the concept, measured in terms of its frequency within the category. At the same time, modulations of the core application make their appearance: leggings that are slightly less tight-fitting, that are made of other materials than the basic stretch fabric, that are shorter than the original type. As predicted by the prototype model, these modulations on the prototype appear gradually: over the years, the new types that are introduced are further and further removed from the centre.

By emphasizing the extensional non-discreteness of lexical-semantic structure, prototype theory highlights the phenomenon of incidental, transient changes of word meaning. That is to say, the synchronic uncertainties regarding the delimitation of a category have a diachronic counterpart in the form of fluctuations at the boundaries of the item. A specifically striking example of such fluctuations is the occurrence of 'semantic polygenesis'. Semantic polygenesis involves the phenomenon that one and the same reading of a particular lexical item may come into existence more than once in the history of a word, each time on an independent basis. Such a situation involves what may be called extremely peripheral instances of a lexical item-readings that are so marginal that they seem to crop up only incidentally, and that disappear as fast as they have come into existence. Specifically, when the same marginal reading occurs at several points in time separated by a considerable period, we can conclude that the discontinuous presence of that meaning is not due to accidental gaps in the available textual sources, but that the meaning in question must actually have come into existence independently at the two moments. The theoretical importance of semantic polygenesis resides in the fact that it illustrates the existence of transient applications in the diachronic development of lexical categories. In terms of the model discussed in section 5.4.1, these are applications of a category that do not make it to conventionalized status. They do not leave sufficient traces to be stored and transmitted as a 
separate meaning, but they are nevertheless available in the meaning potential of the word.

2 Cognitive semantics has given rise to a renewed interest in the possible regularity of semantic change. Are there any constraints or tendencies on the evolution of word meanings? Specifically, is there any directionality in semantic change, in the sense that certain kinds of meaning would naturally evolve towards another kind, but not the other way round? Two related lines of research illustrate this approach.

First, the subjectification approach is closely linked to the Invited Inferencing Theory of Semantic Change, and was in fact first formulated and developed by the same scholars. The background notion of the theory is the recognition that some linguistic forms involve the subjective perspective of the speaking subject more than others. Calling someone a boor is more subjective than describing someone as a sales manager: whether the latter description is correct may be settled objectively, but whether the former ascription is appropriate is likely to be a matter of opinion and debate. Against the background of this concept of subjectivity, subjectification is the process through which words acquire more subjective senses. In the words of Traugott (1999: 179),

If the meaning of a lexical item or construction is grounded in the socio-physical world of reference, it is likely that over time, speakers will develop polysemies grounded in the speakers' world, whether reasoning, belief, or meta-textual attitudes to the discourse. Subjectification, then, is the semasiological development of meanings associated with a form such that it comes to mark subjectivity explicitly.

A standard example of subjectification is the development of the epistemic senses of must. In the deontic reading, must expresses obligation: Mary must go home now. In the epistemic reading, as in Mary must be home by now, it expresses the speaking subject's personal conviction rather than a situation that exists independently of the speaker's judgement: the speaker believes that he or she can conclude with some certainty that Mary has reached her destination. A precise analysis of the word's history is required to establish whether the alleged order of development is indeed correct, but also to identify bridging contexts that support the idea that subjectification comes about through invited inferences. Traugott and Dasher's minute analysis of the history of must (2005: 120-37) includes a number of Middle English examples in which a deontic and an epistemic reading seem to co-exist.

The general notion of subjectification encompasses a number of more specific types. One of these involves the emergence of evaluative meanings, such as boor 'unmannered person' from boor 'farmer'. Another, which features 
prominently in Sweetser's seminal monograph on semantic change and polysemy patterns (1990), concerns the rise of textual and metalinguistic uses, such as when in fact develops into a discourse marker. In a passage like the following, in fact indicates that the second utterance is a more elaborate version of the first one, in particular, a more precise formulation than the first: It's purple. In fact, it's mauve. In cases like these, in fact signals the discourse relationship between the two utterances, rather than describing any fact outside the text.

Second, the search for regular patterns of polysemy and semantic change may be approached from a typological perspective, by looking at regularities-possibly even universals - in the historical relationship between (metaphoric) source and target domains in as many languages as possible. If the pattern is dominant in the languages of the world, occurring in many unrelated languages, it is a good candidate for a universal mechanism. At that point, the question arises as to what experiential factors might explain the salience of the association. This kind of perspective lies at the basis of the grammaticalization theory developed by Bernd Heine and his associates; important publications are Heine, Claudi and Hünnemeyer (1991), Heine (1997), and Heine and Kuteva (2002). The central question of the paradigm involves the motivation behind the creation of grammatical categories: can we understand why particular ways of forming grammatical categories are cross-linguistically more common than others?

An example, taken from Heine (2004), may illustrate the perspective. Looking at cardinal numbers in a wide variety of languages, Heine makes a number of observations. First, numeral systems having 5, 10, or 20 as the basis of their system are statistically predominant in the languages of the world, with systems based on 10 being most widespread. Second, the numerals for 5 and 10 often have nominal characteristics, while numerals from 6 to 9 often have a propositional, clause-like structure (like a phrase meaning 'add the big finger', or 'jump from one hand to the other'). Third, expressions used for the mathematical operation of addition frequently find their source in function words with the meaning 'with' or 'on, upon'. These observations find a plausible explanation in human experience. The hands provide an obvious model for structuring a counting system, and so the most common structure in the world's languages is one in which the expression for 5 is derived from that for 'hand', the expression for 10 from that for 'two hands', and the expression for 20 from that for 'hands and feet' or 'whole person'. Even when these numerals no longer have a nominal meaning but have become pure numerals, they may still have morphological and grammatical properties that show that they are relics from nouns. In a similar way, it seems plausible that the expression of an abstract mental operation like arithmetical addition finds its source in more 
concrete acts, like putting things together ('with') or on top of each other ('on, upon').

But the search for regularity does not necessarily yield universal patterns that occur in unrelated languages. It could just as well be the case that a given pattern is specific to a language family, language type, or culture (Wilkins 1996). An example of the latter situation is Vanhove's typological study of the sources of verbs of mental perception (2008). She makes a distinction between the source domain of vision (I can see what you mean), hearing as a source domain (will you listen to me, i.e. obey), and prehension verbs as a source domain (he didn't grasp her meaning). She notes that, contrary to the suggestion in among others Sweetser (1990), the connection between vision and knowledge is not dominant cross-culturally. This is in line with the findings of Evans and Wilkins (2000), who pointed out that this particular association is marginal in the Australian languages. Also, in the sample studied by Vanhove, the semantic association between vision and cognition is not geographically universal, but is by contrast restricted to specific areas. It occurs only in Europe, a European-based creole of South America, and parts of Africa, to the exclusion of the other language families and areas. In such a case, explanations might look for cultural factors rather than universal, experientialist ones-which does not mean that they would easily be found.

3 The cognitive interest in differences of weight may be translated into an investigation into lexicogenetic salience effects. 'Lexicogenesis', it will be recalled, involves the mechanisms for introducing new pairs of word forms and word meanings - all the traditional mechanisms, in other words, like word formation, word creation, borrowing, blending, truncation, ellipsis, and folk etymology, that introduce new items into the onomasiological inventory of a language. Crucially, semasiological change is a major mechanism of lexicogenesis, i.e. of introducing new pairings of forms and meanings. Within the set of lexicogenetic mechanisms, some could be more salient (i.e. might be used more often) than others. Superficially, this could involve, for instance, an overall preference for borrowing rather than morphological productivity as mechanisms for introducing new words, but from a cognitive semantic perspective, there are other, more subtle questions to ask: do the ways in which novel words and expressions are being coined reveal specific (and possibly preferred) ways of conceptualizing the onomasiological targets? An example of this type of research (though not specifically situated within a cognitive semantic framework) is Alinei's work (1996) on the etymological patterns underlying the European dialects: he argues, for instance, that taboo words in the European dialects may be motivated either by Christian or Islamic motifs, or by pre-Christian, pre-Islamic heathen motifs; the 'quantitative' perspective 


\begin{tabular}{|c|c|c|}
\hline \multicolumn{3}{|c|}{$\begin{array}{c}\text { target concept: 'match; short, slender piece of wood or other material } \\
\text { tipped with a chemical substance which produces fire when rubbed } \\
\text { on a rough or chemically prepared surface' }\end{array}$} \\
\hline target form & process/relation & source form \\
\hline English match & $\begin{array}{l}\text { semantic change / } \\
\text { metaphorical similarity }\end{array}$ & English match 'wick' \\
\hline French allumette & $\begin{array}{l}\text { semantic change / } \\
\text { taxonomic subordination }\end{array}$ & $\begin{array}{l}\text { French allumette 'splinter } \\
\text { for the transport of fire' }\end{array}$ \\
\hline German Streichholz & $\begin{array}{c}\text { compound / } \\
\text { metonymy + metonymy }\end{array}$ & $\begin{array}{c}\text { German streichen 'to rub' } \\
+ \text { Holz 'wood' }\end{array}$ \\
\hline Spanish fósforo & $\begin{array}{c}\text { loan + conversion / } \\
\text { metonymy }\end{array}$ & $\begin{array}{l}\text { Old Greek phosphóros } \\
\text { 'fire-bringing' }\end{array}$ \\
\hline Spanish cerilla & $\begin{array}{l}\text { semantic change / } \\
\text { metaphorical similarity }\end{array}$ & $\begin{aligned} & \text { Spanish cera 'wax' } \\
+ & \text { diminutive suffix - illa }\end{aligned}$ \\
\hline
\end{tabular}

FIGURE 5.9. The diachronic onomasiology of 'match' according to Blank

then involves the question whether one of these motifs is dominant or not. On a broader scale, the etymological research project started by Andreas Blank and Peter Koch (Koch 1997, Blank and Koch 1999, 2003), intends to systematically explore motivational preferences in the etymological inventory of the Romance languages. In comparison with much of the metaphor-oriented research that was introduced in the previous section, the approach put forward by Blank and Koch takes into account all possible pathways of lexicalization (and not just metaphor).

Descriptively, the approach takes the form of overviews like that in Figure 5.9, adapted from Blank (2003). The figure charts the different names for the target concept 'match' in a number of European languages, as identified in the first column. Each of these names is itself derived from a source form, as may be found in the final column. Source form and target form are related in specific ways, specified in the second column of the table. The relationship involves both a formal process and a semantic relation. The English target form match, for instance, is related by a process of semasiological change to the older reading match 'wick'. Semantically, the relationship between 'wick' and 'short, slender piece of wood or other material tipped with a chemical 
substance which produces fire when rubbed on a rough or chemically prepared surface' is one of metaphoric similarity. German Streichholz, on the other hand, is related to the verb streichen and the noun Holz through a process of compounding; semantically, the relationship between target form and source form is metonymical. Needless to say, the source forms may often themselves be further analysed as target forms: allumette 'splinter designated to transport fire, for instance, is related by a process of suffixation and a semantic relationship of metonymy to the verb allumer 'to light' and the suffix -ette.

If sufficient materials of the form illustrated in Figure 5.9 are available, it will be possible to compare the relative salience of different lexicogenetic mechanisms, not just on the abstract level—where, for instance, the importance of metonymy in general would be gauged against the importance of metaphor in general-but, more importantly, also on a more fine-grained level, where the conceptualization of a specific target concept can be investigated:

Combining diachronic lexicology with onomasiology and applying it to more than just one or a few languages allows us to show, in an empirically justified way, which conceptualizations are proper to a single or very few speech communities versus those that can be found universally and thus may match a biological predisposition of perceiving the world. Cognitive onomasiology hence can procure us deeper insight into the way our mind works.

(Blank 2003: 44)

At the same time, we need to be aware that this type of 'quantitative' onomasiological work is still situated at the level of language structure: the basic data are lexical items with an entrenched position in a language. If we try to understand how such mechanisms reach such a position, we will have to change to a different kind of onomasiology, in which the onomasiological choices that language users make in specific usage contexts are investigated; only such a pragmatic onomasiology might lead to an insight into the invisible hand processes that promotes a given onomasiological possibility to an entrenched position in the language.

\subsection{Cognitive semantics in context}

In the previous sections, we saw that cognitive semantics makes significant contributions to the development of lexical semantics. Let us summarize the main points. First, by focusing on differences of salience between members of categories (and different readings of polysemous items), cognitive semantics leads to innovative ways of analysing the internal semasiological structure of words. Second, a renewed interest in the semantic relations between the elements of such semasiological structures triggers a 
reconsideration of metaphor and metonymy and their interaction. Third, by highlighting the importance of conceptualization phenomena that transcend the level of the individual lexical item, cognitive semantics stimulates research into regular patterns of polysemy and semantic change, and-in the form of frames-identifies new forms of onomasiological structures in the lexicon.

All of this establishes that cognitive semantics is a major force in contemporary lexical semantics. But does it also mean that cognitive semantics entirely lives up to its own programme? Cognitive semantics emerged as a 'maximalist' form of semantics, in which the structuralist heritage of isolating semantics within the language is substituted for a contextualized approach, in which natural language semantics is seen against the background of different types of context: psychology, language use, and a broader cultural and historical canvas. But to what extent has cognitive semantics achieved that programme? In this section, we will look at each of those three major context factors (the psychological study of the mind, the sociocultural environment, the usagebased study of actual text and discourse) and point to a number of areas that should be developed further if cognitive semantics is to complete what appears to be its intrinsic programme. In each section, we will focus on two specific areas of research: first, linking up with section 5.2, the study of metaphor, and next, linking up with section 5.1, the study of polysemy and categorization at large.

\subsubsection{Meaning in the mind}

The maximalist orientation of cognitive semantics suggests a close alliance with psychological research: a theory that aspires to cognitive realism should ideally link up with what other disciplines have to say about meaning and the mind. In this section, we will see that the actual situation does not yet correspond to that ideal. We will pay attention to two cornerstones of cognitive semantics that we have learnt about in the previous sections-prototypicality and metaphor-and we will briefly compare what we have learnt about the linguistic theories with how psychologists study the phenomenon in question. A relatively short section like this one can obviously not aim to give an overview of psycholexicological research as such, but will serve the purpose of comparison only. Regarding prototypicality research, we can notice that, in spite of their common origin, linguistic and psycholinguistic categorization research have gone largely separate ways, at least in practical terms of mutual interaction and communication. Regarding metaphor research, we will notice more interaction, but we will also see that the findings of the psychological approach are not always consonant with that of the linguistic approach as represented by standard Conceptual Metaphor Theory. In both cases (and 
this is the major point to be made in this section), there appears to be a lot of room for a further rapprochement between cognitive semantics and psycholinguistics.

1 In the domain of metaphor research, there is a considerable degree of interaction between linguistic metaphor studies and psychology. In the context of Conceptual Metaphor Theory as a linguistic theory, the psycholinguist Raymond W. Gibbs has consistently argued, since the inception of the theory in the 1980s, for experimental corroboration of the linguistic analyses (Gibbs 1994, 1999a, 2006). In more recent years, neuroscience has been added to the repertoire of tools for studying metaphor in the brain (see Coulson 2008 for an overview). At the same time, psychologists who have developed major theories of metaphor processing, like Sam Glucksberg and Dedre Gentner, are well aware of the developments in linguistic semantics.

An overview of the state of the art in experimental metaphor research is beyond the scope of the present book, but we will introduce two particularly relevant examples. The first establishes one of the basic claims of the recent rise of interest in metaphor: metaphor is not mere rhetorical ornament, but it interacts with experience and imagination. The second illustrates how the linguistic characteristics of metaphoric expressions may influence their online processing. Here, the basic idea is that the degree of conventionalization of metaphors influences the way they are processed psychologically: the difference between novel and established metaphors-typically a characteristic that usage-based approaches in linguistics are interested in-affects psychological processes.

If at least some metaphors have an embodied experiential background, then understanding those metaphors may involve imagining or re-enacting the embodied experience behind that metaphor. Take the metaphors of motion that we use to talk about time: would the use of such metaphors interact with actual or imaginary movements? Boroditsky and Ramscar (2002) studied the interpretation of sentences like next Wednesday's meeting has been moved forward two days. Such a sentence is ambiguous: the meeting could be moved to Friday (forward in time in the direction in which we imagine time to move) or to Monday (forward in the sense of being closer to the moment of speaking). In a series of studies, the sentence was presented to students waiting in line at a café, with the question when the meeting would be held. Students who were further up the line, i.e. who had moved more than the ones at the back of the queue, were more likely to say that the meeting had been moved to Friday. In other words, actual physical experience of movement influences the interpretation of motion metaphors. In a further experiment, Matlock, Ramscar, and Boroditsky (2004, 2005) revealed the same effect with fictive 
motion sentences like the road runs along the coast, in contrast with the nonfictive motion sentences like the road is next to the coast. Subjects who read a fictive motion sentence before answering the test question were more likely to respond Friday than the ones who read the non-fictive motion sentence. Movement as a bodily process, in other words, is evoked by motion metaphors: at least some metaphors are not entirely dead; in the right circumstances, they may exhibit clear signs of life, in the sense of activating the source of the metaphoric image.

But how lively might some metaphors be? Two important theories of metaphoric processing specifically take into account the distinction between novel and conventional metaphors. According to the 'career of metaphor' framework (Bowdle and Gentner 2005, Gentner and Bowdle 2008), metaphoric expressions undergo a process of gradual abstraction as they move from being a novel metaphor to a conventionalized one. Crucially, the type of processing that the metaphors are subject to differs in the two stages. When metaphors are new, they are processed (so the claim goes) according to the structure-mapping theory that Gentner (1983) developed as a general theory for the processing of analogy. According to the structure mapping theory, analogies are interpreted through a process of structural alignment. The starting point for the structural alignment hypothesis is the idea that lexical concepts are no isolated entities, but form part of larger semantic structures. Needless to say, this is a standard idea both in structuralist and cognitive linguistic semantics: lexical items are seen in the context of lexical fields, relational networks, input spaces in blends, frames, or other 'larger chunks of knowledge', as the case may be. The interpretation of metaphors and analogies then implies finding parallelisms between the structures in which target concept and source concept appear. For instance, if Socrates is compared to a midwife (a classic metaphor from Plato, studied in detail in Kittay and Lehrer 1981), the source concept exhibits a structure in which the source term midwife has an instrumental, supporting role in a process in which one entity (an expecting mother) gives birth to another entity (a child). The target structure for Socrates is structurally similar: Socrates has an instrumental, supporting role in a process in which one entity (Socrates' pupil) produces another entity (an idea). Crucially, this parallelism does not exist before the novel metaphor is used, but is creatively computed by looking for a maximally coherent alignment. The idea of structural alignment is developed by Gentner with specific reference to the sophisticated (but somewhat neglected) theory of metaphor formulated by Kittay (1987), but it will be clear that it is not incompatible with the kind of source/target correspondences that are used in Conceptual Metaphor Theory and blending theory, as introduced earlier. 
However (and this is a point with which the proponents of Conceptual Metaphor Theory might have more difficulties), the process in which language users actively search for structural alignments between source and target is not activated with all metaphors. As metaphoric mappings are repeated, they become more and more entrenched, and the metaphoric reading of the source term establishes itself as a stable non-literal meaning alongside the initial sense-again, a process of usage-based language change that is entirely consonant with what we discussed in section 5.4.1 and elsewhere. When a metaphoric expression has reached this stage of polysemy, on-line processing does not conform to the structure-mapping theory, but rather to the categorization theory developed by Glucksberg (2001, Glucksberg and Keysar 1990). According to this approach, metaphor comprehension is not based on comparison, not even in the form of a creative structure mapping of the type suggested by Gentner, but on categorization. Interpreting a metaphor involves retrieving or creating a superordinate category that includes both the source and the target. My lawyer is a shark, for instance, categorizes the lawyer as a member of a category that includes lawyers and sharks: a category of 'vicious, aggressive, merciless predators'. Glucksberg intends the categorization model to apply to novel and conventionalized metaphors alike, but in Gentner's view, it would only be valid for conventional metaphors.

Conventionalization, in fact, is a matter of degree. Next to metaphors that automatically activate their source domain, like the shark example, dormant metaphors are those whose source domains may be activated by the right kind of priming. (The results with the motion verbs mentioned above are probably of this kind.) Finally, there are entirely dead metaphors, whose motivating context can no longer be retrieved by the contemporary language users. (Why is a red herring 'a misleading topic, a distraction' called a red herring?) Both the structure-mapping and the categorization approaches agree that a processing model needs to make a distinction between novel and established metaphors: there is ample experimental evidence that conventional metaphors are processed more quickly (Gildea and Glucksberg 1983). Gentner describes the difference by allocating the structure-mapping model to one type and the categorization model to the other. Glucksberg describes the difference in terms of relative salience: in novel metaphors, the superordinate figurative category has to be computed on the spot, whereas in conventional models, it may be retrieved from the mental lexicon; it may, in fact, be more prominent than the literal meaning (Giora 2003).

Although Gentner proposes the career-of-metaphor model as a kind of compromise between the categorization view and the structure-mapping view, the debate is not settled: see Glucksberg (2008), who argues that both models assume too much similarity between metaphors and similes. For our present 
purposes, the essential point is not to decide between both models, but rather to note how the attention that both devote to the distinction between novel and conventional metaphors suggests interesting forms of cooperation between linguistics and psychology. Given that conventionalization is a diachronic process, a collaboration with historical linguistics may be envisaged, and if degrees of conventionalization can be measured through corpus analysis, a link with corpus linguistics is advisable.

2 Current categorization studies in cognitive semantics, as a linguistic discipline, and psychology both have their origin in the prototype-theoretical research conducted by Rosch in the late 1970s and early 1980s, which we presented in section 5.1. The psychological research reported in Smith and Medin (1981), a then state-of-the-art overview of categorization studies, was by and large familiar to the cognitive semanticians working in that era. But if we take Murphy (2002), the contemporary counterpart to Smith and Medin (1981), it would be difficult to maintain that the studies of the last 20 years that are covered by Murphy are well known in circles of cognitive semanticists. And the reverse, to be sure, is just as true: there are hardly any references in Murphy's book to linguistic work of the type that we sketched in section 5.1. If we try to take a more systematic look at the situation, in what ways exactly do the two traditions differ? Concentrating on essentials, we need to point to differences of method on the one hand and differences of theoretical and descriptive scope on the other.

In methodological terms, psychological categorization research is characterized by two features that are all but absent in mainstream cognitive semantic research into prototypicality effects: experimentation and quantitative modelling. As we saw earlier in this section, experimentation is not a dominant method in cognitive semantics, and in addition, the role of quantitative modelling tends to be much less important (not to say highly marginal). In psychological categorization research, statistical techniques for data analysis and formalized quantitative representations of categorical structure are of prime importance. This is in keeping with the overall methodological perspective of experimental psychology, and cognitive science in the larger sense. Analysing large sets of experimental data requires statistical analysis, and if you want to test specific hypotheses about semantic memory or online processing of semantic information, those hypotheses will have to be formulated explicitly. The type of formal modelling that may be found in psychological categorization research goes well beyond the informal types of representation that we find in most research in cognitive semantics, but it also goes further than the major types of formalization that we discussed in Chapter 4 , in the sense that the attention paid to quantifiable information 
in psychological research is much greater than it tends to be in mainstream linguistics.

In fact, some of the models that were initially suggested as psychological representations of category structure link up closely with basic ways of thinking about the lexicon that were introduced by structuralist semantics. Thus, we can distinguish between feature-based models and network models. An example of the former is the feature comparison theory described in Smith, Shoben, and Rips (1974). In this model, a distinction is made between the defining and the characteristic features of a category. Defining attributes hold for all members of the category; characteristic attributes only hold for the most, or the most typical, members. Those non-defining features have different weighting according to their salience within the category (say, the proportion of members of the category that they apply to). Defining features-i.e. features that apply to all the members of a category-have the maximum feature weight. The overall logic of a model like this one assumes that questions about category membership (is a bat a bird?) are answered by comparing categories and calculating a membership degree on the basis of the weighted features.

Network models, like relational approaches in structuralist semantics, connect concepts and features by means of labelled links. Analogously, a structuralist lexical relations model may be thought of as a set of labelled links between lexical items: swallow and bird are connected by a hyponymy/hyperonymy link, while black and white are connected by an antonymy link, and so on. In the network models used in psychology (and cognitive science in the broader sense), the labels are not of the same kind as in relational semantics. Rather, the labels would themselves be predicates like is $a$ or has. An early example of a network model in psychology is the spreading activation model proposed by Collins and Loftus (1975). In this model, if we take the concept swallow and the concept bird, both would be connected to sing by a can link, or to feathers by a has link, or to winged by an is link. But in addition, the links would receive weighting, largely like the features in the feature comparison theory. The link to sing, for instance, would be stronger for swallow than for bird, because singing is more typical for the swallow than for birds in general. When two concepts are activated in the mind, the activation spreads through all the links connected with those concepts. So, if 'swallow' and 'bird' are activated simultaneously, the activated lines would meet at the feature of feathers, among others. If the labels on the intersecting links are the same, the features would count as matching. A calculation of matches and mismatches may then lead to a decision about category membership. The weighting on the links comes into play to explain the speed with which such decisions are made, by influencing how easily a point of intersection is reached. 
The feature comparison theory and the spreading activation model are mentioned here not because of their current relevance: they have long been superseded by alternative models. Rather, we present them because they nicely illustrate important features of early representational models in psychology. In both cases, they resemble representational formats used in linguistics: a decompositional approach, and a relational approach. But in both cases, they go beyond those linguistic formats in two crucial ways. First, they take the non-classical view of concepts for granted, and translate the absence of classical, necessary-and-sufficient definitions into weightings attached to different elements in the knowledge representation. Second, they try to be explicit about the ways in which such mental representations of semantic information are used in conceptual tasks like assessing the truth of $a$ bat is a bird-the kind of tasks investigated in the psychological experiments that constitute the empirical basis of psychology. Now, if we think back to the distinction that we introduced earlier between symbolic and probabilistic models of knowledge (see the introduction to section 4.2), it will be clear that psychological modes of representation of the type just discussed are on the probabilistic side. Without giving an overview of the further developments (see Murphy 2002, Storms 2003), we should note that statistical modes of representation have been gaining in importance.

Let us now turn to the theoretical and descriptive part of our comparison of linguistic and psychological research into concepts and categories. To do so, we will summarize Murphy's state of the art overview, as a basis for a contrastive analysis with the situation in linguistics. Murphy distinguishes between four models of category structure: the classical view, the prototype view, the exemplar view, and the theory view.

The classical view, as Murphy calls it, holds that concepts are defined by necessary and sufficient conditions. We have described the major problems faced by this view in section 5.1. From a linguistic point of view (and also a philosophical one, if we include Wittgenstein's discussion), it turns out to be very difficult to specify such necessary and sufficient conditions for actual concepts. From an experimental point of view, the classical conception encounters difficulties with the experimental investigations conducted by Rosch and her colleagues in the 1970s. Gradience of category membership, for instance, is difficult to represent in terms of a classical approach.

The prototype, exemplar, and theory view of concepts are probabilistic alternatives to the classical view-probabilistic, in the sense that they allow for gradient membership and differences of salience of descriptive features. According to the prototype and exemplar models, semantic memory for concepts is based on a subject's memories of past experiences with instances of those concepts. In an exemplar approach, concepts are represented in terms of 
individually remembered instances: our knowledge of dogs in general resides, for instance, in what we know about the neighbour's Jack Russell, and in our childhood memories of Lassie, the collie that starred in the television series of the same name. In a so-called prototype approach (we will have to come back to the terminology in a moment), these memory traces are summarized into a single descriptive representation. Concepts are schematic summary representations-definitions, if you like-abstracted from the category members that we have experience of. The theory view, finally, emphasizes that concepts are part of our general knowledge of the world. But that knowledge is not a loose collection of separate facts and assumptions; instead it takes the form of internally coherent complexes of beliefs and expectations. As such, concepts exhibit structured relationships with other concepts, and those relations influence the way in which the concepts are used and retained.

Murphy meticulously reviews the experimental work on the four models, but does not reach a conclusion that indubitably favours one model over the others. With the exception of the classical view, each of the approaches turns out to be the best explanation for a particular series of empirical findings. Murphy's overall conclusion, then, tends towards a multi-model representation that does not assume that a single form of conceptual representation accounts for all the observed phenomena:

On the proposal I am making, people attempt to form prototypes as part of a larger knowledge structure when they learn concepts. But at the same time, they remember exemplars and these memories may influence them in a variety of ways. In short, concepts are a mess.

(Murphy 2002: 492)

If we now compare the theoretical situation described by Murphy with what we know about categorization research in linguistics, a number of striking similarities and differences emerge. Overall, the type of phenomena that Murphy considers are homologous to what we find in linguistics. The exemplar view corresponds to an extensional view of prototypicality effects. The prototype view corresponds to an intensional perspective. And the theory view corresponds to the idea, looming large in cognitive semantics, that individual concepts have to be seen in the context of larger meaningful structuresIdealized Cognitive Models, or frames, or more structuralistic ensembles like taxonomies and semantic fields. These correspondences reveal that, starting with the common rejection of a classical theory of concepts, there is a whole area of common ground between cognitive semantics and psychological categorization research. However, there are also quite important differences.

First, the most remarkable is the divergence in the terminology. The notion of 'prototype-based approaches' in linguistics covers both the 'exemplar view' and the 'prototype view' in psychology. In fact, 'prototype' in linguistics 
probably refers primarily to an extensional, exemplar-based perspective, while the intensional perspective is seen as an extension of the initial emphasis on category members. A fundamental term like 'prototype', in short, receives radically different interpretations in both disciplines. That in itself is not disastrous, but it does show that the two disciplines are not communicating very actively.

Second, the descriptive and theoretical scope of psychological research is restricted in comparison with linguistics. Descriptively, the set of concepts studied in psychology very much stays within a specific range, with a predominance of concrete nominal concepts, either natural kinds or artefacts. Although concrete nouns tend to occupy an important position in linguistic semantics as well, the net is cast wider in linguistics: abstract nouns, adjectives, and verbs have been extensively studied in cognitive semantics from the point of view of polysemy and prototypicality—not forgetting the prolific literature on prepositions. Theoretically, questions of polysemy (which occupy a major position in linguistic discussions) are peripheral in psychological studies, in spite of their close relationship with the rejection of a classical view of categorization (as we learnt in 5.1.2).

And third, the degree of integration between the various views that Murphy distinguishes is much bigger in linguistics. In Murphy's account, the exemplar view, the prototype view, and the theory view are considered as competing accounts, leading to the conclusion that it is not possible to make a definitive choice between them, and to the tentative suggestion that different concepts may demand different models. But that is a point of view that would be more or less taken for granted in linguistics. We have seen in section 5.1 how an intensional ('prototype') and an extensional ('exemplar') view of categories hang together, and how different concepts may be variously characterized with regard to these different prototype effects. We have also seen, in section 5.3, that the relevance of situating individual concepts in 'larger chunks of knowledge' is a fundamental assumption of cognitive semantics, and how these broader encyclopedic structures may help to explain prototype effects. The integrated perspective towards which psychological categorization research seems to be heading is already part and parcel of linguistic research.

Summarizing our overview of psychological categorization research, if we combine the methodological and the theoretical comparison of linguistic and psychological categorization research, the two disciplines appear to share a historical and a conceptual common ground, but they are not as perfectly aligned as the implicit claim of cognitive semantics to psychological realism would suggest. Still, we can readily see how an increased interaction between the disciplines could start to take shape: the psychological approaches could 
draw inspiration from the theoretical advances in linguistics, and cognitive semantics could profit from the methodological caution and thoroughness of psychological research. Formulating models and hypotheses with sufficient accuracy so that they can be tested against the empirical basis is not the dominant practice in cognitive semantics, where the bold formulation of theories tends to receive more attention.

\subsubsection{Meaning in culture and society}

We noted earlier that historical research may be necessary to establish the exact source of a metaphor. But the question is broader: if the metaphoric status of an expression may depend on historical circumstances, then there may also be cultural variation in metaphors. And if we envisage the possibility of cultural variation, the scope of the question may be widened even further: what is the role of social factors in linguistic meaning, and how does cognitive semantics deal with the sociohistorical situatedness of meaning? We will first discuss the question with regard to metaphor research, with specific attention to the tension between a universalist and a sociohistorical reading of metaphors. In the second part of the section, we discuss the distinction between stereotypes and prototypes, with specific attention to the role of semantic norms.

1 A diachronic perspective on metaphors is not just important for deciding between an onomasiological and a semasiological motivation for metaphors; it also touches upon a matter that is at the core of cognitive metaphor research-the experiential nature of metaphors. We saw earlier that the experiential grounding of metaphors is very often seen from a universalist perspective, in terms of embodiment. But historical and cross-cultural research has made clear that metaphors may have historically and culturally specific sources, i.e. sources that are not universal but that tie in with a specific culture and a specific historical development. We will consider two examples, one from historical linguistics and one related to anthropological linguistics.

An ongoing debate concerning image schemas involves their contextualized and situated nature. Talking about spatial containment, Gibbs (1999b: 154) aptly expresses the basic idea as follows:

Containment is not just a sensorimotor act, but an event full of anticipation, sometimes surprise, sometimes fear, sometimes joy, each of which is shaped by the presence of other objects and people that we interact with. Image schemas are therefore not simply given by the body, but constructed out of culturally governed interactions.

Other voices following this line are Sinha (1999), Sinha and Jensen de López (2000), Zlatev (2005), and Kimmel (2005). In a contextualized view 
of image schemas, bodily experience is situated in a sociocultural environment, and social setting is seen as co-determining the corporeal experience. Shore (1995) provides examples from the field of comparative anthropology. He demonstrates that two basic image schemas, front-back and centre-periphery, correlate with specific organizational principles of Samoan villages.

On the one hand, Samoan villages are commonly situated along the coast, with a seaward or front part separated from an inland or back part by a road or path, following the coastline. This organizational model is a 'conventional social geography', as Shore calls it (1995: 268). In general, the front for Samoans stands for high rank, social authority, and constrained, correct behaviour, while the back stands for low rank and impulsive behaviour. Analogously, the spatial layout of the villages has a moral orientation. The sea area of the village suggests organized society, the authority of the village chiefs, and dignified, publicly visible behaviour. The bush area, on the other hand, is considered rural instead of urban, unsophisticated, and possibly antisocial.

On the other hand, the front-back spatial model coexists with another spatial-cultural model, which distinguishes the centre of the village (with the village green and the chiefs' houses) from the outskirts. In contrast with the front-back orientation, this centre-periphery distinction does not take the form of a binary opposition, but it defines a gradual dimension of dignity, order, and formality. Moving away from the centre of the village in concentric zones, the domain of the sacred shifts into the domain of the profane, and accordingly, certain types of behaviour are more acceptable in the periphery than in the centre, where formally respectful and polite behaviour is required. The gist of Shore's discussion is that bodily experience has a cultural component: in the Samoan villages, experiencing front-back or centre-periphery schemata is not a purely spatial or corporeal phenomenon, but is associated with a culturally conventional symbolic pattern.

A diachronic example of the importance of cultural and historical specificities comes from the ANGER IS HEAT metaphor. Conventionalized phrases such as those below have been subsumed by Lakoff and Kövecses (1987) under the conceptual metaphor ANGER IS HEAT, which is further specified into ANGER IS THE HEAT OF A FLUID IN A CONTAINER when the heat applies to fluids, and into ANGER IS FIRE when the heat is applied to solids.

I had reached the boiling point. She was seething with rage. He lost his cool. You make my blood boil. He was foaming at the mouth. He's just letting off steam. Don't get hot under the collar. Billy's a hothead. They were having a heated argument. When I found out, I almost burst a blood vessel. He got red with anger. She was scarlet with rage. I 
was fuming. When I told him, he just exploded. Smoke was pouring out of his ears. He was breathing fire. Those are inflammatory remarks. That kindled my ire. He was consumed by his anger.

At a lower level of analysis, these and many similar expressions are grouped together under labels like the following: when the intensity of anger increases, the fluid rises (his pent-up anger welled up inside him), intense anger produces steam (I was fuming), and when anger becomes too intense, the person explodes (when I told him, he just exploded). Lakoff and Kövecses interpret these findings in terms of physiological effects: increased body heat is taken to be a physiological effect of being in a state of anger, and anger is metonymically conceptualized in terms of its physiological effects. Geeraerts and Grondelaers (1995), however, drew attention to emotion expressions like the following, which appear in a number of European languages.

English phlegmatic 'calm, cool, apathetic', French avoir un flegme imperturbable 'to be imperturbable', Dutch valling (dialectal) 'cold';

English spleen 'organ filtering the blood; sadness', French mélancolie 'sadness, moroseness', Dutch zwartgallig 'sad, depressed' (literally 'blackbilious');

English bilious 'angry, irascible', French colère 'anger', Dutch z'n gal spuwen 'to vent (literally 'to spit out') one's gall';

English full-blooded 'vigorous, hearty, sensual', French avoir du sang dans les veines 'to have spirit, pluck', Dutch warmbloedig 'passionate' (literally 'warm-blooded').

All of these are lexical relics whose historical source seems to lie with the theory of humours, the highly influential doctrine that dominated medical thinking in western Europe for several centuries. The foundations of the humoral doctrine were laid by Hippocrates of Kos (460-370 BC). Physiologically, the four humoral fluids regulate the vital processes within the human body; the secretion of the humours underlies the dynamical operation of our anatomy. Psychologically, on the other hand, they define four prototypical temperaments, i.e. a person's character is thought to be determined by the preponderance of one of the four vital fluids in his body. Thus, the choleric temperament (given to anger and irascibility) is determined by a preponderance of yellow bile, while the melancholic, gloomy and fearful, suffers from a constitutional excess of black bile. The phlegmatic personality is typically placid and unmoved, while the sanguine temperament (defined in correlation with blood, the fourth humour) is passionate, optimistic, and brave. The singular combination of physiological and psychological concepts that 
characterizes the theory of humours also shows up in the fact that a disequilibrium of the fluids does not only characterize constitutional temperaments, but also causes temporary diseases - which are then typically described in bodily, biological terms as well as in psychic terms. In this sense, the humoral theory is a medical doctrine: it identifies diseases and their symptoms, and defines a therapy. Obviously, the basic therapeutic rule will be to restore the balance of the humours, given that a disturbance of their well-balanced proportion is the basic cause of the pathological situation. The long-lasting popularity of blood-letting, for instance (a standard medical practice that continued well into the nineteenth century), has its historical origins in the theory of humours.

The examples given above (and numerous others) relate to the humoral doctrine. Respectively, the four sets of examples refer to the humoral characteristics of choler, black bile, yellow bile, and blood. But if the lexical relics of the humoral doctrine are so pervasive, the conceptual metaphor ANGER Is THE HEAT OF A FLUID IN A CONTAINER appears also to fit into the humoral views: the body is the container of the four cardinal fluids, and anger involves the heating up of specific fluids (either yellow bile as the direct source of ire, or blood as the mixture of the four humours). As a consequence, the purely physiological interpretation put forward by Lakoff and Kövecses needs to be interpreted along cultural and historical lines. When we recognize that the medieval physiological-psychological theory of the four humours and the four temperaments has left its traces on our emotional vocabulary, we learn to consider the ANGER IS THE HEAT OF A FLUID IN A CONTAINER metaphor as one of those traces. It is then not motivated directly by the physiological effects of anger, as Kövecses and Lakoff suggest, but is instead part of the historical (but reinterpreted) legacy of the humoral theory.

More generally, an adequate analysis of the motivation behind cultural phenomena in general and language in particular has to take into account the diachronic dimension. Cultural models, i.e. the more or less coherent sets of concepts that cultures use to structure experience and make sense of the world, are not reinvented afresh with every new period in the culture's development. Rather, it is by definition part of their cultural nature that they have a historical dimension. It is only by investigating their historical origins and their gradual transformation that their contemporary form can be properly understood. In recent years, the importance of culture for metaphor research has received increasing recognition, including among the major advocates of Conceptual Metaphor Theory: see Kövecses (2005), and compare the following section. At the same time, the methodological importance of adding a diachronic dimension to metaphor research has not yet gained a wide acceptance. Cross-cultural studies of metaphoric patterns and conceptual metaphors are gathering 
momentum (for examples see Yu 1998, 2009, Dirven, Frank, and Ilie 2001, Dirven, Hawkins, and Sandikcioglu 2001, Dirven, Frank, and Pütz 2003, Boers 2003, Littlemore and Low 2006, Sharifian, Dirven, Yu, and Niemeier 2008), but diachronic research into the history of metaphors (as in the work of Fabiszak 2001, Tissari 2001, Gevaert 2005, Trim 2007, Allan 2009) is not yet a standard counterpart of the synchronic approaches.

2 When we turn our attention to prototypicality research, the relevance of a sociocultural perspective becomes clear if we consider the role of convention in the constitution of lexical categories. In a category like 'fruit', social convention is so to speak built in: if a feature of the kind 'commonly used as dessert' is relevant, then there is an implicit link to particular social customs. In China the cherry tomato is considered a fruit, and treated as such in the culinary repertoire: you will find it served together with bananas and apples and the like. More generally, assuming the absence of necessary and sufficient conditions, there is no general measure that determines in how many features an application may differ from the core and still count as a member of the category. In such cases, there is room for a conventional demarcation of the boundaries of a category. But how should we conceptualize that conventionality? What theory do we have of semantic norms and their relationship with prototypicality? The question has not been subject to much theorizing, but there are nevertheless two important models of normativity that we need to present: Hilary Putnam's rigid designation theory and Renate Bartsch's theory of communicative norms. Broadly speaking, the first may be called an authoritarian theory, while the second is a cooperative one.

Let us first present Putnam's conception of meaning as expounded in his highly influential paper 'The meaning of meaning' (1975). Three concepts are crucial: the theory of rigid designation, the division of linguistic labour, and the notion of stereotype.

The core of Putnam's argumentation is an attack on the intensionalist view of meaning. According to Putnam, this view rests on two major tenets: first, the assumption that knowing the meaning of an expression is a particular psychological state, and second, the view that the intension (the meaning) of an expression determines its extension (its referent). He goes on to show that both assumptions cannot be maintained at the same time, because there are situations in which two individuals are in the same psychological state, i.e. attach the same intension to an expression, but nevertheless refer to different extensions. A fictitious 'Twin Earth' serves to give an example of such a situation. Twin Earth resembles earth in all respects, except for the fact that what we call water is represented on Twin Earth by a liquid that has the same appearance and properties as earthly water, but that does not 
have the chemical composition $\mathrm{H}_{2} \mathrm{O}$. Rather, its chemical composition is very complex; it is symbolized by the formula XYZ. Putnam further elaborates as follows.

The expression water has a different extension on earth from that on Twin Earth, because the set of molecules referred to by the formula XYZ is distinct from the set of molecules referred to by $\mathrm{H}_{2} \mathrm{O}$. Now, imagine that Twin Earth is visited by a human being $\mathrm{A}$ who is living around 1750, and who is therefore unaware of the fact that one molecule of (earthly) water consists of two molecules of hydrogen and one molecule of oxygen. In analogous circumstances, a native B of Twin Earth visits the earth. Because the only difference between the liquids referred to by water on both planets is not yet discovered, $\mathrm{A}$ and $\mathrm{B}$ have the same convictions and beliefs with regard to the liquids in question; they are in the same psychological state. Still, the extensions of water in English and Twin English differ: A refers to $\mathrm{H}_{2} \mathrm{O}$, and B to XYZ. In this way, Putnam exemplifies that the two crucial assumptions of intensionalism mentioned above need not always be true simultaneously.

Putnam then suggests that it is not the intension, but the internal essence of a category that determines the use of the expression referring to that category. If a human observer were able to make out that $\mathrm{XYZ}$ is not really $\mathrm{H}_{2} \mathrm{O}$, terminologies would have to change. Following Kripke (1972), Putnam defends the thesis that natural kind terms such as water are 'rigid designators'; because they implicitly refer to one and the same, uniquely determined category with one and the same internal essence, they more or less function like proper names, which refer to one and the same individual, regardless of what is intensionally known about that individual. Natural kind terms refer to a class of entities that share a particular hidden structure (such as $\mathrm{H}_{2} \mathrm{O}$ or XYZ).

However, not all members of a linguistic community are required to know the hidden structure of the extension of an expression of their language. A 'division of linguistic labour' ensures that there are societal experts who know that water is $\mathrm{H}_{2} \mathrm{O}$, that there is a difference between pyrites and gold, what the specific differences between elms and beeches are, and so on. On the other hand, laymen attune their own linguistic usage to that of the expert scientists and technicians. The members of the non-specialized group are not required to have expert knowledge, but they are supposed to know the 'stereotype' connected with a category if they are to be regarded as fullfledged members of the linguistic community. A stereotype is a socially determined minimum set of data with regard to the extension of a category. For the category 'water' $\left(\mathrm{H}_{2} \mathrm{O}\right)$, the stereotype includes the information that refers to a natural kind that is a colourless, transparent, tasteless, thirstquenching liquid that boils at $100^{\circ}$ Celsius and that freezes when the temperature drops below $0^{\circ}$ Celsius. For the natural kind 'tiger' (Felis tigris), 
the stereotype includes the information that it is a yellowish, black-striped, cat-like, dangerous predatory animal. The two crucial aspects of Putnam's views are also known under other names than the ones used above. The rigid designation theory is known as 'semantic externalism' (meanings are external, i.e. not in the head), and the division of linguistic labour is known as 'semantic deference' (in order to decide on questions of meaning, we defer to experts).

One important lesson that linguistic prototype theory may learn from Putnam's model is that linguistic communities are not necessarily homogeneous: semantic knowledge may be unevenly distributed over the members of the speech community. Prototype-theoretical studies generally tend to ignore the question whether and to what extent the prototype structure of the category is shared by all the speakers of the language. This is remarkable, because the prototypical model of category structure might be plausibly interpreted as involving social variation over individuals rather than just psychological variation over contexts of use. For instance, if a lexical category consists of a core reading $A$ and peripheral senses $A_{1}, A_{2}$, and $A_{3}$, the subconcepts might be variously distributed over subgroups of the linguistic community. A natural assumption could be that at least the core reading A would be shared by all, and only the peripheral senses $A_{1}, A_{2}$, and $A_{3}$ would be distributed in different combinations over different individuals or groups. According to such a model, the central application of the prototypically structured concept, the prototype, implicitly receives a social function rather than a purely psychological one. The shared knowledge of the speakers of the language then consists of a common central reading plus rules of semantic extension that could lead to either $A_{1}$, $A_{2}$, or $A_{3}$. But whether a particular individual ever puts rule 1 into practice to derive $A_{1}$ from $A$ (and further, whether he or she subsequently stores $A_{1}$ in his/her long-term semantic memory) would depend on the specific circumstances of the individual's linguistic history, i.e. on whether he or she ever experienced a context in which $A_{1}$ was relevant. In most actual studies of prototypicality in linguistics, however, the social interpretation is largely ignored.

But while prototype studies may learn from Putnam's insistence on the heterogeneity of semantic knowledge, there are a number of reasons for doubting whether his division of linguistic labour is an adequate sociosemantic theory. Two basic points may be mentioned here. (These critical remarks may already be found in Ware's 1978 early philosophical critique of Putnam's views.) First, to the extent that semantic deference plays a role at all, the relevant experts are not always scientists. Putnam's theory holds only for natural kind terms, but most of the words in a language do not involve natural kind terms, whereas they may still be subject to semantic normativity effects. For distinguishing 
between daubes and stew, for instance, people may refer to chefs, and for distinguishing between schooners and sloops, they would invoke the authority of boat builders or seamen.

Second, and most importantly, the extent to which speakers rely on the experts may differ according to the specific purposes and interests of the speakers. The priority of rigid designation would imply that natural language follows the developments and discoveries of science in a strict fashion, which is not true. In practice, the informational content of natural language is determined not only by the state of affairs in the sciences, but also by the communicative and cognitive requirements of the linguistic community in its own right. One of Putnam's own examples can be used as an illustration. Although science has discovered that jade refers to two kinds of materials, one with the hidden structure of being a silicate of calcium of magnesium, the other being a silicate of sodium and aluminium, ordinary usage continues to refer to both substances indiscriminately as jade. If the communicative purposes of the linguistic community can entail that not all scientifically discovered facts have to be included in the average individual's cognitive system, they can also entail that everyday usage lumps together categories that should be distinguished from a purely scientific point of view. Kripke, the founding father of the theory of rigid designation, implicitly accepts the existence of two ways of speaking, a rigid one and a vague one, where he admits that it is possible to designate things in a non-rigid manner, 'speaking loosely' (1972: 332). Similar remarks concerning the relative autonomy of natural language vis-à-vis scientific essentialism (and conversely, concerning the observation that the division of linguistic labour may involve other experts than just scientists) may be found in Evans (1977) and Dupré (1981). Braisby, Franks, and Hampton (1996) provide experimental evidence for the view that natural kind terms are often used in a non-essentialist way.

Faced with these critical points regarding Putnam's model, let us consider an alternative. The most articulate theory to date of the normativity of ordinary (rather than scientific or technical) concepts is Renate Bartsch's theory of linguistic norms (1987). Her starting point is a communicative one: linguistic activity is geared towards communication, and the norms of language arise from the fact that communication requires some form of coordination. The efficient transfer of information requires rules and guidelines for speakers and hearers, and these rules are the norms that speakers and hearers abide by (at least to the extent that it is their purpose to achieve successful communication at all). Importantly, within the set of linguistic norms, a distinction has to be made between the highest norm of communication and lower norms. The 'highest norm of communication' is defined as follows (1987: 212): 
All specific linguistic norms are justified relative to the highest norm of communication, which is: 'Express yourself in such a way that what you say is recognizable and interpretable by your partner in agreement with what you intend him to understand'. And, correspondingly, for the hearer it is: 'Interpret such that the interpretation will be in agreement with what the speaker intends'.

The activities of a speaker expressing himself, and the receptive activities of the hearer interpreting the message, are not arbitrary. In order to guarantee efficiency, expression and interpretation have to be constrained by a shared agreement about the communicative value of the linguistic means of expression. In order to comply with the highest norm of communication, the speaker will have to code the information he wishes to transmit in a format that he knows to be interpretable for the hearer. Conversely, the hearer will only be able to reconstruct the speaker's intentions adequately if he is familiar with the value that the speaker attaches to the means of expression that he employs. The specific agreements that exist concerning the communicative value of the linguistic means of expression are the 'lower linguistic norms'. Among other things, these involve the meanings that may be attached to individual words.

Crucially, Bartsch accepts the semantic flexibility of the language: lower linguistic norms may be breached when the highest norm of communication requires as much. How can new meanings arise at all? Any time a word is used with a new meaning, the given norms of the language are broken-or at least, the lower norms of the language are broken, but the highest norm may still be intact: using a word flexibly with a new nuance may be important precisely because of communicative exigencies. When speakers are expressing new attitudes, evaluations, or points of view, when they develop new scientific insights or when they communicate new technical developments, in all these circumstances the new context may not be easily communicated by remaining with the existing lower norms. When the lower norms of the language are too narrow, they may be creatively infringed by the speaker, and the hearer should be flexible enough to accept the violation. In specific contexts, then, the highest norm of communication may lead to breaking the lower level norms. And the structural characteristics of linguistic categories reflect this situation. The semantic flexibility that is descriptively elaborated by prototype theory is interpreted by Bartsch as a necessary feature of the sociosemantic function of categories. Linguistic categories have to possess a potential of semantic flexibility and even vagueness, precisely because the highest norm of communication may require going beyond existing usage at the level of the lower norms (1987: 215):

The necessary tolerance in the application of semantic norms is the vehicle of semantic change. Semantic norms structurally carry the possibility of change with them. 
Because of this, we can adjust our language to change in our physical and social world. If vagueness and context-dependence of meaning were not part of the meanings of words, language would be a less efficient means of communication.

So, if we accept the Bartschian model, the prototype-based semantic fabric of linguistic categories has a normative background: it derives from the hierarchy of communicative norms and the communicative necessity to contextually override the lower linguistic norms.

Could we now combine Bartsch's inspiring interpretation of prototypicality effects in normative terms with what we learnt from Putnam about sociosemantic norms? It appears that there are basically three types of sociosemantic relations: cooperation as described by Bartsch, compliance with authorities as described by Putnam, and perhaps also conflict. The 'semantics of cooperation' generally underlies the unproblematic prototype-based expansion of meaning as described by Bartsch. Existing norms for linguistic behaviour are stretched towards novel ways of using words, but the departure from the existing norms is socially acceptable because it conforms to the highest norm of communication. The 'semantics of authority' comes into play when discussions and debated issues are settled by deference to recognized experts. Although these need not be scientific experts-as in Putnam's theory of the division of linguistic labour - the semantics of authority generally follows the model of semantic deference put forward by Putnam. The 'semantics of conflict and competition' plays a role when semantic choices are implicitly questioned or explicitly debated. Such debates may be settled by invoking the semantics of authority, but they may also occur in the absence of a mutually accepted authority that could settle the discussion.

It would seem, to summarize, that it is possible to develop a theory of semantic norms and conventions along the lines set out by Putnam and Bartsch. Such a model would be useful, among other things, to allow us to get a grip on the forces behind the 'invisible hand' processes that we mentioned in section 5.4.1. But it should also be clear that actual empirical research focusing on the identification of those factors is not yet a major trend in lexical semantics: here is a challenge for a contextualist theory of meaning.

\subsubsection{Meaning in text and discourse}

The most immediate type of discourse-related investigation in cognitive lexical semantics is the study of discourse particles and pragmatic markers, as in Fischer (2000). There is, however, a more fundamental link between cognitive semantics and the study of performance: more and more, Cognitive Linguistics conceives of itself as a usage-based approach to language. The essential idea of a usage-based linguistics is the dialectic nature of the relation between 
language use and the language system (Langacker 1991, 1999). The grammar does not only constitute a knowledge repository to be employed in performance, but it is also itself the product of language use. Usage events define and continuously redefine the language system in a dynamic way-which is the same basic position that we explored in section 5.4.1. The consequences of such a position are both thematic and methodological. Thematically speaking, a usage-based approach fosters an interest in specific topics and fields of investigation: if the analysis of discourse is a legitimate (and, in fact, important) goal for Cognitive Linguistics, looking at meaning phenomena in different types of discourse is a natural course of action. At the same time, there are methodological consequences: you cannot have a usage-based linguistics unless you study actual usage-as it appears in an on-line and elicited form in experimental settings, but more specifically also as it appears in its most natural form in corpora in the shape of spontaneous, non-elicited language data.

The thematic consequences of the usage-based perspective are most visible in metaphor research: a dynamic community of metaphor researchers is investigating the way in which metaphoric thinking appears in different types of discourse: in literature, in politics, in science, in advertising, and other genres. Apart from the suggested readings at the end of this chapter, we will not try to give an overview of this development: see Semino (2008) for an accessible and comprehensive introduction. Rather, we will concentrate on the methodological consequences, which are relevant for metaphor research and for categorization research in the broader sense: how should cognitive semantics deal with the abundance of materials that becomes available when one starts doing corpus research? As in the previous two sections, we look first at metaphor studies and then at categorization research.

1 Standard Conceptual Metaphor Theory, originating in Lakoff (1980) and synthesized in Kövecses (2002), studies metaphor in a highly decontextualized way, treating metaphoric expressions by and large as if they were abstract items listed in a dictionary. But to live up to the maximalist intentions of cognitive semantics at large, metaphor studies have to take the step from the relative isolation of abstracted linguistic structures to the contextualized level of actual language use. Probably the major development in metaphor research of the last decade has been an increasing attention to the study of metaphor in its actual context of use, in real discourse. Metaphor studies from this usage-based perspective have not yet yielded an encompassing theory of the pragmatics of metaphor, but the field is a lively one, and several interesting developments need to be summarized. Basically, two questions are asked: first, 
how can metaphors be identified in texts, and second, what is the role and function of metaphors in discourse?

The identificational question addresses the problem that the recognition of metaphors often seems to be an individual and subjective matter: we may remember the complaint voiced by Haser (2005) about the arbitrariness in choosing a level for identifying conceptual metaphors. Methods that are currently being suggested for overcoming such subjectivity explore two directions: trying to achieve intersubjective agreement in the manual identification of metaphors, and enlisting the help of automated techniques of text analysis.

The best-known method of the first type is the Metaphor Identification Procedure, or MIP, developed by the Pragglejaz group (Pragglejaz 2007; Pragglejaz is an acronym for an international group of prominent metaphor researchers, including Peter Crisp, Raymond Gibbs, Alice Deignan, Graham Low, Gerard Steen, Lynne Cameron, Elena Semino, Joe Grady, Alan Cienki, and Zoltan Kövecses). The steps in the Pragglejaz identification procedure are the following (Pragglejaz 2007: 3).

1. Read the entire text-discourse to establish a general understanding of the meaning.

2. Determine the lexical units in the text-discourse.

3. (a) For each lexical unit in the text, establish its meaning in context, that is, how it applies to an entity, relation, or attribute in the situation evoked by the text (contextual meaning). Take into account what comes before and after the lexical unit.

(b) For each lexical unit, determine if it has a more basic contemporary meaning in other contexts than the one in the given context. For our purposes, basic meanings tend to be: more concrete [what they evoke is easier to imagine, see, hear, feel, smell, and taste]; related to bodily action; more precise (as opposed to vague); historically older.

Basic meanings are not necessarily the most frequent meanings of the lexical unit.

(c) If the lexical unit has a more basic current-contemporary meaning in other contexts than the given context, decide whether the contextual meaning contrasts with the basic meaning but can be understood in comparison with it.

4. If yes, mark the lexical unit as metaphorical.

Applying the procedure to the word struggled in the sentence For years, Sonia Gandhi has struggled to convince Indians that she is fit to wear the mantle of the political dynasty into which she married, let alone to become premier leads to the recognition that the word is used metaphorically. With regard to the crucial steps $3(\mathrm{~b})$ and 3 (c) in the procedure, it is first observed that the basic meaning of struggle is 'to use one's physical strength against someone or 
something'; further, the contextual reading of struggle contrasts with the basic meaning, but the notion of abstract effort, difficulty, opposition, and conflict that is expressed in the sentence can be understood in terms of physical effort, difficulty, opposition, and conflict.

It is part of the Pragglejaz MIP procedure to subject the metaphoricity judgements of different raters to a statistical reliability test. The example included in Pragglejaz (2007) reveals that the consistency across items is marginally significant in the statistical sense, while the consistency across raters is not reliable. This should not surprise us entirely, because the MIP procedure as described above does not really avoid a number of traditional difficulties with the identification of semantic phenomena like metaphor and metonymy. For one thing, the possibility of understanding one reading 'in comparison' with another depends on the interpreter's ability to see the analogy—a highly subjective skill. For another, identifying the 'basic meaning' is not an objective procedure either, as it relies heavily on the interpreter's knowledge of the customary range of application of the word and its history. It is not surprising, then, that subjective differences occur in the identification of metaphors. The Pragglejaz authors, by the way, concede as much (2007: 30-31). In this respect, we should also note that the MIP procedure does not avoid the problem that we identified previously. In automatically determining metaphoricity in terms of the 'basic sense' of an item, the procedure seems to exclude the possibility that an item is metaphorically derived from one of the subsidiary senses of a word.

Manual identification of metaphor in corpora is now more and more combined with corpus techniques that relate to the type of distributional corpus analysis that we learnt about in section 4.2.3. A basic procedure that combines automation with manual selection is illustrated by Deignan $(2005 \mathrm{~b})$, who uses concordances as in Figure 4.3: metaphor candidates are concordanced, and the concordances are then manually filtered for metaphoricity. In this approach, the initial set of metaphor candidates may be extracted from existing reference works like dictionaries and thesauri, or it may be retrieved by manual analysis from a small 'learning corpus'. Both methods are illustrated by Koller (2004).

A computationally more sophisticated approach is to work on the basis of distributional patterns in the corpus. Veale and Hao (2008), for instance, describe a procedure for identifying the characteristics that are stereotypically associated with a given target word. Similes in particular reveal stereotypical properties: a web search on the pattern as skinny as a... shows that rakes, rails, brooms and twigs are among the objects that are typically associated with skinniness. When looking for metaphoric expressions for a given target, these expressions may then be used to fill the 'vehicle' slot in a pattern of 
the type 'vehicle like target'. If you are interested in figurative references to Paris Hilton, for instance, the pattern a rake (rail, broom, twig) like Paris Hilton may then be used to retrieve the metaphoric expressions from the corpus.

In the CorMet algorithm introduced by Mason (2004), the distribution of formal patterns over domain-specific source texts is the basis of the procedure. When we notice that money flows, we may wonder whether there is a general metaphor of the type MONEY IS A LIQUID. To determine whether this is indeed the case, Mason collects texts that have to do specifically with money (like financial information issued by banks) and liquids (like laboratory reports), and determines the verbs that are typical for each of the two domains, like spend, invest, save, deposit on one side, and pour, flow, evaporate, freeze on the other. In each of the two sets of texts, the typical arguments of the verbs are identified. It appears that there is an asymmetric structure between the two domains: verbs that select the concept 'liquid' in the laboratory texts also select 'money' in the financial texts, but conversely, verbs that select 'money' in the financial texts do not select 'liquid' in the laboratory texts. Liquids can flow, and money can flow; you can invest money, but you cannot invest liquid. If this occurs for a range of typical verbs, then this is taken as an indication of the MONEY IS A LIQUID metaphoric mapping.

In spite of promising approaches such as these, there is as yet no standard computational or statistical technique for corpus-based metaphor identification-nor should that be expected, given the recent nature of the field. From a methodological perspective, we should also note that most of the studies mentioned here take the source domains of the metaphors as the starting point of the analysis. Onomasiologically speaking, there is a double danger involved: an initial selection of possible source domains may mean that relevant source domains are overlooked and, further, that the literal references to the target are ignored. In Geeraerts and Gevaert (2008), for instance, expressions for anger in English are charted from Old English to Early Modern English. In all of the texts studied, the proportion of metaphoric expressions for anger is always considerably less than the literal denominations. In this respect, the corpus approach for metaphor identification followed by Stefanowitsch (2006) offers a theoretically important reversal of the perspective for corpus-based metaphor identification. Stefanowitsch in fact starts from a set of terms belonging to the (emotional) target domain, and then performs a concordance analysis to identify the metaphoric expressions associated with the relevant emotion concepts.

Turning from the identificational to the functional and empirical question, corpus-based metaphor identification procedures have been used primarily from two perspectives: first, as an instrument for comparing the use of 
metaphor in different text genres, and second, as a method for determining the force of a particular metaphor in a given text. The first perspective is geared towards identifying differences of conceptualization in different kinds of texts. Koller (2004), for instance, investigates the ideological background of recurrent metaphoric patterns in business discourse, and concludes on the basis of the frequency of 'war' and 'fighting' metaphors that there is a masculine, aggression-based conceptualization at work in journalists' representation of business events. (This type of ideological analysis has an affinity with the older tradition of Critical Discourse Analysis. Further examples include Lakoff 1996, 2004, Charteris-Black 2004, 2005, Chilton 2004, Musolff 2004, Goatly 2007, and Hart and Lukeš 2007.)

The second perspective, which may be found among others in the work of Goatly (1997) and Cameron (2003, Cameron and Stelma 2005), investigates how specific metaphors occur in given texts. Several patterns are discerned, like the grouping or mixing of metaphors from unrelated source domains, but also the clustering of figurative expressions belonging to the same or similar source domains. A metaphoric expression that is introduced at one point in a stretch of discourse may be continued by what Cameron calls 'vehicle development'. If the metaphor SEEING IS UNDERSTANDING is used at one point, words like picture, view, or perceive may readily appear in the proximity of the initial expression, or when the notion of $i l l$ is introduced in a metaphoric reading, the following lines and sections may feature figurative uses of words like diseased, crippled, complaint, disorder, remedy. In theoretical terms, this links up with a position that we specified in section 5.5.1: with the activation of a metaphor, the lexical field - or more broadly, the cognitive model to which the source term belongs-becomes available for use along the lines of the same metaphoric mapping. In methodological terms, investigations of this type are important because they help to answer one of the major questions in metaphor research, viz. when a metaphor is more than just a dead relic.

2 In categorization and polysemy studies of the kind introduced in section 5.1, corpus research has a longer and stronger tradition than in cognitive metaphor research. Conversely, experimental investigations-which were present from the start in cognitive metaphor research through the efforts of Ray Gibbs-have always been less prominent in linguistic categorization studies: examples like Sandra and Rice (1995), Cuyckens, Sandra, and Rice (1997), Gilquin (2003), and the sophisticated work of Levinson (2003) on the linguistic relativity thesis in the domain of spatial language do not constitute a dominant approach. Corpus data, on the other hand, was used early on in the history of cognitive semantics. The methodology of European 
studies in Cognitive Linguistics in particular has tended to be more corpusbased than the early American studies, which were predominantly introspective. The use of corpus materials was already part of early European studies like Dirven, Goossens, Putseys, and Vorlat (1982), Dirven and Taylor (1988), Rudzka-Ostyn (1988a, 1989), Schulze (1988), Schmid (1993), and Geeraerts et al. (1994). In the first decade of the twenty-first century, corpus studies in cognitive lexical semantics are undergoing an evolution with two closely related facets. In the first place, we notice an increasing reliance on quantitative methods. In the context of Cognitive Linguistics in the broad sense, the tendency towards quantitative corpus studies is not restricted to lexical semantics; lexical semantics, in fact, is not the main focus of the approach, which is rather geared towards grammatical studies, with a specific link with construction grammar: see Gries and Stefanowitsch (2006) for a representative collection of papers, and compare Tummers, Heylen, and Geeraerts (2005) for a global description of the trend. This link with construction grammar has a certain influence on the type of lexical studies that are found in this emerging field of studies; very often, the items under investigation have a specific link with grammatical phenomena and constructions, like auxiliary verbs. In the second place, many of the studies have an onomasiological orientation. This does not exclude the presence of semasiological studies (like Gries 2006 or Bertels 2006), but overall, there seems to be a dominant tendency towards pragmatic onomasiology-the analysis of onomasiological variation at the level of actual usage. Two lines of research may be distinguished within this onomasiological orientation.

A first line of investigation looks at pairs or sets of near-synonyms, and uses the corpus data to disentangle the differences between the items and the factors that determine the choice for one item rather than the other. Cases in point are Divjak (2006), Divjak and Gries (2006), Schönefeld (2006), Grondelaers, Speelman, and Geeraerts (2008), Glynn (2008), Arppe (2008), and Speelman and Geeraerts (in press). In technical terms, research of this kind often makes use of the collocational distributional methodology developed in the tradition of John Sinclair (see section 4.2.3), but it regularly goes beyond that by using more advanced statistical techniques of a multivariate kind, like some form of clustering technique (Divjak and Gries 2006, Glynn 2008), or logistic regression (Grondelaers et al. 2008, Speelman and Geeraerts in press).

In a second line of research, the focus is not on the multifactorial differentiation of near-synonyms, but on the way in which the choice between denotationally equivalent synonyms is determined by contextual factors of an 'external' kind, like sociolinguistic variation. To sketch the background, we need to cite some of the factors that were identified in Geeraerts et al. (1994) 
as determinants of lexical choices. Using corpus materials, this study established that the choice for one lexical item rather than the other as the name for a given referent is determined by the semasiological salience of the referent, i.e. the degree of prototypicality of the referent with regard to the semasiological structure of the category; by the onomasiological entrenchment of the category represented by the expression; and by contextual features of a classical sociolinguistic and geographical nature, involving the competition between different language varieties. By zooming in on the latter type of factor, the distribution of denotational synonyms over language varieties may then be used as a measure of the distance between language varieties, leading to a lexical sociolectometry: see Geeraerts, Grondelaers and Speelman (1999), Speelman, Grondelaers, and Geeraerts (2003), and Soares da Silva (2005).

Although the community of researchers involved in this statistical, onomasiological turn of corpus-based cognitive lexical semantics is as yet a very small one, the importance of the development in the larger scheme of things can hardly be underestimated. Taking up the points in the reverse order in which we introduced them a moment ago, let us first note that the development of a pragmatic kind of onomasiology is of crucial relevance for cognitive semantics. The mental act of categorization is an onomasiological one, not a semasiological one. Speakers choose a category, and onomasiological change in the language at large cannot be understood unless we take into account pragmatic onomasiology: changes are always mediated through the onomasiological choices made on the level of parole. Words die out because speakers refuse to choose them, and words are added to the lexical inventory of a language because some speakers introduce them and others imitate these speakers; similarly, words change their value within the language because people start using them in different circumstances. Structural change, in other words, is the output of processes that are properly studied in the context of pragmatic onomasiology. Also, this pragmatic, parole-based perspective automatically takes the form of a sociovariational investigation: in choosing among existing alternatives, the individual language user takes into account their sociolinguistic, non-referential value, and conversely, the expansion of a change over a language community is the cumulative effect of individual choices. In this sense, it is only through an investigation into factors determining these individual choices that we can get a grasp on the mechanisms behind the invisible hand of lexical change.

With regard to the other facet that we noted (the evolution towards more sophisticated quantified forms of research), its importance resides in the convergence it creates with what we were able to identify as one of the most dynamic (and most contextualized) neostructuralist approaches, viz. the 
tradition of distributional corpus analysis. The statistical techniques used by the scholars mentioned above, like measures of collocational behaviour, overlap to no small extent with what is being developed in the tradition that we introduced in section 4.2.3. In the Conclusion, we will put this convergence in a wider context, arguing that it is a plausible development in the light of the overall evolution of lexical semantics, one which is likely to generate much new research.

We may now also draw some conclusions from this section as a whole. To round off our discussion of cognitive semantics, we have focused on three major context factors, working on the assumption that cognitive semantics is indeed a maximalist, maximally contextualized framework. If that interpretation is correct, there are still some domains to be conquered by cognitive semantics. The main areas for further development arising from the discussion are the following. First, the link with psychology may be strengthened. Specifically in the area of categorization research from a prototypebased perspective, the absence of systematic interactions between linguistic lexical semantics and psychology is striking. Second, the constitution of socio-semantic norms, and the social variation of lexical meaning, are under-researched. Third, in the study of the cultural models and conceptual metaphors, more attention should be paid to the historical transmission of models. For the distinction between novel and dead metaphors, historical studies should likewise be relevant. Fourth, there is plenty of room for the further development of a usage-based methodology. 


\section{Further sources for Chapter 5}

An indispensable textbook for semantic research within the framework of Cognitive Linguistics is Taylor (2003b). Of equal importance is Aitchison (2003) as an introduction to the study of the lexicon from a psychological point of view. Introductions to Cognitive Linguistics in general include Violi (2001), Croft and Cruse (2004), Ungerer and Schmid (2006), Evans and Green (2006), and Kristiansen, Achard, Dirven, and Ruiz de Mendoza Ibáñez (2006). Geeraerts and Cuyckens (2007) is a multi-authored handbook, while Geeraerts (2006c) and Evans, Bergen, and Zinken (2007) are collections with important articles in Cognitive Linguistics. For the position of Cognitive Linguistics vis à vis other functionalist approaches to grammar, see Gonzalvez-García and Butler (2006) or Nuyts (2007). (The literature in cognitive semantics is vast, and it is even more the case than in the previous chapters that the works listed in these pages are no more than an initial selection. The suggestions brought together here are restricted to the four first sections of the chapter; the references for the fifth section are included in the main text.)

An overview of the development of prototype theory within Cognitive Linguistics may be found in Mangasser-Wahl (2000). Foundational monographs like Lakoff (1987) and Langacker (1987), and successful textbooks like Taylor (1989) and Aitchison (1987) (the first editions of the textbooks mentioned above) contributed considerably to the expansion of prototype-based descriptions. Testifying to the early adoption of prototype-based models in linguistics are collective volumes like Craig (1986), Rudzka-Ostyn (1988b), and Tsohatzidis (1989), and monographs like Kempton (1981), Geeraerts (1985), Sweetser (1990), Persson (1990), and Schmid (1993).

The preposition over, with which Brugman introduced the radial network model, remained a rallying point for discussions of semasiological structure in cognitive semantics, from Vandeloise (1990), through Cuyckens (1991), Geeraerts (1992), Dewell (1994), and Tyler and Evans (2003), to Deane (2005) the list is not complete. The role of over in the discussions is typical for a broader interest in spatial language: see Zelinsky-Wibbelt (1993), Pütz and Dirven (1996), and Cuyckens, Hubert and and Günter Radden (2002) for significant collective volumes, and Herskovits (1986), Vandeloise (1986, 2001), Cienki (1989), Svorou (1994), Di Meola (1994), Boers (1996), and Levinson (2003) as a sample of relevant monographs.

Additional aspects of the adoption of prototype models in Cognitive Linguistics are as follows. First, for a discussion and comparison of the various representational models of prototype effects, like radial sets in comparison to family resemblance models, see Lewandowska-Tomaszczyk (2007). Second, 
for the impact of prototype models on lexicography, see Geeraerts (1990, 2007) and Hanks (1994). Third, prototype models are not just used for the description of word meaning, but are generally applied in Cognitive Linguistics, i.e. to grammatical meaning just as much as to lexical meaning; for illustrations and references, see the general introductions to Cognitive Linguistics mentioned above. Fourth, it should be borne in mind that cognitive semantics does not have a monopoly on the incorporation of the notion of prototypicality, nor, more generally, on a flexible conception of word meaning. We saw in the previous chapters how other approaches dealt with the issues at hand, and the overall idea that words have a meaning potential rather than a fixed and stable meaning that is actualized in all usage events has been formulated in different quarters: see for instance Halliday (1973) or Rommetveit (1988), and compare the notion of a signifié de puissance formulated by Gustave Guillaume (see Picoche 1984, 1992).

In the context of contemporary French linguistics in particular, there are a number of tendencies that are fundamentally consonant with the international trends in cognitive semantics, even though the lines of communication between the two have so far been unfortunately restricted. Without attempting an in-depth analysis, let us mention the following three. First, an attempt to develop semantics by applying strict Saussurean and Hjelmslevian principles is set out by François Rastier (1987, 1991, 2001 and many more) and his team (Rastier, Cavazza, and Abeillé, 2001). Rastier takes a radical textual orientation to structural analysis, focusing on the way in which isotopies (the recurrence of semantic features in a text) determine interpretations-or, so to speak, how syntagmatic combinations determine whether paradigmatic semantic components are realized, neutralized, or transferred. This dynamic interpretation of structural semantics ties in neatly with the cognitive semantic interest in the pragmatic, contextual dynamics of meaning. Second, Vincent Nyckees (1998, 2006) has developed a sociohistorical theory of language as a cultural semiotic. The fundamental tenets of this framework correspond to some of the points discussed in section 5.5.2: an adequate view of the synchronic relation between language and cognition needs to take into account the history of culturally transmitted meanings. Third, the work of Catherine Fuchs and Bernard Victorri (1996, Victorri 1997) illustrates a corpus-based analysis of polysemy that is consonant, both theoretically and methodologically, with the developments sketched in section 5.5.3: theoretically, they assume a dynamic interaction between schematic meaning and contexts of use, and practically, they perform a digitized corpus analysis of the textual environment in which the investigated items occur.

In the context of cognitive semantics, next to the papers mentioned in the main text, discussions of the theoretical issues concerning polysemy 
include Sweetser (1986, 1987), Geeraerts (1994), Cruse (1995b), Schmid (2000), Janssen (2003), Taylor (2003a, 2006), Zlatev (2003), Allwood (2003), Riemer (2005), and Evans (2006). These authors do not all take a radically maximalist approach: some adopt a more parsimonious position. More broadly, recent volumes focusing on the theoretical nature of polysemy are LewandowskaTomaszczyk (1998), Peeters (2000), Ravin and Leacock (2000), Cuyckens and Zawada (2001), Nerlich, Todd, Herman, and Clarke (2003), and Cuyckens and Taylor (2003).

Basic levels, entrenchment, and salience in linguistics are discussed in Geeraerts (2000) and Schmid (2007); further work on a generalized notion of onomasiological salience is found in Grondelaers and Geeraerts (2003). In the ethnobiological field of study which lies at the basis of the notion of basic levels, there has developed a discussion between a line of research that primarily tries to derive cognitive universals from cross-cultural similarities in ethnobiological classifications (Brown 1984, Berlin 1992), and a line with a less universalist orientation, which insists on the importance of the variability of categorization, of the social context of acts of classification, and of the dialectic interplay between ecology and culture (Hunn 1977, Ellen 1993). The current state of affairs in the discipline may be gathered from Ellen (2006).

An indispensable handbook for metaphor research is Gibbs (2008). Steen (2007) contains a detailed, up-to-date coverage of theory and method in metaphor research, including Conceptual Metaphor Theory, the mental spaces approach, structure-mapping and categorization-based approaches; methodologically, it specifically develops the attempt to arrive at intersubjectively reliable metaphor identifications. Edited volumes of specific interest include Paprotté and Dirven (1985), Ortony (1979, 1993), Gibbs and Steen (1999), Barcelona (2000), Dirven and Pörings (2002), Coulson and Lewandowska-Tomaszczyk (2005), and Baicchi, Broccias, and Sansò (2005). Popular areas of application for metaphor theory (the domain is huge) include the study of emotion concepts (Kövecses 1986, 1990, 2000, Athanasiadou and Tabakowska 1998), literary and stylistic studies (Turner 1987, Lakoff and Turner 1989, Turner 1996), religious discourse (Feyaerts 2003), and ideology and cultural models (as referred to in section 5.5.3).

Apart from the descriptively oriented criticism that we discussed in the main text, Conceptual Metaphor Theory has been subject to various fundamental objections, three of which will be mentioned here. First, Rakova (2002, 2003) questions the reductionist aspects of Lakoff and Johnson's experientialism, but as we have seen, there are internal developments within cognitive semantics towards more historically and culturally situated forms of analysis that provide an answer to Rakova's objections. Second, the tradition of 
neo-Gricean pragmatics, most conspicuous in the form of Relevance Theory, takes a sparse view of semantics which yields a maximal role for pragmatics: when the regular, literal sense of an item is flouted, a mechanism of pragmatic inference yields a contextually relevant figurative reading (see Song 1997, Papafragou 1996). As we noted in section 5.4.1, such a mechanism definitely has a place in a fully-fledged model of semantics, but it is unlikely that it works any time a metaphor is processed: mechanisms of entrenchment and conventionalization need to be taken into account. Since the neo-Gricean model does not work well unless literalness can be clearly established, a thorough discussion of the notion of literalness has been taking place within pragmatics; in the context of this debate, 'contextualist' theories such as Récanati (2003) appear to be taking a position that is compatible with cognitive semantic assumptions. Third, Leezenberg (2001), working within the framework of analytical philosophy, makes a convincing case for a sociocultural conception of metaphor, taking into account social practices and gradual processes of conventionalization. Needless to say, such a position is concordant with what was said in section 5.5.2 about the importance of a sociocultural perspective on metaphor and meaning at large.

An up-to-date view of research on image schemas is provided by Hampe (2005). The evaluative dimensions of image schemas are highlighted by Krzeszowski (1993). Discussions of embodiment in its various interpretations may be found in Ziemke, Zlatev, and Frank (2007). Fauconnier and Sweetser (1996), Brandt (2004), and Oakley and Hougaard (2008) are collections of work illustrating various applications of the mental spaces approach.

In addition to the metonymy-related discussions treated in the main text, three further topics may be mentioned. First, Feyaerts $(1999,2000)$ and Panther (2005) explore the existence of metonymi hierarchies, in which more schematic and more specific metonymical patterns coexist. Second, Paradis (2004) argues for a distinction between 'facets' and metonymy, building on Cruse (1995a). Examples like This book is old but highly instructive are treated by Paradis under the heading of facetization, because the relevant aspects of book (in this case, age and relevance) appear to be compatible, in contrast with 'real' metonymies (*Washington is a beautiful town and changing its position on the Kyoto norms). Third, the function of metonymy in texts has not yet been studied as extensively as that of metaphors, but see for instance Nunberg (1978) for pragmatic constraints on referential metonymy, Panther and Thornburg $(1998,2003)$ and Ruiz de Mendoza Ibáñez (2005) for the role of metonymy in inferencing and speech acts, and Barcelona (2005) for an analysis of the functions of metonymies in discourse. 
The position of Fillmore's frame theory in comparison with structuralist field approaches is discussed in Post (1988) and Nerlich and Clarke (2000); more broadly, a comparison between different approaches to lexical structure (semantic fields, frames, prototypes, and lexical relations) is pursued in Lehrer and Kittay (1992) and Lutzeier (1992). Examples of descriptive work in the frame approach include Dirven, Goossens, Putseys, and Vorlat (1982), Lawler (1989), Rojo and Valenzuela (1998), and Martin (2001). The impact of the frame approach on applied lexicography may be measured in Atkins, Rundell and Sato (2003); this article appeared in a thematic issue of the International Journal of Lexicography, edited by Thierry Fontenelle and devoted exclusively to FrameNet. An example of the use of FrameNet in the context of computational linguistics is Shi and Mihalcea (2005), which explores the combination of WordNet and Framenet. A theoretically important extension which falls outside of the scope of the present book is the link between frame theory and so-called construction grammar. Construction grammar is then used as the descriptive framework for dealing with the grammatical aspects of frame theory; see Fillmore, Kay, and O'Connor (1988) and compare Glynn (2004), who analyses the relationship between construction grammar, semantic field theory, and frame semantics.

The prototype structure of semantic change in its various aspects is acknowledged and illustrated in one form or another in many studies, among them Dirven (1985), Lewandowka-Tomaszczyk, Barbara (1985), Casad (1992), Goossens (1992), Nerlich and Clarke (1992), Dekeyser (1990), Soares da Silva (1999, 2003), Koivisto-Alanko (2000), De Mulder and Vanderheyden (2001), Tissari (2003), and Molina (2005). A related approach is the 'vantage theory' formulated by MacLaury $(1991,1997)$, which offers a model for describing the way in which attention to similarity or difference between competing categories may expand or shrink the range of those categories. This focus on the dynamic interaction and the differential attraction of prototypically structured near-synonyms is also present in Rastier's use of a 'morphodynamic' representation in the line of Petitot (1985): see Rastier (1999). Contributions like Rastier's and MacLaury's provide models for certain aspects of diachronic onomasiology, but in order to become of lasting value, these models may need to become less abstract than their current version. Eckardt (2003) is an original attempt to describe prototype-based semantic change in the framework of formal semantics.

Issues of subjectification are covered in Athanasiadou, Canakis, and Cornillie (2006). Both Traugott's notion of subjectification and Heine's approach are to be situated in the broader context of grammaticalization research (which we will not review here). As mentioned earlier, a general outline 
of lexicogenetic mechanisms may be found in Tournier (1985). The search for regular patterns of name-giving extends to emotive vocabulary: see Allan and Burridge (1991) on euphemism and dysphemism. For more work by Blank, Koch, and their associates, see Gévaudan and Neu (2003) and Gévaudan (2007), and compare Grzega's overview of contemporary onomasiology (2002). 


\section{Conclusion}

Given all that went before, what are the main forces that have shaped the development of linguistic lexical semantics? What are the currents and undercurrents in lexical semantics? And if we can put our finger on those motivating tendencies, could we perhaps also make predictions about future developments? In this conclusion, we will take a bird's-eye view of the evolution of word meaning research, focusing on two lines of development: the theoretical development of lexical semantics, and its descriptive expansion. For each of these perspectives, we will be able to identify underlying trends-and the emerging picture may then suggest further steps in the evolution. To begin with, let us recapitulate. We have found it convenient to distinguish between five theoretical currents, where in each case a 'current' is no more than a broad and rather loose grouping of theoretically related descriptive approaches.

Historical-philological semantics dominates the scene from roughly 1830 to 1930. This does not mean, to be sure, that there is no form of lexical semantics before 1830, but it is only by the middle of the nineteenth century that research into word meaning establishes itself as a distinct subdiscipline of the new science of linguistics. At the level of individual researchers, historicalphilological semantics is represented by Michel Bréal, Hermann Paul, and many others, like Albert Carnoy and Gustaf Stern, who symbolically close off the period. At the methodological level, the type of semantic research meant here may be characterized by the following three features. First, in line with the overall nature of nineteenth-century linguistics, the orientation is a diachronic one: what semantics is interested in, is change of meaning. Second, change of meaning is mostly narrowed down to change of word meaning, i.e. to changes in individual words: the orientation is predominantly semasiological rather than onomasiological. Third, the dominant conception of meaning is psychological, in a double sense. Lexical meanings are considered to be psychological entities, that is to say, (a kind of) thoughts or ideas. Further, meaning changes are explained as resulting from psychological processes. The general mechanisms that are supposed to underlie semantic changes, and whose presence can be established through the classsificatory study of the history of words, correspond with patterns of thought of the human mind. A concept like metonymy, for instance, is not just a linguistic concept, it is also a cognitive capacity of the human mind. 
The origins of structuralist semantics may be attributed to Jost Trier, whose 1931 monograph is the first major descriptive work in structuralist semantics, and to Leo Weisgerber, whose 1927 article provides the first theoretical and methodological exposé of the new approach (which, needless to say, takes its theoretical inspiration from de Saussure). Weisgerber criticizes historicalphilological semantics precisely on the three characteristic points mentioned a moment ago. First, the study of meaning should not be atomistic but should be concerned with semantic structures; second, it should be synchronic instead of diachronic; and third, the study of linguistic meaning should proceed in an autonomously linguistic way. Because the meaning of a linguistic sign is determined by its position in the linguistic structures of which it is a part, linguistic semantics should deal with those structures directly. Because the subject matter of semantics consists of autonomous linguistic phenomena, the methodology of linguistic semantics should be autonomous, too.

The actual realization of this attempt to develop a synchronic, nonpsychological, structural theory of semantics depends on the way in which the notion of semantic structure is conceived. In practice, three distinct kinds of structural relations among lexical items are singled out as the proper methodological basis of lexical semantics. First, a relationship of semantic similarity lies at the basis of semantic field analysis, inaugurated by Trier and ultimately, in the 1950 s and early 1960s, leading to componential analysis. Second, unanalysed lexical relations such as synonymy, antonymy, and hyponymy are suggested as the descriptive foundation of structural semantics by John Lyons in 1963. Third, syntagmatic lexical relations are identified by Walter Porzig in 1934 under the name of wesenhafte Bedeutungsbeziehungen; they later appear in other forms, among them the 'selectional restrictions' in the componential type of semantics that is incorporated into generative grammar by Jerrold Katz and Jerry Fodor.

All through the second half of the 1960s and the major part of the 1970s, the generativist semantics introduced by Katz and Fodor and later mainly developed by Katz, forms a major reference point for studies in lexical semantics. The appeal of Katzian semantics is at least partly due to its incorporation into generative grammar; it profits from the superior position that the generative paradigm occupied in linguistic theorizing in the period in question. As an approach to lexical semantics, Katzian semantics combined an essentially structuralist approach with two characteristics that are intimately connected with its incorporation into generative grammar: it presented a singular combination, within the framework of generative grammar, of a basic structural semantic methodology, a mentalist philosophy of language, and a formalized descriptive apparatus. Within the generativist approach, this combination leads to a tension between a maximalist approach 
to semantics (Generative Semantics) and a more restricted one (Interpretive Semantics), with the former indirectly paving the way towards cognitive semantics.

Under the heading of neostructuralist semantics, we bring together the miscellaneous set of contemporary approaches that extrapolate the major types of structuralist semantics, but that do so in a post-generativist fashion. These theories build on structuralist ideas, in particular the notion of a decompositional and that of a relational description of semantic structure, but they predominantly do so with specific attention to the issues raised by generativist semantics, i.e. the possibility of formalization and/or the exact borderline between linguistic meaning and cognition in general. These approaches do not as a rule take the maximalist approach suggested by the internal tensions within generativist semantics; overall, they try to restrain semantic description either by maintaining some form of distinction between meaning and cognition and/or between meaning and use, or by subjecting semantic descriptions to the requirements of a formal representation. This interest in formalization lies at the basis of the link that exists between a number of these approaches and formal semantics or computational linguistics. The internal differences within this group of approaches are considerable, however. For instance, although Anna Wierzbicka's Natural Semantic Metalanguage and James Pustejovsky's Generative Lexicon both build on the idea of a componential analysis, the former relies on an informal representation in terms of a universal 'alphabet of human thoughts', whereas the latter links up with the formalism of logical semantics. Within the group of relational approaches, distributional corpus analysis stands out because of its contextual perspective and its elaboration into statistical forms of lexical knowledge representation.

Cognitive semantics emerged in the 1980 as an explicitly 'maximalist' attempt to integrate rather than separate meaning and cognition, and similarly, to integrate rather than separate semantics and pragmatics. Through the introduction of new models of description and analysis, like prototype theory and frame semantics, and through the revivification of metaphor studies in Conceptual Metaphor Theory, it has proved to be a highly productive approach, with a wide appeal among lexical semanticians.

Given this overview of the traditions that have dominated the course of development of lexical semantics, Figure C.1 suggests a schematic representation of the relevant lines of development. Each of the boxes in the figure represents one of the approaches identified above. While the vertical axis is basically a historical one, the bottom line of the figure charts the approaches that are currently around. The lines connecting the boxes indicate the relationships between the approaches. The double arrow between historical-philological 


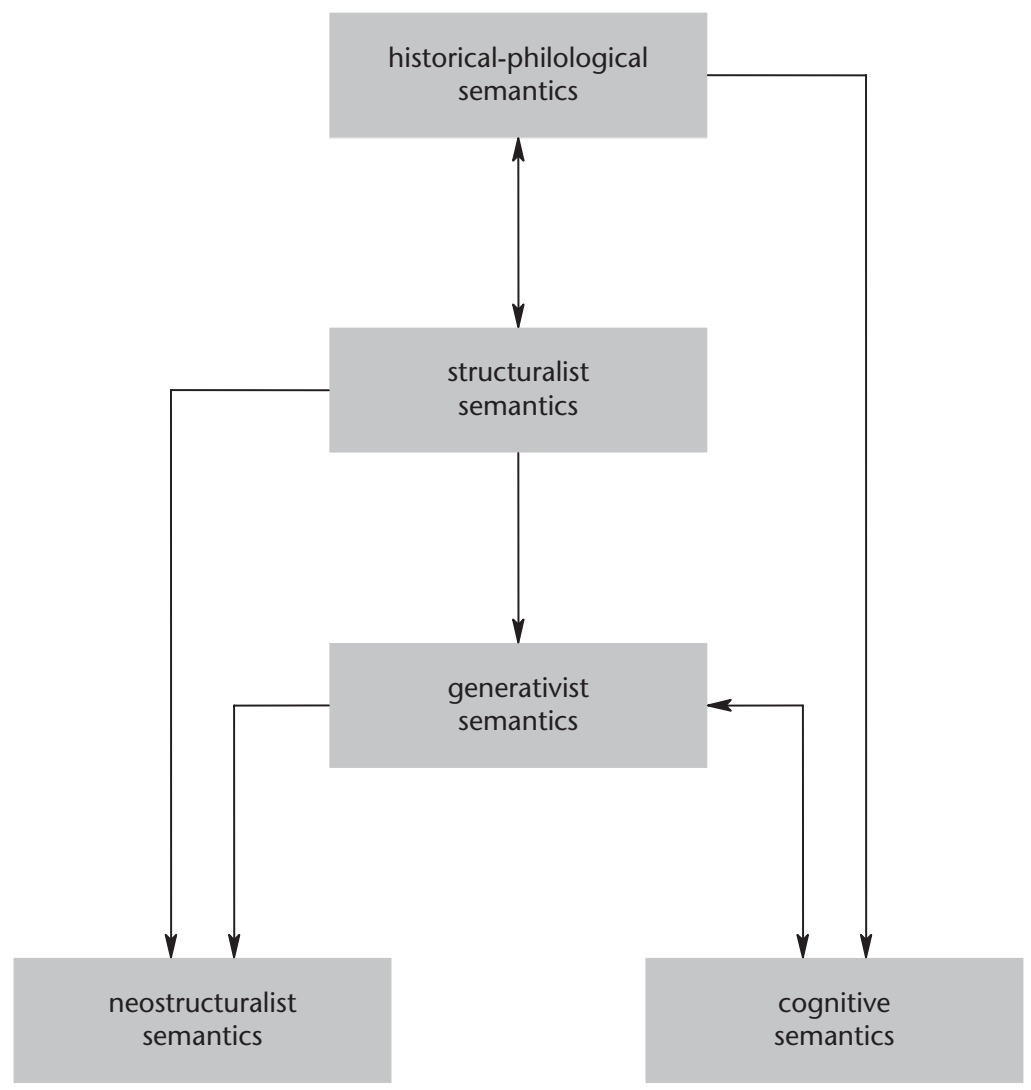

Figure C.1. Main lines in the theoretical history of lexical semantics

semantics and structuralist semantics indicates that the latter is a reaction to the former. The single arrow between structuralist semantics and generativist semantics emphasizes the methodological continuity between both; as described above, though, generativist semantics also adds some crucial new features to the study of the lexicon. The current frameworks each link up with two of the previous ones. The neostructuralist approaches build on structuralist fundamentals, viz. componential analysis and relational perspectives, but they do so largely against the background of generativist semantics. Although only some of them could properly be called 'neogenerativist' (as is done in Geeraerts 2006b: 398-415), most of them devote specific attention either to questions of formalization or to the demarcation between word knowledge and world knowledge and the differentiation between semantics and pragmatics. Cognitive semantics reacts against the restrictive and autonomist aspects of generativist semantics, but at the same time links up with prestructuralist 
historical-philological semantics. Although this link is considerably (if not entirely) obscured by the unfamiliarity and inaccessibility of the historicalphilological tradition, there is in fact a remarkable correspondence between the basic positions of historical-philological and cognitive semantics (see Geeraerts 1988).

To what extent, in fact, can we say that cognitive semantics is a return to the fundamental position of historical-philological semantics? First, cognitive semantics and traditional historical semantics share, by and large, a psychological conception of meaning. Second, both approaches start from an encyclopedist conception of meaning, in the sense that lexical meaning is not considered to be an autonomous phenomenon, but is instead inextricably bound up with the individual, cultural, social, and historical experience of the language user. Third, both are specifically interested in the flexibility and polysemy of meaning and the mechanisms underlying those phenomena; in the case of historical-philological semantics, the perspective is almost exclusively diachronic, whereas cognitive semantics also considers polysemy and flexibility from a synchronic point of view. This correspondence on essentials is further corroborated by striking (but again, largely unnoticed) similarities on particular points. Erdmann's description of the vagueness of word boundaries reads like an early statement on prototype effects; Paul's usage-based model of semantic change fits seamlessly in any contemporary view on the dialectic relationship between semantics and pragmatics; and the regular patterns of metaphor and metonymy investigated in cognitive semantics may sometimes be found almost literally in the older literature.

In the light of this more or less cyclic process, in which cognitive semantics is a return to some of the basic concerns and the fundamental conceptions of historical-philological semantics, we may recognize the tension between a maximalist approach and a more restrained point of view as the main theoretical divide in the progression of lexical semantics. The difference of perspective relates to a number of oppositions: that between usage and structure, between pragmatics and semantics, between context and system, between flexibility and permanence, between cognition and meaning. The maximalist perspective is wary of the distinction between semantic knowledge and encyclopedic knowledge, that is to say, of the belief in an autonomous level of linguistic structure that is strictly separated from cognition in the broader sense, and it tends to see pragmatics (the level of actual usage) as an integral part of semantics. The minimalist perspective, by contrast, tends to maintain these distinctions. Whatever the specific form taken by the two perspectives, structuralist and (in a much more attenuated and diverse form) neostructuralist semantics lean towards the minimalist side, whereas historical-philological and cognitive semantics are situated firmly on the maximalist side. But the 
differences may appear within one overall approach as well: the field conception of Ducháček, Matoré, or Gipper is less limiting than that of Trier or Coseriu. In particular, generativist semantics exhibits an internal tension between a minimalist and a maximalist perspective, and as such occupies an undecided position. At the same time, it is instrumental in the emergence of the current, post-generativist studies: like generative grammar in general, it contributes to the interest in formalization that characterizes many of the neostructuralist approaches, but at the same time, through the intermediary of Generative Semantics, its interest in cognitive adequacy also contributes to the birth of the radically contextualizing position of cognitive semantics. If this interpretation is correct, the overall history of lexical semantics can be written as a process of structuralist decontextualization followed by a marked tendency towards recontextualization-a pattern that to some extent also characterizes the history of modern linguistics at large (see Geeraerts in press).

The contextualizing and decontextualizing trends may be brought out schematically when we map the various approaches to lexical semantics on the semiotic triangle - or at least, on a revised version of the interpretation that was given to the semiotic triangle by Charles W. Morris (1938), which is itself a revised version of Charles S. Peirce's ideas. Morris defined semiotics as consisting of the triad 'syntax', 'semantics', and 'pragmatics'. (Quotation marks are advised here, because the terms are not used in the way they are commonly understood in contemporary linguistics.) 'Syntax' studies the interrelation of signs, at the level of the sign system. 'Semantics' studies the relation between the signs and the objects to which they apply. 'Pragmatics' studies the relation between the sign system and its human user. To make this model convenient for our purposes, two adaptations will be useful. In Morris's behaviourist view of the matter, 'syntax' does not take into account meaning, but the interrelation of signs can surely be studied from the point of view of meaning; that is what structuralism is basically about. Further, there should be different interpretations for the user pole of the triangle: the user can be considered from a psychological point of view, but we can also look at usage, i.e. at language use as a contextualized event. Terminologically, we may then distinguish the crucial relations as follows. The structural perspective looks at the sign-sign relationship, the interrelation of signs. The pragmatic perspective looks at the sign-use(r) relationship, the relation between the sign and the context of use, including the language user. The referential perspective looks at the sign-object relation, the relation between the sign and the world. The corresponding model is summarized in Figure C.2.

The evolution of lexical semantics can now be described as an oscillation along the dimensions of this triangle, and more particularly between the bottom and the top of the triangle. In the initial, historical-philological 


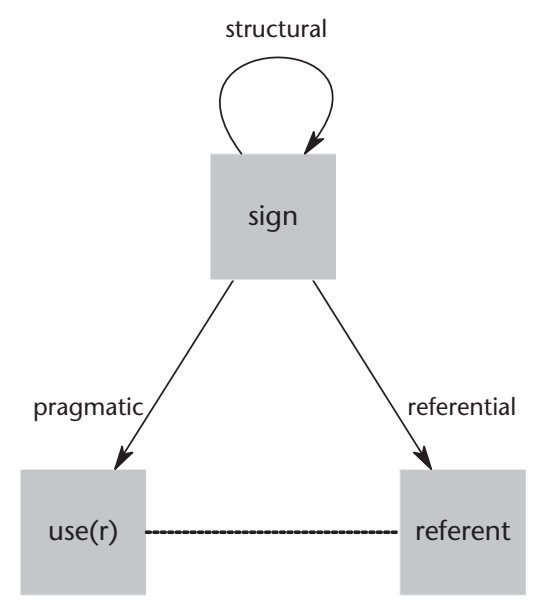

Figure C.2. A semiotic triangle for lexical semantics

stage, the referential and the pragmatic view determine the perspective: the bottom of the triangle is naturally included in the theoretical perspective. Structuralist theorizing, however, signals a retraction to the top of the triangle: the structural relations become dominant, and the theoretical perspective is so to speak severed from the bottom of the triangular schema, which represents the extralinguistic context of use of language. Current cognitive theorizing recontextualizes semantics by again taking into account that bottom line. (The neostructuralist approaches, it will be remembered, take various intermediate positions.) With maximal simplification, we might then say that the history of lexical semantics is broadly characterized by an uncomfortable attempt to reduce semantics to structural, sign-sign relations, at the expense of pragmatic and referential perspectives - an 'uncomfortable' attempt, because time and again, pragmatic and referential phenomena keep breaking into the structuralist positions, as we have seen. A purely linguistic autonomy of semantics, unhampered by extralinguistic factors, may have been pursued as an ideal by the most ideologically minded brands of structuralism, but in the descriptive practice of many structuralists, matters take a less strict form.

However, it would be wrong to confine the undercurrents in the history of lexical semantics to this pattern of ( $\mathrm{de})$ contextualization alone. There may be theoretical vaccillation or tension, but there is also a more linear evolution, which takes the form of a steady expansion of the domain of application of word meaning research. On the most general level, this is obvious if we consider the shift of attention achieved by structuralist semantics: from the single word to onomasiological structures in the lexicon, and from an exclusively diachronic to a synchronic perspective. These extensions are not abandoned 
by later theories. The theoretical affinity between cognitive semantics and historical-philological semantics does not imply a return to the more limited, prestructuralist scope of the latter tradition. Cognitive semantics contributes to diachronic semantics, but it also builds flexibility into the synchronic picture it paints of the lexicon, in the form of a prototype model of semasiological structure. And it is obviously interested in those lexical architectures that overarch groups of individual expressions, like conceptual metaphors or frames.

Our idea of the empirical progress made in lexical semantics can be further refined if we have a look at the specific contribution of the various traditions of research. In order to do so, we need to invoke two distinctions that we encountered a number of times earlier in the book: the distinction between semasiology and onomasiology, and the distinction between an approach that focuses on elements and relations only, and one that takes into account the differences of structural weight between those elements and relations. In section 5.1.3, we used the terms 'qualitative' and 'quantitative approach' to refer to these perspectives; these terms are far from perfect, but they may do for our purposes. If we cross-classify the two distinctions, we get four areas of research. 'Qualitative' semasiology deals with word senses and the semantic links among those senses, like metaphor and metonymy at the level of individual words. 'Qualitative' onomasiology deals with the semantic relations among lexical items (fields, taxonomies, and so on). 'Quantitative' semasiology deals with prototype effects: differences of salience and structural weight within an item or a meaning. 'Quantitative' onomasiology deals with the differences in cognitive salience between categories, like basic-level phenomena and generalized onomasiological entrenchment. Now, if we take these four areas of research, it is easy to see that the major traditions of lexical semantics focus on different parts of the map, and so successively elaborate the field of lexical semantics. The historical-philological tradition of diachronic semantics, to begin with, deals predominantly with the 'qualitative' aspects of semasiology — with processes like metaphor and metonymy, which do not just function as mechanisms of semantic extension but at the same time constitute the synchronic links between the various readings of a lexical item. Structuralist and neostructuralist semantics, next, focus on 'qualitative' phenomena of an onomasiological kind, such as field relations, taxonomical hierarchies, and lexical relations like antonymy. Cognitive semantics, finally, shifts the attention towards the 'quantitative' aspects of lexical structure: all forms of prototypicality effects in the semasiological realm, and basic levels and other types of entrenchment on the onomasiological side. As summarized in Figure C.3, there is a historical progression, from qualitative semasiology to qualitative onomasiology, and hence to an interest in quantitative phenomena on the semasiological as well as on the onomasiological level. 


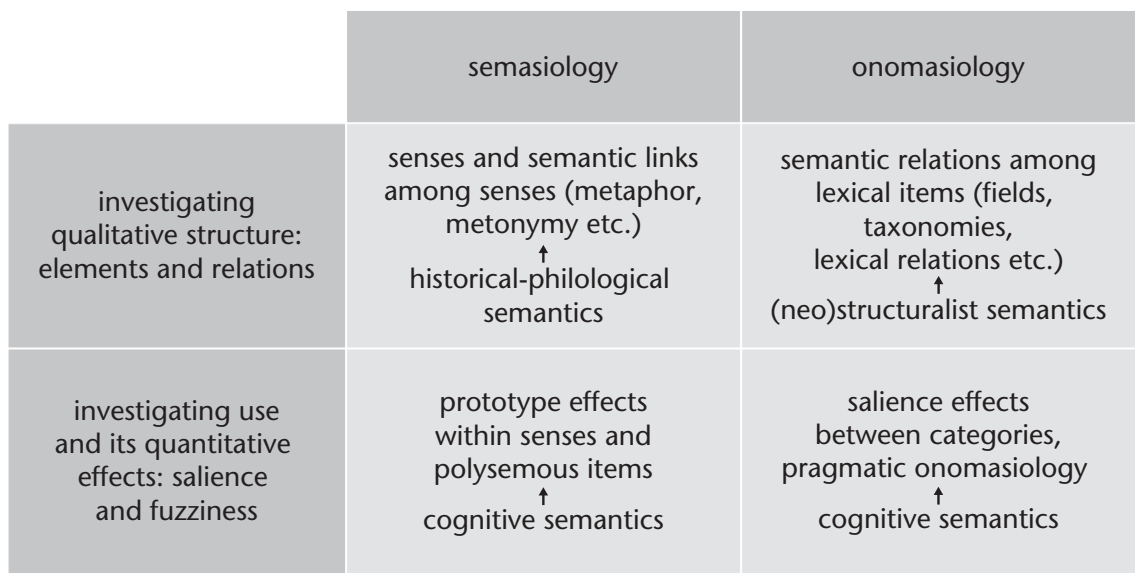

Figure C.3. Main lines in the descriptive history of lexical semantics

In order to avoid misunderstanding, it is important to strike a note of warning: the summary in Figure C.3 defines dominant domains of activity rather than strictly confined fields. The various traditions, that is, are certainly not restricted in their activities to the empirical areas mentioned in the figure. For instance, historical-philological semantics does not have an exclusively semasiological orientation: the notion of analogical change of meaning implicitly assumes an onomasiological perspective, and the Wörter und Sachen movement does so explicitly. In a comparable way, even though componential analysis initially derives from a structural, onomasiological way of thinking, some neostructuralist approaches, like the Generative Lexicon and the Natural Semantic Metalanguage, have an outspoken semasiological orientation. And cognitive semantics contributes to 'qualitative' onomasiology with the concept of frames. Conceptual metaphors too have an onomasiological status; they define sets of expressions that have a similar metaphorical meaning, and so demarcate what might be called 'figurative' lexical fields. In the light of these nuances, Figure C. 3 does not mean to say that all cognitive semantics deals with the 'quantitative' perspective or that all types of historical-philological semantics focus on semasiological phenomena only, and so on. Rather, the figure expresses the idea that the traditions mentioned in each of the cells were those that put that particular area of research centre stage, and that gave a major impetus to its development.

In the light of these nuances, we can get an even better idea of the underlying unity of lexical semantics, and its historical progress, when we appreciate the fundamental parallelism between semasiology and onomasiology: the conceptual relations that are usually studied in semasiology, i.e. in the 
semantic structure of a single expression, are fundamentally of the same kind as those studied onomasiologically between different expressions. (This applies only to paradigmatic relations, to be sure. Syntagmatic relations of cooccurrence by definition require different items.) As a starting point, let us remember that the standard semantic relations in the semasiological domain are specialization/generalization, metaphor, and metonymy. The underlying categorization mechanisms behind these phenomena are hierarchical inclusion, similarity, and contiguity, respectively. Now, the same kinds of relations that shape semasiological structures appear to shape onomasiological structures. First, hierarchical categorization lies at the basis of onomasiological research into lexical taxonomies and lexical fields. (A nuance will follow presently.) Second, conceptual metaphor research transposes the concept of metaphor from the semasiological to the onomasiological domain: conceptual metaphors combine various individual lexical expressions, rather than senses of lexical items, as is the case in the traditional, semasiological conception of metaphor. Third, the typical perspective of Fillmorean frame semantics is of a metonymical kind. To consider an example first, studying verbs like buy and sell by bringing buyers and sellers and goods and prices into the picture equals studying the 'referential syntagmatics' of a lexical item: the way in which the referent of the item (in this case, a particular commercial transaction) occurs in reality in temporal and spatial and functional conjunction with other entities, locations, processes, activities, or whatever. Such co-occurrence of referents is precisely what is meant by contiguity as the basis of metonymy in the semasiological sense. When in cases of synecdoche the name of the whole occurs as the name of the part (fill up the car), the semantic shift is made possible by the referential contiguity, the co-occurrence, the spatial conjunction of the part and the whole. Similarly, the onomasiological 'field' studied by frame semantics includes such items as buyer and product and price next to buy and sell, because there is a contiguity in reality between the activity denoted by sell and the referents of price and product. A traditional analysis of lexical fields, by contrast, would mostly be restricted to the analysis of the verbs buy and sell (which belong together under the superordinate concept of 'commercial transactions').

So, we find a basic similarity between the conceptual relations within words and those between words. Although this is not often observed, it is not really surprising. As we noted at the end of section 5.1.3, why should semantic categories be different when they are found within the structure of a single word, or when they are found within the vocabulary as a whole? In both cases, we are looking for the links between concepts, and the patterns of thought at work on both levels are likely to be the same. But we can refine the picture to a further degree if we take into account that there is a certain mismatch 
between the notion 'metaphor' and the concept of 'semantic relation based on similarity' (a point hinted at in section 1.3.1). Many semantic links that are undoubtedly based on similarity are in fact not metaphorical in nature. An example would be artillery. When the medieval bows and catapults and slings (the original extension of artillery) are replaced by guns and canons, the new weapons take over the name artillery. There is an obvious similarity between the new weapons and the old ones, in the sense that both are of a ballistic kind; they involve throwing or hurling projectiles towards the enemy. One would not say, however, that artillery is being used in a metaphorical way when applied to firearms; rather, the similarity involved is of a non-figurative kind. If this is correct, the category of 'sense relations based on similarity' should be split between metaphor and literal similarity. The distinctive characteristic of metaphorical changes within the group of changes based on similarity, then, would seem to be the figurative nature of metaphors: metaphorical changes are based on figurative rather than literal similarity. Literal similarity, on the other hand, seems to be typical of prototypical clustering at the referential level; one may think here of the similarity between the different members of the category 'fruit'. Even though the distinction between literal and figurative changes is likely to be a continuous rather than a dichotomous one (and although it should be noted that lexical semantics has not yet come up with an adequate, operational definition of figurativeness), we may now distinguish between four basic conceptual relations as the basis of semasiological relations between senses: taxonomical categorization, contiguity, literal similarity, and figurative similarity.

Can such a change be carried through on the onomasiological side as well? It can, by refining the relationship between taxonomical structures and lexical fields. When it was said a moment ago that a hierarchical categorization lies at the basis of onomasiological research into lexical taxonomies and lexical fields, lexical fields were implicitly equated with sets of co-hyponyms in a taxonomy. But co-hyponyms are typically related by (literal) similarity, whereas the hierarchical taxonomical relationship, strictly speaking, applies only to the relationship between a hyponym and its hyperonym. Moreover, defining lexical fields in terms of a literal similarity relation instead of co-hyponymy has the additional advantage of greater flexibility. Not all the terms that would customarily be considered to constitute a lexical field need be co-hyponymous: the superordinate concept is not necessarily lexicalized. For instance, terms such as cupboard, wardrobe, cabinet, dresser, and locker intuitively belong together in the field of 'pieces of furniture for storing things', but there is no single term to act as hypernym for the set. So, by separating the 'vertical' relations in a taxonomy from the 'horizontal' relationship of similarity between co-hyponyms, the parallelism between semasiological and onomasiological 


\begin{tabular}{|c|c|c|}
\hline & semasiological relations & onomasiological relations \\
\hline inclusion & $\begin{array}{c}\text { specialization/generalization } \\
\uparrow \\
\text { historical-philological semantics }\end{array}$ & $\begin{array}{c}\text { taxonomies } \\
\stackrel{\uparrow}{\uparrow} \\
\text { structuralist semantics }\end{array}$ \\
\hline literal similarity & $\begin{array}{l}\text { family resemblances } \\
\uparrow \\
\text { cognitive semantics }\end{array}$ & $\begin{array}{c}\text { lexical fields } \\
\stackrel{\uparrow}{\uparrow} \\
\text { structuralist semantics }\end{array}$ \\
\hline figurative similarity & $\begin{array}{c}\text { lexical metaphor } \\
\stackrel{\uparrow}{\text { historical-philological semantics }}\end{array}$ & $\begin{array}{c}\text { conceptual metaphor } \\
\uparrow \\
\text { cognitive semantics }\end{array}$ \\
\hline contiguity & $\begin{array}{c}\text { metonymy } \\
\uparrow \\
\text { historical-philological semantics }\end{array}$ & $\begin{array}{c}\underset{\uparrow}{\text { frames }} \\
\text { cognitive semantics }\end{array}$ \\
\hline
\end{tabular}

FIgURE C.4. The parallelism between semasiology and onomasiology

structuring is refined. The resulting map of semasiological and onomasiological relations is represented in Figure C.4. In the same schema, the contribution of the traditions of lexical semantics is mapped according to the same principles as in Figure C.3. Again, we notice a stepwise completion of the domain, even though the process is less linear than in Figure C.3. The majority of the semasiological relations, except for prototypicality and family resemblances, come into focus in the era of historical-philological semantics. Structuralist semantics then introduces the attention for lexical fields and taxonomical relations, and cognitive semantics brings to the fore the remaining cells.

To summarize, then, the progress of lexical semantics can be adequately characterized by two central lines of development: a cyclic theoretical movement of decontextualization and recontextualization, and a linear movement of descriptive expansion to which each of the major traditions has made its own substantial contribution. What then could the next steps be? Naturally, each of the traditions and frameworks that we reviewed has its own agenda to follow. As we saw in the final section of the previous chapter, for instance, the recontextualization has not yet come to completion in cognitive semantics, and there is still a lot to do in the domain of pragmatic, usage-based onomasiology. Similarly, the most dynamic and appealing forms of neostructuralist semantics will continue to elaborate their specific points of view. Going beyond these obvious developments, the question is rather whether there is any possibility for a convergence between the various traditions, and in particular, between the two main strands of research that we have distinguished in the contemporary situation, the neostructuralist and the cognitive. Predictions are precarious in principle, but there are two cogent reasons to 
assume that the corpus approaches that we discussed in section 4.2.3 may lead to a rapprochement with cognitive semantics.

In general, the corpus approach is attractive for any theoretical framework in lexical semantics, for the basic reason that it provides an unparalleled empirical basis for lexical research. The wealth of data contained in the corpora-regardless from what perspective they are analysed-will simply benefit any research endeavour in lexical semantics, no less so in cognitive semantics than in other approaches. But more specifically and more importantly, there is a certain theoretical affinity between cognitive semantics and the distributional analysis of corpus data, an affinity that rests on at least the following three features. First, both approaches are explicitly usage-based. In fact, it is difficult to see how cognitive semantics can live up to its self-declared nature as a usage-based model if it does not start from actual usage data and a methodology that is suited to deal with such data (see Geeraerts 2006a for an extended version of this argument). Second, as we analysed at the end of section 4.2.3, the distributional perspective is the least typically structuralist and the most contextualized of the neostructuralist approaches. This provides a principled basis for linking up with the contextualizing developments in cognitive semantics. And third, the quantitative elaboration of a distributional corpus analysis and its incorporation into Statistical Natural Language Processing provide a formal perspective on semantic data that is more congenial to cognitive semantics than the formal frameworks that link up with the more classical symbolic trend in Natural Language Processing. Quite a number of the phenomena that cognitive semantics is interested in-fuzzy boundaries, graded category membership, differences of structural weight, onomasiological salience-are characteristics that are not optimally described by the discrete, all-or-none categories of classical linguistic formalization, but that require a quantitative perspective.

The methodological picture of the history of lexical semantics that is implicit in this comparison may be represented as in Figure C.5. For the various stages in the development that were charted in Figure C.1, we indicate the dominant method associated with it, or the methodological innovation that it introduced. On one side of the picture, the historical-philological focus on semantic change shifts into the contemporary interest of cognitive semantics in synchronic rather than merely diachronic flexibility. In this methodological line, the primary basis of lexical semantics is the study of variabilityvariability through time, or variability in a given period. On the other side of the picture, structure rather than use is the primary focus. The structuralist analysis of paradigmatic and syntagmatic relations, filtered through the generativist interest in formalization, leads to different types of formal modellingof the symbolic type or, in the case of syntagmatic relations, of the probabilistic 


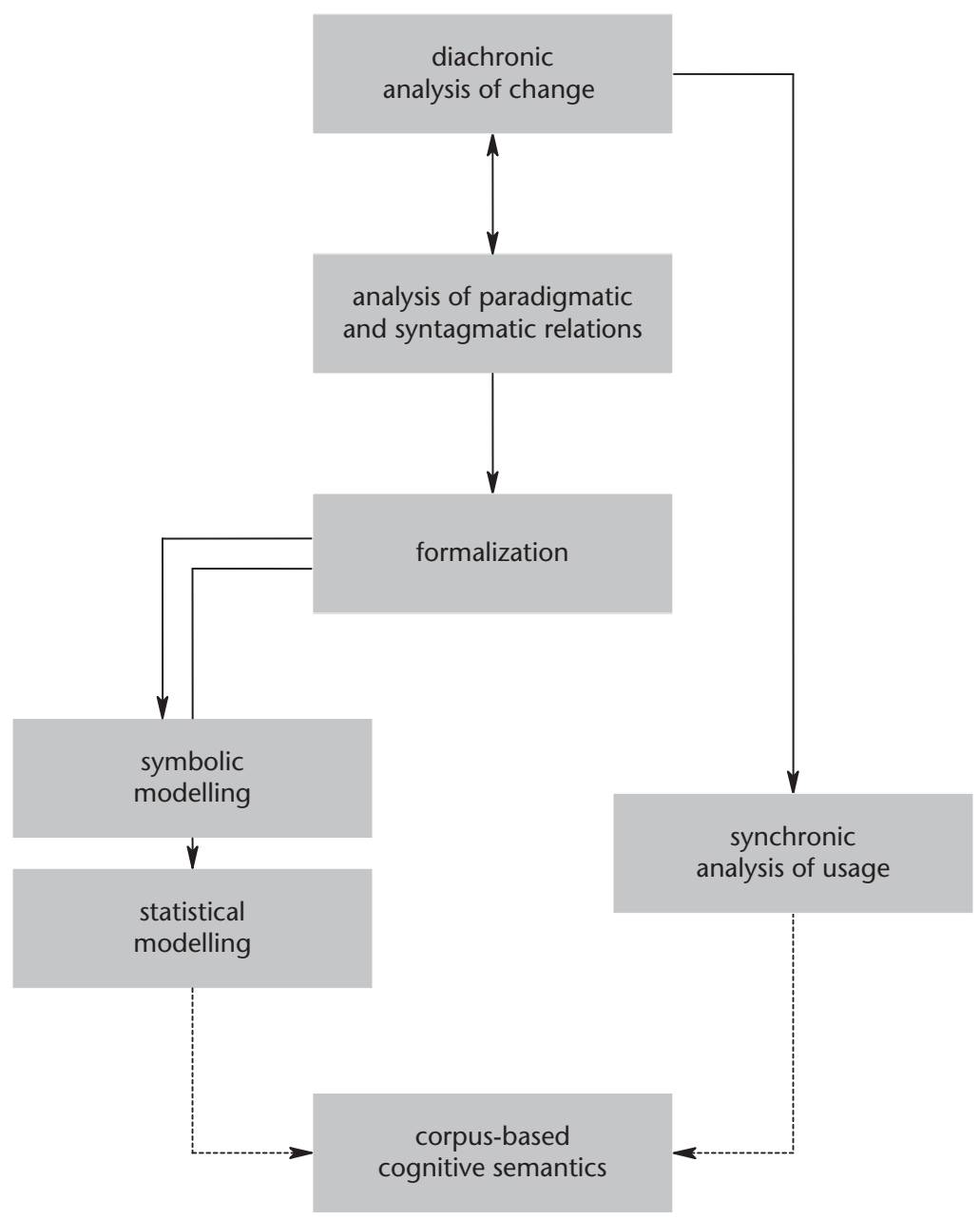

Figure C.5. Main lines in the methodological history of lexical semantics

type. But precisely because the latter corpus-based approach is congenial to a usage-based approach, a convergence with cognitive semantics is possibleand we saw in section 5.5.3 how such an alliance is cautiously but actually emerging. The picture, it should be observed, is simplified and incomplete, not least because it does not reserve a place for the kind of experimental research that is fostered by an interest in cognitive reality. This method is not included because it is not yet a major trend in (cognitive) semantics. In the longer run, however, a further convergence between corpus-based cognitive semantics and psycholinguistic research of the type covered in section 5.5.1 may also be envisaged. 
For the more immediate developments, if the sketch in Figure C.5 is correct, we may conjecture that distributional corpus analysis and cognitive semantics share a firm basis on which to grow closer, thus diminishing the distance between the traditions of neostructuralist semantics and cognitive semantics. Theoretically, descriptively, and methodologically, a contextualizing turn characterizes some of the main contemporary approaches to lexical semantics. The usage-based aspects of lexical semantics would therefore seem to provide an excellent starting point for exploring the possibility of convergences-or, as the case may be, for establishing fundamental incompatibilities.

To conclude, in the metaphor with which we started, the geography of word meaning research in linguistics is indeed a mountainous one, and a cartographical expedition through this varied landscape inspires modesty: with each of the steps forward on our tour d'horizon, we passed vistas to the left and right - thematic domains, individual positions, applied perspectives, interdisciplinary connections - that invited a more detailed investigation than we could afford. Undoubtedly, then, given the scale of the map that we were able to draw, all the areas we travelled through remain underrepresented. But the inspiration works in the other direction as well: none of the tribes that cultivate the different regions occupies the complete territory, and none may claim to dominate the entire field. So, even though these communities are not overwhelmingly exogamous, an awareness of their limits may hopefully stimulate their most inquisitive members to explore the regions beyond their native scenery, exchanging hypotheses and methods and results. 


\section{References}

The publications are cited in the version in which they are consulted or quoted. Relevant information about earlier or later editions is mentioned in the main text, but is not repeated here.

Agirre, Eneko, and Philip Edmonds (2006) Word Sense Disambiguation: Algorithms and Applications. Berlin: Springer.

Aitchison, Jean (1987) Words in the Mind: An Introduction to the Mental Lexicon. Oxford: Blackwell.

(2003) Words in the Mind: An Introduction to the Mental Lexicon. 3rd edn. Oxford: Blackwell.

Alinei, Mario (1996) Aspetti teoretici della motivazione. Quaderni di Semantica 17: 7-17.

Allan, Kathryn (2009) Metaphor and Metonymy: A Diachronic Approach. Oxford: Wiley-Blackwell.

Allan, Keith (2001) Natural Language Semantics. Oxford: Blackwell.

— and Kate Burridge (1991) Euphemism and Dysphemism: Language Used as Shield and Weapon. New York: Oxford University Press.

Allwood, Jens (2003) Meaning potentials and context: some consequences for the analysis of variation in meaning. In Cuyckens et al. (2003: 29-66).

Apresjan, Juri (1966) Analyse distributionelle des significations et champs sémantiques structurés. Langages 1: 44-74.

— (1971) Ideen und Methoden der modernen strukturellen Linguistik. Berlin: Akademie.

(1973) Regular polysemy. Linguistics 142: 5-32.

- (2000) Systematic Lexicography. Oxford: Oxford University Press.

_ Igor A. Mel'čuk, and Aleksander Zholkovsky (1969) Semantics and lexicography: towards a new type of unilingual dictionary. In Ferenc Kiefer (ed.), Studies in Syntax and Semantics, 1-33. Dordrecht: Reidel.

Armstrong, Sharon L., Lila R. Gleitman, and Henry Gleitman (1983) What some concepts might not be. Cognition 13: 263-308.

Arppe, Antti (2008) Univariate, bivariate, and multivariate methods in corpus-based lexicography: a study of synonymy. Ph.D thesis, University of Helsinki.

Asher, Nicholas, and Alex Lascarides (1996) Lexical disambiguation in a discourse context. In James Pustejovsky and Branimir Boguraev (eds.), Lexical Semantics: The Problem of Polysemy, 69-108. Oxford: Clarendon Press.

- (2001) Metaphor in discourse. In Bouillon and Busa (2001: 262-89).

Athanasiadou, Angeliki, Costas Canakis, and Bert Cornillie (eds.) (2006)

Subjectification: Various Paths to Subjectivity. Berlin: Mouton de Gruyter. 
and Elzbieta Tabakowska (eds.) (1998) Speaking of Emotions: Conceptualization and Expression. Berlin: Mouton de Gruyter.

Atkins, B. T. Sue, and Michael Rundell (2008) The Oxford Guide to Practical Lexicography. Oxford: Oxford University Press.

- and Hiroaki Sato (2003) The contribution of FrameNet to practical lexicography. International Journal of Lexicography 16: 333-57.

and Antonio Zampolli (eds.) (1994) Computational Approaches to the Lexicon. Oxford: Oxford University Press.

Atran, Scott (1990) Cognitive Foundations of Natural History: Towards an Anthropology of Science. Cambridge: Cambridge University Press.

Austin, John L. (1962) How to Do Things with Words. Oxford: Clarendon Press.

Baicchi, Annalisa, Cristiano Broccias, and Andrea Sansò (eds.) (2005) Modelling Thought and Constructing Meaning: Cognitive Models in Interaction. Milan: Franco Angeli.

Baldinger, Kurt (1957) Die Semasiologie: Versuch eines Ueberblicks. Berlin: Akademie.

(1960) Alphabetisches oder begrifflich gegliedertes Wörterbuch? Zeitschrift für romanische Philologie 76: 521-36.

- (1964) Sémasiologie et onomasiologie. Revue de Linguistique Romane 28: 249-72.

— (1980) Semantic Theory. Oxford: Blackwell.

Bally, Charles (1940) L'arbitraire du signe: valeur et signification. Le Français Moderne 8: $193-206$.

Bar Hillel, Yehoshua (1967) Dictionaries and meaning rules. Foundations of Language 3: 409-14.

Barcelona, Antonio (ed.) (2000) Metaphor and Metonymy at the Crossroads: A Cognitive Perspective. Berlin: Mouton de Gruyter.

- (2002) Clarifying and applying the notions of metaphor and metonymy within Cognitive Linguistics: an update. In Dirven and Pörings (2002: 207-77).

(2005) The multilevel operation of metonymy in grammar and discourse, with particular attention to metonymic chains. In Francisco Ruiz de Mendoza Ibáñez and Sandra Peña Cervel (eds.), Cognitive Linguistics: Internal Dynamics and Interdisciplinary Interaction, 313-52. Berlin: Mouton de Gruyter.

Bartlett, Frederick C. (1932) Remembering: An Experimental and Social Study. Cambridge: Cambridge University Press.

Bartsch, Renate (1987) Norms of Language: Theoretical and Practical Aspects. London: Longman.

Bechtoldt, Heinrich (1935) Der französische Wortschatz im Sinnbezirk des Verstandes: die geistliche und lehrhafte Literatur von ihren Anfängen bis zum Ende des 12. Jahrhunderts. Romanische Forschungen 49: 21-180.

Beckwith, Richard, Christiane Fellbaum, Derek Gross, and George A. Miller (1991) WordNet: a lexical database organized on psycholinguistic principles. In Uri Zernick (ed.), Lexical Acquisition: Exploiting On-line Resources to Build a Lexicon, 211-32. Hillsdale, NJ: Erlbaum. 
Bendix, Edward H. (1966) Componential Analysis of General Vocabulary: The Semantic Structure of a Set of Verbs in English, Hindi, and Japanese. Bloomington: Indiana University Press.

Berlin, Brent (1976) The concept of rank in ethnobiological classification: some evidence from Aguarana folk botany. American Ethnologist 3: 381-400.

- (1978) Ethnobiological classification. In Eleanor Rosch and Barbara B. Lloyd (eds.), Cognition and Categorization, 9-26. Hillsdale, NJ: Erlbaum.

- (1992) Ethnobiological Classification: Principles of Categorization of Plants and Animals in Traditional Societies. Princeton, NJ: Princeton University Press.

- Dennis E. Breedlove, and Peter H. Raven (1973) General principles of classification and nomenclature in folk biology. American Anthropologist 75: 214-42. (1974) Principles of Tzeltal Plant Classification: An Introduction to the Botanical Ethnography of a Mayan-Speaking People of Highland Chiapas. New York: Academic Press.

and Paul Kay (1969) Basic Color Terms: Their Universality and Evolution. Berkeley: University of California Press.

Bertels, Ann (2006) La polysémie du vocabulaire technique: une étude quantitative. Ph.D thesis, University of Leuven.

Bierwisch, Manfred (1969) On certain problems of semantic representation. Foundations of Language 5: 153-84.

— (1970) Semantics. In John Lyons (ed.), New Horizons in Linguistics, 166-84. Harmondsworth: Penguin.

- (1971) On classifying semantic features. In Danny D. Steinberg and Leon A. Jakobovits (eds.), Semantics: An Interdisciplinary Reader in Philosophy, Linguistics and Psychology, 410-35. Cambridge: Cambridge University Press.

- (1983a) Formal and lexical semantics. Linguistische Studien 114: 56-79.

(1983b) Major aspects of the psychology of language. Linguistische Studien 114: $1-38$.

— (1987) Linguistik als kognitive Wissenschaft: erläuterungen zu einem Forschungsprogramm. Zeitschrift für Germanistik 6: 645-67.

- (1988) On the grammar of local prepositions. In Manfred Bierwisch, Wolfgang Motsch, and Ilse Zimmermann (eds.), Syntax, Semantik und Lexikon, 1-66. Berlin: Akademie.

and Ewald Lang (eds.) (1989) Dimensional Adjectives: Grammatical Structure and Conceptual Interpretation. Berlin: Springer.

Blank, Andreas (1997) Prinzipien des lexikalischen Bedeutungswandels am Beispiel der romanischen Sprachen. Tübingen: Niemeyer.

- (2001) Einführung in die lexikalische Semantik. Tübingen: Niemeyer.

- (2003) Words and concepts in time: towards diachronic cognitive onomasiology. In Regine Eckardt, Klaus von Heusinger, and Christoph Schwarze (eds.), Words in Time: Diachronic Semantics from Different Points of View, 37-65. Berlin: Mouton de Gruyter.

— and Peter Koch (1999) Onomasiologie et étymologie cognitive: l'exemple de la tête. In Mario Vilela and Fatima Silva (eds.), Actas do $1^{\circ}$ Encontro Internacional de Linguística Cognitiva, 49-72. Oporto: Faculdade de Letras. 
and Peter Koch (eds.) (2003) Kognitive romanische Onomasiologie und Semasiologie. Tübingen: Niemeyer.

Bloomfield, Leonard (1933) Language. New York: Holt.

Boden, Margaret (2006) Mind as Machine: A History of Cognitive Science. Oxford: Clarendon Press.

Boers, Frank (1996) Spatial Prepositions and Metaphor: A Cognitive-Semantic Journey along the Up-down and the Front-back Dimensions. Tübingen: Narr.

- (2003) Applied linguistics perspectives on cross-cultural variation in conceptual metaphor. Metaphor and Symbol 18: 231-8.

Bohnemeyer, Jürgen (2003) NSM without the Strong Lexicalization Hypothesis. Theoretical Linguistics 29: 211-22.

Bolinger, Dwight (1965) The atomization of meaning. Language 41: 555-73.

Boroditsky, Lera, and Michael Ramscar (2002) The roles of body and mind in abstract thought. Psychological Science 13: 185-8.

Bouillon, Pierrette, and Federica Busa (eds.) (2001) The Language of Word Meaning. Cambridge: Cambridge University Press.

(2001) Qualia and the structuring of verb meaning. In Bouillon and Busa (2001: 149-67).

Bowdle, Brian F., and Dedre Gentner (2005) The career of metaphor. Psychological Review 112: 193-216.

Braisby, Nick, Bradley Franks, and James Hampton (1996) Essentialism, word use, and concepts. Cognition 59: 247-74.

Brandt, Per Aage (ed.) (2004) Spaces, Domains, and Meaning: Essays in Cognitive Semiotics. Bern: Lang.

Bréal, Michel (1897) Essai de sémantique: science des significations. Paris: Hachette.

Brown, Cecil H. (1984) Language and Living Things: Uniformities in Folk Classification and Naming. New Brunswick, NJ: Rutgers University Press.

Brugman, Claudia (1988) The Story of Over: Polysemy, Semantics and the Structure of the Lexicon. New York: Garland.

Buitelaar, Paul (1998) CoreLex: systematic polysemy and underspecification. Ph.D thesis, Brandeis University.

Burling, Robbins (1964) Cognition and componential analysis: God's truth or hocuspocus? American Anthropologist 66: 20-28.

Cameron, Lynne J. (2003) Metaphor in Educational Discourse. London: Continuum. and Juurd H. Stelma (2005) Metaphor clusters in discourse. Journal of Applied Linguistics 1: 107-36.

Carnap, Rudolf (1956) Meaning and Necessity. Chicago: University of Chicago Press.

Carnoy, Albert (1927) La science des mots: traité de sémantique. Leuven: Editions Universitas.

Carter, Ronald (1998) Vocabulary: Applied Linguistic Perspectives. London: Routledge.

Casad, Eugene H. (1992) Cognition, history and Cora yee. Cognitive Linguistics 3: 151-86.

Catlin, Jane-Carol, and Jack Catlin (1972) Intentionality: a source of ambiguity in English? Linguistic Inquiry 3: 504-8. 
Charniak, Eugene (1996) Statistical Language Learning. Cambridge, MA: MIT Press. Charteris-Black, Jonathan (2004) Corpus Approaches to Critical Metaphor Analysis. Basingstoke: Palgrave Macmillan.

- (2005) Politicians and Rhetoric: Persuasive Power of Metaphor. Basingstoke: Palgrave Macmillan.

Chierchia, Gennaro, and Sally McConnell-Ginet (2000) Meaning and Grammar: An Introduction to Semantics. 2nd edn. Cambridge, MA: MIT Press.

Chilton, Paul (2004) Analysing Political Discourse: Theory and Practice. London: Routledge.

Chomsky, Noam (1957) Syntactic Structures. The Hague: Mouton.

- (1965) Aspects of the Theory of Syntax. Cambridge, MA: MIT Press.

Church, Kenneth, and Patrick Hanks (1990) Word association norms, mutual information, and lexicography. Computational Linguistics 16: 22-9.

Cienki, Alan (1989) Spatial Cognition and the Semantics of Prepositions in English, Polish, and Russian. Munich: Sagner.

Cienki, Alan J., and Cornelia Müller (eds.) (2008) Metaphor and Gesture. Amsterdam: Benjamins.

Coleman, Linda, and Paul Kay (1981) Prototype semantics: the English verb lie. Language 57: 26-44.

Collins, Allan M., and Elizabeth Loftus, F. (1975) A spreading-activation theory of semantic processing. Psychological Review 82: 407-28.

Conklin, Harold (1955) Hanunóo color categories. Southwestern Journal of Anthropology 11: 339-44.

- (1962) Lexicographical treatment of folk taxonomies. In Fred W. Householder and Sol Saporta (eds.), Problems in Lexicography, 119-41. Bloomington: Indiana University Press.

(1964) Ethnogenealogical method. In Ward H. Goodenough (ed.), Explorations in Cultural Anthropology, 25-55. New York: McGraw-Hill.

Copestake, Ann, and Ted Briscoe (1996) Semi-productive polysemy and sense extension. In James Pustejovsky and Branimir Boguraev (eds.), Lexical Semantics: The Problem of Polysemy, 15-67. Oxford: Clarendon Press.

Coseriu, Eugenio (1962) Teoría del lenguaje y lingüística general: cinco estudios. Madrid: Gredos.

- (1964) Pour une sémantique diachronique structurale. Travaux de linguistique et de littérature 2: 139-86.

- (1966) Structure lexicale et enseignement du vocabulaire. Actes du premier Colloque international de linguistique appliquée, 175-217. Nancy: Faculté des lettres et des sciences humaines de l'Université de Nancy.

_- (1967) Lexikalische Solidaritäten. Poetica 1: 293-303.

(1975) Vers une typologie des champs lexicaux. Cahiers de Lexicologie 27: 30-51.

(1980) Textlinguistik. Tübingen: Narr.

and Horst Geckeler (1981) Trends in Structural Semantics. Tübingen: Narr.

Coulson, Seana (2001) Semantic Leaps: Frame-Shifting and Conceptual Blending in Meaning Construction. Cambridge: Cambridge University Press. 
(2008) Metaphor comprehension and the brain. In Gibbs (2008: 177-94).

and Barbara Lewandowska-Tomaszczyk (eds.) (2005) The Literal and Nonliteral in Language and Thought. Frankfurt: Lang.

Craig, Colette (ed.) (1986) Noun Classes and Categorization. Amsterdam: Benjamins.

Croft, William (1993) The role of domains in the interpretation of metaphors and metonymies. Cognitive Linguistics 4: 335-70.

and D. Alan Cruse (2004) Cognitive Linguistics. Cambridge: Cambridge University Press.

Cruse, D. Alan (1982) On lexical ambiguity. Nottingham Linguistic Circular 11: 65-80.

_ (1986) Lexical Semantics. Cambridge: Cambridge University Press.

- (1995a) Between polysemy and monosemy. In Henryk Kardela and Gunnar Persson (eds.), New Trends in Semantics and Lexicography, 25-34. Umeå: Swedish Science Press.

- (1995b) Polysemy and related phenomena from a cognitive linguistic viewpoint. In Patrick Saint-Dizier and Evelyne Viegas (eds.), Computational Lexical Semantics, 33-49. Cambridge: Cambridge University Press.

- (2004) Meaning in Language: An Introduction to Semantics and Pragmatics. 2nd edn. Oxford: Oxford University Press.

- (2006) A Glossary of Semantics and Pragmatics. Edinburgh: Edinburgh University Press.

_ Franz Hundsnurscher, Michael Job, and Peter Rolf Lutzeier (eds.) (2002) Lexikologie: ein internationales Handbuch zur Natur und Struktur von Wörtern und Wortschätzen/Lexicology: An International Handbook on the Nature and Structure of Words and Vocabularies. Berlin: de Gruyter.

Culler, Jonathan (1975) Structuralist Poetics: Structuralism, Linguistics and the Study of Literature. Ithaca, NY: Cornell University Press.

Cuyckens, Hubert (1991) The semantics of spatial prepositions in Dutch: a Cognitive Linguistics exercise. Ph.D thesis, University of Antwerp.

— René Dirven, and John Taylor (eds.) (2003) Cognitive Approaches to Lexical Semantics. Berlin: Mouton de Gruyter.

— and Günter Radden (eds.) (2002) Perspectives on Prepositions. Tübingen: Niemeyer.

_ Dominiek Sandra, and Sally Rice (1997) Towards an empirical lexical semantics. In Birgit Smieja and Meike Tasch (eds.), Human Contact through Language and Linguistics, 35-54. Frankfurt: Lang.

— and Britta Zawada (eds.) (2001) Polysemy in Cognitive Linguistics. Amsterdam: Benjamins.

D’Andrade, Roy G. (1995) The Development of Cognitive Anthropology. Cambridge: Cambridge University Press.

Darmesteter, Arsène (1886) The Life of Words as Symbols of Ideas. London: Kegan Paul. _ (1887) La vie des mots étudiée dans leur significations. Paris: Delagrave. and Adolphe Hatzfeld (1890) Dictionnaire générale de la langue française du commencement du XVIIe siècle jusqu'à nos jours. Paris: Delagrave.

Dauzat, Albert (1922) La géographie linguistique. Paris: Flammarion. 
Davidson, Donald (1967) Truth and meaning. Synthese: 304-23.

de la Cruz Cabanillas, Isabel (1999) The conflict of homonyms: does it exist? Cuadernos de investigación filológica 25: 107-16.

De Mulder, Walter, and Anne Vanderheyden (2001) L'histoire de contre et la sémantique prototypique. Langue Française 130: 108-25.

De Saussure, Ferdinand (1916) Cours de linguistique générale. Paris: Payot.

Deane, Paul D. (1996) On Jackendoff's conceptual semantics. Cognitive Linguistics 7: 35-92.

- (2005) Multiple spatial representation: on the semantic unity of over. In Beate Hampe (ed.), From Perception to Meaning: Image Schemas in Cognitive Linguistics, 235-82. Berlin: Mouton de Gruyter.

Deignan, Alice (2005a) A corpus perspective on the relationship between metaphor and metonymy. Style 39: 72-91.

- (2005b) Metaphor and Corpus Linguistics. Amsterdam: Benjamins.

Dekeyser, Xavier (1990) The prepositions with, mid and again(st) in Old and Middle English: a case study of historical lexical semantics. Belgian Journal of Linguistics 5: $35-48$.

Del Bello, Davide (2007) Forgotten Paths: Etymology and the Allegorical Mindset. Washington, DC: Catholic University of America Press.

Desmet, Piet (1996) La linguistique naturaliste en France (1867-1922): nature, origine et évolution du langage. Leuven: Peeters.

Dewell, Robert B. (1994) Over again: on the role of image-schemas in semantic analysis. Cognitive Linguistics 5: 351-80.

Di Meola, Claudio (1994) Kommen und gehen: Eine kognitiv-linguistische Untersuchung der Polysemie deiktischer Bewegungsverben. Tübingen: Niemeyer.

Dilthey, Wilhelm (1910) Der Aufbau der geschichtlichen Welt in den Geisteswissenschaften. Berlin: Königlichen Akademie der Wissenschaften.

Dirven, René (1985) Metaphor as a basic means for extending the lexicon. In Wolf Paprotté and René Dirven (eds.), The Ubiquity of Metaphor: Metaphor in Language and Thought, 85-120. Amsterdam: Benjamins.

- (1993) Metonymy and metaphor: different mental strategies of conceptualisation. Leuvense Bijdragen/Leuven Contributions in Linguistics and Philology 82: 1-28.

- (2002) Metonymy and metaphor: different mental strategies of conceptualisation. In Dirven and Pörings (2002: 75-111).

Roslyn Frank, and Cornelia Ilie (eds.) (2001) Language and Ideology 2: Descriptive Cognitive Approaches. Amsterdam: Benjamins.

and Martin Pütz (eds.) (2003) Cognitive Models in Language and Thought; Ideology, Metaphors and Meanings. Berlin: Mouton de Gruyter.

— Louis Goossens, Yvan Putseys, and Emma Vorlat (1982) The Scene of Linguistic Action and Its Perspectivization by Speak, Talk, Say and Tell. Amsterdam: Benjamins. _ Bruce Hawkins, and Esra Sandikcioglu (eds.) (2001) Language and Ideology 1: Theoretical Cognitive Approaches. Amsterdam: Benjamins.

- and Ralf Pörings (eds.) (2002) Metaphor and Metonymy in Comparison and Contrast. Berlin: Mouton de Gruyter. 
and John R. Taylor (1988) The conceptualisation of vertical space in English: the case of tall. In Brygida Rudzka-Ostyn (ed.), Topics in Cognitive Linguistics, 379-402. Berlin: Mouton de Gruyter.

Divjak, Dagmar (2006) Ways of intending: delineating and structuring nearsynonyms. In Gries and Stefanowitsch (2006: 19-56).

— and Stefan Th. Gries (2006) Ways of trying in Russian: clustering behavorial profiles. Corpus Linguistics and Linguistic Theory 2: 23-60.

Dornseiff, Franz (1944) List und Kunst. Deutsche Vierteljahrsschrift für Literaturwissenschaft und Geistesgeschichte 22: 231-6.

- (1959) Der deutsche Wortschatz nach Sachgruppen. 5th edn. Berlin: de Gruyter.

_ (1966) Bezeichnungswandel unseres Wortschatzes: Ein Blick in das Seelenleben der Sprechenden. Lahr: Schauenburg.

Dowty, David R. (1979) Word Meaning and Montague Grammar. Dordrecht: Reidel.

— Robert E. Wall, and Stanley Peters (1981) Introduction to Montague Semantics. Dordrecht: Reidel.

Du Marsais, César Chesneau (1730) Des tropes ou Des diferens sens dans lesquels on peut prendre un même mot dans une même langue. Paris: Brocas.

Dubois, Jean (1964) Distribution, ensemble et marque dans le lexique. Cahiers de Lexicologie 4: 5-16.

- (1965-9) Grammaire structural du français. Paris: Larousse.

Ducháček, Otto (1959) Champ conceptuel de la beauté en français moderne. Vox Romanica 18: 297-323.

- (1960) Le champ conceptuel de la beauté en français moderne. Prague: Státní pedagogické nakladatelství.

- (1961) Sur le problème de la migration des mots d'un champ conceptuel dans l'autre. Lingua 10: 57-78.

(1968) Différents types de champs linguistiques et l'importance de leur exploration. Zeitschrift fur franzözische Sprache und Literatur: Beihefte, Neue Folge 1: $25-36$.

Dunning, Ted (1993) Accurate methods for the statistics of surprise and coincidence. Computational Linguistics 19: 61-74.

Dupré, John (1981) Natural kinds and biological taxa. Philosophical Review 90: 66-90.

Durst, Uwe (2003) The Natural Semantic Metalanguage approach to linguistic meaning. Theoretical Linguistics 29: 157-200.

Ebeling, Carl L. (1960) Linguistic Units. The Hague: Mouton.

Eckardt, Regine (2003) Meaning change in conceptual Montague semantics. In Regine Eckardt, Klaus Von Heusinger, and Christoph Schwarze (eds.), Words in Time: Diachronic Semantics from Different Points of View, 225-47. Berlin: Mouton de Gruyter.

Ellen, Roy (1993) The Cultural Relations of Classification: An Analysis of Nuaulu Animal Categories from Central Seram. Cambridge: Cambridge University Press.

- (ed.) (2006) Ethnobiology and the Science of Humankind. Journal of the Royal Anthropological Institute 12: S1-S160. 
Erdmann, Karl-Otto (1910) Die Bedeutung des Wortes: Aufsätze aus dem Grenzgebiet der Sprachpsychologie und Logik. 2nd edn. Leipzig: Avenarius.

Esnault, Gaston (1925) Métaphores occidentales: essai sur les valeurs imaginatives concrètes du français parlé en Basse-Bretagne comparé avec les patois, parlers techniques et argots français. Paris: Presses Universitaires de France.

Evans, Gareth (1977) The causal theory of names. In Stephen P. Schwartz (ed.), Naming, Necessity, and Natural Kinds, 192-215. Ithaca, NY: Cornell University Press.

Evans, Nicholas, and David P. Wilkins (2000) In the mind's ear: the semantic extensions of perception verbs in Australian languages. Language 76: 546-92.

Evans, Vyvyan (2006) Lexical concepts, cognitive models and meaning-construction. Cognitive Linguistics 17: 491-534.

_ Benjamin Bergen, and Jörg Zinken (eds.) (2007) The Cognitive Linguistics Reader. London: Equinox.

Evans, Vyvyan, and Melanie Green (2006) Cognitive Linguistics: An Introduction. Mahwah, NJ: Erlbaum.

Evens, Martha W., Bonnie E. Litowitz, Judith E. Markowitz, Raoul N. Smith, and Oswald Werner (1980) Lexical-Semantic Relations: A Comparative Survey. Edmonton: Linguistic Research.

Fabiszak, Malgorzata (2001) The Concept of Joy in Old and Middle English: A Semantic Analysis. Pila: Wyzsza Szkola Biznesu.

Fauconnier, Gilles (1985) Mental Spaces: Aspects of Meaning Construction in Natural Language. Cambridge, MA: MIT Press.

- (1997) Mappings in Thought and Language. Cambridge: Cambridge University Press.

and Eve E. Sweetser (eds.) (1996) Spaces, Worlds, and Grammar. Chicago: University of Chicago Press.

and Mark Turner (1994) Conceptual projection and middle spaces. Technical Report 9401. San Diego: Department of Cognitive Science, University of California.

(1995) Conceptual integration and formal expression. Journal of Metaphor and Symbolic Activity 10: 183-204.

- (1998) Conceptual integration networks. Cognitive Science 22: 133-87.

- (2002) The Way We Think: Conceptual Blending and the Minds Hidden Complexities. New York: Basic Books.

Fellbaum, Christiane (ed.) (1998) WordNet: An Electronic Lexical Database. Cambridge, MA: MIT Press.

- and Piek Vossen (2007) Connecting the universal to the specific: towards the Global Grid. In Toru Ishida, Susan R. Fussell, and Piek Vossen (eds.), Intercultural Collaboration, 1-16. Berlin: Springer.

Feyaerts, Kurt (1999) Metonymic hierarchies: the conceptualization of stupidity in German idiomatic expressions. In Panther and Radden (1999: 309-32). Amsterdam: Benjamins.

- (2000) Refining the Inheritance Hypothesis: interaction between metaphorical and metonymic hierarchies. In Barcelona (2000: 59-78). 
(ed.) (2003) The Bible through Metaphor and Translation: A Cognitive Semantic Perspective. Bern: Lang.

Fillmore, Charles J. (1975) An alternative to checklist theories of meaning. In Cathy Cogen, Henry Thompson, Graham Thurgood, Kenneth Whistler, and James Wright (eds.), Proceedings of the First Annual Meeting of the Berkeley Linguistics Society, 123-31. Berkeley, CA: Berkeley Linguistics Society.

- (1977a) The case for case reopened. In Peter Cole and Jerrold M. Sadock (eds.), Grammatical Relations, 59-81. New York: Academic Press.

- (1977b) Scenes-and-frames semantics. In Antonio Zampolli (ed.), Linguistic Structures Processing, 55-81. Amsterdam: North-Holland.

- (1982) Towards a descriptive framework for spatial deixis. In Robert J. Jarvella and Wolfgang Klein (eds.), Speech, Place, and Action: Studies of Deixis and Related Topics, 31-59. Chichester: Wiley.

- (1985) Frames and the semantics of understanding. Quaderni di Semantica 6: 222-54.

- (1987) A private history of the concept frame. In René Dirven and Günter Radden (eds.), Concepts of Case, 28-36. Tübingen: Narr.

- (1992) Corpus linguistics vs. computer-aided armchair linguistics. In Jan Svartvik (ed.), Directions in Corpus Linguistics, 35-66. Berlin: Mouton de Gruyter.

- and B. T. Sue Atkins (1992) Toward a frame-based lexicon: the semantics of risk and its neighbors. In Adrienne Lehrer and Eva Feder Kittay (eds.), Frames, Fields and Contrasts: New Essays in Semantic and Lexical Organization, 75-102. Hillsdale, NJ: Erlbaum.

_ (1994) Starting where dictionaries stop: the challenge of corpus lexicography. In B. T. Sue Atkins and Antonio Zampolli (eds.), Computational Approaches to the Lexicon, 349-93. Oxford: Oxford University Press.

(2000) Describing polysemy: the case of crawl. In Yael Ravin and Claudia Leacock (eds.), Polysemy: Theoretical and Computational Approaches, 91-110. Oxford: Oxford University Press.

- Paul Kay, and Catherine O'Connor (1988) Regularity and idiomaticity in grammatical construction: the case of let alone. Language 64: 501-38.

Firth, John R. (1957a) Papers in Linguistics 1934-51. Oxford: Oxford University Press.

_ (1957b) A synopsis of linguistic theory 1930-1955. In John R. Firth (ed.), Studies in Linguistic Analysis, 1-32. Oxford: Philological Society.

Fischer, Kerstin (2000) From Cognitive Semantics to Lexical Pragmatics: The Functional Polysemy of Discourse Particles. Berlin: Mouton de Gruyter.

Fodor, Janet D. (1977) Semantics: Theories of Meaning in Generative Grammar. New York: Harper \& Row.

Fodor, Jerry A. (1970) Three reasons for not deriving kill from cause to die. Linguistic Inquiry 1: 429-38.

(1975) The Language of Thought. Hassocks: Harvester Press.

— Janet D. Fodor, and Merrill F. Garrett (1975) The psychological unreality of semantic representations. Linguistic Inquiry 6: 515-32. 
Fodor, Jerry A. Merrill F. Garrett, Edward C. T. Walker, and Cornelia H. Parkes (1980) Against definitions. Cognition 8: 263-367.

— and Ernest Lepore (1992) Holism: A Shopper's Guide. Oxford: Blackwell.

Fontenelle, Thierry (1997) Turning a Bilingual Dictionary into a Lexical-Semantic Database. Tübingen: Niemeyer.

- (1998) Discovering significant lexical functions in dictionary entries. In Anthony P. Cowie (ed.), Phraseology. Theory, Analysis, and Applications, 189-207. Oxford: Clarendon Press.

(ed.) (2003) FrameNet and Frame Semantics. International Journal of Lexicography 16: 231-366.

(ed.) (2008) Practical Lexicography: A Reader. Oxford: Oxford University Press.

Forceville, Charles (1996) Pictorial Metaphor in Advertising. London: Routledge.

Fowler, Harold North (ed.) (1963) Plato: Cratylus, Parmenides, Greater Hippias, Lesser Hippias. London: Heinemann.

Frake, Charles (1962) The ethnographic study of cognitive systems. In Thomas Gladwin and William C. Sturtevant (eds.), Anthropology and Human Behavior, 7285. Washington, DC: Anthropological Society of Washington.

Fritz, Gerd (1974) Bedeutungswandel im Deutschen: Neuere Methoden der diachronen Semantik. Tübingen: Niemeyer.

- (1998) Historische Semantik. Stuttgart: Metzler.

Fuchs, Catherine, and Bernard Victorri (1996) La polysémie: construction dynamique du sens. Paris: Hermès.

Fumaroli, Marc (ed.) (1999) Histoire de la rhétorique dans l'Europe moderne 1450-1950.

Paris: Presses Universitaires de France.

Geckeler, Horst (1971a) Strukturelle Semantik und Wortfeldtheorie. Munich: Fink.

_ (1971b) Zur Wortfelddiskussion. Munich: Fink.

(1973) Strukturelle Semantik des Französischen. Tübingen: Niemeyer.

(1988) Major aspects of the lexematics of the Tübingen school of semantics. In Hüllen and Schulze (1988: 11-22).

(1993) Strukturelle Wortfeldforschung heute. In Peter Rolf Lutzeier (ed.), Studien zur Wortfeldtheorie/Lexical Field Theory, 11-22. Tübingen: Niemeyer.

Geeraerts, Dirk (1981) Review of G. Lakoff and M. Johnson, Metaphors We Live By. Quaderni di Semantica 2: 389-96.

- (1985) Paradigm and Paradox: Explorations into a Paradigmatic Theory of Meaning and its Epistemological Background. Leuven: Leuven University Press.

— (1986) Woordbetekenis: een overzicht van de lexicale semantiek. Leuven: Acco.

(1988) Cognitive grammar and the history of lexical semantics. In Brygida Rudzka-Ostyn (ed.), Topics in Cognitive Linguistics, 647-77. Amsterdam: Benjamins. Repr. in Geeraerts (2006b: 367-97).

(1990) The lexicographical treatment of prototypical polysemy. In Savas L. Tsohatzidis (ed.), Meanings and Prototypes: Studies in Linguistic Categorization, 195210. London: Routledge. Repr. in Geeraerts (2006b: 327-44).

- (1992) The semantic structure of Dutch over. Leuvense Bijdragen/Leuven Contributions in Linguistics and Philology 81: 205-30. Repr. in Geeraerts (2006b: 48-73). 
(1993) Vagueness's puzzles, polysemy's vagaries. Cognitive Linguistics 4: 223-72. Repr. in Geeraerts (2006b: 99-148).

- (1994) Classical definability and the monosemic bias. Rivista di Linguistica 6: 149-72. Repr. in Geeraerts (2006b: 149-72).

(1997) Diachronic Prototype Semantics: A Contribution to Historical Lexicology. Oxford: Clarendon Press.

(1999) Idealist and empiricist tendencies in Cognitive Linguistics. In Theo Janssen and Gisela Redeker (eds.), Cognitive Linguistics: Foundations, Scope, and Methodology, 163-94. Berlin: Mouton de Gruyter. Repr. in Geeraerts (2006b: 416-44).

- (2000) Salience phenomena in the lexicon: a typology. In Liliana Albertazzi (ed.), Meaning and Cognition, 79-101. Amsterdam: Benjamins. Repr. in Geeraerts (2006b: 74-96).

- (2002) The interaction of metaphor and metonymy in composite expressions. In Dirven and Pörings (2002: 435-65). Repr. in Geeraerts (2006b: 198-223).

- (2006a) Methodology in Cognitive Linguistics. In Kristiansen et al. (2006: 21-49).

- (2006b) Words and Other Wonders: Papers on Lexical and Semantic Topics. Berlin: Mouton de Gruyter.

- (ed.) (2006c) Cognitive Linguistics: Basic Readings. Berlin: Mouton de Gruyter.

- (2007) Lexicography. In Geeraerts and Cuyckens (2007: 1160-75). (in press) Recontextualizing grammar: underlying trends in thirty years of Cognitive Linguistics. In Elzbieta Tabakowska (ed.), Cognitive Linguistics in Action: From Theory to Application and Back. Berlin: Mouton de Gruyter.

— and Hubert Cuyckens (eds.) (2007) The Oxford Handbook of Cognitive Linguistics. New York: Oxford University Press.

— and Caroline Gevaert (2008) Hearts and (angry) minds in Old English. In Farzad Sharifian, René Dirven, Ning Yu, and Susanne Niemeier (eds.), Culture and Language: Looking for the Mind Inside the Body, 319-47. Berlin: Mouton de Gruyter.

- and Stefan Grondelaers (1995) Looking back at anger: cultural traditions and metaphorical patterns. In John Taylor and Robert E. MacLaury (eds.), Language and the Construal of the World, 153-80. Berlin: Mouton de Gruyter. Repr. in Geeraerts (2006b: 227-51).

and Peter Bakema (1994) The Structure of Lexical Variation: Meaning, Naming, and Context. Berlin: Mouton de Gruyter.

and Dirk Speelman (1999) Convergentie en divergentie in de Nederlandse woordenschat: een onderzoek naar kleding- en voetbaltermen. Amsterdam: Meertens Instituut.

Gentner, Dedre (1983) Structure-mapping: a theoretical framework for analogy. Cognitive Science 7: 155-70.

and Brian F. Bowdle (2008) Metaphor as structure-mapping. In Gibbs (2008: 109-28). 
Gevaert, Caroline (2005) The ANGER Is HEAT question: detecting cultural influence on the conceptualisation of anger through diachronic corpus analysis. In Nicole Delbecque, Johan van der Auwera, and Dirk Geeraerts (eds.), Perspectives on Variation: Sociolinguistic, Historical, Comparative, 195-208. Berlin: Mouton de Gruyter.

Gévaudan, Paul (2007) Typologie des lexikalischen Wandels: Bedeutungswandel, Wortbildung und Entlehnung am Beispiel der romanischen Sprachen. Tübingen: Stauffenburg.

— Peter Koch, and Antonia Neu (2003) Hundert Jahre nach Zauner: Die romanischen Namen der Körperteile im DECOLAR. Romanistisches Jahrbuch 54: $1-27$.

Gibbs, Jr., Raymond W. (1994) The Poetics of Mind: Figurative Thought, Language, and Understanding. Cambridge: Cambridge University Press.

- (1999a) Intentions in the Experience of Meaning. Cambridge: Cambridge University Press.

- (1999b) Taking metaphor out of our heads and putting it into the cultural world. In Gibbs and Steen (1999: 145-66).

- (2006) Embodiment and Cognitive Science. Cambridge: Cambridge University Press.

- (ed.) (2008) The Cambridge Handbook of Metaphor and Thought. Cambridge: Cambridge University Press.

and Gerard J. Steen (eds.) (1999) Metaphor in Cognitive Linguistics. Amsterdam: Benjamins.

Gildea, Patricia, and Sam Glucksberg (1983) On understanding metaphor: the role of context. Journal of Verbal Learning and Verbal Behavior 22: 577-90.

Gilliéron, Jules, and Mario Roques (1912) Etudes de géographie linguistique d'après l'Atlas linguistique de la France. Paris: Champion.

Gilquin, Gaetanelle (2003) Causative get and have: so close, so different. Journal of English Linguistics 31: 125-48.

Giora, Rachel (2003) On Our Mind: Salience, Context and Figurative Language. New York: Oxford University Press.

Gipper, Helmut (1959) Sessel oder Stuhl? Ein Beitrag zur Bestimmung von Wortinhalten im Bereich der Sachkultur. In Helmut Gipper (ed.), Sprache, Schlüssel zur Welt: Festschrift für Leo Weisgerber, 271-92. Düsseldorf: Schwann.

— and Hans Schwarz (1962-89) Bibliographisches Handbuch zur Sprachinhaltsforschung. Cologne: Westdeutscher Verlag.

Glinz, Hans (1954) Die Darstellung eines Wortschatzes: zum Begriffssystem als Grundlage für die Lexikographie von R. Hallig und W. von Wartburg. Zeitschrift für Mundartforschung 22: 34-45.

Glucksberg, Sam (2001) Understanding of Figurative Language: From Metaphors to Idioms. Oxford: Oxford University Press.

- (2008) How metaphors create categories-quickly. In Gibbs (2008: 67-83).

— and Boaz Keysar (1990) Understanding metaphorical comparisons: beyond similarity. Psychological Review 97: 3-18. 
Glynn, Dylan (2004) Constructions at the crossroads: the place of construction grammar between field and frame. Annual Review of Cognitive Linguistics 2: 197-233.

- (2008) Mapping meaning: towards a usage-based methodology in Cognitive Semantics. Ph.D thesis, University of Leuven.

Goatly, Andrew (1997) The Language of Metaphors. London: Routledge.

- (2007) Washing the Brain: Metaphor and Hidden Ideology. Amsterdam: Benjamins.

Goddard, Cliff (1994) Semantic theory and semantic universals. In Goddard and Wierzbicka (1994: 7-30).

— (1998) Semantic Analysis: A Practical Introduction. Oxford: Oxford University Press.

- (2002) The search for the shared semantic core of all languages. In Goddard and Wierzbicka (2002: 5-41).

- (2006a) Ethnopragmatics: a new paradigm. In Goddard (2006b: 1-30).

- (ed.) (2006b) Ethnopragmatics: Understanding Discourse in Cultural Context. Berlin: Mouton de Gruyter.

- (2008) Cross-Linguistic Semantics. Amsterdam: Benjamins.

— and Anna Wierzbicka (eds.) (1994) Semantic and Lexical Universals: Theory and Empirical Findings. Amsterdam: Benjamins.

—_ (eds.) (2002) Meaning and Universal Grammar: Theory and Empirical Findings. Amsterdam: Benjamins.

Goffman, Erving (1974) Frame Analysis: An Essay on the Organization of Experience. New York: Harper \& Row.

Gonzalvez-García, Francisco, and Christopher S. Butler (2006) Mapping functionalcognitive space. Annual Review of Cognitive Linguistics 4: 39-96.

Goodenough, Ward H. (1956) Componential analysis and the study of meaning. Language 32: 195-216.

Goossens, Jan (1969) Strukturelle Sprachgeographie. Heidelberg: Winter.

Goossens, Louis (1990) Metaphtonymy: the interaction of metaphor and metonymy in expressions for linguistic action. Cognitive Linguistics 1: 323-40.

- (1992) Cunnan, Connen(n), Can: the development of a radial category. In Günter Kellermann and Michael D. Morrissey (eds.), Diachrony within Synchrony: Language, History and Cognition. Frankfurt: Lang.

Gordon, W. Terrence (1980) Semantics: A Bibliography 1965-1978. Metuchen: Scarecrow Press.

- (1982) A History of Semantics. Amsterdam: Benjamins.

_ (1987) Semantics: A Bibliography 1979-1985. Metuchen: Scarecrow Press.

_ (1992) Semantics: A Bibliography 1986-1991. Metuchen: Scarecrow Press.

Grady, Joseph (1997) Theories are buildings revisited. Cognitive Linguistics 8: 267-90.

- (1999) A typology of motivation for conceptual metaphor: correlation vs. resemblance. In Gibbs and Steen (1999: 79-100).

- Todd Oakley, and Seana Coulson (1999) Conceptual blending and metaphor. In Gibbs and Steen (1999: 101-24). 
Grady, Joseph, Sarah Taub, and Pamela S. Morgan (1996) Primitive and compound metaphors. In Adele E. Goldberg (ed.), Conceptual Structure, Discourse and Language, 177-87. Stanford, CA: CSLI Publications.

Greimas, Algirdas (1966) Sémantique structurale: recherche de méthode. Paris: Larousse.

- (1970) Du sens: essais sémiotiques 1. Paris: Seuil.

- (1983) Du sens: essais sémiotiques 2. Paris: Seuil.

Gries, Stefan Th. (2006) Corpus-based methods and cognitive semantics: the many senses of to run. In Gries and Stefanowitsch (2006: 57-99).

— and Anatol Stefanowitsch (eds.) (2006) Corpora in Cognitive Linguistics: CorpusBased Approaches to Syntax and Lexis. Berlin: Mouton de Gruyter.

Grondelaers, Stefan, and Dirk Geeraerts (2003) Towards a pragmatic model of cognitive onomasiology. In Cuyckens et al. (2003: 67-92).

— Dirk Speelman, and Dirk Geeraerts (2008) National variation in the use of er 'there': regional and diachronic constraints on cognitive explanations. In Gitte Kristiansen and René Dirven (eds.), Cognitive Sociolinguistics: Language Variation, Cultural Models, Social Systems, 153-203. Berlin: Mouton de Gruyter.

Grygiel, Marcin, and Grzegorz A. Kleparski (2007) Main Trends in Historical Semantics. Rzeszów: Wydawnictwo Uniwersytetu Rzeszowskiego.

Grzega, Joachim (2002) Some aspects of modern diachronic onomasiology. Linguistics 40: $1021-45$.

- (2004) Bezeichnungswandel: Wie, Warum, Wozu? Ein Beitrag zur englischen und allgemeinen Onomasiologie. Heidelberg: Winter.

Guiraud, Pierre (1956) Les champs morpho-sémantiques. Bulletin de la Société de Linguistique de Paris 52: 265-88.

Haack, Susan (1978) Philosophy of Logics. Cambridge: Cambridge University Press.

Haase, Friedrich (1874-80) Vorlesungen über lateinische Sprachwissenschaft, gehalten ab 1840. Leipzig: Simmel.

Habel, Christoph (1989) Zwischen-Bericht. In Christoph Habel, Michael Herweg, and Klaus Rehkämper (eds.), Raumkonzepte in Verstehensprozessen, 37-69. Tübingen: Niemeyer.

Halliday, Michael A. K. (1973) Explorations in the Functions of Language. London: Arnold.

Wolfgang Teubert, Colin Yallop, and Anna Cermáková (2004) Lexicology and Corpus Linguistics: An Introduction. London: Continuum.

Hallig, Rudolf, and Walther Von Wartburg (1952) Begriffssystem als Grundlage für die Lexikographie: Versuch eines Ordnungsschemas. Berlin: Akademie.

Hampe, Beate (ed.) (2005) From Perception to Meaning: Image Schemas in Cognitive Linguistics. Berlin: Mouton de Gruyter.

Hanks, Patrick W. (1994) Linguistic norms and pragmatic exploitations, or why lexicographers need prototype theory and vice versa. In Ferenc Kiefer, Gábor Kiss, and Júlia Pajzs (eds.), Papers in Computational Lexicography, 89-113. Budapest: Hungarian Academy of Sciences. 
(2006) The organization of the lexicon: semantic types and lexical sets. In Elisa Corino, Carla Marello, and Cristina Onesti (eds.), Proceedings of the 12th Euralex International Congress, 1165-8. Alessandria: Edizioni dell'Orso.

— (ed.) (2007) Lexicology: Critical Concepts in Linguistics. London: Routledge.

- (2008) The lexicographical legacy of John Sinclair. International Journal of Lexicography 21: 219-30.

and James Pustejovsky (2005) A pattern dictionary for natural language processing. Revue Française de Linguistique Appliquée 10: 63-82.

Harris, Randy A. (1993) The Linguistics Wars. New York: Oxford University Press.

Harris, Zellig (1954) Distributional structure. Word 10: 146-62.

Hart, Christopher, and Dominik Lukeš (eds.) (2007) Cognitive Linguistics in Critical Discourse Analysis: Application and Theory. Newcastle upon Tyne: Cambridge Scholars.

Hartmann, Reinhard R. K. (2001) Teaching and Researching Lexicography. Harlow: Longman.

Haser, Verena (2005) Metaphor, Metonymy, and Experientialist Philosophy: Challenging Cognitive Semantics. Berlin: Mouton de Gruyter.

Hecht, Max (1888) Die griechische Bedeutungslehre: eine Aufgabe der klassischen Philologie. Leipzig: Teubner.

Heerdegen, Ferdinand (1875-81) Ueber Umfang und Gliederung der Sprachwissenschaft im Allgemeinen und der lateinischen Grammatik insbesondere: versuch einer systematischen Einleitung zur lateinischen Semasiologie. Erlangen: Deichert.

Heger, Klaus (1964) Monem, Wort, Satz und Text. Tübingen: Niemeyer.

Heider, Eleanor R. (1972) Universals in color naming and memory. Journal of Experimental Psychology 93: 10-20.

- and D. C. Olivier (1972) The structure of the color space in naming and memory for two languages. Cognitive Psychology 3: 337-45.

Heine, Bernd (1997) Cognitive Foundations of Grammar. Oxford: Oxford University Press.

- (2004) On genetic motivation in grammar. In Günter Radden and Klaus-Uwe Panther (eds.), Studies in Motivation, 103-20. Berlin: Mouton de Gruyter.

Ulrike Claudi, and Friederike Hünnemeyer (1991) Grammaticalization: A Conceptual Framework. Chicago: University of Chicago Press.

- and Tanya Kuteva (2002) World Lexicon of Grammaticalization. Cambridge: Cambridge University Press.

Herbermann, Clemens-Peter (1981) Moderne und antike Etymologie. Zeitschrift für vergleichende Sprachforschung 95: 22-48.

Herskovits, Annette H. (1986) Language and Spatial Cognition: An Interdisciplinary Study of Prepositions in English. Cambridge: Cambridge University Press.

Herweg, Michael (1991) Zeitaspekte: die Bedeutung von Tempus, Aspekt und Temporalen Konjunktionen. Wiesbaden: Deutscher Universitäts-Verlag.

Hey, Oskar (1892) Semasiologische Studien. Jahrbücher für classische Philologie 18: 83-212. 
Heylen, Kris, Yves Peirsman, Dirk Geeraerts, and Dirk Speelman (2008) Modelling word similarity: an evaluation of automatic synonymy extraction algorithms. Proceedings of the Sixth International Language Resources and Evaluation. Marrakech: European Language Resources Association.

Hjelmslev, Louis (1953) Prolegomena to a Theory of Language. Bloomington: Indiana University Press. (Original Danish edition 1943.)

-(1958) Dans quelle mesure les significations des mots peuvent-elles être considérées comme formant une structure? In Eva Sivertsen (ed.), Proceedings of the Eighth International Congress of Linguists, 636-54. Oslo: Oslo University Press.

Hoberg, Rudolf (1970) Die Lehre vom sprachlichen Feld: ein Beitrag zu ihrer Geschichte, Methodik und Anwendung. Düsseldorf: Schwann.

Hoey, Michael (1991) Patterns of Lexis in Text. Oxford: Oxford University Press.

- (2005) Lexical Priming: A New Theory of Words and Language. London: Routledge.

Honeck, Richard P., and Robert R. Hoffman (eds.) (1980) Cognition and Figurative Language. Hillsdale, NJ: Erlbaum.

Horn, Laurence R. (1984) Toward a new taxonomy for pragmatic inference: Q-based and R-based implicature. In Deborah Schiffrin (ed.), Meaning, Form, and Use in Context: Linguistic Applications, 11-42. Washington, DC: Georgetown University Press.

Hüllen, Werner (1999) English Dictionaries 800-1700: The Topical Tradition. Oxford: Clarendon Press.

— and Rainer Schulze (eds.) (1988) Understanding the Lexicon: Meaning, Sense and World Knowledge in Lexical Semantics. Tübingen: Niemeyer.

Hunn, Eugene (1977) Tzeltal Folk Zoology: The Classification of Discontinuities in Nature. New York: Academic Press.

Hurford, James R., Brendan Heasley, and Michael B. Smith (2007) Semantics: A Coursebook. 3rd edn. Cambridge: Cambridge University Press.

Ipsen, Gunther (1924) Der alte Orient und die Indogermanen. In Johannes Friedrich and Johannes B. Hofmann (eds.), Stand und Aufgaben der Sprachwissenschaft. Festschrift für Wilhelm Streitberg, 200-237. Heidelberg: Winter.

_ (1932) Der neue Sprachbegriff. Zeitschrift für Deutschkunde 46: 1-18.

Jaberg, Karl (1901) Pejorative Bedeutungsentwicklung im Französischen mit Berücksichtigung allgemeiner Fragen der Semasiologie 1. Zeitschrift für romanische Philologie 25: 561-601.

_ (1903) Pejorative Bedeutungsentwicklung im Französischen mit Berücksichtigung allgemeiner Fragen der Semasiologie 2. Zeitschrift für romanische Philologie 27: 25-71.

— (1905) Pejorative Bedeutungsentwicklung im Französischen mit Berücksichtigung allgemeiner Fragen der Semasiologie 3. Zeitschrift für romanische Philologie 29: 57-71.

Jackendoff, Ray (1972) Semantic Interpretation in Generative Grammar. Cambridge, MA: MIT Press.

(1983) Semantics and Cognition. Cambridge, MA: MIT Press. 
(1990) Semantic Structures. Cambridge, MA: MIT Press.

(1996) Conceptual semantics and Cognitive Linguistics. Cognitive Linguistics 7: 93-129.

- (2002) Foundations of Language. Oxford: Oxford University Press.

(2007a) Conceptual semantics and natural semantic metalanguage theory have different goals. Intercultural Pragmatics 4: 411-18.

- (2007b) Language, Consciousness, Culture: Essays on Mental Structure. Cambridge, MA: Harvard University Press.

— and David Aaron (1991) Review article: George Lakoff and Mark Turner, More than Cool Reason. Language 67: 320-38.

Jackson, Howard (2002) Lexicography: An Introduction. London: Routledge.

Jäkel, Olaf (1997) European predecessors of a cognitive theory of metaphor. In Birgit Smieja and Meike Tasch (eds.), Human Contact through Language and Linguistics, 69-86. Frankfurt: Lang.

- (1999) Kant, Blumenberg, Weinrich: some forgotten contributions to the cognitive theory of metaphor. In Gibbs and Steen (1999: 9-27).

Jakobson, Roman (1971) The metaphoric and metonymic poles. In Roman Jakobson and Morris Halle (eds.), Fundamentals of Language 2: 90-96. The Hague: Mouton.

Janssen, Theo (2003) Monosemy versus polysemy. In Cuyckens et al. (2003: 93-122).

Jayez, Jacques (2001) Underspecification, context selection, and generativity. In Bouillon and Busa (2001: 124-48).

Johnson, Christopher R., Charles J. Fillmore, Esther J. Wood, Josef Ruppenhofer, Margaret Urban, Miriam R. L. Petruck, and Collin F. Baker (2002) FrameNet: Theory and Practice. Berkeley, CA: International Computer Science Institute.

Johnson, Mark (1987) The Body in the Mind: The Bodily Basis of Meaning, Imagination, and Reason. Chicago: University of Chicago Press.

Jolles, André (1934) Antike Bedeutungsfelder. Beiträge zur Geschichte der deutschen Sprache und Literatur 58: 97-109.

Jones, Steven (2002) Antonymy: A Corpus-Based Approach. London: Routledge.

Joos, Martin (1958) Semology: a linguistic theory of meaning. Studies in Linguistics 13: 53-70.

Jurafsky, Daniel, and James H. Martin (2008) Speech and Language Processing: An Introduction to Natural Language Processing, Computational Linguistics, and Speech Recognition. 2nd edn. Englewood Cliffs, NJ: Prentice-Hall.

Kandler, Günther (1959) Die Lücke im sprachlichen Weltbild: zur Synthese von Psychologismus und Soziologismus. In Helmut Gipper (ed.), Sprache, Schlüssel zur Welt: Festschrift für Leo Weisgerber, 256-70. Düsseldorf: Schwann.

Kastovsky, Dieter (1982) Wortbildung und Semantik. Düsseldorf: Schwann.

Katz, Jerrold J. (1966) The Philosophy of Language. New York: Harper \& Row.

- (1967) Recent issues in semantic theory. Foundations of Language 3: 124-94.

(1972) Semantic Theory. New York: Harper \& Row.

(1977a) The advantage of semantic theory over predicate calculus in the representation of logical form in natural language. The Monist 60: 380-405. 
Katz, Jerrold J. (1977b) The real status of semantic representation. Linguistic Inquiry 8: 559-84.

- (1981) Language and Other Abstract Objects. Oxford: Blackwell.

— Jerry and A. Fodor (1963) The structure of a semantic theory. Language 39: 170-210.

— and Richard I. Nagel (1974) Meaning postulates and semantic theory. Foundations of Language 11: 311-40.

- and Paul M. Postal (1964) An Integrated Theory of Linguistic Description. Cambridge, MA: MIT Press.

Kaufmann, Ingrid (1993) Semantic and conceptual aspects of the preposition durch. In Cornelia Zelinsky-Wibbelt (ed.), The Semantics of Prepositions: From Mental Processing to Natural Language Processing, 221-47. Berlin: Mouton de Gruyter.

Kay, Paul (2003) NSM and the meaning of color words. Theoretical Linguistics 29: 237-45.

Kearns, Kate (2000) Semantics. Basingstoke: MacMillan.

Keller, Rudi (1994) On Language Change: The Invisible Hand in Language. London: Routledge.

Kempton, Willett (1981) The Folk Classification of Ceramics: A Study in Cognitive Prototypes. New York: Academic Press.

Kennedy, George A. (1994) A New History of Classical Rhetoric. Princeton, NJ: Princeton University Press.

Kiefer, Ferenc, Gábor Kiss, and Júlia Pajzs (eds.) (2005) Papers in Computational Lexicography. Budapest: Hungarian Academy of Sciences.

Kilgarriff, Adam (1997) 'I don't believe in word senses'. Computers and the Humanities 31: 91-113.

(2001) Generative Lexicon meets corpus data: the case of nonstandard word uses. In Bouillon and Busa (2001: 312-28).

— Pavel Rychlý, Pavel Smrž, and David Tugwell (2004) The Sketch Engine. In Geoffrey Williams and Sandra Vessier (eds.), Proceedings of the Eleventh Euralex Conference, 105-16. Lorient: Université de Bretagne Sud.

Kimmel, Michael (2005) Culture regained: situated and compound image schemas. In Beate Hampe (ed.), From Perception to Meaning: Image Schemas in Cognitive Linguistics, 285-312. Berlin: Mouton de Gruyter.

Kintsch, Walter (2008) How the mind computes the meaning of metaphor: a simulation based on LSA. In Gibbs (2008: 129-42).

Kittay, Eva F. (1987) Metaphor: Its Cognitive Force and Linguistic Structure. Oxford: Clarendon Press.

— and Adrienne Lehrer (1981) Semantic fields and the structure of metaphor. Studies in Language 5: 31-63.

Kleiber, Georges (1988) Prototype, stéréotype: un air de famille? DRLAV-Revue de Linguistique 38: 1-61.

- (1990) La sémantique du prototype: catégories et sens lexical. Paris: Presses Universitaires de France. 
Kleparski, Grzegorz A. (1990) Semantic Change in English: A Study of Evaluative Developments in the Domain of Humans. Lublin: Redakcja Wydawnictw KUL.

Klinck, Roswitha (1970) Die lateinische Etymologie des Mittelalters. Munich: Fink.

Knobloch, Clemens (1988) Geschichte der psychologischen Sprachauffassung in Deutschland von 1850 bis 1920. Tübingen: Niemeyer.

Koch, Peter (1997) La diacronica quale campo empirico della semantica cognitiva. In Mario Carapezza, Danielle Gambarara, and Franco Lo Piparo (eds.), Linguaggio e cognizione: atti del XXVIII Congresso Internazionale della Società di Linguistica Italiana, 225-46. Rome: Bulzoni.

Koivisto-Alanko, Paivi (200o) Abstract Words in Abstract Worlds: Directionality and Prototypical Structure in the Semantic Change in English Nouns of Cognition. Helsinki: Société Néophilologique de Helsinki.

Koller, Veronika (2004) Metaphor and Gender in Business Media Discourse: A Critical Cognitive Study. Basingstoke: Palgrave Macmillan.

König, Ekkehard, and Elizabeth C. Traugott (1988) Pragmatic strengthening and semantic change: the conventionalizing of conversational implicature. In Hüllen and Schulze (1988: 110-24).

Koptjevskaja-Tamm, Maria, and Inger Ahlgren (2003) NSM: theoretical, methodological and applicational problems. Theoretical Linguistics 29: 247-61.

Kövecses, Zoltán (1986) Metaphors of Anger, Pride and Love: A Lexical Approach to the Structure of Concepts. Amsterdam: Benjamins.

- (1990) Emotion Concepts. Berlin: Springer.

- (2000) Metaphor and Emotion: Language, Culture and Body in Human Feeling. Cambridge: Cambridge University Press.

- (2002) Metaphor: A Practical Introduction. Oxford: Oxford University Press.

- (2005) Metaphor in Culture: Universality and Variation. Oxford: Oxford University Press.

— and Günter Radden (1998) Metonymy: developing a cognitive linguistic view. Cognitive Linguistics 9: 37-77.

Kripke, Saul (1972) Naming and necessity. In Donald Davidson and Gilbert Harman (eds.), Semantics of Natural Language, 253-355. Dordrecht: Reidel.

Kristiansen, Gitte, Michel Achard, René Dirven, and Francisco Ruiz de Mendoza Ibáñez (eds.) (2006) Cognitive Linguistics: Applications and Future Perspectives. Berlin: Mouton de Gruyter.

— and Dirk Geeraerts (2007) On non-reductionist intercultural pragmatics and methodological procedure. In Istvan Kecskes and Laurence R. Horn (eds.), Explorations in Pragmatics: Linguistic, Cognitive and Intercultural Aspects, 257-86. Berlin: Mouton de Gruyter.

Kroeber, Alfred L. (1952) The Nature of Culture. Chicago: University of Chicago Press.

Kronasser, Heinz (1952) Handbuch der Semasiologie: Kurze Einführung in die Geschichte, Problematik und Terminologie der Bedeutungslehre. Heidelberg: Winter.

Kronenfeld, David B. (1996) Plastic Glasses and Church Fathers: Semantic Extension from the Ethnoscience Tradition. New York: Oxford University Press. 
Krzeszowski, Tomasz P. (1993) The axiological parameter in preconceptual image schemata. In Richard A. Geiger and Brygida Rudzka-Ostyn (eds.), Conceptualizations and Mental Processing in Language, 307-29. Berlin: Mouton de Gruyter.

Kühlwein, Wolfgang (2002) Beschreibungsansätze für Sinnrelationen I: Strukturalistische (Merkmals-)Ansätze. In D. Alan Cruse, Franz Hundsnurscher, Michael Job, and Peter Rolf Lutzeier (eds.), Lexikologie: ein internationales Handbuch zur Natur und Struktur von Wörtern und Wortschätzen/Lexicology: An International Handbook on the Nature and Structure of Words and Vocabularies 1: 533-42. Berlin: de Gruyter.

Kytö, Merja, and Anke Lüdeling (eds.) (2008) Corpus Linguistics: An International Handbook. Berlin: Walter de Gruyter.

Labov, William (1973) The boundaries of words and their meanings. In Charles-James Bailey and Roger W. Shuy (eds.), New Ways of Analysing Variation in English, 340-71. Washington, DC: Georgetown University Press.

— (1978) Denotational structure. In Donka Farkas, Wesley M. Jacobsen, and Karol W. Todrys (eds.), Papers from the Parasession on the Lexicon, 220-60. Chicago: Chicago Linguistic Society.

Lakoff, George (1970) A note on vagueness and ambiguity. Linguistic Inquiry 1: 357-9.

_ (1971a) On generative semantics. In Danny D. Steinberg and Leon A. Jakobovits (eds.), Semantics: An Interdisciplinary Reader in Philosophy, Linguistics and Psychology, 232-96. Cambridge: Cambridge University Press.

(1971b) Presuppositon and relative well-formedness. In Danny D. Steinberg and Leon A. Jakobovits (eds.), Semantics: An Interdisciplinary Reader in Philosophy, Linguistics and Psychology, 329-40. Cambridge: Cambridge University Press.

- (1972) Linguistics and natural logic. In Donald Davidson and Gilbert Harman (eds.), Semantics of Natural Language, 545-665. Dordrecht: Reidel.

(1977) Linguistic gestalts. In Woodford A. Beach, Samuel E. Fox, and Shulamith Philosoph (eds.), Papers from the Thirteenth Regional Meeting of the Chicago Linguistic Society, 236-87. Chicago: Chicago Linguistic Society.

- (1987) Women, Fire and Dangerous Things: What Categories Reveal about the Mind. Chicago: University of Chicago Press.

(1996) Moral Politics: How Liberals and Conservatives Think. Chicago: University of Chicago Press.

_ (2004) Don't Think of an Elephant! Know Your Values and Frame the Debate. White River Junction, VT: Chelsea Green.

— and Mark Johnson (1980) Metaphors We Live By. Chicago: University of Chicago Press.

(1999) Philosophy in the Flesh: The Embodied Mind and its Challenges to Western Thought. Chicago: University of Chicago Press.

and Zoltán Kövecses (1987) The cognitive model of anger inherent in American English. In Dorothy Holland and Naomi Quinn (eds.), Cultural Models in Language and Thought, 195-221. Cambridge: Cambridge University Press.

and Rafael E. Núñez (2000) Where Mathematics Comes From: How the Embodied Mind Brings Mathematics into Being. New York: Basic Books. 
and Mark Turner (1989) More than Cool Reason: A Field Guide to Poetic Metaphor. Chicago: University of Chicago Press.

Lamb, Sidney M. (1964) The sememic approach to structural semantics. American Anthropologist 66: 57-78.

Landau, Sidney I. (1989) Dictionaries: The Art and Craft of Lexicography. Cambridge: Cambridge University Press.

Landauer, Thomas K., and Susan T. Dumais (2007) A solution to Plato's problem: the Latent Semantic Analysis theory of acquisition, induction and representation of knowledge. Psychological Review 104: 211-40.

Lang, Ewald (1991) A two-level approach to projective prepositions. In Gisa Rauh (ed.), Approaches to Prepositions, 127-67. Tübingen: Narr.

— (1993) The meaning of German projective prepositions: a two-level approach. In Cornelia Zelinsky-Wibbelt (ed.), The Semantics of Prepositions: From Mental Processing to Natural Language Processing, 249-91. Berlin: Mouton de Gruyter.

_ (1994) Semantische vs. konzeptuelle Struktur: Unterscheidung und Überschneidung. In Monika Schwarz (ed.), Kognitive Semantik/Cognitive Semantics. Ergebnisse, Probleme, Perspektiven, 25-40. Tübingen: Narr.

Langacker, Ronald W. (1987) Foundations of Cognitive Grammar 1: Theoretical Prerequisites. Stanford, CA: Stanford University Press.

- (1991) A usage-based model. In Ronald W. Langacker (ed.), Concept, Image, and Symbol: The Cognitive Basis of Grammar, 261-88. Berlin: Mouton de Gruyter.

- (1999) A dynamic usage-based model. In Ronald W. Langacker (ed.), Grammar and Conceptualization, 91-145. Berlin: Mouton de Gruyter.

Lappin, Shalom (ed.) (1996) The Handbook of Contemporary Semantic Theory. Oxford: Blackwell.

Larrivée, Pierre (2008) Une histoire du sens: panorama de la sémantique linguistique depuis Bréal. Bern: Lang.

Lascarides, Alex, and Ann Copestake (1998) The pragmatics of word meaning. Journal of Linguistics 34: 387-414.

Laurence, Stephen, and Eric Margolis (1999) Concepts and cognitive science. In Eric Margolis and Stephen Laurence (eds.), Concepts: Core Readings, 3-81. Cambridge, MA: MIT Press.

Lausberg, Heinrich (1990) Handbuch der literarischen Rhetorik: Eine Grundlegung der Literaturwissenschaft. 3rd edn. Stuttgart: Steiner.

Lawler, John M. (1989) Lexical semantics in the commercial transaction frame: value, worth, cost and price. Studies in Language 13: 381-404.

Lazarus, Moritz (1856-7) Das Leben der Seele in Monographien über seine Erscheinung und Gesetze. Berlin: Dümmler.

Leech, Geoffrey (1974) Semantics. Harmondsworth: Penguin.

Leezenberg, Michiel (2001) Contexts of Metaphor. Amsterdam: Elsevier Science.

Lehrer, Adrienne (1974) Semantic Fields and Lexical Structure. Amsterdam: NorthHolland.

(1978) Structure of the lexicon and transfer of meaning. Lingua 45: 95-123. 
Lehrer, Adrienne (1985) The influence of semantic fields on semantic change. In Jacek Fisiak (ed.), Historical Semantics: Historical Word-Formation, 283-96. Berlin: Mouton.

- (1992) Names and naming: why we need fields and frames. In Adrienne Lehrer and Eva F. Kittay (eds.), Frames, Fields and Contrasts: New Essays in Semantic and Lexical Organization, 123-42. Hillsdale, NJ: Erlbaum.

(2002) Paradigmatic relations of exclusion and opposition I: Gradable antonymy and complementarity. In D. Alan Cruse, Franz Hundsnurscher, Michael Job, and Peter Rolf Lutzeier (eds.), Lexikologie. Lexicology: Ein internationales Handbuch zur Natur und Struktur von Wörtern und Wortschätzen/Lexicology: An International handbook on the Nature and Structure of Words and Vocabularies 1: 498-507. Berlin: de Gruyter.

— and Eva Feder Kittay (eds.) (1992) Frames, Fields, and Contrasts: New Essays in Semantic and Lexical Organization. Hillsdale, NJ: Erlbaum.

Leisi, Ernst (1975) Der Wortinhalt: Seine Struktur im Deutschen und Englischen. 5 th edn. Heidelberg: Quelle \& Meyer.

Lepschy, Giulio C. (1970) A Survey of Structural Linguistics. London: Faber \& Faber.

Levin, Beth (1993) English Verb Classes and Alternations: A Preliminary Investigation. Chicago: University of Chicago Press.

Levinson, Stephen C. (1995) Three levels of meaning. In Frank R. Palmer (ed.), Grammar and Meaning: Essays in Honour of Sir John Lyons, 90-115. Cambridge: Cambridge University Press.

- (2003) Space in Language and Cognition: Explorations in Cognitive Diversity. Cambridge: Cambridge University Press.

Lewandowka-Tomaszczyk, Barbara (1985) On semantic change in a dynamic model of language. In Jacek Fisiak (ed.), Historical Semantics: Historical Word-Formation, 297-323. Berlin: Mouton de Gruyter.

— (ed.) (1998) Lexical Semantics, Cognition and Philosophy. Lódz: Lódz University Press.

- (2007) Polysemy, prototyes, and radial categories. In Geeraerts and Cuyckens (2007: 139-69).

Lewis, David K. (1972) General semantics. In Donald Davidson and Gilbert Harman (eds.), Semantics of Natural Language, 169-218. Dordrecht: Reidel.

Lindsay, Peter H., and Donald A. Norman (1972) Human Information Processing. New York: Academic Press.

Lipka, Leonhard (1972) Semantic Structure and Word-Formation: Verb-Particle Constructions in Contemporary English. Munich: Fink.

- (1990) An Outline of English Lexicology: Lexical Structure, Word Semantics, and Word-Formation. Tübingen: Niemeyer.

- (2002) English Lexicology. Tübingen: Narr.

Littlemore, Jeannette, and Graham Low (2006) Figurative Thinking and Foreign Language Learning. Basingstoke: Palgrave Macmillan.

Löbner, Sebastian (2002) Understanding Semantics. London: Arnold. 
Lounsbury, Floyd (1956) A semantic analysis of Pawnee kinship usage. Language 32: 158-94.

— (1964) The structural analysis of kinship semantics. In Horace G. Lunt (ed.), Proceedings of the Ninth International Congress of Linguists, 1073-93. The Hague: Mouton.

Louw, Bill (1993) Irony in the text or insincerity in the writer? The diagnostic potential of semantic prosodies. In Mona Baker, Gill Francis, and Elena TogniniBonelli (eds.), Text and Technology: In Honour of John Sinclair, 157-76. Amsterdam: Benjamins.

Lutzeier, Peter Rolf (1981) Wort und Feld: Wortsemantische Fragestellungen mit besonderer Berücksichtigung des Wortfeldbegriffes. Tübingen: Niemeyer.

_ (1992) Wortfeldtheorie und kognitive Linguistik. Deutsche Sprache 20: 62-81.

_ (ed.) (1993) Studien zur Wortfeldtheorie/Studies in Lexical Field Theory. Tübingen: Niemeyer.

Lyons, John (1963) Structural Semantics. Oxford: Blackwell.

- (1968) Introduction to Theoretical Linguistics. Cambridge: Cambridge University Press.

— (1977) Semantics. Cambridge: Cambridge University Press.

— (1996) Linguistic Semantics: An Introduction. Cambridge: Cambridge University Press.

MacArthur, Tom (1986) Worlds of Reference: Lexicography, Learning and Language from the Clay Tablet to the Computer. Cambridge: Cambridge University Press.

McCawley, James D. (1968) Lexical insertion in a transformational grammar without deep structure. In Bill J. Darden, Charles-James Bailey, and Alice Davidson (eds.), Fourth Regional Meeting of the Chicago Linguistic Society, 71-80. Chicago: Chicago Linguistic Society.

(1971) Where do noun phrases come from? In Danny D. Steinberg and Leon A. Jakobovits (eds.), Semantics: An Interdisciplinary Reader in Philosophy, Linguistics and Psychology, 217-31. Cambridge: Cambridge University Press.

MacLaury, Robert E. (1991) Prototypes revisited. Annual Review of Anthropology 20: 55-74.

(1997) Color and Cognition in Mesoamerica: Constructing Categories as Vantages. Austin: University of Texas Press.

McNeill, David (1995) Hand and Mind: What Gestures Reveal about Thought. Chicago: University of Chicago Press.

Maienborn, Claudia (1991) Verbs of motion and position: on the optionality of the local argument. In Otthein Herzog and Claus-Rainer Rollinger (eds.), Text Understanding in LILOG: Integrating Computational Linguistics and Artificial Intelligence, 621-31. Berlin: Springer.

Malinowski, Bronislaw (1935) Coral Gardens and their Magic: A Study of the Methods of Tilling the Soil and of Agricultural Rites in the Trobriand Islands, 2: The Language of Magic and Gardening. London: Allen \& Unwin.

Malkiel, Yakov (1993) Etymology. Cambridge: Cambridge University Press. 
Mandler, Jean M. (1992) How to build a baby: conceptual primitives. Psychological Review 99: 587-604.

Mangasser-Wahl, Martina (200o) Von der Prototypentheorie zur empirischen Semantik. Frankfurt: Lang.

Manning, Chris, and Hinrich Schütze (1999) Foundations of Statistical Natural Language Processing. Cambridge, MA: MIT Press.

Martin, Willy (2001) A frame-based approach to polysemy. In Cuyckens and Zawada (2001: 57-81).

Mason, Zachary J. (2004) CorMet: a computational, corpus-based conventional metaphor extraction system. Computational Linguistics 30: 23-44.

Matlock, Teenie, Michael Ramscar, and Lera Boroditsky (2004) The experiential basis of motion language. In Augusto Soares da Silva, Amadeus Torres, and Miguel Gonçalves (eds.), Linguagem, cultura e cognicão: estudos de linguística cognitiva, 43-57. Coimbra: Almedina.

- (2005) The experiential link between spatial and temporal language. Cognitive Science 29: 655-64.

Matoré, Georges (1951) Le vocabulaire et la société sous Louis-Philippe. Geneva: Slatkine.

- (1953) La méthode en lexicologie. Paris: Didier.

- (1985) Le vocabulaire et la société médiévale. Paris: Presses Universitaires de France.

— (1988) Le vocabulaire et la société du XVIe siècle. Paris: Presses Universitaires de France.

Matthewson, Lisa (2003) Is the meta-language really natural? Theoretical Linguistics 29: 263-74.

Meillet, Antoine (1906) Comment les mots changent de sens. Année Sociologique 9: 1-38. Repr. in Antoine Meillet, Linguistique historique et linguistique générale (Paris: Champion, 1921), 230-71.

Mel'cuk, Igor A. (1988a) Dependency Syntax: Theory and Practice. Albany: State University of New York Press.

(1988b) Semantic description of lexical units in an Explanatory Combinatorial Dictionary. International Journal of Lexicography 1: 165-88.

(1989) Semantic primitives from the viewpoint of Meaning-Text linguistic theory. Quaderni di Semantica 10: 65-102.

- (1995) Phrasemes in language and phraseology in linguistics. In Martin Everaert, Erik-Jan Van der Linden, André Schenk, and Rob Schreuder (eds.), Idioms: Structural and Psychological Perspectives, 167-232. Hillsdale, NJ: Erlbaum.

(1996) Lexical functions: a tool for the description of lexical relations in a lexicon. In Leo Wanner (ed.), Lexical Functions in Lexicography and Natural Language Processing, 37-102. Amsterdam: Benjamins.

- (1998) Collocations and lexical functions. In Anthony P. Cowie (ed.), Phraseology. Theory, Analysis, and Applications, 23-53. Oxford: Clarendon Press.

- André Clas, and Nadia Arbatchewsky-Jumarie (1984-99) Dictionnaire explicatif et combinatoire du français contemporain: recherches lexico-sémantiques I-IV. Montréal: Presses de l'Université de Montréal. 
and Alain Polguère (1995) Introduction à la lexicologie explicative et combinatoire. Louvain la Neuve: Duculot.

—_ (2007) Lexique actif $d u$ français: l'apprentissage $d u$ vocabulaire fondé sur 20,0oo dérivations sémantiques et collocations du français. Brussels: De Boeck.

Meringer, Rudolf (1909) Wörter und Sachen. Germanisch-Romanische Monatsschrift 1: 593-8.

(1912) Zur Aufgabe und zum Namen unserer Zeitschrift. Wörter und Sachen 3: 22-56.

Mervis, Carolyn B., and Eleanor Rosch (1981) Categorization of natural objects. Annual Review of Psychology 32: 89-115.

Mettinger, Arthur (1994) Aspects of Semantic Opposition in English. Oxford: Clarendon Press.

Meyer, Ralf (1910) Bedeutungssysteme. Zeitschrift für vergleichende Sprachforschung 43: 352-68.

Meyer, Richard M. (1994) Probleme von Zwei-Ebenen-Semantiken. Kognitionswissenschaft 4: 32-46.

Miller, George A. (ed.) (1990) WordNet: an on-line lexical database. International Journal of Lexicography 3: 235-312.

— and Christiane Fellbaum (1991) Semantic networks of English. Cognition 41: 197-229.

- (2007) WordNet then and now. Language Resources and Evaluation 41: 209-14.

Minsky, Marvin (1974) A framework for representing knowledge. In Patrick H. Winston (ed.), The Psychology of Computer Vision, 211-77. New York: McGrawHill.

Molina, Clara (2005) On the role of onomasiological profiles in merger discontinuations. In Nicole Delbecque, Johan Van der Auwera, and Dirk Geeraerts (eds.), Perspectives on Variation: Sociolinguistic, Historical, Comparative, 177-94. Berlin: Mouton de Gruyter.

Moon, Rosamund (1998) Fixed Expressions and Idioms in English. Oxford: Clarendon Press.

Morris, Charles W. (1938) Foundations of the theory of signs. In Otto Neurath, Rudolf Carnap, and Charles W. Morris (eds.), International Encyclopaedia of Unified Science, 79-137. Chicago: University of Chicago Press.

Murphy, Gregory L. (2002) The Big Book of Concepts. Cambridge, MA: MIT Press.

Murphy, M. Lynne (2003) Semantic Relations and the Lexicon: Antonymy, Synonymy, and Other Paradigms. Cambridge: Cambridge University Press.

Murray, James A. H. (1884) A New English Dictionary on Historical Principles. Oxford: Clarendon Press.

Musolff, Andreas (2004) Metaphor and Political Discourse: Analogical Reasoning in Debates about Europe. Basingstoke: Palgrave Macmillan.

Nerlich, Brigitte (1992) Semantic Theories in Europe 1830-1930: From Etymology to Contextuality. Amsterdam: Benjamins. 
Nerlich, Brigitte and David D. Clarke (1992) Outline of a model for semantic change. In Günther Kellermann and Michael D. Morrissey (eds.), Diachrony within Synchrony: Language History and Cognition, 125-41. Frankfurt: Lang.

- (2000) Semantic fields and frames: historical explorations of the interface between language, action and cognition. Journal of Pragmatics 32: 125-50.

- (2001) Serial metonymy: a study of reference-based polysemisation. Journal of Historical Pragmatics 2: 245-72.

- (2007) Cognitive Linguistics and the history of linguistics. In Geeraerts and Cuyckens (2007: 589-607).

Zazie Todd, Vimala Herman, and David D. Clarke (eds.) (2003) Polysemy: Flexible Patterns of Meaning in Mind and Language. Berlin: Mouton de Gruyter.

Newmeyer, Frederick J. (1980) Linguistic Theory in America: The First Quarter-Century of Transformational Generative Grammar. New York: Academic Press.

Nida, Eugene A. (1945) Linguistics and ethnology in translation problems. Word 1: 194-208.

_ (1951) A system for the description of semantic elements. Word 7: 1-14.

(1975) Componential Analysis of Meaning. The Hague: Mouton.

Niles, Ian, and Adam Pease (2003) Linking lexicons and ontologies: mapping WordNet to the Suggested Upper Merged Ontology. In Hamid R. Arabnia (ed.), Proceedings of the International Conference on Information and Knowledge Engineering, 412-16. Las Vegas, NV: CSREA Press.

Norrick, Neal R. (1981) Semiotic Principles in Semantic Theory. Amsterdam: Benjamins. Nunberg, Geoffrey (1978) The Pragmatics of Reference. Bloomington: Indiana University Linguistics Club.

- (1979) The non-uniqueness of semantic solutions: polysemy. Linguistics and Philosophy 2: 143-84.

Nuyts, Jan (2007) Cognitive Linguistics and functional linguistics. In Geeraerts and Cuyckens (2007: 543-65).

Nyckees, Vincent (1998) La sémantique. Paris: Belin.

_ (2006) Rien n'est sans raison: les bases d'une théorie continuiste de l'évolution sémantique. In Danielle Candel and François Gaudin (eds.), Aspects diachroniques $d u$ vocabulaire, 15-88. Mont-Saint-Aignan: Publications des Universités de Rouen et du Havre.

Nyrop, Kristoffer (1901-34) Ordenes liv. Copenhagen: Gyldendalske Boghandel Nordisk Forlag.

- (1913) Grammaire historique de la langue française IV: Sémantique. Copenhagen: Gyldendalske Boghandel Nordisk Forlag.

Oakley, Todd, and Anders Hougaard (eds.) (2008) Mental Spaces Approaches to Discourse and Interaction. Amsterdam: Benjamins.

Oertel, Hans (1902) Lectures on the Study of Language. New York: Scribner's. Ohmann, Suzanne (1951a) Theories of the linguistic field. Word 9: 123-34.

- (1951b) Wortinhalt und Weltbild: Vergleichende und methodologische Studien zu Bedeutungslehre und Wortfeldtheorie. Stockholm: Norstedt. 
Oksaar, Els (1958) Semantische Studien im Sinnbereich der Schnelligkeit: Plötzlich, schnell und ihre Synonymik im Deutsch der Gegenwart und des Früh-, Hoch- und Spätmittelalters. Stockholm: Almqvist \& Wiksell.

Ortony, Andrew (ed.) (1979) Metaphor and Thought. Cambridge: Cambridge University Press.

— (ed.) (1993) Metaphor and Thought. 2nd edn. Cambridge: Cambridge University Press.

Osgood, Charles E., William H. May, and Murray S. Miron (1975) Cross-Cultural Universals of Affective Meaning Urbana: University of Illinois Press.

George J. Suci, and Percy H. Tannenbaum (1957) The Measurement of Meaning. Urbana: University of Illinois Press.

Padó, Sebastian, and Mirella Lapata (2007) Dependency-based construction of semantic space models. Computational Linguistics 33: 161-99.

Palmer, Frank R. (ed.) (1968) Selected Papers of J. R. Firth. Harlow: Longman.

Palmer, Gary B. (1996) Toward a Theory of Cultural Linguistics. Austin: University of Texas Press.

Palmer, Martha, and Alain Polguère (1995) A preliminary lexical and conceptual analysis of break: a computational perspective. In Patrick Saint-Dizier and Evelyne Viegas (eds.), Computational Lexical Semantics, 231-50. Cambridge: Cambridge University Press.

Panther, Klaus-Uwe (2005) The role of conceptual metonymy in meaning construction. In Francisco Ruiz de Mendoza Ibáñez and Sandra Peña Cervel (eds.), Cognitive Linguistics: Internal Dynamics and Interdisciplinary Interaction, 353-86. Berlin: Mouton de Gruyter.

_- (2006) Metonymy as a usage event. In Kristiansen et al. (2006: 147-85).

— and Günter Radden (eds.) (1999) Metonymy in Language and Thought. Amsterdam: Benjamins.

and Linda Thornburg (1998) A cognitive approach to inferencing in conversation. Journal of Pragmatics 30: 755-69.

(1999) The potentiality for actuality metonymy in English and Hungarian. In Panther and Radden (1999: 333-57).

(eds.) (2003) Metonymy and Pragmatic Inferencing. Amsterdam: Benjamins. (2007) Metonymy. In Geeraerts and Cuyckens (2007: 236-63).

Papafragou, Anna (1996) Figurative language and the semantics-pragmatics distinction. Language and Literature 5: 179-93.

Paprotté, Wolf, and René Dirven (eds.) (1985) The Ubiquity of Metaphor: Metaphor in Language and Thought. Amsterdam: Benjamins.

Paradis, Carita (2004) Where does metonymy stop? Senses, facets, and active zones. Metaphor and Symbol 19: 245-64.

Paris, Gaston (1887) La vie des mots. Journal des Savants 52: 65-77, 149-56, 241-9.

Partee, Barbara H. (1975) Montague grammar and transformational grammar. Linguistic Inquiry 6: 203-300.

_ (ed.) (1976) Montague Grammar. New York: Academic Press. 
Partington, Alan (1998) Patterns and Meanings: Using Corpora for English Language Research and Teaching. Amsterdam: Benjamins.

Paul, Hermann (1897) Deutsches Wörterbuch. Halle: Niemeyer.

- (1920) Prinzipien der Sprachgeschichte. 5th edn. Halle: Niemeyer.

Peeters, Bert (ed.) (2000) The Lexicon-Encyclopedia Interface. Oxford: Elsevier Science.

(ed.) (2006) Semantic Primes and Universal Grammar. Empirical Evidence from the Romance Languages. Amsterdam: Benjamins.

Peirsman, Yves, and Dirk Geeraerts (2006) Metonymy as a prototypical category. Cognitive Linguistics 17: 269-316.

Persson, Gunnar (1990) Meanings, Models and Metaphors: A Study in Lexical Semantics in English. Stockholm: Almqvist \& Wiksell.

Petitot, Jean (1985) Morphogenèse du sens. Paris: Presses Universitaires de France.

Picoche, Jacqueline (1984) Précis de lexicologie française: l'étude et l'enseignement du vocabulaire. Paris: Nathan.

— (1992) Signifié de puissance et prototype en lexicologie. In Ramón Lorenzo (ed.), Actas do XIX congreso internacional de lingüística e filoloxía románicas 4: 207-20. Coruña: Fundación Pedro Barrié de la Maza.

Portner, Paul H. (2005) What is Meaning? Fundamentals of Formal Semantics. Oxford: Blackwell.

— and Barbara H. Partee (eds.) (2002) Formal Semantics: The Essential Readings. Oxford: Blackwell.

Porzig, Walter (1934) Wesenhafte Bedeutungsbeziehungen. Beiträge zur Geschichte der deutschen Sprache und Literatur 58: 70-97.

- (1950) Das Wunder der Sprache: Probleme, Methoden und Ergebnisse der modernen Sprachwissenschaft. Bern: Francke.

Posner, Michael (1986) Empirical studies of prototypes. In Colette Craig (ed.), Noun Classes and Categorization, 53-61. Amsterdam: Benjamins.

Post, Michael (1988) Scenes-and-frames semantics as a neo-lexical field theory. In Hüllen and Schulze (1988: 36-47).

Pottier, Bernard (1964) Vers une sémantique moderne. Travaux de linguistique et de littérature 2: 107-137.

- (1965) La définition sémantique dans les dictionnaires. Travaux de linguistique et de littérature 3: 33-39.

- (1992) Sémantique générale. Paris: Presses Universitaires de France.

Pragglejaz (2007) MIP: a method for identifying metaphorically used words in discourse. Metaphor and Symbol 22: 1-39.

Pustejovsky, James (1995a) The Generative Lexicon. Cambridge, MA: MIT Press.

(1995b) Linguistic constraints on type coercion. In Patrick Saint-Dizier and Evelyne Viegas (eds.), Computational Lexical Semantics, 71-97. Cambridge: Cambridge University Press.

-(2006) Type theory and lexical decomposition. Journal of Cognitive Science 7: $39-76$. 
and Branimir Boguraev (eds.) (1996) Lexical Semantics: The Problem of Polysemy. Oxford: Clarendon Press.

and Elisabetta Jezek (2008) Semantic coercion in language: beyond distributional analysis. Italian Journal of Linguistics/Rivista di Linguistica 20: 175-208.

- and Anna Rumshisky (2008) Between chaos and structure: interpreting lexical data through a theoretical lens. International Journal of Lexicography 21: 337-55.

Putnam, Hilary (1975) The meaning of Meaning. In Hilary Putnam (ed.), Mind, Language and Reality: Philosophical Papers II , 215-71. Cambridge: Cambridge University Press.

Pütz, Martin and René Dirven (eds.) (1996) The Construal of Space in Language and Thought. Berlin: Mouton de Gruyter.

Quadri, Bruno (1952) Aufgaben und Methoden der onomasiologischen Forschung. Eine entwicklungsgeschichtliche Darstellung. Bern: Francke.

Quillian, M. Ross (1968) Semantic memory. In Marvin Minsky (ed.), Semantic Information Processing, 227-70. Cambridge, MA: MIT Press.

Quine, Willard V. O. (1953) From a Logical Point of View. Cambridge, MA: Harvard University Press.

- (1960) Word and Object. Cambridge, MA: MIT Press.

Radden, Günter (2002) How metonymic are metaphors? In Dirven and Pörings (2002: 407-34).

Rakova, Marina (2002) The philosophy of embodied realism: a high price to pay? Cognitive Linguistics 13: 215-44.

- (2003) The Extent of the Literal: Metaphor, Polysemy, and Theories of Concepts. New York: Palgrave Macmillan.

Ramos, Margarita Alonso, Agnes Tutin and Guy Lapalme (1995) Lexical functions of the Explanatory Combinatorial Dictionary for lexicalization in text generation. In Patrick Saint-Dizier and Evelyne Viegas (eds.), Computational Lexical Semantics, 351-66. Cambridge: Cambridge University Press.

Rastier, François (1987) Sémantique interprétative. Paris: Presses Universitaires de France.

_ (1991) Sémantique et recherches cognitives. Paris: Presses Universitaires de France.

- (1999) Cognitive semantics and diachronic semantics: the values and evolution of classes. In Andreas Blank and Peter Koch (eds.), Historical Semantics and Cognition, 109-44. Berlin: Mouton de Gruyter.

- (2001) On signs and texts: cognitive science and interpretation. In Paul Perron, Leonard G. Sbrocchi, Paul Colilli and Marcel Danesi (eds.), Semiotics as a Bridge between the Humanities and the Sciences, 409-50. Ottawa: Legas.

— Marc Cavazza, and Anne Abeillé (2001) Semantics for Descriptions: From Linguistics to Computer Science. Stanford: CSLI Publications.

Ravin, Yael and Claudia Leacock (eds.) (2000) Polysemy: Theoretical and Computational Approaches. Oxford: Oxford University Press.

Récanati, François (2003) Literal Meaning: The Very Idea. Cambridge: Cambridge University Press. 
Reddy, Michael J. (1979) The conduit metaphor: a case of frame conflict in our language about language. In Andrew Ortony (ed.), Metaphor and Thought, 284-324. Cambridge: Cambridge University Press.

Reichling, Anton (1935) Het woord. Zwolle: Tjeenk Willink.

Reisig, Karl (1839) Vorlesungen über die lateinische Sprachwissenschaft (abgehalten ab 1825). Leipzig: Lehnhold.

Richards, Ivor A. (1936) The Philosophy of Rhetoric. Oxford: Oxford University Press.

Riemer, Nick (2001) Remetonymizing metaphor: hypercategories in semantic extension. Cognitive Linguistics 12: 379-401.

— (2005) The Semantics of Polysemy: Reading Meaning in English and Warlpiri. Berlin: Mouton de Gruyter.

- (2006) Reductive paraphrase and meaning: a critique of Wierzbickian semantics. Linguistics and Philosophy 29: 347-79.

Rohrer, Tim (2006) Three dogmas of embodiment: Cognitive Linguistics as a cognitive science. In Kristiansen et al. (2006: 119-46).

Rojo, Ana and Javier Valenzuela (1998) Frame semantics and lexical translation. Babel 44: $128-38$.

Rommetveit, Ragnar (1988) On literacy and the myth of literal meaning. In Roger Säljö (ed.), The Written World, 13-40. Berlin: Springer.

Romney, A. Kimball, and Roy G. D’Andrade (1964) Cognitive aspects of English kinship. American Anthropologist 67: 146-70.

Rosch, Eleanor (1973a) Natural categories. Cognitive Psychology 4: 328-50.

- (1973b) On the internal structure of perceptual and semantic categories. In Timothy E. Moore (ed.), Cognitive Development and the Acquisition of Language, 111-44. New York: Academic Press.

- (1975a) Cognitive reference points. Cognitive Psychology 7: 532-47.

(1975b) Cognitive representations of semantic categories. Journal of Experimental Psychology 104: 192-233.

- (1977) Human categorization. In Neil Warren (ed.), Studies in Cross-Cultural Psychology 1, 1-49. New York: Academic Press.

(1978) Principles of categorization. In Eleanor Rosch and Barbara B. Lloyd (eds.), Cognition and Categorization, 27-48. Hillsdale, NJ: Erlbaum.

- (1988) Coherences and categorization: a historical view. In Frank S. Kessel (ed.), The Development of Language and Language Researchers: Essays in Honor of Roger Brown, 373-92. Hillsdale, NJ: Erlbaum.

and Carolyn B. Mervis (1975) Family resemblances: studies in the internal structure of categories. Cognitive Psychology 7: 573-605.

—_ Wayne D. Gray, David Johnson, and Penny Boyes-Braem (1976) Basic objects in natural categories. Cognitive Psychology 8: 382-439.

Rothwell, William (1962) Medieval French and modern semantics. Modern Language Review 57: 25-30.

Roudet, Léonce (1921) Sur la classification psychologique des changements sémantiques. Journal de Psychologie Normale et Pathologique 18: 676-92. 
Rudzka-Ostyn, Brygida (1988a) Semantic extensions into the domain of verbal communication. In Brygida Rudzka-Ostyn (ed.), Topics in Cognitive Linguistics, 507-54. Amsterdam: Benjamins.

— (ed.) (1988b) Topics in Cognitive Linguistics. Amsterdam: Benjamins.

- (1989) Prototypes, schemas, and cross-category correspondences: the case of ask. Linguistics 27: 613-61.

Ruhl, Charles (1989) On Monosemy: A Study in Linguistic Semantics. Albany: State University of New York Press.

Ruimy, Nilda, Elisabetta Gola, and Monica Monachini (2001) Lexicography informs lexical semantics: the SIMPLE experience. In Bouillon and Busa (2001: 350-62).

Ruiz de Mendoza Ibáñez, Francisco (2000) The role of mappings and domains in understanding metonymy. In Barcelona (2000: 109-32).

— and José Luis Otal Campo (2002) Metonymy, Grammar, and Communication. Albolote: Editorial Comares.

and Sandra Peña Cervel (2005) Conceptual interaction, cognitive operations and projection spaces. In Francisco Ruiz de Mendoza Ibáñez and Sandra Peña Cervel (eds.), Cognitive Linguistics: Internal Dynamics and Interdisciplinary Interaction, 249-79. Berlin: Mouton de Gruyter.

Rumshisky, Anna (2008) Resolving polysemy in verbs: contextualized distributional approach to argument semantics. Italian Journal of Linguistics/Rivista di Linguistica 20: forthcoming.

Ruppenhofer, Josef, Michael Ellsworth, Miriam R. L. Petruck, Christopher R. Johnson, and Jan Scheffczyk (2006) FrameNet II: Extended Theory and Practice. Berkeley, CA: FrameNet.

Russell, Stuart, and Peter Norvig (2003) Artificial Intelligence: A Modern Approach. 2nd edn. Englewood Cliffs, NJ: Prentice-Hall.

Saeed, John I. (2009) Semantics. 3rd edn. Malden, MA: Wiley-Blackwell.

Saint-Dizier, Patrick, and Evelyne Viegas (eds.) (1995) Computational Lexical Semantics. Cambridge: Cambridge University Press.

Sandra, Dominiek, and Sally Rice (1995) Network analyses of prepositional meanings: mirroring whose mind-the linguists or language users? Cognitive Linguistics 6: 89-130.

Sapir, Edward (1929) The status of linguistics as a science. Language 5: 207-14.

Sappan, Raphael (1987) The Rhetorical-Logical Classification of Semantic Changes. Braunton: Merlin.

Schank, Roger C., and Robert P. Abelson (1977) Scripts, Plans, Goals and Understanding: An Inquiry into Human Knowledge Structures. Hillsdale, NJ: Erlbaum.

Scheidweiler, Felix (1941a) Kluoc. Zeitschrift für deutsches Altertum und deutsche Literatur 78: 184-233.

— (1941b) Kunst und list. Zeitschrift für deutsches Altertum und deutsche Literatur 78: $62-87$.

- (1942) Die Wortfeldtheorie. Zeitschrift für deutsches Altertum und deutsche Literatur 79: 249-72. 
Schmid, Hans-Jörg (1993) Cottage und Co., idea, start vs. begin: Die Kategorisierung als

Grundprinzip einer differenzierten Bedeutungsbeschreibung. Tübingen: Niemeyer.

- (2000) English Abstract Nouns as Conceptual Shells: From Corpus to Cognition. Berlin: Mouton de Gruyter.

- (2007) Entrenchment, salience, and basic levels. In Geeraerts and Cuyckens (2007: 117-38).

Schmidt, Lothar (ed.) (1973) Wortfeldforschung: Zur Geschichte und Theorie des sprachlichen Feldes. Darmstadt: Wissenschaftliche Buchgesellschaft.

Schmitter, Peter (ed.) (1990) Essays towards a History of Semantics. Münster: Nodus.

Schönefeld, Doris (2006) From conceptualization to linguistic expression: where languages diversify. In Gries and Stefanowitsch (2006: 297-344).

Schreuder, Hindrik (1929) Pejorative Sense Development in English. Groningen: Noordhoff.

Schuchardt, Hugo (1912) Sachen und Wörter. Anthropos: Internationale Zeitschrift für Völker- und Sprachenkunde 7: 827-39.

Schulze, Rainer (1988) A short story of down. In Hüllen and Schulze (1988: 395-414).

Scott, Mike (1997) PC analysis of key words-and key key words. System 25: 233-45.

- (1999) WordSmith Tools. Oxford: Oxford University Press.

Semino, Elena (2008) Metaphor in Discourse. Cambridge: Cambridge University Press.

Seuren, Pieter A. M. (1998) Western Linguistics: An Historical Introduction. Oxford: Blackwell.

Sharifian, Farzad, René Dirven, Ning Yu, and Susanne Niemeier (eds.) (2008) Culture, Body, and Language: Conceptualizations of Internal Body Organs across Cultures and Languages. Berlin: Mouton de Gruyter.

Shi, Lei, and Rada Mihalcea (2005) Putting pieces together: combining FrameNet, VerbNet and WordNet for robust semantic parsing. In Alexander F. Gelbukh (ed.), Computational Linguistics and Intelligent Text Processing, 100-111. Berlin: Springer.

Shore, Bradd (1995) Culture in Mind: Cognition, Culture, and the Problem of Meaning. New York: Oxford University Press.

Sinclair, John M. (1991) Corpus, Concordance, Collocation. Oxford: Oxford University Press.

_ (1996) The search for units of meaning. Textus 9: 75-106.

- (2004) Trust the Text: Language, Corpus and Discourse. London: Routledge.

— and Patrick Hanks (1987) Collins Cobuild English Language Dictionary. London: Collins.

Sinha, Chris (1999) Grounding, mapping, and acts of meaning. In Theo Janssen and Gisela Redeker (eds.), Cognitive Linguistics: Foundations, Scope, and Methodology, 223-55. Berlin: Mouton de Gruyter.

— and Kristine Jensen de López (2000) Language, culture, and the embodiment of spatial cognition. Cognitive Linguistics 11: 17-41.

Smith, Edward E., and Douglas L. Medin (1981) Categories and Concepts. Cambridge, MA: Harvard University Press. 
Edward J. Shoben, and Lance J. Rips (1974) Structure and process in semantic memory: a featural model for semantic decisions. Psychological Review 81: 214-41.

Snider, James G., and Charles E. Osgood (eds.) (1969) Semantic Differential Technique: A Sourcebook. Chicago: Aldine.

Soares da Silva, Augusto (1999) A semântica de deixar: uma contribuição para a abordagem cognitiva em semântica lexical. Lisbon: Fundação Calouste Gulbenkian.

- (2003) Image schemas and category coherence: the case of the Portuguese verb deixar. In Cuyckens et al. (2003: 281-322).

- (2005) Para o estudo das relações lexicais entre o Português Europeu e o Português do Brasil: elementos de sociolexicologia cognitiva e quantitativa do Português. In Inês Duarte and Isabel Leiria (eds.), Actas do XX Encontro Nacional da Associação Portuguesa de Linguística, 211-26. Lisbon: Associação Portuguesa de Linguística.

Song, Nam Sun (1997) Metaphor and metonymy. In Robyn Carston and Seiji Uchida (eds.), Relevance Theory: Applications and Implications, 87-104. Amsterdam: Benjamins.

Speelman, Dirk, and Dirk Geeraerts (in press) Causes for causatives: the case of Dutch doen and laten. In Ted Sanders and Eve Sweetser (eds.), Linguistics of Causality.

— Stefan Grondelaers, and Dirk Geeraerts (2003) Profile-based linguistic uniformity as a generic method for comparing language varieties. Computers and the Humanities 37: 317-37.

Spence, Nicol C. W. (1961) Linguistic fields, conceptual systems and the Weltbild. Transactions of the Philological Society 1961: 88-106.

Sperber, Hans (1914) Über den Affekt als Ursache der Sprachveränderung. Halle: Niemeyer.

- (1923) Einführung in die Bedeutungslehre. Bonn: Dümmler.

Staal, Frits (1967) Some semantic relations between sentoids. Foundations of Language 3: $66-88$.

Steele, James (ed.) (1990) Meaning-Text Theory. Ottawa: University of Ottawa Press. Steen, Gerard J. (2007) Finding Metaphor in Grammar and Usage: A Methodological Analysis of Theory and Research. Amsterdam: Benjamins.

Stefanowitsch, Anatol (2006) Words and their metaphors: a corpus-based approach. In Gries and Stefanowitsch (2006: 63-105).

Steinthal, Heymann (1860) Charakteristik der hauptsächlichsten Typen des Sprachbaues. Berlin: Dümmler.

Stern, Gustaf (1931) Meaning and Change of Meaning, with Special Reference to the English Language. Gothenberg: Elanders Boktryckeri Aktiebolag.

Stöcklein, Johann (1898) Bedeutungswandel der Wörter: seine Entstehung und Entwicklung. Munich: Lindaursche Buchhandlung.

Storms, Gerrit (2003) Concept representation and the structure of semantic memory. In Peter Paul De Deyne, Evert Thiery, and Rudy D'Hooge (eds.), Memory: Basic Concepts, Disorders and Treatment, 121-33. Leuven: Acco. 
Stubbs, Michael (1993) British traditions in text analysis: from Firth to Sinclair. In Mona Baker, Gill Francis, and Elena Tognini-Bonelli (eds.), Text and Technology: In Honour of John Sinclair, 1-36. Amsterdam: Benjamins.

- (2002) Words and Phrases: Corpus Studies of Lexical Semantics. Oxford: Blackwell. Svensén, Bo (1993) Practical Lexicography: Principles and Methods of DictionaryMaking. Oxford: Oxford University Press.

Svorou, Soteria (1994) The Grammar of Space. Amsterdam: Benjamins.

Sweetser, Eve E. (1986) Polysemy vs. abstraction: mutually exclusive or complementary? In Vassiliki Nikiforidou, Mary Van Clay, Mary Niepokuj, and Deborah Feder (eds.), Proceedings of the Twelfth Annual Meeting of the Berkeley Linguistics Society, 528-38. Berkeley, CA: Berkeley Linguistics Society.

(1987) The definition of lie: an examination of the folk models underlying a semantic prototype. In Dorothy Holland and Naomi Quinn (eds.), Cultural Models in Language and Thought, 43-66. Cambridge: Cambridge University Press.

- (1990) From Etymology to Pragmatics: Metaphorical and Cultural Aspects of Semantic Structure. Cambridge: Cambridge University Press.

Taylor, John R. (1989) Linguistic Categorization: Prototypes in Linguistic Theory. Oxford: Clarendon Press.

- (1992) How many meanings does a word have? Stellenbosch Papers in Linguistics 25: $133-68$.

_ (1994) The two-level approach to meaning. Linguistische Berichte 149: 3-26.

(1995) Models of word meaning: the network model (Langacker) and the twolevel model (Bierwisch) in comparison. In René Dirven and Johan Vanparys (eds.), Current Approaches to the Lexicon, 3-26. Frankfurt: Lang.

- (1996) On running and jogging. Cognitive Linguistics 7: 21-34.

- (2002) Category extension by metonymy and metaphor. In Dirven and Pörings (2002: 323-47).

_ (2003a) Cognitive models of polysemy. In Brigitte Nerlich, Zazie Todd, Vimala Herman, and David D. Clarke (eds.), Polysemy: Flexible Patterns of Meaning in Mind and Language, 31-47. Berlin: Mouton de Gruyter.

- (2003b) Linguistic Categorization. 3rd edn. Oxford: Oxford University Press.

(2006) Polysemy and the lexicon. In Kristiansen et al. (2006: 51-80).

Terra, Egidio, and Charles L. A. Clarke (2003) Frequency estimates for statistical word similarity measures. In Marti Hearst and Mari Ostendorf (eds.), Proceedings of the 2003 Conference of the North American Chapter of the Association for Computational Linguistics on Human Language Technology 1: 165-72. Morristown, NJ: Association for Computational Linguistics.

Thomas, Robert (1894) Über die Möglichkeiten des Bedeutungswandels I. Bayerische Blätter für das Gymnasialschulwesen 30: 705-32.

_ (1896) Über die Möglichkeiten des Bedeutungswandels II. Bayerische Blätter für das Gymnasialschulwesen 32: 193-219.

Thomason, Richmond (1974a) Introduction. In Thomason (1974b: 1-69).

- (ed.) (1974b) Formal Philosophy: Selected Papers of Richard Montague. New Haven, CT: Yale University Press. 
Tissari, Heli (2001) Metaphors we love by: on the cognitive metaphors of love from the 15th century to the present. Studia Anglica Posnaniensia 36: 217-42.

- (2003) LOVEscapes: Changes in Prototypical Senses and Cognitive Metaphors since 1500. Helsinki: Société Néophilologique de Helsinki.

Tournier, Jean (1985) Introduction descriptive à la lexicogénétique de l'anglais contemporain. Paris and Geneva: Champion and Slatkine.

Traugott, Elizabeth C. (1982) From propositional to textual and expressive meaning: some semantic-pragmatic aspects of grammaticalization. In Winfred P. Lehmann and Yakov Malkiel (eds.), Perspectives on Historical Linguistics, 245-71. Amsterdam: Benjamins.

— (1985a) Conventional and dead metaphors revisited. In Wolf Paprotté and René Dirven (eds.), The Ubiquity of Metaphor: Metaphor in Language and Thought, 17-56. Amsterdam: Benjamins.

- (1985b) On regularity in semantic change. Journal of Literary Semantics 14: 155-73. (1988) Pragmatic strengthening and grammaticalization. In Shelley Axmaker, Annie Jaisser, and Helen Singmaster (eds.), Proceedings of the Fourteenth Annual Meeting of the Berkeley Linguistics Society, 406-16. Berkeley, CA: Berkeley Linguistics Society.

- (1989) On the rise of epistemic meanings in English: an example of subjectification in semantic change. Language 65: 31-55.

- (1999) The rhetoric of counter-expectation in semantic change: a study of subjectification. In Andreas Blank and Peter Koch (eds.), Historical Semantics and Cognition, 177-96. Berlin: Mouton de Gruyter.

— and Richard B. Dasher (2005) Regularity in Semantic Change. Cambridge: Cambridge University Press.

Trier, Jost (1931) Der deutsche Wortschatz im Sinnbezirk des Verstandes: Die Geschichte eines sprachlichen Feldes I. Von den Anfängen bis zum Beginn des 13. Jhdts. Heidelberg: Winter.

- (1932) Die Idee der Klugheit in ihrer sprachlichen Entfaltung. Zeitschrift für Deutschkunde 46: 625-35.

— (1934) Das sprachliche Feld: eine Auseinandersetzung. Neue Jahrbücher für Wissenschaft und Jugendbildung 10: 428-49.

_ (1968) Altes und Neues vom sprachlichen Feld. Duden-Beiträge 34: 9-20.

Trim, Richard (2007) Metaphor Networks: The Comparative Evolution of Figurative Language. Basingstoke: Palgrave Macmillan.

Tsohatzidis, Savas L. (ed.) (1989) Meanings and Prototypes: Studies in Linguistic Categorization. London: Routledge.

Tuggy, David (1993) Ambiguity, polysemy, and vagueness. Cognitive Linguistics 4: 273-90.

Tummers, José, Kris Heylen, and Dirk Geeraerts (2005) Usage-based approaches in Cognitive Linguistics: a technical state of the art. Corpus Linguistics and Linguistic Theory 1: 225-61.

Turner, Mark (1987) Death is the Mother of Beauty: Mind, Metaphor, Criticism. Chicago: University of Chicago Press. 
Turner, Mark (1991) Reading Minds: The Study of English in the Age of Cognitive Science. Princeton, NJ: Princeton University Press.

- (1996) The Literary Mind: The Origins of Thought and Language. New York: Oxford University Press.

Tyler, Andrea, and Vyvyan Evans (2003) The Semantics of English Prepositions: Spatial Scenes, Embodied Meaning and Cognition. Cambridge: Cambridge University Press.

Ullmann, Stephen (1957) The Principles of Semantics. 2nd edn. Oxford and Glasgow: Blackwell and Jackson.

- (1959) Précis de sémantique française. 2nd edn. Bern: Francke.

- (1962) Semantics. An Introduction to the Science of Meaning. Oxford: Blackwell.

Ungerer, Friedrich (2000) Muted metaphors and the activation of metonymies in advertising. In Barcelona (2000: 321-40).

— and Hans-Jörg Schmid (2006) An Introduction to Cognitive Linguistics. 3rd edn. London: Pearson Longman.

Van der Plas, Lonneke (2008) Automatic lexico-semantic acquisition for question answering. Ph.D thesis, University of Groningen.

Van Dongen, Gerrit A. (1933) Amelioratives in English. Rotterdam: De Vries.

Van Ginneken, Jac (1911-12) Het gevoel in taal en woordkunst 1. Leuvensche Bijdragen 9: $265-356$.

- (1912-13) Het gevoel in taal en woordkunst 2. Leuvensche Bijdragen 10: 1-156, $173-273$.

Van Helten, Willem (1912-13) Semasiologie. Zeitschrift für deutsche Wortforschung 14: $161-73$.

Van Noppen, Jean-Pierre (1985) Metaphor: A Bibliography of Post-197o Publications. Amsterdam: Benjamins.

and Edith Hols (1990) Metaphor II: A Classified Bibliography of Publications from 1985 to 1990. Amsterdam: Benjamins.

Van Sterkenburg, Piet (ed.) (2003) A Practical Guide to Lexicography. Amsterdam: Benjamins.

Vandeloise, Claude (1986) L'espace en français: sémantique des prépositions spatiales. Paris: Seuil.

- (1990) Representation, prototypes, and centrality. In Savas L. Tsohatzidis (ed.), Meanings and Prototypes: Studies in Linguistic Categorization, 403-37. London: Routledge.

_- (2001) Aristote et le lexique de l'espace: rencontres entre la physique grecque et la linguistique cognitive. Stanford, CA: CSLI Publications.

Vanhove, Martine (2008) Semantic associations between sensory modalities, prehension and mental perceptions: a crosslinguistic perspective. In Martine Vanhove (ed.), From Polysemy to Semantic Change: Towards a Typology of Lexical Semantic Associations, 341-70. Amsterdam: Benjamins.

Veale, Tony and Yanfen Hao (2008) A fluid knowledge representation for understanding and generating creative metaphors. In Harold Somers (ed.), COLING 
2008: Proceedings of the 22nd International Conference on Computational Linguistics, 945-52. Manchester: University of Manchester.

Vendryès, Joseph (1921) Le langage: introduction linguistique à l'histoire. Paris: La Renaissance du Livre.

Verhagen, Arie (2007) Construal and perspectivization. In Geeraerts and Cuyckens (2007: 48-81).

Victorri, Bernard (1997) Modéliser les interactions entre une expression polysémique et son co-texte. In Claude Guimier (ed.), Co-texte et calcul du sens, 233-45. Caen: Presses Universitaires de Caen.

Viegas, Evelyne (ed.) (1999) Breadth and Depth of Semantic Lexicons. Dordrecht: Kluwer Academic.

Violi, Patrizia (2001) Meaning and Experience. Bloomington: Indiana University Press.

Voigt, Moritz (1874) Ueber den Bedeutungswechsel gewisser die Zurechnung und der öconomischen Erfolg einer That bezeichnender technischer lateinischer Ausdrücke. Abhandlungen der philologisch-historischen Klasse der königlich Sächsichen Gesellschaft der Wissenschaften 6: 1-160.

von Humboldt, Wilhelm (1836) Über die Verschiedenheit des menschlichen Sprachbaues und ihren Einfluss auf die geistige Entwickelung des Menschengeschlechts. Berlin: Dümmler.

von Stechow, Arnim, and Dieter Wunderlich (eds.) (1991) Ein internationales Handbuch der zeitgenössischen Forschung/An International Handbook of Contemporary Research. Berlin: Mouton de Gruyter.

von Wartburg, Walther (1931) Das Ineinandergreifen von historischer und deskriptiver Sprachwissenschaft. Verhändlungen der Sächsichen Akademie der Wissenschaften zu Leipzig 83: 1-23.

(1957) Betrachtungen über die Gliederung des Wortschatzes und die Gestaltung des Wörterbüches. Zeitschrift für romanische Philologie 57: 296-312.

Vossen, Piek (ed.) (1998) EuroWordNet: A Multilingual Database with Lexical Semantic Networks. Dordrecht: Kluwer Academic.

- (2004) EuroWordNet: a multilingual database of autonomous and languagespecific wordnets connected via an inter-lingual index. International Journal of Lexicography 17: 161-73.

Voyles, James K. (1973) Accounting for semantic change. Lingua 31: 95-124.

Waag, Albert (1908) Bedeutungsentwicklung unseres Wortschatzes: Ein Blick in das Seelenleben der Wörter. 2nd edn. Lahr: Schauenburg.

Waldron, Ronald A. (1967) Sense and Sense Development. London: Deutsch.

Wallace, Anthony F. C., and John Atkins (1960) The meaning of kinship terms. American Anthropologist 62: 57-80.

Wanner, Leo (ed.) (1996) Lexical Functions in Lexicography and Natural Language Processing. Amsterdam: Benjamins.

(ed.) (2007) Selected Lexical and Grammatical Issues in the Meaning-Text Theory: In Honour of Igor Mel'čuk. Amsterdam: Benjamins. 
Ware, Robert (1978) The division of linguistic labor and speaker competence. Philosophical Studies 34: 37-61.

Warren, Beatrice (1992) Sense Developments: A Contrastive Study of the Development of Slang Senses and Novel Standard Senses in English. Stockholm: Almqvist \& Wiksell.

Watson, John Selby (ed.) (1856) Quintilians Institutes of Oratory: Or, Education of an Orator. London: Bohn.

Wegener, Philipp (1885) Untersuchungen über die Grundfragen des Sprachlebens. Halle: Niemeyer.

Weinreich, Uriel (1963) On the semantic structure of language. In Joseph H. Greenberg (ed.), Universals of Language, 142-216. Cambridge, MA: MIT Press.

- (1966) Explorations in semantic theory. In Thomas A. Sebeok (ed.), Current Trends in Linguistics 3, 395-477. The Hague: Mouton.

Weisgerber, Leo (1927) Die Bedeutungslehre-ein Irrweg der Sprachwissenschaft? Germanisch-Romanische Monatsschrift 15: 161-83.

_ (1962a) Die sprachliche Gestaltung der Welt. 3rd edn. Düsseldorf: Schwann.

(1962b) Grundzüge der inhaltsbezogenen Grammatik. 3rd edn. Düsseldorf: Schwann.

Wellander, Erik (1917) Studien zum Bedeutungswandel im Deutschen 1. Uppsala: Berling.

_ (1921) Studien zum Bedeutungswandel im Deutschen 2. Uppsala: Almqvist \& Wiksell.

Werth, Paul (1974) Accounting for semantic change in current linguistic theory. In John M. Anderson and Charles Jones (eds.), Historical Linguistics, 377-413. Amsterdam: North-Holland.

White, Morton G. (1952) The analytic and the synthetic: an untenable dualism. In Leonard Linsky (ed.), Semantics and the Philosophy of Language, 272-86. Urbana: University of Illinois Press.

Whitney, William Dwight (1875) The Life and Growth of Language: An Outline of Linguistic Science. New York: Appleton.

Whorf, Benjamin L. (1956) The relation of habitual thought and behavior to language. In John B. Carroll (ed.), Language, Thought, and Reality: Selected Writings of Benjamin Lee Whorf, 134-59. Cambridge, MA: MIT Press.

Wierzbicka, Anna (1972) Semantic Primitives. Frankfurt: Athenaeum.

- (1985) Lexicography and Conceptual Analysis. Ann Arbor, MI: Karoma.

- (1992) Semantic, Culture, and Cognition: Universal Human Concepts in CultureSpecific Configurations. New York: Oxford University Press.

- (1996) Semantics. Primes and Universals. Oxford: Oxford University Press.

- (1997) Understanding Cultures Through Their Key Words: English, Russian, Polish, German, and Japanese. New York: Oxford University Press.

- (1999) Emotions Across Languages and Cultures. Cambridge: Cambridge University Press.

- (2003) Cross-Cultural Pragmatics: The Semantics of Human Interaction. 2nd edn. Berlin: Mouton de Gruyter. 
- (2007) Theory and empirical findings: a response to Jackendoff. Intercultural Pragmatics 4: 399-409.

Wilcox, Phyllis P. (2001) Metaphor in American Sign Language. Washington, DC: Gallaudet University Press.

Wilkins, David P. (1996) Natural tendencies of semantic change and the search for cognates. In Mark Durie and Malcolm Ross (eds.), The Comparative Method Reviewed, 224-304. New York: Oxford University Press.

Wilks, Yorick (1972) Grammar, Meaning, and the Machine Analysis of Natural Language. London: Routledge \& Kegan Paul.

- (2001) The Fodor-Fodor fallacy bites back. In Bouillon and Busa (2001: 75-85).

- Brian M. Slator, and Louise M. Guthrie (eds.) (1996) Electric Words: Dictionaries, Computers and Meanings. Cambridge, MA: MIT Press.

Winograd, Terry (1972) Understanding Natural Language. New York: Academic Press.

Winston, Morton E., Roger Chaffin, and Douglas Herrmann (1987) A taxonomy of part-whole relations. Cognitive Science 11: 417-44.

Wittgenstein, Ludwig (1953) Philosophical Investigations. Oxford: Blackwell.

Wolski, Werner (1982) Aspekte der sowjetrussischen Lexikographie: Übersetzungen, Abstracts, bibliographische Angaben. Tübingen: Niemeyer.

Wotjak, Gerd (1977) Untersuchungen zur Struktur der Bedeutung: Ein Beitrag zu Gegenstand und Methode der modernen Bedeutungsforschung unter besonderer Berücksichtigung der semantischen Konstituentenanalyse. 2nd edn. Berlin: Akademie.

Wunderlich, Dieter (1991) How do prepositional phrases fit into compositional syntax and semantics? Linguistics 29: 591-621.

_ (1993) On German um: semantic and conceptual aspects. Linguistics 31: 111-33.

Wundt, Wilhelm (1900) Völkerpsychologie: Eine Untersuchung der Entwicklungsgesetze von Sprache, Mythus und Sitte. Leipzig: Kröner.

Yu, Ning (1998) The Contemporary Theory of Metaphor: A Perspective from Chinese. Amsterdam: Benjamins.

_- (2009) The Chinese Heart in a Cognitive Perspective: Culture, Body, and Language. Berlin: Mouton de Gruyter.

Zauner, Adolf (1903) Die romanischen Namen der Körperteile: eine onomasiologische Studie. Romanische Forschungen 14: 339-530.

Zelinsky-Wibbelt, Cornelia (ed.) (1993) The Semantics of Prepositions: From Mental Processing to Natural Language Processing. Berlin: Mouton de Gruyter.

Ziemke, Tom, Jordan Zlatev, and Roslyn M. Frank (eds.) (2007) Body, Language, and Mind 1: Embodiment. Berlin: Mouton de Gruyter.

Zlatev, Jordan (2003) Polysemy or generality? Mu. In Cuyckens et al. (2003: 447-94).

- (2005) What's in a schema? Bodily mimesis and the grounding of language. In Beate Hampe (ed.), From Perception to Meaning: Image Schemas in Cognitive Linguistics, 313-42. Berlin: Mouton de Gruyter.

Zwicky, Arnold, and Jerry Sadock (1975) Ambiguity tests and how to fail them. In John Kimball (ed.), Syntax and Semantics 4, 1-36. New York: Academic Press. 


\section{Author Index}

Aaron, David 179

Abeillé, Anne 268

Abelson, Robert P. 224

Achard, Michel 267

Agirre, Eneko 176, 181

Ahlgren, Inger 179

Aitchison, Jean 267

Alinei, Mario 237

Allan, Kathryn 253

Allan, Keith 45, 272

Allwood, Jens 269

Apresjan, Juri 59-60, 99, 148, 180

Arbatchewsky-Jumarie, Nadia 161

Aristotle 94, 150, 197

Armstrong, Sharon L. 192

Arppe, Antti 264

Asher, Nicholas 152-6

Athanasiadou, Angeliki 269, 271

Atkins, B. T. Sue $46,180-1,222-3,226-7$, 271

Atkins, John 100

Atran, Scott 203

Austin, John L. 168

Baicchi, Annalisa 269

Bakema, Peter 135, 202

Baker, Collin F. 227

Baldinger, Kurt 23, 45, 80, 92, 94, 99

Bally, Charles 98

Bar Hillel, Yehoshua 122

Barcelona, Antonio 214-5, 269-70

Barnden, John 216

Bartlett, Frederick C. 224

Bartsch, Renate 253, 256-8

Bechtoldt, Heinrich 98

Beckwith, Richard 160

Bendix, Edward H. 100

Bergen, Benjamin 267

Berlin, Brent 184, 200, 269

Bertels, Ann 264

Bierwisch, Manfred 107, 122, 125-7, 142-6, 148

Blank, Andreas 45-6, 238-9, 272

Bloomfield, Leonard 71-2, 75

Boden, Margaret 123

Boers, Frank 253, 267
Boguraev, Branimir 179

Bohnemeyer, Jürgen 133, 179

Bolinger, Dwight 112-3

Boroditsky, Lera 241

Bouillon, Pierrette 155, 179

Bowdle, Brian F. 242

Boyes-Braem, Penny 183

Braisby, Nick 256

Brandt, Per Aage 270

Bréal, Michel xvi, 10-4, 16-8, 20-1, 25, 273

Breedlove, Dennis E. 200

Briscoe, Ted 152

Broccias, Cristiano 269

Brown, Cecil H. 269

Brugman, Claudia 193, 267

Buitelaar, Paul 180

Burling, Robbins 100

Burridge, Kate 272

Busa, Federica 155, 179

Butler, Christopher S. 267

Cameron, Lynne J. 260, 263

Canakis, Costas 271

Carnap, Rudolf 111, 114

Carnoy, Albert 26, 35-41, 43, 57, 64, 273

Carter, Ronald 46

Casad, Eugene H. 271

Catlin, Jack 198

Catlin, Jane-Carol 198

Cavazza, Marc 268

Čermáková, Anna 168

Chaffin, Roger 88

Charniak, Eugene 181

Charteris-Black, Jonathan 263

Chierchia, Gennaro 122

Chilton, Paul 263

Chomsky, Noam 106, 109, 138, 168

Church, Kenneth 173

Cienki, Alan 206, 260, 267

Clarke, Charles L. A. 176

Clarke, David D. 204, 221, 269, 271

Clas, André 161

Claudi, Ulrike 236

Coleman, Linda 187

Collins, Allan M. 245

Conklin, Harold 70, 100 
Copestake, Ann 152-4

Cornillie, Bert 271

Coseriu, Eugenio 53, 58, 70, 75-80, 86, 98, 100, 278

Coulson, Seana 210, 213, 241, 269

Craig, Colette 267

Croft, William 215-6, 267

Cruse, D. Alan 45, 82-3, 100, 199, 216, 267, 269, 270

Culler, Jonathan 100

Cuyckens, Hubert 263, 267, 269

d'Andrade, Roy G. 100

Darmesteter, Arsène 9, 17, 31, 36

Dasher, Richard B. 230-1, 235

Dauzat, Albert 99

Davidson, Donald 118

de la Cruz Cabanillas, Isabel 99

De Mulder, Walter 271

De Saussure, Ferdinand xiv, 47-8, 51, 55, 57, $60,63,74,75,77,79,167,171,268,274$

Deane, Paul D. 179, 267

Deignan, Alice 220, 260-1

Dekeyser, Xavier 271

Del Bello, Davide 46

Desmet, Piet 45

Dewell, Robert B. 267

Di Meola, Claudio 267

Dilthey, Wilhelm 13-4

Dirven, René 214, 217, 253, 264, 267, 269, 271

Divjak, Dagmar 264

Dornseiff, Franz 46, 108-9

Dowty, David R. 114, 120, 122

Du Marsais, César Chesneau 7, 31

Dubois, Jean 59, 98

Ducháček, Otto 68-9, 79, 92-3, 98, 278

Dumais, Susan T. 176

Dunning, Ted 174

Dupré, John 256

Durst, Uwe 179

Ebeling, Carl L. 100

Eckardt, Regine 271

Edmonds, Philip 176, 181

Ellen, Roy 269

Ellsworth, Michael 227

Erdmann, Karl-Otto 16, 19, 20, 22, 42, 67, $85,111,141,183,199,277$

Esnault, Gaston 16, 31-33

Evans, Gareth 257

Evans, Nicholas 237

Evans, Vyvyan 267, 269

Evens, Martha W. 100
Fabiszak, Malgorzata 253

Fauconnier, Gilles 210-3, 270

Fellbaum, Christiane 158-160, 180

Feyaerts, Kurt 215, 269, 270

Fillmore, Charles J. 110, 222-7, 271, 282

Firth, John R. 58-9, 108-9, 168-170

Fischer, Kerstin 258

Fodor, Janet D. 122

Fodor, Jerry A. xvii, 58, 70, 101-6, 108-13, $115-7,122-3,156,274$

Fontenelle, Thierry 46, 164-5, 271

Forceville, Charles 206

Fowler, Harold North 2

Frake, Charles 100

Frank, Roslyn M. 253, 70

Franks, Bradley 256

Fritz, Gerd 46, 122

Fuchs, Catherine 268

Fumaroli, Marc 46

Garrett, Merrill F. 116, 123

Geckeler, Horst 80, 98, 100

Geeraerts, Dirk 46, 126, 135, 176, 179, 196, $198,202,209,217-8,220,233-4,251,262$, 264-5, 267-9, 276-8, 285

Gentner, Dedre 241-3

Gevaert, Caroline 253, 262

Gévaudan, Paul 272

Gibbs, Raymond W. 241, 249, 260, 263, 269

Gildea, Patricia 243

Gilliéron, Jules 24, 62-3

Gilquin, Gaetanelle 263

Giora, Rachel 243

Gipper, Helmut 45, 66-7, 93-4, 97, 126, 130, $141,178,183,278$

Gleitman, Henry 202

Gleitman, Lila R. 202

Glinz, Hans 99

Glucksberg, Sam 241, 243

Glynn, Dylan 264, 271

Goatly, Andrew 263

Goddard, Cliff 128, 132-3, 179

Goffman, Erving 224

Gola, Elisabetta 179

Gonzalvez-García, Francisco 267

Goodenough, Ward H. 70, 72-6

Goossens, Jan 63

Goossens, Louis 220

Gordon, W. Terrence 45

Grady, Joseph 208, 213, 221, 260

Gray, Wayne D. 183

Green, Melanie 267

Greimas, Algirdas 53, 70, 75, 80, 100 
Gries, Stefan Th. 264

Grondelaers, Stefan 135, 202, 251, 264-5, 269

Gross, Derek 160

Grygiel, Marcin 46

Grzega, Joachim 46, 272

Guiraud, Pierre 60-1

Guthrie, Louise M. 181

Haack, Susan 122

Haase, Friedrich 7, 17, 43

Habel, Christoph 179

Halliday, Michael A. K. 168, 268

Hallig, Rudolf 99

Hampe, Beate 270

Hampton, James 256

Hanks, Patrick

Hanks, Patrick W. 45, 152, 169, 173, 180, 268

Hao, Yanfen 261

Harris, Randy A. 122

Harris, Zellig 59

Hart, Christopher 263

Hartmann, Reinhard R. K. 46

Haser, Verena 209, 260

Hatzfeld, Adolphe 9

Hawkins, Bruce 253

Heasley, Brendan 45

Hecht, Max 7, 9, 16, 47

Heerdegen, Ferdinand 7, 17

Heger, Klaus 80, 92

Heider, Eleanor R. 184-5

Heine, Bernd 236, 271

Herbermann, Clemens-Peter 46

Herman, Vimala 269

Herrmann, Douglas 98

Herskovits, Annette H. 208, 267

Herweg, Michael 179

Hey, Oskar 7, 16

Heylen, Kris 176, 264

Hjelmslev, Louis 70, 74

Hoberg, Rudolf 98

Hoey, Michael 180

Hoffman, Robert R. 204

Hols, Edith 45

Honeck, Richard P. 204

Horn, Laurence R. 230

Hougaard, Anders 270

Hüllen, Werner 98

Hünnemeyer, Friederike 236

Hundsnurscher, Franz 45

Hunn, Eugene 269

Hurford, James R. 45
Ilie, Cornelia 253

Ipsen, Gunther 54, 68, 98

Jaberg, Karl 20, 24

Jackendoff, Ray 122, 124-7, 138-44, 151, 166,179

Jackson, Howard 46

Jäkel, Olaf 204

Jakobson, Roman 63, 217

Janssen, Theo 269

Jayez, Jacques 155

Jensen de López, Kristine 249

Jezek, Elisabetta 152

Job, Michael 45

Johnson, Christopher R. 227

Johnson, David 183

Johnson, Mark 204-5, 207-10, 213-5, 269

Jolles, André 108

Jones, Steven 88

Joos, Martin 92

Jurafsky, Daniel 123, 181

Kandler, Günther 70

Kastovsky, Dieter 98

Katz, Jerrold J. xvi, 53, 58, 70, 101-18, $122-3,139,148-9,156,172,274$

Kaufmann, Ingrid 179

Kay, Paul 137, 179, 184, 187, 200, 271

Kearns, Kate 122

Keller, Rudi 232

Kempton, Willett 267

Kennedy, George A. 46

Keysar, Boaz 243

Kiefer, Ferenc 181

Kilgarriff, Adam 152, 176, 181

Kimmel, Michael 249

Kintsch, Walter 176

Kiss, Gábor 181

Kittay, Eva F. 98, 242, 271

Kleiber, Georges 195-6

Kleparski, Grzegorz A. 46, 122

Klinck, Roswitha 46

Knobloch, Clemens 45

Koch, Peter 238, 272

Koivisto-Alanko, Paivi 271

Koller, Veronika 261, 263

König, Ekkehard 147, 231

Koptjevskaja-Tamm, Maria 179

Kövecses, Zoltán 204, 206, 215, 221, 250-2, 259-60, 269

Kripke, Saul 254, 256

Kristiansen, Gitte 179, 267 
Kroeber, Alfred L. 70

Kronasser, Heinz 45

Kronenfeld, David B.

Krzeszowski, Tomasz P. 270

Kühlwein, Wolfgang 98

Kuteva, Tanya 236

Kytö, Merja 281

Labov, William 130-1, 140

Lakoff, George 110, 122, 179, 193, 198, 204-10, 213-5, 250-2, 259, 263, 267, 269

Lamb, Sidney M. 100

Landau, Sidney I. 46

Landauer, Thomas K. 176

Lang, Ewald 143-4

Langacker, Ronald W. 110, 179, 201, 259, 267

Lapalme, Guy 164

Lapata, Mirella 186

Lappin, Shalom 122

Larrivée, Pierre 100

Lascarides, Alex 152-6

Laurence, Stephen 123

Lausberg, Heinrich 46

Lawler, John M. 271

Lazarus, Moritz 18, 51

Leacock, Claudia 269

Leech, Geoffrey 100, 107

Leezenberg, Michiel 270

Lehrer, Adrienne 65, 86, 98, 99, 223, 242, 271

Leisi, Ernst 100

Lepore, Ernest 123

Lepschy, Giulio C. 108

Levin, Beth 166-7

Levinson, Stephen C. 231, 263, 267

Lewandowska-Tomaszczyk, Barbara 267, 269

Lewis, David K. 118

Lindsay, Peter H. 123

Lipka, Leonhard 45, 47, 98, 100

Litowitz, Bonnie E. 100

Littlemore, Jeannette 253

Löbner, Sebastian 45

Loftus, Elizabeth, F. 245

Lounsbury, Floyd 70, 74, 92, 100

Louw, Bill 180

Low, Graham 253, 260

Lüdeling, Anke 181

Lukeš, Dominik 263

Lutzeier, Peter Rolf 45, 98, 100, 271

Lyons, John 53, 56-7, 60, 80-2, 86, 89, 90, $92,94,100,161,164,274$
MacArthur, Tom 46

MacLaury, Robert E. 271

Maienborn, Claudia 179

Malinowski, Bronislaw 168

Malkiel, Yakov 46

Mandler, Jean M. 208

Mangasser-Wahl, Martina 267

Manning, Chris 181

Margolis, Eric 123

Markowitz, Judith E. 100

Martin, James H. 123, 181

Martin, Willy 271

Mason, Zachary J. 262

Matlock, Teenie 241

Matoré, Georges 95, 98, 278

Matthewson, Lisa 179

May, William H. 100

McCawley, James D. 108, 122

McConnell-Ginet, Sally 122

McNeill, David 206

Medin, Douglas L. 244

Meillet, Antoine 21, 25

Mel'čuk, Igor A. 125-6, 156, 161-5, 180, 229

Meringer, Rudolf 24

Mervis, Carolyn B. 183, 186-7

Mettinger, Arthur 87-8, 90

Meyer, Ralf 98

Meyer, Richard M. 179

Mihalcea, Rada 271

Miller, George A. 158, 160, 180

Minsky, Marvin 224

Miron, Murray S. 100

Molina, Clara 271

Monachini, Monica 179

Moon, Rosamund 180

Morgan, Pamela S. 208

Müller, Cornelia 206

Murphy, Gregory L. 244-8

Murphy, M. Lynne 82, 90, 98, 100

Murray, James A. H. 8, 169

Musolff, Andreas 263

Nagel, Richard I. 123

Nerlich, Brigitte 45, 204, 221, 269, 271

Neu, Antonia 272

Newmeyer, Frederick J. 122

Nida, Eugene A. 71-2, 92, 100

Niemeier, Susanne 253

Niles, Ian 180

Norman, Donald A. 123

Norrick, Neal R. 199

Norvig, Peter 123 
Nunberg, Geoffrey 198, 270

Núñez, Rafael E. 206

Nuyts, Jan 267

Nyckees, Vincent 268

Nyrop, Kristoffer 16, 21, 31-3, 35, 43

Oakley, Todd 213, 270

O'Connor, Catherine 271

Oertel, Hans 16

Ohmann, Suzanne 108

Oksaar, Els 100

Olivier, D. C. 185

Ortony, Andrew 204, 269

Osgood, Charles E. 99, 100

Otal Campo, José Luis 216

Padó, Sebastian 176

Pajzs, Júlia 181

Palmer, Frank R. 99

Palmer, Gary B. 100

Palmer, Martha 164

Panther, Klaus-Uwe 214-5, 217, 219, 270

Papafragou, Anna 270

Paprotté, Wolf 269

Paradis, Carita 270

Paris, Gaston 16

Parkes, Cornelia H. 123

Partee, Barbara H. 122

Partington, Alan 180

Paul, Hermann 9, 10, 14-21, 25, 31-3, 35, 43, 81, 146, 230, 273, 277

Pease, Adam 180

Peeters, Bert 179, 269

Peirsman, Yves 176, 217-8

Persson, Gunnar 267

Peters, Stanley 122

Petitot, Jean 271

Petruck, Miriam R. L. 227

Picoche, Jacqueline 268

Plato 2-3, 242

Polguère, Alain 164

Pörings, Ralf 215, 269

Portner, Paul H. 122

Porzig, Walter 58, 98, 274

Posner, Michael 187

Post, Michael 271

Postal, Paul M. 122

Pottier, Bernard 53, 70, 75-9, 80, 93-4, 100, $102,106,126,130,166,178$

Pragglejaz 260-1

Pütz, Martin 253, 267

Pustejovsky, James 120, 125-7, 147-54, $156-7,165,179,275$
Putnam, Hilary 253-6, 258

Putseys, Yvan 264, 271

Quadri, Bruno 45, 98

Quillian, M. Ross 123

Quine, Willard V. O. 122, 197-8

Quintilian 5-7, 27

Radden, Günter 214, 215, 221, 267

Rakova, Marina 269

Ramos, Margarita Alonso 164

Ramscar, Michael 241

Rastier, François 268, 271

Raven, Peter H. 200

Ravin, Yael 269

Récanati, François 270

Reddy, Michael J. 206

Reichling, Anton 93

Reisig, Karl 7, 17, 23

Rice, Sally 263

Richards, Ivor A. 206

Riemer, Nick 133, 215, 269

Rips, Lance J. 245

Rohrer, Tim 207

Rojo, Ana 271

Rommetveit, Ragnar 268

Romney, A. Kimball 100

Roques, Mario 62

Rosch, Eleanor 183-7, 189-90, 201, 244, 246

Rothwell, William 108

Roudet, Léonce 16

Rudzka-Ostyn, Brygida 264, 267

Ruhl, Charles 180

Ruimy, Nilda 179

Ruiz de Mendoza Ibáñez, Francisco 216, 267, 270

Rumshisky, Anna 152

Rundell, Michael 46, 180

Ruppenhofer, Josef 227

Russell, Stuart 123

Rychlý, Pavel 181

Sadock, Jerry 197

Saeed, John I. 45

Saint-Dizier, Patrick 152, 181

Sandikcioglu, Esra 253

Sandra, Dominiek 263

Sansò, Andrea 269

Sapir, Edward 51, 72

Sappan, Raphael 46

Sato, Hiroaki 271

Schank, Roger C. 224 
Scheffczyk, Jan 227

Scheidweiler, Felix 98

Schmid, Hans-Jörg 264, 267, 269

Schmidt, Lothar 98

Schmitter, Peter 45

Schönefeld, Doris 264

Schreuder, Hindrik 20

Schuchardt, Hugo 24

Schütze, Hinrich 181

Schulze, Rainer 98, 264

Schwarz, Hans 45

Scott, Mike 174, 181

Semino, Elena 154, 259, 260

Seuren, Pieter A. M. 122

Sharifian, Farzad 253

Shi, Lei 271

Shoben, Edward J. 245

Shore, Bradd 250

Sinclair, John M.

Sinha, Chris 249

Slator, Brian M. 181

Smith, Edward E. 244-5

Smith, Michael B. 45

Smith, Raoul N. 100

Smrž, Pavel 181

Snider, James G. 99

Soares da Silva, Augusto 265, 271

Song, Nam Sun 270

Speelman, Dirk 176, 264, 265

Spence, Nicol C. W. 98

Sperber, Hans 20

Staal, Frits 122

Steele, James 180

Steen, Gerard J. 260, 269

Stefanowitsch, Anatol 262, 264

Steinthal, Heymann 18, 51

Stelma, Juurd H. 263

Stern, Gustaf xvi, 23, 26, 35-41, 43, 47, 64, 273

Stöcklein, Johann 16

Storms, Gerrit 246

Stubbs, Michael 169-70, 172, 180

Suci, George J. 99

Svensén, Bo 46

Svorou, Soteria 267

Sweetser, Eve E. 236-7, 267, 269, 270

Tabakowska, Elzbieta 269

Tannenbaum, Percy H. 99

Taub, Sarah 208

Taylor, John R. 142, 145, 155, 179, 196, 215, 264, 267, 269

Terra, Egidio 176
Teubert, Wolfgang 168

Thomas, Robert 16

Thomason, Richmond 118, 120, 122

Thornburg, Linda 215, 217, 219, 270

Tissari, Heli 253, 271

Todd, Zazie 279

Tournier, Jean 46, 272

Traugott, Elizabeth C. 147, 209, 230-1, 235, 271

Trier, Jost 26, 47, 53-7, 59-61, 65, 68, 70, 74, $81,98,274,278$

Trim, Richard 253

Tsohatzidis, Savas L. 267

Tuggy, David 196

Tugwell, David 181

Tummers, José 264

Turner, Mark 208, 210-3, 215, 279

Tutin, Agnes 164

Tyler, Andrea 267

Ullmann, Stephen $27,45-6,63-4$

Ungerer, Friedrich 206, 267

Urban, Margaret 227

Valenzuela, Javier 271

Van der Plas, Lonneke 176

Van Dongen, Gerrit A. 20

Van Ginneken, Jac 20

Van Helten, Willem 16

Van Noppen, Jean-Pierre 45

Van Sterkenburg, Piet 46

Vandeloise, Claude 208, 267

Vanderheyden, Anne 271

Vanhove, Martine 237

Veale, Tony 261

Vendryès, Joseph 21

Verhagen, Arie 225

Victorri, Bernard 268

Viegas, Evelyne 152, 181

Violi, Patrizia 267

Voigt, Moritz 98

von Humboldt, Wilhelm 18-9, 51, 72

von Stechow, Arnim 122

Von Wartburg, Walther 92, 99

Vorlat, Emma 264, 271

Vossen, Piek 180

Voyles, James K. 122

Waag, Albert 26, 31-3, 35

Waldron, Ronald A. 46

Walker, Edward C. T. 123

Wall, Robert E. 122

Wallace, Anthony F. C. 100 
Wanner, Leo 180

Ware, Robert 255

Warren, Beatrice 46

Watson, John Selby 5

Wegener, Philipp 16, 21

Weinreich, Uriel 58, 107, 113, 122

Weisgerber, Leo 19, 26, 47, 49-53, 55-7, 59, $72,81,96,98,274$

Wellander, Erik 16

Werner, Oswald 100

Werth, Paul 122

White, Morton G. 122

Whitney, William Dwight 16

Whorf, Benjamin L. 51, 72

Wierzbicka, Anna 95, 124-32, 135-7, 156, 165, 179-8o, 275

Wilcox, Phyllis P. 206

Wilkins, David P. 237

Wilks, Yorick 123

Winograd, Terry 123
Winston, Morton E. 88

Wittgenstein, Ludwig 168, 187, 246

Wolski, Werner 99

Wood, Esther J. 227

Wotjak, Gerd 100

Wunderlich, Dieter 122, 179

Wundt, Wilhelm 18-9, 36, 51

Yallop, Colin 168

Yu, Ning 253

Zampolli, Antonio 181

Zauner, Adolf 23

Zawada, Britta 269

Zelinsky-Wibbelt, Cornelia 267

Zholkovsky, Aleksander 180

Ziemke, Tom 270

Zinken, Jörg 267

Zlatev, Jordan 249, 269, 270

Zwicky, Arnold 197 


\section{Subject Index}

adequation 36,40

allolexy 129

alloseme 72, 76, 92, 93

amalgamation 103,107

ambiguity $63,103-4,110,111,113,185,197-8$, 241

see also fuzziness, indeterminacy, polysemy, underspecification, vagueness

ameliorative change of meaning $20,29-9$

amphisémie $36-7$

analogical change of meaning $26,36,37,38$, $40,54,61,91,99,281$

analytic definition $83,162,165$

analyticity $111-2,122$

anthropological linguistics 51, 53, 70, 72 , $100,166,168,184,186,203,249,250$

see also ethnosemantics

antisémie $36-8$

antonymous n-tuple 104, 107

antonymy $52,80-2,85-7,90,96,104-5,107$ $159-60,163,245,274,280$

aposémie $36-7$

archilexeme 76

archisememe 76

Artificial Intelligence 118, 120, 123, 224

see also Natural Language Processing

associative field 79

auto-hyponymy 82

avoidance of homonymy $62-3$

avoidance of polysemy 63

basic level hypothesis 199-201, 269, 280

Bedeutung/Bezeichnung 78

bibliographical resources for lexical semantics 45

blending 23, 30, 210-3, 237, 242

see also conceptual integration, mental spaces

borrowing $23-4,29,237$

bridging context $147,231,235$

broadening of meaning see generalization of meaning

canonical context $13-4$

career of metaphor $242-4$ categorization model of metaphor

243-4

champ associatif 98

circularity of definitions $70,127,134$

classème 77,78

coercion 151, 153, 155, 157

cognitive adequacy 115, 117, 229, 278

see also psychological adequacy

cognitive science $118,123,175-6,244-5$

cognitive semantics 45, 66, 98, 100, 110, 117 , $119,121,124,126-7,131,141,154,170$, $179,182-272,275-81,284-87$

affinity with historical-philological semantics $277-8$

co-hyponym $82-3,85-6,283$

colligation 170,172

collocate $170-4$

collocation $58,85,167-178,180,181,264$, 266

colour terms 30, 130, 184-5, 196

communicative norm 253,258

comparative philology 11-4, 17

competence 106, 116, 138, 168

complementaries $86-7$

complex metaphor 206, 211

componential analysis $52,53,65,66,70-80$,

$83,88,93,94,98,100,101,102,105,108$,

$111,113-5,122,124,126,127,141,149,167$,

$177,190,274,275,276,281$

computational semantics 118, 119, 121, 156

conceptual field $56-7,65,68$

conceptual integration 204, 210-3

see also blending, mental spaces

Conceptual Metaphor Theory 179, 204-10,

$211,213,221,222,240-3,252,259,269$,

275

conceptual metonymy 213-221

Conceptual Semantics 125, 127, 137-43, 147,

$151,154,166$

conceptual structure $51,52,79,138,140$,

$141,143,222,225$

concordance 170, 261, 262

connotation $19,26,38,43,84-5,98,172$, 211

content figurae $74-5$

context of situation 168 
contextualization $15,16,96,145,168,178$, $183,219,230,232,240,249,259,265$, $266,278,285,287$

contiguity $27,63-4,215-20,282-4$

conventionalization of meaning $16,231-4$, 241-4, 270

converseness 86

corpus linguistics $98,118,168,244$

corpus-based approaches to lexical semantics $46,60,88,126,158,166,168$, $169,173,174,178,181,262,265,268$, 286

Critical Discourse Analysis 263

cultural factors in lexical semantics $1,13-4$, $19,51,72,73,109,128,237,240,249-53$,

cycle 87 $266,268-70,277$

dead metaphor 209, 266

decontextualization $177,278,284$

definition see analytic definition, circularity of definitions, componential analysis, generality and distinctiveness of definitions, necessary and sufficient conditions, reductive paraphrase, synonym definition

definitional test of polysemy $197-8$

denotational meaning 19, 26, 28-9, 84, 98, 130, 166, 210, 264-5

diachronic semantics $1,4,9,42,44,46,56$, $64,79,92,99,122,146,147,148,230$, 233,280

see also semantic change

dialectology 24, 61-3, 237

diasémie $36-8$

differences of structural weight see salience directional opposition 86

disambiguation 103, 110, 112, 153, 176, 181, 196

discourse prosody 172

discreteness $65,66,131,132,180,188,189$, $191,234,285$

see also fuzziness

distinctive feature $74-5,94$

distinctive opposition $75,78,115,124$

distinguisher 102-3, 106, 111-3

distributional corpus analysis $125,158,165$, $168,173,176-8,261,266,275,285,287$

distributionalism 59-60, 98

division of linguistic labour $253-6,258$

domain matrix $216-7$

dysphemism 29, 38, 272

dyssémie 38 ecsémie $36-8$

ellipsis 23, 39-40, 60, 64, 237

embodiment 117, 203, 207, 221, 225, 241, 249, 270

emotion terms 251, 262, 269

emotive meaning $20,25,26,28-9,84,99$, 172,272

encyclopedic information $43,72,77,79,81$, $88-91,94-7,110-3,116-7,121,126,145$, $155,165,203,222-3,225,229,248,277$

see also extralinguistic factors in semantics, world knowledge

entrenchment 201-2, 261, 269, 270, 285

épisémie 38

essentialist approaches to lexical semantics 2, 83-4, 256

ethnosemantics 71, 75-7, 100, 102

see also anthropological linguistics

ethnoseme 72

etymology 9, 26, 237-8

euphemism 5, 29, 38-9, 272

eusémie 38

exemplar view of categorization in psycholexicology 246-8

experiential factors in semantics 14, 192, 204, 207-8, 256-7, 261, 269, 289

experimental approaches to lexical semantics $116,130-1,161,184-6,189$, 192, 241-7, 256, 259, 263, 286

Explanatory Combinatorial

Dictionary 161, 164-5, 229

expressivity 14, 20, 36, 41, 213, 233

extensional perspective on meaning 83 , 188-90, 247, 253-4

extralinguistic factors in semantics 16,21 , 70, 71, 77, 134, 137, 141, 153, 155, 279

see also encyclopedic information, world knowledge

family resemblance $187-9,192-3,267,284$ feature comparison theory 245,246

figurative meaning $28,30,69,87,133,153$, 192-4, 203, 209, 213, 220-1, 231, 243, $262-3,270,281,283-4$

focal colour $184-5$

folk etymology 23-4, 64, 237

fonctème 77

formal approaches to lexical semantics 100, 101, 102, 105, 106, 109, $117-8,121,122,124,125,128,143,147$, $156,166,229,244,274-6,278,285-6$

formal semantics 118-21, 122, 125, 271, 275 see also logical semantics 
frame $46,181,223-9,271,275,282$

frame semantics $46,225-9,271,275$, 282

FrameNet 224, 225, 227-9, 271

framing 223

functional opposition 75, 79, 106

fuzziness $93,95,126,132,141-2,146,183$, $189,196,201,202,203,219,281,285$

see also ambiguity, discreteness, indeterminacy, polysemy, underspecification, vagueness

Gefühlswert 19, 26

Geisteswissenschaft 13

generality and distinctiveness of definitions $136-7,189-95,197-8$

generalization of meaning $26-7,31,37,39$, $193,195,282,284$

generalized onomasiological salience 201

generative grammar $53,70,101-3,107-10$, $117,122,124-5,166,204,274,278$

Generative Semantics 107-10, 113-4, 122, 204, 275, 278

generativist semantics $58,101-23,124-5$, $148,177,182,229,274-8$

see also neogenerativist semantics

genus proximum et differentias specificas 76,83

gestalt 93, 185, 200, 202, 207, 224

gradable antonym 86,87

ground 206

hermeneutics $13-4$

historical-philological semantics 1-46, 47, $49-50,54,59,63-4,91,93,203-4,229$, $273,276-81,284$

affinity with cognitive semantics $277-8$ historiography of lexical semantics 45

holism 123

holonym 88, 159

homonymy $61-3,99,169$

homosémie $36-8$

hypallage 6

hyperbole $29,38,39$

hypernym 82,283

hyperonym 82, 83, 159, 160, 202, 245, 283

hypersémie 38

hyponym $82,83,84,85,86,88,89,96,105$, $111,150,159,160,198,202,245,274,283$

hyposémie 38

Idealized Cognitive Model 182, 222, 223 , 224-5, 247 identity test of polysemy 197

image schema 207-8, 249-50, 270

implicature 147, 231, 232

inclusion, semantic $82-3,89,105,202,282$, 284

indeterminacy 132, 190, 196, 197

see also ambiguity, fuzziness, polysemy, underspecification, vagueness

inheritance $83,150-1$

innateness 123,139

innere Sprachform 18, 51

intensional perspective on meaning 83 , 188-90, 247, 253-4

intentional and unintentional change of meaning 36-41

Interpretive Semantics 109-10, 122, 275

invisible hand 232-3, 239, 258, 265

Invited Inference Theory of semantic change 230-33, 235

isotopies 268

Katzian semantics $101-17,118,139,148,172$, 274

keyword 95, 161, 163-5, 174-5

kinship terms 50, 51, 52, 70, 72, 73, 74, 102, 166

KWIC index 170-1

langue/parole 96, 167-8, 265

lexical field 30, 52, 53-70, 74-9, 87-8, 92-6, 98, 99, 100, 102, 105, 115, 124, 145, 166, 200, 201, 222-3, 242, 263, 281-4

lexical functions 125, 157, 161-5, 229

lexical gap 56,65

lexical priming 180

lexical profile 172

lexical rule $152-4,156$

Lexical Units 228

lexicogenesis 23, 30, 40, 46, 64, 91, 237-9, 272

lexicography 46

and computational linguistics 120, 176, 181

and corpus-based distributional semantics $169,173,180-1$

and formal semantics 120 and frame semantics 271 and historical-philological semantics 7-9, 14, 44 and Meaning-Text Theory 164 and prototype semantic 268 and structuralist semantics 99 and WordNet 180 
lexicology 23, 45-6, 98, 99, 131, 152, 160, $166,168,174,239$

lexikalische Solidaritäten 58, 79

linguiseme 72

linguistic relativity 51, 263

literary studies 75, 80, 100, 206, 212, 269

litotes 29, 38, 39

logical polysemy 92, 148

logical semantics 107-8, 111, 113-6, 118-20, 122, 143, 149, 275

see also formal semantics

logical-rhetorical classification of semantic change $17,25,26,31$

loglikelihood 174

Lückenlosigkeit 65

marker 102, 103, 106-7, 111, 112-3, 118

Markerese 118

maximalist approaches to lexical semantics 106-113, 116-7, 121, 127, 132, 141, 182-3, 222, 240, 259, 266, 269, 274-8

meaning postulate $114-5$

meaning potential 199, 235, 268

Meaning-Text Theory 125, 156, 157, 161-5, 180

mental spaces 204, 210-3, 269, 270

see also blending, conceptual integration

mentalism 101, 106, 116-7, 274

meronymy $82,88-9,90,95,159,165$

metaphor $27-8,33-5,37-40,152-5,155-6$, 204-10, 220-2, 241-4, 259-263, 280-4

defined in terms of domains $216-7$

defined in terms of similarity $6,27-8$, 283-4

diachronic perspectives $208-10,251-3$

discourse perspectives $259-63$

in blending theory 213

interaction with metonymy 220-2

metaphor from metonymy 220

Metaphor Identification Procedure 260, 262

metaphor within metonymy 220

psychological perspectives $241-4$

regular patterns $33-5,205-7$

sociocultural perspectives $249-53$

see also career of metaphor,

categorization model of metaphor,

Conceptual Metaphor Theory, dead metaphor, ontological metaphor, orientational metaphor, primary metaphor, structural metaphor

metaphtonymy 215, 220 métasémie $36-7$

métecsémie $36-8$

métendosémie $36-7,40$

metonymy $4-6,8,21,23,25-6,31,35,37-9$, $40,42,88,92,148,182-3,194-5,199$, 203-4, 213-22, 225, 227, 230-1, 238-9, $240,251,261,270,273,277,280-1$

defined as contiguity $27,63-4,215-20$, 282-4

defined as prototype category $215-20$

defined in terms of domains $215-17$

interaction with metaphor $220-2$

metonymy within metaphor 220

regular patterns $32-3,147,152,217-9$

minimalist approaches to lexical semantics 106-113, 116, 120, 182, 277-8

see also parsimonious approaches to

lexical semantics, reductionist

approaches to lexical semantics

morphosemantic field 60

mot-clé 95

mot-témoin 95

multiple antonymy 86

narrowing of meaning see specialization of meaning

natural kind terms 190, 254-6

Natural Language Processing 118, 123, $157-8,174,177,181,285$

see also Artificial Intelligence

Natural Semantic Metalanguage 95, 124-29, 132-5, 137, 141, 145, 154, 275, 281

near-synonymy $85,159,163,264,271$

Nebensinn 19, 42

necessary and sufficient conditions 141, $187-8,190,246,253$

neogenerativist semantics 126,276

neostructuralist semantics $124-81,275-7$, $280,284,287$

network representation 123

see also radial network

nomenclature 78

nomination $36-7,39-40$

non-denotational meaning 28,84

norms of communication $256-8$

okkasionelle Bedeutung 15, 20, 81, 230

onomasiology $16,23-6,30,40-1,43,45,46$, $49,50,54,63,64,79,91-3,96-7,99$, 199, 200-3, 222, 233, 237-40, 249, 262, $264-5,269,271,272,273,279-85$

ontological metaphor 207 
ontology 119, 139, 180, 215

orientational metaphor 207, 221

paradigmatic relations $57-8,63,77-8,81$, $105,125,161,164-5,217,268,282,285-6$

parole see langue/parole

parsimonious approaches to lexical semantics 43, 127, 144-7, 180, 232, 269 see also minimalist approaches to lexical semantics, reductionist approaches to lexical semantics

pejorative change of meaning 20, 28-9

performance $116,168,258,259$

périsémie $36-7$

permutation 36,40

perspectival opposition 86

perspectivization 182,225

phraseological tendency 178

Pointwise Mutual Information 173, 174

polar antonymy 86

polysemy $7-8,15,21-22,29,30-34,42,44$, $50,63,85,90,92-3,134,143-8,152,155$, $156,180,183,192-9,209,232,235-6$, 239-40, 243, 248, 263, 268-9, 277, 281

criteria for polysemy 197-9

see also ambiguity, fuzziness, indeterminacy, underspecification, vagueness

popular etymology see folk etymology

pragmatic approaches to lexical semantics $5,16,21,25,43,45,81,89$, 91, 96-7, 127, 145-7, 153-5, 168, 177, 179, $180,182,222,230,239,258-9,264-5$, 268, 270, 275-81, 284

see also contextualization, usage-based approaches to lexical semantics

pragmatic onomasiology 97, 239, 264-5, 281

pragmatist philosophy 168

preference rule 141

prestructuralist semantics 1, 230, 276, 280

primary metaphor 208, 221

projection rule $103-5,107$

prossémie 36,37

prossémie $36-7$

prototype theory $46,66-7,83,93,100,132$, $182-203,210,215,217,218,220,224$, $232-4,240,244-9,251,253,255,257-8$, 264-6, 267, 268, 271, 275, 277, 280, 281-4

prototype view of categorization in psycholexicology 246-8

psycholexicology 183,240 psychological adequacy 121, 126, 160 see also cognitive adequacy

psychological categorization research $244-8$

psychological factors in semantics 273-4, 277-8

in historical-philological semantics $9-25,42-3$

in structuralist semantics $47-50$

in generativist semantics $101,105,113-7$, 119,121

in neostructuralist semantics $124-6,138$, 160

in cognitive semantics 185-92, 200, 203, 232, 240-9, 243-5

qualia $149,150,153-6$

qualitative and quantitative perspectives in semasiology and onomasiology 199, 280-1

radial network 192-3, 195, 209, 267 rank 87 recontextualization 278,284 reductionist approaches to lexical semantics 95, 115, 126, 176-7, 269 see also minimalist approaches to lexical semantics, parsimonious approaches to lexical semantics

reductive paraphrase $124,128-9,132$ redundancy rule 115

referential meaning see denotational meaning

regular polysemy 147-8, 152, 155

reinterpretation 112, 221

relational network $96,123,242$

relational semantics 52, 53, 80-91, 100, 125, $158,163,164,245$

restriction of meaning see specialization of meaning

reversive 87

rhetoric 2, 5-7, 9, 27, 66

rigid designation $253,255-6$

salience $269,280-1,285$

among metaphors 243

among patterns of metonymy 33, 217-9

in diachronic prototype semantics 233-4

generalized onomasiological salience and entrenchment 201-2

in pragmatic onomasiology 265

in psycholexicological models 245 
salience (cont.)

semasiological salience as prototype effect $183-200$

onomasiological salience and basic levels 199-203

onomasiological salience among lexicogenetic mechanisms 237-9

Sapir-Whorf hypothesis 51

scale $86-7$

selection restriction $58,104,112,172$ semantic axiom see meaning postulate semantic borrowing 29, 38

semantic calque, see semantic borrowing semantic change

in historical-philological semantics 4,6 , $9,10,12,16,18,20,25-41,43,91$

in structuralist semantics $61,63-4$

in cognitive semantics 203, 230-9

semantic deference 255,258

semantic differential 99

semantic externalism 255

semantic feature 106, 108, 111, 113, 268

semantic field $56-8,60,66,70,87,98,223$, $247,271,274$

semantic loan, see semantic borrowing semantic norm 249, 253, 255, 257-8, 266 semantic preference 170,172 semantic primitive 115, 123, 124, 128, 134 semantic prosody $170,172,173,180$ semantics of authority 258 semantics of conflict and competition 258 semantics of cooperation 258

semasiology 23-6, 29, 30, 40, 41, 43-4, 45, $46,50,64,90,91-3,96-7,184,199,200$, 202, 203, 210, 220, 232, 233, 235, 237-8, $239,249,264-5,267,273,280-4$

seme $72-3,75-6$

sememe $72-3,75-6$

sense relations 81-2, 85, 89-90, 92, 158, 159, $160,164,283$

shortening $36,39-40$

signifiant/signifié 63-4

signifié de puissance 268

similarity $6,27,28,41,57-8,61,63,64,104$, 129, 175-6, 186, 193-4, 203, 215-7, 220, 238-9, 243, 271, 274, 282-4

social factors in lexical semantics $21,24,28$, $48,55,70,78,95,110,142,166,223,233$, 249-58, 266, 269, 270, 277

sociosemantics $21,25,255-8$

source/target in the analysis of metaphor and metonymy $31,35,206,21,214,216$, 242 source-in-target metonymy 216

spatial language $32-5,86-7,138,143,179$, 217-9, 249-50, 263, 267

specialization of meaning $16,26-7,30,31$, $37,221,282,284$

speculative etymology $2-4,9$

spreading activation model 245, 246

statistical approaches to lexical semantics $152,157-8,165,173-8,181$, 236, 244, 246, 261-6, 275, 285-6

statistical Natural Language Processing 157, 285

stereotype $249,253-5$

Strong Lexicalization Hypothesis 128, 133

structural metaphor 207

structuralist semantics $1,9,43,45,47-100$, 101, 104-6, 120, 124, 156, 165, 223, 245, 274-7, 279-81, 284, 287

structure and use, dialectic relationship of $16,20,168,258-9,277$

see also usage-based approaches to lexical semantics

stylistic meaning $29,78,84-85$

stylistics 5, 46, 204, 269

subcategorization frame 138

subjectification 235,271

subordinate $68,82,163$

substitution 36,39

superordinate $26,75-6,82-6,105,186,203$, $243,282-3$

symbolic logic 106-7

symbolic Natural Language Processing 157, 285

symmetry of predicates 114

synecdoche $6,27,31,282$

synonym definition 83

synonymy $38,52,56,80-2,84-5,90,96,99$, $105,111,130,148,158-9,163,176,223$, 264-5, 271, 274

synset $158-60,180$

syntagmatic relations $38,57-61,63,75-8$, $103,105,112,125,160-1,164-6,168,177$, $217,226,268,274,282,285-86$

syntheticity $111-2,122$

sysémie $36,37,38$

taboo 5, 237

target-in-source metonymy 217

taxonomy $82,83,200,201-2,283$

tenor 206

terminological tendency 178

theory of humours $251-2$ 
theory view of categorization in psycholexicology $246-8$

transfer 36

transfer feature 58

transitivity of predicates 114

tropes 5-7

troponym 160

truth-theoretical approaches to lexical semantics see logical semantics

truth-theoretical test of polysemy 197

Two-Level Semantics 125, 127, 142-7

typicality, degrees of $141,187-90$

underspecification 196, 197 see also ambiguity, fuzziness, indeterminacy, polysemy, vagueness

usage-based approaches to lexical semantics 241, 258-9, 266, 287 and corpus-based methods $167-8$, $176,285-6$

and onomasiology 97,284

and semantic change $16,43,230-2$, 243, 277

usuelle Bedeutung 15, 20, 81, 146, 230 vagueness $6,11,22,69,70,98,111,130,145$, $156,192,196-9,207-8,217,256-8,260$, 277

see also ambiguity, fuzziness, indeterminacy, polysemy, underspecification

vehicle 206, 261, 263

virtuème 77

Völkerpsychologie 18, 20, 25

wesenhafte Bedeutungsbeziehungen 58, 98,274

word field $56-7,74$

word formation $23,36,78,237$

word sense disambiguation 176,181

word sense discrimination 176

word space models $174-6$

WordNet 125, 126, 156, 157, 158-60, 164, 180, 227, 229, 271

world knowledge $80,111-3,117,119,137$, $142-3,182,276$

see also encyclopedic information, extralinguistic factors in lexical semantics

Wörter und Sachen 24-5, 281

Zwei-Ebenen-Semantik 143 